


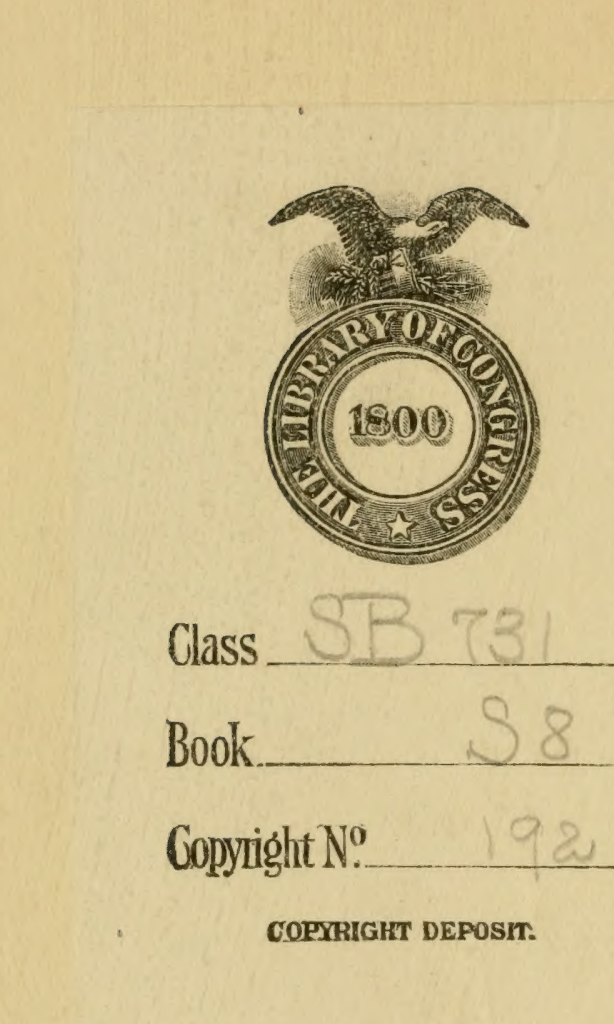




DISEASES OF ECONOMIC PLANTS 


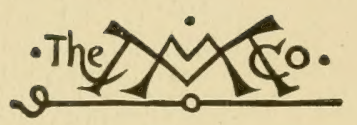

THE MACMILLAN COMPANY

NEW YORK - BOSTON - CHICAGO - DALLAS ATLANTA - SAN FRANCISCO

\section{MACMILLAN \& CO., LIMITED \\ LONDON - BOMBAY - CALCUTTA \\ MELBOURNE}

THE MACMILLAN CO. OF CANADA, Ltd.

TORONTO 



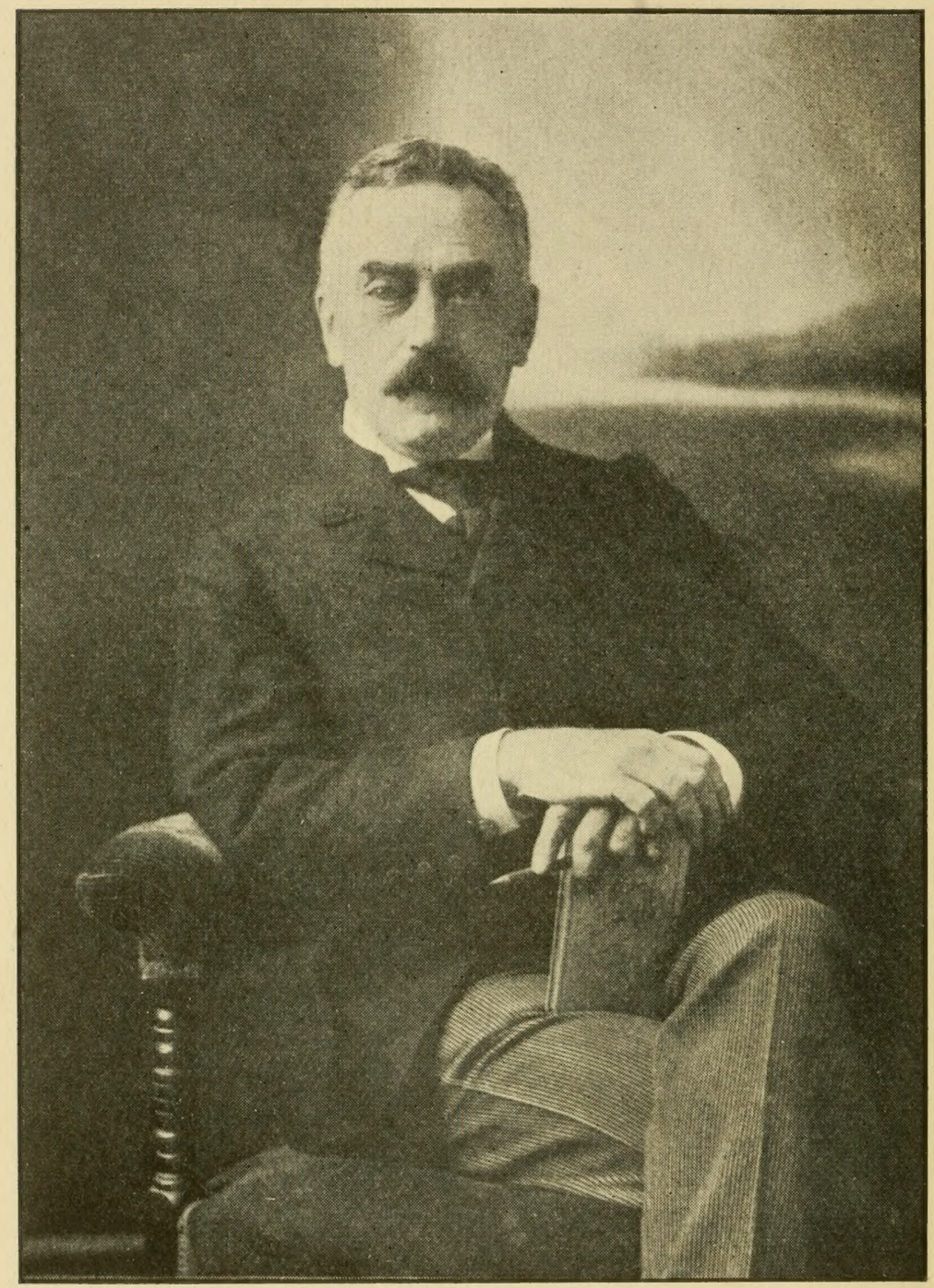

Qaves troog

Mr E. Zraveru 


\section{DISEASES}

\section{$\mathrm{OF}$ \\ ECONOMIC PLANTS}

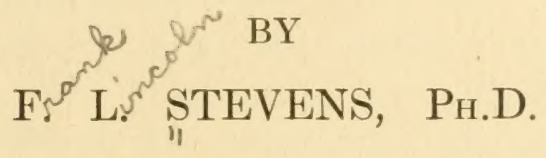

PROFESSOR OF PLANT PATHOLOGY IN THE UNIVERSITY OF ILLINOIS

AND

J. G. HALL, M.A.

FORMERLY ASSISTANT IN VEGETABLE PATHOLOGY IN THE NORTH CAROLINA AGRICULTURAL EXPERIMENT STATION

REVISED EDITION BY F, L. STEVENS

How Hork

THE MACMILLAN COMPANY

1921

All rights reserved 


\section{SBr31 \\ .58 \\ 1921}

COPYRIGHT, 1910 and 1921, .

BY THE MACMILLAN COMPANY.

Set up and electrotyped. Published September, 1910.

Revised Edition, January, 1921.

\section{JAN $19192 !$}




\section{PREFACE}

THE present edition of this text-book is designed primarily for college students, but it is hoped that it may serve also as a useful handbook for others who may wish to recognize plant diseases or to apply treatments. It aims to give a comprehensive view of the field and its importance, with diagnostic symptoms and suggested treatment of all of the more important diseases prevalent on the (rop plants of the continental United States with brief notes or mere mention of those less serious. A few of the more important diseases not of the United States are also discussed hriefly. Diagnostic characters are limited in the descriptions to those that may be recognized without the aid of the microscope. For further discussion of morbid histology, or of the morphology of the parasites concerned, the reader is referred to other books on these subjects. Descriptions and discussions of treatment are as full as the space admits and the reader who desires more complete information is referred to the pertinent literature cited.

Since conditions are so diverse as to geographic location, climate, and soils the treatment here suggested must be more or less general. Crop growers should in all cases endeavor to secure from the nearest Agricultural Experiment Station the information best applicable to local conditions.

The segregation of certain diseases under the caption "Minor diseases" is arbitrary and it is quite possible that diseases here included may locally or seasonally be of major importance, and conversely that certain major diseases may be of but minor importance. The aim, however, is to indicate to the student those which in general are less widespread or less likely to be serious. Ample cross references are 
given to render the information more aceessible and to avoid repetition.

The conmon names selected are those that are in general use.

Diseases due to insects romprise a group) which involves knowledge of the classification of insects and of their lifehabits. Such diseases are set aside in the special field of the Entomologist and are not here treated. The diseases due to adverse inanimate environmental conditions, the sickening of plants due to lack of soil fertility, to excess of some element, to overabundance or lack of water or to improper physical condition of soil, etc., are recognized as properly belonging in the field of Agronomy and are treated in this book only in exceptional cases.

During the decarle that has elapsed since the publication of the first elition there have come into prominence in the United States numerous diseases at that time unknown in Anerica. Therefore the present edition includes discussion of several scores of diseases of major importance, some of minor importance, as well as many modifications of treatment that did not appear in the carlier edition.

The author desires to express his especial thanks for aid in the preparation of this volume as follows: To R. J. Haskell of the Plant Discase Survey of the U. S. Department of Agriculture, who has kindly read the proof with particular reference to the usage of common and scientific names and as to the estimates of losses and statements regarding geographic distribution; to $\mathrm{H}$. W. Anderson of the University of Illinois for valuable aid in the preparation of the sections treating of fruit disease; to E. C. Stakman of the University of Minnesota in connection with the cereal diseases; to G. L. Pelticr of the Alabama Experiment Station and W. A. Ruth of the University of Illinois for the preparation of special articles.

Urbana, Illinois,

F. L. Stevens.

August, 1920. 


\section{CONTENTS}

Historical . . . . . . . . . . 1

Damage Causeid by Plant Diseases . . . . 10

Prevention or Cure of Plant Diseases a . . . 13

Methods of Prevention . . . . . . 14

General Diseases . . . . . . . 19

Diseases of Special Crops . . . . . . . . 31

Pomaceous Fruits . . . . . . . . 31

Drupaceous Fruits . . . . . . . . 74

Small Fruits . . . . . . . . . 102

Tropical Fruits . . . . . . . 135

Vegetable and Field Crops . . . . . . . 149

Cereals . . . . . . . . . 266

Cereal Smuts in General . . . . . . . 266

Cereal Rusts in General . . . . . . . . . 275

Anthracnose of Cereals . . . . . . 280

Special Diseases of Cereals . . . . . 280

Forage Crops . . . . . . . . . . . 321

Fiber Plants . . . . . . . . 343

Trees and Timber . . . . . . . . . . 354

General Diseases . . . . . . . 354

Special Hosts . . . . . . . . . 381

Ornamental Plants . . . . . . . . . 406

General Diseases . . . . . . . . 407

Special Diseases . . . . . . . 408

Fungicides . . . . . . . . . . . . 440

Spraying Apparatus . . . . . . . . 452

Soil Disinfection . . . . . . . . . 460

BiBLIOGRAPHY . . . . . . . . . . 467

INDEX . . . . . . . . . . . . 491 


\section{DISEASES OF ECONOMIC PLANTS}





\title{
DISEASES OF ECONOMIC PLANTS
}

\author{
HISTORICAL 1, 2, 26, 27
}

The science of Plant Disease or Phytopathology was ir its early formative period between 1853 and 1870 , the foundations being laid in the pioneer work of Berkeley, De Bary and the Tulasne brother's in establishing the parasitism of the fungi, and in Pasteur's fundamental work on Bacteria and Spontaneous Generation.

To be sure some of the most conspicuous diseases had long been known by sight. Blight and mildew were referred to in both the Old and the New Testament. Wheat rust was mentioned by Aristotle, 350 B.C. and reference to mildew is found in King Lear, Act III, Sc. 4. There was legislation even regarding wheat rust as early as 1660 . However, there was little or no real knowledge of plant diseases in those times, beyond the fact that various diseases existed, and this knowledge was shrouded in superstition.

Following the pioneer publications of Berkeley, De Bary, and the Tulasne brothers came the more complete treatises of Kuehn (1858), Hartig (1874), Frank (1880, 1895), Sorauer (1874, 1886, 1908), Kirchner (1890), Tubeuf (1894), Prillieux (1895), Delacroix (1902, 1908, 1911), Ward (1896, 1901, 1909), and others.

It was not until 1873 that plant pathology became a part of instruction in botany, and not until 1875 that special courses in pathology were given in any of the schools of America.

A series of papers begun by Burrill in 1873, another by Farlow in 1875, and other publications isy Bessey, con- 


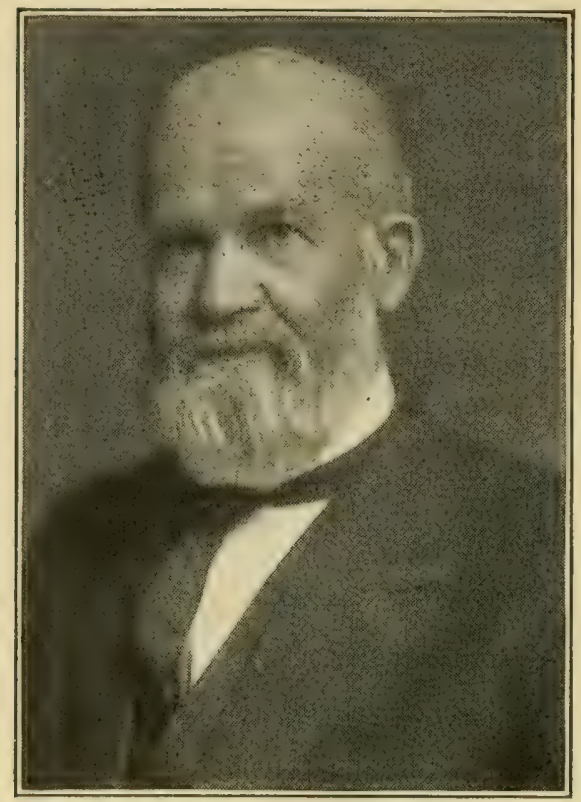

T. J. Burrill, 1839-1916

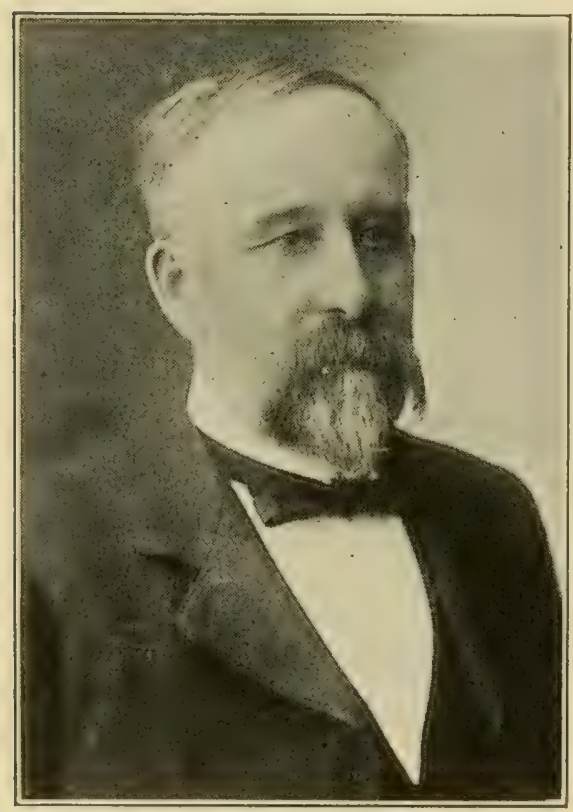

C. E. Bessey, 1845-1915

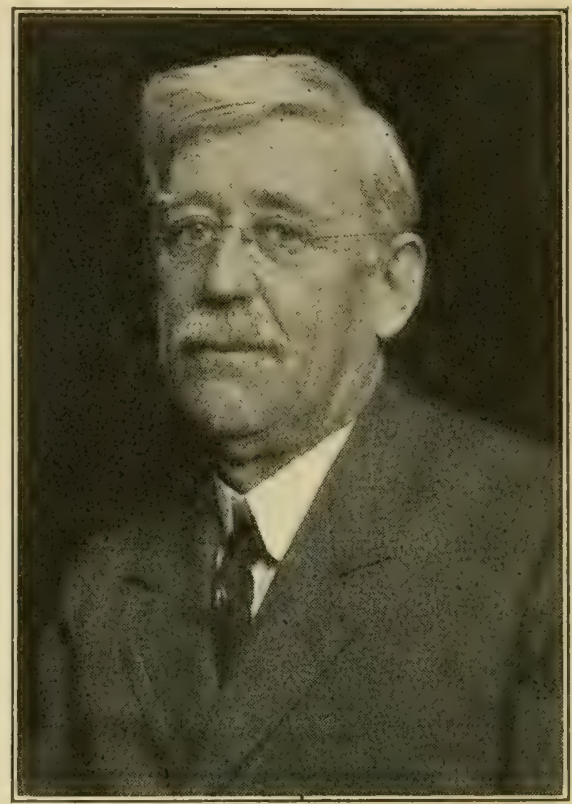

B. D. Halsted, 1852-1916

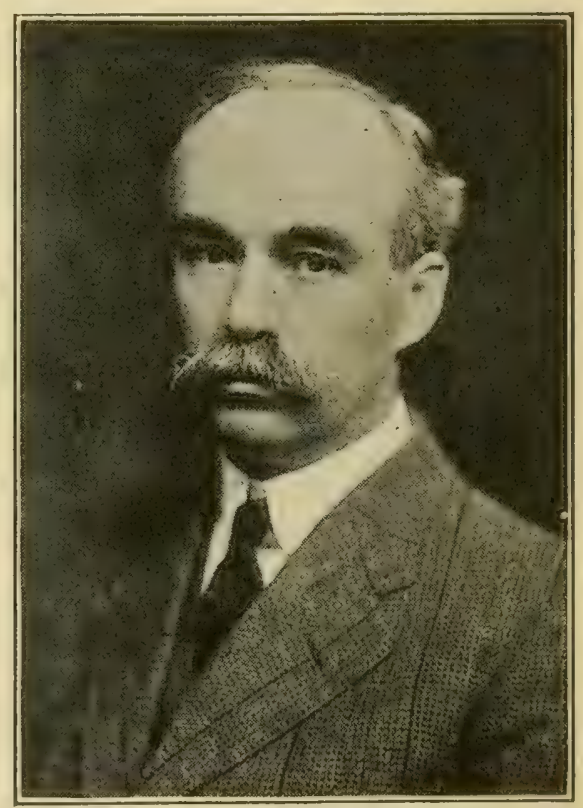

G. F. Atkinson, 1854-1918 
tributed to the knowledge of plant disease and served especially to awaken interest in the problems of, and to attract students to, this field of research.

In 1879 Burrill, working upon the blight of the pear and apple, was the first to attribute a plant disease to bacterial origin. His work was confirmed and his conclusions more fully established by Arthur.

During the seventies, from two or three workers in this field, the number rapidly grew, augmented in the middle eighties by the introduction of plant pathology into the Agricultural Experiment Stations and the United States Department of Agriculture, until the number of papers published in the United States upon plant pathology between 1888 and 1900 is estimated at over four thousand. While only a few dozen plant diseases had been even cursorily described in the United States prior to 1880, in 1910 a total of some 525 diseases, of which more than 250 were serious, had been carefully investigated and the number since that date has been greatly increased.

Historical concerning plant-disease prevention. ${ }^{3,} 488$ Though little could be done to devise rational methods of combating plant diseases until their causes were known, a very few rule-of-thumb, empirical ways of meeting them had been suggested in very early days. As might be expected, many of the methods used were valueless. Thus Parkinson early in the seventeenth century advocated the use of vinegar to prevent canker on trees, and Forsyth in 1790 gave the following directions for making a mixture to "cure disease, defects, and injuries of plants." 1 "Take one bushel fresh cow dung, one half bushel lime rubbish from old buildings, one half bushel wood ashes, one sixteenth bushel pit or river sand. The last three are to be sifted fine before they are mixed. Then work them well together with a spade, and afterward with a wooden beater until the stuff is very smooth, like fine plaster used for the ceilings of rooms." Soapsuds or urine was used to make the composition of the consistency of plaster or paint. After being applied it was 
covered with a sifting of powder made of "dry powder of wood ashes, mixed with the sixth part of the same quantity of the ashes of burnt bones."

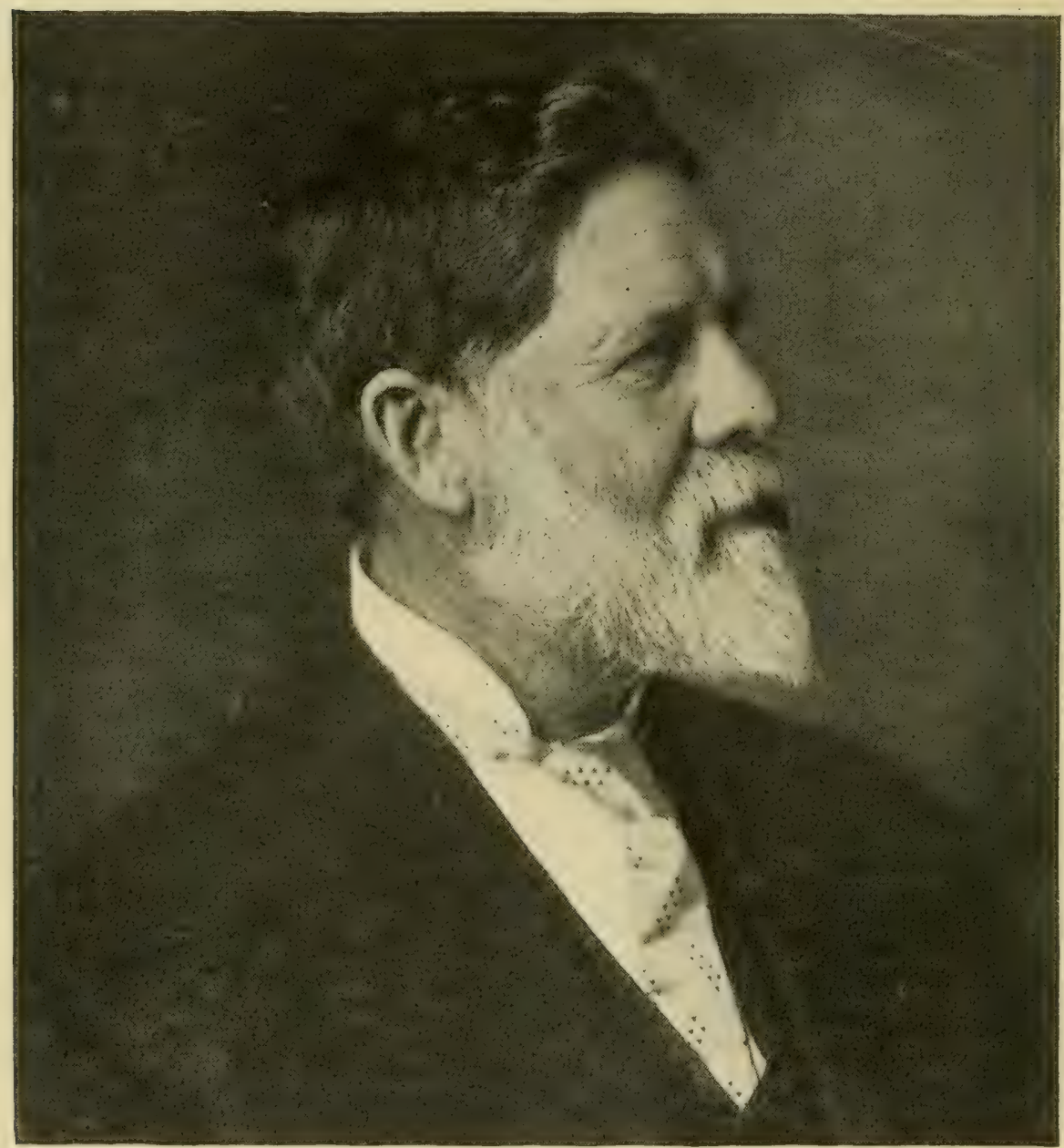

Fig. 1. - Erwin F. Smith of the United States Department of Agriculture.

Among the early chaff, however, there were some grains of wheat. Thus Riedel in 1751 advised excision followed by grafting wax for canker, and Robertson in 1821 said: "Sulfur is the only specific remedy that can be named for the treat- 
ment of mildew on peaches. It should be mixed with soapsuds and then applied by dashing it violently against the trees by means of a rose syringe;" thus advocating a remedy which, modified, is still prominent for this class of diseases.

The aggressiveness of several plant diseases in Europe between 1878 and 1882, particularly the downy-mildew upon the grape, which, about 1878, had invaded Europe

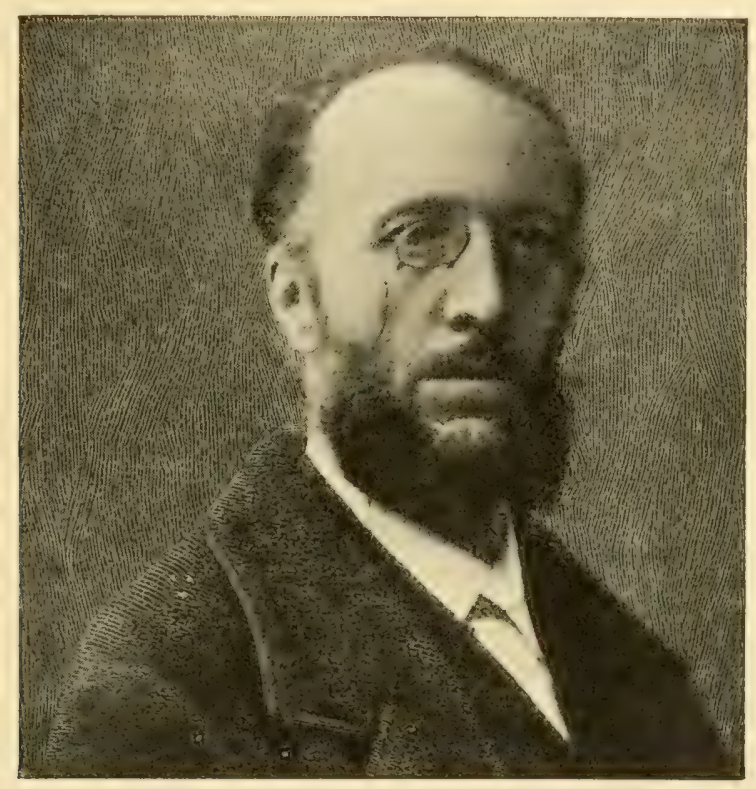

FIG. 2. - Millardet, 1838-1902, father of the Bordeaux mixture. Professor at the University of Bordeaux.

from America, stimulated a search in the former country for effective spraying mixtures. Trials of many chemicals were made, but it was left to accident to suggest, and to the genius of Millardet, of Bordeaux, France, to perfect, the happy combination of lime and bluestone that we now know as Bordeaux mixture. It was customary in certain vineyards to sprinkle a few rows of grapevines near the road with a mixture of milk of lime and bluestone to give 
them a poisonous appearance to ward off depredation of the hungry passer-by. The vines so treated in 1882 were noted by Prillieux and Millardet to be less injured by the mildew than were other vines, and they ascribed the beneficial effect to its proper cause, the lime-bluestone mixture.

While several investigators were engaged simultaneously in experimenting with these chemicals upon the mildew, it was Millardet who first planned and executed experiments and published results which demonstrated the commercial value of the lime-bluestone treatment.

The first systematic applications of copper, and of copper with lime as a disease preventive, were made under the direction of Millardet, August 18, 1883. In 1884 the work was repeated, and in 1885 Millardet published the first directions for preparing Bordeaux mixture:

Water

Bluestone

Lime
130 liters

8 kilograms (17.6 pounds)

15 kilograms
(34 gallons)

(33 pounds)

This mixture was to be shaken upon the plants with a broom.

Following this demonstration came the introduction of an era, not yet at an end, of active experimentation with fungicides, wet and dry, which has already yielded results of incalculable value.

In 1885 also appeared for the first time the Ammoniacal Copper Carbonate proposed by Professor Audoynaud of the Montpelier Agricultural School.

Saunders, in the Canadian Horticulturist in 1884, suggested the use of several liquid spraying mixtures for apple scab, but little if any liquid spraying for plant diseases was done in America prior to 1885.

In 1885, from the Section of Mycology, Division of Botany, United States Department of Agriculture, appeared an article by Lamson-Scribner, giving directions for making "the copper mixture of Gironde," the primitive Bordeaux 
mixture. In 1886 the spraying campaign may be said to have been well started in this country.

The disinfection of seeds by bluestone was practiced first with the cereals as early as 1807 by Prévost of France, and improved by Dreisch in 1873 , by the addition of a limewater bath to follow the bluestone. In 1887 Jensen of Denmark improved upon these methods by developing his hot-water treatment, which has since proved of great value, not so much for its primary use, in which it has been superseded by formalin, but owing to its applicability to those loose smuts which cannot be successfully treated by surface disinfection. Similar seed treatments have been extended to the potato by Bolley, and to cabbage by Harding.

The production, by breeding, of new and disease-resistant varieties is one of the latest and most promising methods of combating plant diseases. Grapes resistant to Phylloxera were produced by Millardet; cotton, cowpeas, and watermelons resistant to wilt by Orton; cabbage by Jones; tomato by Durst and others; tobacco resistant to Thielavia by Johnson.

No small part in the progress that has been made in the prevention of plant disease is due to the improve-

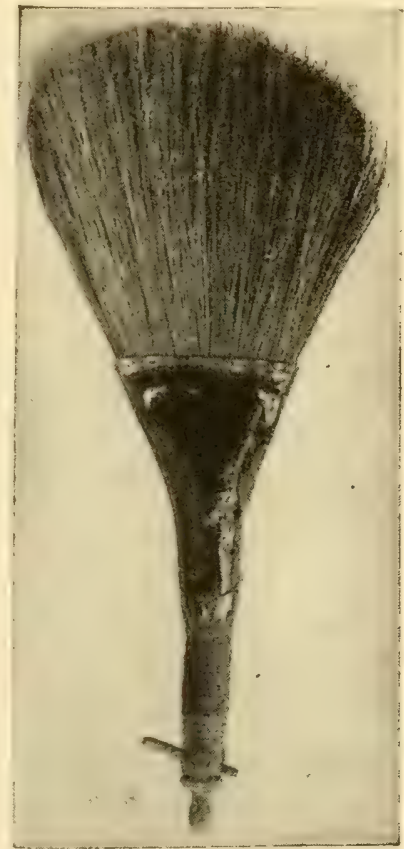

FIG. 3. - An improved brush for distributing Bordeaux mixture. After Lodeman. ment of appliances, dusters, pumps, nozzles, etc., for distributing the disinfectants upon the plants. This progress is well illustrated by comparing the broom of Millardet with the knapsack, barrel, or power sprayer of to-day. 


\section{Important Events in Plant Disease History}

Ancient. Recognition of the existence of plant diseases in early Biblical times.

1683 The discovery of bacteria. Loewenhoek.

1807 The efficiency of copper against smut spores discussed. Prévost.

1821 The use of sulfur as a fungicide recommended. Robertson. 1845 The use of boiled sulfur and lime for mildew advocated.

1846 The studies of Rev. M. J. Berkeley.

1853 The beginning of the "Morphology and Physiology of the Fungi" and the proof of parasitism of fungi. De Bary.

1861 The publication of the first American paper on plant pathology. Engelmann.

1860-1864 The founding of bacteriology. Pasteur.

1864 The proof of alternation of hosts, heterœecism. De Bary.

1869 The first university publication in America regarding plant pathology. University of Illinois.

1873 Plant pathology taught incidentally with botany in America. Burrill.

1875 Plant pathology first taught as a special subject in America. Farlow.

1879-1880 Proof of bacterial disease in plants. Burrill.

1880 The discovery of the cyclone principle in nozzles. Barnard. 1882 The beginning of "Sylloge Fungorum." Saccardo.

1884 Systematic introduction of plant pathology into American Agricultural Experiment Station work. Arthur.

1885 The announcement of the Bordeaux mixture. Millardet.

1885 Organization of a Section of Mycology in the Division of Botany, United States Department of Agriculture. Lamson-Scribner.

1886 Proof that mosaic is infectious. Mayer.

1887 The hot-water treatment for smut. Jensen.

1888 The introduction of formalin as a disinfectant. Trillat.

1888 Organization of the State Agricultural Experiment Stations.

1890 The beginning of pump improvement for spraying.

1894 Establishment of the fact that biologic races exist. Eriksson. 
1906 The passage by Congress of the Adams Act.

1906 The introduction of the use of lime-sulfur. Cordley.

1907 Establishment of the first university department of plant pathology: Cornell.

1909 The organization of the American Phytopathological Society. 1912 The passage by Congress of the Plant Quarantine act. 


\section{DAMAGE CAUSED BY PLANT DISEASES}

THE crop grower often suffers much damage from plant diseases, entirely unconscious of the fact that his crop is affected by disease. Or, if the presence of disease is recognized, the amount of damage is often underestimated. Thus the presence of oat smut to the extent of 15 or even 40 per cent, is sometimes entirely overlooked by an otherwise observant man.

An attitude of willful disbelief in the prevalence of a disease is often couched in such terms as these: "I don't see why I must work to protect my apples from rot. My grandfather used to raise fine apples without any attention to these things."

It must be recognized that plant diseases are with us; that they are increasing by importation from other countries or other states; that diseases formerly insignificant are, in many instances, becoming serious; that long, intensive culture of one crop in a locality permits new diseases to develop. Diseases have many means of dispersal; on seed, hay, or other produce shipped by mail, express, or freight; on animals; by wind; by water; by birds. Diseases will continue to spread and to increase in destructiveness until the individual and the general public are aroused to such active appreciation that conditions of plant sanitation and plant protection become much more general and effective than they now are.

Conspicuous examples of the advent of diseases in countries where they were before unknown, are afforded by the following: grape powdery-mildew, native to America and first seen in Europe in 1845; the American gooseberry mildew, first found in Europe in 1900; the potato late-blight, native to South America, noted in Europe in 1830; the asparagus rust, introduced from Europe about 1896; the hollyhock 
rust introduced about 1886; the white-pine blister-rust introduced from Germany shortly prior to 1906; the chestnut bark-disease, introduced from the Orient about 1904. Other examples are cabbage club-root, potato-wart, grape anthracnose, grape black-rot, the carnation rust, and citrus canker.

Cases of interstate migration of plant diseases are numerous, ${ }^{488}$ most prominent being, perhaps, the asparagus, hollyhock, carnation, and chrysanthemum rusts, and the pearblight.

Fungi introduced into new environment, into a new continent, for example, owing to the change in biologic equilibrium, to the absence, perhaps, of their natural enemies or to readier access to susceptible hosts are often much more destructive than in the countries from which they came. This fact finds illustration in many of the diseases mentioned above, notably so in the case of the chestnut bark-disease.

Aside from diminishing the value of the produce and the thrift and future productiveness of perennials, as trees, vines, etc., plant diseases entail depreciation in the value of land, and in some eases even occasion large loss of life. Thus the famine in Ireland in 1845 is directly traceable to the injury done to the potato crop by the potato late-blight. The presence of ergot in grain used as food for cattle or man results in disease and death.

The presence in land of the causal germ of the melon, cowpea, cotton or tobacco wilts, of onion smut, cabbage club-root or black-rot, or of any one of many other soil-borne pathogenes precludes the possibility of successful culture of the susceptible plant for a long period of years, perhaps forever, upon the soil in question. Such restriction may prevent the raising of the crops that are most profitable in a particular section, and in some instances depreciation of 50 per cent or more in the market value of land has resulted from the invasion of one of these ineradicable soil pests. Still more serious is this kind of injury if the crop in question is one which requires large money outlay befere the 
presence of the disease germs is manifest. In the case of Sumatra tobacco under shade, or lettuce grown under canvas, the money expended to prepare for the crop may aggregate from $\$ 700$ to $\$ 1000$ or even more per acre the first year. The capture of such acreage by the lettuce drop or the tobacco wilt is a far more serious matter than a plant disease is usually considered to be.

The diseases which develop on the product after harvest, while in storage, are of peculiar destructiveness since they cause the loss of a large percentage of the finished agricultural yield. ${ }^{4,5}$ Thus a large part of the total yield of sweet potatoes is lost. Those diseases that develop in transit entail, in addition to the loss of the product, also the freight charges and many hundreds of thousands of dollars in litigation.

Some of the losses caused by discases of a few crops are given below, merely as illustrative instances. The authority is named with each estimate. These losses are in many instances much larger than is indicated, due to increase in market value of the product.

The California vine disease in $1892, \$ 10,000,000$.

Pierce.

Wheat rust in the United States, $1898, \$ 67,000,000$.

Wheat rust in Illinois, 188.5, $\$ 1,875,000$.

Violet leaf-spot in the United States, 1900, $\$ 200,000$.

Peach leaf-curl in the United States, 1900, \$2,335,000.

Potato late-blight in New York, 1904, $\$ 10,000,000$.

Oat smut in the United States, annual, $\$ 6,500,000$.

Galloway.

Burrill.

Dorsett.

Wheat loose smut, United States, annual, $\$ 3,000,000$.

Wheat bunt in the United States, annual, $\$ 11,000,000$.

Potato blight in the United States, annual, $\$ 36,000,000$.

Wheat, 1917, all diseases, $64,440,000$ bu.

Oats, 1917, all diseases, $153,973,000 \mathrm{bu}$.

Corn, 1917, all diseases, $175,344,000 \mathrm{bu}$.

Pierce.

Potato, 1917, all diseases, $117,174,000$ bu.

Stewart.

Orton.

Orton.

Orton.

Orton.

Lyman. ${ }^{6}$

Lyman.

Lyman.

Sweet potato, 1917, all diseases, 41,707,000 bu.

Lyman.

Cotton, 1917, all diseases, 1,866,000 bales.

Lyman.

Lyman. 


\section{PREVENTION OR C'URE OF PLANT DISEASES}

THE burden of the efforts of the plant pathologist must be directed toward methods of prevention, which are here worth far more than their proverbial ratio, since, owing to the comparatively small value of the individual among plants, treatment of a plant already sick is seldom attempted except in the case of plants of exceptional value. Such value very rarely attaches to annuals or biennials; hence it is only with perennials, valuable vines, bushes, or trees that cure of the individual is attempted, and here only in a few special cases.

The science of plant pathology, barely antedating 1880 , is yet young. Several of its founders in America are living and are still vigorous workers. In comparing this youthful science with its far more aged prototypes, human and veterinary medicine, one is astonished at the progress already made, rather than abashed at the multitude of diseases as yet unconquered. ${ }^{488}$

Among all classes of crops are diseases, single or many, which have given way to the control of man, many of them diseases of great destructiveness, yet which are now practically under the subjugation of the intelligent, educated crop producer.

The remedies, with one or two exceptions, are entirely the result of patient, scholarly investigation, careful deduction, followed by experimenting, testing, and improving. Such investigation is ever proceeding with increasing activity, and each year, new or improved methods of combat are devised, so that the future may with confidence be relied upon to see the subjugation of many of the foes that are as yet unconquered. 


\section{Methods of Prevention}

All methods of prevention of plant diseases due to parasites aim at the destruction of the causal organism, the diminution of its numbers, or the strengthening of the crop plant so as to withstand its attack. The various methods employed may, for convenience, be summarized as follows:-

1. Killing the causal organism as it rests upon the seed. - Examples: oat or wheat smut, cabbage black-rot. For this purpose the seeds (sometimes cuttings or even whole plants are similarly treated) are subjected to the action of heat or clisinfecting chemicals long enough to kill the causal organism, but not long enough to kill the seeds. Chief among such disinfectants are:-

Formalin (40 per cent formaldehyde).

Corrosive sublimate.

Copper sulfate, followed by weak limewater.

Heat.

2. Killing superficial fungi by applications upon the green parts of the plant. - Examples: powdery-mildew upon grape, gooseberry, or rose. This method is applicable only with the purely superficial fungi, since internal parasites cannot be so reached without injury to the host plant itself. It finds prominent application with the powderymildews. The chief applications used are:-

Liver of sulfur.

Bordeaux mixture.

Ammoniacal copper carbonate.

Sulfur, or sulfur and lead arsenate.

Lime-sulfur.

3. Killing superficial fungi hibernating upon the bark of the dormant plant or plant supports. - Examples: apple hypochnose, peach curl. For this purpose cleansing sprays, often called dormant sprays, may be used. Since the parts of the host receiving the spray are highly resistant to their poisonous action, the sprays thus employed may be much 
stronger than could safely be used when the plant is in foliage. For this purpose use:-

Copper sulfate with lime sufficient to color.

Lime-sulfur mixtures.

4. The use of protective sprays or dusts. - Examples: grape black-rot, apple scab. A protective spray or dust is one applied to the plant upon its bark, foliage, or fruit, to kill any offensive germs that may fall upon its surface, or to prevent their growth upon or into the plant. Such sprays are distinguished from the cleansing sprays, which are not primarily for protection against future invasion, but rather for the purpose of cleaning off or killing all spores actually upon the plant. Protective applications are usually employed when the plant is in foliage, and therefore must be used with due regard to the susceptibility of the plant to the poison employed. They should be applied:

1. Often enough to replace any previous protective applications that may have been removed by rain or other means.

2. To give protection to any new surface of twig, leaf, or fruit which has developed since the last protective treatment was made.

The first protective application should be given as soon as possible after susceptible surfaces have developed, and before the attacking organisms are expected to make their invasion. The time varies of course with each special crop, with each disease, with the climatic relations and section of the country. Nor can any absolute rule be laid down for the use of subsequent protective applications. Frequency of rain is an important controlling factor. A fungicide, if rained upon just after it is applied and before it has time to dry, is easily washed off.

New tissue and new surfaces develop every day; therefore, theoretically to secure complete protection, sprayings should be very frequent, much more frequent than is practicable. To meet the needs occasioned by new growth, pro- 
tective sprays are usually given at intervals of from ten to fourteen days, though special rules must govern special cases.

The chief protective applications are:-

Bordeaux mixture, full strength or weak.

Ammoniacal copper carbonate.

The latter solution possesses the advantage that it does not spot the fruit and may therefore be used near the period of maturity, when the Bordeaux mixture, owing to its spotting effect, would be less desirable.

Lime-sulfur mixtures.

Sulfur and lead arsenate.

5. Excision of the affected parts. - Examples: Ash white-rot. Excision is resorted to chiefly in the case of trees which from their location or quality possess value sufficient to warrant the necessary outlay of labor. It is so practiced as to remove the diseased wood and sufficient of the healthy wood to expose an entirely uncontaminated surface. The wounded surface is then treated with an antiseptic such as tar or carbolineum.

6. Removal and destruction of diseased twigs, leaves, or fruit. - Examples: fire-blight, peach brown-rot. The removal and destruction of diseased parts diminishes the number of bacteria, spores, etc., that are available to spread the disease and thus lessens infection. Mummified fruit should be picked from the plant or the ground and destroyed, or it may be removed by appropriate pasturage by fowls, swine, etc. Affected leaves in many instances should be similarly removed. Blighted twigs and cankers should be cut out when seen.

7. Removal, in whole or in part, of complementary hosts. - Examples: apple rust, wheat rust. Complementary hosts always serve as multiplying places for the causal parasite, and in some instances are absolutely essential to its hibernation. Such complementary hosts should, when practicable, be removed from the immediate vicinity, and, when possible, not allowed to exist within considerable distance, one eighth 
to one half mile, or better still, a greater distance. When it is not practicable to remove the host, the offending portions may be cut away, $e . g$. in the case of the apple rust the cedar-balls may be removed from adjacent trees.

8. Avoidance of disease-bearing material or material favoring disease. - Infection may reach hay through sick melon vines (melon wilt), or manure may be contaminated by infected plant parts (potato scab), cabbage rot, melon wilt, etc.). Soil may wash from one field to another and bear disease with it (tobacco wilt, melon wilt, ete.).

9. Prevention of wound infection. - Examples: heartrots, sap-rots, cankers, fruit-rots. Wound infection may often be avoided by eare in handling the plant so as not to wound it. In trees place ladders carefully, not roughly, among the limbs; avoid walking on limbs with nailed or hard boots, etc. Gather all fruit, root-crops, etc., carefully to avoid breaking the skin or bruising the underlying tissue. In case of removal of large limbs, coat the exposed wood with paint or tar to prevent invasion by parasites.

10. Avoidance of susceptible varieties; selection of resistant varieties. - There is much difference in the susceptibility of different varieties of plants. Study the different varieties of the crop to be raised, particularly in this regard, and use those that are most resistant. In case resistant individuals are observed among sick plants, save their seed carefully and test the resistance in succeeding years. In this way new and resistant varieties may be developed.

11. Avoidance of disease-infested localities. - This is in many cases imperative where the soil is invaded by a germ inimical to the growth of crops of certain kinds, as in the case of cabbage black-rot, cotton and melon wilt, etc. Similarly, low damp locations favor diseases of some crops (potato lateblight), and the proximity of certain kinds of plants leads to disease with others (apple rust). All this should be considered in the selection of land for the crop.

12. The practice of crop rotation. - Constant growth of the same crop in any locality tends to increase the enemies 
of that crop. Rotation breaks the continuity and hinders the multiplication of the parasite.

13. Avoidance of practices that aid in dissemination of the parasite. - Examples: bean pod-spot, tomato leaf-spot. In certain instances the spore of the causal fungus is transferred from plant to plant most freely when the host is wet. To avoid picking or cultivating under such conditions is to lessen the spread of infection. Similarly in the greenhouse, surface watering may spread the spores. By sub-irrigation this may be avoided.

The importance of sanitary methods cannot be overemphasized and stress on such methods rather than on the employment of specific treatment against disease is a growing tendency. Many crops from their very nature are but slightly amenable to direct treatment; others will not need it if they are given surroundings that are, in general, sanitary. Increased attention should, therefore, be given to soil condition both chemical and physical, to the fitness of the crop to the particular soil and climate, to water relations, to crop rotation, to closeness of planting, ventilation, to proper seed selection, and modes of propagation. 


\section{GENERAL DISEASES}

The diseases discussed below are present upon so many different species of plants that it would seem that they are almost indifferent to the nature of their hosts. They may, therefore, be expected upon any kind of plant, and are here mentioned so that it will not be necessary to discuss them repeatedly in succeeding pages. Special reference is also made to them under the hosts upon which they are most destructive.

Damping-off. ${ }^{10}, 11,12$ - Seedlings, cuttings, and other weak, soft plants which lack in the vigor that affords them natural protection against their enemies, are subject to a disease which has come to be generally known to gardeners as "damping-off." Damping-off is most injurious to seedlings grown indoors or under crowded conditions, but it sometimes occurs in the field. It is particularly injurious to seedling trees in the nursery where many young seedlings die and disappear, or even die before they come above ground. The loss is thus often 90 per cent of the stand. Typically damping-off occurs upon seedlings as a rot originating at or near the surface of the ground. The decay at this point so weakens the stem that the plant topples over or "damps.off." Subsequently the whole plant may decay, either from the primary cause or from secondary attacks. A short time prior to the fall of the plant the leaves may appear sickly, although this sign is so evanescent that it may not be noted.

Upon cuttings the toppling over does not, of course, occur, but the rot at the ground line is of the same nature as in the case of seedlings, and since the diseases in the two cases are of similar nature and due to similar causes, they are placed under the same caption.

Damping-off may be caused by any one of several species 
of fungi, prominent among them being Pythium, Thielavia, Corticium, Fusarium, Botrytis, Sclerotinia, Sclerotium, Phoma, Volutella, Phytophthora, Colletotrichum, Gloespo-

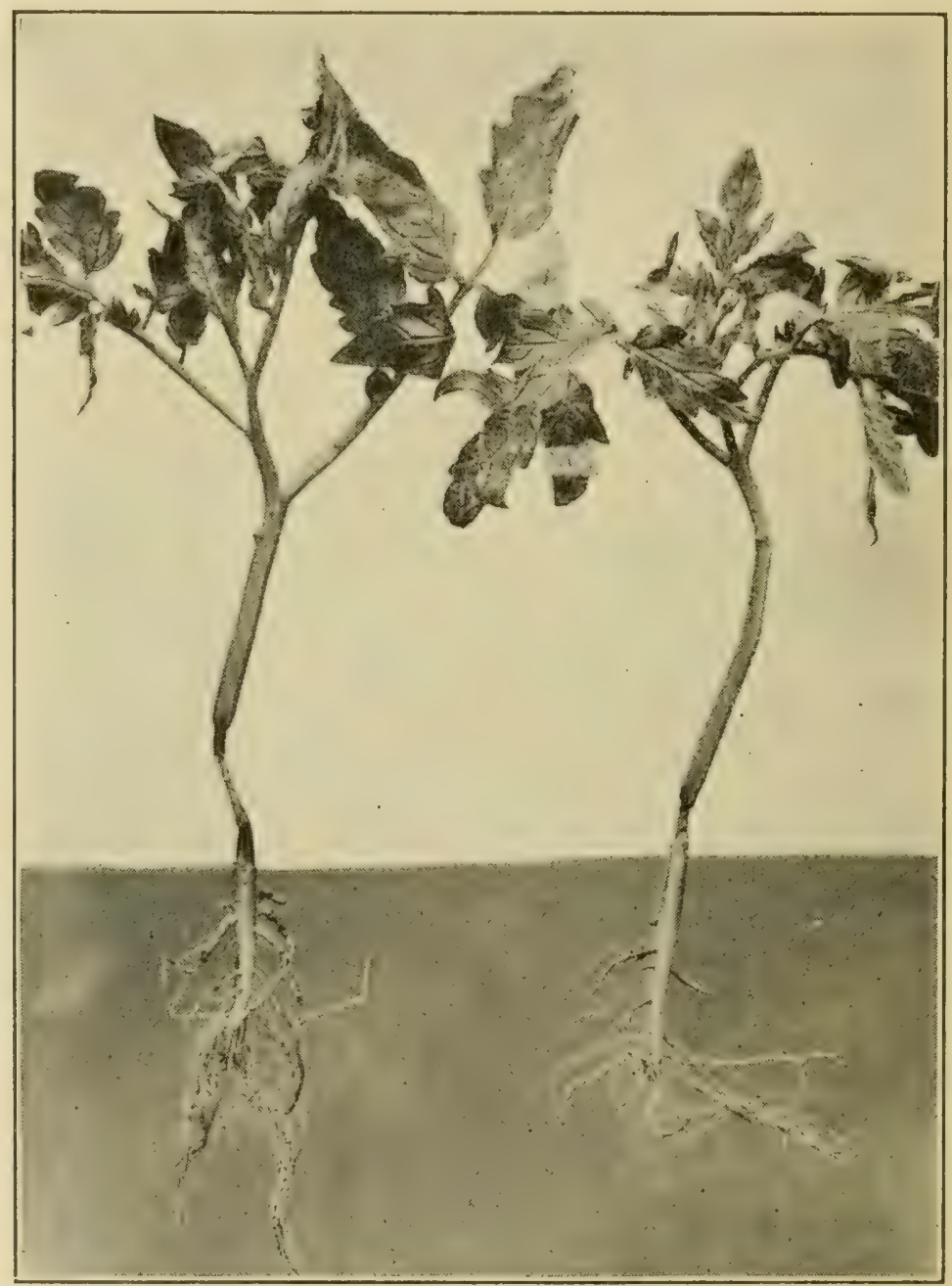

Firi. 4. - Stems of young greenhouse tomato plants dampedoff frcm attacks of Corticium. After Humbert.

rium. The fungus which causes this condition may often be seen as a weft of mycelium around the base of the diseased plant, or even creeping over the ground to some distance. 
From its original points of attack it may spread rapidly to adjacent plants, often sweeping the whole seed bed.

Since the growth of these fungi is favored by moisture and warmth, the trouble may often be checked or prevented by keeping the beds cool and withholding any excess of water; also by means of adequate ventilation, preventing the accumulation of a vapor-laden atmosphere around the bases of the plants. Thick sowing should be avoided. Frequent stirring of the top soil around the plants aids in drying it and may stop an incipient attack of damping-off. Organic matter in the soil favors the growth of dampingoff fungi, and should be avoided. Fresh, clean sand is best for most purposes of the seed bed and cutting bench.

Soil known once to have sustained damping-off may be regarded as infested with the fungus which caused it. Such soils should not be used for seedlings or cuttings without disinfection. If disinfection is impracticable, the soil should be removed, the containers thoroughly cleansed with a spray of Bordeaux, bluestone, or formalin, and new uninfested soil introduced or, in the case of seed beds, a new site selected.

Stem-rot, Root-rot ${ }^{13,}{ }^{14}$ (Corticium vagum B. \& C., Rhizoctonia).--The affected plants are usually attacked near the soil-line or on the roots where cankers of small or large extent. develop. These cankers vary in character and color with the host and conditions so that reliable diagnosis can be made only by recognition of the fungus with a compound microscope. There appear very fine, cobwebby threads, pale or dark, which are often barely visible around the roots of the affected plants as they are pulled from the ground. Masses of fungus threads (sclerotia), also often occur. These are black, irregular in shape, the size of a pin-head or larger. Usually the fungus does not bear spores, but in relatively rare instances sporiferous regions develop encircling the stem.

This stem-rot has long been known in Europe, and is now found in North and South America, the West Indies, India, 


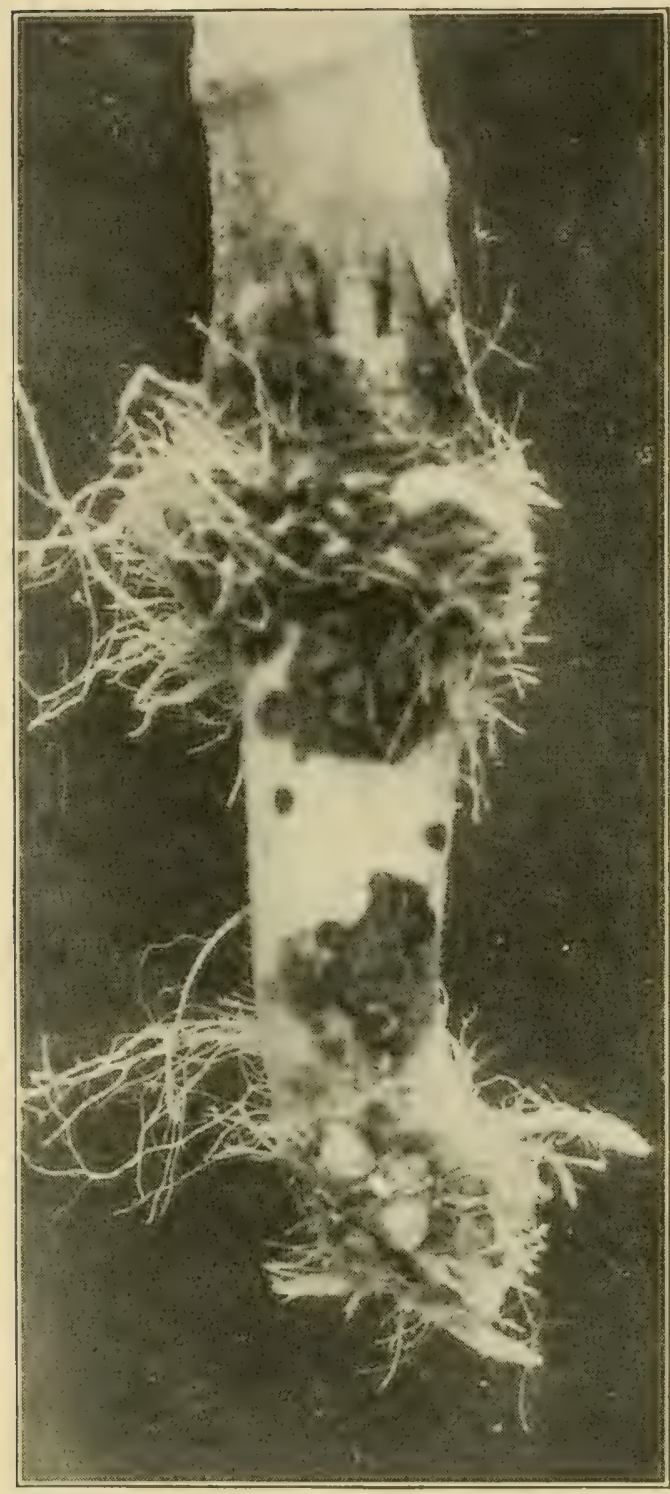

FIG. 5. - Corticium on cabbage. After Peltier. and Australia, and may be regarded as of worldwide distribution. The first account of it in the United States was made by Pammel in 1891. Since then numerous bulletins dealing with it on various hosts have been published. It is quite indifferent to its hosts, embracing especially members of the pink, crucifer, legume, potato, and sunflower families and in all about fifty families of plants including conifers and ferns. Some 165 species and varieties of host plants are recorded. Among these, the most important in America are: potato, beet, lettuce, bean, celery, carrot, cabbage, eggplant, tomato, sweet potato, cucumber, watermelon, pumpkin, squash, pea, corn, radish, rhubarb, alfalfa, clover, buckwheat, tobacco, cotton, aster, carnation, violet, cherry, raspberry, currant, pine. If conditions favorable to its attack obtain, the fungus may well be ex- 
pected upon almost any species of plant, so wide is its range of hosts.

Soil disinfection (p. 460), when practicable, may be employed; otherwise general sanitary measures, destruction of infective refuse, and the use of resistant plants are remedial.

Southern-blight ${ }^{15}$ (Sclerolium rolfsii Sace.).-Plants affected with this discase lose color, wilt, and may die. The fungus is found, usually, around the base of the stem or on the roots, producing lesions of rot, a dense white mycelial mat, and large numbers of spherical, yellow sclerotia, closely resembling mustard seeds, which are diagnostic. The causal fungus may be recognized upon numerous hosts particularly in the Southern states, and as far north, at least, as central Illinois. It has been identified upon tomato, eggplant, Irish potato, sweet potato, beet, peanut, pepper, cauliflower, bean, cowpea, cabbage, carrot, squash, muskmelon, watermelon, rhubarb, fig, cotton, violet, hydrangea, daphne, chrysanthemum, pinks, bellflower, morning-glory, Japanese fiber-plant, grasses, sugar cane, and several weeds and may be looked for on any plant. Treatment is the same as for stem-rot.

Texas root-rot ${ }^{16,17}$ (Ozonium omnivorum Sh.).* - Most destructive to cotton (see p. 346) this disease affects a very wide range of plants in Texas, California, Oklahoma, New Mexico, and Arizona. It has been noted upon nursery stock, apple, mulberry, chinaberry, linden, ash, quince, locust, Prunus, hibiscus, persimmon, elm, lime, maple, beet, peanut, bean and various legumes, flax, cotton, sweet potato, Sida, ragweed, cocklebur, alfalfa, and several other plants. The chief characteristics are a sudden wilting or dying of the diseased plant, or if the main root is not completely diseased merely a slight yellowing and unhealthy appearance. The roots of plants that have recently died are closely invested with a cinnamon-buff felt of hyphæ, in which strands are conspicuous. Treatment is as for stem-rot.

* Duggar believes the conidial stage to be Phymatotrichum omnivorum (Sh.) Dug. ${ }^{17}$ 
Root-rot ${ }^{18,19}$ (Thielavia basicola (B. \& Br.) Zopf.). The roots of the diseased plants, especially the tips of the rootlets, turn black and decay. Sometimes the stem just above the roots is eracked and deformed and the plant is dwarfed. Damping-off may occur in seed beds. This rootrot was first noted in the United States on tobacco in 1904 and is now known to be widely distributed. It is found primarily on members of the legume, potato, and cucurbit families but has been identified on plants of fifteen other families as well, including the violet, composite, crucifer, and mallow families. In all, something over a hundred species of host plants are known to be susceptible, though to largely differing degrees. In the case of tobacco alone the average annual loss is placed at millions of dollars. There appears to be no biologic specialization and the fungus that can affect one crop can pass readily to the others. For treatment, see under Tobacco, page 253.

Root-knot, nematode galls. ${ }^{21,22,23}$ - Root galls, varying from a few millimeters to a centimeter or more in size and superficially resembling the root tubercles of the legumes, are common upon a large variety of crops, causing large field loss in all but the most northern states as well as serious injury in greenhouses everywhere. Plants badly affected are dwarfed and are more susceptible to attacks of fungi than are normal healthy plants. Large indirect loss arises from the fact that nematode-infested soil often prohibits the planting of certain profitable crops. These galls are due to a microscopic eel-worm (nematode) which enters the root from the soil and by irritation of the root causes the gall to develop. Following is a list of the more important highly susceptible plants. A complete list would number over five hundred hosts. Field crops: alfalfa, clover, cotton, cowpea (except Iron, Brabham, and hybrids of Whippoorwill crossed on Iron), field pea, flax, pumpkin, soy bean, sugar beet, sugar cane, sweet potato, tobacco, vetch. Ornamental and drug plants: begonia, cineraria, clematis, coleus, dahlia, hollyhock, ginseng, goldenseal, peony, rose, sweet pea, violet. 
Truck crops: asparagus, bean, carrot, celery, cucumber, eggplant, garden beet, garden pea, Irish potato, lettuce, muskmelon, okra, onion, pepper, salsify, spinach, strawberry, tomato. Woody plants: almond, catalpa, cherry, European elm, fig, Old World grapevine, mulberry, peach, pecan, Persian walnut, weeping willow.

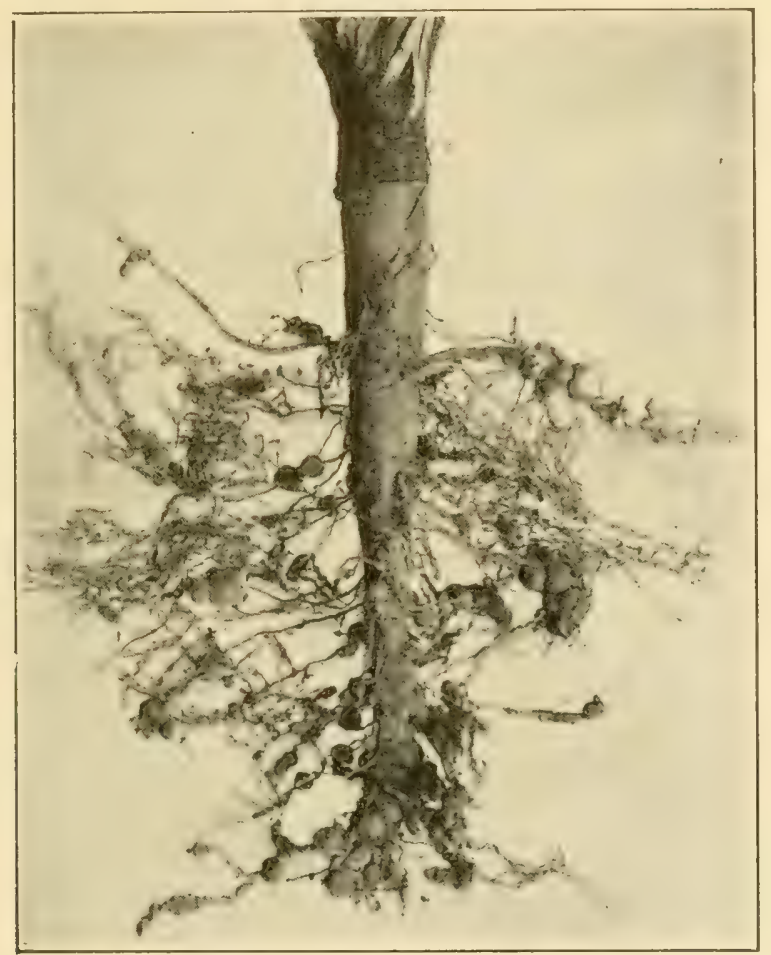

FIG. 6. - Root-knot (nematode) on salsify.

Original.

In limited areas soil disinfection (p. 460) may be employed. Thorough cultivation and fertilization induces the roots of perennials to extend deeper into the soil, thus reaching below the nematode zone, affording at least temporary alleviation. Three years of rotation with non-susceptible crops as corn, timothy, red-top, velvet beans, resistant cowpeas, barley, winter rye, or oats with care to keep down susceptible weeds largely reduces the amount of soil infection. 
Certain varieties of cowpeas (p. 335), tobacco, grapes, figs, and watermelon show resistance. Calcium cyanamide, 1,000 to 5,000 pounds per acre applied several weeks before planting and followed by abundant water, reduces the number of nematodes.

Hairy-root, also due to nematodes, is discussed on p. 162.

Certain fungi as Penicillium (Soft-rot or Dry-rot) p. 51, Phytophthora omnironum, Sclerotinia libertiana (Drop, Wilt) p. 196, are so general in their habits as to be found on almost any host.

Disease due to Impure Air..$^{24,} 25$ - Plants are sensitive to certain chemical impurities of the air and may either be killed or greatly retarded in growth by them. These impurities are chiefly smoke and gases or solids resulting from industrial operations. The aërial emanations of smelters are of a character peculiar to the processes involved and of a quantity to make their effect apparent to considerable distances. It has been clearly shown that even small quantities of illuminating gas or sulfur dioxid are very deleterious in their effect upon plants. So marked are the effects upon vegetation that definite zones of injury may be mapped in the vicinity of large air-pollution centers, the outer zone extending to a distance of from 75 to 100 miles. Illuminating gas escaping from mains into the air of the soil frequently causes death of trees. There is considerable difference in resistance between different varieties of plants and if the air pollution cannot be abated the more resistant varieties should be planted.

Soil diseases..$^{20}$ - A group of plant diseases of special destructiveness comprises those of which the causal organism resicles in the soil from year to year ready to infect any susceptible crop planted thereon.

Notorious among such are the wilts of the cotton, tobacco, tomato, cucumber, muskmelon, eggplant, cowpea, watermelon, cabbage, flax, sweet potato and potato; the clubroot of cabbage and other crucifers; black-rot of similar plants; smut of onion. Other soil diseases are potato wrert 
and scabs, beet seab, lettuce drop, and numerous others mentioned on following pages as well as the general diseases discussed above. Since these diseases are similar in their mode of multiplication and dissemination they are given general consideration here.

The peculiar destructiveness of these diseases is due to the fact that they not only kill the crop, but they also prohibit successful culture of susceptible crops in succeeding years. This crop limitation, if the crop in question be an important one, perhaps the only really profitable one suited to the soil affected, may result in large depreciation in land values.

It is unknown how long the germs can live in the soil without susceptible host plants. That they can live from one season to the second season following is certain. A field slightly affected one year, if put to a susceptible crop the second year after, will be even more scriously infested, and the trouble will grow so long as such crops are cultivated with but short intervening periods. Many cases are known where a rest of five and even eight your's does not materially restore the soil to normal condition.

The application of chemicals to the soil is of value only in rare instances, and eren then is questionable. No means of soil disinfection applicable to fields is known. Land once infested, therefore, can become again usable only by eliminating the causal organisms by a long system of rotation which is usually only partially effective, or by the use of resistant. varieties of plants, and these in most instances are not as yet known or do not as yet exist.

In view of these facts it is especially necessary to stress the importance of protection of soils against infestation. To understand the means of protection the modes of dissemination must be known.

All plants affected with these diseases harbor immense numbers of the reproductive parts of the causal organisms, bacteria, spores, mycelium, sclerotia, ete. U'pon the death and disintegration of the host plant they are liberated in 


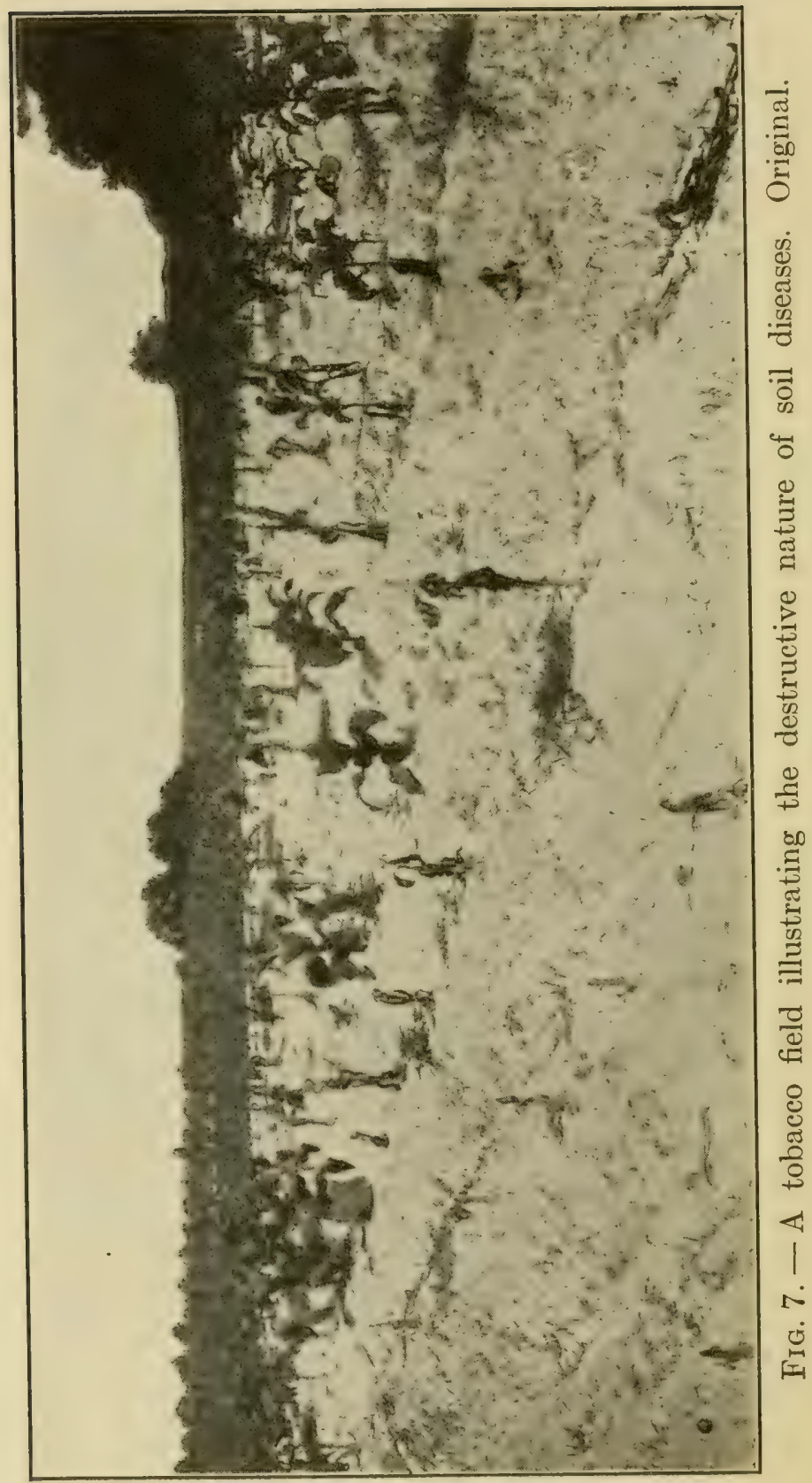


the soil, where they are able to live for considerable time, frequently for years. The immensity of their number in a diseased plant is inconceivable. Even a few diseased stems, roots, or leaves in the field will stock the soil thoroughly. Infected plants, or soil in which infected plants have grown, or which bears parts of infected plants can therefore convey such contagion to new fields.

Instances may be cited where the contagion has spread by washing from higher to lower land; moreorer contagion may be carried by any means which can convey soil from one field to another, notably through tools which have been used on infested soil. Though apparently clean, such tools, if they bear even minute particles of soil, may convey hundreds of germs and thus start an epidemic in a field. The hoofs of animals or the feet of laborers may in a similar way bear disease-laden soil. Wind passing over an infested field may pick up broken bits of sick plants or germ-laden soil, and convey these to other fields. Infestation by wind, however, seems to be rare, possibly because of the germicidal action of the sun's rays upon the surface layer of soil upon which the wind must act. If the erop be one which is used for stock feed or one which may become mixed with stock feed, the organisms may be spread widely through manure which has here become infested from the feed (cf. watermelon, cabbage).

A field may be protected from higher land that is infested by proper arrangement of dykes. In some cases a thorough cleansing of tools so that there is no possibility of conveying the germs will aid in repression. The dirt may be knocked off, then wiped off, and the implement finally disinfected with a solution of 2 per cent formalin or 5 per cent carbolic acid. It is difficult to insure complete protection against disease dissemination by the feet of animals and man, but if uninfested land remains to be protected, every precaution should be exercised in this particular.

Where but a few plants in a field are affected, they should be removed from the soil and destroyed by fire, - root, 
branch, and leaf. Prompt action here may materially lessen the rapidity of sprear of the discase in the field. Every particle of the sick plant burned means the destruction of millions of the causal organisms.

A long rotation of crops, one that will hring the susceptible plant back upon the affected field only after an intervening period of several years, perhaps after a period of eight or ten years, is useful in some cases, notably with tobacco wilt and onion smut, though in other cases, notably watermelon wilt, such rotation is of little avail.

The one means of overeoming these soil diseases, which is most promising to farmers, lies in the discovery of a variety of the crop plant that will not suecumb to attack even when planted upon infected soil. Varicties of cotton, tobacco, tomatoes, cabbage, flax, cowpeas, and watermelon that are resistant to their respective soil diseases have been discovered or developed by breeding. There is similar hope in regard to other crops. 


\section{DISEASES OF SPECIAL CROPS}

\section{POMACEOUS FRUITS ${ }^{28}$}

The pomaceous fruit plants, owing to the fact that they are long-lived peremnials, that their products are standard and of high value, that they are universally grown throughout the United States, when subject to an injurious disease justify

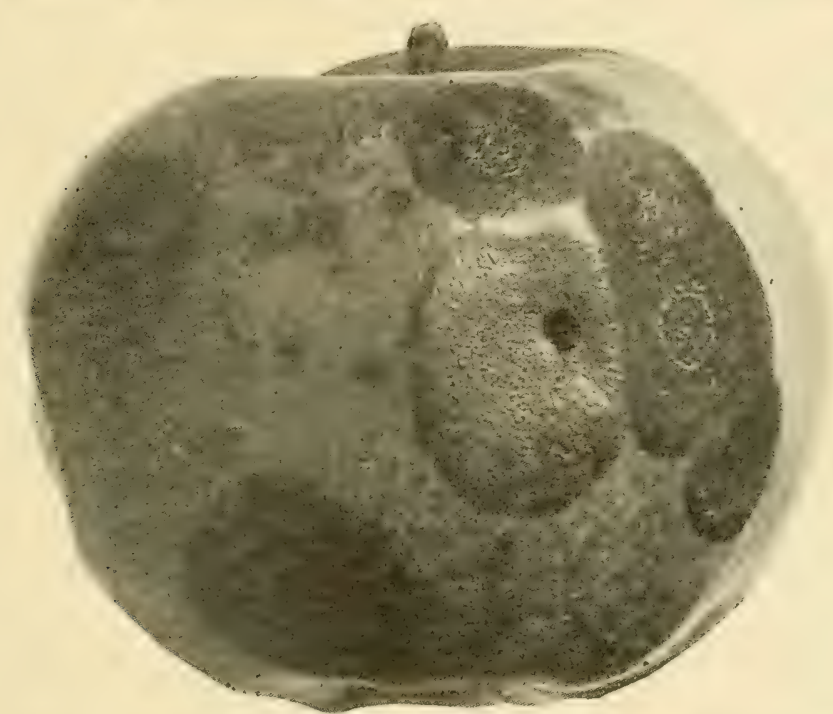

FIG. S. - Apple bitter-rot in early stages showing acervuli. After Scott.

careful consideration of the means of combating the disease and the employment of even expensive methods to attain the end.

\section{APPLE}

Bitter-rot 29-33 (Glomerella cingulata (Stonem.) S. \& v. S., Gloosporium). The effect of the disease is seen upon both the fruit and the twig. Upon the fruit the rotten spot is 
at first soft and wet, in later stages corky, more or less dry, and brown, tan-colored, or black. This spot under favorable conditions increases in diameter at a rate varying from 1$10 \mathrm{~mm}$. each day. Single or numerous lesions may appear upon the fruit, depending upon the abundance of the infecting spores and their ability to gain access through the cuticle. When a spot becomes quite large, it is usually somewhat de-

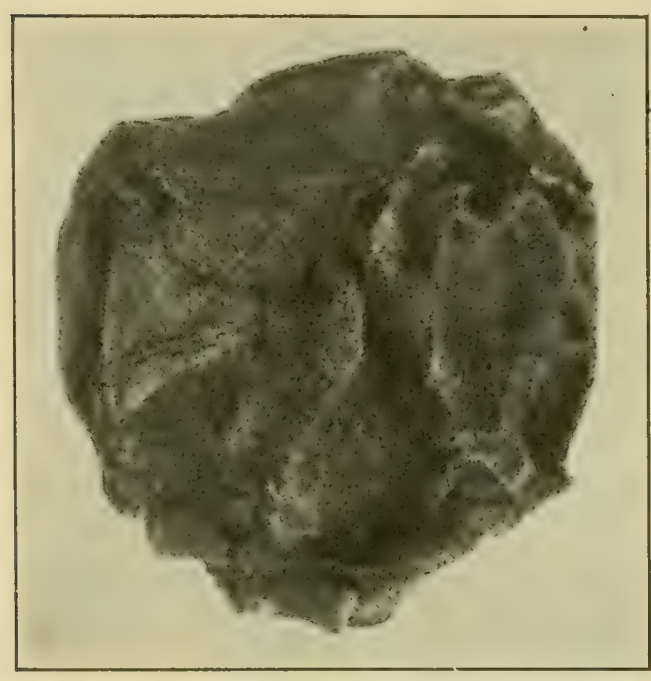

Fig. 9. - Apple in advanced stage of bitter-rot. After Scott. pressed, with a shriveled, wrinkled surface, due to loss of turgor of the underlying tissue caused by evaporation. As the spot ages minute spore-bearing pustules of the causal fungus, barely visible to the naked eye, appear, first at or near the center. The tissue of the fruit is affected to some depth, although the progress of the disease is not so rapid downward as laterally. The pulp of the apple at the margin of the rotten region is usually bitter, thus giving rise to the common name of the disease.

Fruit of any age after its formation is liable to infection if suitable climatic conditions and infective material obtain, though the disease is most noticeable and does most damage as the fruit approaches maturity. A series of hot, wet days favor's a destructive attack, while cold checks it. The fruit as soon as it is badly rotted usually falls from the tree, covering the ground beneath, while apples less advanced in disease still hang upon the limbs.

This same disease occasionally affects twigs and young branches, causing cankers or rough spots in the bark. Young cankers are slightly rough, owing to the dead bark, and ex- 
tend only partly around the twigs. Old cankers are very rough, and may extend sevcral centimeters longitudinally along the twig, thus giving it a flattened appearance.

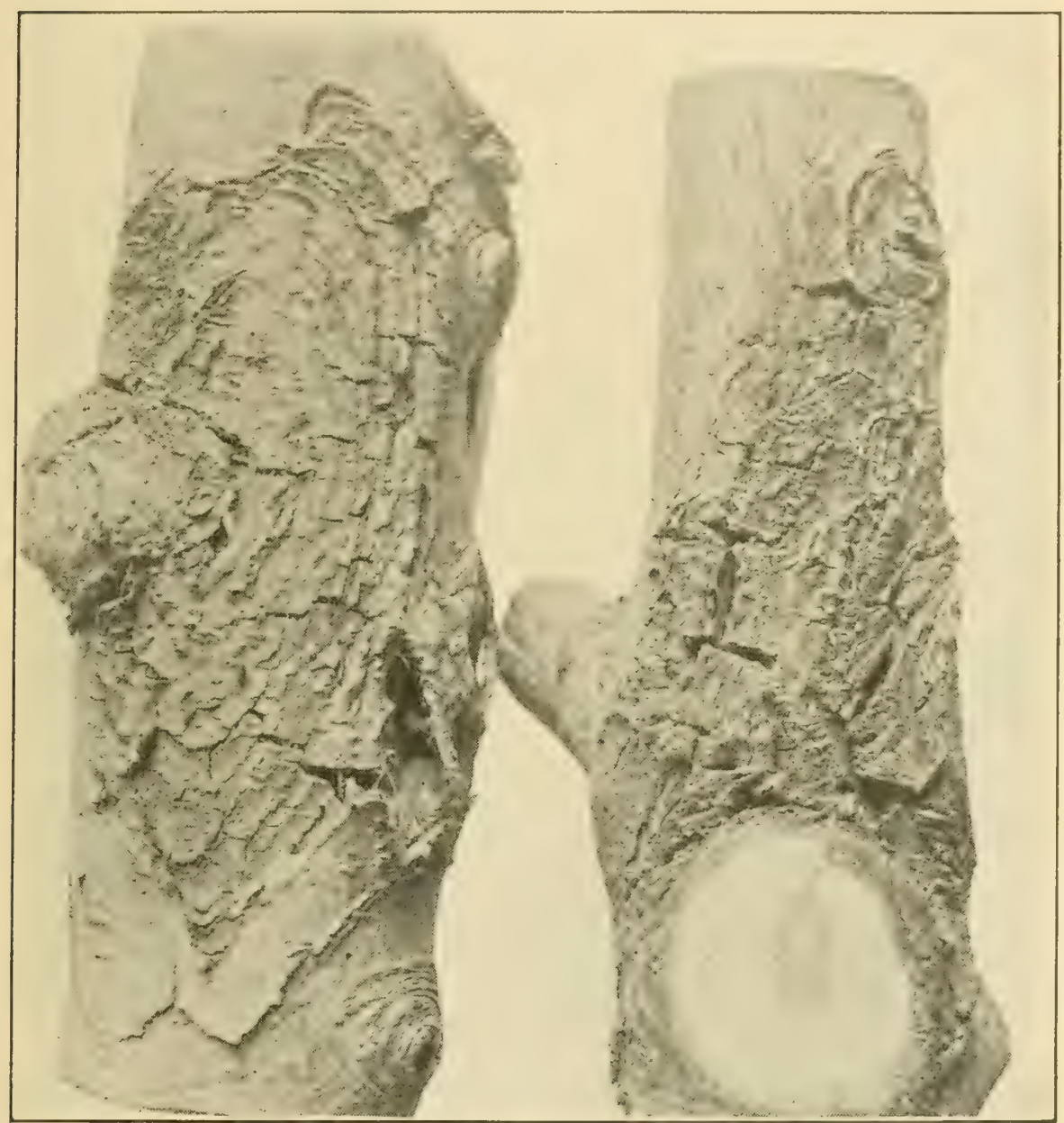

FIG. 10. - Bitter-rot cankers. After U. S. Dept. Agr.

The fungus causing the rot upon the fruit was (lescribed in 1856 by Berkeley. That the cankers are caused by the same fungus was recognized independently by two research parties, Burrill and Blair, and von Schrenk and Spaulding 
in 1902. Upon both twigs and fruit the spores are borne in great numbers. The fungus is, moreover, perennial upon the twigs, the cankers serving as initial points of infection for each year's epidemic.

The natural course of the disease is through twig infection; spores from some older lesion are transferred to points of weakness on the twig, such as bark ruptured from any cause. The fungus may also develop and overwinter in old cankers caused by other fungi, on clead twigs or scars on the fruit spurs, or even in the crevices in the bark and at these points produce spores the following year. These in turn, carried chiefly by rain, partly by insects, possibly birds, or other agencies, fall upon apples, and there initiate spots of rot. Apples thus infected serve as multiplying ground for the further infection of other apples. Six days after an apple is infected a crop of spores may mature and be ready to further spread the disease. To some extent the causal fungus hibernates in mummified fruits, which thus become sources of initial infection in the succeeding year.

Bitter-rot occurs throughout the United States wherever apples grow, but has been most destructive heretofore in sections southwest of Virginia between the parallels of $35^{\circ}$ and $39^{\circ}$ north latitude. It is known also in comparatively harmless form in Europe and Australia. In 1900 it was estimated that the loss in four counties of Illinois was $\$ 1,500,000$. The president of the National Apple Shippers Association estimated the damage to the apple crop of the United States that year as $\$ 10,000,000$. There is often a loss of from 50 to 75 per cent of the crop.

Two modes of treatment are useful: first, to cut off and burn the cankers in so far as is practicable, and to hand-pick and destroy mummified fruit; second, to spray the growing fruit with a fungicide. The trees should be sprayed frequently with Bordeaux mixture, or lime-sulfur (summer strength) from the time the petals fall until the fruit is almost ripe. A non-spotting spray should be used for the last application. Cf. p. 447. 


\section{Pomaceous Fruits}

Scab ${ }^{34,} 35,509$ (Venturia incequlis (Cke.) Wint., Fusicladium). - This is justly called the most injurious disease with which the apple grower has to contend. Originally imported

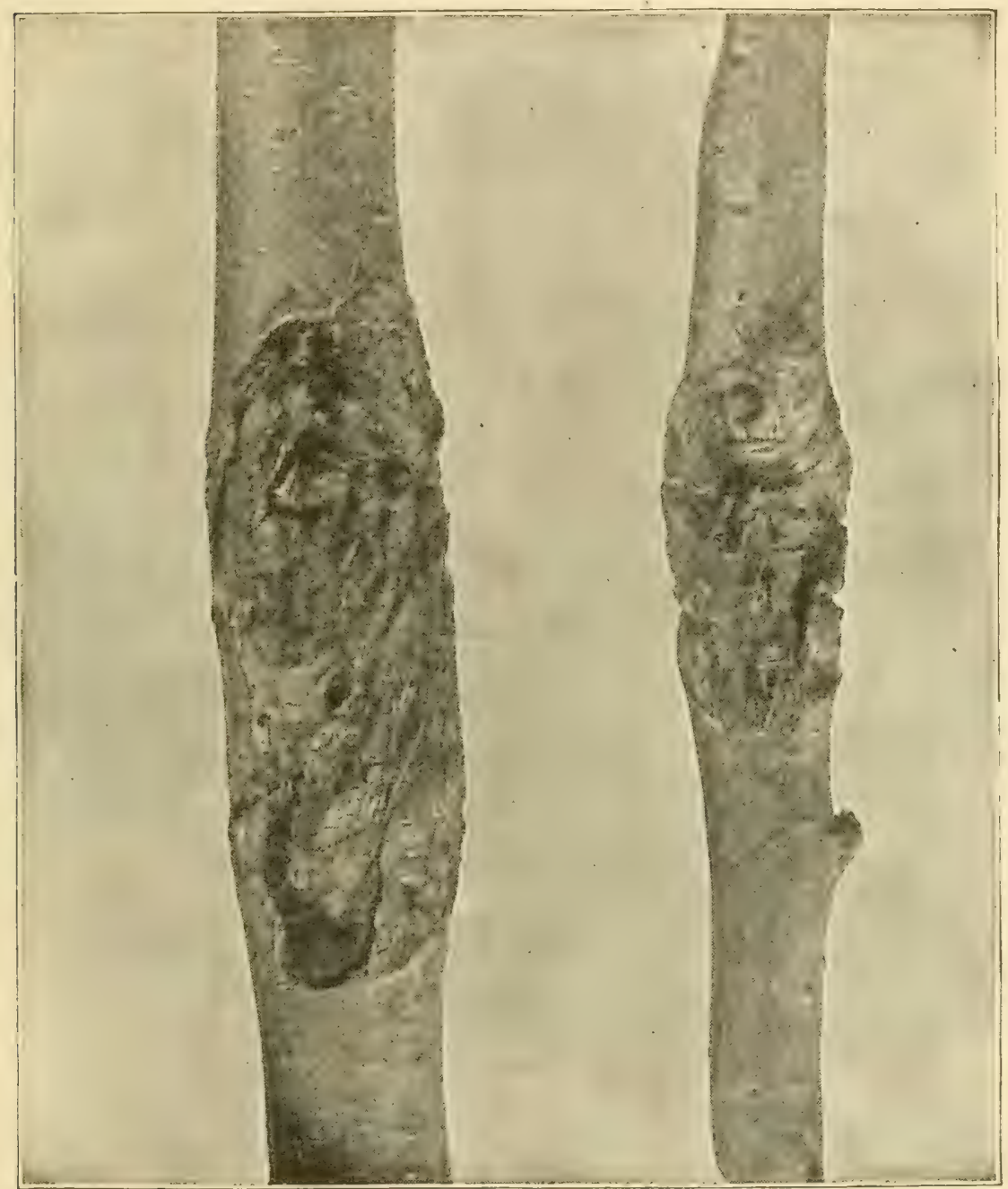

FIG. 11. - Bitter-rot cankers in which perithecia were found. After Burrill.

from alroad, the first record is in Europe, 1819. Later it was noted in America, both in New York and Pennsylvania, in 1834 , whence it apparently spread westward. It affects 
both fruit and leaves, probably in all localities where apples are grown, and is serious in Europe, Australia, Africa, and New Zealand, as well as in America.

Upon the fruit, the scab first causes the skin to take on a dark olive-green color; later, as the outer skin breaks and

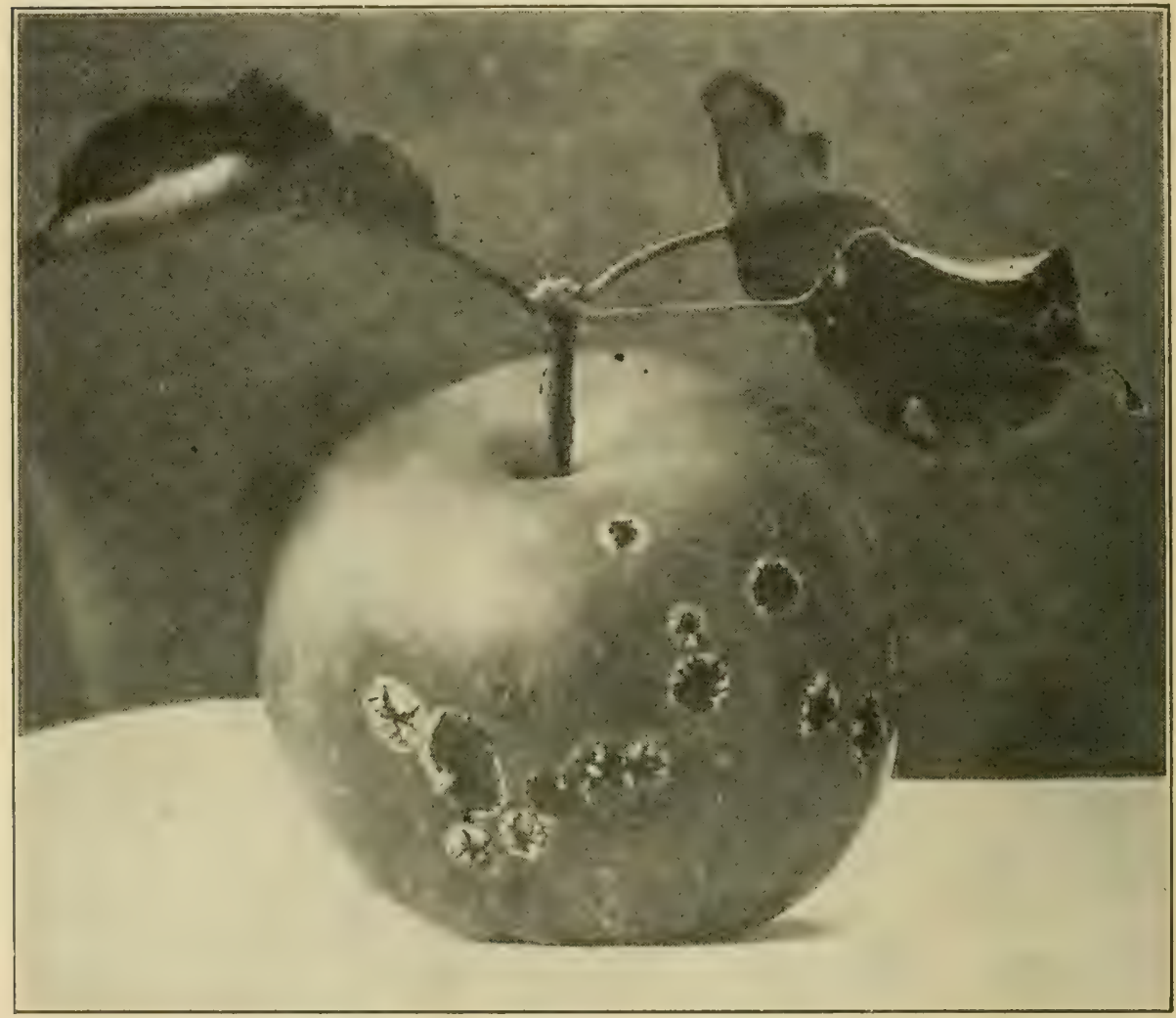

FIG. 12. - Apple scab. After Craig.

exposes the fungus underneath, the color changes to black. An apple in this stage is shown in Fig. 12. Still later the scab enlarges, and the spores and fungous cells at the center of the spot may fall away, leaving a skin of rusty appearance surrounded by a dark ring where the fungus has not yet fallen off. Farther from the center of the spot may be an olive-green or silvery ring, showing the still younger stage of the disease. Cracking and distortion occur in cases of very 
badly affected fruits. Scably fruits are much more susceptible to storage rots than are clean fruits (p. 49).

Upon the leaves and more rarely upon twigs the fungus forms a thick velvety coat, varying from dark olive-green to black, in spots at first circular in outline, later irregular and coalescing. The irritation and retardation of growth caused by the presence of the fungus often induces the leaves to curl and wrinkle in a characteristic manner. The fungus winters on fallen leaves, and wind-borne spores from them give rise to spring infection. Cf. pp. 58, 60.

The injuries by this disease may be enumerated as follows: lessened leaf value, retarded twig and wood growth, premature fall of fruit, retardation of full development of fruit, and injury to sale and keeping quality of fruit.

Baldwin, Golden Russet, and Hubbardston are among the most resistant varieties, though scab-resistance seems to vary geographically and even seasonally. Cf. p. 60 .

Bordeaux mixture and lime-sulfur are effective sprays. It is especially important to apply the mixture immediately be-

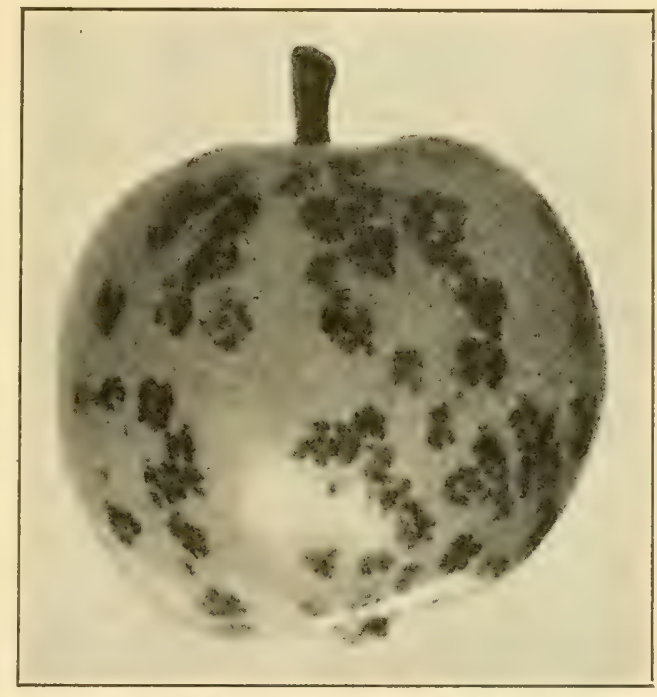

FIG. 13. - Apple blotch. After Scott and Rorer. fore the blossoms open, again just after the petals fall, followed by one or two later sprayings. (Cf. p. 57. Dusting is discussed on page 446. Burning of infected, fallen leaves is a good sanitary measure.

Blotch ${ }^{36-40,521}$ (Phyllosticta solitaria E. \& E.). - In some sections of the country this disease of bark, leaf, and fruit is even more troublesome than any of the preceding, though its 
distinct identity was not recognized until 1895 . Since then the disease has been observed in the Eastern and South-

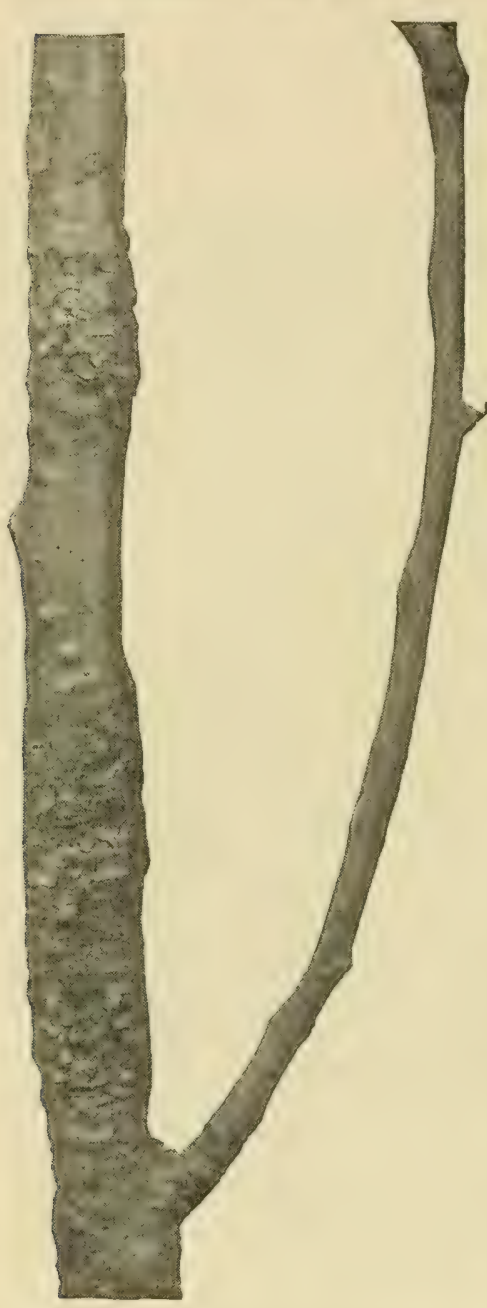

Fig. 14. - Apple bloteh on twigs. Original. eastern states, though not in serious form. Its most destructive center, heretofore, has been in the Ozarks of Arkansas and Missouri and in southern Illinois, Ohio, and Indiana where a large per cent of the crop is commonly rendered unfit for barreling. One county alone in Arkansas is estimated to have suffered a loss of $\$ 950,000$ in 1906. Owing to its superficial similarity, blotch has been confounded with scab in some instances. The first publication concerning the disease appeared in 1902, and the first detailed description in 1907.

Upon fruit the blotches are from 5-20 $\mathrm{mm}$. in diameter, dark in color, with an advancing margin of peculiar, irregular, jagged, or fringed appearance. By coalescence large spots may form, and owing to tension, cracks appear, enlarging to a centimeter in length, or even girdling the fruit, and reaching to the core. In the older portions of the blotch, minute pycnidia develop. These blotches mar the appearance of the fruit and injure it as a salable product.

Upon twigs, spurs, or shoots are produced cankers, which, during the first year, consist of small spots $2-10 \mathrm{~mm}$. in diameter, tan-colored, each bearing several pycnidia. The margins of the spots are sharply limited, and are usually 
bordered with a narrow red line. In older cankers the diseased bark becomes cracked, furrowed, and much roughened.

On the leaf this fungus causes small, regular, light brown, yellowish, or whitish spots, usually $1-2 \mathrm{~mm}$. in diameter, each of which may bear one or several pycnidia.

The Ben Davis, Missouri Pippin, Limber Twig, and Maiden Blush are highly susceptible, while Winesap, Jonathan, and York Imperial are almost immune.

Ordinarily three applications of 3-4-50 Bordeaux mixture suffice to control blotch. The first spraying should be made two or three weeks after the petals have fallen; the second about two weeks later; the third two weeks thereafter. Lime-sulfur should be substituted during wet weather to avoid Bordeaux injury. Careful pruning to remove affected twigs is beneficial.

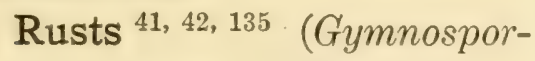
angium sps., Rœstelia).Rusts of the apple may usually be recognized by their char-

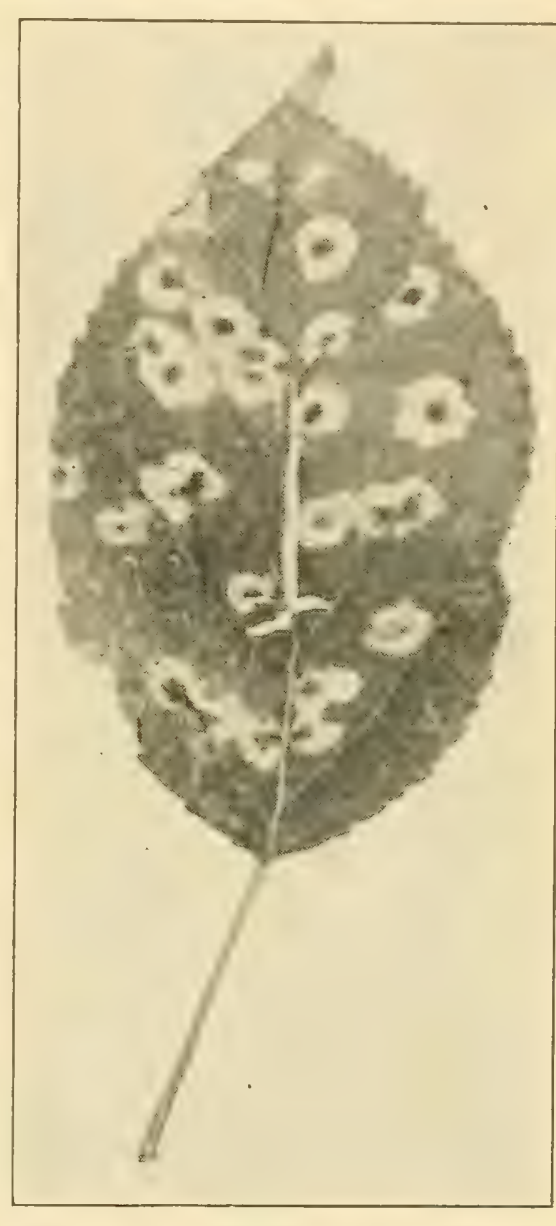

FIG. 15. - Apple leaf affected with rust. After Anderson. acteristic spots on the leaf, or more rarely upon the fruit or twig. These spots, yellowish green at first, gradually become darker, approaching orange. Upon close examination, the upper surface of one of these discolored spots is seen to contain numerous pustules, at first honey yellow, finally black, 
smaller than a pinhole, while upon the lower surface of the diseased spot appear some weeks later the fringe-toothed cluster-cups. This spot is sometimes so abundant that its presence upon orchards may be recognized at great distances by the characteristic hue imparted to the foliage mass as a whole. Rust robs the tree of nourishment and renders normal fruitage impossible.

A peculiar relation exists, in that the causal fungus spends part of its life on one plant, the apple; and the remainder upon a totally different plant, the red cedar (Juniperus), the Alternate Host of the apple rust. The fungus summers upon the cultivated apple or the wild crab-apple tree, from which later spores are borne by the wind to adjacent juniper or red cedar trees. There the fungus grows and causes the familiar "cedar apple."

In the spring the cedar apple produces gelatinous, hornlike projections, each bearing myriads of spores, which, when conveyed by the wind to the susceptible apple tree, under suitable conditions, cause the apple rust. Evidence that this relation really exists is readily found if one examines an orchard having red cedar trees upon its windward boundary.

It is clear that the more red cedar trees there are in the neighborhood of an orchard, especially to windward, the more probability there is of damage from the rust. The rational treatment, therefore, is to remove these trees in so far as possible, or if the value of the cedar warrants it to hand-pick the cedar galls.

In rare instances spores may be carried several miles, but orchards are reasonably secure if all possibility of infection from the immediate neighborhood be removed; that is to say, for a radius of two miles. In case the red cedars are too numerous, or if for other reasons it is impossible to cut them, spraying the apple trees at a time corresponding with the spore discharge from the cedar-galls will lessen the evil, but the success of spraying is neither complete nor certain.

Resistant apple varieties are: Yellow Transparent, Maiden 
Blush, Baldwin, Grimes, Stayman, Winesap. The following are more susceptible: Wealthy, Jonathan, Rome, York Imperial, Ben Davis, Greening.

Fire-blight ${ }^{ \pm 3}$ (Bacillus amyloromes (Burr.) Trev.). - Description and discussion of this disease will be found on

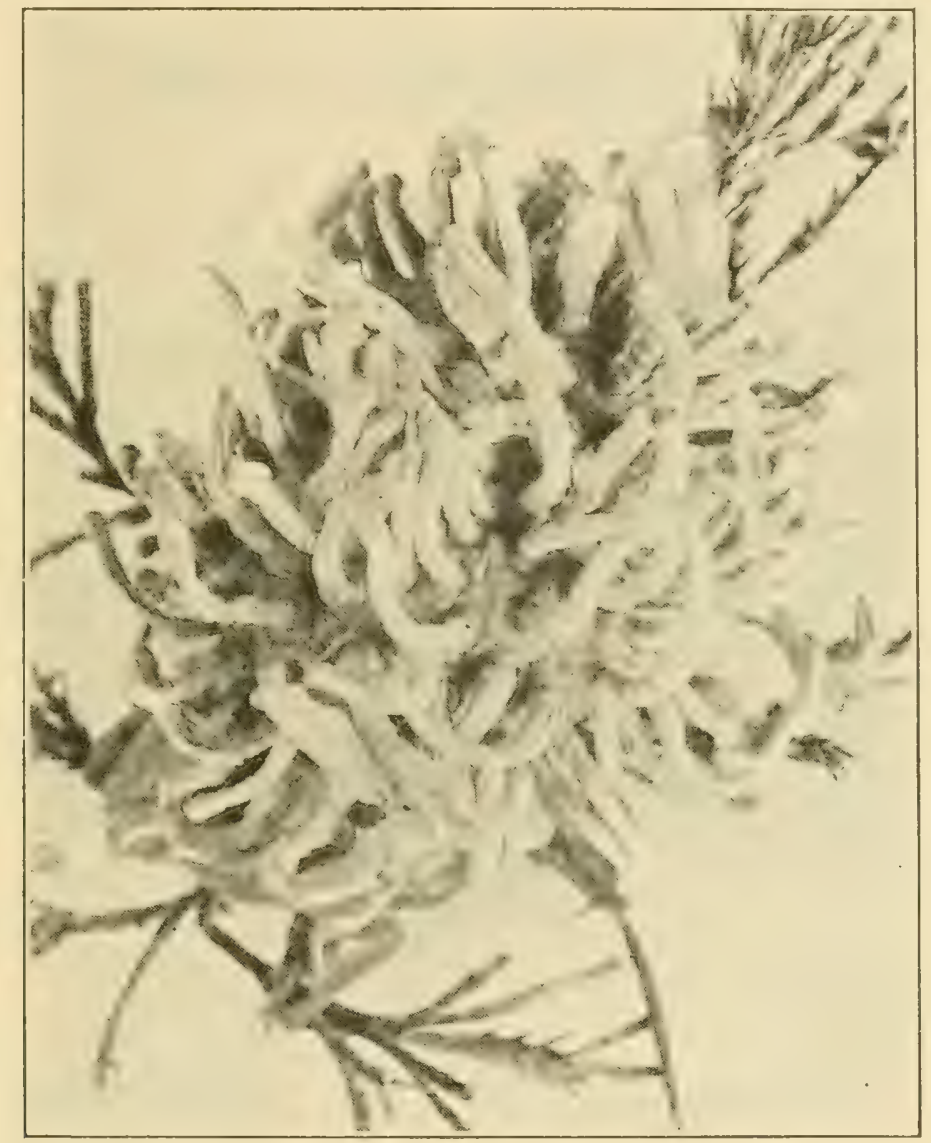

FIG. 16. - A cedar apple in condition to give off spores. After Anderson.

page 62 under pear, the blight of which is identical with the apple disease. Its character and treatment, are the same upon both hosts. While the blight is preëminently a pear disease, it also affects the apple very seriously, particularly in the form of blossom-blight and body-blight. 
The Lowell, Isham, Smith Cider, Yellow Transparent, Jonathan, and Willow Twig are especially susceptible varieties, while Celestia, Buckingham, Mammoth Black Twig, White Winter Pearmain, Winesap, and Ben Davis

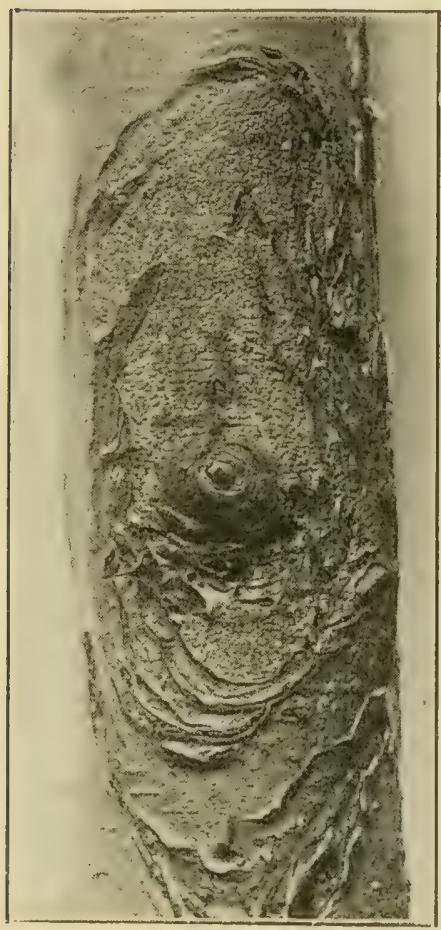

Fig. 17. - Apple black-rot canker showing numerous pycnidia. After Whetzel. are resistant, the last almost entirely so. In general the crab varieties are more susceptible than others.

Black-rot, canker ${ }^{44,}{ }^{45}$ (Physalospora cydonia Arn., Sphoropsis). In many respects this disease closely resembles the bitter-rot, particularly in that it appears both as rot of the fruit and as cankers upon the limbs. In some instances it also appears as a twig blight and as a leaf spot. As seen under the hand lens the coils of exuding spores are black, instead of pink, as is the case with bitter-rot. A compound microscop? is necessary to bring out other distinguishing characters.

The limb cankers, first studied by Paddock, consist of swellings, with the bark rough, and black. In other cases the black, decayed wood from which the bark has disappeared is exposed. This cankerous infection sometimes extends for nearly a meter along the branch, and occasionally girdles it. When occurring upon the trunk or main branches it is called black-rot body-blight.

The Tolman Sweet is said to be quite resistant to canker, while Twenty Ounce is very susceptible. Four other varieties range in susceptibility as follows: Baldwin, Wagener, Greening, King.

Black-rot twig-blight somewhat resembles fire-blight with 
which it is often associated, but may he distinguished from it by the presence of myriads of minute pimples distributed thickly over the affected region. With a hand lens coils of spores may often be clearly seen issuing from these pustules.

Upon the leaf, blighted spots are produced, irregularly circular in outline, oíten marked by concentric rings. The body of the spot is brownish and the margin sharply limited. Similar spots are caused in several other diseases, and definite knowledge of the nature of leaf spots must depend upon microscopic diagnosis in each special case.

The various forms of this disease which have been noted above are found in Nebraska, Michigan, the Ozarks,

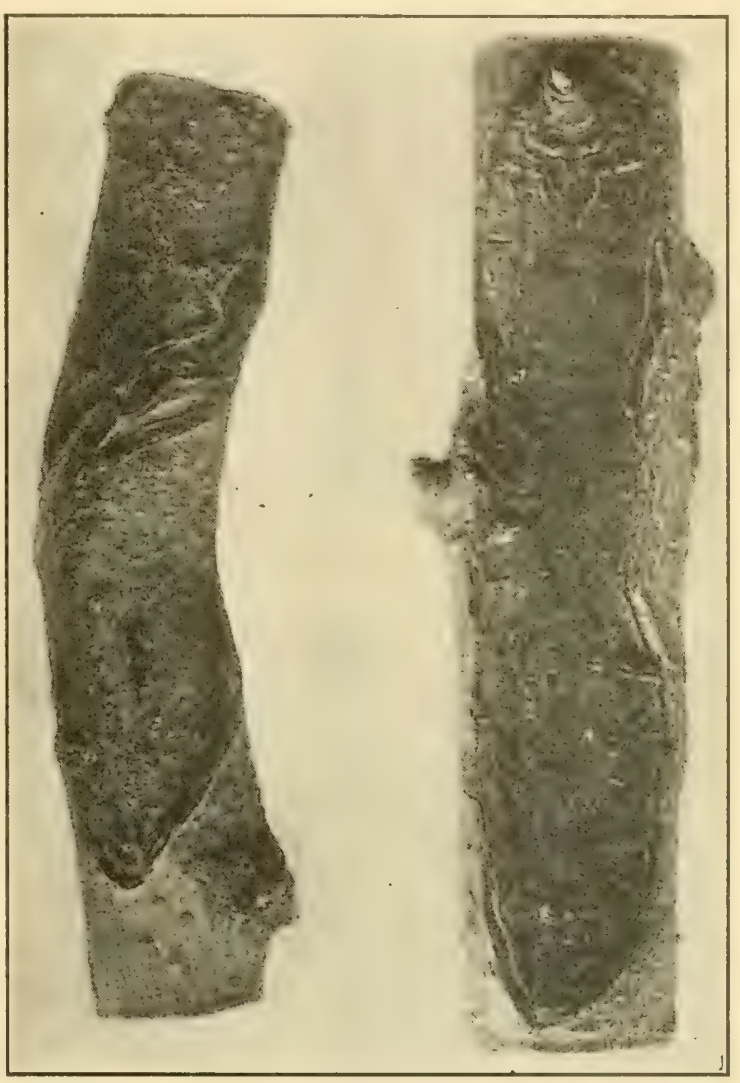

Fig. 18. - Pacific coast canker. After Cordley. Ohio, Wisconsin, and throughout the Allegheny and eastern apple sections, and are troublesome each year.

The treatment should be the same as that recommended for bitter-rot with special care to avoid bark wounds of all kinds, as from ladders and workmen's boots.

A rot upon fruit very similar to bitter-rot, and a twig- 
blight very similar to that of black-rot, though less important, is caused by Coniothyrium fuckelii Sacc. ${ }^{46}$

Pacific coast canker ${ }^{47,}{ }^{48}$ (Neofabrøa malicorticis (Cord.) Jack., Gloosporium). - The Pacific coast canker, first noted about 1893, is particularly destructive in the Northwestern states and British Columbia west of the Cascade Mountains.

The bark or sapwood of twigs and larger branches is the seat of infection, but the disease may occur also upon the fruit when in storage. The loss of an entire orchard within a few years has resulted. Young trees, owing to their tender bark, are especially susceptible.

Upon twigs, cankers in the early stage appear as round or oval, slightly sunken, dark areas which increase but slowly in diameter. As soon, however, as the fungus penetrates into the cambium and sapwood the canker enlarges very rapidly, making its most rapid development through the cambium, and advancing more tardily through the overlying bark. The resulting spots are nearly circular, quite black, and from $5 \mathrm{~mm}$. to $12-14 \mathrm{~cm}$. in diameter. When old, the bark becomes brittle and a definite fissure separates the dead from the healthy portions, indicating cessation of advance of the fungus. The diseased bark eventually falls away, leaving a scar. Branches, or even trees, may be killed by girdling cankers.

Upon stored fruit the disease appears first as light-brown, circular, rotten spots. These later turn very dark or black, and become depressed, dry, and tough. Acervuli similar to those upon the bark soon develop in concentric circles.

When the cankers are few, on small trees, excision may be practiced to advantage; when, however, there are hundreds of cankers upon each tree, this treatment is manifestly impracticable. Spraying with strong Bordeaux mixture in the fall, after the crop is gathered and again after an interval of about three weeks, is valuable to prevent the formation of new cankers, and has established practical control of the disease.

Blister-canker ${ }^{49-51}$ (Nummularia discreta (Schw.) Tul.). Attention in America was first called to this active, parasitic 
disease in 1902 by Hasselbring, who attributed to it more serious results than from any other canker disease of Illinois. In many cases large limbs and even whole trees are killed. It has been reported in many states, including Arkansas, Oklahoma, Nebraska, New Hampshire, New York, and Virginia.

The cankers are at first inconspicuous, unhealthy, dirty brown, usually depressed spots in the bark, sometimes $15 \mathrm{~cm}$. in diameter, which enlarge rapidly, particularly lengthwise upon the limb, a crack often marking the boundary between dead and sound bark. The interior of the bark of such spots is mottled with dead regions.

In autumn the sporiferous bodies appear near the borders of the diseased spots, first pushing through cracks in the bark, and exposing pale grayish ochre-colored fungous growths 3-6 $\mathrm{mm}$. in diameter,which, when mature, are slightly saucer-shaped, and dark in color. These bodies are attached to the dead wood, and remain there even after the bark has fallen away, thus constituting a
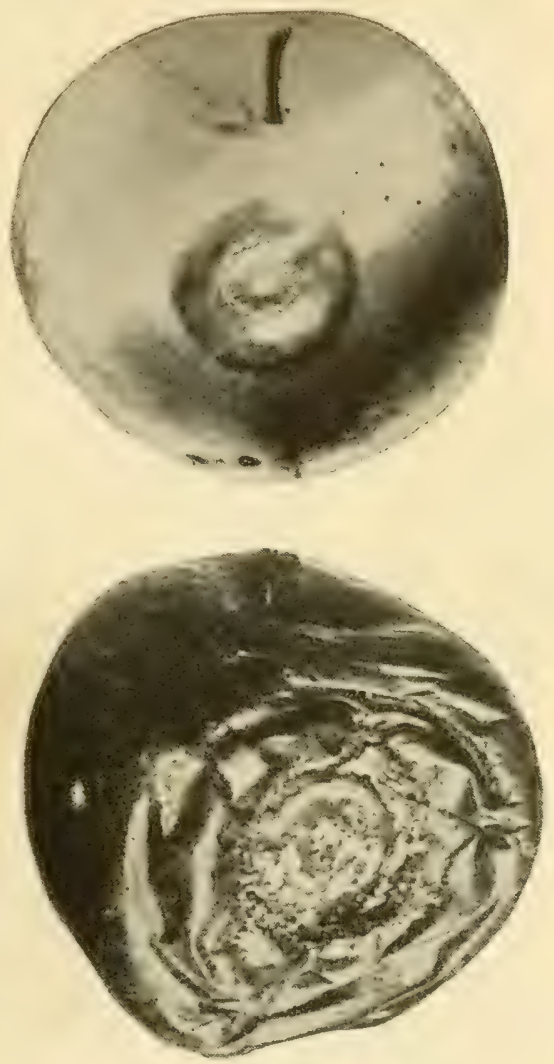

FIG. 19. - Black-spot on fruit. After Lawrence.

diagnostic character of absolute reliability, separating this from all other cankers. Discoloration of the heartwood often occurs at a distance of a meter or more from the apparent seat of disease.

When the cankers become large, injury to the distal parts through interruption of the water supply results. The 
leaves show symptoms of cliscase, and the fruit fails to grow to full size. With complete girdling the limb dies.

Since all infection seems to occur through wounds, prevention must look largely toward the avoidance of wounds

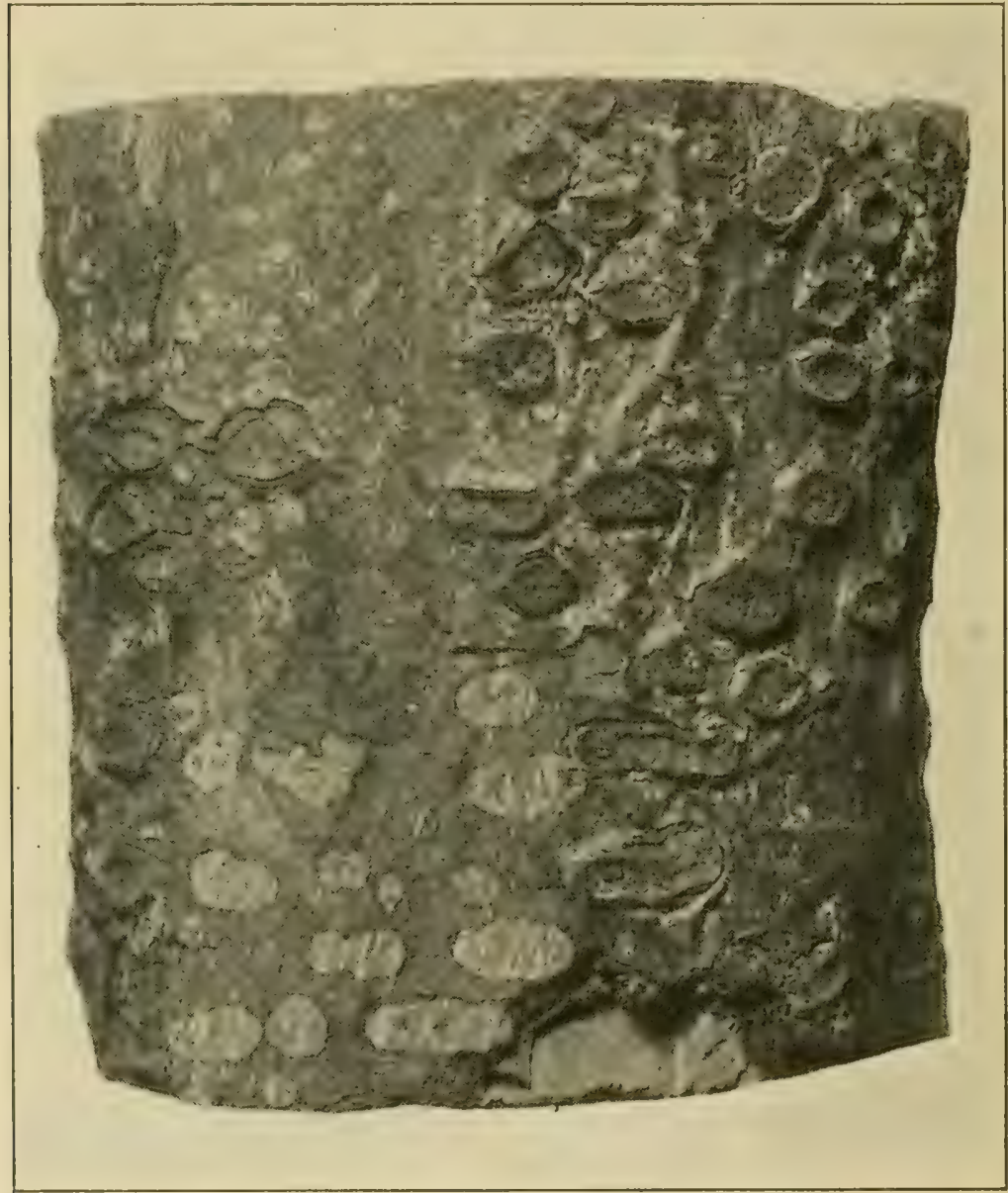

Fic. 20. - Blister-canker. Some of the dises have been removed to show the underlying marking.

by tools, machinery, harnesses, pickers' ladders, boots, etc. It is also an excellent sanitary measure to cut out and burn all infective material, and in incipient cases excision of discased tissue in a limb may be practiced with nrofit. 
Leaf-spots ${ }^{53-55}$ (various fungi) (see also black-rot, p. 42). - Aside from the leaf diseases of apple already mentioned, there are numerous other leaf-spots due to various causes. These spots partake of the same general character. That is, they are brown to tan-colored, at first circular, later irregularly circular, definitely bordered, and usually concentrically marked. If abundant, or if they enlarge rapidly upon the leaves, they cause their premature fall, and largely defoliate the tree. Such spots prevail to greater or less extent in all apple orchards but are most destructive in the Southern states. Numerous species of fungi have been isolated from these spots; some of them undoubtedly sustain a causal relation to the disease. Sheldon claims that in West Virginia much of the apple leaf-spot is due to an Illosporium.

Whatever the actual sausal fungi may be, these spots are all, or nearly all, of fungous origin and are amenable to preventive

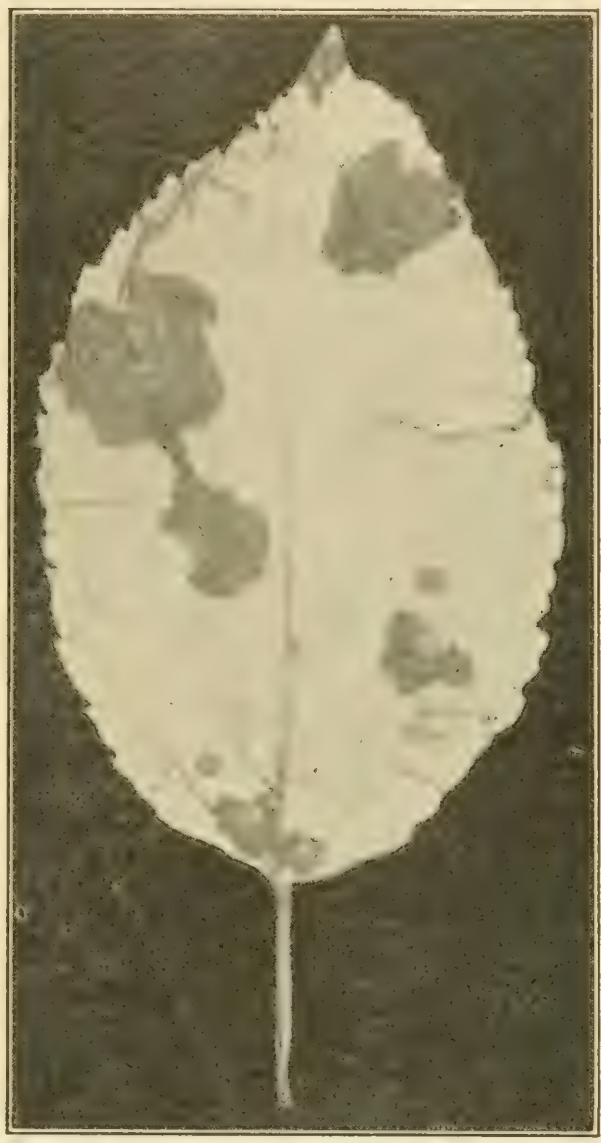

FIG. 21. - Apple leaf-spot in late stage of development, showing concentric rings. Original. spraying. The first of three or four applications should be given with the opening of the leaf buds.

Hypochnose 56, 57 (Corticium stevensii. (Noack) Burt). Superficially this disease resembles the blight, with which it is likely to be confounded by the casual observer. It may 
readily be distinguished, however, by two characters: first, the manner in which the leaves droop and mat together,

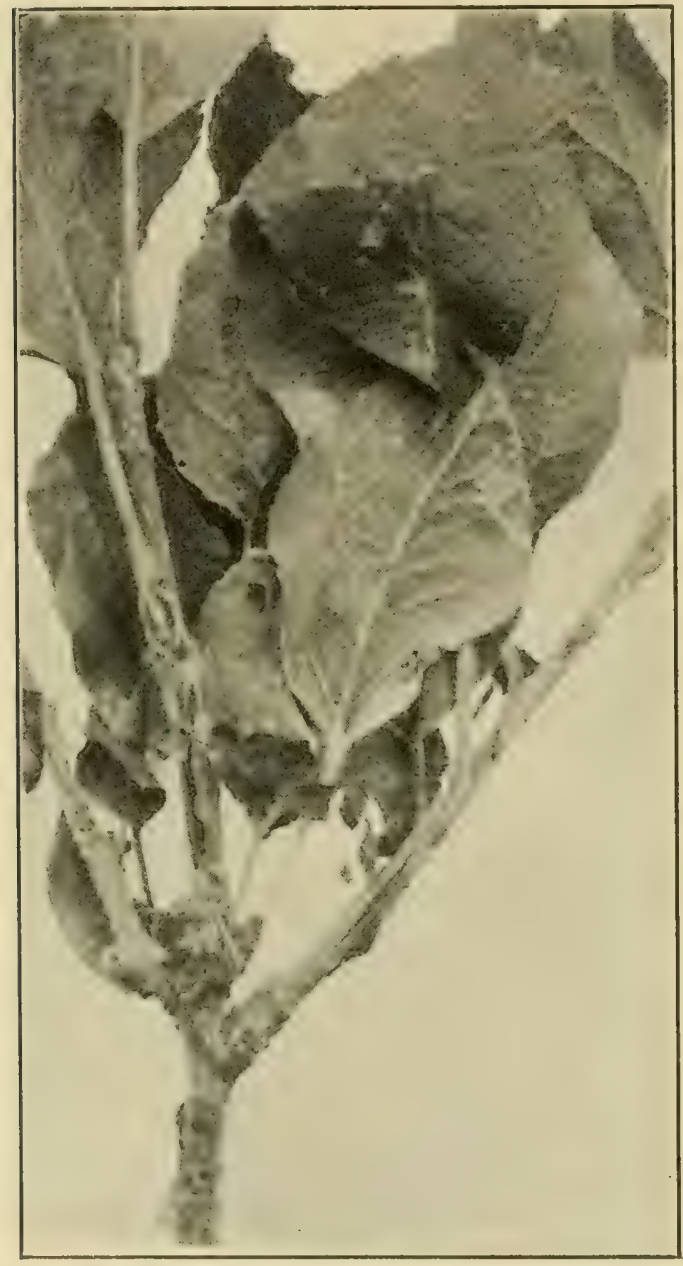

HIG. 22. - Hypochnose, showing matting of leaves. Original. which is quite different from the habit of the blight, the leaves of which neither droop nor become matted; second, by the presence of small sclerotia, white when young, cinnamon-brown when mature, upon the twigs adjacent to the affected leaves. These sclerotia usually measure about 2-3 $\mathrm{mm}$. in diameter. Together with the sclerotia and extending along the twig longitudinally are also found silvery, glistening, thread-like, fungous growths.

This fungus hibernates in the sclerotia on or near the terminal bud and thence invades the new twigs as they develop, reaching out upon each leaf, spreading over its under surface in almost invisible thinness, and causing it to droop, die, and eventually to fall away. Thus, in early autumn, such trees are nearly or quite defoliated. The fruit may also be invaded by the fungus.

Hypochnose, first described from Brazil, is known from Maine to Florida and Texas. It seems to be especially de- 
structive in regions of excessive humidity, particularly in the deep mountain valleys of the Appalachians, where whole orchards are sometimes seriously affected.

Owing to the entirely superficial nature of the fungus which causes the disease, and its habit of hibernating upon the twigs, the trees should be sprayed with a strong cleansing mixture, Bordeaux or bluestone, before the buds open, and again just before the blossoms open.

Pink-rot ${ }^{58}$ (Cephalothecium roseum Cda.). - This rot is known in many states. It follows apple or quince scab and may be recognized by the white, mildew-like growth which appears in conjunction with the scab which it soon after entirely overgrows and turns to a pink color.

While the decay is really caused by Cephalothecium, a rupture made in the skin by the scab fungus is the usual place of entrance. The decayed spot is shallow and slow-growing as compared with other rots. It is accompanied by a bitter taste

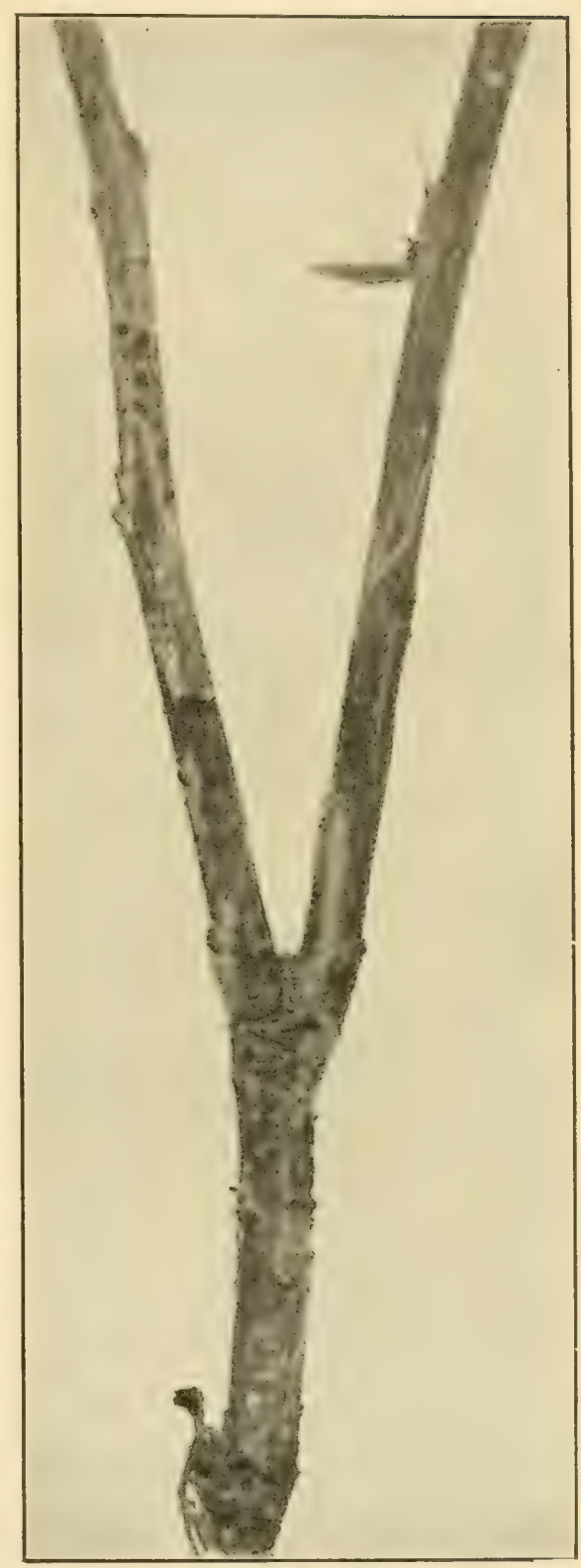

FIG. 23. - Hypochnose, showing sclerotia on twig at left and rhizomorphic strands on twig at right. Original. 
which is so pronounced as to injure cider made from affected apples. The chief destruction follows the harvest, though the disease is sometimes found in fruit still upon the tree.

The Rhode Islañd Greening, Fall Pippin, Fameuse, Maiden Blush, Tompkins King, and Twenty Ounce are especially susceptible.

Chief attention should be directed to the prevention of

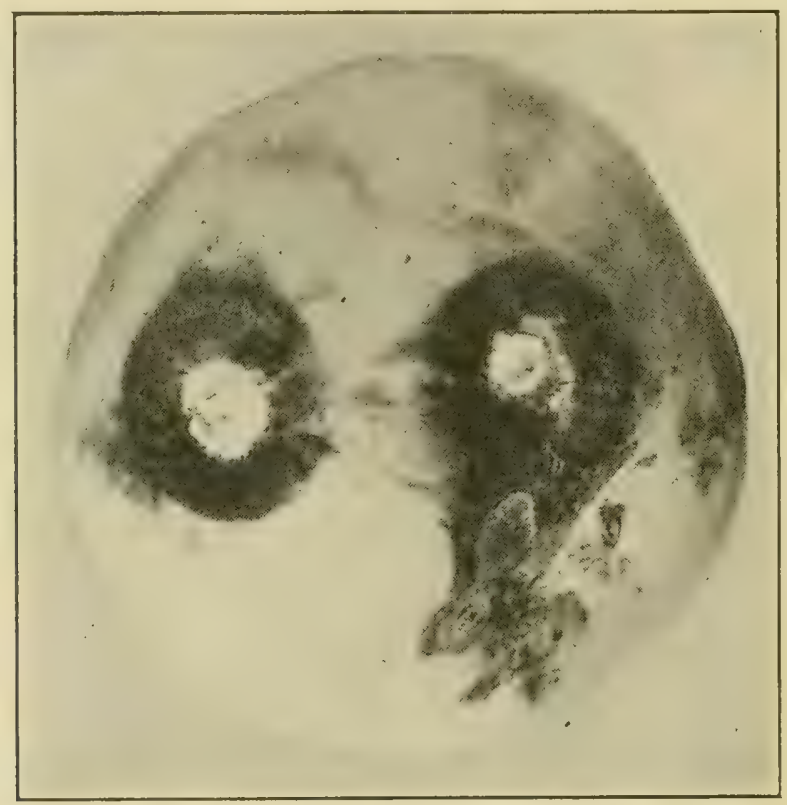

FIG. 24. - Pink-rot following scab. After Anderson.

scab. In storage a dry house, well ventilated, kept at $0^{\circ} \mathrm{C}$. $\left(32^{\circ} \mathrm{F}\right.$.) gives best rot resistance.

Another form of pink-rot due to a species of Hypochnus has been described by Eustace ${ }^{59}$ especially upon Baldwins and Rhode Island Greenings. There is no large surface growth of the fungus on the diseased spot, but the rot often extends to the core.

Powdery-mildew ${ }^{61,62}$ (Podosphoral eucotricha (E. \& E.) Salm., Oidium). - The general appearance of this mildew is similar to grape mildew; that is, the surfaces of the leaves 
are more or less covered with a white or grayish fungous growth, in the later stages of which are found numerous very small black fruiting bodies approximately $0.25 \mathrm{~mm}$. in diameter. This fungus, while of comparatively little significance to old apple trees, causes much injury to nursery stock, often becoming so serious as to prevent successful budding. Mildew has been reported as especially serious in California and other states west of the Rocky Mountains, and is of some importance in all apple regions. In the Pajaro Valley the fungous mycelium has been shown to hibernate in the buds, resulting in early spring infection of shoots.

Another species of mildew, P. oxyacanthe (DC.) De Bary, shows the same general characters as the mildew described above, but is of less economic importance. Three or four lime-sulfur sprayings at intervals of about two weeks, beginning when the buds commence to open, have given best results.

Crown-gall. See peach.

Soft-rot, blue-mold rot (Penicillium expansum Lk.). - Perhaps the most common apple rot is found upon stored apples late in the year. The light, tan-colored rotted area is soft and watery. The decay results in the complete loss of the affected fruit, and, by contagion, in loss to the fruit mass.

Upon cracks in the decayed surface, and eventually over the whole rotten part, appear tufts of very short delicate fungous threads, at first white, soon bluish-green, very like the common blue-mold so familiar to the housewife upon canned fruit, the seal of which has permitted air to enter. This blue substance upon the rotten apple consists of myriads of the spores of the causal fungus. This fungus is comparatively unaggressive and cannot force its way into perfectly healthy tissue; a bruise or rupture of the skin is necessary to its invasion. The best preventive is care to avoid bruising.

Root-rot ${ }^{65}$ (various fungi). - Death of trees, without apparent reason from evidence above ground, is frequently due to disease and decay of the roots. While the earlier symptoms may vary, in general they include an abnormally 
large set of small fruits, and in the following season few flowers, deficient growth, and small leaf development and perhaps chlorosis. In cases where only a few roots are diseased the evident effects may be limited to the correspond-

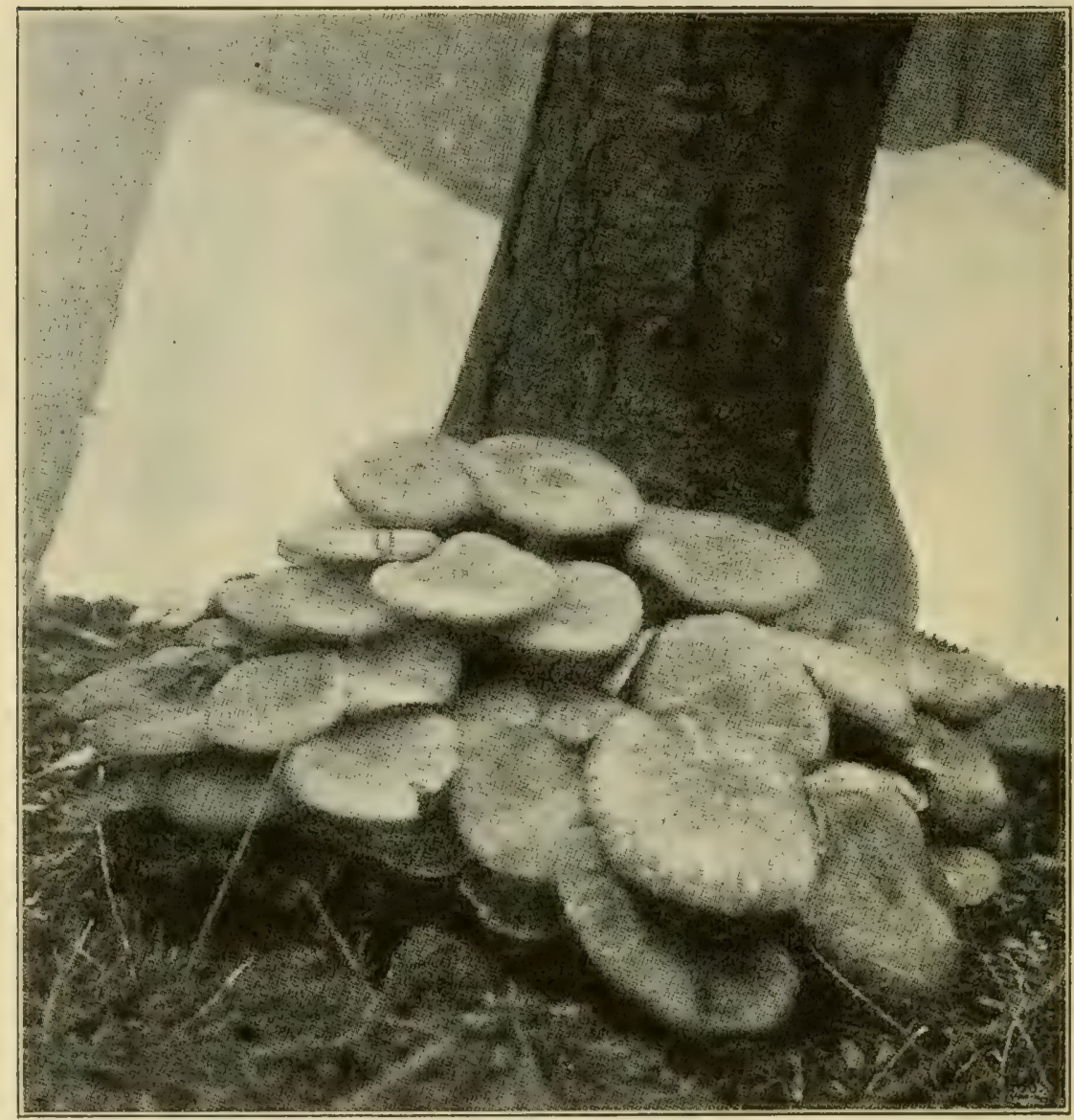

FIG. 25. - Clitocybe upon apple. After Wilcox.

ing side of the tree. Several years may elapse between the appearance of the first symptoms and final death. The roots, one or all, of trees well advanced in disease show decay, dependent in character upon the causal fungus. Several different fungi cause root-rot (see p. 370). Among those most common on fruit trees are: Clitocybe parasitica Wil. A 
gummy exudate is usually present around the base of the tree and black rhizomorphs arthere to the roots. In late stages clusters of the gill-bearing sporophores (Fig. 25) develop; Armillaria mellea Vahl. Quantities of black, stringy, hard, shiny strands 1 to $2 \mathrm{~mm}$. in diameter occur around the roots and in the adjacent soil. The gilled sporophores appear later (p. 370); Fomes annosus (Fr.) Cke. The sporophores are pore-bearing (p. 371); Septobasidium sps. with smooth pore-bearing surfaces; Ozonium omnivorum. Sh. See Texas root-rot (p. 23); Xylaria sps. ${ }^{66}$ The affected roots are covered with a thin, compact growth of mycelium, white at first, later developing into a black incrustation. Minute, threadlike rhizomorphs radiate several centimeters along the root.

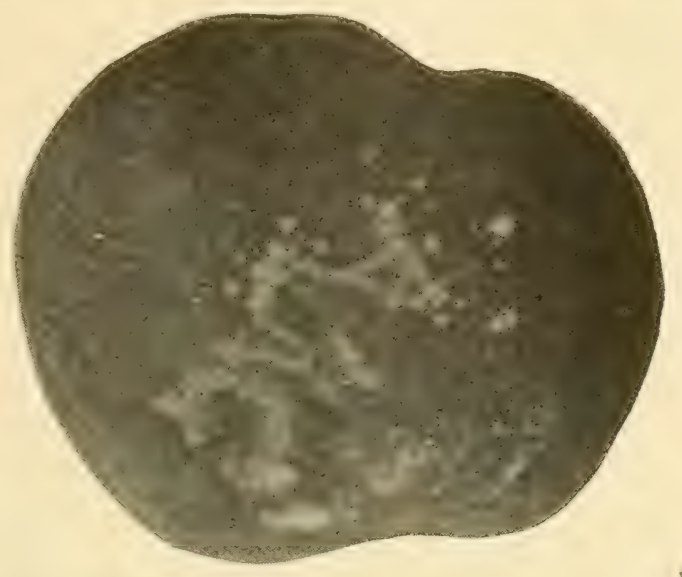

FIG. 26. - Brown-rot produced by inoculation. Note the fungus forms the letters A. M. C. Original.

Affected roots are soon girdled and the distal parts die.

Root-rot, due to one or another of these causes, is of wide and common occurrence, and results in large loss. It is found more frequently on newly cleared land than elsewhere. When the disease has advanced far enough to be recognized, no cure is available, and it is unsafe to replant in the infested place. Wood bearing root-rot fungi should be burned to lessen infection.

Wood-rot ${ }^{67}$ of orchard trees is of the general character discussed under Decay in live trees on page 354. It is a very important source of loss on fruit trees of all kinds, about one-half of all bearing trees being infected. The rot may chiefly be avoided by preventing wounds or by treating them with disinfectants. See p. 378 . 
Frost Injury. ${ }^{94}$ - Varieties of apples differ from each other in their susceptibility to injury from cold. The injury may be local, on single twigs, or spots on twigs, body, or branch; or general, affecting the whole tree. The damage may be apparent externally or show at first only in a discolored cambium. "Sun scald," in which the frosted bark occurs as a cankered area and either peels off, or elings tightly and is sunken, is a frost injury. Twigs may be killed outright, especially if the wood has not ripened properly. Late spring frosts injure, as is well known, the buds, blossoms, etc. Frost cankers may form the threshold for the entrance of various fungi and thus pave the way to disease, $e . g$. blackrot or bitter-rot cankers. A cover crop tends to lessen frost injury, by diminishing excess moisture in the fall, while avoidance of cultivation late in the season hastens maturing of the wood.

Bitter-Pit ${ }^{68}$ consists of a pitting of the fruits with slightly sunken circular spots varying from mere dots to $5 \mathrm{~mm}$. in diameter, which finally become brown. The tissue at the bottom of the pit is dead, brown, and spongy. Similar lesions may occur deep within the tissue of the apple. No parasite is present and the trouble seems to be due to improper water relations. The disease causes considerable loss over a large range of territory. Thinning the fruit to a proper set lessens the damage. Pitted fruit should either be consumed at once or stored or shipped under low-temperature conditions $\left(30^{\circ}-32^{\circ} \mathrm{F} .,-1^{\circ}-0^{\circ} \mathrm{C}\right.$. $)$

Jonathan-Spot ${ }^{69,}, 473$ occurs on several varieties of apples including the Jonathan, Esopus, Wealthy, Ortley, and Wolf River. The spots are circular, $2-15 \mathrm{~mm}$. in diameter, abruptly but slightly depressed, light brown in color, and are more superficial than those of bitter-pit. The disease may appear on fruit still on the tree or may develop during storage or transit. The cause is unknown. Fruits of variety tending to spot should be consumed early or placed in cold storage.

Scald ${ }^{t i t}$ is a storage trouble particularly serious on im- 
mature apples. It is due to gases given off from apples and may be avoided by aëration.

\section{Minor diseases.}

European canker ${ }^{\text {'2 }}$ (Nectria galligena Bres.). - The European canker was not recorded upon the apple in America prior to 1899, when Paddock mentioned its presence in Nova Scotia and New York. Later it was noted in New Hampshire and Ohio and is now known to be widely distributed from the Atlantic to the Pacific. It constitutes a serious discase in Europe and may become of importance here. The canker enlarges year after year, but more slowly than black-rot canker, and displays, when fruiting, numerous minute, deep red perithecia which serve to distinguish it from other cankers.

Brown-rot ${ }^{60}$ (Sclerotinia cinerea, Monitia). - One of the most serious apple rots in Europe, this disease fortunately is not as yet destructive in America, though Sclerotinia cinerea is occasionally met with as one of the minor causes of apple losses. It has been observed in sereral states, notably New York, Missouri, Nebraska, the Virginias, North Carolina, Illinois, Minnesota, Arkansas, and New Mexico frequently enough to call for printed mention. Brown-rot produces complete decay of the affected apples, which turn brown, or later black, become soft and wrinkled, and soon show pustules of bushy mycelium breaking through rifts and fissures in the skin over the diseased tissue. The diseased fruits may mummify upon the tree or more frequently fall to the ground and there shrivel to dry, hard, wrinkled masses, in which the rot fungus winters.

Sooty-blotch ${ }^{472}$ (Gloodes pomigena (Schw.) Colby).Irregular, sooty, black blotches, especially conspicuous on the lighter colored varieties of apples, are frequently seen upon unsprayed fruit. The individual blotches measure from $0.5-2 \mathrm{~cm}$. across and are often so abundant that they coalesce, giving the fruit a dirty appearance. The fungus attacks the fruit late in the season, and is strictly superficial. 
It may easily be rubbed off with a cloth. The loss in ready salability, due to the unsightliness of the fruit, is reason enough for protective sprayings. Bordeaux mixture applied at intervals of about two weeks from the middle of June until the middle of August is effective.

Fly-speck. ${ }^{472}$ - Growing upon the surface of the fruit and forming numerous clustered black specks closely resembling

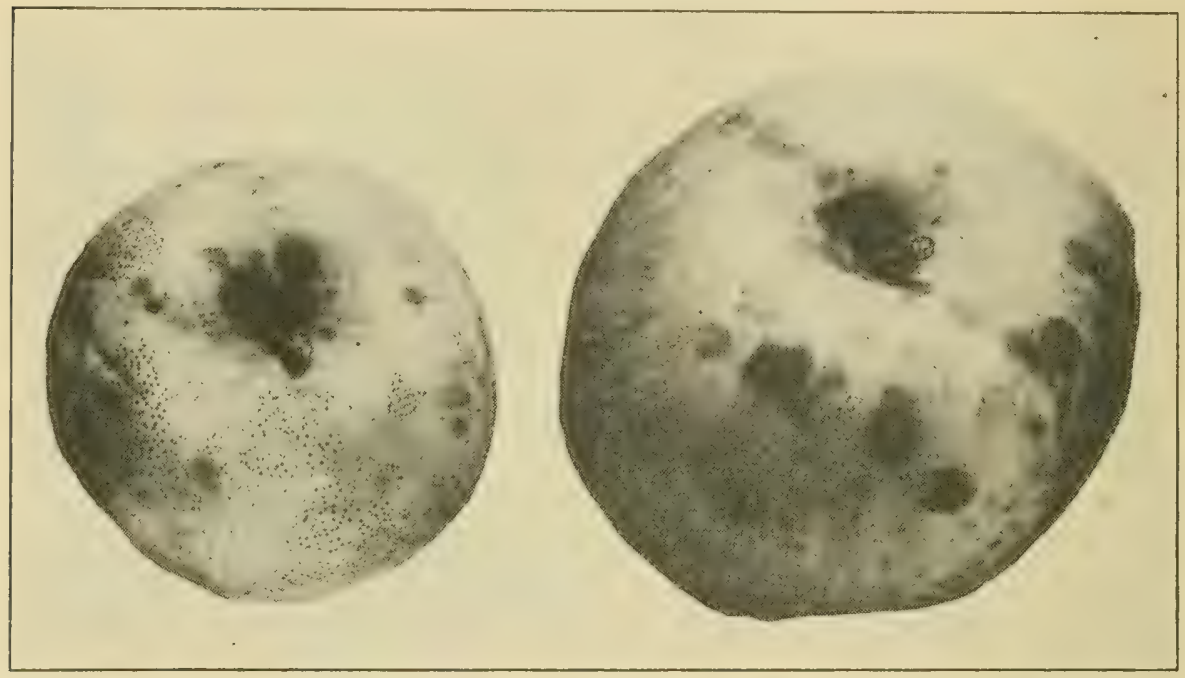

FIG. 27. - Fiy-speck (at left); Sooty-blotch (at right). After Colby.

fly-specks, this fungus causes disfigurement of the apple. The generic position of the fungus is in doubt, though it was originally named Labrella pomi by Montagne.

Volutella rot $^{63}$ (Vo'utella fructi S. \& H.). - In general appearance the volutella rot is not readily distinguished from black-rot, though the texture of the rotted tissue is much firmer and drier. Under the hand lens the sporiferous pustules are seen to be clothed with numerous hairs, which character sufficiently marks it as a separate disease. It has been reported from North Carolina, New York, Wisconsin, and is probably of general distribution.

Scurf, an affection of the bark of twigs, is due to Phyllosticta prunicola (Opiz.) Sacc.; Bark-canker ${ }^{72}$ (lue to Myxospo- 
rium corticolum Edg. is superficial on both apples and pears and of little importance; the Fruit-spot, ${ }^{61,71}$ (Phoma pomi Pass.), occurs in the northeastern United States, the spots are small, sunken, brown or black; Rough-bark ${ }^{\text {t2 }}$ is caused by Phomopsis mali Rob. The Septobasidium canker is due to Septobasidium pedicillatum (Schw.) Pat. Phytophthora cactorum (L. \& C.) Schr. causes a fruit rot. Black-mold, due to Fumago vagans, is superficial, while black-mold due to Alternaria sps. produces a core rot. Plenodomus canker ${ }^{400}$ (Plenodomus fusco-maculans (Sacc.) Coons) kills the cortex, which eventually flakes off in long strips leaving the wood bare. Die-back canker ${ }^{480}$ (sce peach) is occasionally present, also Fruit rots due to Endomyces and Rhizopus. Rosette, which rescmbles peach rosette, has been noted in three states.

\section{Conditions Infidencing the Spraying Schedule for Apple Disease*}

A spraying schedule which may give the best result in one part of the country when used in spraying a certain variety may be unsatisfactory in another part of the country, or for another variety or in another season, or in another orchard in the same part of the country. No attempt is made, therefore, to present definite spraying schedules, although an attempt is made to present briefly the considerations which govern them.

Primarily, sprays are applied commercially to control apple scab, apple blotch, and bitter-rot. The control of other fungi with the exception of apple rust is usually incidental to the control of these three.

To secure the best results it is necessary to make the first application of fungicide before the first infections take place, and to repeat at sufficient intervals to give protection from this time on. In general, it may be said that the first apple-

* Prepared by W. A. Ruth. 
scab infections usually occur about the time the trees are blossoming, and that serious damage may be caused by infections taking place for four or five wecks after the petals have fallen; that the first serious infections of apple blotch may take place three or four weeks after the petals have fallen, and that further infections, resulting in serious damage, may occur for a period of five or six weeks; that the first infections of bitter-rot may occur about the middle of June,

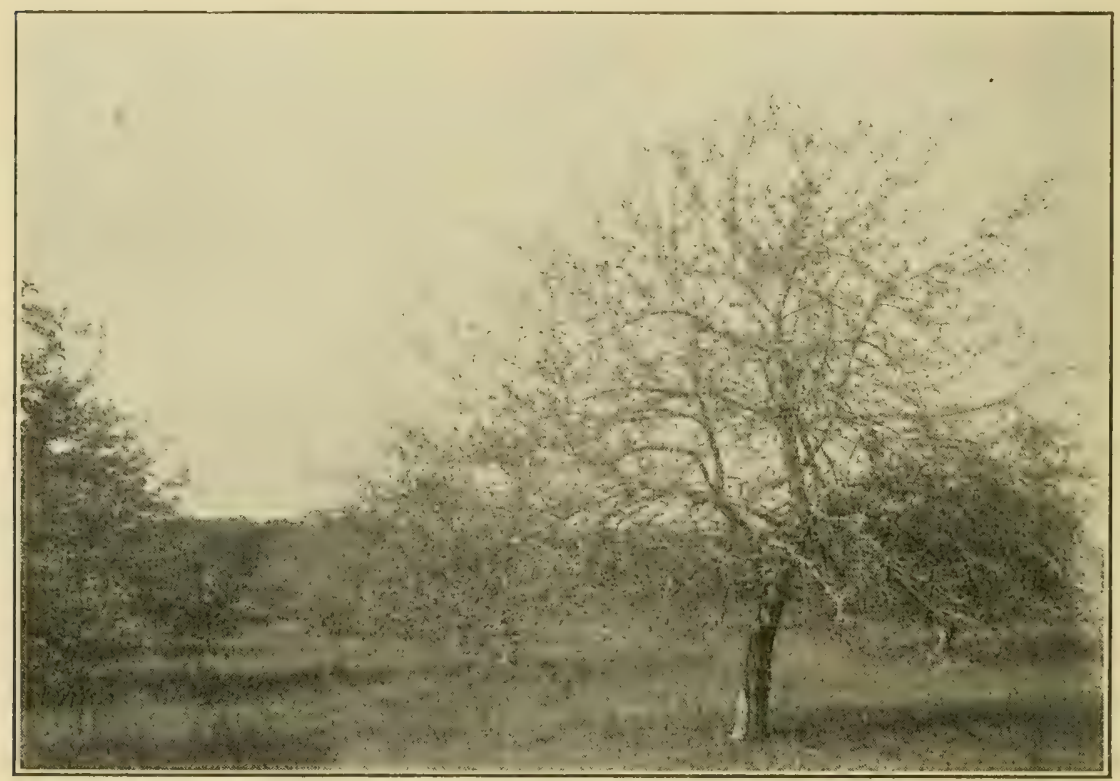

Frg. 28. - Unsprayed apple trees. After Scott and Rorer.

the period of possible infection continuing throughout the season, the probability of infection being greatest in hot, wet weather.

The choice of the fungicide and the decision as to when to spray are governed by several considerations. These include the local conditions, among which may be placed varietal susceptibility to apple scab, and the probable local varietal susceptibility to other fungi, seasonal weather conditions, and varietal susceptibility to spray injury.

Locality. - Apple scab, apple blotch, and bitter-rot are so 
distributed, as to the localities in which they produce serious injury, that in the northern apple-growing regions of the eastern United States orchardists spray chiefly to control apple scab; in southern apple-growing regions, it may be necessary to control apple scab, apple blotch, and bitter-rot; and in other regions to control scab and blotch. The general climatic relationship of these fungi in the eastern United States may be illustrated roughly by their behavior in

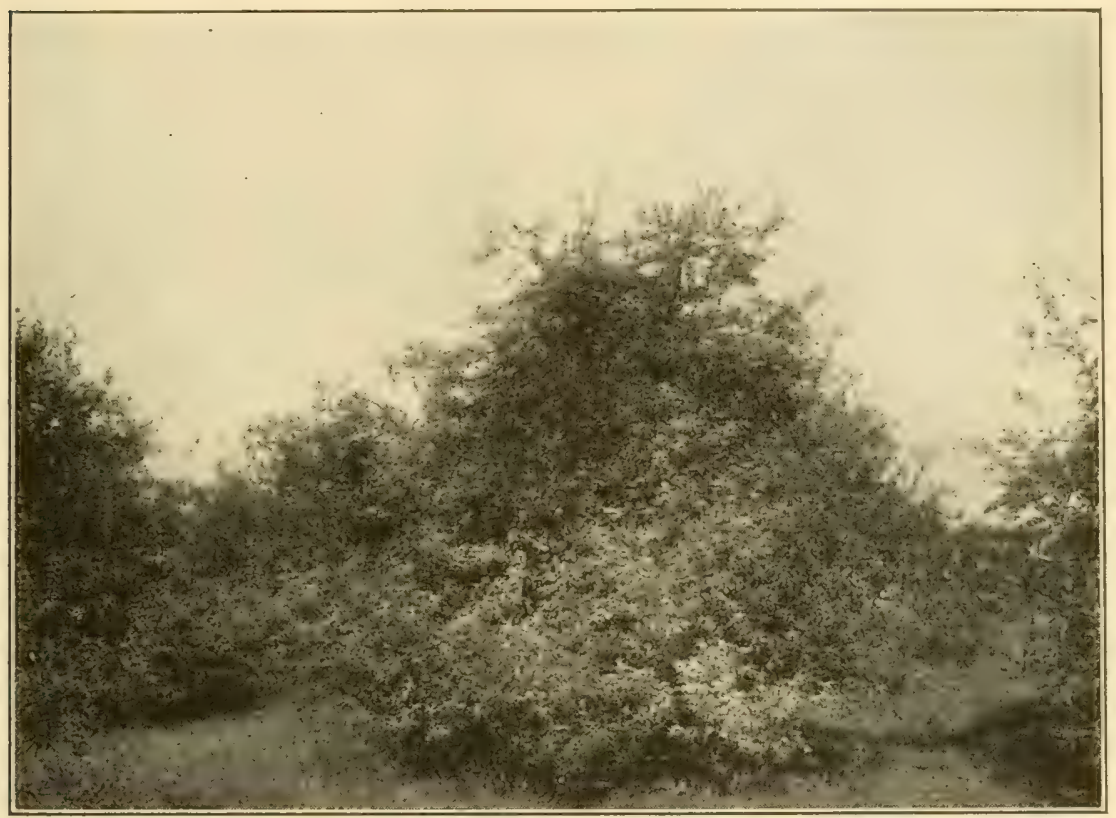

FIG. 29. - Sprayed apple trees from the same orchard as those shown in Fig. 28.

Illinois. Apple seab is a serious disease in all parts of the state; apple blotch is a serious disease as far as $40^{\circ}$ north latitude; and, ordinarily, bitter-rot does not cause serious damage north of $39^{\circ}$ latitude. It is thus necessary, in the northern part of the state, to spray for apple scab only; toward the southern part, it is necessary to spray for apple scab and apple blotch; and still farther south, to spray to control apple seab, apple blotch, and bitter-rot. 
The relation between the apple and its parasitic fungi seems to vary, however, within more restricted areas. This may be illustrated as follows: The practice in the eastern United States has been to apply the first spray for apple scab just before the blossoms open, when the flowers in the cluster have separated from each other, and the pink petals are showing. (This is called the "pink," ol "cluster-bud," spray.) Wallace, ${ }^{34}$ after studying the period of ascospore discharge, stated, in 1913, that there seems to be little clanger in New York that infections of apple scab will occur much earlier than blossoming time, and that the cluster-bud spray is sufficiently carly. Childs, ${ }^{509}$ as a result of similar study, later showed that, in Oregon, two applications must be made before the bloom, the first coming when the leaves are quite small, followed by the "cluster-bud" spray. Since then various spraying schedules have been worked out experimentally in the East. Thus, Blair ${ }^{510}$ in Nova Scotia, recommends two applications before the bloom, while Morse's work 511 in Maine may be talien to show that in the locality from which his data were drawn little or no infection occurs before the blossoming period.

The relation differs not only with the locality but also with the variety of apple. Varietal susceptibility to or immunity from attack by one fungus is not necessarily correlated with the same relation toward another. This relationship seems to require local determination. The most susceptible varicties demand, of course, the most thorough treatment. The subject of varietal susceptibility to apple scab has been summarized by Wallace. ${ }^{34}$ (1) Certain varieties may appear to be immune in one season but may be very susceptible in another season, under different weather conditions. variety may be resistant in one year and susceptible in another year under conditions which for average varieties are as favorable to the discase in the one case as in the other. (3) Varietal susceptibility may cliffer in different localities. (4) Only in rare cases is a variety consistently and relatively immune over as short a period as five year's. The apparent 
immunity may increase or decrease.

(5) No variety is absolutely immune.

Varietal susceptibility to scab differs so markedly in different localities that general lists are of lit te value. The Ben Davis, for example, which is generally considered relatively immune to scab, is very susesptible in Illinois. The Yellow Transparent, stated to be seriously injured by scab in Ohio, ${ }^{512}$ is relatively immune in southern Illinois, and the Grimes, which, in Ohio, is moderately injured by seab, is relatively immune in Illinois. The Rome Beauty is seriously injured in both localities.

Weather Conditions. - IVeather conditions play a very important rôle in the outbreak of a discase. Wallace ${ }^{3+}$ states that "The ideal condition for scab infection is a gentle, continued rain followed by cloudy, calm weather and a saturated atmosphere, in which cases the spores are kept wet for a long time in one position. Ascospores have been known to germinate in a period of four hours, but it is probable that in order to produce abundant infection the trees must be kept wet for eight or ten hours or even longer." Ascospore discharge begins almost as soon as rain begins, or within five minutes after the time the leaves are wet and, under continuously wet conditions, an interrupted discharge of spores can be expected for some time. ${ }^{34}$

Roberts ${ }^{40}$ states that the dependence of apple-bloteh infection upon rainy weather in orchards in the Ozark section is very noticeable, but in Kansas, where the sources of infection - that is, the twig cankers - are much more numerous, the dependence is less noticeable.

"The conditions most favorable for the development of bitter rot are (1) a period of hot weather accompanied by frequent rains and heary dews at a period when the apple crop is approaching maturity, $i$. e., from the middle of July to the end of August. (2) Numerous sources of infection, $i . e$. cankers on the limbs and mummified fruits left hanging on the trees." Blair, ${ }^{31}$ from whom the above is quoted, sum- 
marizes the results of observation covering six years in Illinois as follows:

"It may be safely conclucled that moist weather with a considerable precipitation and a high temperature are favorable to the spread and growth of bitter-rot. There was no opportunity to note the effect of moist, cold weather though it might be argued from analogy, there being no evidence of the disease in northern and very little in central Illinois, where the rainfall is abundant and the mean temperature lower, that moisture without high temperature is not favorable to the development of the disease. Hot weather alone unaccompanied by moisture proved unfavorable to the spread of the disease, as seen in the season of 1901, but hot weather alone did not prevent the disease from accomplishing its work of destruction after infection had once occurred, as was observed in 1900 when the dry month of August followed the abnormally wet months of June and July."

The spraying schedule should be adjusted to meet the weather conditions. Rainy weather not only provides favorable conditions for infection but removes the protecting spray.

\section{PEAR ${ }^{536}$}

Fire-blight, blight ${ }^{73-76,115}$ (Bacillus amylovorus (Burr.) Trev.). - The name "fire-blight" is well chosen, since the affected tree, with its shriveled branches and shrunken, blackened twigs, gives the impression of fire injury. During the winter diseased twigs may be recognized by the dead, shriveled leaves still clinging to them. In the early spring, these leaves still persist, while on closer examination the bark and wood of the blighted twigs are seen to be black and dead. This blight is the most important disease of the pear and is also serious on the apple, quince, and hawthorn, and to some extent it affects plum, apricot, and mountain ash. 
Fire-blight was first described in 1794 from the Hudson Valley, whence it spread in every direction, reaching California about 1900. In many cases even whole orchards have

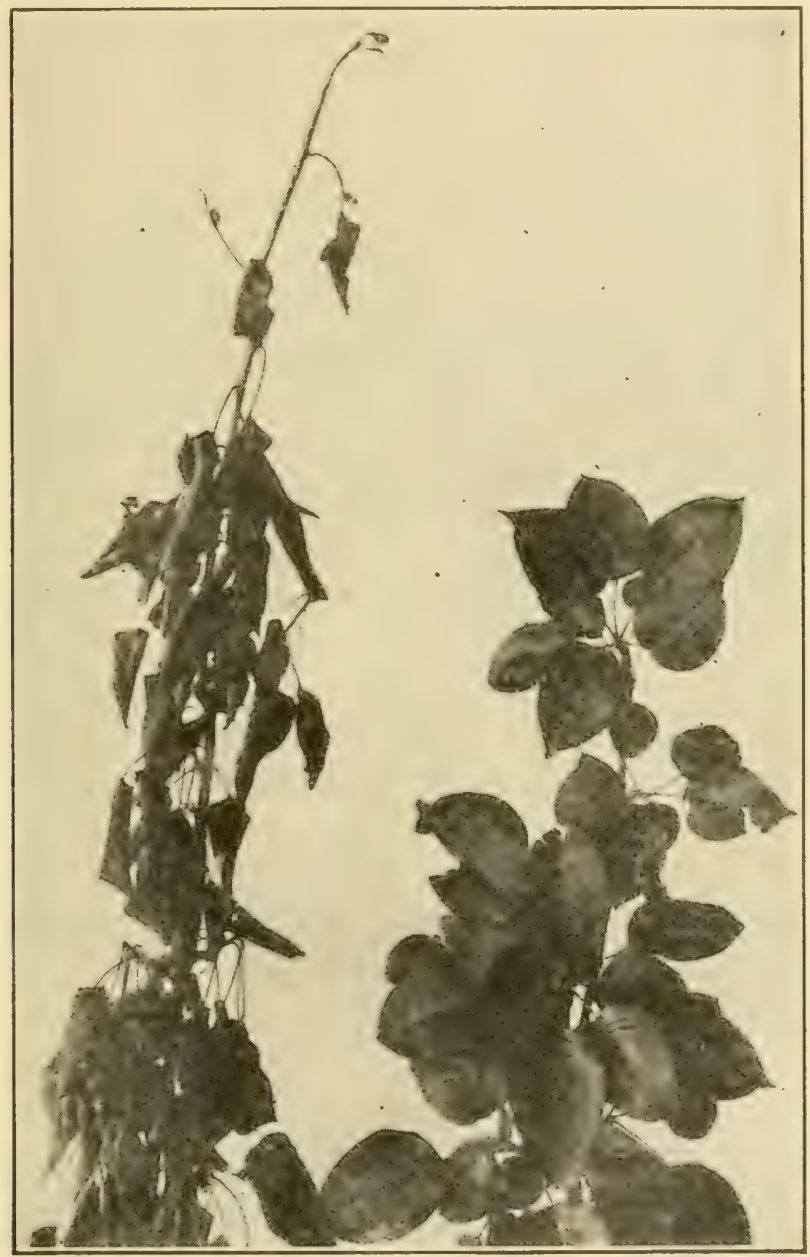

F'IG. 30. - Fire-blight; healthy and diseased twigs.

Original.

succumbed to its attack. One pear grower near Washington, D. C., estimated his loss from this one disease in one year at $\$ 10,000$. It is as yet confined to North America and is more severe in the Southern than in the Northern states. 
So diverse and numerous were the early theories as to the nature and cause of blight, and so fruitless were the discussions in earlier years that the Western New York Horticultural Society passed resolutions to prohibit further reference to the subject until entirely new facts were forthcoming. Among the numerous theories may be mentioned those depending upon electrical or atmospherical influences, freezing of the bark, too long culture of particular varieties, freezing of the roots, too high culture, insects, fungi, and lack of nutrition. One of the most prominent of these was Downing's "frozen sap theory," according to which the disease is due to the freezing and thawing of the sap, resulting in loss of vitality and development of poisons in the tissues. It is unnecessary to discuss any of these theories further than to say that none of them explains the facts.

In 1878 Burrill discovered bacteria in the diseased twigs, and by transferring to healthy twigs some of the exudate from diseased tissue bearing these bacteria was able to cause the disease. Arthur later grew the bacteria in pure cultures and with these cultures produced the disease. It - was thus proved beyond question that bacteria cause the blight.

It has been demonstrated that the germs cannot gain access through healthy, mature bark, but will readily penetrate into wounds, or into floral parts.

This blight bacillus deposited upon the flower, or upon tender shoots, gains entrance and rapidly grows downward through the wood and bark, causing the foliage upon the affected twig to die. The disease rarely progresses more than $5-8 \mathrm{~cm}$. in one day, though even 0.3 meter is occasionally reached. Ordinarily, sick twigs dry out, progress of the disease soon stops, and the germs in the twig die. Waite found that in some limbs, probably one of several hundred, the disease remains active. Two forms of blight are thus distinguished : one very dangerous, the other no longer offensive. It is the limbs still in condition of "active blight" that carry the pest over winter. 
With the flow of sap in the spring these infested limbs exude a milky fluid teeming with the bacteria and thus become centers of reproduction. It has been demonstrated that several species of insects can carry infection, but it is not probable that they are really important agents of transmission. ${ }^{76}$ Two additional forms of this disease, according to the part affected, are recognized: (1) blossom-blight, (2) bodyblight and canker.

Neither of these differs essentially from twig-blight, though body-blight or canker is especially worthy of men. tion on account of its peculiar destructiveness. This form occurs where infection is led by a spur, shoot, or sucker, or where the germ enters through a wound into the body or main limbs of the tree. The result is a canker more or less circular, which may even girdle the tree or branch, and which in any event causes serious injury.

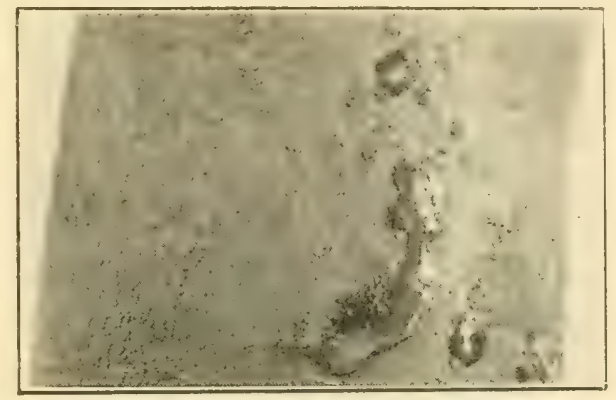

FIG. 31. - Fire-blight showing exudate from bark, much enlarged. This teems with the causal bacteria. After Whetzel.

The susceptibility of the tree is largely influenced by external conditions. In general, anything that leads to rapid growth, resulting in tender shoots, favors the development of the disease. There is also much difference in resistance offered by different varieties. The Anjou, Kieffer, Angoulême, and Seckel possess more resistance than the Bartlett, Clapp, or Flemish Beauty.

Based on the facts as stated above, the following sugges tions for avoiding the blight were deduced, and tested by Waite.

1. Pruning in winter when the tree is dormant promotes growth and favors blight. Withholding the pruning knife, which may not otherwise be best for the tree, will reduce this tendency. 
2. Overstimulation with fertilizers, especially those rich in nitrogen, is to be avoided.

3. A well-cultivated tree is more inclined to blight than one growing on sod or untilled land.

4. In irrigated orchards a reduction of the water supply to the minimum has been found effective.

In nurseries or small orchards or in regions where the blight is not excessive, the disease may be reduced by cutting out and burning every particle of blight when the trees are dormant. Not a single case of blight should be allowed to survive the winter, either in the orchard or within half a mile of it. Every pomaceous tree near by, including the apple, pear, quince, Siberian crab apple, wild crab apple, the mountain ash, service berry, and all the species of Cratægus, or hawthorns, should be examined for this purpose, the blight being the same in all. The orchardist should not stop short of absolute extermination in every case, for a few trees or branches overlooked may go a long way toward undoing all of his work. Cutting out the blight may be done at any time in the winter or spring up to the period when growth begins. The best time, however, is undoubtedly in the fall, when the foliage is still on the trees and the contrast between the blighted and the healthy limbs is strong. It is further necessary to make a weekly inspection of every tree throughout the growing season, beginning when the blossoms fall, in order to cut out blight whenever it is found.

In each case it is essential to cut well below any external evidences of the disease. To avoid spreading the infection, in case the pruning tools should accidentally cut into the diseased tissue, the cutting blade should each time be disinfected by wiping it with a cloth saturated with a strong solution of corrosive sublimate ( 1 part to 1000 ). When the wound made by this excision is at all large, it also should be disinfected with the corrosive-sublimate solution. Particular care should be taken to remove and burn all diseased spurs and water sprouts. 
Unless continued, careful inspection is given, and concerted action in a community maintained, but little benefit will follow.

Rust 41, 42, 135 (Gymnosporangium sps., Rostelia). - Rust of pear is very similar in nature to rust of the apple, though less often injurious. It consists of a summer stage and a winter stage. The former produces rust on the leaves of the pear, while the winter stage of the eastern form of rust pro-
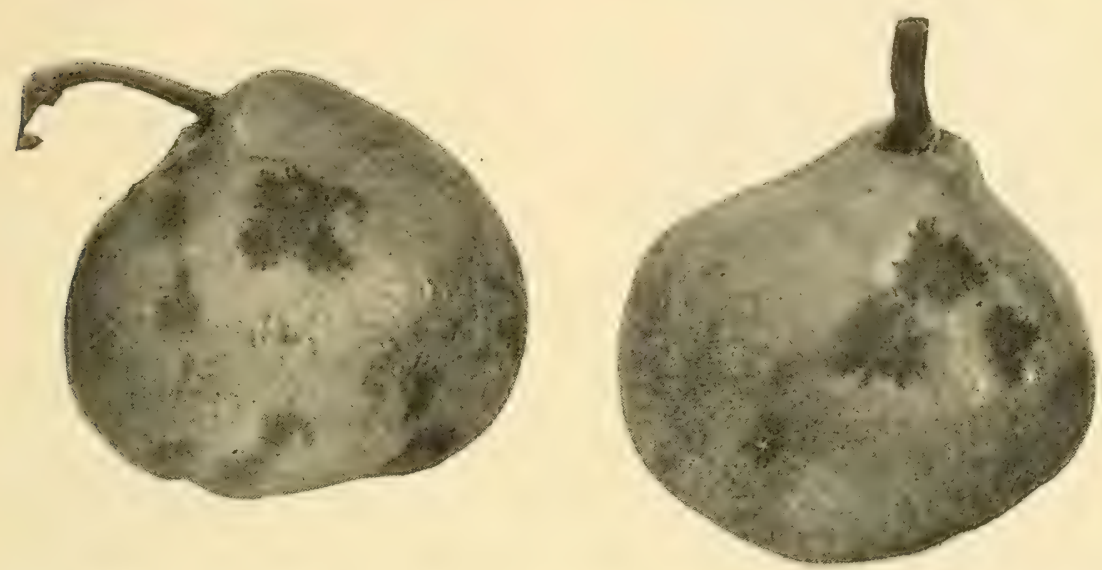

FIG. 32. - Scab on California pears bought in Raleigh, N. C. Original.

duces the familiar cedar-apple upon the cedar tree. The pear rust of the West is a distinct species, with the incense cedar as the alternate host.

The remedy, as in the case of the apple, consists in removing all red cedar trees from the neighborhood of the pear orchard; thus eliminating the source of infection. When this is impossible, the pear trees should be sprayed with Bordeaux mixture immediately after the early rains which cause the gelatinous horns to emerge on the cedarapple, and thus furnish the supply of spores for the spring infection. This disease of pears is particularly abundant upon varieties of the Japanese strain.

Powdery-mildews. See apple. 
Scab ${ }^{77,78}$ (Venturia pyrina Aderh., Fusicladium). - This scab much resembles that of the apple and is often accompanied by a peculiar cracked appearance of the skin. This symptom, however, is secondary and is not necessarily present. Rough cankers are formed upon the twigs. Pear scab is generally distributed

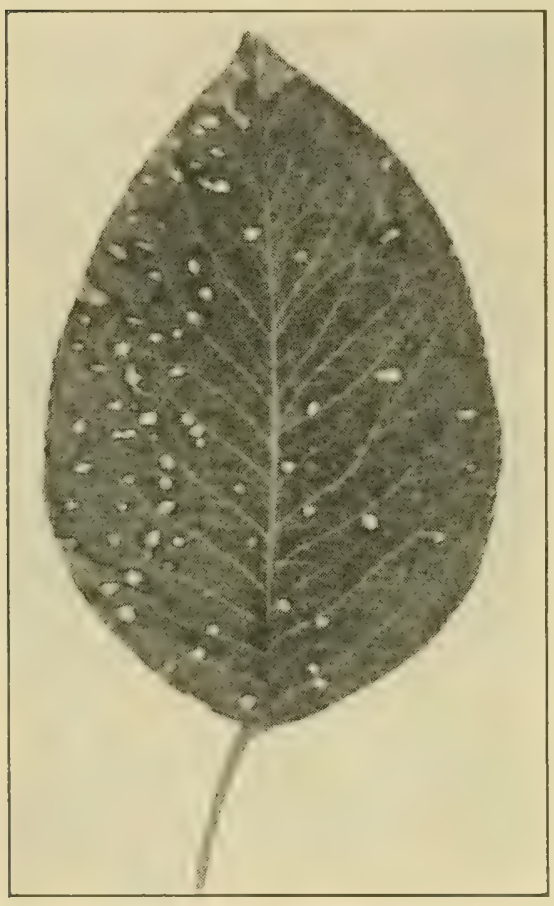

FIG. 33. - Pear leaf-spot. After Anderson. throughout the United States and Europe.

The use of a dormant spray followed by two applications of Bordeaux mixture, while the buds are unfolding, is recommended.

\section{Leaf-spot ${ }^{79}$}

rella sentina (Fr.) Schr., Septoria). - Leaf-spot, while rarely completely destructive to foliage or crop, does interfere with the general productiveness and health of the tree by diminishing its green surface, often causing defoliation. It is known over a wide range and is common, especially in the Eastern United States and in Europe.

Leaf-spot may be distinguished from scab and blight by the fact that the diseased area is rather sharply defined and characteristically angular in outline. The center of the spot, usually ashen in color, is surrounded by a narrow brown zone, and this in turn by one of purplish hue. The ashen center bears several minute, dark-colored pycnidia.

The treatment recommended for pear scab is preventive.

Leaf-blight ${ }^{79}$ (Fabrœa maculata (Lév.) Atk., Entomosporium). - This leaf-blight, more serious than leaf-spot, is almost as widely distributed as is the pear itself, though 
less prevalent in the South and West than in the North and East.

The entire leaf area often presents a diseased appearance, and there is no striking zonal arrangement in the infected spots as in leaf-spot. Eventually the leaf yellows, or turns brown and falls. The blight may attack the fruit itself, causing a red spot, which in a later stage resembles pear scab.

The treatment already recommended for pear scal) will suffice for pear leaf-blight.

Black-rot canker (Physalosporce cydonia, SPhoropsis.).In appearance and treatment this disease is similar to blackrot of the apple.

\section{Minor diseases}

Pink-rot often follows scab. The cause and general relations are given uncler apple; Bark-canker, Frost injury, Crown-gall, Sooty-blotch, Fly-speck, Black-mold, Brownrot, Texas root-rot, Hypochnose, Septobasidium canker, Die-back canker, Alternaria, see apple. Bitter-rot is identical with that of the apple but is of slight importance on the pear. Red-leaf, a disease of unknown cause, has been noted in New York.

\section{QUINCE. ${ }^{80}$}

Rust 41, 42, 135 (Gymnosporangium clavipes C. \& P., Rostelia). - The quince rust, spring stage, agrees with apple rust in general characters. The causal fungus grows upon the fruit in the summer and produces there myriads of spores which, on the approach of fall, are carried by the wind to adjacent red cedar trees (Juniperus), and there produce swellings upon the branches and twigs during the fall and winter. In the spring, these give origin to masses of spores embedded in a matrix of jelly. These spores are conveyed to the quince tree by the wind, and there again produce the quince rust. The redar is a necessary resting place for this fungus cluring the winter. 
The remedy, therefore, if practicable, is to remove the cedar trees from the neighborhood of quince trees. This will almost entirely prevent the rust, although in rare instances a few spores may be carried a considerable distance. In case the cedar is too abundant to permit of its complete removal, resort must be had to spraying the leaves and fruit of the quince trees with Bordeaux mixture at the

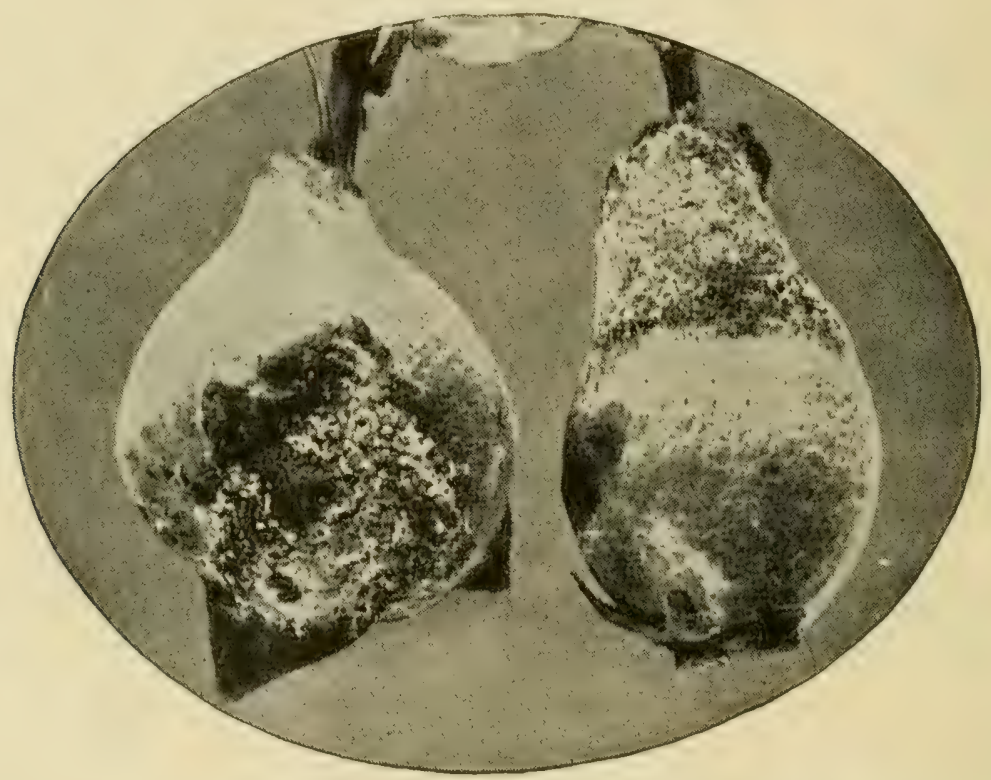

FIG. 34. - Young quinces showing rust. After Bailey.

time when the rust spores are expected to arrive; that is, at the time when the gelatinous spore masses are present on the cedar-apple.

Blight (Bacillus amylovorus). - This disease has been sufficiently discussed in connection with the pear and apple. It is only necessary here to indicate that it is the most serious known disease of the quince. The treatment is the same as that recommended for this disease on other pomaceous trees.

Leaf-blight, black-spot ${ }^{80}$ (Fabroa maculata (Lév.) Atk., Entomosporium). - Both the fruit and foliage are affected 
by this blight, the foliage spotting and falling prematurely so that the vitality and vigor of the tree is much reduced. Upon the fruit it causes black blotches, first seen as small brown spots, which soon increase in size and turn darker

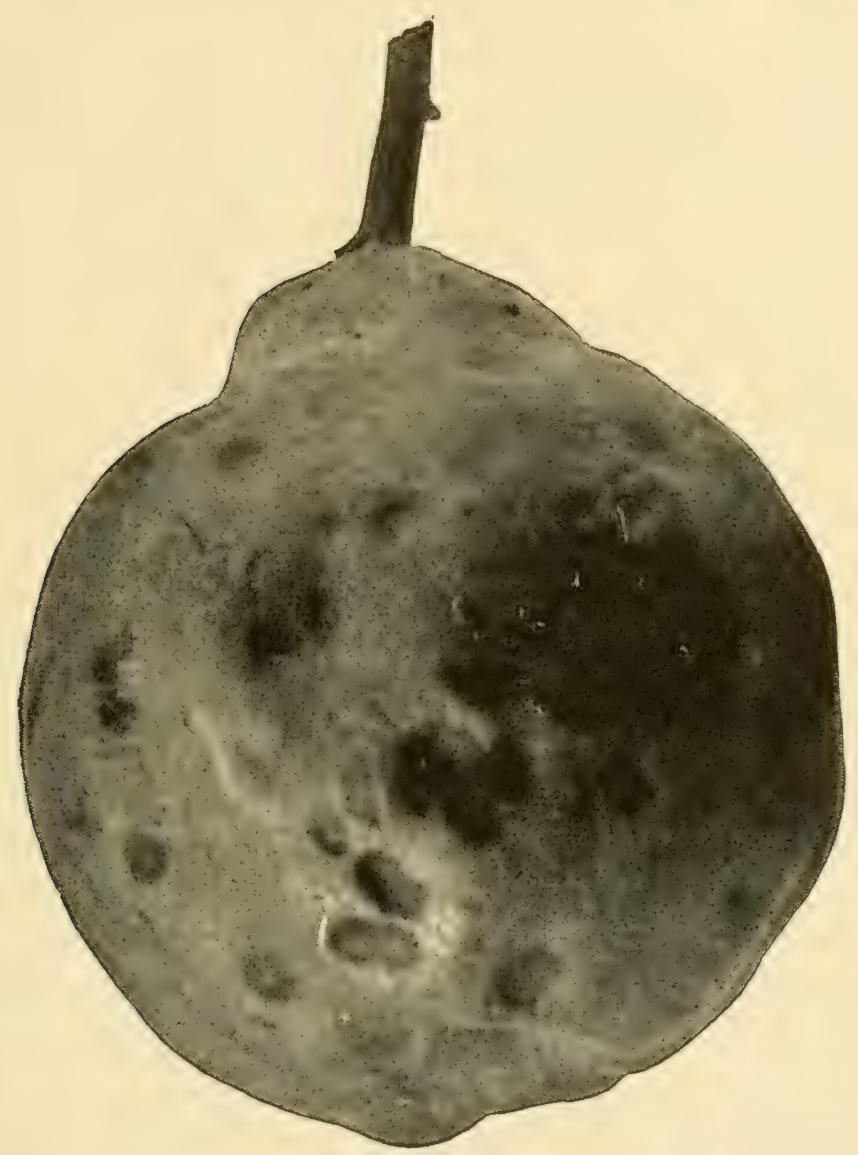

Fig. 35. - Black-spot of the quince, natural size. After Bailey.

in color. While this spot does not materially injure the fruit for use, it does retard its full development, and, because of impaired beauty, decreases its selling price. It also, as in the case of apple scab, gives entrance to the pink-rot fungus.

The means of prevention consists in application of lime- 
suifur. Pepeated trials have shown that this is thoroughly effective, increasing the value of the quince crop very materially both in size and quality of the fruit. The first application should be made soon after the blossoms fall, and should be followed at intervals of two or three weeks with two more treatments.

Black-rot (Physalospora cydonice, Sphoropsis). - This rot of wide distribution, and often amounting to a loss of 10 per cent, is clue to the same fungus which causes black-rot of the apple, and the treatments recommended for the apple will prove efficient for the quince disease. It has not yet been proved that this fungus causes cankers on the quince trees such as have been described for the apple. The grower should, however, watch carefully for the presence of canker, as the relation between the canker and the rot in apple indicates that the canker may possibly be found on the quince also.

Bitter-rot (Glomerella cingulata, Gloosporium). - This disease is caused by a fungus identical with that causing bitter-rot of the apple. The treatments already recommended for other diseases will also prove efficient here.

European canker (Nectria galligena Bres.). - This canker is readily distinguished from the ordinary cankers produced by Physalospora or Glomerella by its brilliant red or cinnamon-colored pustules scattered profusely over the affected areas. While cankers due to this fungus have been observed upon quince in America, no case of serious injury is known.

Pale-rot (Phoma cydonice S. \& S.). - This is one of the most prevalent decays of quince fruit in market. The lesions usually appear in the region of bruises and are at first pale blue or bluish-green in color and circular in outline. The rot spreads rapidly, involving the entire fruit in a few days. The surface becomes wrinkled and darker in color. Later numerous white fruiting pustules stud the surface of the decayed area. Care in handling the fruit to avoid external injuries is the only control measure recommended. 
Minor diseases

Brown-rot, Crown-gall, and Hypochnose: see apple.

\section{MEDLAR}

Though not extensively cultivated the medlar is occasionally affected with fungi allied to those present on other pomaceous hosts, e.g. Fabrace mespili (Sor.) Atk. causing leaf-blight; Oidium mespilimum Thüm, and Sclerotinia linhartiana. P.\& D. 


\section{DRUPACEOUS FRUITS ${ }^{28}$}

The drupes as the pomes, comprising highly valuable individual trees, warrant protective, curative, even though expensive measures. The diseases of the drupes, to some extent, are identical with those of the pomes, since both belong to the Rosacex. There are, however, several important diseases peculiar to this group of hosts. The drupes are especially sensitive to injury by fungicides, a fact which complicates all questions of control of drupe diseases by spraying.

\section{ALMOND}

The chief diseases: Yellows, Blight, Crown-gall, and Shot-hole are discussed under peach.

\section{APRICOT}

The diseases of the apricot are essentially those of the peach and will be more fully diseussed under that head. The most important are: Yellows, less common than on the peach; Phyllosticta Shot-hole; Brown-rot, especially destructive in the southwest; Fire-blight (Bacillus amylovorus), rarely reported ${ }^{82}$; Scab, reported from California, Texas, and Connecticut; Die-back (Valsa leucostoma); Crown-gall; Black-spot (Pseudomonas pruni), less troublesome than on the peach; Silver-leaf; Rust, especially injurious in the Southwest; Coryneum blight, ${ }^{81}$ known in California, New York, Australia, and northern Africa; Frost injury. Gummosis is not a specific disease but a symptom brought about by any one of various agencies; see peach. 


\section{CHERRY}

Leaf-spot ${ }^{7,83-85}$ (Coccomyces sps., Cylindiosporium). The disease, first reported in Europe in 1884, is widespread wherever cherries are cultivated and is usually very destructive. Sweet cherries are most susceptible. In Ohio the loss in one year was estimated at $\$ 25,000$. This disease, on fruit, pedicels, and leaves is nearly identical in symptoms with that of leaf-spot of the plum. For description see p. 98. Diseased refuse, leaves, etc., should be plowed under or destroyed. Sour cherry trees should be sprayed with limesulfur solution diluted at the rate of $1 \frac{1}{2}$ gallons to 50 gallons of water, or with 3-4-50 Bordeaux mixture: (1) as soon as the petals have fallen, (2) about three weeks later, (3) directly after the fruit is picked. Arsenate of lead, 1 pound of powder to 50 gallons of spray, may be added for the control of insect pests.

Sweet cherries should receive the same treatment as the sour except that lime-sulfur solution diluted at the rate of 1 gallon to 50 gallons of water should be the fungicide used. Bordeaux mixture should never be used on sweet cherry trees, because of the risk of injury. Dusting has proved satisfactory in some localities. The results of spraying by Scott are shown in the accompanying figures. These trees, located in Illinois, were sprayed three times.

Black-knot (Dibotryon morbosum). - As upon the plum, this knot causes serious injury to the cherry. In some sections it is so prevalent on the wild cherry and plum trees as to render control practically impossible, and in certain regions has caused the abandonment of the cherrygrowing industry. Taken in time it is easy to control. For treatment see plum.

Brown-rot, mold (Sclerotinia cinerea, Monitia). - The same fungus which produces disastrous results upon the peach also causes the most serious disease of the cherry, being especially destructive on sweet cherries. Several stages of its development are illustrated in Fig. 38. The disease is 


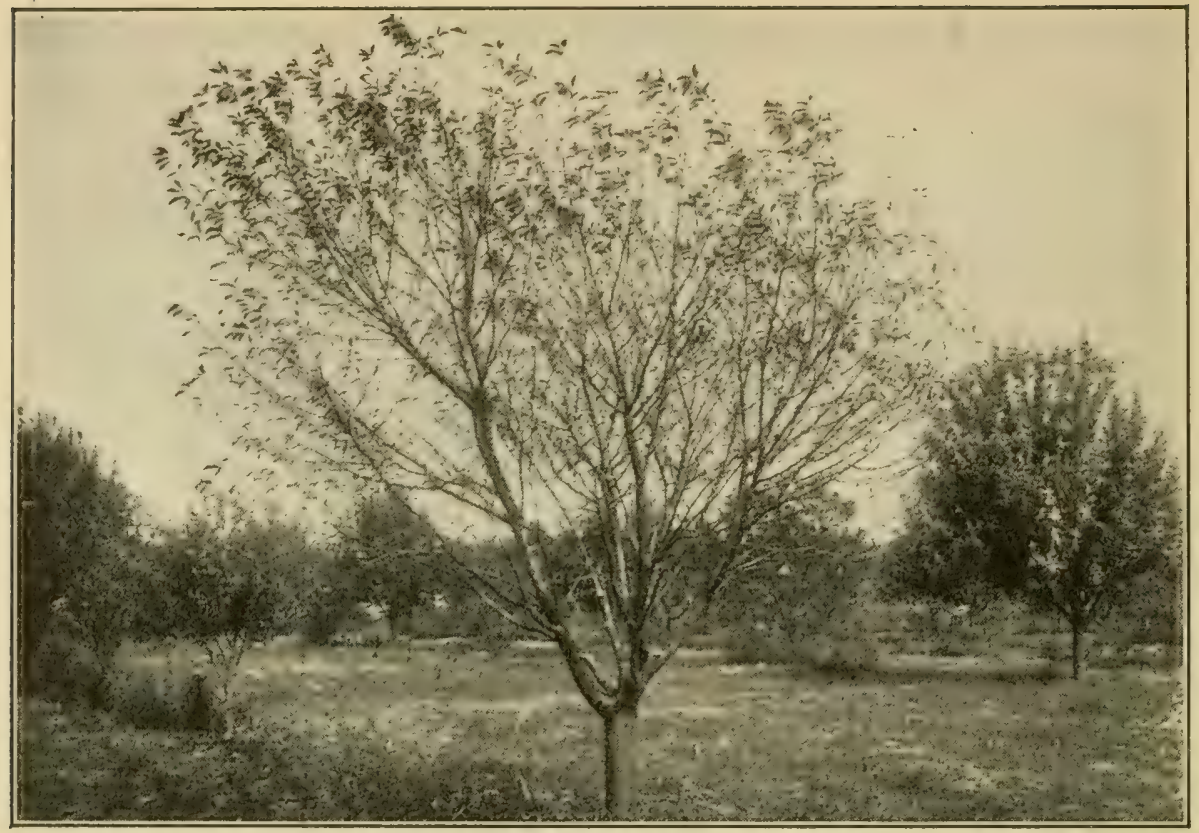

FIG. 36. - Unsprayed cherry tree defoliated by leaf-spot. After Scott.

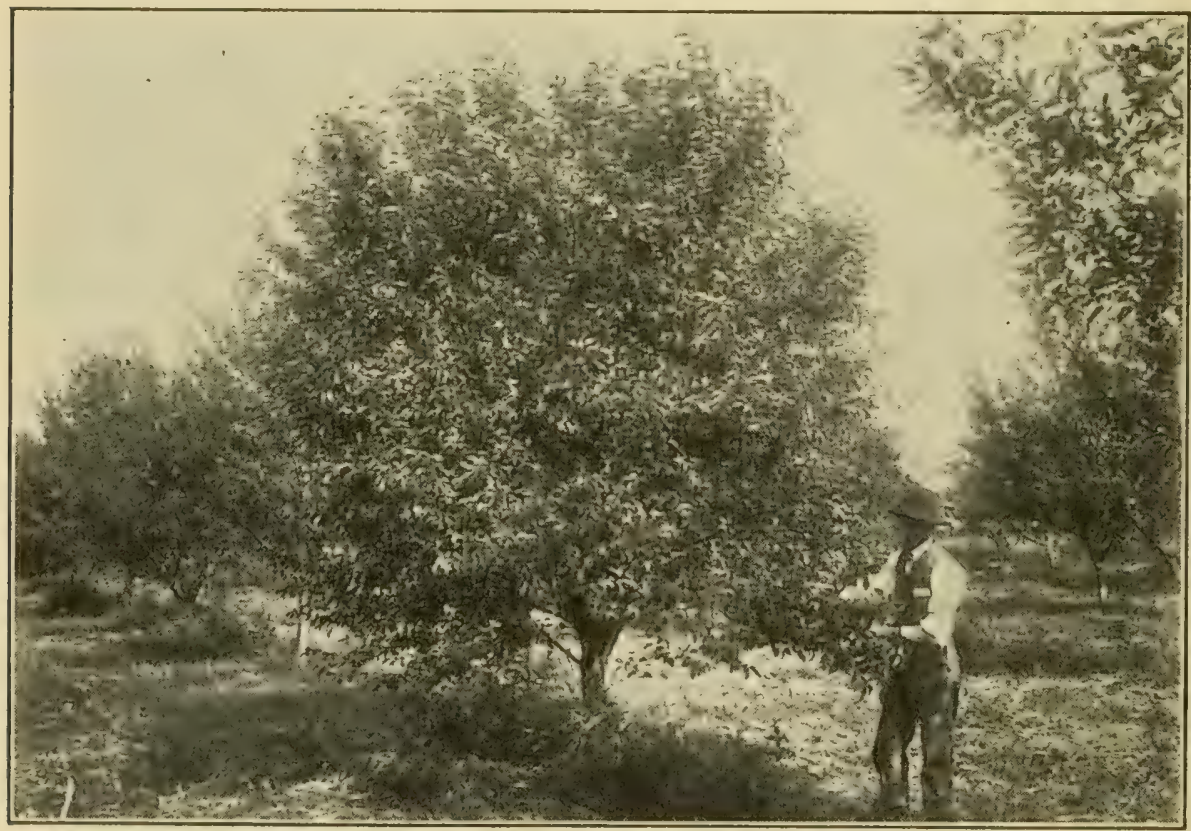

FIG. 37. - Cherry tree from same orchard shown in Fig. 36, sprayed with self-boiled lime-sulfur to control leaf-spot. After Scott. 
known practically wherever the cherry is grown, and large losses are frequent. Fifty per cent loss was reported from New York, and 25 per cent from Missouri in a single year. Treatment is the same as for the peach brown-rot.

Curl (Taphrina cerasi (Fel.) Sad.). - Cherry curl is closely related to that of the peach. The leaves become wrinkled before they are full size, and spores are produced on

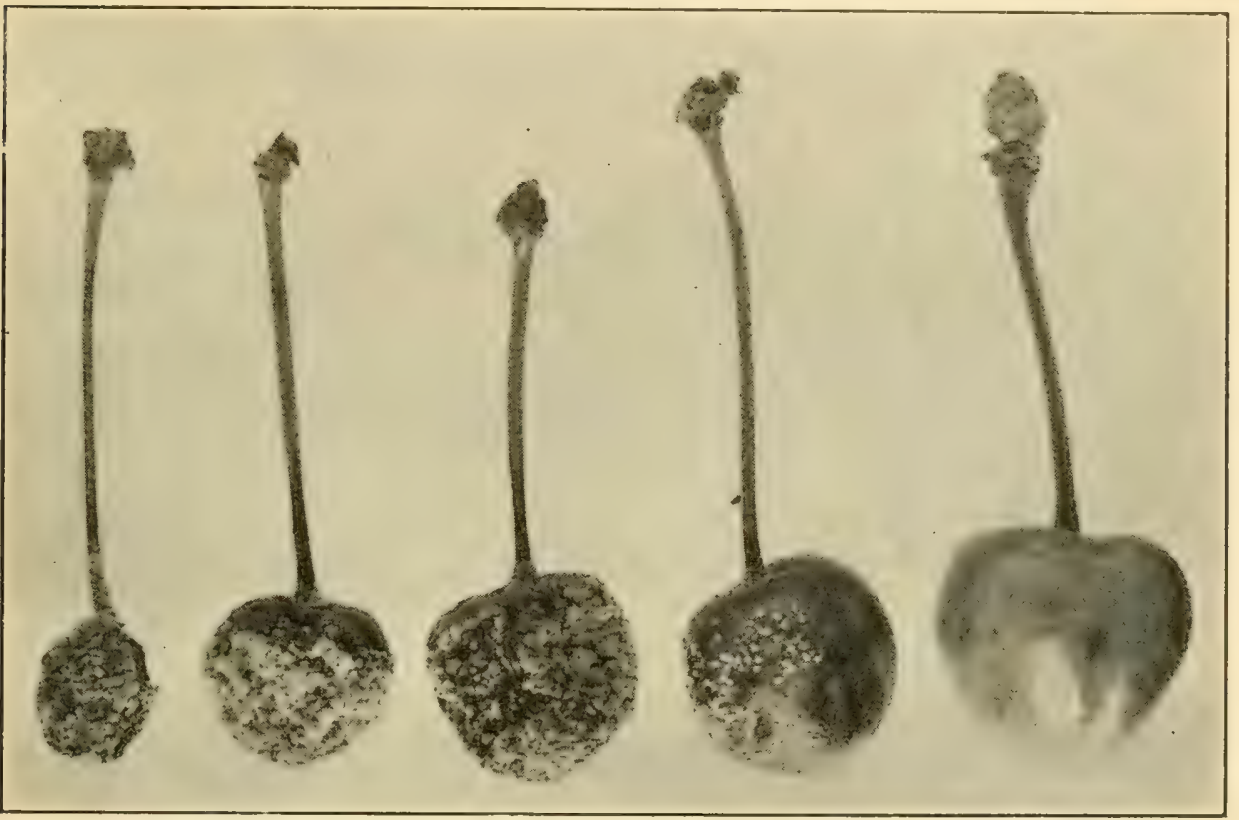

FIg. 38. - Brown-rot showing various stages of decay. After Clinton.

the surface of the leaf, as they are in other curls. Instead of forming flower buds and spurs, affected regions develop a profusion of twigs, "witches' brooms." The disease is not common in America; but should it become so, it can be held in check by pruning out the diseased twigs. It is perennial in the twigs and should be avoided in budding and grafting.

Powdery-mildew ${ }^{86,87}$ (Pod.osphora oxyacanthce (DC.) De Bary). - This mildew, similar to that described in connection with apple diseases, sometimes does damage to the plum and cherry, especially on nursery stock, where it pre- 
vents either the growth of the seedling or successful budding or grafting.

On old leaves, though often abundant, the fungus does not cause great damage, but when the attack is made on young growing tips, or on young leaves, these delicate structures suffer greatly from loss of nourishment. The disease is common from the Atlantic to the Pacific.

Unlike most fungi the mildew grows best during fair, dry weather. A light rain, which spreads the spores and

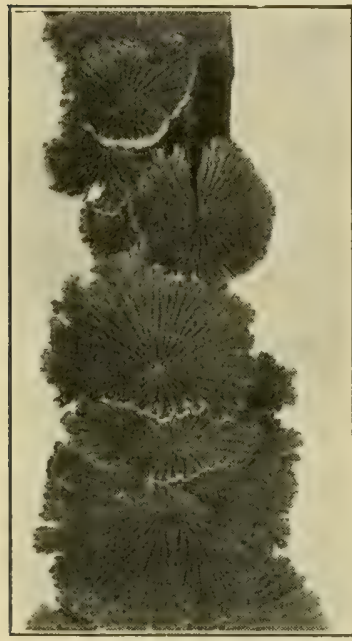

Fig. 39. - Schizophyllum alneum, frequently the causal fungus of wood-rot of cherry and other trees. After Atkinson. furnishes sufficient moisture for germination, followed by a dry spell, best favors the development of powderymildew.

The use of Bordeaux mixture, sulfur dust, or lime-sulfur has proved satisfactory. Apply about every ten days during the early growing season; more frequently, if necessary to replace the poison washed off by rain.

Wood-rot ${ }^{88}$ (Schizophyllum alneum (L.) Schr.). - Small white specks, the sporophores, appear upon the limbs and trunk in early summer. In the autumn they are well developed and abundant; white and very hairy, $1-3 \mathrm{~cm}$. in diameter, usually attached on one side with the margins incurved. The gills are white, woolly, branched, deeply split along the edge, and revolute.

The affected wood is brittle and penetrated by black lines. Apparently this disease starts in roots injured by tools during cultivation or in wounds upon limbs.

\section{Minor diseases}

Die-back ${ }^{91}$ (Valsa leucostoma, Cystospora). - The discussion of die-back on p. 86 is applicalle in this connection. The disease is common on the cherry in the United States 
and other countries. For Crown-gall, Rust, and Yellows, see peach. Armillaria root-rot, see apple. Blight (Bacillus amylovorus) has been rarely reported in the Northwest. Scab is much less common than on the peach. Black-spot (Pseudomonas pruni) has been noted on the IVragg cherry in Colorado. See peach.

\section{PEACH}

Brown-rot ${ }^{85}$, 89, 90 (Sclerotinia cinerea (Bon.) Schr., Monilia). - Probably no other disease is so destructive to

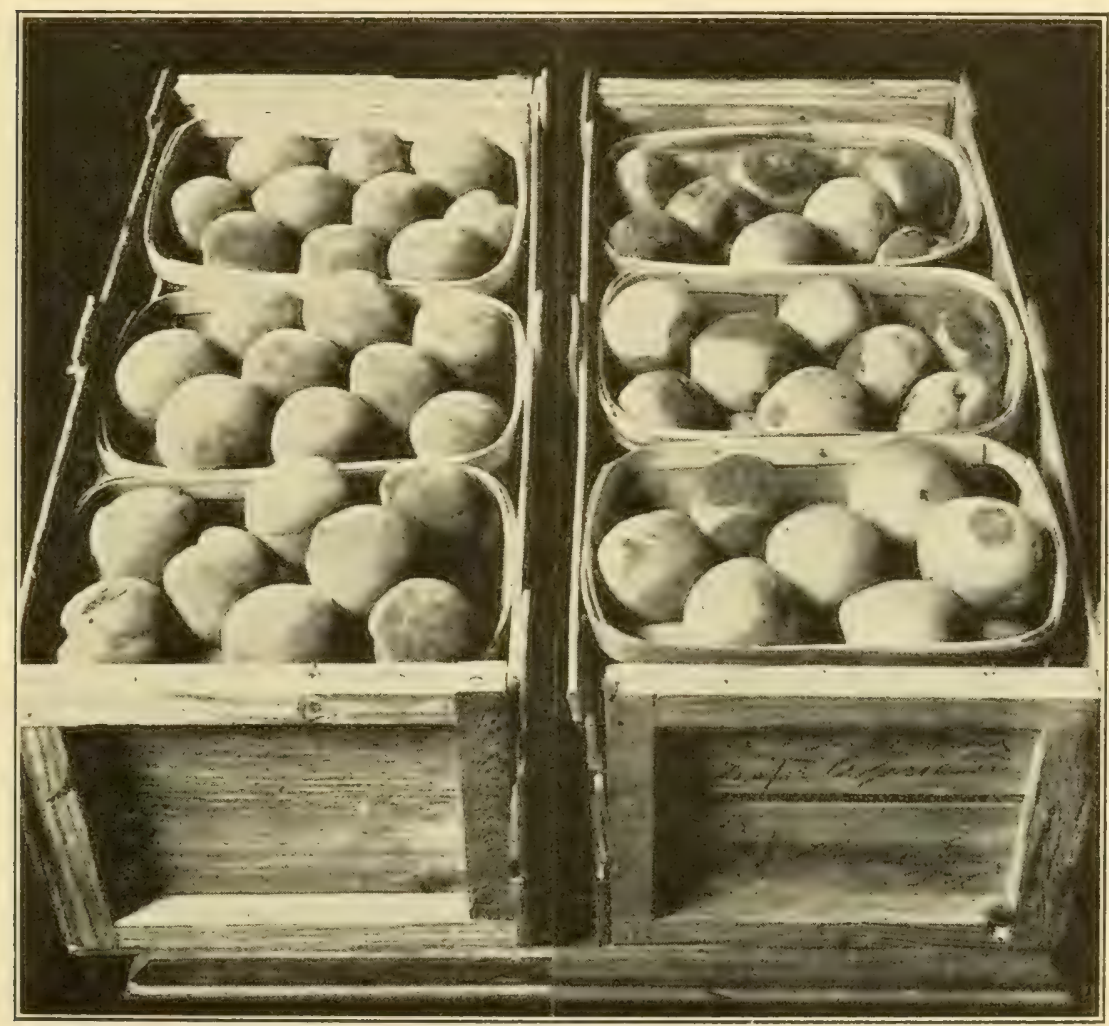

FIG. 40. - Two packages of peaches, one healthy, the other affected with brown-rot. After Scott.

peaches, plums, cherries, and kindred drupes, as the brownrot, which attacks the fruits as they approach maturity, 
turning them brown, soft, and rendering them worthless. Aside from injuring the mature fruit, the rot attacks the flowers and twigs. The disease ranges over the entire peachgrowing territory, but is usually most severe in the South. In some years the loss has amounted to more than 50 per cent of the crop, or an aggregate annual loss of $\$ 5,000,000$. The estimated damage in Ohio alone in one year was a quarter of a million dollars; in one year in Pennsylvania twenty carloads were lost. Apples, pears, and quinces are attacked, but to lesser extent.

Its characteristic appearance on the fruit enables one to recognize it easily. It first appears as small, circular, brown, decayed spots. These rapidly en-

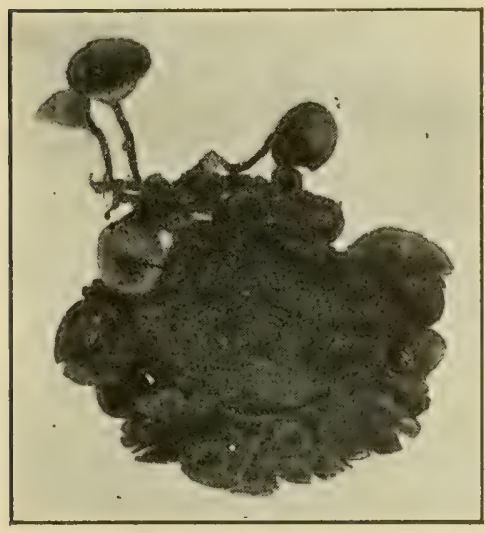

FIG. 41. - Mummy peach showing Sclerotinia ascophores. After Scott. large until they embrace the whole fruit, which at the same time shrinks slightly. As the decay advances, small tufts of brown threads appear near the centers of the original spots, and spread rapidly until the whole fruit is covered.

If the fruit hangs in clusters, adjacent fruits begin to decay at the points of contact, and the disease spreads from fruit to fruit until whole clusters are lost. Fruit, after it is picked, may also succumb to attack, and peaches that were apparently sound at picking may be seriously damaged when they reach market. Thus the loss falls upon grower, carrier, dealer, and consumer. The decay is so rapid that infection to-day may mean a totally unsalable peach two days hence. Peaches diseased on the tree may fail to the ground, or remain on the tree, where they shrivel and hang over winter, to constitute the "mummy" peaches so familiar in infected orchards.

Upon the blossom the disease is first evident as a slight, brownish discoloration, which spreads rapidly, causing the 
flower to wither and eventually fall off as a rotten mass, carrying contagion to everything in its path. This damage to the flower is often confounded with frost effects. From the flower the rot may spread to adjacent tivigs, through the flower stalk. Smith states that the examination of hundreds of twigs in all stages of disease showed that every one was associated with blighted and persistent flowers. Infection of the twigs may also occur directly from diseased fruit. Even large branches may become seriously cankered. From repeated observations, however, it seems probable that branches cannot be infected except through wounds.

The inroads of this disease are so serious that many peach and plum growers have been obliged either to secure a remedy for this pest or abandon the crop. Years in which there is full fruitage, accompanied by damp, warm weather, are almost certain to bring a severe attack. But it is not the weather which directly causes the rot; rather it is the rapid development of the fungus under proper weather conditions.

The mummified fruits and cankers serve as the hibernating quarters of the causal fungus. If these mummies be carefully observed in the spring, some of them will be seen to bear small stalked disks (Fig. 41). These are the organs which furnish spores for the spring infection.

It follows that any practice which destroys the mummified fruits lessens the risk of infection as does also the pruning out of cankers. Observations by Pollock, ${ }^{516}$ extended over a period from 1909 to 1918, show that the sclerotia of the causal fungus may remain alive for at least ten years, and some of them produce ascocarps every year; old mummies or fragments of mummies giving rise to smaller sporebearing structures than those formed from younger sclerotia. In the light of these observations attesting to the long life of the sclerotia, the plowing under of diseased fruits, heretofore advised, cannot be regarded as a good practice. Active treatment in the form of spraying is necessary. The most successful spray is that employed by Scott, which gave the following results:- 
Results of Experiments for the Control of the Peach BrownRot, Marshallville, Ga., 1908

\begin{tabular}{|c|c|c|c|c|}
\hline Plot & Treatment & $\begin{array}{c}\text { PEACHES } \\
\text { AFFECTED WITH } \\
\text { BROWN-Rot }\end{array}$ & $\begin{array}{l}\text { Peaches } \\
\text { Scabbed }\end{array}$ & $\begin{array}{l}\text { Peaches } \\
\text { BAdLi } \\
\text { SCABBed }\end{array}$ \\
\hline $\begin{array}{l}1 \\
18 \\
36\end{array}$ & $\begin{array}{l}\text { Lime-sulfur wash }(15-10- \\
50) \text {, hot water. . . . . . } \\
\text { Lime-sulfur wash }(15-10- \\
50) \text {, cold water....... } \\
\text { Check - no treatment... }\end{array}$ & $\begin{array}{l}\text { Per cent } \\
10.56 \\
12.22 \\
36.98\end{array}$ & $\begin{array}{l}\text { Per cent } \\
20.75 \\
16.60 \\
93.63\end{array}$ & $\begin{array}{r}\text { Per cent } \\
0.80 \\
\\
0.60 \\
42.12\end{array}$ \\
\hline
\end{tabular}

For the combined treatment of peach scab and brown-rot, at least three applications of the self-boiled lime-sulfur, 8-8-50, are necessary; first, when the petals drop; second, about three weeks later; third, about a month before the fruit ripens. The time of the last application must be determined by the ripening date of the variety. Though a late treatment would be effective against brown-rot, to avoid staining the fruit the last spraying should be made a month before the fruit ripens. Three applications are sufficient for the Elberta and earlier varieties. A fourth treatment is often desirable for later maturing varieties.

There seems to be no question as to the advisability of spraying the peach orchard where brown-rot and scab are troublesome, but other risks are oftentimes to be encountered. The curculio and other insects readily break the skin of the peach and admit the brown-rot fungus even through a coating of the spray mixture, so that a certain amount of rot may always be expected when the conditions are favorable.

Scab ${ }^{89}, 92$ (Cladosporium carpophilum Thüm.). - This disease, which is widespread and so common that many people regard it as an integral part of the peach, may consist of isolated, sooty, black specks, or of black specks so numerous as to coalesce into large blotches. These sometimes cover as much as one-third or one-half of the peach. 
The side which is attacked is dwarfed, often cracked, and the flesh adjacent to the diseased part is green and bitter, even after the normal portions are ripe. Leaves and twigs are also affected.

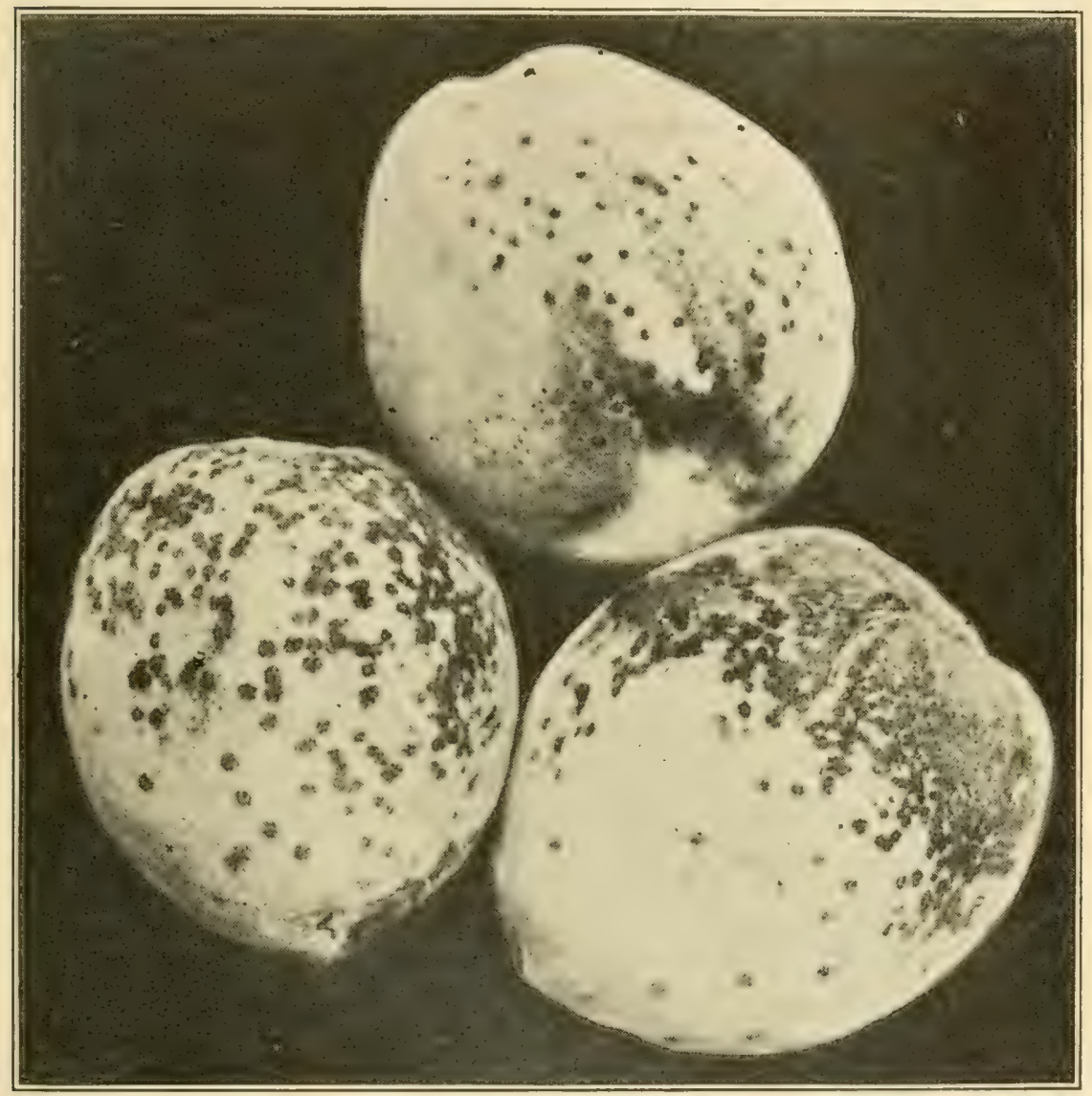

FIG. 42. - Peach scab. Original.

Scab develops in most serious form during rainy seasons, and is more prevalent upon certain late varieties as Health, Salway, and Bilgen. It is reported from Missouri to have done damage equal to 70 per cent of the value of the crop, and Selby estimated the loss in one crop in Ohio at from 20 to 50 per cent. 
Self-boiled lime-sulfur, 8-8-50, applied as indicated for peach brown-rot, gives excellent results.

Curl ${ }^{93}$ (Taphrina deformans (Fel.) Tul.).* - Throughout the peach-producing region this disease abounds, being particularly injurious in moist localities. The annual loss approximates $\$ 3,000,000$ in the United States.

Curl is due to a fungus which grows in the leaves, causing the peculiar malformation which justly gives rise to its

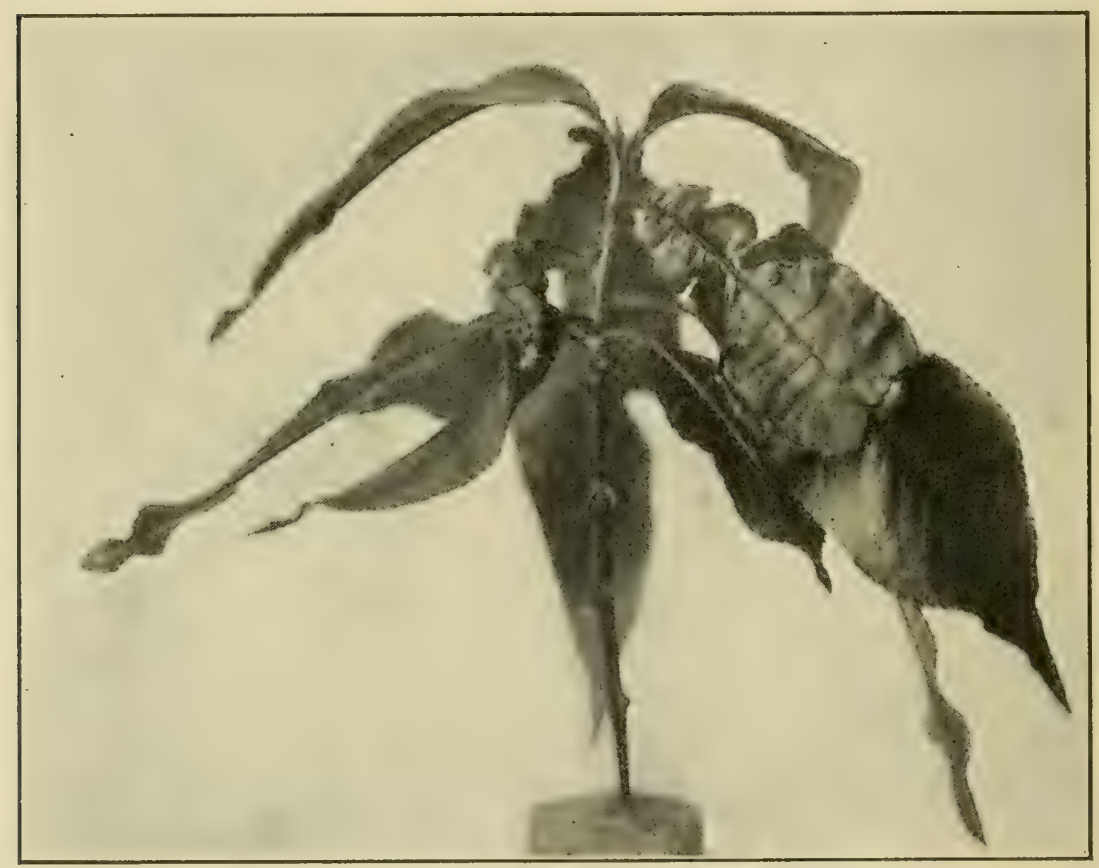

FIG. 43. - Peach leaf-curl. After Atkinson.

popular name. This fungus destroys the utility of the leaf as a starch-producing organ, and eventually causes defoliation. This loss may be manifest in two ways: first, by the present effect upon the vitality and vigor of the tree, and immediate injury to the crop; second, by a weakening of the tree in succeeding years, due to the lack of full nourishment

* The sub-genus Exoascus is by some regarded as of specific rank and the name as Exoascus deformans. 
during the period of attack. The injury in the present year, manifest by a loss in productiveness, is obvious to the grower. The injury in succeeding years, often fully as great, is frequently overlooked, or is not attributed to its true cause.

It was formerly thought that this fungus persisted in the twigs over winter, and thus lurked ready to infect the new leaves as they began to develop. It has, however, been proved that nearly, if not quite, all spring infection is due, not to perennial mycelium, but to spores which remain on the bark of the trees.

Prevention of the disorder lies in killing these spores of the fungus by winter spraying. For this purpose Bordeaux mixture, lime-sulfur, or a simple copper-sulfate solution is efficient. There is probably little choice between these solutions on the ground of efficiency; hence, the cost of the various sprays may become the deciding factor. Limesulfur is preferable when insects also are to be met. The spray should be applied from one to three weeks before the buds open in the spring, and thoroughness should be the chief aim. Spraying should be done in dry, calm weather, during the middle of the day, in order to avoid dew or frost upon the limbs.

Pierce states that as a result of the treatment of peach curl in California, from 95 to 98 per cent of the spring foliage was saved. A net gain of 600 per cent in the foliage over that retained by adjoining unsprayed trees resulted in the case of several different sprays. Bordeaux mixture, when applied to the dormant tree, increased the weight and starch-producing power of the leaves, and the sprayed trees showed great gain over the unsprayed in the number and quality of the fruit buds which they produced for the following year. The gain in the number of spur buds was over 100 per cent in some cases. The sprayed trees also produced more vigorous growth of new wood, the wood to produce the crop for the next year. Thus, in one experiment the spring growth of the unsprayed tree averaged 7.85 inches; on the sprayed trees it was 24.75 inches. The average value of 
fruit, per tree, in rows treated with the most effective Bordeaux mixture ranged as high as $\$ 6.20$ above that in adjoining untreated rows, or the equivalent of a net gain of $\$ 427.80$ per acre. Over one thousand per cent net gain in the set fruit has resulted from the use of some of the more effective sprays.

The trees should be sprayed each season, since experiments prove that treatment one season will not prevent the disease the following year. Spraying should be done even though the trees are not expected to bear, since the loss of the crop of leaves is as great a drain upon the trees as is the maturing of one-half to two-thirds of a crop of fruit.

Die-back ${ }^{94}$ (Valsa leucostoma (Pers.) Fr., Cytospora).This disease of limbs, trunk, and twigs was first fully described in the United States by Rolfs of Missouri in 1907 who noted it upon peach and Japanese plum. It is present also in Europe and Australia.

Infection occurs upon buds or wounds during the growing season, and in early winter and spring the tips of young branches, especially water sprouts, are killed back from 2.5 to $46 \mathrm{~cm}$. As many as 300 such dead twigs have been noted on a single tree. It develops most rapidly in a warm spell following freezing weather in the spring, and is more serious upon trees that have been weakened by other causes.

Twigs killed during the winter show at first a dark purplish skin, changing later to leathery, scarlet, or purple, finally drab. Then the skin loosens and wrinkles. At this time black pyenidia appear under the skin. These soon push out a white cap through a transverse slit in the skin, and in wet weather exude very fine, red threads of spores. Gum flow usually accompanies the constriction, marking the juncture of dead and healthy wood. During summer, leaves on infected twigs frequently wilt, owing to the girdling of the stem. Upon the trunk large wounds, often regarded as sun scald, are produced, while upon young limbs the wounds appear as enlargements or "knots." Large limbs or even whole trees succumb. 
Excision should be practiced. Spraying lessens the disease but is not wholly effective.

Coryneum-blight ${ }^{93,9.5}$ (Coryneum beijerinckii Oud.). First noted by Pieree and fully described by Sinith, Coryneum-blight, troublesome in California for years, has been observed as far east as New York, also in Europe and Australia.

The symptoms are dying of the buds of fruiting wood, spotting of green twigs, and dropping or underdevelopment of young leaves and fruit, accompanied by gummy exudate, especially upon the one-year-old fruiting twigs. Leaves opening from buds which survive the disease are marked by small dead areas of tissue, which soon fall out, leaving "shot holes." It is essentially a winter or early spring disease of fruiting twigs and one-year-old wood, and the principal damage is from death of buds and twigs before the fruit develops. Infection occurs in winter before new growth begins.

Pruning, followed by spraying with Bordeaux mixture or other dormant sprays, during the early winter (in California between November 1 and December 15), produces best results.

Crown-gall and Hairy-root ${ }^{96}$ 102, 522. (Pseudomonas tumefaciens EFS.). - Crown-gall causes a tumor-like outgrowth near the ground line on certain trees and shrubs (Fig. 44), particularly upon members of the rose family, pomes, drupes, raspberries, etc. Hairy-root consists of a profuse development of small tufts of fine roots.

Careful cross inoculations by Hedgcock, using fragments of galls, have demonstrated that crown-gall of the almond, apricot, blackberry, cherry, peach, plum, prune, chestnut, and walnut are intercommunicable. It has also been demonstrated by Smith and Townsend that crown-gall of the peach tree as well as of tomato, potato, tobacco, beet, hop, carnation, grape, raspberry, and apple can be produced by inoculation with Pseudomonas tumefaciens, also that the organisms of the peach, apple, hop, rose, and chestnut galls are interchangeable. 
In addition to the above-named plants, natural galls on quince, plum, dewberry, raspberry, corn, turnip, salsify, parsnip, lettuce, radish, cotton, alfalfa, clover, pecan, willow,

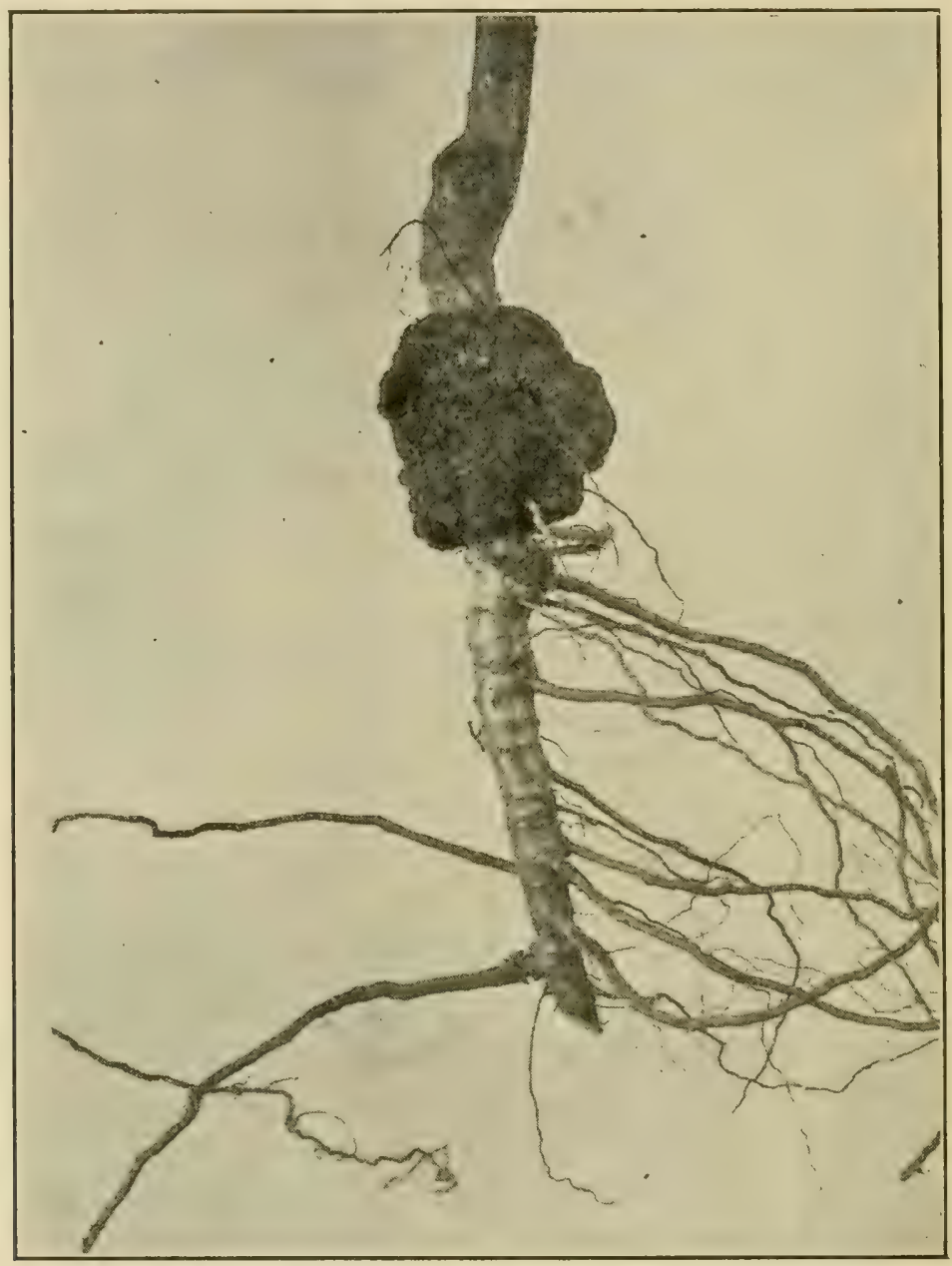

FIG. 44. - Peach crown-gall. After Hedgcock.

poplar, chrysanthemum, honeysuckle, euonymus, arbutus, marigold, pyrethrum, peony, and oleander have been studied, while a complete list of susceptible plants would include many more. The disease in a form known as soft-gall is found commonly on herbaceous plants or cane fruits. 
On many plants crown-gall is practically harmless, while on others, especially the fruit and nut trees and the cane fruits, it is injurious. The chief injury seems to arise from the fact that crown-gall paves the way for the entrance of rot-producing parasites, interferes with proper root development and the conduction of foods and water. Whatever

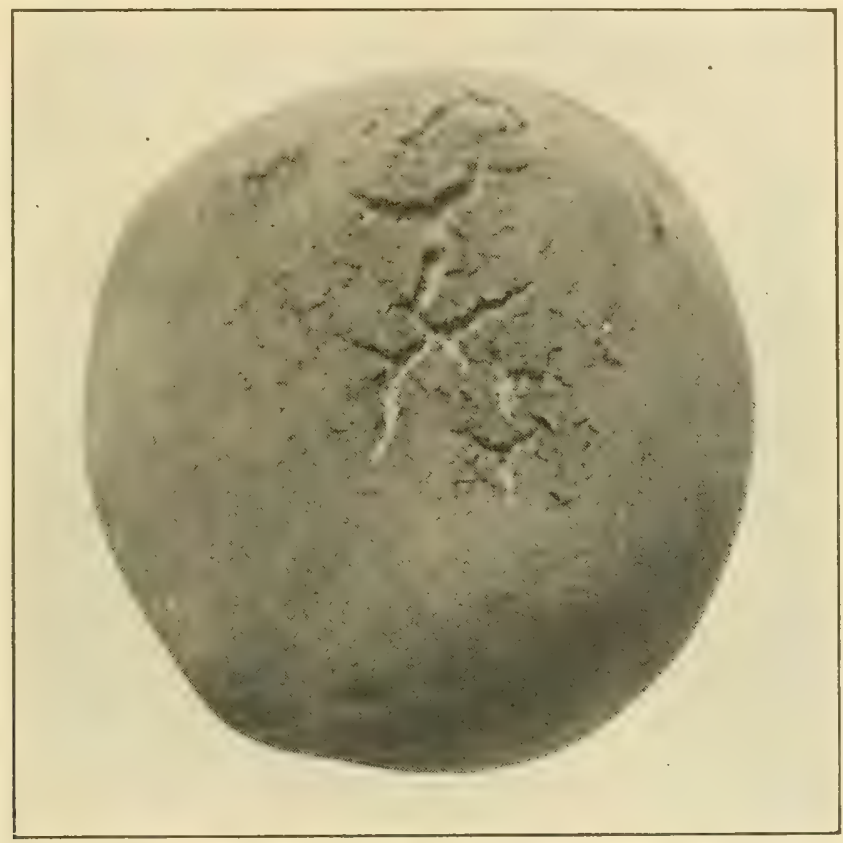

Fig. 45. - Cracked peach, caused by Pseudomonas pruni. Advanced stage on fruit nearly ripe. After Roberts.

may be the actual mode of producing injury, the fact is well established that trees with crown-gall do not, in general, develop or yield as well as trees without galls, though in rare cases, trees with crown-gall may fully equal ungalled trees.

All diseased stock should be avoided, as well as stock from nurseries where the disease is known to exist. Care on the part of nurserymen to use soil free from crown-gall; to avoid wounding the young trees and to make close-fitting grafts, and protect them well with wax, will lessen infection. 
Black-spot ${ }^{103-106}$ (Pseudomonas pruni EFS.). - Peaches, plums, apricots, nectarines, and more rarely cherries are

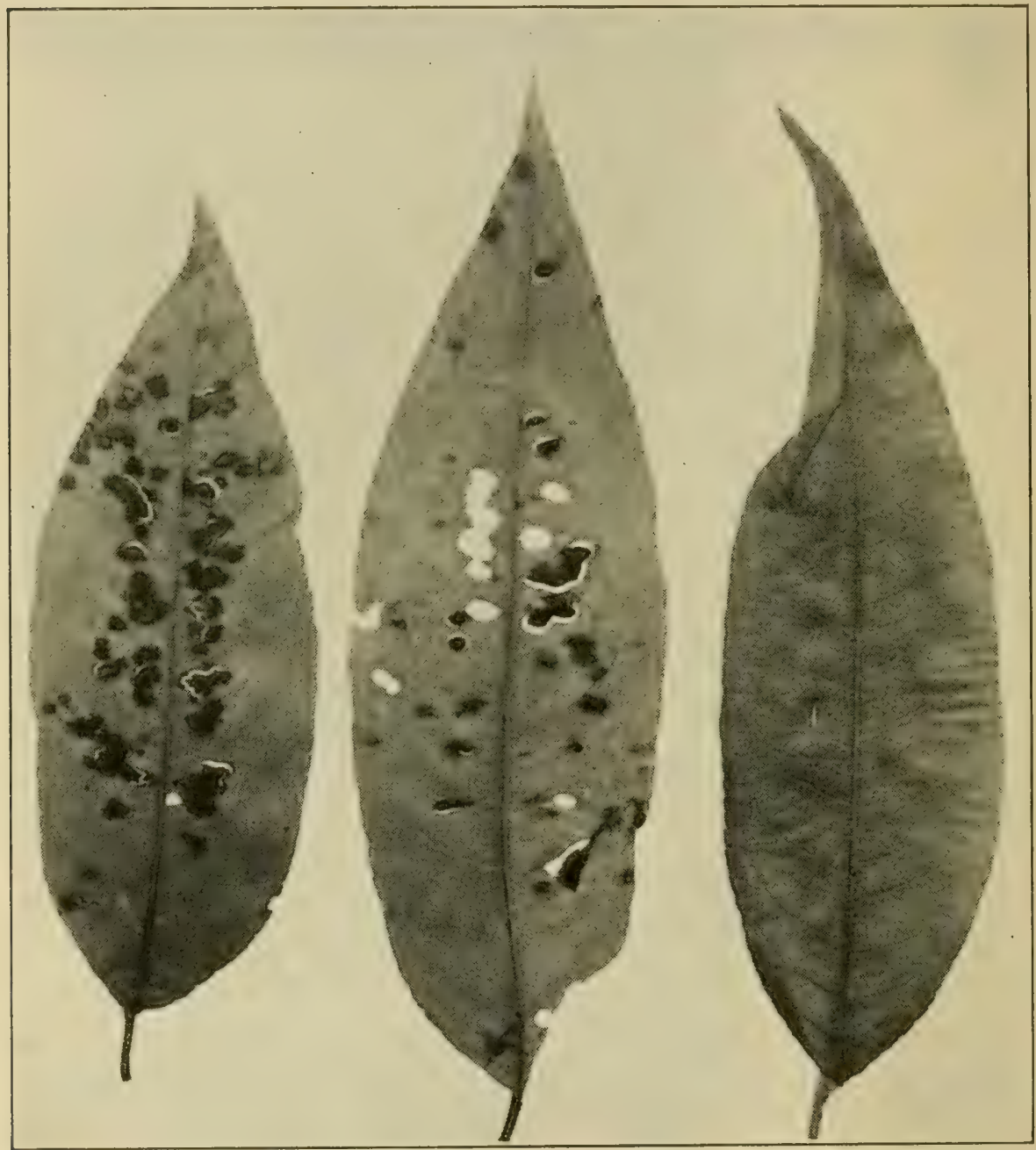

I'IG. 46. - Peach leaves inoculated with culture of Pseudomonas pruni. Photograph taken 43 days after inoculation. After Rolfs.

susceptible to black-spot, affecting chiefly the leaves, but occurring, also, on fruit and branch. It constitutes a really serious disease on peaches, being next in importance to 
brown-rot and scab, and occurs in the Eastern and Central United States, though unknown outside of the United States. It was first noted about 1903.

Spots first appear on the leaves as small, gray specks which soon become angular and water-soaked, later brown. Single spots measure 1-5 $\mathrm{mm}$. in diameter. The diseased tissue usually drops out, leaving "shot-holes." Badly diseased leaves fall and a large percentage of defoliation is common. On twigs, water-soaked spots surrounding the lenticels appear, developing to a length of four centimeters or more. The diseased areas become sunken and brown in age, and often develop into perennial cankers. On fruit, the specks are at first similar to those on the leaves, but the skin soon breaks and cracks appear. (Fig. 45.)

Trees that are kept in good growing condition by proper pruning and cultivation are not seriously injured by blackspot.

Powdery-mildew (Podosphera oxyacantho (DC.) De Bary, and Sphorotheca pannosa (Wallr.) Lév.). - These widespread mildews, in general appearance, are similar to the powdery-mildew of the grape, cherry, lilac, and rose. Sometimes the attack is so general, on twig, leaf, and fruit as to practically destroy the crop. When on fruit, the mildew appears first while the peach is small, causing irregular, grayish, moldy blotches. As these enlarge, cracks often develop.

Sulfur may be used as a dust, or a lime-sulfur spray, 1-50, may be applied. Treatment should be made as soon as the mildew is seen. Two or three treatments may be required.

Yellows. ${ }^{109,}$ 110, 112 - Peach yellows has been known in the United States since 1760. From a region near Philadelphia, as a center, it has spread until now it is known throughout a large territory embracing Virginia, Arkansas, Texas, and Canada, and is constantly extending its frontier in every direction. It is not known to occur outside of North America. The disease is of unknown origin, but it has been proved beyond question that it is contagious. The roots of discased plants, however, do not infect the soil, and trees may safely 
be set in the places from which diseased trees have been removed.

Recognition marks, which leave no uncertainty as to its identity, are described by Smith as follows: "Prematurely ripe, red-spotted fruits, and premature unfolding of the leaf buds into slender, pale shoots, or into branched, broom-

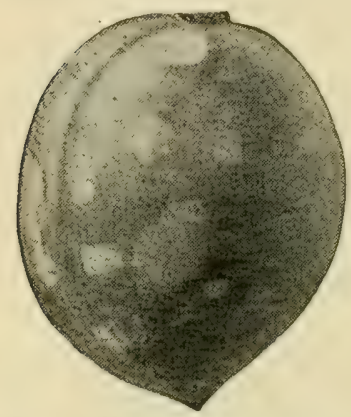

FIg. 47. - Mildew upon peach fruit. After Bailey. like growths, are the most characteristic symptoms of yellows. The time of ripening of premature fruit varies within wide limits; sometimes it precedes the normal ripening by only a few days, and at other times by several weeks. The red spots occur in the flesh as well as on the skin, making the peach more highly colored than is natural. The taste of the fruit is generally inferior and often insipid, mawkish, or bitter. Often this premature ripening is the first symptom of yellows. The peaches are then of good size and quite showy, and occur on trees in full vigor, upon limbs bearing abundant green foliage, and sometimes also other fruits which afterward ripen normally.

"Often during the first year of the disease this kind of fruit is restricted to certain limbs, or even to single twigs, which, however, do not differ in appearance from other limbs of the tree. The following year a larger part of the tree becomes affected and finally the whole of it, the parts first attacked now showing additional symptoms, if they have not already done so. These symptoms are the development of the winter buds out of their proper season. Like the prematuring of the fruit, the date of this also varies within wide limits. The buds may push into shoots only a few days in advance of the proper time in the spring, or may begin to grow in early summer, soon after they are formed, and while the leaves on the parent stem are still bright green. This is a very common and characteristic symptom, and is especially noticeable in autumn when the normal foliage has fallen. 


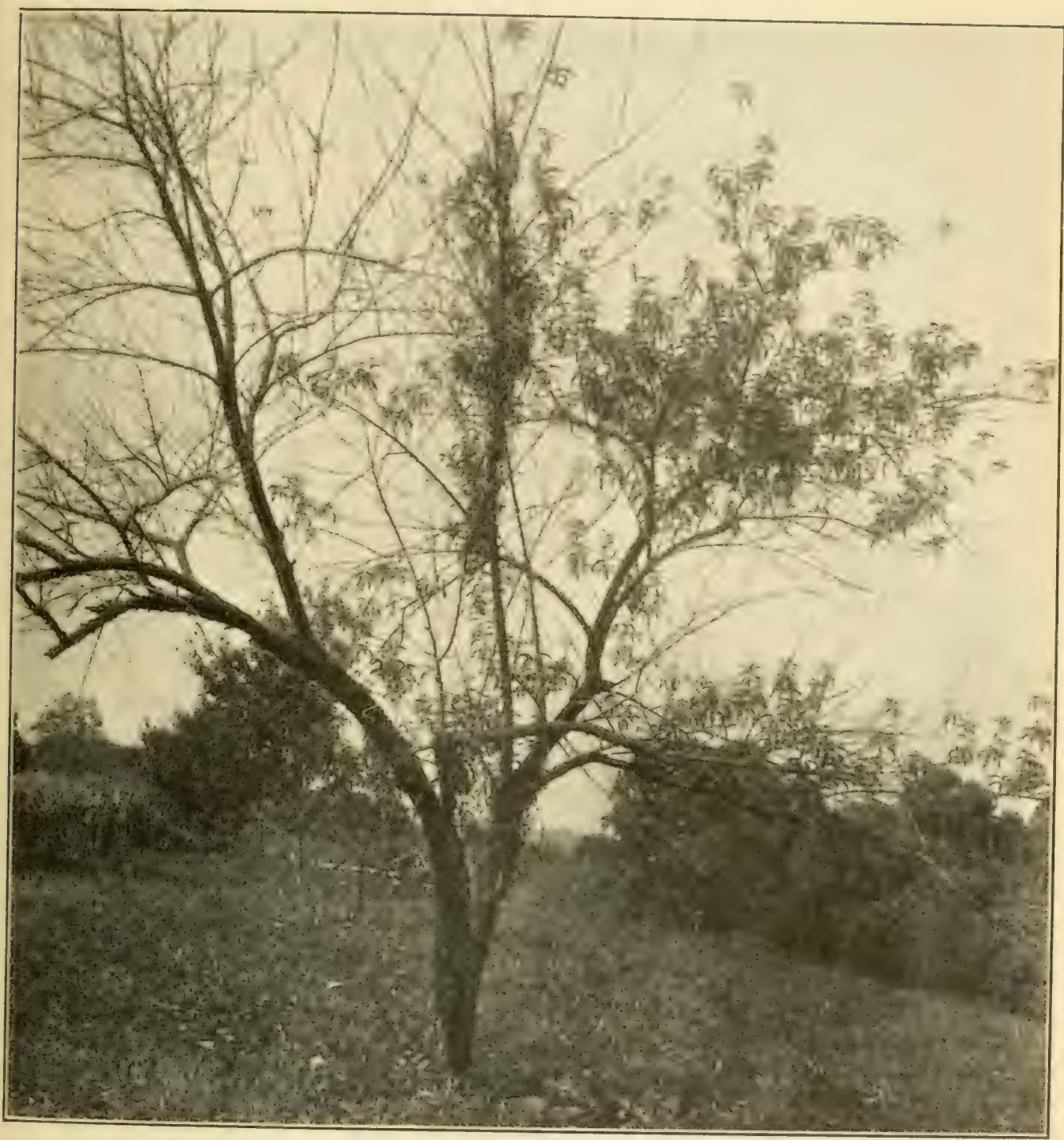

Fig. 48. - Peach tree showing yellows. After Sheldon. 
Usually under the influence of this disease feeble shoots also appear in considerable numbers on the trunk and main limbs. These arise from old resting buds, which are buried deep in the bark and wood, and remain dormant in healthy trees. Such shoots are sometimes unbranched, and nearly colorless, but the majority are green and repeatedly branched, making a sort of broomlike, erect, pale green, slender growth, filling the interior of the tree."

A tree exhibiting these symptoms should be cut and burned. It is valueless, and its presence is a serious menace to the owner as well as to the country at large.

Rosette. ${ }^{109-110}$ - The peach rosette is southern in distribution, being known chiefly in Georgia (where it was first noted in 1879), South Carolina, and Kansas. As to its nature, means of spread and prevention, precisely what has been said of yellows applies. Its distinguishing characters are given by Smith as follows:-

"Rosette clearly belongs to the same type of diseases as yellows, but its first stages are more striking and its progress is much more rapid. It may first attack part of the tree and then the remainder, the same as the yellows, but it is more likely to appear at once on the whole tree, and generally in early spring. In trees attacked in this manner, all of the leaf buds grow into compact tufts or rosettes. These rosettes, though seldom more than two or three inches long, usually contain several hundred small leaves. A tree thus attacked always dies dluring the following winter or autumn. When part of a tree is thus attacked, that part dies as above described, and the remainder shows symptoms the next spring, to die in turn after about six months.

"The prevailing color of the foliage is yellowish green or olivaceous. The older leaves at the base of the tufts are largest, and frequently grow to a length of several inches, but have inrolled margins and a peculiar stiff appearance, due to the fact that they are straighter than healthy leaves. These outer leaves turn yellow in early summer and drop as readily as though it were autumn, while the inner leaves 
of the rosette are still green and delicate. The compact bunching of the leaves is very conspicuous, and makes the trees look quite unlike those affected by yellows. Where a tree is attacked in all parts, it matures no fruit. In all the cases which have been noticed the fruit borne by affected trees either shrivels while green and drops off, or else ripens naturally.

"In the absence of premature, red-spotted fruit, in the severity of the disease from the outset, and in its rapid progress, it is quite unlike yellows, which is decidedly chronic, and the first slight symptoms of which usually occur in very green and thrifty trees, and are frequently overlooked the first season."

The treatment is to cut and burn infected trees. No carelessness should be tolerated as regards this disease or yellows.

Little-peach. ${ }^{111-112}$ — This seems first to have been publicly noted by Smith in an address in Michigan in 1898, in which state it had been of alarming character prior to 1893 ; since these years it has appeared in New York, New Jersey, and Canada. The most prominent symptom is small, undeveloped fruit, one-half to one-third the usual diameter, ripening some 10 to 14 days later than normal fruit, and having "stringy" flesh and insipid or bitter flavor. The somewhat drooping leaves are small, one-half normal size. and vary from light green to yellowish-green. An orchard once affected is of no further value, and should be removed and burned because of the danger of contagion.

Frost Injury. - Peaches are especially susceptible. For discussion, see apple.

\section{Minor diseases}

Pustular-spot ${ }^{107}$ (Helminthosporium carpophilum Lév.). Peaches affected with this disease are described by Selby as "Badly disfigured, having numerous pimply red spots with light brown centers." Upon yellow varieties the pustule is commonly lacking, there being simply a light brown center with a red border. As the fungus which causes this spot rests 
purely upon the surface its development may be prevented by spraying. Selby reduced the injury from 16 per cent to 1 per cent by three applications of Bordeaux mixture.

Rust (Transchelia punctata (Pers.) Arth.). - A true rust exists upon the peach, plum, and cherry and near kin. While more common upon the plum, it very frequently does damage to the peach, in some cases being so serious as to cause almost complete defoliation. The alternate stage is not uncommon upon the hepatica in the spring.

This malady will be recognized by the presence of small, round, dusty sori on the lower surface of the leaves and on the young shoots, while in the immediate region of these spore-bearing pustules, the leaf, seen from above, often presents a reddish or reddish yellow color.

Stem-blight (Phoma persica Sacc.). - A fungus on the bark which fructifies in minute pustules sometimes causes twigs to die. The disease may be recognized by the dead bark thickly studded with small pycnidia. Burning the diseased branches will prevent spread of the pest.

Frosty-mildew (Cercosporella persica Sacc.). - In damp, shaded localities, especially on trees of dense foliage, a disease occurs in the form of pale-yellowish leaf spots. These show, on the underside, a delicate frostlike appearance, due to the growth of white spore-bearing hyphæ. It is not usually serious, though widespread, and sprays recommended elsewhere suffice to hold frosty-mildew in check also.

Cercospora shot-hole (Cercospora circumscissa Sacc.).This is very widespread, producing spots, or, when the diseased tissue falls out, oval holes, in the leaves. It also infects small branches. The chief injury lies in destruction of leaf tissue and of valuable shoots. Dormant spraying recommended for the curl is useful here. Phyllosticta shothole (Phyllosticta circumscissa Cke.). - Similar in appearance and effect to Cercospora shot-hole, it responds to like treatment. Armillaria and Clitocybe root-rots, see apple; Silverleaf, see plum. 


\section{PLUM}

Black-knot ${ }^{113}$ (Dibotryon morbosum (Schw.) T. \& S.).The black-knot receives its name from the swollen black distortions, $3-15 \mathrm{~cm}$. long, upon the branches. In a young condition the galls are olivaceous, but as the season advances they become darker and eventually coal black. At the same time soft tissue changes to a hard, brittle texture.

When the knot completely encircles the twig, the supply of nourishment to more distant parts is seriously interfered with. If less than the whole of the circumference be involved, the damage is not so great, but it is even then sufficient to seriously impair the fruiting of the tree. Black-knot may either kill the tree in a year or two, or simply destroy its value. All varieties of plums, and nearly all cherries, are subject to the dis-

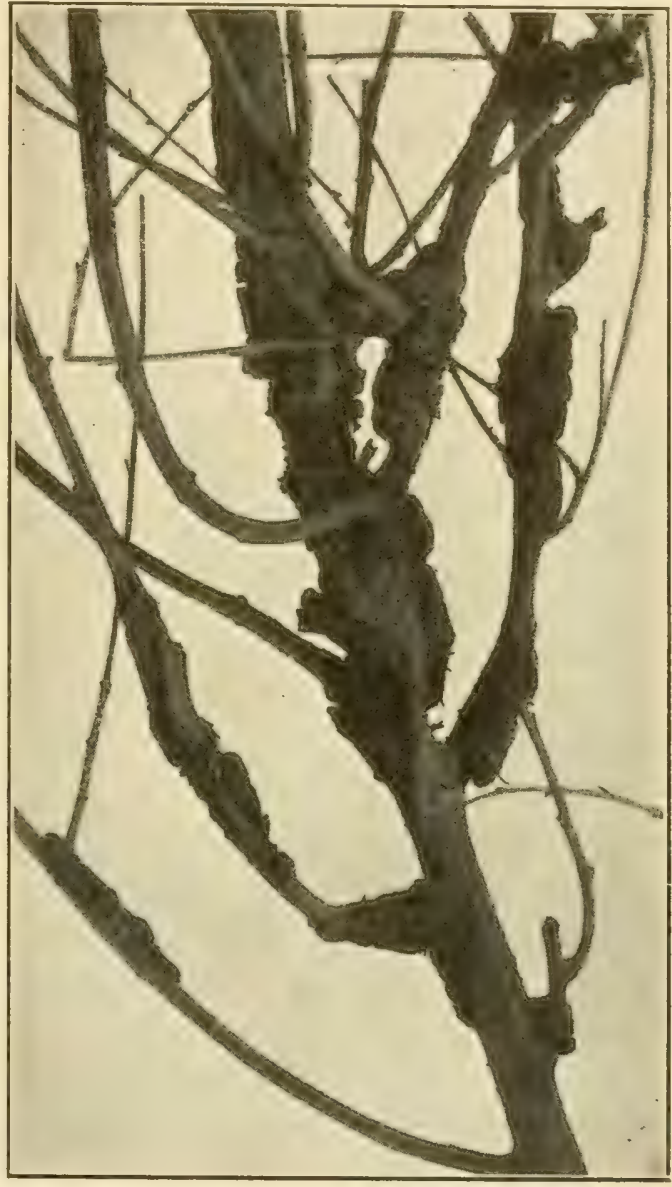

FIG. 49. - Portion of a plum tree badly infested with black-knot. Original. ease, which is therefore very widely distributed. It is more common in the East than in the West.

It is probable that infection can occur only through injured bark. One step toward lessening the disease is, therefore, 
to exercise all care not to bruise the tree. An effective measure, however, consists in pruning out and burning all black knots. This course, if followed persistently and thoroughly, will remove all danger. Experiments show that spraying very materially lessens the spread of black-knot, and while it might not pay to spray to prevent this disease, spraying in an orchard for other reasons really diminishes this risk.

Plum-pockets ${ }^{114,484}$ (Taphrina pruni (Fcl.) Tul. and $T$. communis (Sad.) Gies.). - The disease is widespread in Europe and the United States, and in certain localities it is destructive. The name "plum-pocket," or "plum-bladder," arises from the curious hollow deformity of the plum, which appears soon after the flowers fall. The pulp and stone of the fruit are replaced by a thin, soft, inflated shell, and in place of the seed, merely a hollow cavity exists. The affected fruits vary from $2-5 \mathrm{~cm}$. in length, and can readily be distinguished from the healthy fruit by their pale yellow color. As they age, they become coated over with a fine powder, the spores of the fungus. Later the pockets turn black and fall.

The attack of the fungus is, to some extent, local in character; thus a single tree in an orchard may bear "pockets," sometimes every fruit on the tree being affected, while surrounding trees are normal. A tree once affected may continue to bear pockets in succeeding years. Treatment, in such cases, consists in cutting and burning the affected branches or trees. To some extent the disease is also due to yearly surface infection, which may be prevented by spraying as for peach curl.

Leaf-spot ${ }^{83-85}$ (Coccomyces prunophorce Higg., Cylindrosporium). - Leaf-spot or shot-hole disease, similar to that of plums and cherries, produces discoloration of the leaf tissue, the spot often bearing a red or purple border. If abundant several spots may coalesce as they enlarge. The tissue involved dies, turns brown, and eventually drops from the leaf, leaving circular or ragged holes. The disease is also frequent upon petioles.

The attack is insidious, and the disease often does much 
damage before its presence is really known. Defoliation is the chief injury. This checks starch production, and thus impairs the tree's general vigor and productiveness, even weakening the tree to such an extent that it cannot withstand the winter. As high as 80 per cent damage has been reported. The loss in Ohio was estimated as $\$ 20,000$ in one year. Leaf-spot is especially injurious to nursery stock, as it may interfere with successful budding and grafting: For treatment, see cherry.

Scab (Cladosporium car pophilum Thüm.). - Plum scab appears as spots on the fruit, similar to the scab of peaches. When plums begin to ripen or are just turning in color, small round patches, pale-greenish or grayish in color and not larger than the head of a pin, develop. These increase in size, in some cases to a centimeter in diameter. In older specimens the diseased spots are frequently confluent and of darker brown color. In very old specimens, especially where the fruit has undergone decomposition, the patches become black and uneven.

Treatment identical with that recommended for peach scab will apply in this case.

Wilt ${ }^{117}$ (Lasiodiplodia triflorce Hig.). - Restricted to the Japanese plum and hybrids, this injurious wilt has thus far been observed only in Georgia, North Carolina, and Alabama. Often the first symptom is a sudden wilting of the leaves of a single branch or of a whole tree. At the base of the wilted portion, the bark and cambium are dead and the wood brown or black. The entire tree usually dies within a year from the first observable wilt. The causal fungus appears to gain entrance to the host only through wounds, and in the tree lives chiefly in the ducts. This disease, therefore, presents a case with very few parallels, $i . e$. of a tree killed by plugging of the veins by fungi. Prevention, by avoiding wounds, or by disinfecting them when they occur, is the only recourse.

Silver-leaf (Stereum purpureum Fr.). - The leaves, though normal in size and form, take on an ashen gray luster, this 


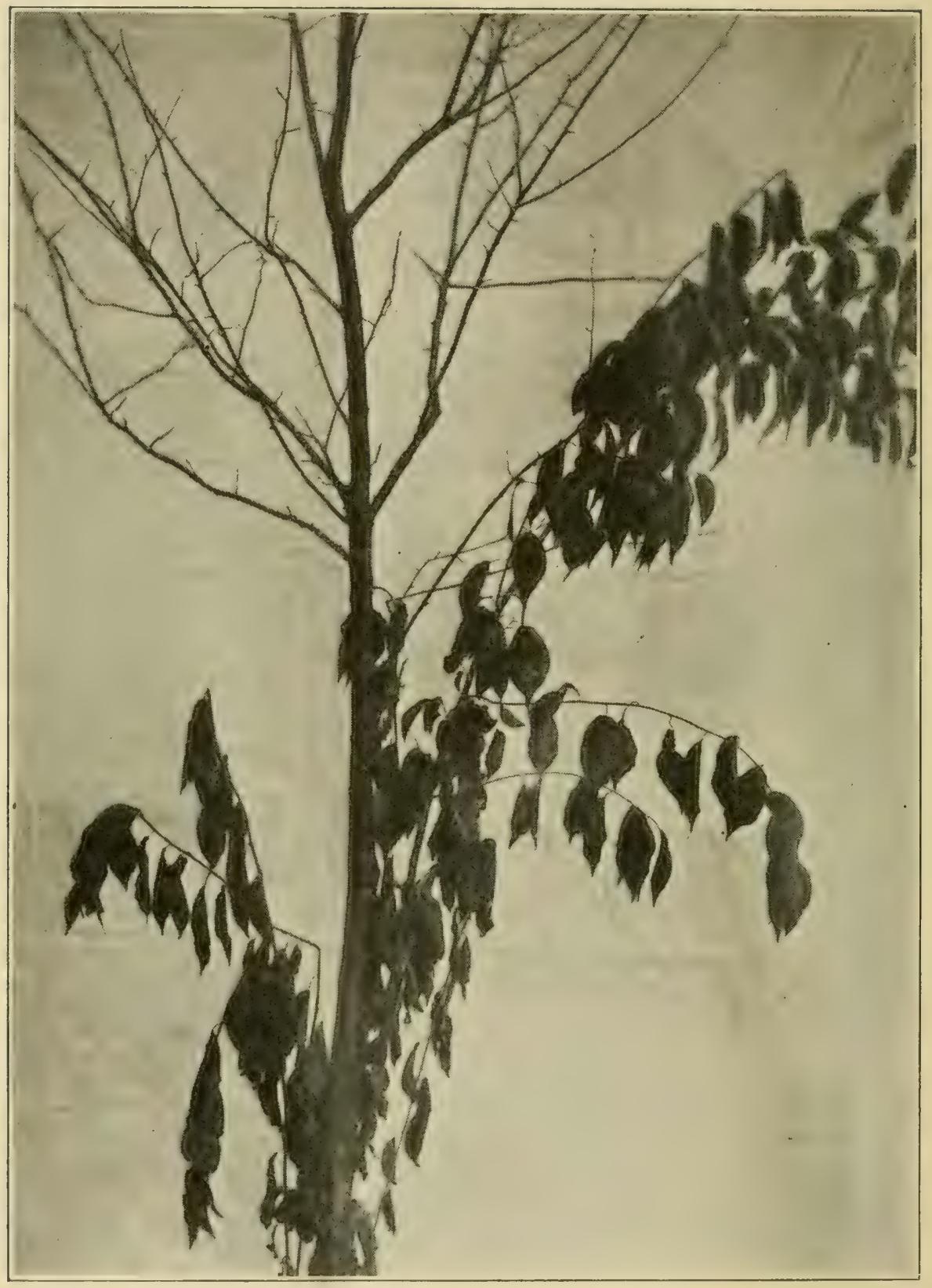

FIG. 50. - Plum wilt. After Higgins. 
symptom showing first on single branches and extending year by year till the whole tree is involved. The twigs first infected soon die, and in the course of a few years the whole tree usually succumbs. The wood of diseased branches is browned. The sporophores of the Stereum, which appears to be the usual causal agent, develop only after the death of the tree. The disease is most common on plum and other drupes, but is known also on apple, pear, currant, gooseberry, chestnut, and ash.

Brown-rot (Sclerotinia cinerea, Monilia). - Brown-rot is serious on the plum as it is with the peach and cherry. The loss in Ohio in one year was estimated at $\$ 25,000$.

For description and treatment, see peach.

\section{Minor diseases}

Blight ${ }^{116}$ (Bacillus amylovorus). - Blight of the apple and pear has been discussed on preceding pages. A similar blight is rarely known to affect the plum tree, and careful studies by Jones show that the diseases on plum and pear are identical. For treatment, see pear. For Powdery-mildew, see cherry. Crown-gall, Armillaria root-rot, Rust, Blackspot (Pseudomonas pruni), see peach. Yellows and Rosette are less injurious than on peach; Little-plum is similar to Little-peach. 


\section{SMALL FRUITS 28}

\section{BLACKBERRY, DEWBERRY, RASPBERRY}

The disease of these three crops, of the genus Rubus, are so nearly identical that they may be treated under one caption.

Anthracnose ${ }^{118-120,150}$ (Plectodiscella veneta Burk., Gloeosporium). - The anthracnose, on both blackberries and raspberries, is one of the most serious and widely distributed diseases of these crops. The first publication in America regarding it seems to have been made in 1882 by Burrill. Since then numerous papers from many sections attest its importance. In 1907 it was estimated to have injured onethird of the crop in Nebraska, one-half in Wisconsin, and even more in Illinois. The chief seat of attack is the cane, especially upon young stalks, though the disease appears also upon both petioles and leaves.

The fungus often appears upon young canes before they are $25 \mathrm{~cm}$. high, making small, purplish spots, which soon become grayish or dirty white in the centers. The borders of the spots are purplish and slightly raised. Later as the spots enlarge they coalesce, making irregular blotches $2 \mathrm{~cm}$. or more long, which often encircle the cane. The stalk then withers and dies from lack of sap supply. Badly diseased canes present a bark of rough, scabby appearance due to the efforts of the cane to heal the wound. Canes occasionally crack from this disease. The chief injury is to the cambium layer or the sappy outer wood. The leaves on affected canes are dwarfed, the fruit ripens prematurely, is undersized, and often dries up.

Upon the petioles of the older leaves the disease appears early, spreading thence along the ribs to the leaf. Owing to the one-sided attack upon the veins and petioles, the 
leaves develop unequally, often with inrolled edges. Upon the lower surface very small spots about $1 \mathrm{~mm}$. in diameter are produced, from which the diseased tissue often falls. In the older diseased spots the sporebearing acervuli are just visible to the naked eye.

Occasionally, an incipient attack may escape observation during the first and second years, and even well into the third year. Then, with prospect of a good yield, the berries shrivel on the stems and later many plants die. More often the disease remains moderately injurious from year to year, weakening the plants and diminishing the yield.

In localities subject to this disease, it is best to rotate crops so as to avoid keeping raspberries or blackberries more than three years on the same soil, and to set out only healthy plants. When the disease appears, cut out and burn diseased parts immediately after picking. Spray-

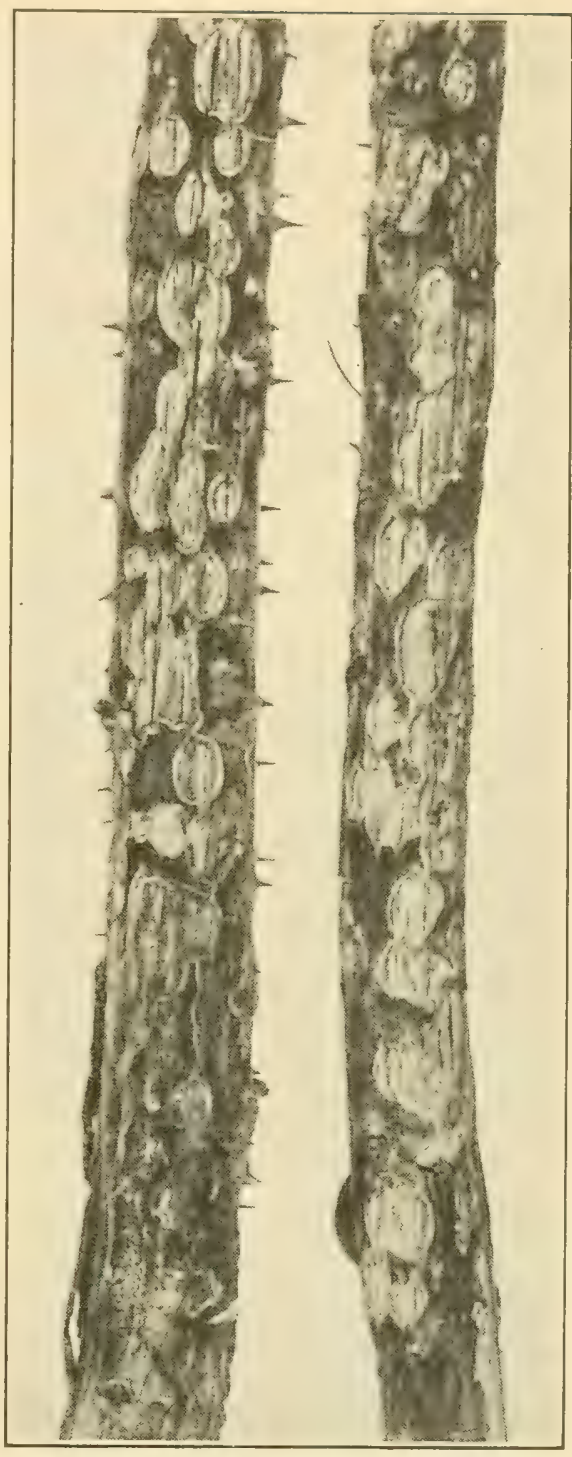

Fig. 51. - Anthracnose on black raspberry, showing typical fissures. After Burkholder. ing with lime-sulfur is effective. Use three applications, (1) before the leaves appear, 1-20, (2) when the shoots are six inches high, 1-50, (3) just before blossoming. 
Crown-gall (Pseudomonas tumefaciens). - Frequently swellings are noticed on the stems near the roots, or even on the higher parts of stems, of the raspberry or blackberry sufficiently numerous to injure the health of the plant. These galls are apparently of the same nature as the crowngall of the peach, almond, apple, ete. It is desirable to puil up and destroy diseased plants and avoid placing blackberries and raspberries on ground which is known to be infected.

Leaf-spot (Septoria rubi West.). - Upon the leaves of blackberries, raspberries, and dewberries small spots frequently appear, having a central region white or ashen in color, and the border brown or often of reddish tint. These spots are about $3 \mathrm{~mm}$. in diameter. Close examination of the central, ashen area, especially with a hand lens, reveals exceedingly small, black pycnidia scattered throughout.

While this disease is exceedingly common and of wide distribution, it does not often develop an epidemic and usually does but little injury, though its damage has been estimated as high as 20 per cent in Florida and Ohio. No treatment has yet proved of sufficient value to warrant its use.

Orange-rust ${ }^{121}$ (Gymnoconia interstitialis (Schlecht) Lager.). - In the early spring the under sides of the leaves of blackberries and raspberries often present a livid red or orange color. This rust was observed as early as 1817, in Kamchatka, and is very widely distributed in the United States, Europe, and Asia, upon some nine species of Rubus, both cultivated and wild. It is known from Maine to Minnesota and Florida to California, and is in some cases very destructive.

Examination of a diseased plant shows that its growth has been much retarded by the fungus; the leaves are curled, distorted, unusually small, and lacking in green color. Plants so affected never recover, and are useless. Preceding by some two or three weeks the conspicuous red rust, above referred to, occurs another stage of the disease that is often overlooked. This consists of a thick growth of small colum- 
nar, glandlike structures, chiefly upon the upper side of the leaf, and present even before the leaves unfold. These structures (pycnia) become more distinct as the leaves enlarge.

The mycelium of the causal fungus when once established in the cane lives in it from year to year, spreading throughout the plant. Spraying is, therefore, ineffectual. In fact the only successful way to combat the rust is to remove and burn all affected plants. Diseased plants are valueless and are a menace to the healthy plants. Resistant varieties, such as the Snyder, should be used.

Late-rust ${ }^{122}$ (Kuehneola albida (Kühn.) Magn.). - As the name implies, this rust usually appears late in the season, distinguishing it from orange-rust, which is prevalent in the spring. The spores are not so abundant as those of orangerust, but occur in small, pale-yellow or whitish spots scattered on the under side of the leaf. This disease has not as yet become sufficiently prevalent to be of serious import, although its increase at any time under favorable climatic conditions may place it among the important plant enemies. It appears to be limited to blackberries, and is known both in Europe and the eastern United States.

Cane-blight ${ }^{151}$ (Leptosphceria coniothyrium Sacc. Coniothyrium). - First mentioned in literature in 1899 by Stewart and Eustace as occurring in the Hudson Valley, this disease seems to be widespread and destructive upon both red and black raspberries. Principal damage occurs to the fruiting canes, the foliage of which suddenly wilts and dries. New canes are frequently killed during the first season's growth.

Infection usually occurs through wounds, especially pruning wounds or those made by insects, and progresses toward the root. Sometimes the disease remains upon one side, while in other cases it encircles the cane.

Upon diseased eanes the bark is lighter colored and disfigured by smoke-colored patches of spores extruded from the pyenidia within. The pycnidia appear as very minute pustules. The wood is much discolored and eventually 


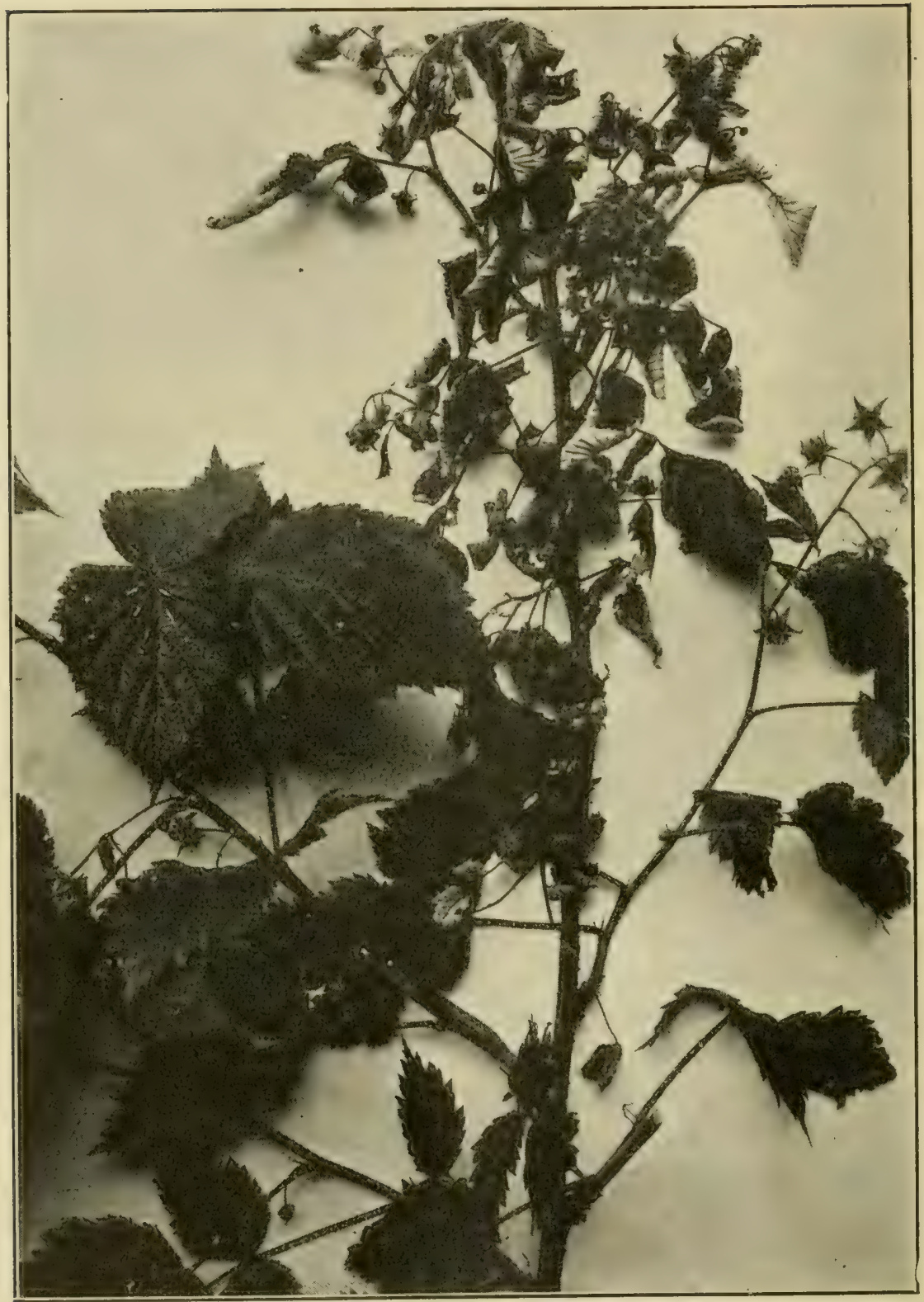

FIG. 52. - Raspberry cane-blight. After Stewart and Eustace. 
brittle. This cane-blight is often crroneously attributed to a borer or to drought, or winter injury.

The damage is often as high as 25 or 50 per cent of the crop, and the disease is said to be present to some extent in nearly all of the raspberry plantations in New York. Cuthbert, Marlboro, Ohio, Gregg, Kansas, and the wild red raspberry are susceptible. The Columbian is more resistant.

The disease is disseminated largely by infected nursery stock or even by the soil adhering to the roots of diseased plants, and is conveyed from plant to plant by wind or rain, by pickers, or by workmen while pruning and layering, also by tools used in cultivation. See soil diseases, p. 26. Since the fungus can live on dead fragments of canes, etc., upon the ground, these prove fruitful means of propagating the pest.

To prevent the disease, care in the selection of healthy plants is necessary. Plants should not be set where the disease has prevailed in previous years. When the fungus has gained access to a plantation, all dead canes should immediately be cut out and burned and all fragments scrupulously removed from the ground. Spraying is of doubtful value.

\section{Spur-blight 151, 152 (Mycosphoerella} rubina (Pk.) Jacz.). - On black and

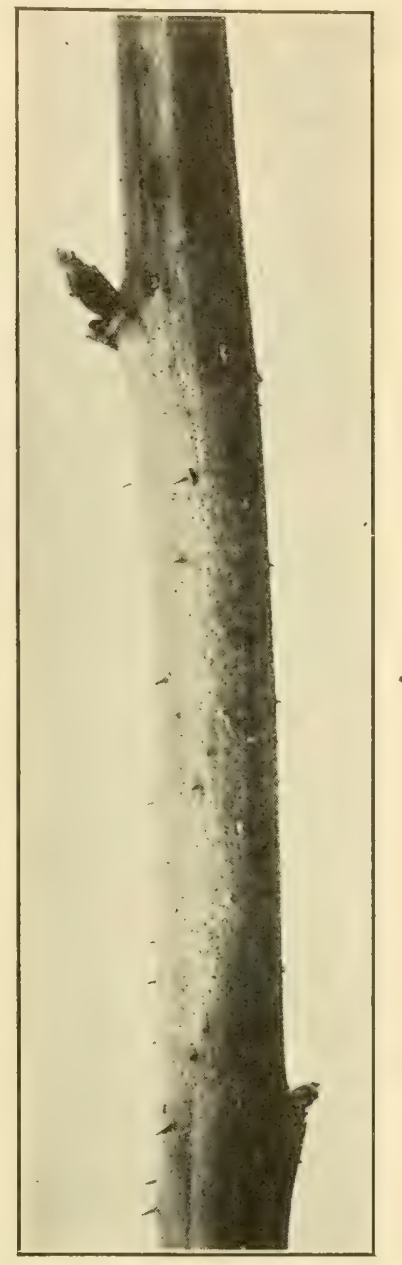

FIG. 53. - Raspberry discolored by spurblight. After Stewart and Eustace. red raspberry canes in autumn, sharply defined, brown or bluish black areas from 2-10 cm. long occur on the bark, never on the wood. In the spring these spots bear numerous small pycnidia. 
This disease has been especially destructive in Colorado. Three applications of Bordeaux mixture, 3-2-50, with 2 pounds of rosin-fish-oil-soap as an adhesive, applied: (1) when the canes were 8-12 in. high; (2) two weeks later; (3) two weeks later, gave excellent results in Colorado.

Yellows. ${ }^{151}$ - Affected plants are stunted, yellowish, and recall peach yellows. Laterals are dwarfed, leaves are small, curled downward at the margins, and yellow-mottled. Berries dry up without ripening or are insipid when mature. Health and disease may occur upon the same plant. The cane itself and roots appear normal. The disease appears to be limited to raspberries and has been recorded in many states from Massachusetts to California.

The cause and remedy are not yet known. Diseased plants should be burned and resistant varieties planted.

Gray-mold (Botrytis), and Blue-mold (Penicillium).These molds cause decay of fruit in transit. Care to avoid wounds and over-ripeness, also prompt cooling and ventilation, are necessary.

Double-blossom *133 (Fusarium rubi Wint.). - Doubleblossom occurs on dewberry and, to some extent, on the high-bush blackberry. It is most abundant on the Lucretias, but is also a serious pest on the Rathbone. The disease makes its appearance in the spring, just as the leaf buds are opening, although it can be detected previous to that time by the enlargement of the diseased buds.

Instead of the normal shoots and leaves a witches' broom is produced; the entire bud being involved or only a part, according to the attack. When the flower buds open, they show a great variety of deformities: sometimes only slightly distorted; sometimes with increased number of stamens and petals and with enlarged, thickened petals and sepals. Even those flowers which appear most nearly perfect have diseased ovaries, and the fruits from these brooms are always worthless.

Double-blossom usually appears during the second harvest * Prepared by M. T. Cook. 
and continues to increase until the plants entirely succumb. Numerous late blossoms appear during the first season and increase in number from year to year.

The disease is due to a fungus, and the infection of new buds occurs during the blooming and fruiting season. For

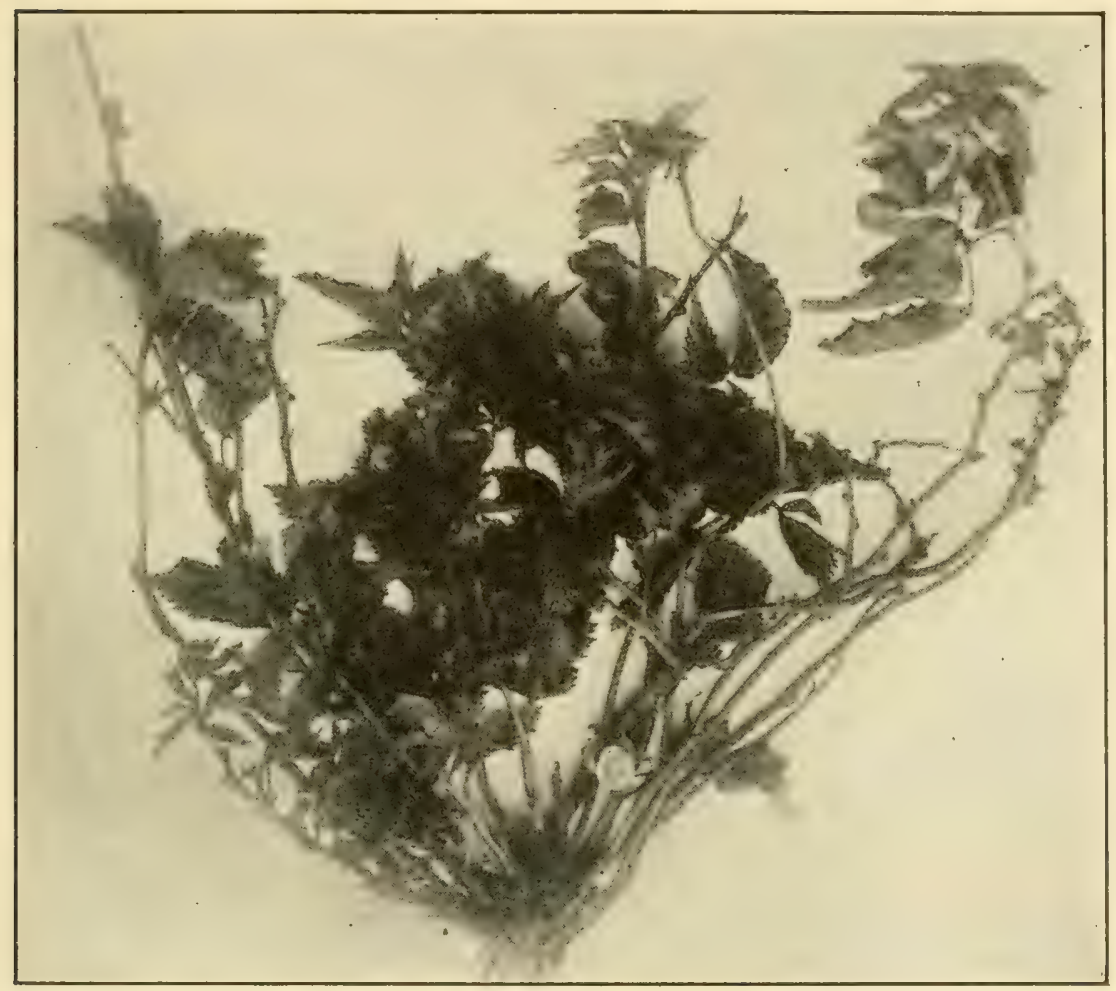

FIG. 54. - The Dewberry double-blossom showing witches-broom of the vine. After Cook.

this reason it is impossible to control the disease by spraying, but it may be held in check by removing and burning the deformed buds as soon as they begin to open, and can be easily detected. If this is done early in the season before the leaves are large enough to hide the diseased parts, a man working alone can care for plants at the rate of 400 per hour. 
Blue-stem ${ }^{123}$ (Verticillium caulophagus (Law). - Raspberries and blackberries in the Pacific Northwest are affected by bluc-stem, the first appearance of which was noted in 1904. The fruit dries up before maturity, the leaves become discolored and wilt. Less commonly the canes turn dark, the first blue-black, striped discoloration of the shoot occurring near the ground. Internally in stems, and even in roots, reddish streaks are evident in the wood. Many affected canes die, others merely show the symptoms mentioned above.

\section{BLUEBERRY AND HUCKLEBERRY}

No diseases involving special treatment are to be noted. Numerous parasitic fungi are recorded, among them Exobasidium, Gibbera, Guignardia.

\section{CRANBERRY ${ }^{124-126}$}

To lessen storage decay, cranberries should not be picked when wet, nor stored with admixture of infected material likely to result from deep "scooping." They should also be well ventilated.

Scald, blast (Guignardia vaccinii Sh.). - The fruits are attacked as soon as the blossom falls, or even the blossom itself may be blighted. The affected berry shrivels, turns black, and is covered with pycnidia. From such fruits the disease spreads to other fruits and to the leaves. In some bogs as much as 50 per cent of the crop is thus dostroyed. This form of disease is commonly designated as "blast," while still another form of it has been termed "scald."

Scald may appear upon the berries, causing small, lightcolored, softened, watery spots. These rapidly increase in circumference, and even envelop the whole fruit. Sometimes the diseased portion shows more or less distinct brownish zones. In other cases the zones are lacking, and the whole fruit becomes very soft and translucent. Upon the leaves 
irregular, reddish brown spots with pyenidia are more rarely produced.

Plants, after several years of disease, die, as do cuttings during the first or second year. Thrifty plants are much more resistant than weak ones. Particular attention should, therefore, be given to provide such irrigation as to best favor the health and vigor of the plants. Sanding the fields often gives good results, doubtless due partly to removal of contagion by covering infective material. It is also advisable,

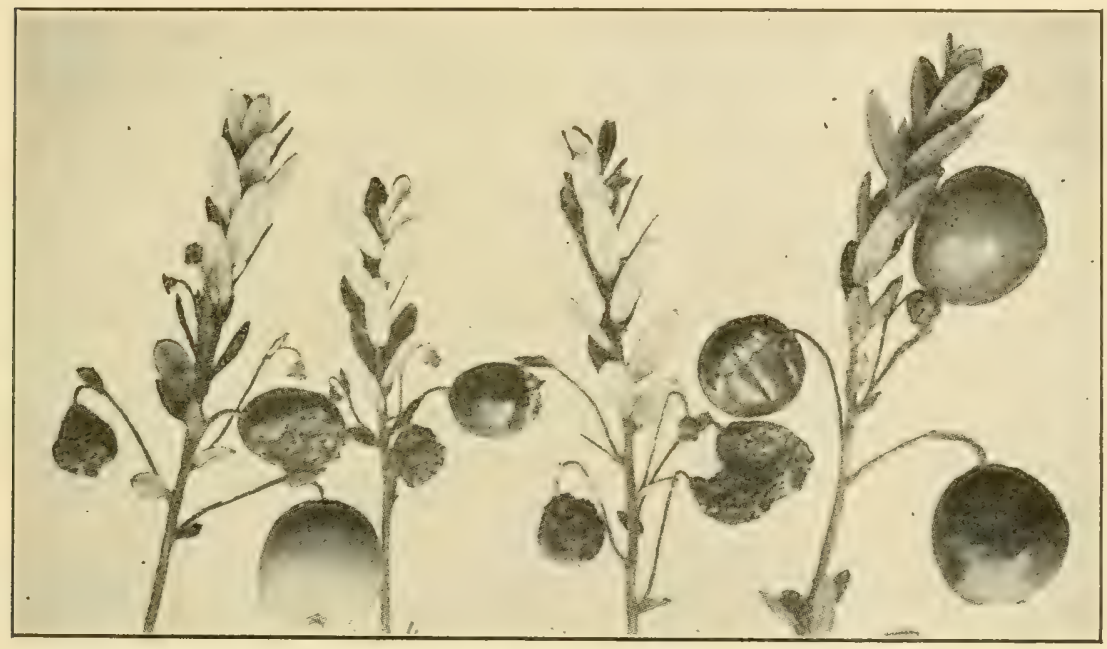

FIG. 55. - Cranberry scald and blast. After Shear.

for the same end, to rake out and burn all dead and infected plants in the autumn. Cuttings should be taken from such plants as show resistance to the disease.

In spraying experiments by Shear, five applications of 6-6-50 Bordeaux mixture, with 4 pounds of rosin-fish-oilsoap added to increase adhering power, showed 2.36 per cent of rotten berries, while the unspraved plats showed 92.6 per cent of rotten berries. The cost of application was $\$ 15$ to $\$ 20$ per acre, using 200 galions of mixture at each application.

Rot (Acanthorhynchus vaccinii Sh.). - An effect upon the berry very similar to that of the scald fungus appears 
first as small, light-colored, soft spots, which soon destroy the whole berry. Later small, dark-colored blotches show under the skin, but no pycnidia appear. The disease is found in New Jersey, West Virginia, Mississippi, Wisconsin, and Nova Scotia. In importance it is the second cranberry disease.

The treatment suggested for scald is also effective against this rot.

Anthracnose (Glomerella cingulata var. vaccinii Sh.). This rot is less injurious in New Jersey than scald, but is more common in Massachusetts and New England.

The three diseases just considered cannot well be distinguished except by microscopic examination. In some cases the berry becomes soft and light-colored, but if the fungus develops slowly, the diseased portion is not so soft. To control them the water supply should be regulated so as to avoid great fluctuations during the growing season. Too little water is more to be avoided than too much. Vines dead from disease should be pulled and burned. Bordeaux mixture, at fourteen-day intervals, as suggested above, is recommended.

End-rot ${ }^{127,}{ }^{544}$ (Fusicoccum putrefaciens Sh.). - This occurs in all cranberry sections of the United States, starting at either end of the fruit and causing softening. Bordeaux mixture, 4-3-50, with adhesive, applied four times, (1) before blossoming, (2) as soon as most of the fruit is set, (3) ten days later, (4) when fruit is three-fourths grown, is effective.

Hypertrophy (Exobasidium oxycocci Rostr.). - Hypertrophy is known only in Massachusetts, where in 1906 it did considerable damage in some bogs.

In this disease the buds in the leaf axils, which normally remain dormant, grow out into short shoots bearing swollen, enlarged leaves of pink or light-rose color. This character has given rise to the name "false blossoms."

Wilt (Sclerotinia oxycocci Wor.). - As the plants begin to blossom the tips of green shoots wither. Then a thin, soft, white moldlike outgrowth appears upon the stem and leaves. 
From here the spores spread to the open blossoms and infect the young fruit. No further evidence of the disease is seen until the berry is nearly mature, when the affected berries are found to be full of a cottonlike growth, the fungous mycelium. At harvest time such berries show a grayish, wrinkled spot, and later the whole berry becomes gray, shriveled, and often spotted with dark-brown masses which break through the skin. Such berries carry the disease over winter.

The destruction by fire of all infected fruit will lessen the evil in succeeding seasons.

Gall (Synchytrium vaccinii Thomas). - The cranberry gall, though not widely known, has been serious in some bogs, and on account of its rapid spread may become of much import in any bog to which it gains entrance. The first collection of the fungus in America was by Halsted in New Jersey in 1886.

It is found upon the leaves, stems, flowers, and fruit as small $(0.8-1 \mathrm{~mm}$.) red galls which occur in such profusion upon the affected part as to cause marked distortion.

The disease is known to recur year after year, resulting in almost complete loss of the crop in infected portions of bogs.

Other plants upon which this gall occurs are: Azalea (Rhododendron viscosum Torr.), sheep laurel (Kalmia angustifolia L.), white alder (Clethra alnifolia L.), leather leaf (Cassandra calyculata Don.), huckleberry (Gaylussacia resinosa T. \& G.), wintergreen (Gaultheria procumbens L.).

Burning over the infested areas is recommended.

Numerous other fungi have been recorded on the cranberry, producing more or less disease. See literature cited.

\section{CURRANT ${ }^{130}$}

Cane-blight ${ }^{128,}{ }^{129}$ (Botryosphoria ribis Gr. \& D., Macrophoma). - This affects both currants and gooseberries and, reported in New York and Delaware, is probably widespread. A sudden wilt of the leaves on one or more canes in a bush 
is the first symptom of disease. The entire bush may succumb, but not usually during the first season. Upon splitting the stems a discoloration of the bark and wood near the base is noticed. No effective treatment is known.

Mycosphærella leaf-spot ${ }^{130,}{ }^{131}$ (Mycosphærella grossularice (Fr.) Lind., Septoria). - The spots on the leaf are small (3 mm.), circular, brown-bordered, with blanched centers

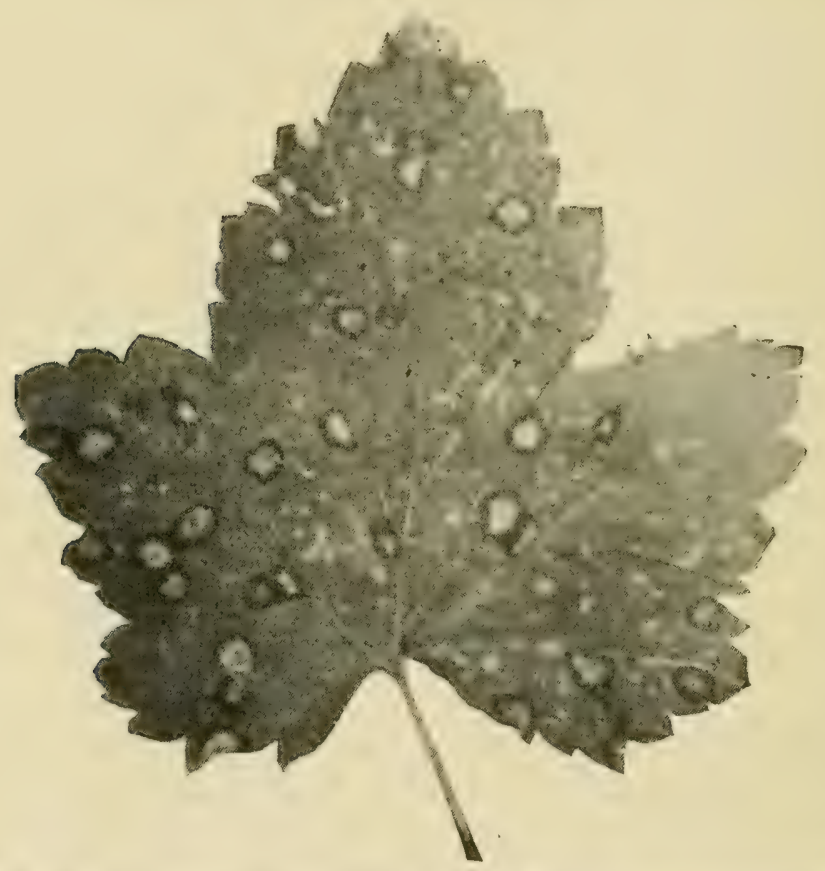

Fig. 56. - Currant leaf-spot. After Stewart and Eustace.

which bear numerous, minute, black pycnidia. Heavy infection causes defoliation. Both currants and gooseberries are affected. Treatment is as for the following disease.

Angular leaf-spot ${ }^{130}$ (Cercospora angulata Wint.). - This term is applied to a peculiar spotting of the leaves of both currants and gooseberries. It is likely to occur wherever these plants are grown. The spot is of rather characteristic appearance, irregular or angular in outline, generally about $3 \mathrm{~mm}$. in diameter. In the center of the brown or gray, dis- 


\section{Small Fruits}

colored area, hyphæ may be seen. Serious defoliation often results. Bordeaux mixture should be used: five applications at ten- to fourteen-day intervals, beginning as soon as the leaves open.

Anthracnose ${ }^{132}$ (Pseudopeziza ribis Kleb., Gloosporium). The leaves, fruit stalks, berries, and canes are affected. Usually the disease is not present to great extent, but a few serious outbreaks have occurred, notably in central New York, in the Hudson River region, and in Oregon. It has

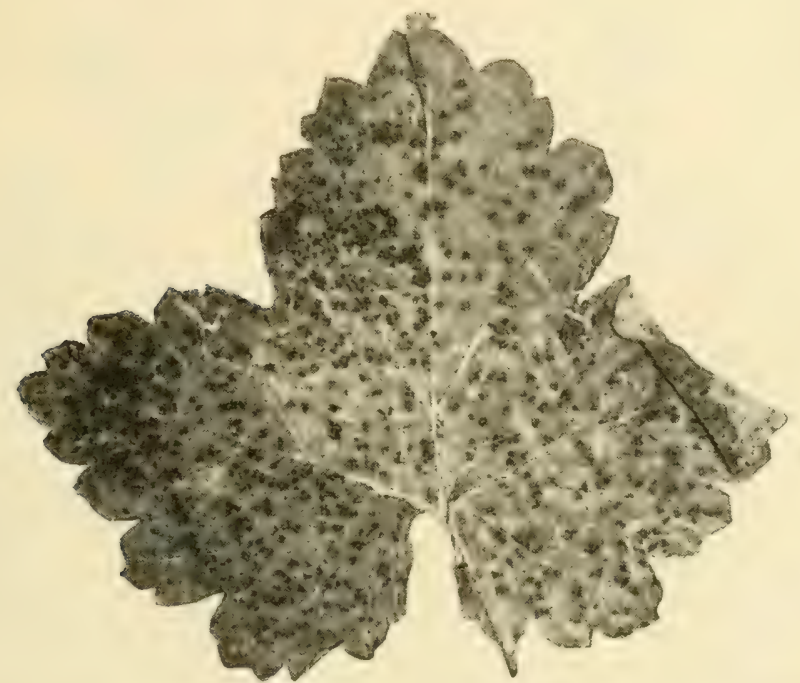

Fig. 57. - Currant anthracnose. After Stewart and Eustace.

also been noted in Ohio, Iowa, New Jersey, and is probably often present to a slight extent in other states. It is less common on gooseberries.

In a severe outbreak the leaves first become covered with small, dark-brown spots, change to yellow, and soon fall. By the time the fruit has ripened, practically all of the leaves may be lost. Upon the leaf stalks, also upon the fruit, stems, and canes, the disease appears as little, black, sunken spots. On the berries the spots are circular and black, much resembling fly specks. The causal fungus probably winters upon the canes, ready to initiate the spring infection. 
Anthracnose can readily be distinguished from the leaf spots mentioned above by the fact that the spots produced in anthracnose are very much smaller, less angular, and lack in every way the distinguishing characters of the other leaf spots.

No conclusive evidence as to the best treatment is at hand. The best recommendation is probably that of the Geneva

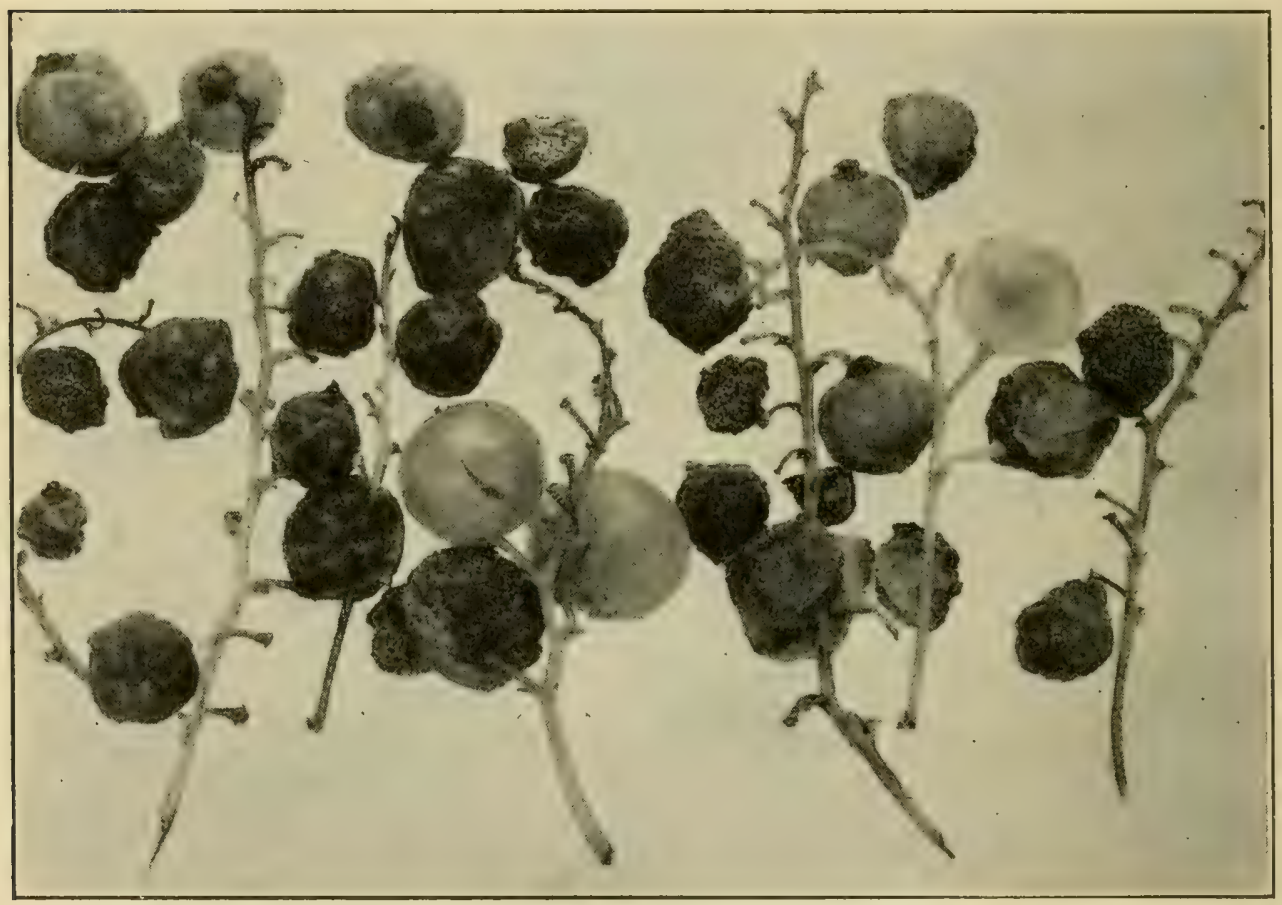

FIG. 58. - Anthracnose of white currants. After Clinton.

Experiment Station: "Spray thoroughly with Bordeaux mixture, commencing before the leaves appear. Make the second treatment as the leaves are unfolding and thereafter at intervals of ten to fourteen days until the fruit is two-thirds grown. In wet seasons make one or two applications after the fruit is gathered. When worms appear, add Paris green or green arsenoid to the Bordeaux."

European rust (Cronartium ribicola F. v. Wal.). - Orange- 
colored powder appears upon the lower surface of the leaves of currants and gooseberries accompanied by but slight damage. The spring stage occurs upon trunks and branches of the white pine, and is there very destructive. For history, distribution, and general discussion, see pine.

\section{Minor diseases}

Powdery-mildew, see gooseberry; Root-rots due to Armillaria, see apple, to Fomes ribis (Schw.) Fr., see gooseberry; Silver-leaf, see plum; Cluster-cup-rust, see gooseberry.

DEWBERRY. See blackberry.

\section{GOOSEBERRY ${ }^{130}$}

Powdery-mildew ${ }^{13 t}$ (Spharotheca mors-une (Schw.) B. \& C.). - This disease appears to be of American origin, whence it invaded Europe, appearing first in Russia in 1890 and in Ireland about 1900. It is now general in Europe where it is much more destructive than here. The mildewed appearance of the leaves, stems, and fruit, all of which appear whitened as though dusted with flour, is characteristic. Close inspection shows each blotch to consist of cobwebby threads densely matted in the central portions of the spot. Later these blotches turn brown, blend irregularly into fewer spots, and form large diseased areas. As the spot ages, its threads weave together into a thick brownish felt.

The young leaves and growing parts are robbed of nourishment, and thus their growth is checked, resulting in serious injury. The berries, if subjected to one-sided attack, become deformed and curved, owing to the retarded growth of the diseased side. They often erack open and decay. Diseased leaves turn brown. Toward the completion of the season's growth small, nearly microscopie, black perithecia are produced in the centers of the diseased spots.

The damage caused by powdery-mildew is excessive and presents the most serious obstacle to the successful culture 
of the gooseberry. It has quite prohibited the cultivation of the finer sorts of English gooseberries in America and is a grave menace to the culture of gooseberries in Europe. Its destructiveness is due not alone to injury to the foliage, bush, and to the fruit yield, but also to lack in

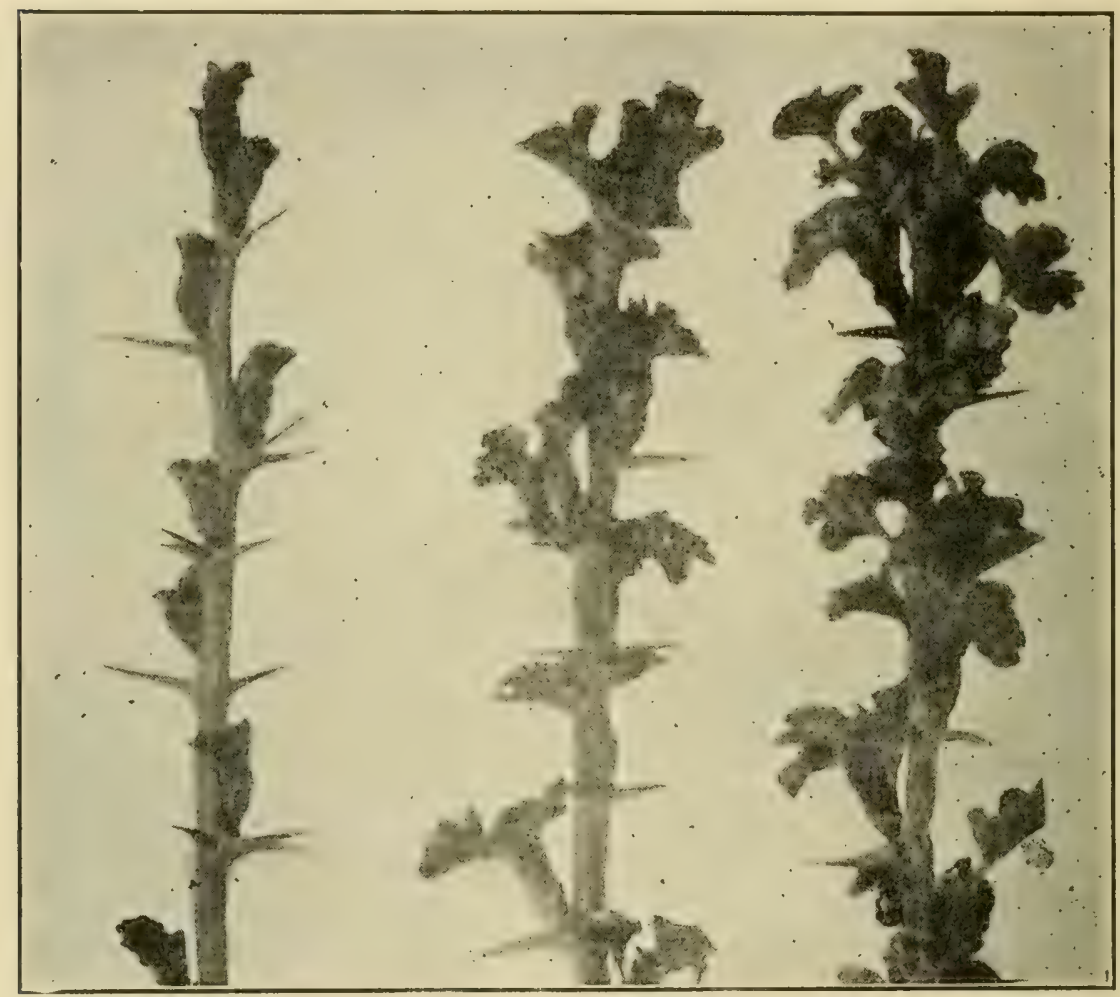

FIG. 59, -- Stages at which spraying should be given for mildew. After Close.

salability, owing to the unsightliness of the partially diseased fruits.

This powdery-mildew has been very successfully combated by use of potassium sulfid, 1 ounce to 2 gallons of water, or lime-sulfur, spraying five or six times. This treatment has been known to reduce the percentage of mildewed fruits from sixty-three on the untreated bushes to eighteen on the treated bushes. The proper time to spray is indicated in the 
accompanying figure. Treatment should be begun at the condition shown in the left-hand figure, and continued at intervals of ten days or two weeks until the requisite number of applications have been made. Spraying begun when the bushes are in the condition shown in the left figure gives decidedly better results than when the spraying is delayed until the condition shown in the other two figures.

Cluster-cup (Puccinia pringsheimiana Kleb., Ecidium).Occasionally reddish, swollen, or thickened spots are noticed over the leaves and sometimes upon the fruit of currants and gooseberries. Close examination shows each spot to consist of a cluster of minute cups embedded in the tissue of the leaf, whence the name "cluster-cup." With a lens each cup is seen to consist of a fringed rim extending above the surface of the leaf, and to be filled with very small, red spores.

The winter condition is found upon quite different plants; namely, various common sedges (Carex) upon the leaves of which it constitutes a genuine rust.

The damage is not serious, and no experiments on a large scale, in prevention, have been undertaken. If it should prove destructive, thorough eradication of the sedges in the neighborhood, particularly any that are rusted in autumn, would be deemed necessary.

Root-rots. - Root-rots upon both the gooseberry and currant have been reported from various states.

The plants die slowly. When dead and living canes are found in the same hill, the living canes are somewhat dwarfed. The fungi apparently spread through the soil, and the infested area enlarges year by year.

Little can be suggested in the way of treatment. It is, however, best to pull up and burn affected plants, and it is inadvisable to place susceptible crops upon soil which is known to be infested. These rots have been attributed in part to Armillaria, see apple.

Anthracnose and Leaf-spots are much as on the currant; the Blister-rust is less common than on the currant. 


\section{GRAPE}

The high acreage value of the crop, the long life of the individual vine, the numerous, serious discases to which the
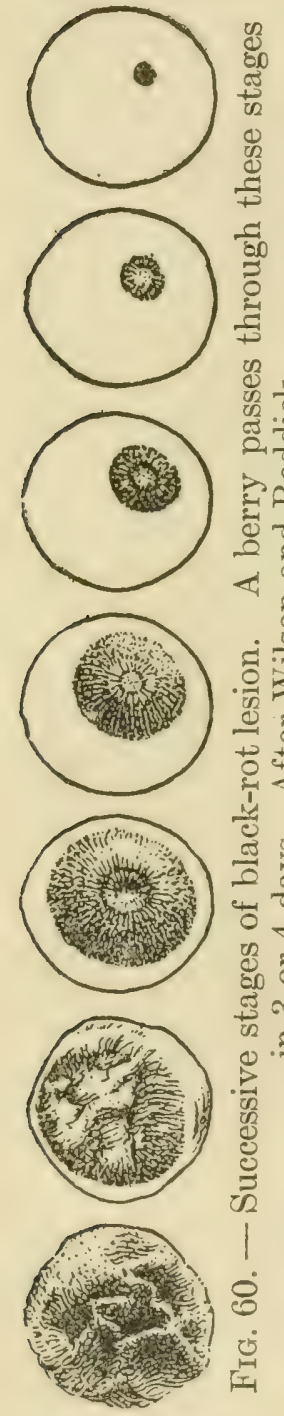

vine is subject, and the fact that it was one of the crops first to be commercially sprayed, render's the grape of especial interest to the plant pathologist.

Black-rot ${ }^{136-139}$ (Guignardia bidwellii (Ell.) V.\& R., Phyllosticta). - This widespread and exceedingly destructive disease, the first record of which dates back to 1861 , has been responsible for the abandonment of grape culture in many sections of the country. It is of general distribution throughout the United States, also in Europe and Asia. In 1906 in Michigan the loss from black-rot was estimated at 30 to 40 per cent of the crop; in Ohio in 1905 at 30 per cent of the crop worth $\$ 95,000$. In many sections the loss is practically total unless measures are taken to check its ravages.

In its most familiar form the disease consists of spotting and decay of the fruit. Black or brown spots, one or more in number, at first infinitesimal in size, appear upon the berry. The spots enlarge with great rapidity, one spot in a few days encompassing the whole berry and changing it into a black mass. As the rot progresses the skin remains intact, and soon the berry begins to shrink and shrivel until it is eventually merely a dry, hard, wrinkled, mummified fruit. The rapidity with which this change takes place is shown in the accompanying figure. Many of the berries so mummified fall to the ground, others remain upon the vine. 
Upon the leaves the disease appears considerably earlier than upon the fruits. Here it produces tan-colored spots about $3-8 \mathrm{~mm}$. in diameter, many or few according to the severity of the infection. In or near the center's of the older spots, upon the upper surface of the leares, are seen the nearly microscopic pycnidia which are often arranged in concentric circles.

On the young shoots the spots are somewhat more reddish and are often cracked longitudinally, but otherwise they are as upon the leaves.

This rot is much more prevalent in warm, humid weather than in dry times, and a few days of muggy weather may so favor the growth of the causal fungus as to develop an epidemic, which may in turn be checked by a dry spell. Often the disease appears in distinct waves during the season, each wave corresponding to a climatic condition favorable to infection and usually lagging behind such favorable condition a period of 8 to 14 days, the time necessary after infection for the disease to become conspicuous enough to attract the attention of the vineyardist.

While the Scuppernong occa-

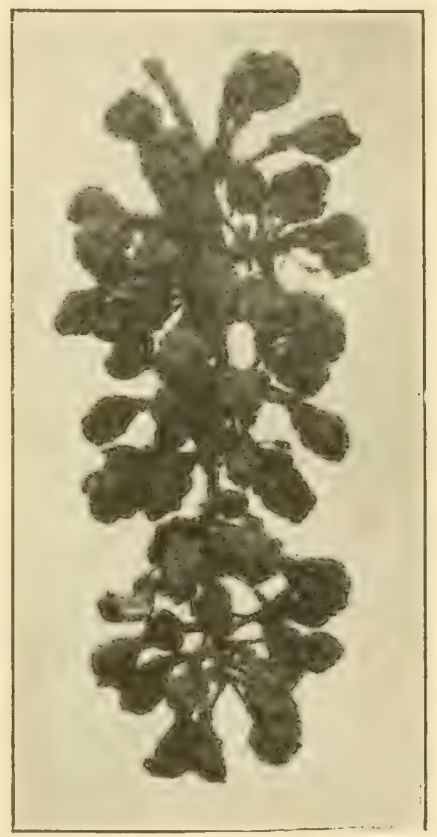

FIG. 61. - Grape blackrot. Original. sionally shows a few spots upon leaf or berry and the blossom is sometimes affected, this variety is practically immune.

To prevent the inroads of black-rot, thorough, clean culture should be practiced. All mummified fruit should be burned to avoid infection. Keep the ground free from sprouts and all other growths and permit no weecls or grass. Cover crops are beneficial. Plow carly so as to cover all remaining leaves and berries that bear the hibernating fungus. 
Use a dormant spray to clean the bark, trellis, etc. The utility of this first spraying may vary with elimatic conditions and latitude. Use foliage sprays of 5-5-50 Bordeaux mixture throughout the summer. Five or six applications are usually necessary. The first should be made when the shoots are 20-30 $\mathrm{cm}$. long, the others at intervals of ten to fourteen days. After the first two applications the spray must reach the clusters to be effective. Spraying each season is necessary; neglect one season brings large increase in the rot the following season.

The following table shows the benefits of careful, thorough spraying.

Result of Black-Rot Experiments in 1908

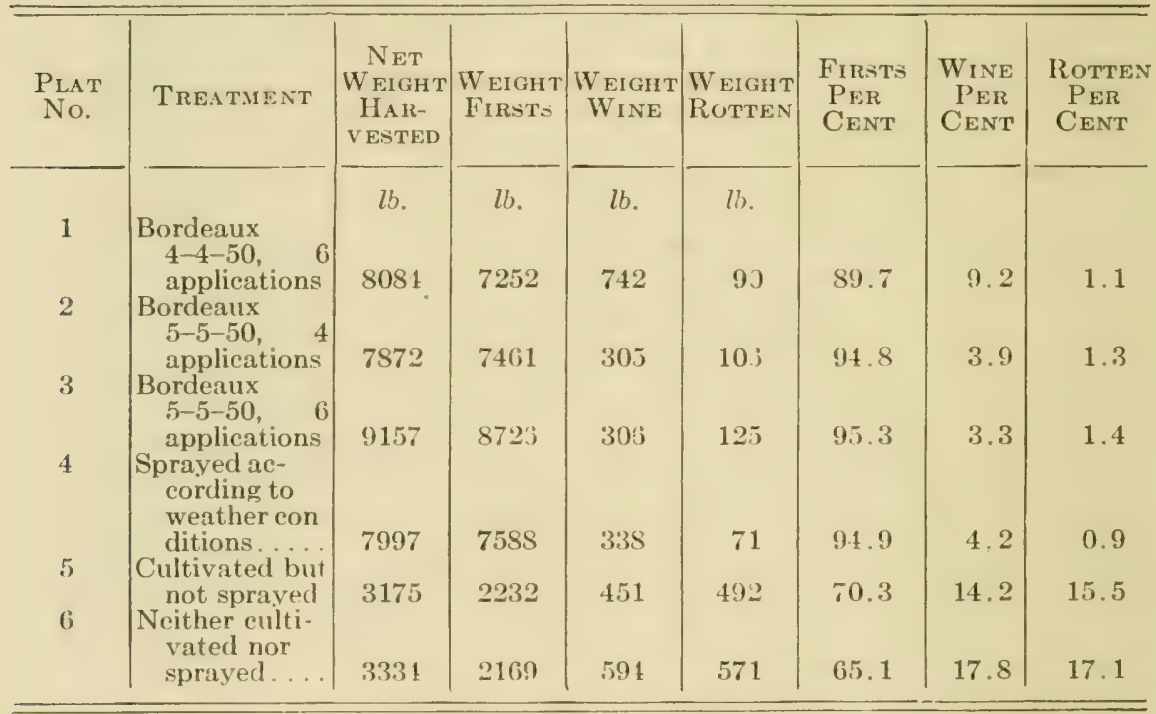

Powdery-mildew ${ }^{140,} 400$ (Uncinula necator (Schw.) Burr., Oidium). - This mildew was first noted in Europe about 1845, near London, and shortly after in Belgium and France, and is said to have reached every grape-growing country of Europe before 1851. It increased in severity until 1854 when it began to be held in check by sulfur applications. It is known in all parts of the United States, but is less destructive here than abroad, though in certain localities in New York, 
(Oregon, and California, it is regarded as the most important grape disease.

Powdery-mildew attacks all parts of the plant except the roots, showing first upon both the upper and lower surface of young leaves as whitish circular spots, which appear somewhat as though dusted with flour. These spots enlarge, coalesce, and may cover the whole leaf. The affected leaf is retarded in growth and becomes distorted. Mildewed blossoms fail to set their fruit, and fruit that

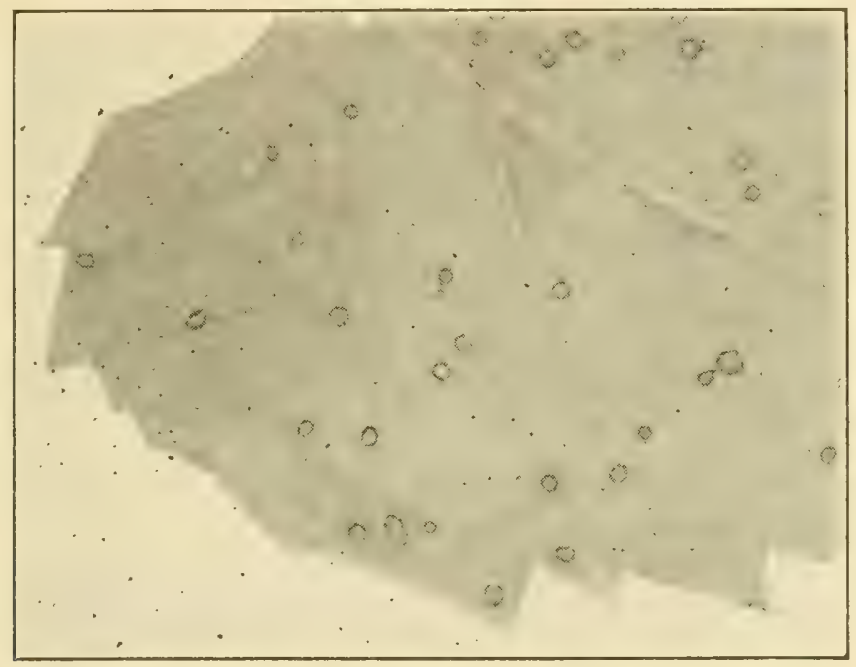

Fig. 62. - Black-rot as it shows on the leaves. After Anderson.

is mildewed soon ceases growth and falls, or develops irregularly and fails to ripen.

The mildew fungus is strictly superficial and may be rubbed off, leaving a discolored spot. In late stages perithecia may be recognized as very small black bodies, about 0.1 $0.12 \mathrm{~mm}$. in diameter, lying within the diseased areas. The disease develops in most destructive form in shaded, damp, poorly ventilated situations. Rain and fogs favor it, while very dry weather inhibits it. The American vines are less susceptible than the European varieties. 
Ventilation and removal of shading trees are beneficial. Close planting should be avoided in order to allow quick drying, trellises should run in such direction as to allow free access of sun. But these means are only palliative.

To control the mildew in dry climates employ flowers of sulfur. The sulfur, when the temperature is above $24^{\circ} \mathrm{C}$. $\left(75^{\circ} \mathrm{F}\right.$.), passes into the air, and its fumes, coming in contact

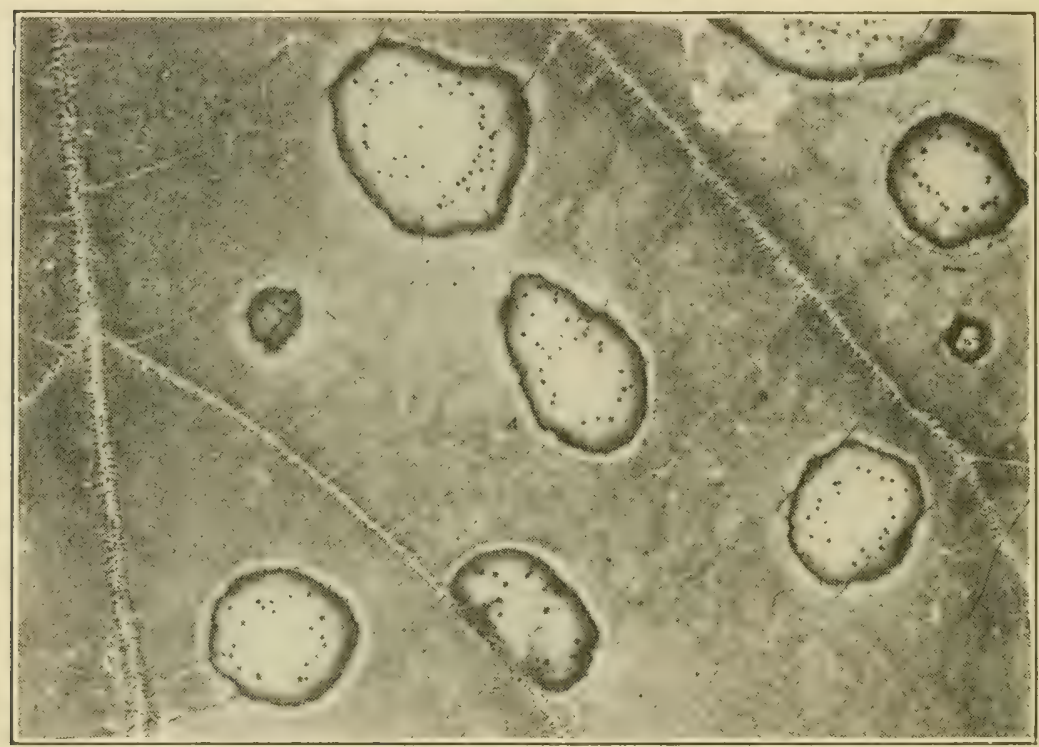

FIG. 63. - Black-rot spots enlarged to show the pyenidia. After Anderson.

with the fungus, kill it. Below the temperature at which sulfur is effective the fungus will make but little progress. When the air, shade temperature, is from $32^{\circ}$ to $35^{\circ} \mathrm{C}$. $\left(90^{\circ}\right.$ to $95^{\circ} \mathrm{F}$.), the killing effect of the sulfur may be seen within 24 hours; if above $38^{\circ} \mathrm{C}$. $\left(100^{\circ} \mathrm{F}\right.$.), one or two days are sufficient to rid the vineyard of the disease. The sulfur must be distributed to every part of the vine. Sulfur upon the ground is of no use. The vines should be dusted from one to seven times, according to conditions, susceptibility, climate, ete. The first sulfuring should be done when the blossoms 
begin to open; a second application should be made before the first sign of the mildew, and other applications should follow as need indicates. It is necessary to resulfur if from one to two days at $32^{\circ}$ to $35^{\circ} \mathrm{C}$. $\left(90^{\circ}\right.$ to $95^{\circ} \mathrm{F}$.) or four to five days at $29^{\circ}$ to $32^{\circ} \mathrm{C}$. $\left(85^{\circ}\right.$ to $90^{\circ} \mathrm{F}$.) do not intervene before the sulfur is removed by rain. If the disease was destructive the previous year, it is well to make application even earlier than indicated above, $i$. $e$, when the shoots are about 15$20 \mathrm{~cm}$. long.

After the grapes commence to ripen they are comparatively safe from mildew, but for the future good of the vine the leaves should be protected by further sulfuring if need be. Young vines should similarly be protected. To properly apply, use good dusting machines which give an even flow of sulfur and are easy of operation.

In climates where sulfur cannot be used to advantage reliance must be placed upon Bordeaux mixture or limesulfur applied as for the black-rot.

Downy-mildew ${ }^{141,} 142,465$ (Plasmopara viticola (B. \& C.) Berl. \& de Toni). - Downy-mildew produces a more or less distinctly visible downy or velvety growth upon the affected surface, caused by myriads of spore-bearing stalks that rise from the diseased surface. If these stalks are close together, the appearance is thoroughly characteristic and the diagnosis clear. As the spores mature the spots assume a gray or frosted appearance.

The European grapes are more susceptible to this mildew than the American varieties. All the green parts of the plant are affected. Upon the lower side of the leaf the disease may be recognized by the description given above. The upper surface of the leaf over a diseased spot becomes pale, yellowish, and finally turns brown and dies. The area so affected is definitely bordered and does not necessarily cause the death of the whole leaf, though it may do so.

Upon shoots the same characteristic appearance is noted as upon the lower surfaces of the leaves. Sometimes the death of the affected twig or even of the whole vine results. 


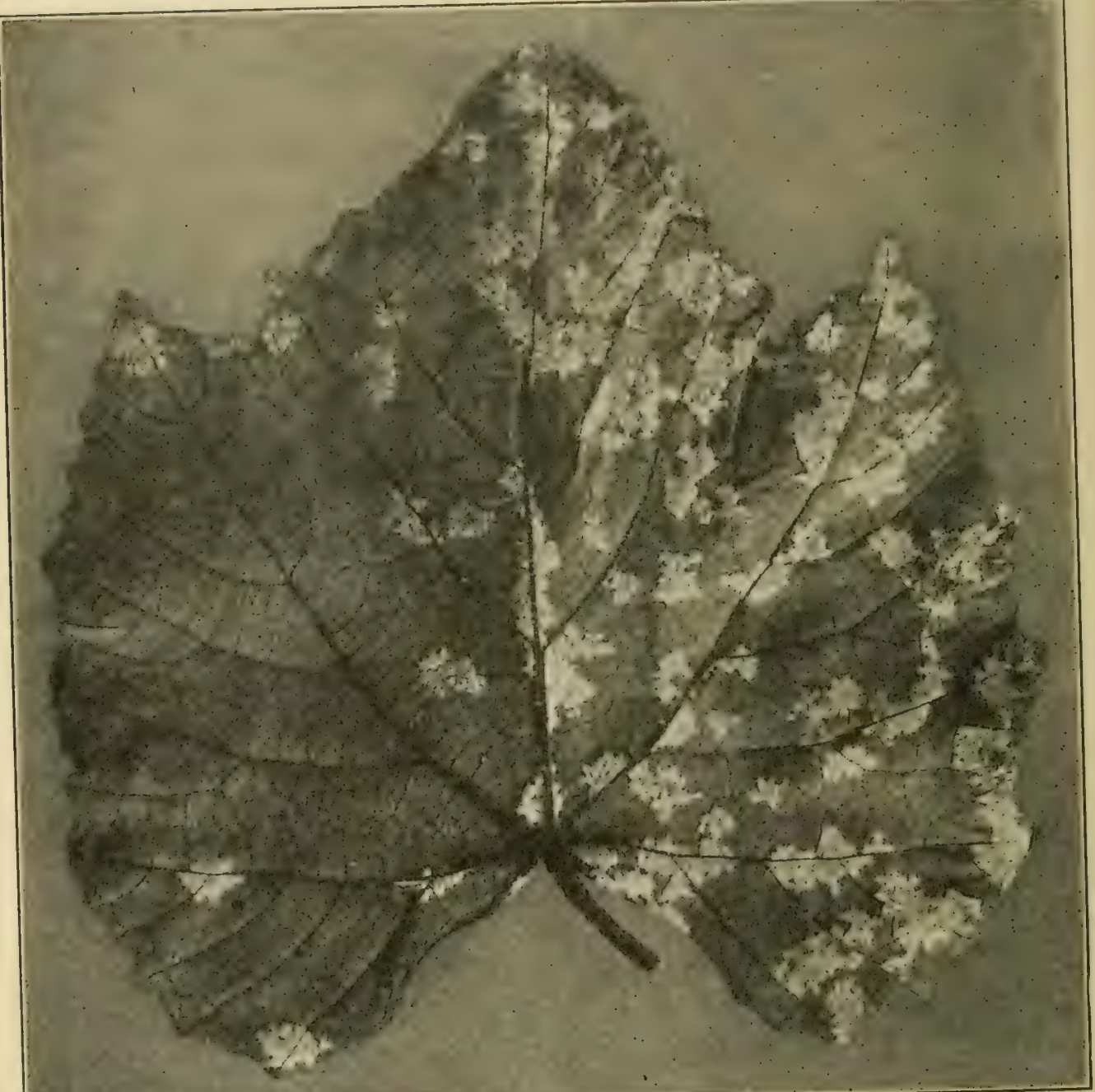

Fic. 64. - Downy-mildew as seen from the lower surface of the leaf. After Heald. 
Immature berries which are affected cease growing and develop the same coating noted upon the leaves, giving rise to the name "gray-rot." If the berries are more mature when attacked, they turn brown, thus calling forth the name "brown-rot." The berry in dying shrivels and becomes

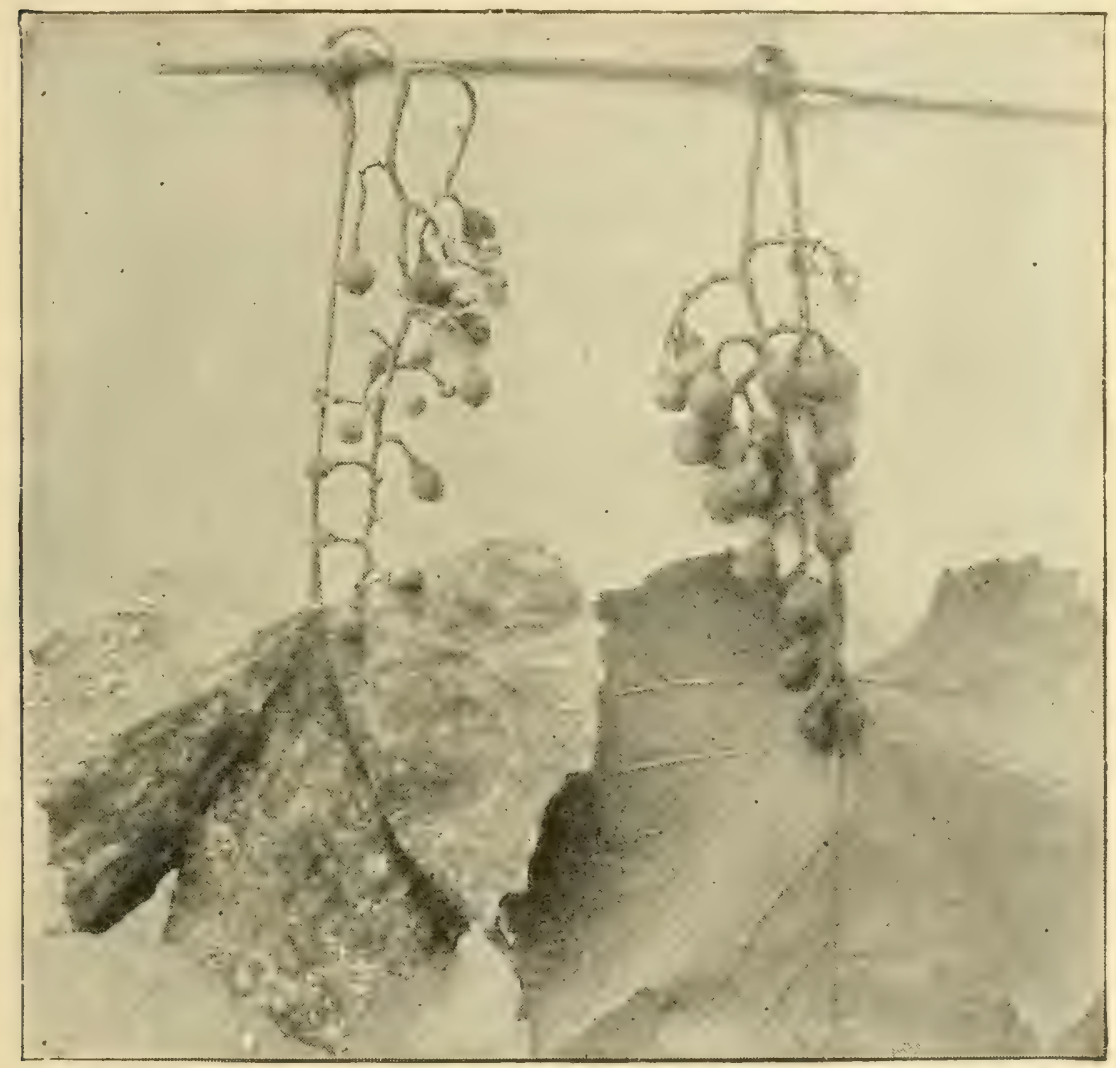

FIG. 65. - Young Niagara clusters attacked by downy-mildew. After Lodeman.

wrinkled, but does not become hard and dry, as in the case of the black-rot. The disease is usually more troublesome in the early part of the season than in autumn. Effective management requires early Bordeaux spraying, just before the blossoms open, and often it will be found advantageous to protect the leaves by two to five additional sprayings at intervals of about two weeks. This disease was noted in 
America as early as 1834, and was carried to Europe about 1878. It is now general both in Europe and the United States.

Anthracnose 142, 143 (Gloosporium ampelophagum Sacc.). This anthracnose, probably introduced into America from Europe prior to 1880 , is now widely distributed throughout

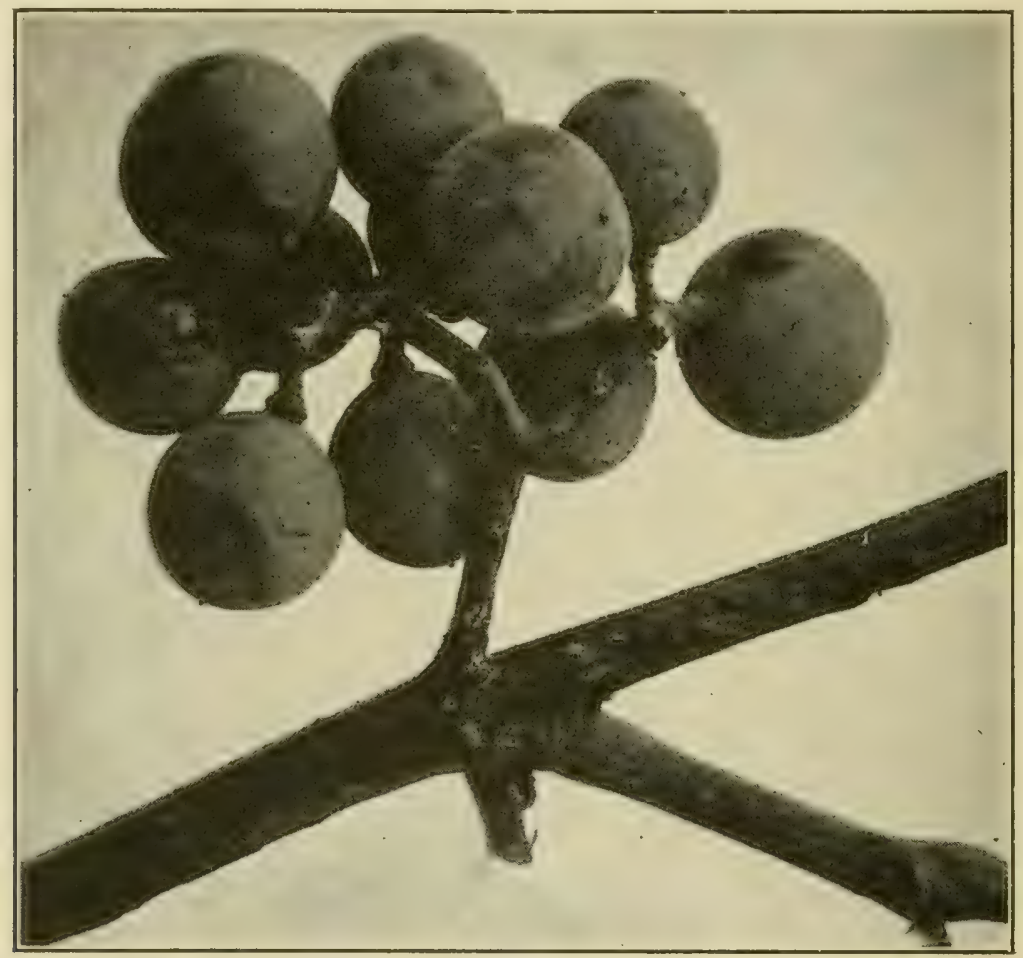

FIG. 66. - Anthracnose on the fruit. After Paddock.

grape-growing sections and is the fourth disease in importance. While not usually so destructive as black-rot or brown-rot, it sometimes increases to such an extent as to do great damage, even causing in some instances the loss of all the berries upon a vine as well as much injury to the canes. During damp, warm weather it develops rapidly, affecting some varieties more than others. The Champion and Moore's Diamond may be mentioned as especially susceptible, while the Concord is resistant. 
Upon the canes the anthracnose is first seen as small, dark brown or black spots, which soon become sunken in the centers. The spots usually enlarge rapidly lengthwise of the stem, though they may sometimes girdle it. Girdling is particularly common upon stem clusters, where it is always fatal. The centers of the older spots are ashen in color, the edges dark, and the cankerlike spot extends from the bark deep into the wood, rendering the shoot weak and brittle.

Upon the fruit, spots $3-5 \mathrm{~mm}$. in diameter are produced similar to those upon the eanes, except that the center does not always become ashen. Here, too, a band of red often surrounds the diseased part. The parts of the berry adjacent to the diseased spot remain green and develop normally, which, associated with the red border, results in the peculiar appearance which has led this disease to bear the name "bird's-eye disease."

If the berry is attacked while young, it may either outgrow the disease or succumb to it. Several spots upon one berry destroy its value, and spots upon one side may cause distortion, cracking, and exposure of the seeds.

Upon the leaves the dead spots are usually bordered by a fine black line, and as the leaf enlarges the dead tissue of the spot may rupture irregularly.

Badly anthracnosed canes must be cut out and burned, and a dormant spray applied, followed by protective sprays as for black-rot.

Necrosis, Dead-arm ${ }^{144,145}$ (Cryptosporella viticola (Red.) Sh., Fusicoccum). - This disease has been noted in New York, Ohio, Georgia, and Indiana. It is said to cause loss of from 1 to 5 per cent annually in New York. The Concord, Niagara, Moore's Early, Agawams, Pocklingtons, Wordens, Lindleys, Catawbas, Isabellas, and Scuppernong are susceptible.

Necrosis may be recognized in the field by the following characters: A trimmed and tied vine that has failed to put out shoots; one that has sent forth shoots, the latter dying after a few weeks; vines on which all or part of the 
shoots and leaves exhibit a dwarfing, with leaves small and often crimped about the margin; leaves of nearly normal size but blanched; apparently healthy vines with leaves and fruit shriveling and dying in the summer; fleshy or corky longitudinal excrescences on the stem, which in the autumn dry down and become reddish brown and the following spring slough off; the presence of minute black pustules on a dead

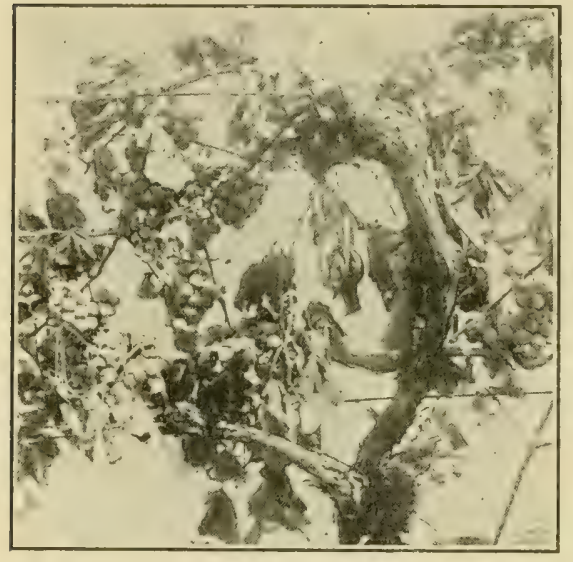

FIG. 67. - Necrosis of the vine. After Reddick. spur, bark, or wood under the bark; small reddish brown spots $3-4 \mathrm{~mm}$. long on the green shoots.

The disease is conveyed to new tissue by spores from the pycnidia, also probably by pruning tools. It may also enter the older parts through wounds. Cuttings bearing the fungus probably spread the disease.

Spraying shoots with Bordeaux mixture when from $71 / 2-15 \mathrm{~cm}$. long will reduce infection. Diseased vines should be pulled and burned, or if the root crown be still sound, they may be cut back to near the ground, when the renewal will be healthy. In the spring and summer it is well to mark sick vines for future eradication. Cut off the diseased parts, using tools not used in ordinary pruning.

Root-rot ${ }^{146}$ (various fungi). - This rot attacks a few roots at first, but eventually reaches all, and results in death of the vine. It is very destructive in Europe and has been noted in several places in the United States.

The top growths of affected vines show symptoms first; then follows one division after another until a large vine is reduced to the size of a bushel basket, though numerous lateral canes may arise, especially near the base of the plant. The leaf color usually remains normal with no dead 
tissue, though the leaves sometimes turn yellow, and many of them are reduced in size. After the vine dies the leaves still remain attached to the canes. The best treatment is to remove and burn the affected stock, thoroughly stir, air, and dry the adjacent soil. For further discussion of root-rot, see p. 370 .

Several diseases, the causes of which are not known, do serious injury to the grape. They may be briefly described as follows: California vine-disease. ${ }^{146}$ Since $188 \pm$ many vineyards in California have been destroyed by this disease. In the first season small, yellow spots appear between the veins. These enlarge and unite to form stripes, leaving only a narrow band of green tissue along the veins. Leaves fall prematurely and the canes turn black and die. The following season there is reduced growth of canes. By the third or fourth season the vines usually die. Cuttings should not be made from diseased vines. An unnamed disease of somewhat similar character has been described in New York. ${ }^{149}$ Brunissure. Irregular brown spots appear on the upper surfaces of the leaves and the epidermis falls away, exposing the underlying tissue. Later the browning extends through to the lower leaf surface. Black zones often appear in the wood. Shelling consists in the grapes falling from their stems before maturity. Diseased berries are matted, thickskinned, and show a brown zone beneath the skin. Though the cause of shelling is unknown, it is more common on weak vines. Good cultural conditions lessen it.

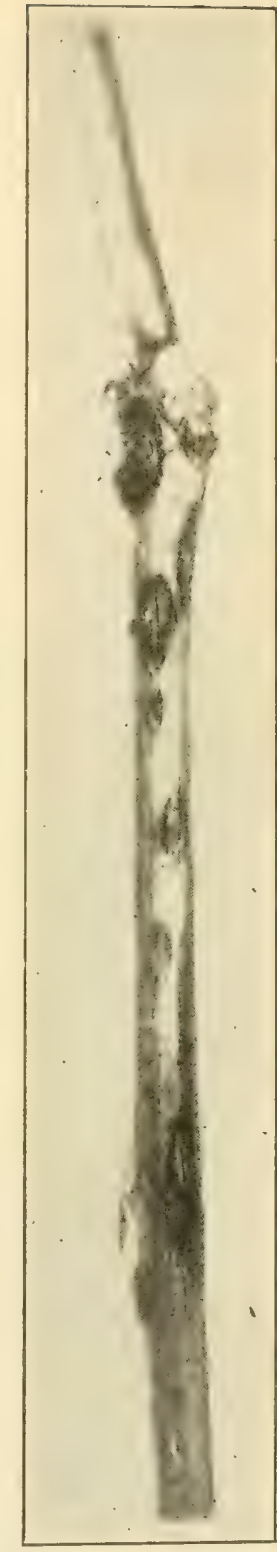

Fig. 68. - Grape necrosis as it appears on the canes. After Reddick. 
Blue-mold rot ${ }^{148}$ (Penicillium). - Grapes should be handled to avoid wounds, carefully packed, and shipped or stored at as nearly $0^{\circ} \mathrm{C}$. $\left(32^{\circ} \mathrm{F}\right.$.) as possible to prevent large loss due to blue-mold.

\section{Minor diseases}

Crown-gall ${ }^{147}$. (see apple) is common on the grape, with a wide difference in susceptibility between varieties; Bitterrot comes late in the season on the fruit when nearly ripe, see apple; White-rot (Charrina), Scab (Cladosporium viticolum Ces.), Gray-rot (Sclerotinia fuckeliana (De Bary) Fcl.), and Cercospora leaf-spot are usually of but little injury.

HUCKLEBERRY. See blueberry.

RASPBERRY. See blackberry.

\section{STRAWBERRY}

Leaf-spot 153, 154 (Mycosphorella fragarioe (Tul.) Lin., Ramularia). - The most conspicuous disease of the strawberry, one nearly always present to some extent on both wild and cultivated varieties in Europe and America, is recognized by the presence of small, 4-6 mm., purple or red-bordered spots upon the leaves, the older spots bearing white or ashen centers. Late in the development of the spots the hyphæ of the causal fungus are barely visible with a good hand lens. The spots, when numerous, may coalesce, forming large, irregular blotches. The disease is also very injurious in its attacks upon the fruit stems, resulting in diminution of food supply to the fruit and its improper development.

It attacks all varieties, precluding the use of especially susceptible varieties in some localities, often killing the plants, and in any event lessening their vigor and productiveness. In some localities entire plantings have been destroyed. One grower reports a loss of $\$ 1500$ on a six-acre field in one season. 
Moisture and heat favor the development of the fungus, while moisture upon the leaves is essential to infection. Weather favorable to infection followed by hot, dry days may be attended by great injury. Heavy, wet, undrained soil also conduces to disease.

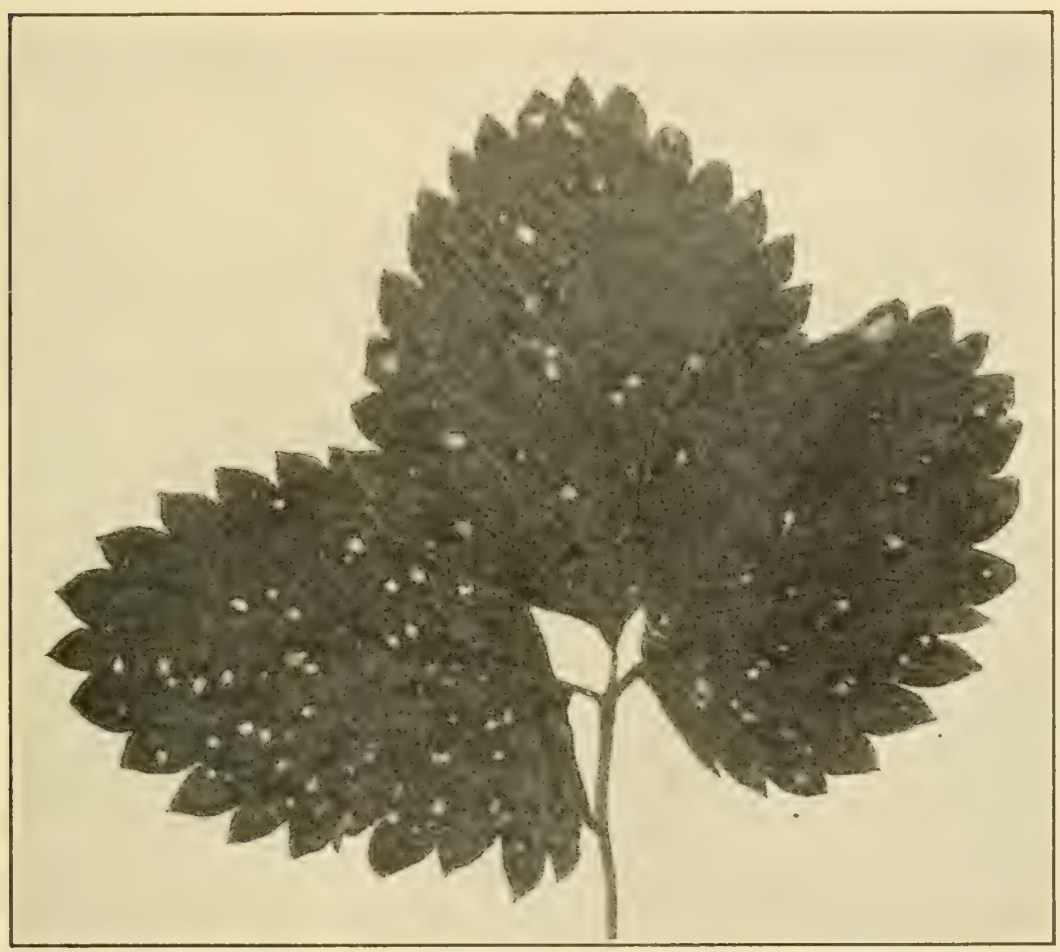

Fig. 69. - Strawberry leaf-spot. After Freeman.

Frequent change of beds; also cutting, gathering, and burning or burying of tops in place after harvest, and the use of Bordeaux mixture after the removal of the diseased leaves will lessen the infection of the next year.

Hume in Florida found that by means of three early sprayings of 4-4-40 Bordeaux mixture, the disease was so checked that "it was a difficult matter to find a leaf at all diseased in the whole patch." Later, when the disease hegan to make headway again, another spraying controlled it. 
Powdery-mildew (Sphørotheca humuli (DC.) Burr.).This mildew may be recognized by the characters usually pertaining to the powdery-mildews. (See grape.)

Upon the strawberry it induces curled, in-rolled leaves, and the white mycelium is found upon their lower surfaces.

The disease is not usually troublesome.

Botrytis-rot ${ }^{155}$ (Botrytis sp.). - This rot, though prevalent in the field, occasions serious loss only on berries which are shipped over long hauls. The rotten spot is dry, tan-colored, and finally covered with downy spore clusters. Careful sorting to avoid shipping of infected berries is necessary. Infected fruit that is sorted out should be buried with lime.

Leak ${ }^{155}$ (Rhizopus nigricans Ehr.). - Berries often decay in shipment, the juices leaking out from the bottoms of the boxes. The berries sink to a feltlike layer covered by mold and its black sporangia. This rot causes millions of dollars loss annually. Only sound berries should be offered for shipment.

\section{Minor diseases}

Leaf-blight ${ }^{156}$ due to Aposphæria; Leaf-spot due to Ascochyta; Fruit rots due to Sphæronemella, ${ }^{157}$ Patellina, ${ }^{157}$ and occasionally to the black-rot fungus, Physalospora, ${ }^{157}$ do some injury. 


\section{TROPICAL FRUITS}

\section{AVOCADO}

Anthracnose (Colletotrichum gløosporioides Penz.).- - Attack upon the leaves eventually causes defoliation. Early infection of the fruit results in its complete loss. If the fruit is not attacked until late, it may remain upon the tree, but becomes brown spotted and finally cracked. On both leaves and fruit anthracnose can be controlled by the use of Bordeaux mixture. A rot of the tree trunk is caused by Pythiacystis, and a leaf-spot by Mycosphærella. ${ }^{187}$

\section{BANANA AND PLANTAINS}

Wilts ${ }^{341,546}$ bacterial and fusarial, are of wide distribution. One of these is said to have caused the abandonment of nearly 20,000 acres of bananas in Panama.

Anthracnose (Gloosporium musarum C. \& M.) frequently develops on ripe fruit in the market, but really does but little injury.

\section{CACAO ${ }^{161}$}

This important crop is subject to numerous destructive diseases, the most serious of which are: Canker and Pod black-rot, due to Phytophthora; Die-back due to Diplodia; Pink-disease (Corticium) which kills even large branches, and Witches-broom (Colletotrichum). Other cankers are caused by Nectrias.

\section{CITRUS FRUITS ${ }^{160}$}

Brown-rot ${ }^{159}$ (Pythiacystis citrophthora S. \& S.). - This disease has caused a very considerable loss, 30 per cent in some cases, in California but the real origin of the trouble 
was not known until 1906 or 1907. It chiefly affects the fruit after it has been packed and shipped to market, although the infection takes place in the orchard or packinghouse, where the disease is largely disseminated by the fruit washers.

The rot has a peculiar characteristic rancid, penetrating odor, and its presence is further indicated by the prevalence

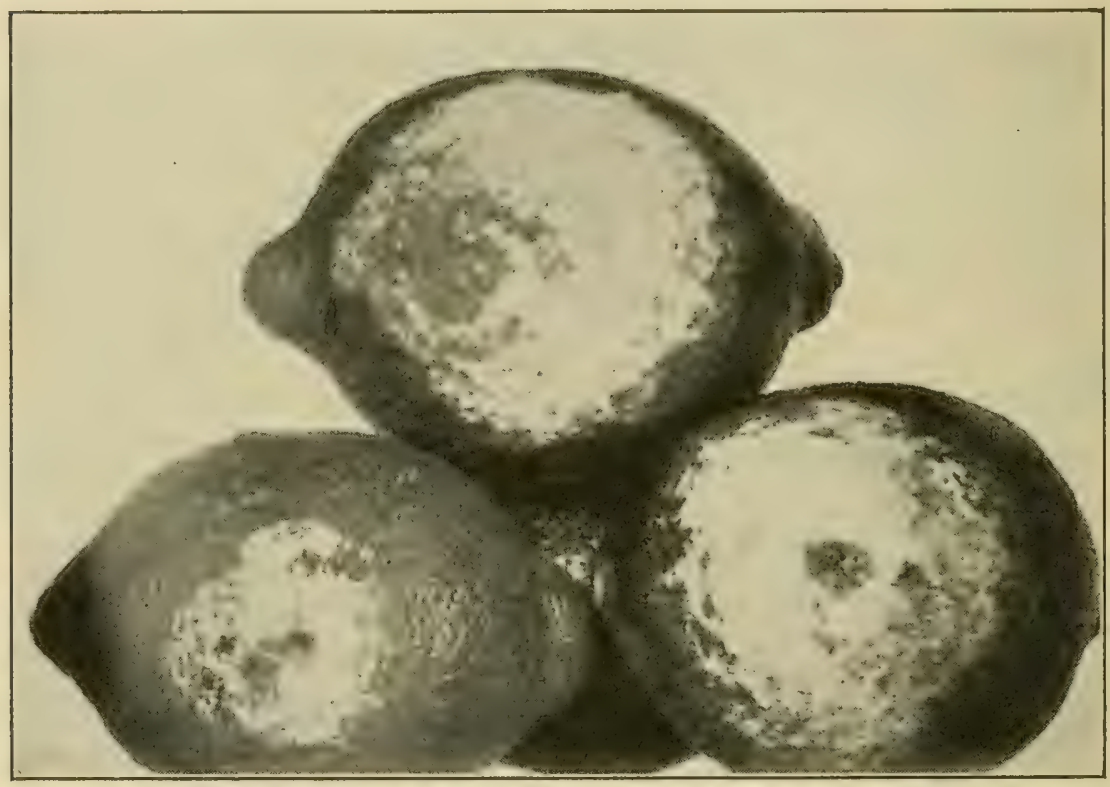

FIG. 70. - Brown-rot of lemons, showing white growth of the fungus. After R. E. Smith.

of small flies in boxes where there is diseased fruit. One affected fruit in a box communicates disease to the whole.

Brown-rot is found in nearly pure condition on the fruit in the orchard, especially on fallen fruit or on fruit hanging low on the tree. It is most prevalent in wet weather or on low ground after irrigation. The fungus is visible to the eye in the packing-house, as a mass of white filaments. It is spread by contact alone.

Orchard infection can be controlled by the use of a heavy mulch under the trees, either straw or a heavy cover crop. 
In the packing-house the use of disinfectants in the washer prevents trouble; one pint of formalin to 1250 gallons of water, or 1 pound of copper sulfate to 625 gallons of water.

Cottony-rot ${ }^{16 ! 2}$ (Sclerotinia libertiana). - The fungus on lemons is identical with that of lettuce drop, and its mycelium and sclerotia appear as described under that disease. The decay spreads rapidly from fruit to fruit in storage, and the loss is considerable. Twig, blossom, or seedling infection of oranges or lemons, aceompanied by gummosis, also oceurs. Disinfection of the fruit with $1 / 50$ per cent solution of copper sulfate is employed.

Canker* ${ }^{489-492}$ (Pseud.omonas citri Hasse). - Citrus canker is one of the most destructive diseases introduced into the United States in recent years. Its nature was first pointed out by Hasse in 1915. Before that time it was thought to be caused by fungi and was confused with citrus scab. The origin of the disease is obscure. It was first described from the southernmost island of Japan in 1899 on navel oranges, where it was undoubtedly introduced from South China. About 1910-11 citrus canker was introduced directly from Japan into Texas on the trifoliate orange and on nursery stock. In a short time it was carried into other Gulf states on infected plants, imported directly from Japan and indirectly from Texas, so that by 1914 it had assumed the aspects of an epidemic in certain parts of Florida, Alabama, Mississippi, Louisiana, and Texas. About the same time outbreaks were reported from two areas in the Transvaal, South Africa, the Philippine Islands, and later from North Australia; originating in importations from Japan.

Citrus canker, while primarily a leaf spot, may attack parts of the tree above ground. On the leaves, the young spots usually appear on the under side as small, yellow, translucent, oily pimples. Later they rupture to form brown, raised, corky spots with an oily outline, and sometimes a wide, yellow margin. The spots break through to the upper side of the leaf. The young spots on the twigs and branches are * Prepared by G. L. Peltier. 
similar to those on leaves, but usually they become more corky and have a tendency to girdle the twig or branch. On the fruit the old cankers are superficial and very corky.

Infection, in the absence of wounds, takes place through the stomata. The period of incubation varies from two or three days to several weeks. The factors favoring infection are a high temperature, a relatively high humidity, and a rapidly growing plant. The organism survives the colder months in the spots on the twigs and branches. Under certain conditions the organisms may lie dormant in the bark for several months.

Pseudomonas citri has a wide range of Rutaceous hosts, including all the plants and hybrids of the genus Citrus, although some show considerable resistance. The order of susceptibility of the more important commercial citrus fruits and stocks is provisionally as follows: grape fruits, trifoliate oranges, lemons, sour oranges, sweet oranges, limes, citrons, mandarin oranges, and kumquats. Several new introductions of citrus fruits and hybrids, originated by Swingle, show considerable resistance and promise to supersede the more susceptible fruits in some instances.

Infected nurscry stock was wholly responsible for the spread of citrus canker from state to state. However, owing to rigid quarantine measures, further danger from this source appears to be eliminated. The combination of wind and rain is most important in the spread of canker from tree to tree; other agents are dust, insects, birds, man, and other animals.

Owing to the rapidity with which citrus canker spreads and its menace to the citrus industry of the Gulf states, drastic measures for its control were adopted in 1914-15 in all the Gulf states. These consisted in burning all infected trees as soon as they were found.

The number of infected citrus trees found in Florida in August, 1914, was 1313. During 1918 only 15 were found, and in 1919 only 4 infected trees. Few possible centers of infection remain in the United States. 


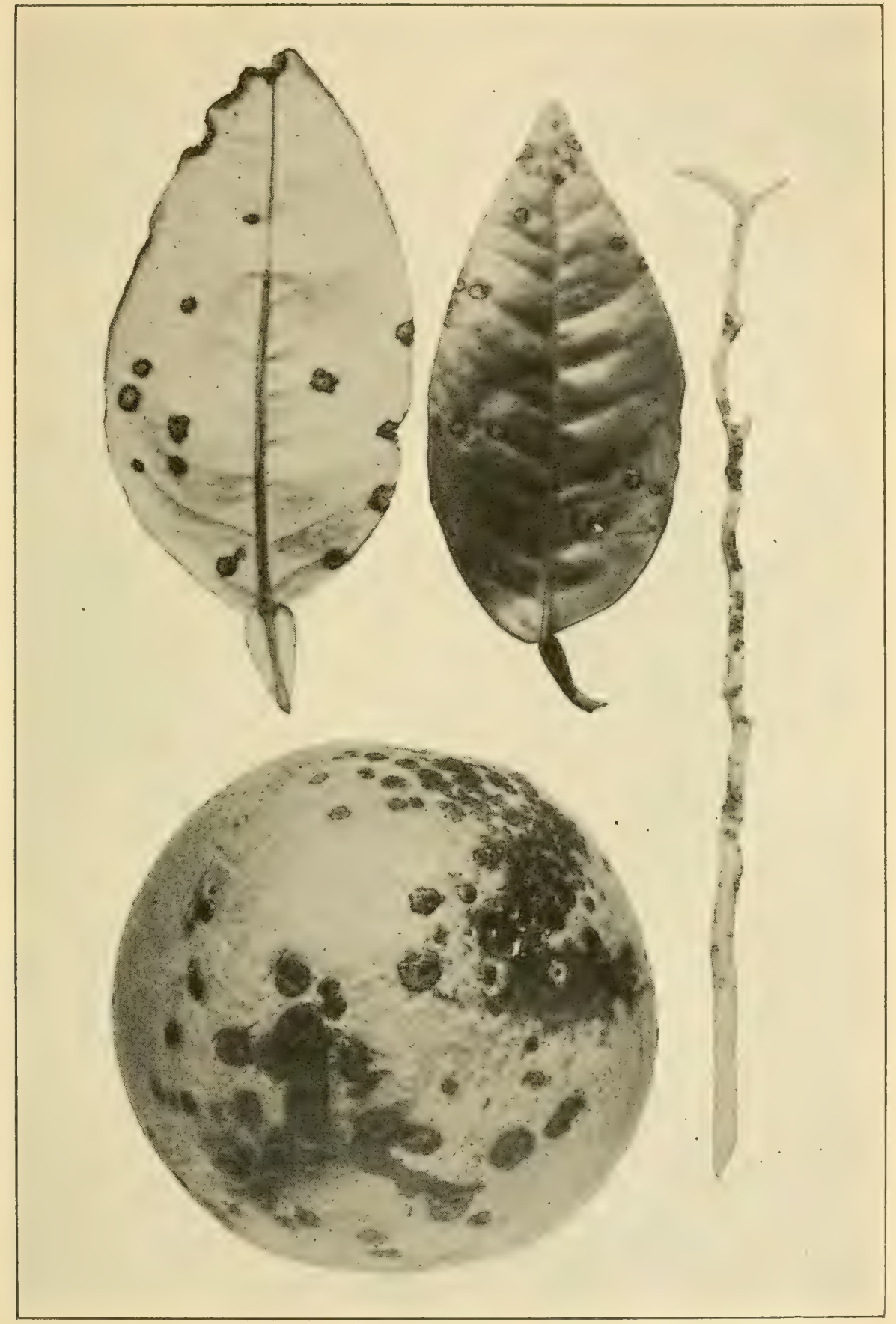

FIg. 71. - Citrus canker. After Webber. 
Scaly-bark ${ }^{163}$ (Cladosporium herbarum Lk. var. citricolum Faw.). - Small, circular, or oval, rusty-colored spots with well-defined margins, on both bark and fruit, characterize this disease. The bark cracks and forms scales. The spots are at first scattered, but in time coalesce and form large areas upon the branches and trunk, giving it a scaly appearance.

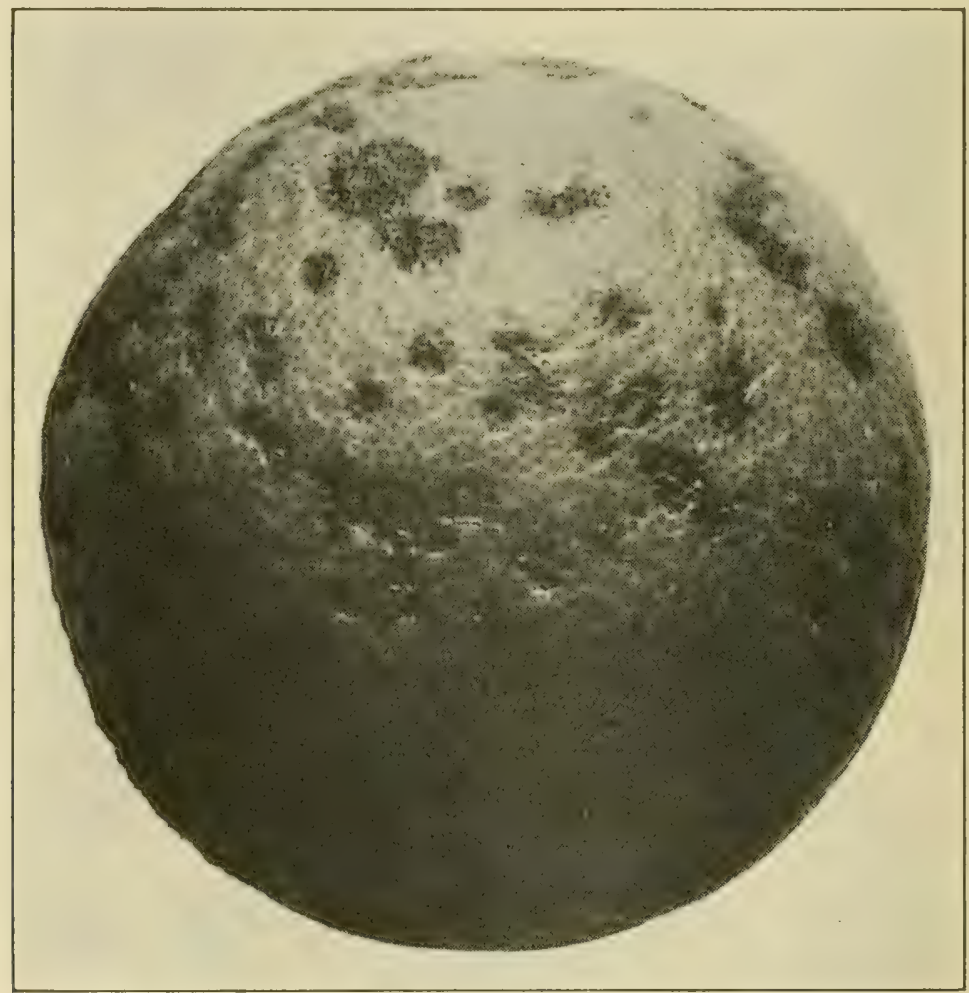

FIG. 72. - Scaly-bark injury to fruit. After Stevens.

Similar injury also occurs on the fruit (Fig. 72). Sweet oranges are most affected, the fruit ripening prematurely.

Top working is recommended, also heading back and painting the trunk and the stumps of the branches with carbolineum and water equal parts.

Gummosis. - Several diseases recognized by the exudation of gum from the trunks and branches of the trees are 
called "gum diseases." Their causes are not definitely known; by some they are attributed to mechanical injury alone; by others to poor cultivation or water injury in irrigation; by others to the presence of soil around the trunk; by still others to fungi.

Blue-mold rot ${ }^{164}$ (Penicillium italicum Wehm., and Penicillium digitatum (Fr.) Sacc.). - This decay of citrus fruits in transit from California causes a loss estimated in 1908 as being between $\$ 500,000$ to $\$ 1,500,000$ annually. Careful investigations of Powell and his assistants have shown that the

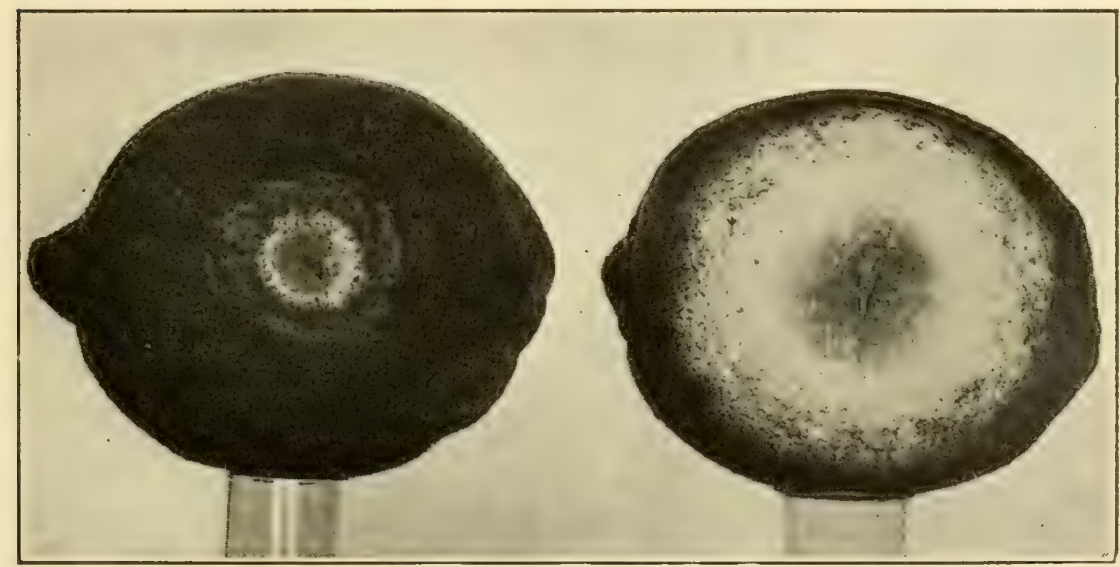

FIG. 73. — Two forms of blue-mold: at left, Penicillium italicum; at right, P. digitatum. After R. E. Smith.

chief trouble results from wounds on fruit in handling, which thus provide an entering point for the fungus. Without mechanical injury no decay from blue-mold can occur. Hence the method of control is painstaking care in handling the fruit to prevent bruising or puncturing the skin.

Black-rot ${ }^{165}$ (Alternaria citri Pierce). - This disease was described and its cause given by Pierce in 1902. It attacks only the navel orange, causing from 2 to 5 per cent loss of the whole crop. It is easily recognized by the premature ripening which it induces, and by the deep red color and extra large size of the fruit. The diseased fruits are very conspicuous on the trees before the main crop has col- 
ored. A considerable portion of the "June-drop" is caused by this disease.

The spores of the fungus gain entrance through slight imperfections of the skin at the navel end, producing decayed areas under the skin.

All diseased fruit should be collected and burned or buried deeply.

Scab (Cladosporium citri Mass.). - Scab has been known

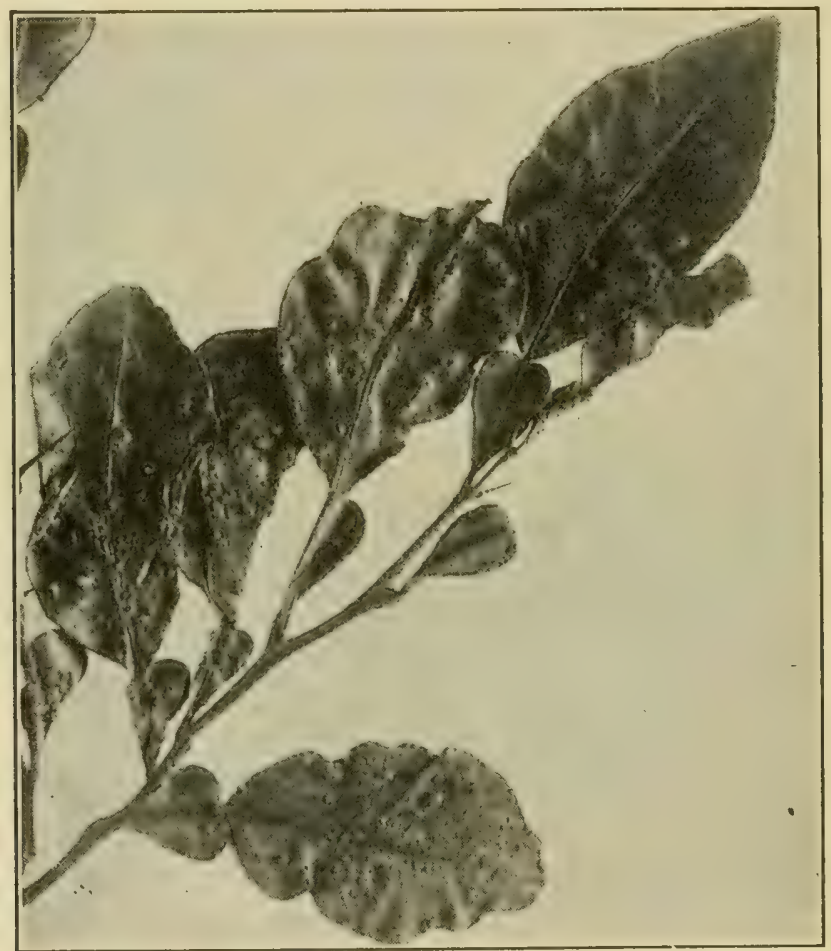

FIG. 74. - Scab of the sour orange. After Hume.

for twenty years, and occurs on the sour citrus fruits, such as the pomelo, kumquat, and sour orange.

The disease attacks the young leaves, twigs, and fruit, and causes them to produce conspicuous, warty, corky growths, that give a rough, uninviting appearance. Often the leaves are twisted and drawn out of shape. The warts 
are at first yellowish, but as the disease advances they become almost black, and finally crack open.

Ammoniacal copper carbonate or Bordeaux mixture will prevent scab.

Anthracnose, wither-tip (Colletotrichum gloosporioides Penz.). - In this disease the leaf spots are circular in outline, yellowish in color, and bear the small dark filaments and spores of the causal fungus. Terminal twigs shed their leaves and die.

The disease also occurs upon the fruit of various citrus trees. Rolfs noted its attack upon the lemon, where it caused the fruit to fall prematurely, and Hume reports that it may occur upon the pomelo either before or after the fruit is picked. The brownish spots enlarge with age and become dirty black in color. The fungus invades the interior of the fruit as well as the rind.
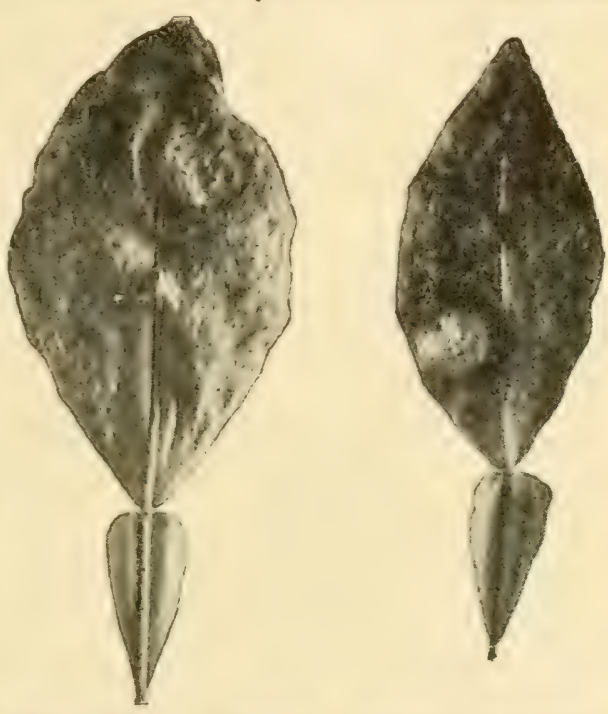

Frg. 75. - Orange leaves showing spots caused by anthracnose. After Hume.

In all cases the diseased parts should be cut out, care being taken to cut far enough back to remove all injured parts; also affected fruits should be removed and destroyed. Spraying with Bordeaux mixture controls the disease upon the fruit.

Root-rot (Phytophthora terrestria Sherb.). - The first symptoms are abundant exudations of gum upon the trunk of the tree; at the same time the bark develops brownish patches, which are thrown off, followed by other patches. The tree appears to lack nut rition, the leaves becoming yellow, scanty, and small. Though the trees bear considerable fruit, the amount of damage in Florida was estimated in 1896 to be 
$\$ 100,000$ annually. Resistant stock should be used; diseased parts should be excised, and antiseptics applied.

Die-back is characterized by gum pockets, stained terminal branches, ammoniated fruits, bark excrescences, and multiple buds. The disease is important but the cause is unknown.

Melanose (Phomopsis citri Faw.) is a disease of foliage, young twigs, and fruits, in which small, dark, elongated spots are produced. Weak Bordeaux mixture should be used.

Blight, with wilting of foliage and death of twigs and branches, is of unknown cause. In many ways it resembles peach yellows.

\section{Minor diseases}

Citrus-knot (Sphceropsis tumefaciens Hed.), troublesome in Jamaica, and once found in Florida; various leaf-spots; Sooty-mold 170, 171 consisting of a black, superficial fungus (Capnodium); Algal leaf-spot produced by Cephaleuros virescens; Crustose lichens; Dodder and Mistletoe, occasionally attacking citrus fruit trees; Sour-rot of lemons (Oidium citri-aurantii), also called slimy-rot and wateryrot occurring during storage; Crown-rot (Sclerotium rolfsii); Wood-rot due to several large fungi; Die-back and stem-endrot (Diplodia), and Pink-disease (Corticium) are of minor importance.

\section{COCOANUT}

Bud-rot ${ }^{167}$ (Bacillus coli (Esch.) Mig.) is the most serious disease of this palm. It is of wide and growing distribution in the American and Eastern tropics. An annual loss of $£ 4500$ is reported from one plantation in Jamaica. A soft rot occurs in the terminal bud, the growing point, resulting in the death of the tree. Badly diseased trees and all infected refuse should be burned.

\section{COFFEE}

Rust (Hemileia vastatrix B. \& B.). - This most destructive coffee disease, believed to have spread to coffee from 
some weedy Rubiaceous host, is widely present through the Old World. It was introduced into Porto Rico some years ago, but prompt recognition and effective action by the Porto Rican Experiment Station exterminated it in the Western Hemisphere.

Viruela (Stilbella flarida (Cke.) Kohl.). - This is the most serious coffee disease of the Western Hemisphere, causing circular, decayed, tan-colored leaf-spots, leading to rapid defoliation.

Leaf-spot (Cercospora coffeicola B. \& C.). - Numerous, circular, brown spots occur, causing leaf-fall. The fungus grows also on the berries. Other leaf-spot fungi are Colletotrichum, Glœosporium, Anthostomella, Hendersonia and Rhabdospora.

Leaf-rot ${ }^{57}$ (Corticium koleroga (Cke.) v. Höhn.). - The causal fungus grows on the stems, leaves, and fruit, spreading as a smooth, tissue-like, whitish film. Rot of the affected parts follows.

Stem-disease (Necator decretus Mass.). - Minute orange spots are produced.

Root-rot due to various fungi is destructive.

\section{FIG ${ }^{166}$}

Fruit-rot (Colletotrichum carica S. \& H.). - This disease, first described in 1909, produces sunken, rotten, more or less circular fruit spots, nearly always covered with a white mass of fungous mycelium. As the spots grow older they bear numerous pustules of the salmon-pink color characteristic of the spores.

The amount of damage caused is very great by reason of premature falling of the fruit, at times destroying the whole of the crop.

Infected fruit should be gathered and destroyed and the bushes should be given a dormant spray and two or more applications of Bordeaux mixture when in foliage.

Rust (Physopella fici (Cast.) Arth.). - This rust does 


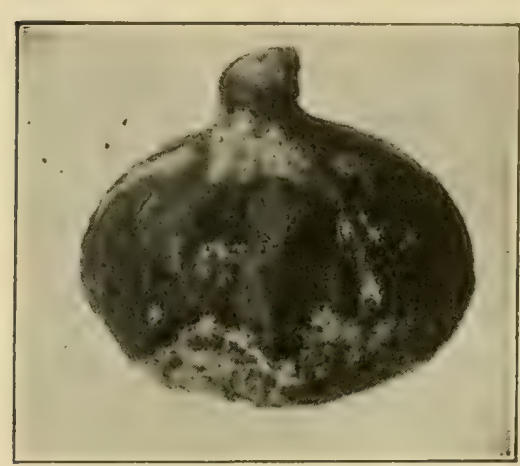

FIG. 76. - Fig in well-advanced stage of fruit-rot. Original.

considerable damage, causing premature falling of leaves. The rust appears as brown spots upon the leaf.

Leaf-blight (Cercospora bolleana (Thüm.) Speg.). - This blight has been noted in the United States, though but slight attention has been given it. It causes injury similar to that of rust.

Other diseases of the fig are: a Rhizoctonia leaf-blight; a root-knot due to nematodes; Southern-blight (Sclerotium rolfsii); Cankers due to Macrophoma, Libertella, and Tubercularia; Limb-blight due to Corticium; Root-rot (Ozonium) and Yellow-rust (Fusarium). Black-smut ${ }^{168}$ (Sterigmatocystis) may affect as high as 15 per cent of the fruits in some instances.

\section{GUAVA}

Ripe-rot (Glomerella psidii (G. Del.) Sheldon).-This disease was described from greenhouse material collected at Washington, D. C., and afterward it was reported from Florida and California. The affected fruit shows circular,

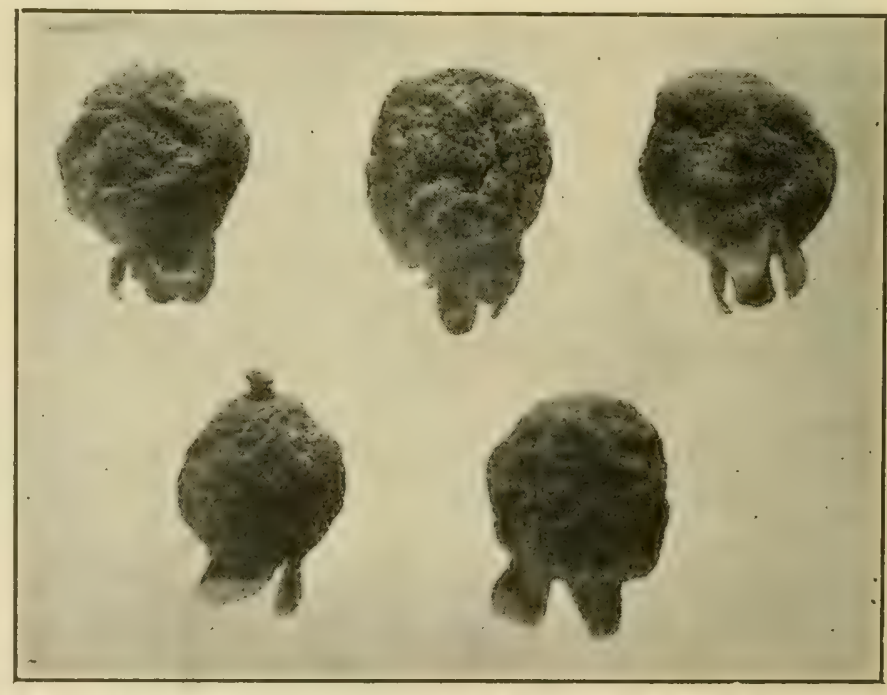

FIG. 77. - Guava affected with ripe-rot. After Rumsey. 
brown decayed areas. In older stages, masses of salmoncolored spores are visible over the decayed areas. The entire fruit at length becomes rotten, wrinkled, and shrunken.

Algal leaf-spot (Cephaleuros virescens) is common.

\section{LOQUAT}

Scab (Fusicladium dendriticum (Wallr.) Fel., var. eriobotryce Scalia.). - In the westem part of California seab is reported as serious upon both fruit and leaves.

\section{IMANGO}

Anthracnose ${ }^{169,543}$ (Colletotrichum gloosporioides Penz.).- This rot of the fruit, flower's, and leaves resembles bitter-rot of the apple, and causes much loss in the Caribbean region, in Hawaii, and the Gulf states.

\section{OLIVE}

Knot (Pseudomonas savastanoi EFS.). - Tubercles or galls upon the leaves and branches, and even upon the trunk of the tree, are the first signs of attack. Upon the leaves, the knots are always small, particularly if they are numerous. Upon the small twigs the knots attain the size of a garden pea, while upon the trunk they become 2-3 cm. or more in diameter and finally destroy the tree. The disease was noticed in California in 1893 and appears to be confined to a very small range. Excision should be practiced.

Leaf-spot (Cycloconium oleaginum Cast). - According to Bioletti

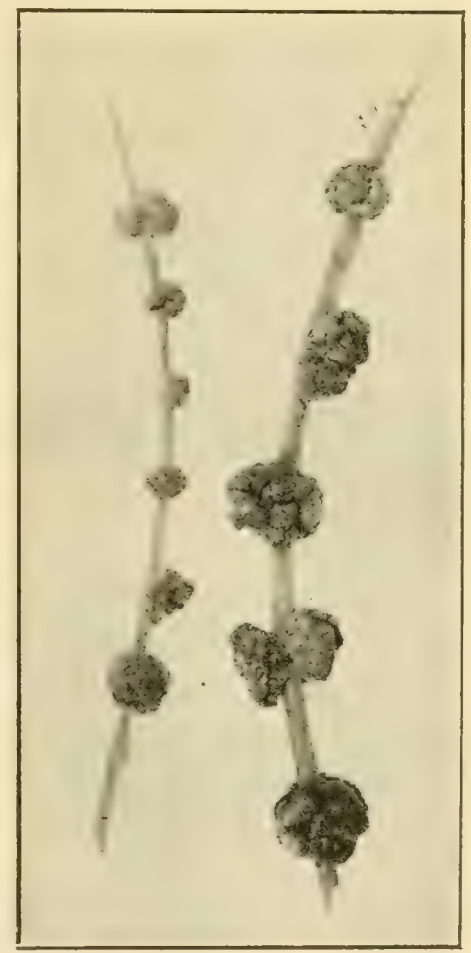

Fig. 78. - Olive knot. After R. E. Smith. 
this disease is prevalent in certain regions of California, occasionally causing the leaves to turn yellow and injuring the appearance of the fruit. Usually it does but little harm. Spots $2-4 \mathrm{~mm}$. in diameter occur upon the leaves. They are composed of concentric rings of different colors, giving them somewhat the appearance of the spots on peacock tail feathers. The spots on the fruit are smaller and more decidedly brown in color.

The use of Bordeaux mixture checks the trouble.

Sooty-mold occurs much as on citrus fruits and Root-rot (Armillaria mellea) as on other orchard trees, p. 51.

\section{PINEAPPLE}

Black-heart (Thiel.niopsis paradoxa (d. Seyn.) v. Höhn). This rot of truit may be found in abundance in any market and causes the loss of many carloads of fruit. It usually begins at the stem-end and progresses through the center of the fruit as a soft rot, in later stages turning black, due to the formation of many spores. Other fruit rots are due to Diplodia, Trichosphæria, Penicillium. Other pineapple diseases are: Rot of young plants due to soil fungi, Wilt and Chlorosis.

PLANTAINS. See banana.

\section{VANILLA}

Numerous diseases are recorded on this orchid. The most destructive is caused by Calospora vanilloe Mass., which grows on stems and leaves, and eventually kills the entire plant. Other parasites are Vermicularia, Colletotrichum, Gloeosporium, Uredo, Uromyces and Nectria. 


\section{VEGETABLE AND FIELD CROPS ${ }^{172,} 177$}

THESE crops cover a wide range in cost of production; some being grown in glass houses with artificial heat, others under canvas in cold frames, still others under ordinary field conditions. With crops of high value, correspondingly expensive methods of disease control are warranted, while with the field crops, resort must be to spraying or to less expensive, general methods of sanitation and field practice.

The crops following are arranged alphabetically by their common names, except that several crops of a botanical family when generally affected by the same diseases, for convenience of discussion, are grouped together.

\section{ASPARAGUS}

Rust ${ }^{173-176}$ (Puccinia asparagi DC.). - Asparagus rust, though observed in Europe as early as 1805, was not noted in epidemic form in the United States until 1896, when it was recorded by Halsted as occurring in several New England States. In 1897, though it had passed to South Carolina and to some extent westward, the interior and western part of the United States seemed still free from it. In 1898 it was first found in Michigan; in 1899 in Illinois, Ohio, and Kansas; in 1900 in Dakota, Nebraska, and Texas, completing its westward march into California in 1900 or 1901. Now it is found in every state where asparagus is grown.

Rust usually first attracts attention by its effect upon the green tops which redden under the disease, this symptom appearing at any time after blossoming or coming to leaf. Diseased areas in the field enlarge rapidly, and soon the affected leaves yellow and fall, leaving the bare, dead stalks. Close examination in the field shows that the twigs and leaves bear many small skin blisters (sori) under which is a 
mass of powder nearly the color of iron rust. In early stages of attack these blisters are few and scattered, but they rapidly increase in number. When young, the skin covering the sori is unbroken; later it ruptures, setting loose the rusty, powdery mass of spores beneath.

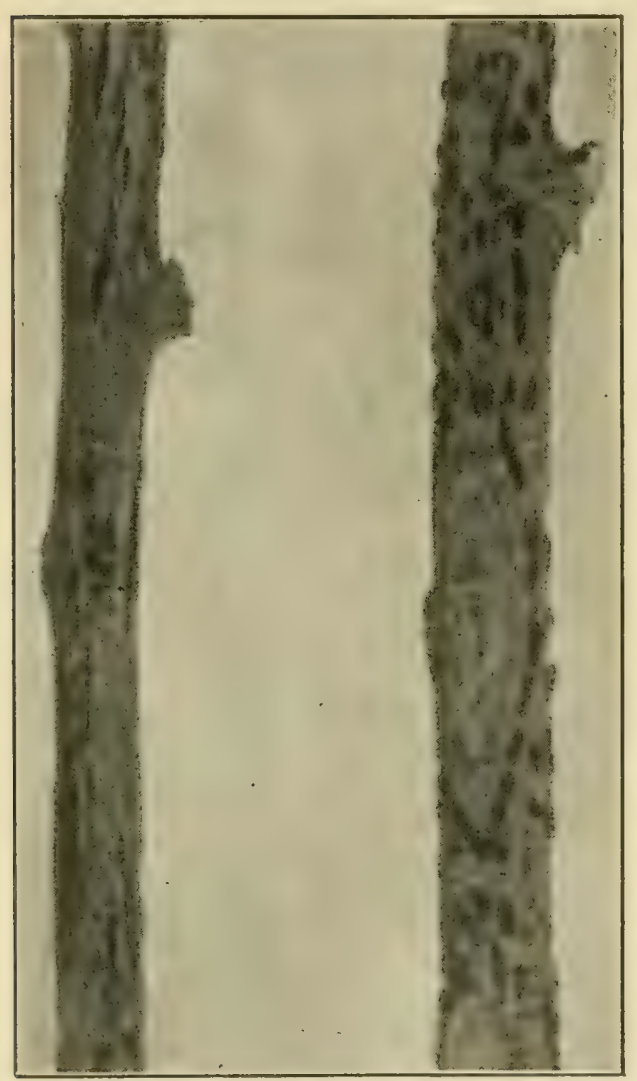

FIG. 79. - Sori of the asparagus rust upon the stems, enlarged. Original.
This, the summer stage, is chiefly responsible for the hibernation of rust in the East. Later in the season the sori become black instead of rusty-colored, thus constituting the winter stage of the rust.

In the spring still another stage, the spring stage, may occasionally be seen, though it is rare east of the Rocky Mountains. This consists of small, oval, pale spots upon the branches or leaves. In the centers of these spots small round pustules develop in concentric lines. Soon each pustule opens, constituting a very minute cup which is sunken into the leaf. From these cups issues a powder quite similar to that from the sori of the summer stage, though more orange in color. All three stages of rust - spring, summer, and winter - may occur simultaneously upon the same plant.

The disease spreads rapidly throughout the field during the spring and summer stages. The winter stage is the typical hibernating condition in which the causal fungus may rest until the following spring before it can induce further infection. 
During the first two stages spores in enormous quantities are liberated by the least movement of the plants, by animals or wind, and the spores, carried to their new prey, produce infection if conditions of moisture are present.

While the salable part of the plant is not attacked, the green part is largely decreased, so that the amount of nutriment that can be stored away in the underground parts is lessened. This results in diminished vigor and productiveness of such roots the following season. The loss may range from 15 to 35 per cent of the crop the year after the first attack, while in three years the more susceptible varieties may be so nearly destroyed as to necessitate the abandonment of the beds.

Rust is most injurious in light, dry soil; irrigation is, therefore, beneficial. Dew has been found to favor rust; therefore shaded, dewy localities should be shunned, as should also rows rumning at right angles to the prevailing winds. Clean culture methods, cutting and burning all tops in the fall, and destroying all wild asparagus, aids in the prevention of rust.

The Palmetto varieties are quite resistant and offer a solution of the rust problem in some localities. Careful breeding has given rise to several strains known as "Washington asparagus" that are highly resistant. In dry climates dusting with sulfur 150 to 200 pounds per acre, about three weeks after cutting is finished and before the rust appears, is beneficial. It is best to sulfur early, and only when dew is present.

In regions subject to rain, where the sulfur treatment is not applicable, three sprayings with sulfur-soda soap are recommended: first in July, other applications at intervals of three weeks. In New York three sprayings with Bordeaux mixture with rosin added as an adhesive gave a gain of $\$ 132.75$ per acre.

\section{Minor diseases}

Anthracnose (Colletotrichum sp.) is known by its numerous black acervuli borne in a blanched background upon the 
stem. It develops late in the season. The name Leopardspot is strikingly suggestive for another disease that produces

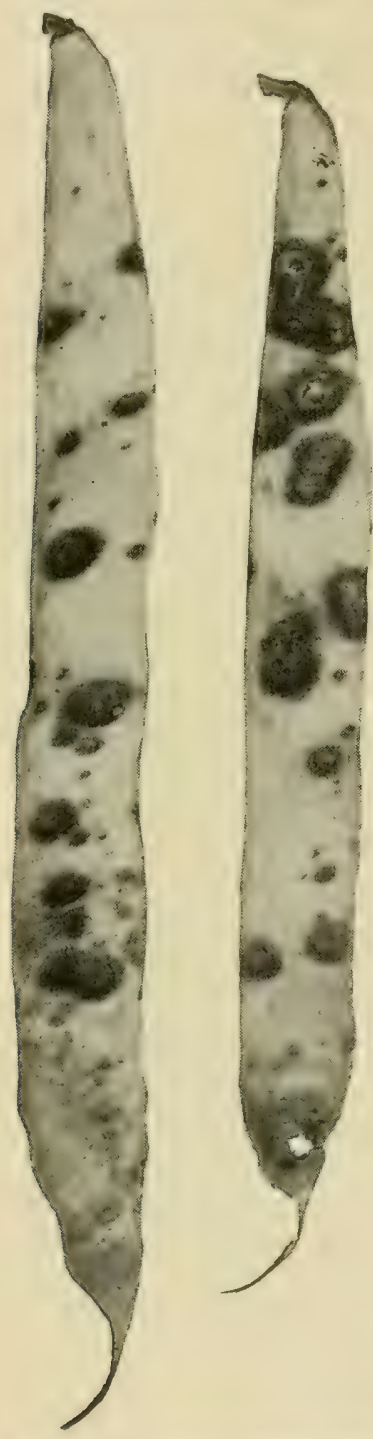

Fig. 80.-Anthracnose spots upon bean pods. After Stewart.

long, irregular spots, ashen in color, with dark borders. No treatment is known.

\section{BEAN ${ }^{458}$}

Pod-spot anthracnose 178-180, 184, 297 (Colletotrichum lindemuthianum (S. \& M.) B. \& C.). - First described in 1878 in Germany, this disease is widely known and is especially destructive. It develops so rapidly that beans delivered to the cars for shipment in apparently healthy condition may, upon arrival at their destination, be quite badly spotted. The loss is often 20 per cent, and occasionally a total loss is reported. Upon the pods the disease appears as darkcolored spots, usually sunken, varying in size from 1-10 mm., or more if several spots coalesce. The border of the spot is often tinged with red, the center rust-colored. Old pod-spots overlying seeds within cause spots upon these seeds. The pod-spots are much more noticeable and unsightly upon light-colored than upon green beans.

Similar spots are found upon the stems and leaves. They are especially noticeable upon young stems still blanched and upon the seed leaves. On older leaves they may appear upon the veins, blackening and killing them and the leaf.

The wax varieties are especially susceptible, while lima beans are quite resistant. The Well's Red Kidney also 
shows valuable resistance. It is claimed that resistance is a dominant Mendelian character.

The fungus is carried to fields largely by diseased seeds;

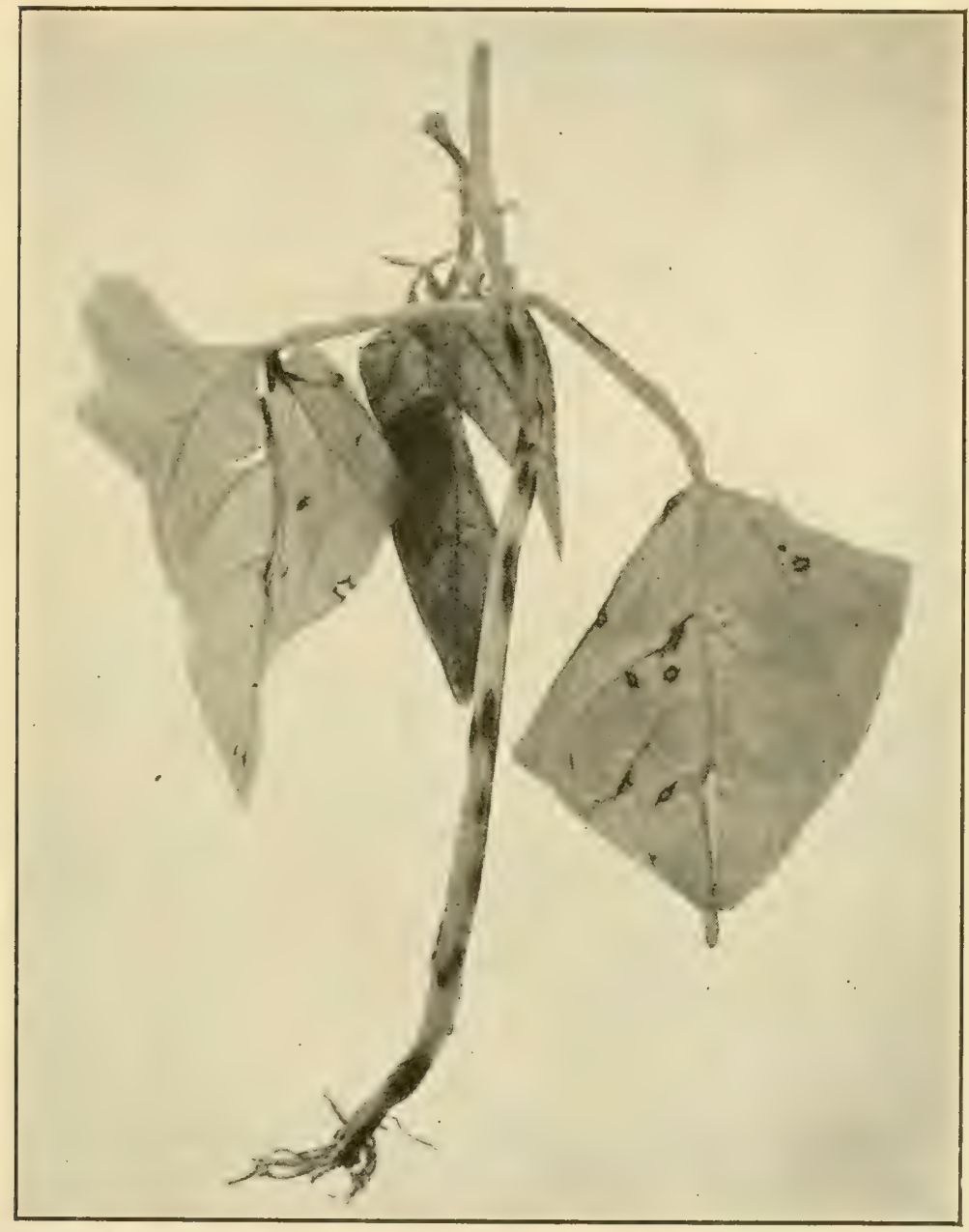

FIG. 81. - Bean anthracnose upon stem and leaves of young plants. After Whetzel.

by beans bearing the spots above mentioned. Such seeds result in infected seedlings which serve as a multiplying medium for the fungus and result in its spread and general attack upon the field. 
In fields where the disease is well established upon stems and leaves the damage is great in loss of starch-producing power. Still greater loss follows from the spread of the disease to the pods, the unsightliness of the spotted pods greatly injuring their salability.

Since the spores are spread only when they are wet, handling or disturbing the vines in any way while the dew or rain is still upon them should be avoided. Seeds already bearing the fungus, $i$. e., spotted seeds, should never be planted, since they not only raise sick plants, but also carry the disease to the field to infect other plants. One infected seed may carry contagion to the field. Spraying is not effective. Since no remerly is at hand except the use of healthy seed, the greatest care should be given to this point. Home, fall-grown seed known to be free from clisease is preferable to seed of unknown origin. If a few seeds known to be free from disease can be secured and multiplied in a special seed plot, they will give clean seed for future use. Clean culture, the removal from the field and destruction of diseased stalks and plant parts, eliminates a source of spring infection which may be important.

Rust 458, 475 (Uromyces appendiculatus (Pers.) Link). This rust may be recognized by its sori upon the leaves and occasionally upon other structures. The sori appear at first as blisters of pinhead size, covered by the epidermis of the plant. Later this covering ruptures and discloses a mass of spores the color of iron rust, or later in the season chestnut-colored, which fall away in quantity, smudging the leaf and spreading the disease. The upper side of the leaf opposite a sorus usually shows a spot, pallid, yellowish, lacking in true leaf-green color. Sori are sometimes found upon the upper surface, but not so frequently as upon the lower.

Rust usually develops somewhat late in the season and therefore is not so destructive as are many of the other bean troubles, though in certain localities, e. g., in Virginia, the crop is sometimes completely destroyed. 
It is reported upon many species of true beans (Phaseolus) and upon related genera as Vigna, Falcata, Strophostyles. Where the disease proves destruetive, the use of resistant

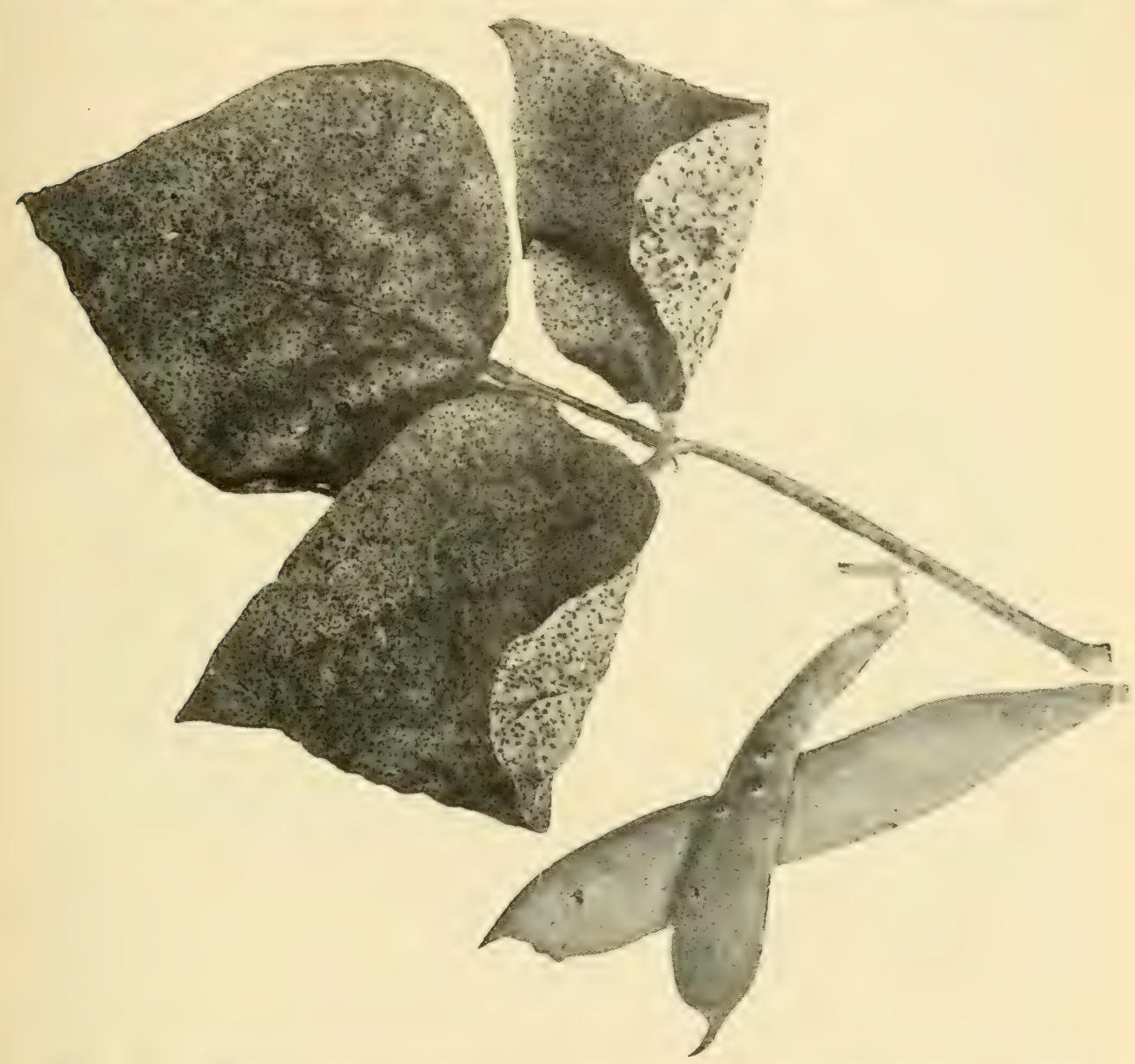

Fig. 82. - Bean rust upon leaf and pods; note the numerous sori upon both surfaces. After Beach.

varieties, clean culture, and the destruction of all wintering forms, is advisable.

Blight ${ }^{181}$ (Pseudomonas phaseoli EFS.). - Beans of various kinds are subject to a blight which manifests itseif upon the pod, leaf, or stem. It has been reported from various states, from Canada, is widely distributed, and 
often quite destructive. It was first observed by Beach in New York in 1892.

Usually the leaves are the parts first attacked. Here large, translucent patches, brown in color, are produced. These spots later dry, become papery in texture, and rupture, leaving the foliage ragged and torn. Later infection spreads to the pods, which develop watery, ulcer-like spots without definite boundary, similar to those upon the leaves, though often amber-coated. Attack upon young pods kills them.

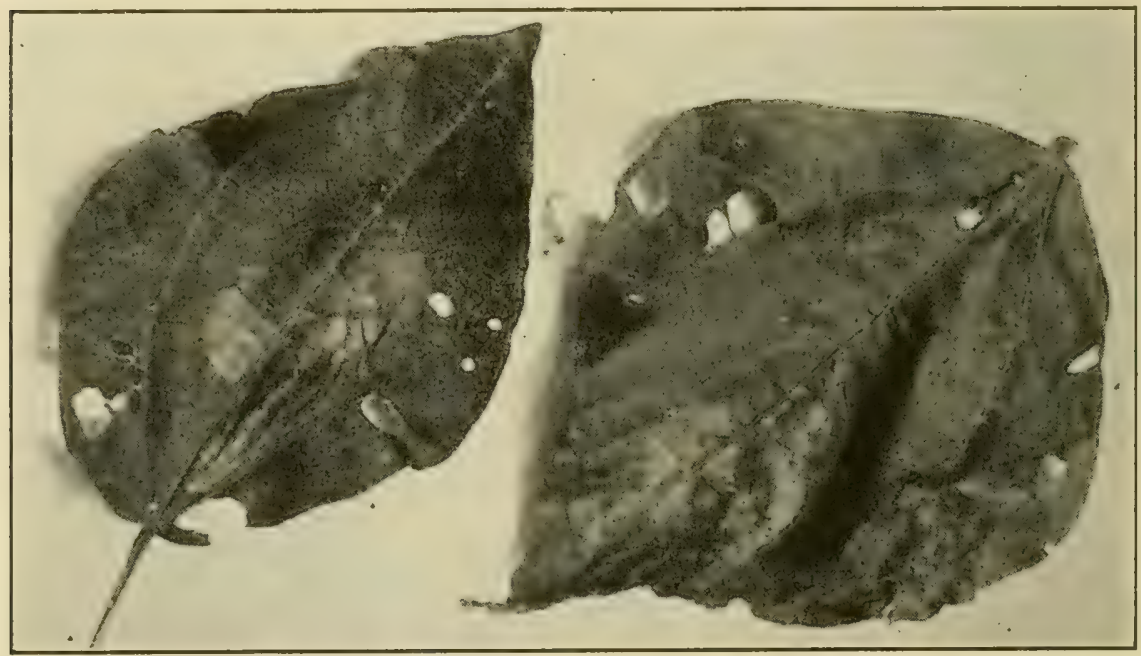

Fig. 83. - Blight of bean leaves. After Fulton.

This disease is carried over the season largely by infected seed and is conveyed from plant to plant in the field by insects.

Diseased seed and seed from fields bearing the disease should be avoided, and clean culture, including the burning of all infected plant parts, should be practiced. The following list shows the variation in resistance, the least susceptible being placed first and the most susceptible last: Schindler's Round Pod Wax, Refugee Wax, Burpee's White Wax, Grenell's Rust-proof Golden Wax, Wardwell's Kidney Wax, Dwarf German Black Wax, Early Valentine. 
Stem-rot, podrot ${ }^{15}, 182,183$ (Corticium vagum). This disease is manifest in three forms:

1. Damping-off of seedlings. See damping-off.

2. Dry-rot of the stem. In this condition the tissue is dead, discolored, and dry-rotted at from 2-5 cm. above the ground. The rot extends to the pith and usually encircles the stem, and thus so weakens the plants that they are often broken by the wind. In any event they soon wilt and die.

3. As brown sunken areas upon pods, penetrating to

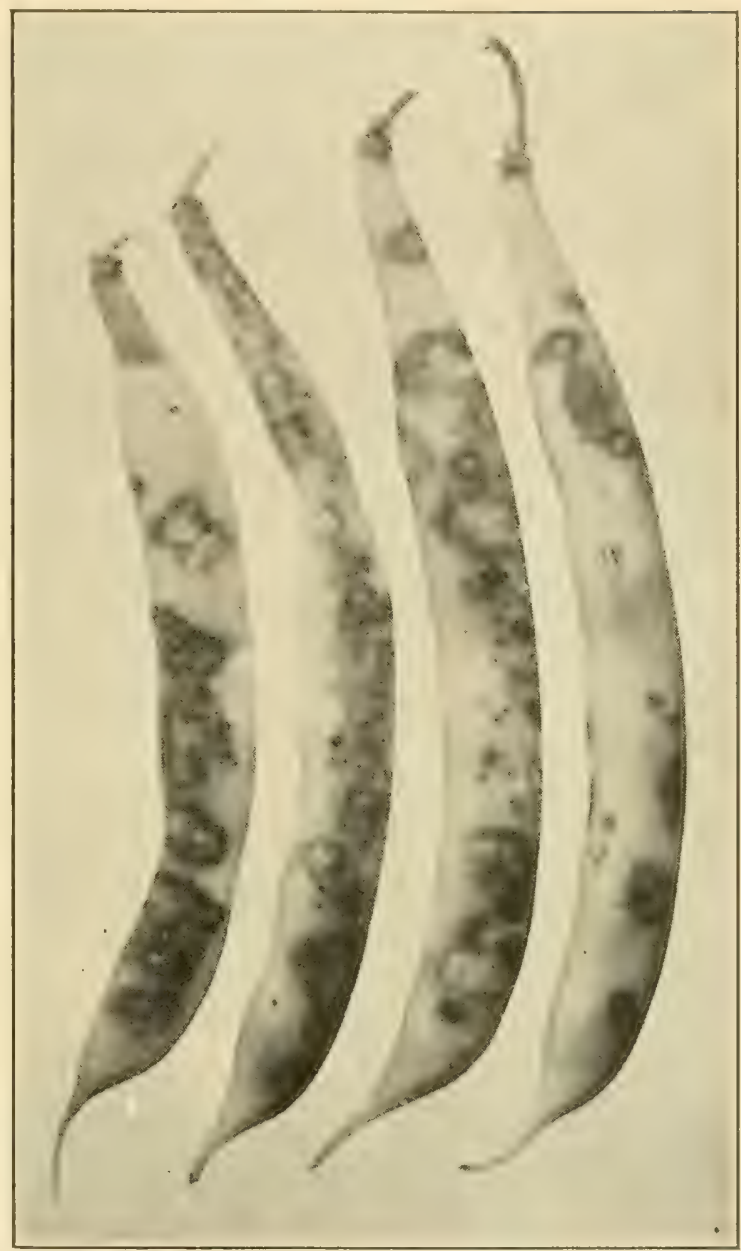

Fig. 84. - Blight of the bean. After Halsted. and discoloring the seeds. The germination of the seed is not

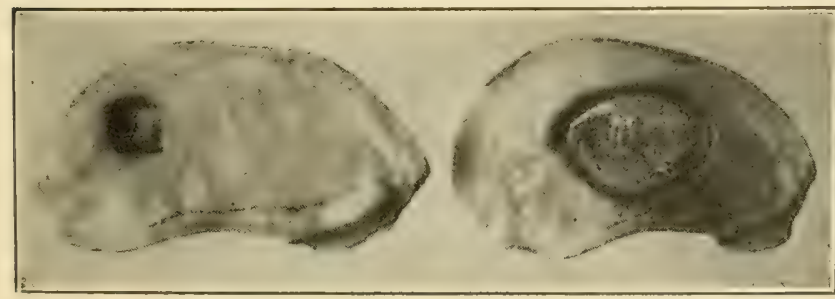

Fig. 85. - Blight upon bean seeds. After Clinton. stopped by this attack, and a fruitful source of dissemination is thus afforded. Such seeds should be avoided. 


\section{Downy-mildew 184, 18.5 (Phytophthora phaseoli Thaxt.). -} Downy-mildew is a northern disease regarded by Halsted as the most serious discase of the lima bean. It was first recorded by Thaxter in 1889 .

Upon the pods growths of dense, woolly-white, irregular patches appear. These consist of myriads of spore-bearing hyphæ of the causal fungus, laden with their spores. The mildew also attacks young shoots, petioles, flower clusters, and leaves, causing them to develop in dwarfed, imperfect fashion and destroying their value. The spores are largely carried by nectar-secking insects, which accounts for the prevalence of flower infection. Spores are also carried by wind.

Even in a season favorable to the development of the disease, thorough use of Bordeaux mixture, three sprayings, will insure the crop. The destruction of infected trash is advisable.

Southern-blight (Sclerotium rolfsii). - The symptoms are wilting of the leaves, temporary recovery, yellowing, dying, and eventually dropping. The fungus usually attacks the plant just below the surface of the ground, invades the cambium, and destroys it. For further details, see pepper.

Pod-blight ${ }^{188}$ (Diaporthe phaseolorum (C. \& E.) Sacc., Phomopsis). - This destructive lima-bean blight was first recognized in New Jersey in 1891, and is now known generally in the East, producing upon pods and leaves large, brown patches, with the pycnidia arranged in concentric circles. When the disease is prevalent, the pods fail to mature their seeds.

Clean seed should be used and the plants sprayed with Bordeaux mixture.

Drop ${ }^{190}$ (Sclerotinia libertiana). - This rot is reported to cause a reduction of 30 per cent in yield in some fields. Loss of nearly $\$ 3,000$ is reported on one 30-acre field in Virginia. It may develop rapidly in transit, and thus cause secondary freight losses. Field refuse should be burned, and crop rotation practiced. See also lettuce. 
Minor diseases

Orobanche is sometimes parasitic on beans. Sunscald ${ }^{189}$ produces discoloration. Powdery-mildew (Erysiphe polygoni DC.) often gives a rusty color to the pods. Leaf-blotch (Cercospora cruenta Sacc.) occurs only upon the foliage as brownish patches, causing the leaves to fall away. The spots are large, angular, and limited by the veins. Leaf-spot (Isariopsis griseola Sacc.) is chiefly limited to the foliage, producing small, angular spots, over the under surface of which the fungus forms a gray, moldy covering. It has been observed in many states, and is most injurious in the South. ${ }^{187}$ Wilt due to Pseudomonas solanacearum has also been reported. Root-knot (nematodes) is injurious in some localities. Streak. - Dark spots occur on stems, leaves, and pods. The cause is unknown. Mosaic ${ }^{186}$ in general character resembles tobacco FIG. $_{\text {8 }}$. - Lima-bean pods showmosaic. It appear's to be of ing pud-blight. After Halsted. wide distribution and to be communicated through the seed. Resistant strains should be grown.

\section{BEET, CHARD, MANGOLD, MANGELS}

Cercospora Leaf-spot ${ }^{191-194}$ (Cercospora beticola Sace.). This, one of the several leaf-spots upon the beet, is very widespread in the eastern and middle states. Very few fields are entirely free from it. It occurs upon all varieties, but is especially injurious to the sugar beet. 
The round, brownish, purple-bordered spots turn ashen in the center, and, when mature, often become so thin and brittle as to drop out, leaving ragged holes. The sporiferous hyphæ upon the spot centers may be seen with a good lens.

These spots frequently destroy the greater part of the green tissue of the leaf, and thus its value to the plant as a sugar producer, or even cause the leaves to die, in which event they blacken and remain standing nearly upright upon the crown. The death of the older leaves causes the crown to elongate, suggesting the name "pineapple disease." Dry weather followed by a damp spell favors the disease. Infested refuse in manure may serve to spread the leaf-spot, but beet tops made into silage do not carry contagion.

Sprayed plants in New Jersey gave a much cleaner foliage and yielded 480 pounds of root as against 380 pounds from the unsprayed plants from an equal area, a gain of nearly 26 per cent. While partial control may thus be had by spraying, the cost may not, however, be justified. Crop rotation and deep fall plowing should be practiced.

Curly-top. ${ }^{199,200,201}$ - The first symptom appears in the inner leaves, which curl inward from the entire margin toward the midrib. Soon the veins become knotted on the dorsal surface. Later, the entire plant is stunted and shows similar changes; whole leaves curl tightly and the petioles remain short and become bent. The roots develop an abnormal number of fine rootlets, leading to the common name "hairyroot." (See also p. 162.) They are also tough and sometimes present a blackened area or cavity within. Curly-top occurs annually on sugar beets in Colorado, Utah, Idaho, and California, and in fact in all states west of Nebraska where sugar beets are grown. In some years thousands of acres are completely destroyed, the total loss during the last sixteen years being estimated at $\$ 16,000,000$. Even though the beets grow to fair size, impurities lower their value for sugar production and their seeding power is injured. The disease, however, is not seed-borne. As to the cause, but little is definitely known beyond the fact that this disease can be 


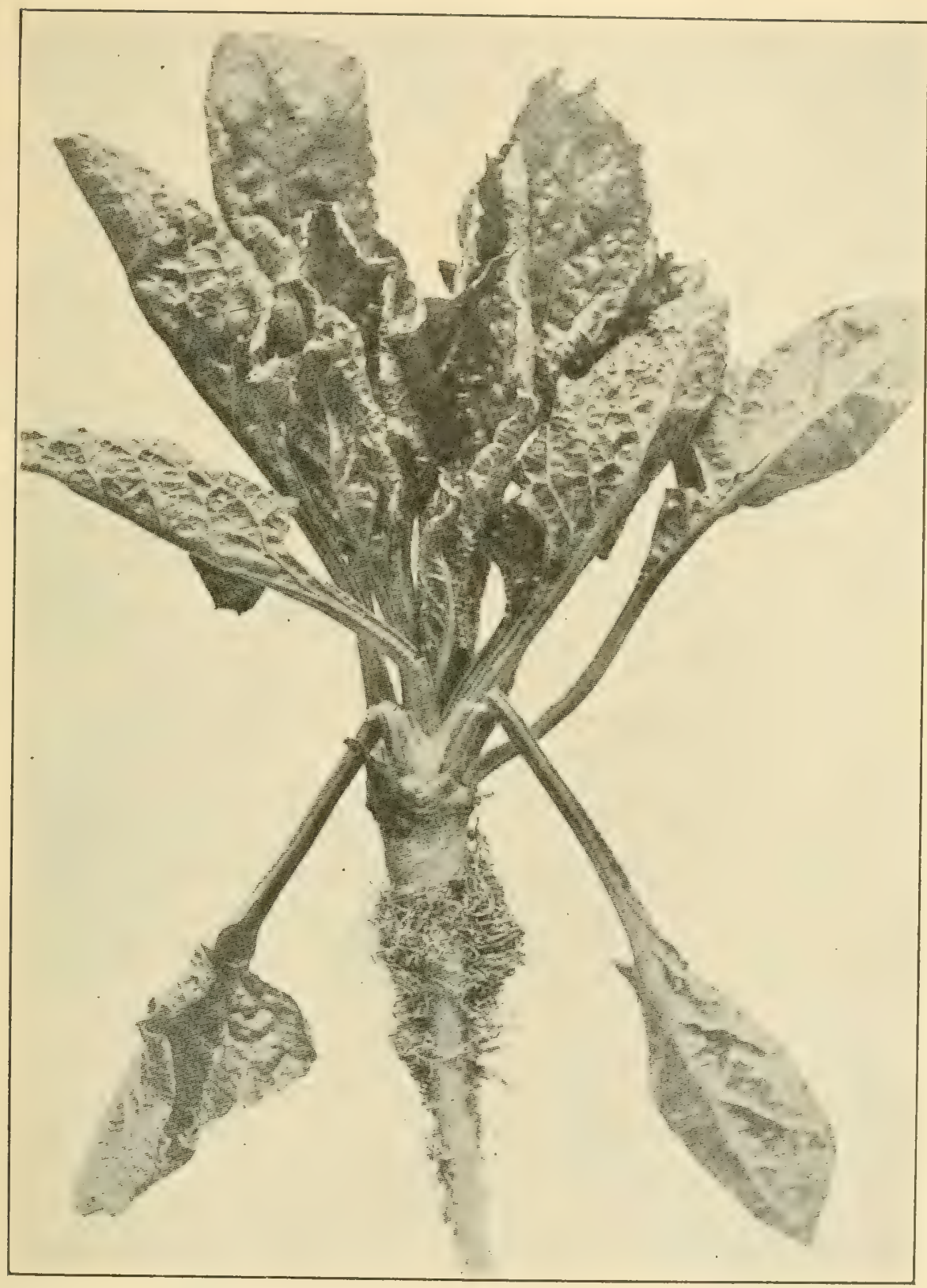

FIG. 87. - Curly-top. After Boncquet. 
conveyed by grafting, but otherwise develops only after the sting of a leaf hopper (Eutettix tenella) that has been in contact with beets affected with curly-top. Bacillus morulans Bonc. has been associated with curly-top, but its causal relation not demonstrated.

Root-rot ${ }^{194}$ (Corticium vagum). - Bects affected with this rot usually show first attack at the bases of the outer leaves, which turn black. The stalks weaken and allow the leaves to fall prostrate, though they do not lose their color at once. The disease thence passes into the crown, turning the involved parts brown and later leading to cracking of the root. In this condition the mycelium of the fungus is clearly evident in the cracks. Eventually the whole top may rot off. The spread is rapid from plant to plant in the field. Dry or cold weather may so retard the invasion that the plant can recover if not too badly affected.

The disease is probably the same that has been destructive to sugar beets in Germany. It has been reported from several places in the United States.

Air-slaked lime, 60 to 70 bushels per acre, has been recommended.

Phoma Root-rot ${ }^{198}$ (Phoma betce (Oud.) Frank.). - Upon the roots a shrunken, coal-black discoloration, extending sometimes quite to the center, indicates the presence of this dry rot. No disagreeable odor attends the rot. Upon the affected surface pycnidia appear as very minute pustules. Upon the leaves this same fungus forms large, circular, dead spots. The disease may also appear on seedlings, causing damping-off.

All infected leaves should be removed from the roots before placing in storage.

Root-knot and Hairy-root (nematodes). ${ }^{203,} 204$ - Two species of nematodes affect beets, one of which produces rootknot, the other hairy-root, both of which are quite destructive. Root-knot, due to nematode-infection, is discussed on p. 24. Hairy-root shows first symptoms, as the hot season begins, in a wilting, yellowing, and dying of the outer leaves, 
and dwarfing of the inner leaves. Dense masses of fine rootlets develop below ground, giving rise to the common name. The really distinctive character is the presence of numerous yellowish, beadlike objects, a little over a millimeter long, clinging to the rootlets. This disease has been very destructive in Europe, and, introduced into the United States prior to 1907, is established in several districts in the West. Following is a partial list of plants known to be susceptible to hairy-root. Those marked with a * are highly susceptible. Alfalfa, allseed, barley, bean, dwarf pea, lima bean, garden beets, ${ }^{*}$ sugar beets, ${ }^{*}$ Brussels sprouts,* cabbage, ${ }^{*}$ Chinese cabbage, ${ }^{*}$ cauliflower, ${ }^{*}$ celery, crimson clover, white clover, corn, cress, ${ }^{*}$ dandelion, green foxtail, hemp, hops, kale,* kohl-rabi,* lentils, yellow lupine, annual meadow grass, tall meadow oat-grass, mustard,* oats, parsnip, garden pea, sweet pea, pink, potato, radish,* rape,* rutabaga,* rye, sorghum, spinach, sunflower, timothy, turnip, ${ }^{*}$ vetch, wheat.

A rotation of four or five years with nonsusceptible crops is the only safe procedure with infected land. Small areas of local infection may be eliminated by a heavy application of unslaked lime well mixed into the soil.

Black-root ${ }^{204}$ (Rheosporangium aphanidermalus Eds.).Black-root occurs on both radish and beet, causing dampingoff and a browning or blackening and often death of the root. Disinfection of seed is advisable.

Damping-off. - Damping-off of seedlings near the surface of the ground soon after they come up, often before thinning, is a frequent cause of loss. The leaves yellow, the roots turn brown, and the plants topple over and die. This is, in some instances, due to the usual causes of dampingoff, Corticium, Pythium, Phoma, but sometimes to a heavy crust formed upon the soil, thus preventing the safe emergence of the seedling.

\section{Minor diseases}

Scab ${ }^{195}$ (Actinomyces scabies) resembles closely the scab of the Irish potato. It usually covers more completely 
the surface of the beet than in the case of the potato, and tends more to form corky growths upon the surface than to make deep cavities. Beets should not be grown upon land known to be infested with the potato scab or to have borne a badly infected crop of beets. See also potato scab.

Bacterial Leaf-spot ${ }^{197}$ (Pseudomonas aptatum (B. \& J.). - The leaves in this disease bear irregular, dark brown or black spots, $1 \mathrm{~mm} .-3 \mathrm{~cm}$. in diameter, chiefly upon the petiole, midrib, and larger veins. Occasionally the discoloration extends along a vein for some distance, and the tissue on either side becomes brown and dry.

The discase was first observed by Townsend in Utah and Colorado, and its bacterial origin was demonstrated by Brown.

Rust (Uromyces betce (Pers.) Kühn) has long been known in Europe, where it was studied as early as 1869 . It is oceasionally met in some of the western states and has been reported as injuring the beet in market gardens in California. It is recognized by the characters of the true rusts, $i$. e., blisterlike sori.

Removal of the leaves bearing the spring stage and spraying with Bordeaux mixture has been recommended. Affected leaves used as feed may carry the disease through the manure to plants of the following season.

White-rust (Albugo bliti (Biv.) Ktz.). - The sori are blisterlike, as in the true rusts. The rupture of the epidermis releases masses of snow-white spores.

Soft-rot ${ }^{196}$ (Bacterium teutlium Met.) was prevalent in Nebraska in 1904. Leaf-scorch. ${ }^{202}$ - The leaves blacken and die, and the roots are small, discolored, and poor in sugar content. Crown-gall and Root-tumor (Urophlyctis), Downy-mildew (Peronospora), and Drop (Sclerotinia) cause some loss.

BROCCOLI. See cabbage.

BRUSSELS SPROUTS. See cabbage. 


\section{BUCKWHEAT}

Blight ${ }^{20.5}$ (Corticium vagum), causing death of plants in large areas in the field, was noted in North Carolina. Leafspot (Septocylindrium rufomaculans (Pk.) P.\& ('.) is reported as diminishing the yield in Connecticut. Powdery-mildew (Erysiphe polygoni) is of slight importance.

CRUCIFEROUS CROPS: CABBAGE, BRUSSELS SPROUTS, CAULIFLOWER, COLLARD, TURNIP, KOHL-RABI, KALE, RAPE, RADISH, BROCCOLI, RUTABAGA

These crop plants are of close kinship and are subject, essentially, to the same diseases. The more important of these are internal parasites from the soil, hence spraying is of less benefit than with other crops.

Black-rot ${ }^{206-208,228,319,340}$ (Pseudomonas campestris (Pam.) EFS.). - Not only does black-rot destroy the current crop, but since its causal germ remains in the soil, it seriously endangers, if it does not quite prohibit, the subsequent use of the same field for susceptible crops. Its damage to cabbage in a single season in two counties in Wisconsin was estimated at between $\$ 50,000$ and $\$ 60,000$. A large per cent of the damage to cabbage in storage is also attributable to this disease. Cabbage, kale, rape, broccoli, kohl-rabi, Brussels sprouts, collards,

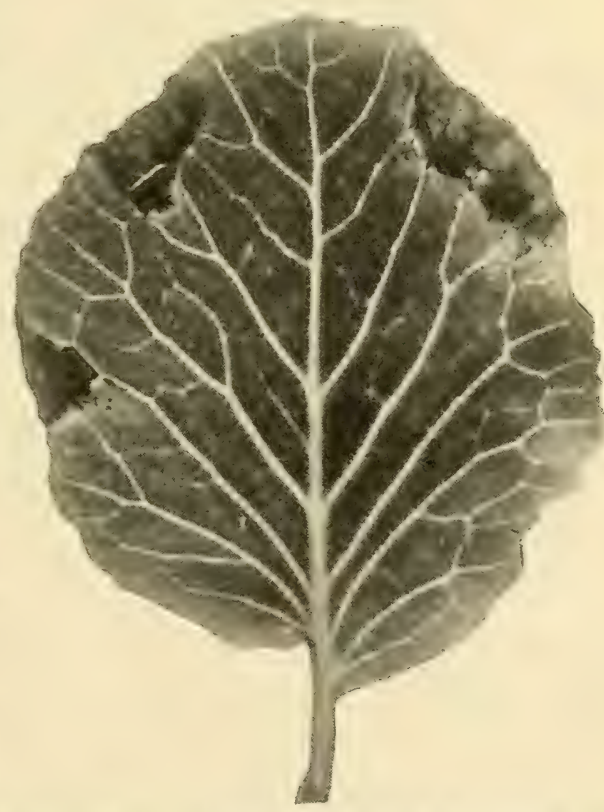

Fig. 88. - Cabbage leaf showing an incipient stage of black-rot. The disease, which enters at the ends of the veins, is progressing toward the base of the leaf. After stewart and Harding. 
turnips, rutabagas, radish, black mustard, charlock, and other members of the cress family are affected.

Black-rot was first noted on turnips in 1892 in Iowa, and on cabbage in 1895 in Wisconsin, and is now very disastrous in its effects in practically al sections of the United States east of the Mississippi River, as well as in the more western states.

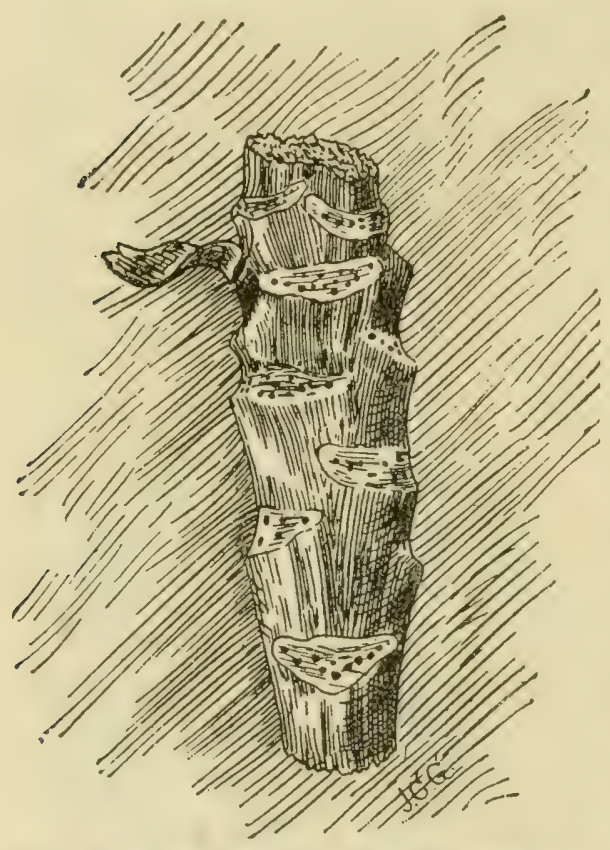

Fig. 89. - Portion of cabbage stem showing blackened veins. Redrawn after Russell.

are infected simultaneously. Affected leaves soon yellow and wilt, owing to the obstruction of the water channels, then dry, become parchment-like, and fall to the ground. General infection of the plant is followed by death. Reliable diagnostic characters are the blackened vein areas of the leaf, blackened veins as seen in cross sections of the leaf stalk or of the stem of the plant. Other rots may supervene, giving offensive odors. If plants with the smallest amount of disease are placed in storage, the disease continues to develop, 
resulting in complete loss. The bacteria may travel upon seed from diseased localities, infect the young plants, and initiate an attack in a new locality. Plants shipped across the country may also carry infection.

The disease may be carried from field to field in any plant part or in infected soil, upon tools, fect, etc., and especially in manure that has become infected by the use of

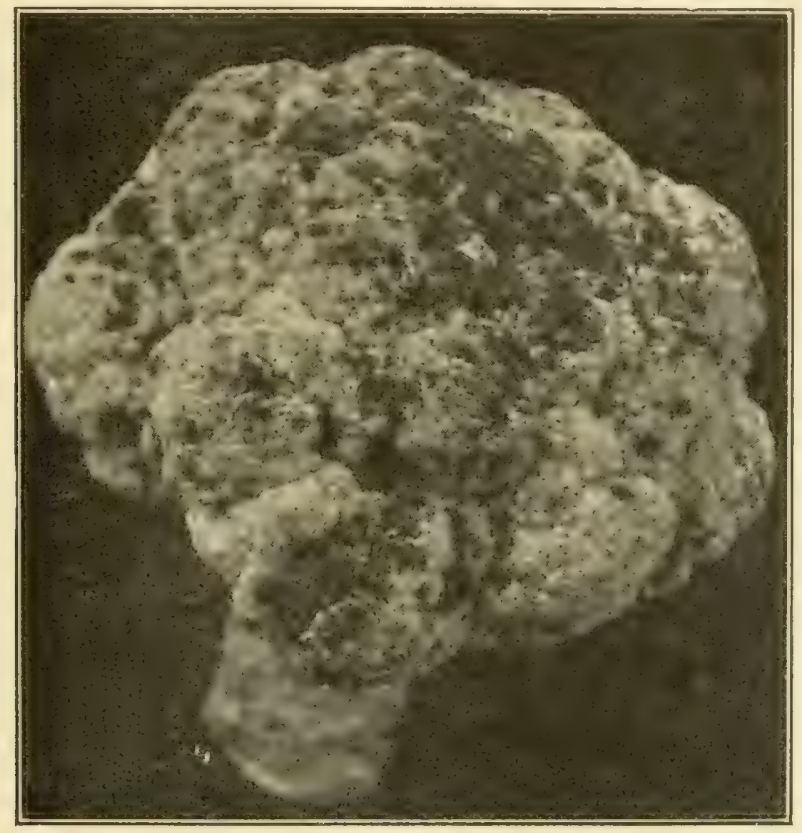

FIG. 90. - Cauliflower affected with black-rot. Original.

diseased plants as feed. To avoid carrying contamination to near-by fields all the precautions suggested under soil diseases must be employed.

With infested land the only recourse is such crop rotation as will avoid the planting of a susceptible crop for a period of several years. Just how long the bacteria can remain alive in the soil is not known. In practicing erop rotation for elimination of this pest all cruciferous weeds, mustard, shepherd's purse, etc., should be avoided, since they are sus- 
ceptible and harbor the disease just as effectively as would cabbage.

Since the seed may carry the bacteria, it is well to soak them for fifteen minutes in formalin, one teaspoonful to a half pint of water, to kill these germs and thus avoid introducing the disease into new localities. If this had been

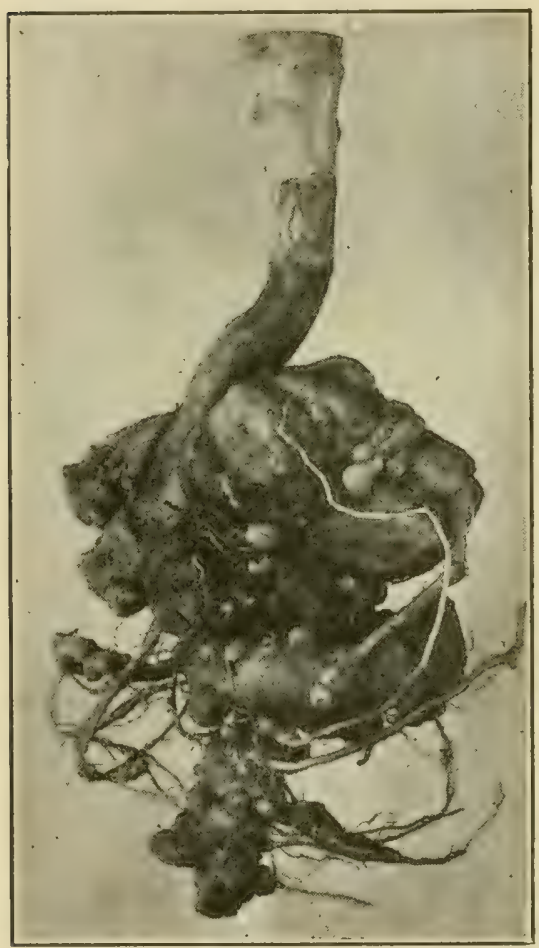

FIg. 91. - Cabbage club-root. Original. done in earlier years, many counties now so infected as to prohibit cabbage culture would still be free from this pest. Resistant varieties will do much to solve the problem.

The cauliflower is affected in much the same way as the cabbage. Local infection in the head often produces the effect shown in Fig. 90.

Club-root 208-211, 227

(Plasmodiophora brassica Wor.). Club-root is practically of world-wide distribution, and destructive to cabbage, kale, cauliflower, turnip, rutabaga, collards, Brussels sprouts, radish, stocks, candytuft, sweet alyssum, and upon wild cruciferous plants, shepherd's purse, peppergrass, pennycress, black mustard, charlock, false flax, hedge mustard. It may readily be recognized by the enlarged growth of either the main root or the lateral roots, or both, as shown in the accompanying figure. It cannot be confounded with any other disease unless that caused by eel worms (ncmatodes), and from this it may easily be distinguished by the larger club-root galls.

These swellings may be noted in the seed bed, though they are usually overlooked until they enlarge in the field. They 
so diminish the vigor of the plant that it assumes a sickly appearance, ceases to develop, and fails to head. The affected parts usually suceumb to offensive secondary rots, the causal organism is released, and the soil is thus infected.

The proof of the parasitic origin of this disease was made by Woronin in 1873, after three years of intensive study.

In general the precautions against its spread are those suggested under the general heading of soil discases. All diseased refuse is infective, as is also manure to which it has had access. Fields which are diseased remain so for several years; therefore rotation to nonsusceptible crops should be followed. Seedlings should be examined carefully to guard against the use of plants from an infected seed bed, and special care should be taken to avoid infecting the seed bed with soil, manure, or refuse. Air-slaked stone lime, 75 bushels per acre, applied each year some weeks before planting, has given beneficial results. In New York, where 90 bushels of shell lime were applied per acre, an excellent crop was grown, while upon untreated soil only 60 heads were cut from 472 plants. The Hollander and the blue or red varieties of cabbage are said to show some resistance.

Root-knot (nematodes). - Root-knot in some respects resembles club-root, but with smaller swellings. It is common on crucifers.

Black-leg 213, 214 (Phoma lingam (Tode) Desm.).- Greatest injury is done to cabbage and cauliflower, less to other crucifers. Dark, sunken areas occur on the stems near the ground; gradually the stem, and later the plant, dies. Spots may also appear on leaves or petioles. The presence of pycnidia in the spots is the really distinctive character. The disease is important chiefly in the East and North, though it has been reported from the South and extreme West, as well as from Europe and Australia. Infection may be carried or maintained by diseased refuse or on the seed. Seeds should be disinfected (pp. 240, 449), and healthy soil used for the seed bed.

Black-mold (Alternaria brassico (Berk.) Sace.). - Upon the cabbage, cauliflower, and collard, particularly in the 
South, this mold is quite destructive both in the field and in storage. The affected spots are nearly black, circular, marked concentrically, and are not definitely bordered, $i . e$, they shade off gradually into the surrounding healthy tissue.

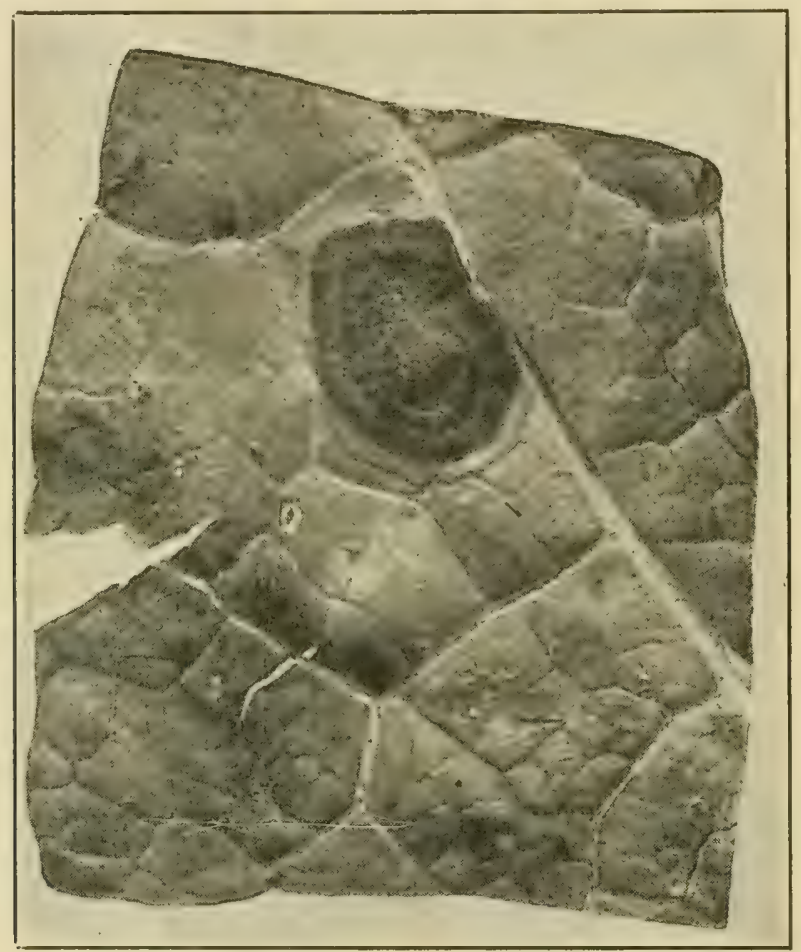

Fig. 92. - Black-mold on collard as seen from upper side of the leaf. Original.

They enlarge sometimes to $2-3 \mathrm{~cm}$. in diameter. The tissue dries, becomes brittle, and often falls away, leaving ragged holes.

In many instances the plants die or fail to mature. In storage the spots continue to enlarge, and it is here that the greatest loss occurs. Storage houses should be disinfected with Bordeaux mixture, and temperature and ventilation regulated as suggested under soft-rot, p. 172.

Drop ${ }^{212}$ (Sclerotinia libertiana). - This malady is discussed under lettuce. Upon the cabbage, rape, cauliflower, 
and radish it may be recognized by the cotton-like mycelium and the black sclerotia which appear in advanced stages of disease. It is particularly troublesome in the Southern states.

A form of this rot is described by Hedgcock as closely resembling black-rot, except that it is more watery. Often, too, the petioles rot away at the base and the leaves droop. The general practices recommended under lettuce drop will apply.

Downy-mildew (Peronospora parasitica (Pers.) De Bary). - Downy-mildew produces the characteristic downy patches of sporophores upon the lower surface of the leaves, much as is the case of the grape. Seen from above the diseased spots are angular, limited by the veins, pale yellow, and the tissue is somewhat shrunken.

The disease is common to cabbage, collard, cauliflower, turnip, radish, and many other members of the cress family. It has been reported in several

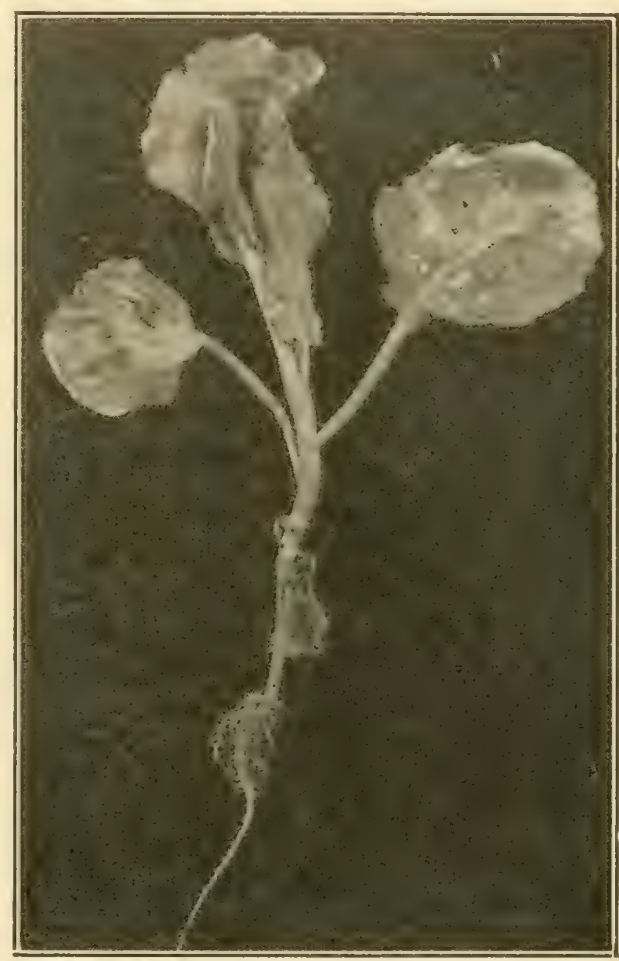

FIG. 93. - Seedling cabbage plant spotted with downy-mildew. Original. states, notably Ohio, New Jersey, New York, Delaware, Maryland, South Carolina, North Carolina, West Virginia, and in Europe and Australia. Though it is seldom of importance in the field, it occasionally does damage in the seed bed.

Spraying the plants in the seed bed with Bordeaux mixture will hold the disease in check. Diseased plants should be destroyed by fire as soon as the bed has been used. 
Yellows, Wilt 201, 214, 229 (Fusarium conglutinans Woll.). This wilt of cabbage is destructive through a large territory, particularly in the Southern states, and at least as far north as Minnesota. As high as 90 per cent of loss has been reported.

The chief symptom is yellowing and falling of lower leaves, and eventually all of the laaves except those of the head. This character may be strongly emphasized upon one side of the plant or even upon one side of single leaves. Affected plants are retarded in growth and often die. After death abundant pink acervuli are seen. Cross section of an affected stem shows the wood ring to be darker than normal.

In treatment the same methods should be followed that are suggested for cabbage black-rot; especially should infested land be avoided, and the young plants grown in healthy soil. The Volga and Houser are the most resistant of the older varieties. The Wisconsin Hollander is a disease resistant variety developed by selection.

White-rust (Albugo candida (Pers.) Ktz.). - White-lust upon radishes often causes curious malformation of the flowers and pods, which become overgrown and distorted; often a flower is five times its normal diameter and is colorless. Chief damage is thus done to the seed crop, which may be quite rumed by this attack upon the flowers. It is quite general on crucifers, but really injurious only to the radish.

Burning of all infected trash is the best preventive.

Soft-rot (Bacillus carotovorus). (See carrot.) - This is a soft, slimy, wet decay affecting any part of the plant, and spreading rapidly throughout. Wounds are necessary to infection. Much injury occurs in the field, but the greatest loss is in storage houses. Here the temperature should be kept a degree or two ahove freezing, and good ventilation secured. Wounds should le avoided in so far as possible, and the crop dried before storing. 
Minor diseases

Malnutrition. ${ }^{208}$ - Leaves, yellowish between the veins and at the margins, are thickened and brittle. The cause chiefly rests in use of too much mineral fertilizer and lack of humus.

Powdery-mildew (Erysiphe); Damping-off (various fungi); Ring-spot (Mycosphorella) do but small harm. Phoma-rot, Black-root (see beet) and a Macrosporium leaf-spot are reported on the turnip. Pale-spot (Cercosporella albomaculans E. \& E.) is also common on leaves of turnips. Anthracnose ${ }^{545}$ (Colletotrichum higginsianum Sacc.) occurs on stems and pods of turnip, and is especially injurious on young plants. Leaf-spot ${ }^{215}$ (Pseudomonas maculicolum $\mathrm{McC}$.) occurs on leaves of cauliflower and cabbage. The spots are brown to purplish-gray, $1-3 \mathrm{~mm}$. in diameter. The leaves become puckered, and when badly diseased, fall off.

CANTALOUPE. See p. 178.

\section{CAPER}

White-rust (Albugo) and Powdery-mildew (Erysiphe) are recorded, but do small harm.

\section{CARROT}

Soft-rot ${ }^{221,} 222$ (Bacillus carotovorus Jones). - In Vermont serious loss from rotting of earrots was reported to the Experiment Station in 1898. Investigation by Jones showed it to be due to bacteria and that numerous other crops - namely, turnip, rutabaga, radish, salsify, parsnip, onion, celery, hyacinth leaves, and the fruit of tomato, eggplant, and pepper - were susceptible to the same disease.

Rot begins in the field and seriously increases during storage. The initial attack is either at the crown or root tip, from which points it proceeds rapidly through the core, which becomes softened and somewhat browned with a rather sharp boundary between diseased and healthy tissue. 
Fields known to be infested should be relieved of susceptible crops by suitable rotation. Manure which may

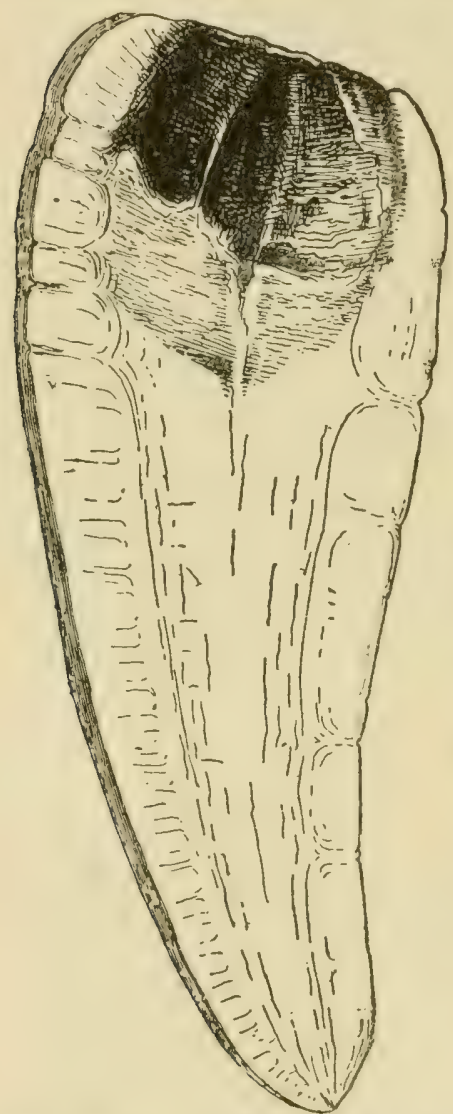

FIG. 94. - Carrot showing soft-rot; shaded portions represent the rotted part of the root. Redrawn after Jones. have become infested in any way, e. g. by feeding diseased crops to stock, should be avoided. Drying of the roots kills the causal organism, as does also exposure to sunlight. Drying in the light is therefore equivalent to surface disinfection and serves to reduce the damage. Storage below $10^{\circ} \mathrm{C} .\left(50^{\circ}\right.$ F.) gives best results.

Drop (Sclerotinia), see lettuce, and Southern-blight (Sclerotium), see pepper, are of some importance.

\section{CASTOR-BEAN}

Wilt (Pseudomonas solanacearum) (see p. 230) does considerable damage, dwarfing the plants, causing typical wilt, and finally death of many plants.

Gray-mold ${ }^{224}$ (Sclerotinia ricini, Godf., Botrytis) of flowers, buds, and pods in some cases affects 50 to 90 per cent of the plants with a wet rot. Diseased tops should be cut and Bordeaux mixture used.

CAULIFLOWER. See cabbage.

\section{CELERY, PARSLEY, PARSNIP}

Late-blight ${ }^{226}$ (Septoria petroselini Desm.). - In Italy lateblight was first reported in 1890; in the United States in 1891. A loss of 1950 carloads and a money loss of $\$ 550,000$ was 
estimated in California in 1908; in Michigan in 1915 a loss of more than a million dollars. A cut in price of 5 to 10 cents per crate is common when the bunches are only slightly disfigured. The disease occurs on celery, also on parsnip and parsley.

In its early stage it consists of leaf spots; in later stages, the infection of the leaf becomes general, numerous black pycnidia are scattered upon all parts and even upon the

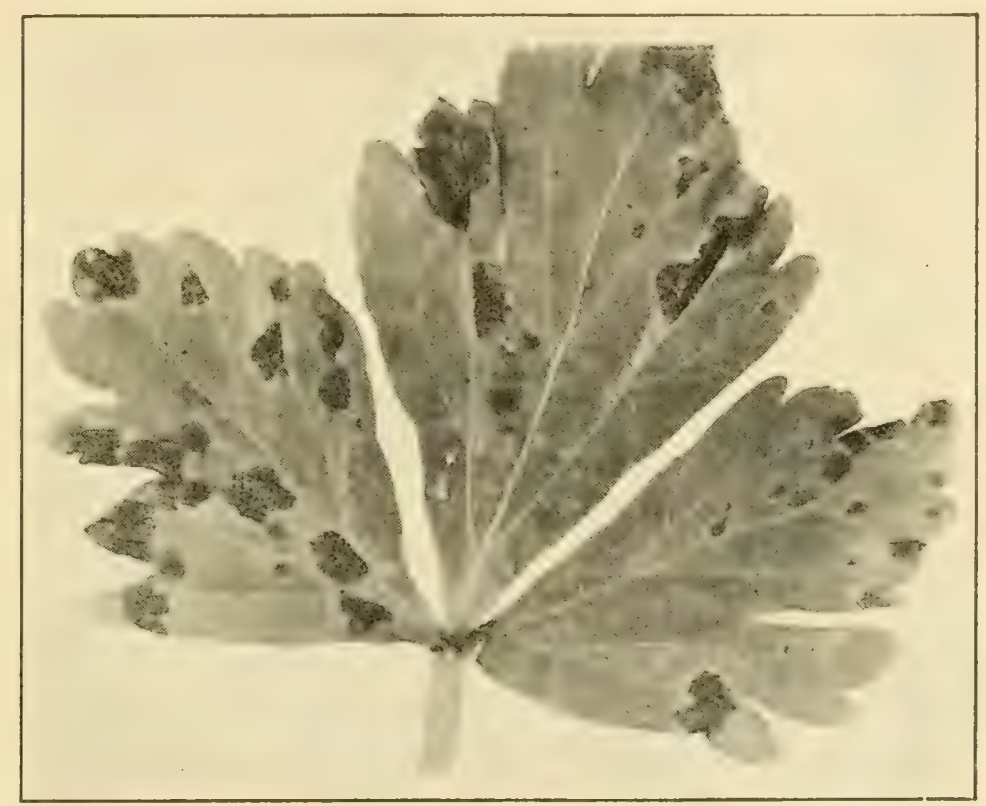

FIG. 95. - Celery leaf infected with Septoria. After Coons.

blanched petioles. In extreme cases wilting of the leaves and destruction of the plant follows. After the celery is put in storage the disease may still progress and do great damage, rotting off the leaves and forcing early marketing. Lateblight is often found in the seed bed, and is probably carried by the seed, since the pycnidia are abundant upon the seeding stalks and fruit.

Seeds should be disinfected and the seed bed rotated. If the disease has been troublesome in preceding years, the 
plants in the seed bed should be sprayed with Bordeaux mixture as soon as they are above ground, and once or twice a week thereafter until transplanted. If the disease develops in the field, the crop should be sprayed with Bordeaux mixture at ten-day intervals. The following is taken from a Michigan publication in 1915:

One-sixth acre (from which accurate returns were kept) sprayed with a knapsack sprayer at a total expense of $\$ 2.00$ for labor and material gave 125 crates (10x10) fine quality at $\$ 1.00$ value . . . . . . . \$125.00 A similar unsprayed area gave 18 crates poor quality at $50 \mathrm{c}$.

Excess return of sprayed plot.

Cost of spraying. . . . . . . . . . . .

Net gain .

On the rest of the acreage, at an expense of not more than $\$ 12.00, \mathrm{Mr}$. Joldersma saved a crop valued at about $\$ 1500$.

To minimize loss no diseased plants should be stored. If storage is imperative, badly infested leaves should be picked off, and in extreme cases the plants should be dipped in a fungicide (ammoniacal copper carbonate) before they are stored away.

Early-blight, leaf-spot, ${ }^{225}$ (Cercospora apii Fr.). - Leafspot is common on celery, parsley, and parsnip in both Europe and America. It is reported from California to New Jersey. In Florida in 1906 it is said to have injured 80 per cent of the crop. The crop is largely reduced, and the unsightliness of the spots injures the salability of the product.

The spots appear first upon the outer, older leaves as pale yellowish areas, showing from both sides of the leaf. They are irregular with slightly raised border and are angular in outline, owing to their limitation by the veins. They seldom exceed 3-6 $\mathrm{mm}$. in diameter unless by the coalescence 
of several spots. The spots soon become brown, and the central part turns ashen-white and is seen by the aid of a hand lens to bear numerous hyphæ. The leaves may bear so many spots as to appear as though scorched, and often death results to the entire plant.

The disease spreads most rapidly in damp, warm weather. Marked difference in varietal resistance was reported by

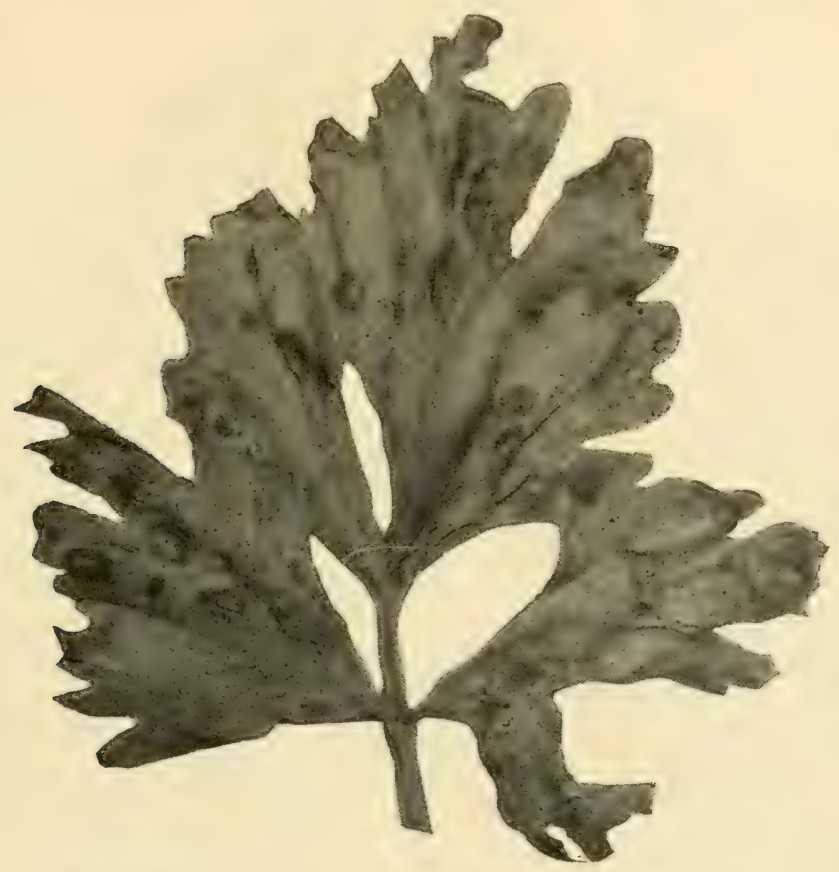

FIG. 96. - Early-blight of celery. Original.

Tracy as early as 1885, the Boston Market and Golden Heart suffering much, while the White Plume was but slightly injured.

All plants showing a trace of disease should be rejected. Healthy plants from infected lots may with advantage be dipped in Bordeaux mixture to cleanse them of adhering spores. Spraying with ammoniacal copper carbonate or Bordeaux mixture is effective. Treatment should be begun before the disease appears, $i . e$, in the seed bed, and con- 
tinued at ten-day to fourteen-day intervals throughout the growing period. All spore-bearing refuse should be burned.

\section{Minor diseases}

Leaf-spot (Phyllosticta apii Halst.). - A dull brown, circular pycnidia-bearing patch, not to be confused with the light, ashen-colored, angular Cercospora spot, is characteristic. Soft-rot (Bacillus carotovorus) consists of a soft, light-brown rot of the central bud, sometimes of the leaf or leaf stalks. It occurs on celery, also on parsley, and is probably identical with the carrot soft-rot. Rust (Puccinia bullata (Pers.) Wint.) has not yet been destructive in America. Damping-off due to Sclerotinia, Rhizoctonia, and Fusarium have caused much loss in the South on both celery and parsley. See also p. 19. Pithiness. ${ }^{230}$-The stalks and hearts are pithy, a condition attributed to the parent plant and heredity, not to parasites or environment. As high as 30 per cent of pithy plants have resulted from certain lots of seed. Proper rogueing of seed plants is recommended. Scab due to Phoma apiicola Kleb). consists of rotting of the roots, leaving the plant with a conical rotten base.

CHARD. See beet.

CHIVE. See onion.

COLLARD. See cabbage.

CUCURBITS: CUCUMBER, ${ }^{239}$ MUSKMELON, MELONS, WATERMELON, PUMPKIN, SQUASH

Downy-mildew ${ }^{231}$ (Peronoplasmopara cubensis (B. \& C.) Clint.).- Downy-mildew first shows its presence by yellowish angular spots, $3-6 \mathrm{~mm}$. in diameter, upon the leaves as seen from above. These appear first upon the older leaves at the center of the plant. The spots become more distinct, enlarge, increase in number, and soon the whole leaf becomes pale, sickly, and dies. If the weather is moist, the 
characteristic white hyphæ and spores tinged with purple may be seen on the under sides of the older spots. The disease progresses to the younger leaves, slowly in dry or cool weather, but very rapidly in warm, wet weather. The field is soon reduced to a mass of dry, dead leaves.

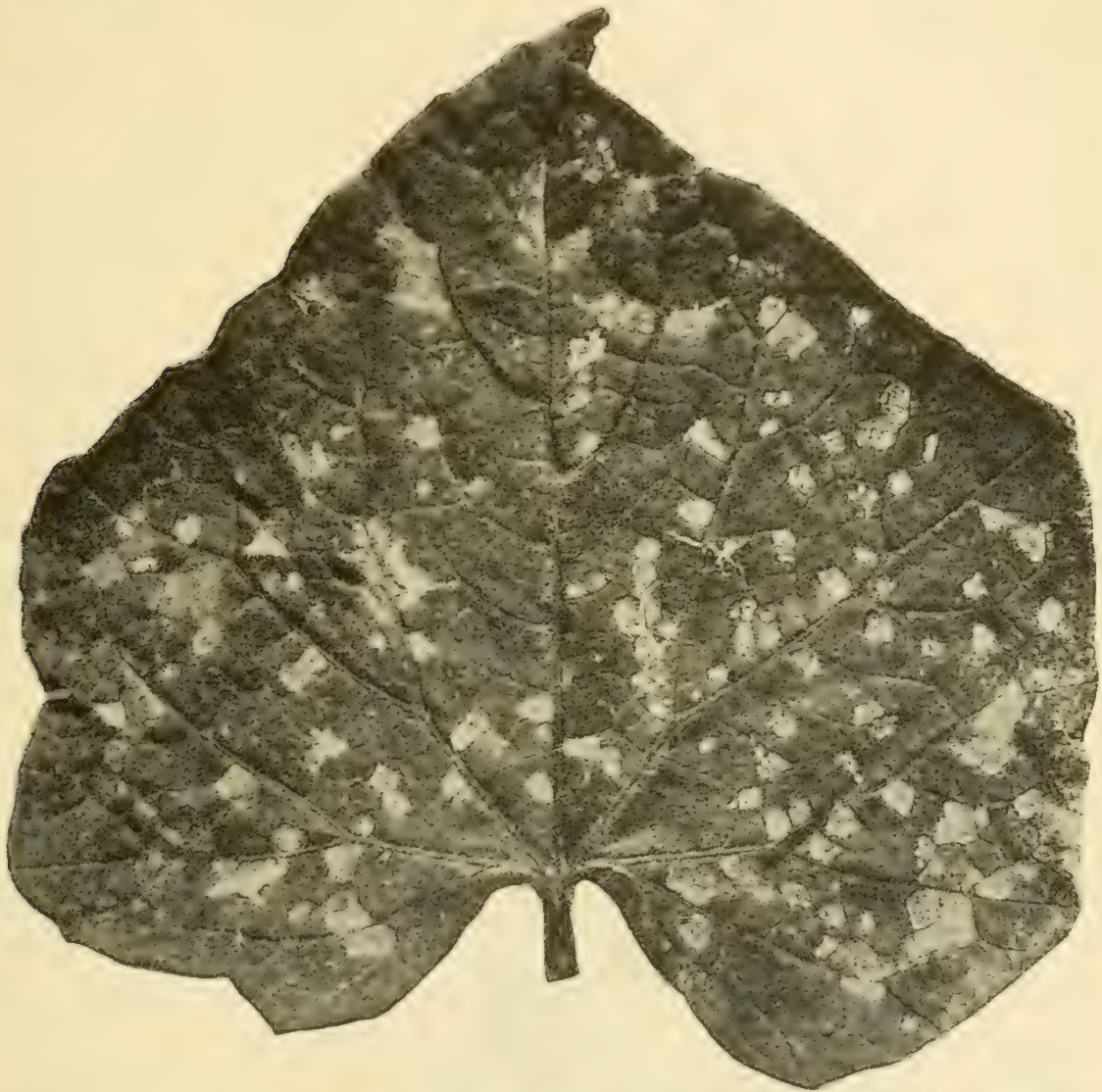

FIG. 97. - Spots of downy-mildew upon cucumber leaf. After Orton.

The mildew was first described in 1868 from Cuba. In 1889 it attracted attention in the United States (New Jersey, Florida, and Texas) and in Japan. Since that time it has been destructive in many states. The loss in Wayne County, Ohio, alone was estimated at $\$ 45,000$ in one season.

It grows upon muskmelons and cucumbers in most destructive form and is less injurious to squash, pumpkin, 
watermelon, gourd, and other cucurbits. The fungus winters out of doors in the South and in the greenhouse in the North and spreads thence to the fields annually if weather conditions are favorable.

This disease is often injurious to cucumbers under glass

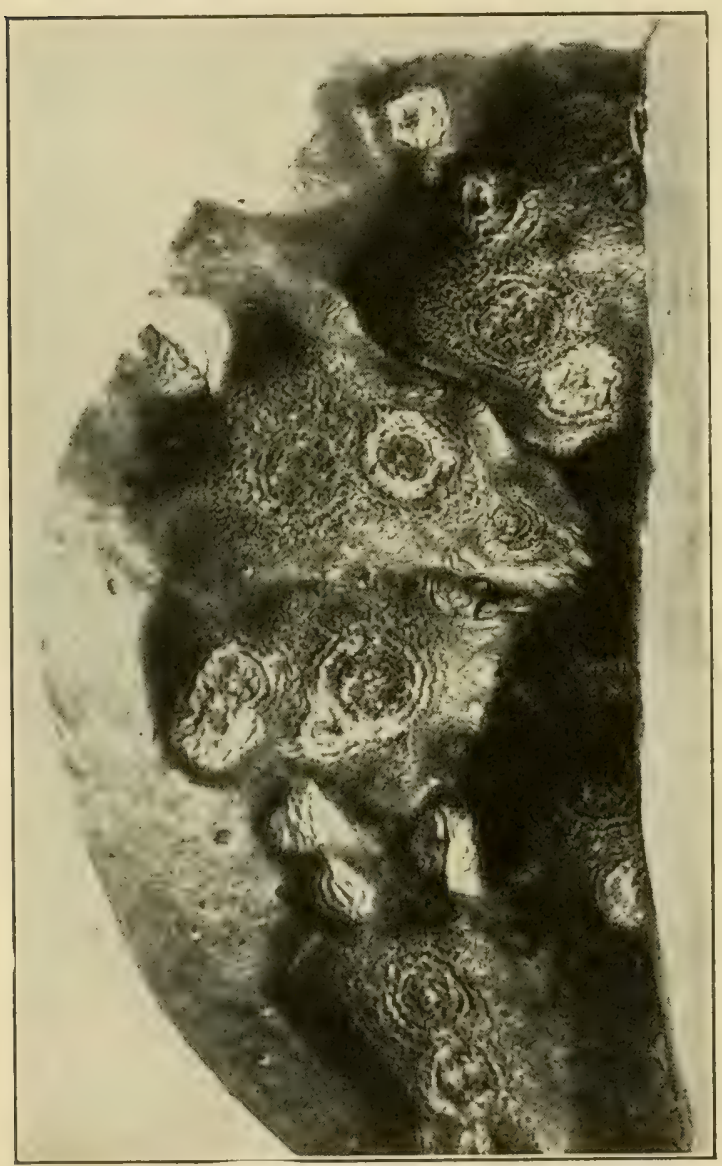

FIG. 98. - Portion of watermelon showing effect of anthracnose. After Sheldon. as well as in the field. It is well to sulfur the $\mathrm{greenhouses}$ thoroughly when not in use and to clean and whitewash all walls and wood in order to kill any fungi present. Should the disease appear, spray at once as in field practice. For direction for field spraying see cucurbit spraying, p. 191.

Anthracnose 232, 297, ${ }^{542}$ (Colletotrichum lagenarium (Pers.) E. \& H.). - This disease was first noted in 1867 in Italy, and is now common in Europe and the United States, occurring on cucumber, muskmelon, watermelon, gourd, and a few other related plants. The loss is severe on the three crops first named, and is of more importance to cold-frame crops and crops under glass than to field crops, though it sometimes does cause almost total loss of the latter. Upon the leaf, circular, not angular, spots occur which, instead of 
yellowing, turn brown, die, and become ragged in appearance. Tendrils, buds, and petioles turn black and die. Upon the stems and fruit the spots are sunken and bear numerous acervuli. Its most conspicuous form is upon the fruit at any age, especially at maturity. Here very characteristic sunken spots with pink centers, much like the bean pod-spot, are produced. Upon old melons they do but slight injury, but to young fruit the attack is often fatal. A bitter taste is often imparted to the fruit. The disease is spread through the field by rain and surface drainage water, and winters in the field. It is probably carried to new fields by the seed.

Spraying with 4-4-50 Bordeaux mixture is recommended. Clean seed should be used, or the seed disinfected. It is also well to destroy infective refuse and to practice rotation.

Wilt ${ }^{216}$ (Fusarium vasinfectum Atk.) - The melon wilt not only destroys the growing crop, but prevents the successful culture of melons upon the field in question in succeeding years. It is less frequently met on the muskmelon than on watermelons. A similar wilt of squash is said to be caused by a different Fusarium. The wilt has spread rapidly during the past decade, and is now known from the Atlantic to the Pacific, and from the Gulf to Iowa.

The first symptom appears in the leaves which droop as though they were suffering from want of moisture. The leaves and runners wilt rapidly, and this is soon followed by the death of the entire plant.

Upon cutting the main tap root across near the surface of the ground, the wood presents a yellow color, making a distinct contrast with the white wood of the healthy plants. This one character, taken together with the wilted appearance of the vine, enables recognition of the true wilt. The further fact that a field once infested shows the same disease in succeeding years in the same or in extended areas is an additional recognition mark.

Its spread may occur in the ways mentioned under soil diseases and in particular through the use of infested manure. To restrict it to its present confines, crop rotation should 
be practiced and infested soil should not be replanted to melons until the wilt fungus is largely diminished in quantity. This will probably take more than four years, possibly eight or ten years, and even at the end of that time it is best to try a few hills before planting the whole field to melons. Cattle should not be allowed to pasture upon diseased vines and thus spread the wilt through manure.

The practice of raising cowpeas after melons leads to the presence of some melon vines in the cowpea hay, and this likewise leads to the presence of the causal fungus in the compost heap. Manure so exposed to infestation should never be placed on land which is still free from the germ, or which is to be used for melon culture, since this is certain to spread the wilt.

There is no objection to the use of stable manure which does not contain the fungus, but experience has shown that when the wilt once gains entrance to the compost heap or barnyard, it remains there for years, and all of the manure taken out of such a yard is likely to spread the disease. Hence it is exceedingly dangerous, in regions where the wilt prevails, to use any stable manure on the field where melons are to be planted.

Varieties resistant to this disease have been developed by the United States Department of Agriculture by crossing the citron, which possesses high resistance, with the watermelon, and then by practicing selection to attain the desired edibility.

Wilt ${ }^{340,} 540$ (Bacillus tracheiphilus EFS.). - The cucumber, muskmelon, pumpkin and squash are susceptible but not the watermelon.

The disease has been reported from many states - among them Nebraska, Wisconsin, Maryland, Massachusetts, Indiana - and is presumably present in many others.

The attack in first stages causes the vine to droop throughout its length. This is followed by death. The infection is spread by insects, particularly beetles on which the bacteria probably hibernate to some extent. 
Spraying with strong Bordeaux mixture, 4-5-50, with two pounds of lead arsenate powder added is recommended. Diseased vines should be pulled and burned, rotation practiced, and in general the suggestions given under soil diseases (p. 26) should be followed.

Timber-rot ${ }^{239}$ (Sclerotinia libertiana Fel.). - Upon cucumbers and other cucurbits under glass this disease oecasions serious loss. It is rare out-of-doors. The first indication is the appearance of a dense mass of white mycelium near the nodes of the stem which is still green. As the disease progresses the stem shrinks and yellows, the softer parts decay, and the stem finally dries up. In the interior of affected stems the white mycelium, and later near the nodes or in the external mycelial masses, smooth, slender, black sclerotia may be found. The germination of the sclerotia, described under lettuce drop (p. 197) results in immense numbers of spores. These falling upon dead tissues germinate and form a mycelium which attains such vigor as to enable it to attack healthy tissue and rapidly destroy it.

To control this disease all infected plants should be destroyed by fire before they have had opportunity to form sclerotia, and the places from which they are taken should be sprayed with a heavy application of some fungicide.

Leaf-blight ${ }^{217}$ (Alternaria brassicae (Berk.) Sace. var. nigrescens Pegl.). - Leaf-blight and downy-mildew are the most destructive diseases of the muskmelon in this country. In Florida, in some seasons, nearly the whole commercial crop is lost. Much damage has been reported from Ohio, Indiana, and Colorado.

Leaf-blight begins as small, round, brown spots usually marked by concentric rings. In the centers of these spots the hyphæ develop a moldlike growth. The spots enlarge to a centimeter or more, coalesce, dry, and cause the leaf to curl and shrivel at the margin. The petioles and veins are also affected. Ripening of the melons is hastened, but the quality is destroyed, the fruit becoming soft, wilted, insipid, and valueless. 


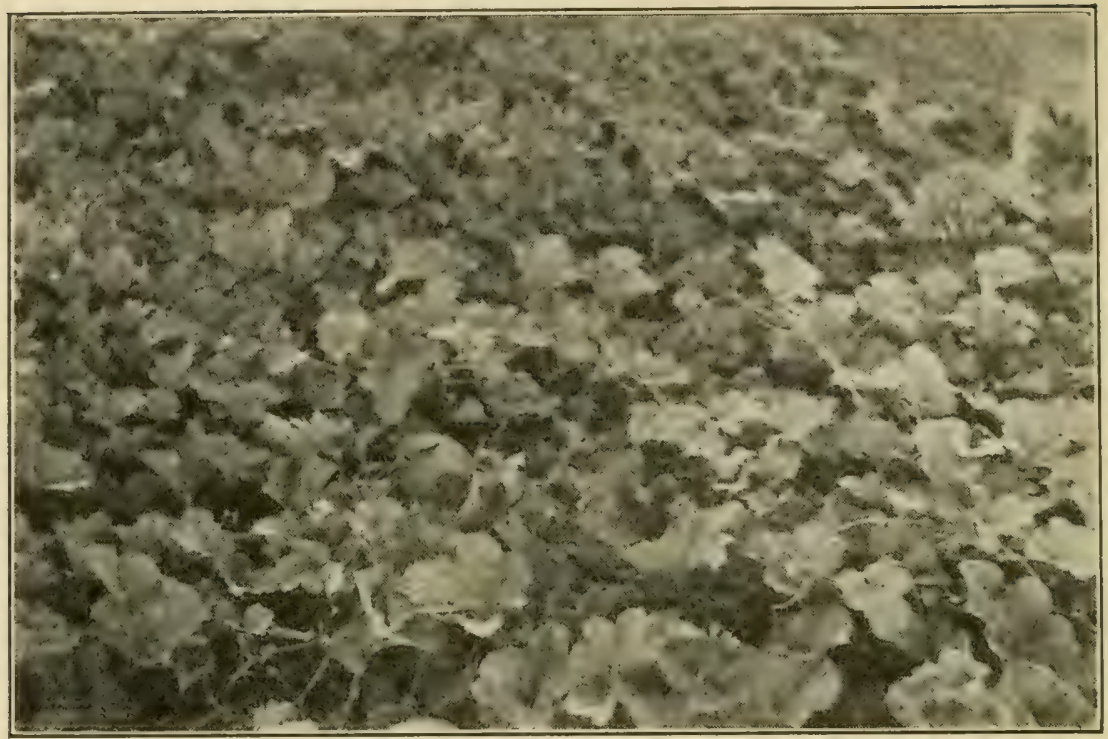

Fig. 99. - The Pollock muskmelon vines adjacent to those shown in Fig. 100, showing complete resistance to the leaf-blight. After Blinn.

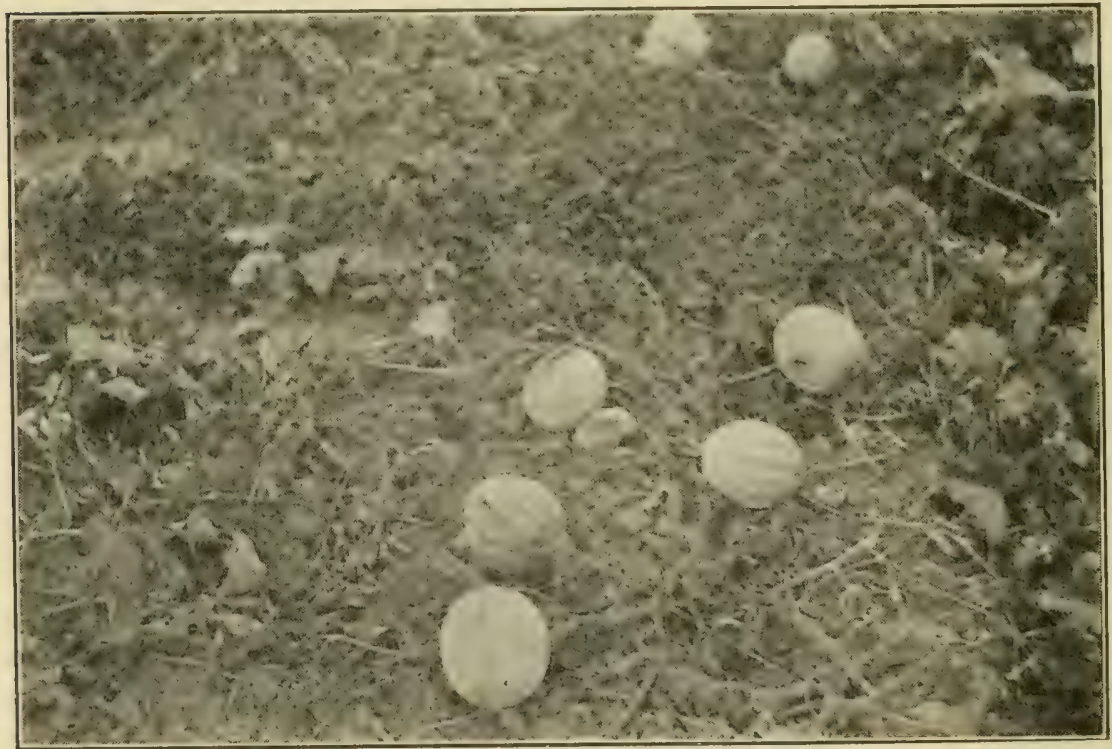

FIG. 100. - Muskmelon showing complete death of vines attacked by leaf-blight. After Blinn. 
If melons be repeatedly grown upon the same field, the disease increases year by year; hence rotation should be practiced, and resistant varieties should be used. A promising resistant variety has been reported by Blimn. Spraying as recommended for cucurbits generally is effective.

Southern-blight (Sclerotium rolfsii Sacc.). - A large percentage of the muskmelon and watermelon crops in the

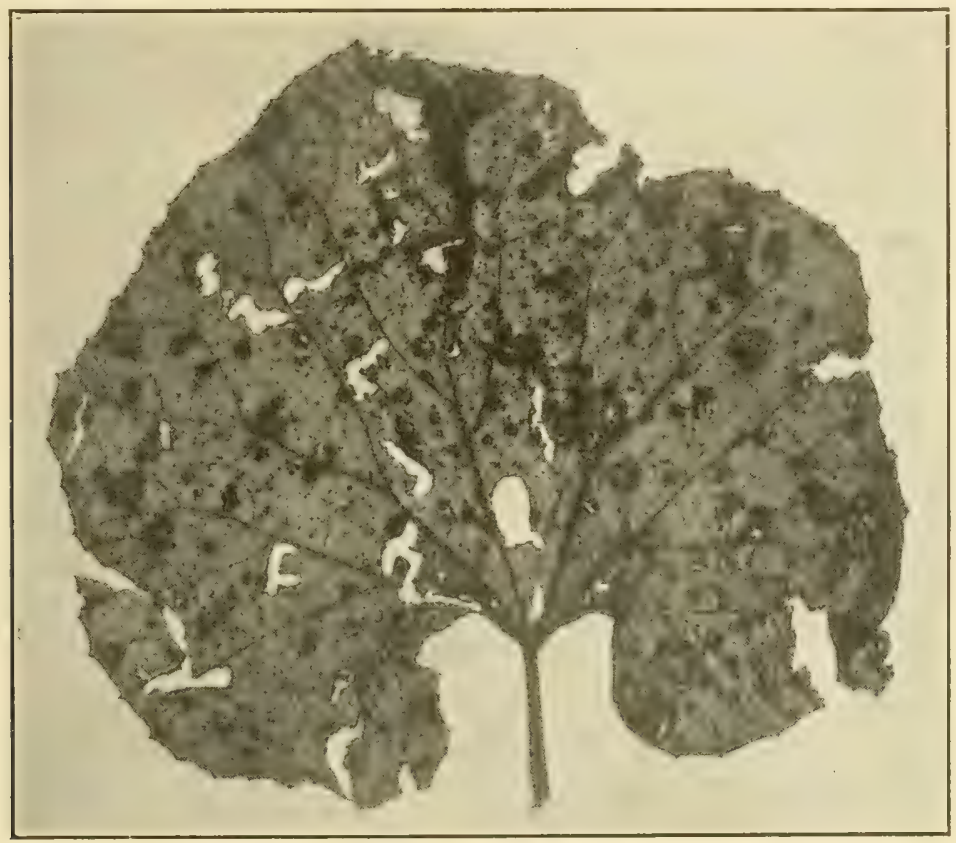

FIG. 101. - Muskmelon leaf spotted with downy-mildew. Original.

southernmost states is often destroyed by this disease. It is particularly noticeable on fruit upon the side touching the ground, first as a slight rot (ground-rot), followed by a white fringe of fungous threads which soon surround the whole fruit. Later sclerotia appear as small round bodies, dirty white to dark brown. For further description and treatment, see pepper.

Angular leaf-spot ${ }^{235,} 236,476$ (Pseudomonas lachrymans (S. $\&$ B.). - This disease is now known in many of the eastem 
and middle states, and causes large loss. Affected fruits rot into a soft, slimy, wet mass, this occurring often in transit. On the leaves dark, watery spots, $3-5 \mathrm{~mm}$. in diameter, appear. The spots later become dry and brown, and the brittle tissue usually falls away, leaving a ragged, irregular

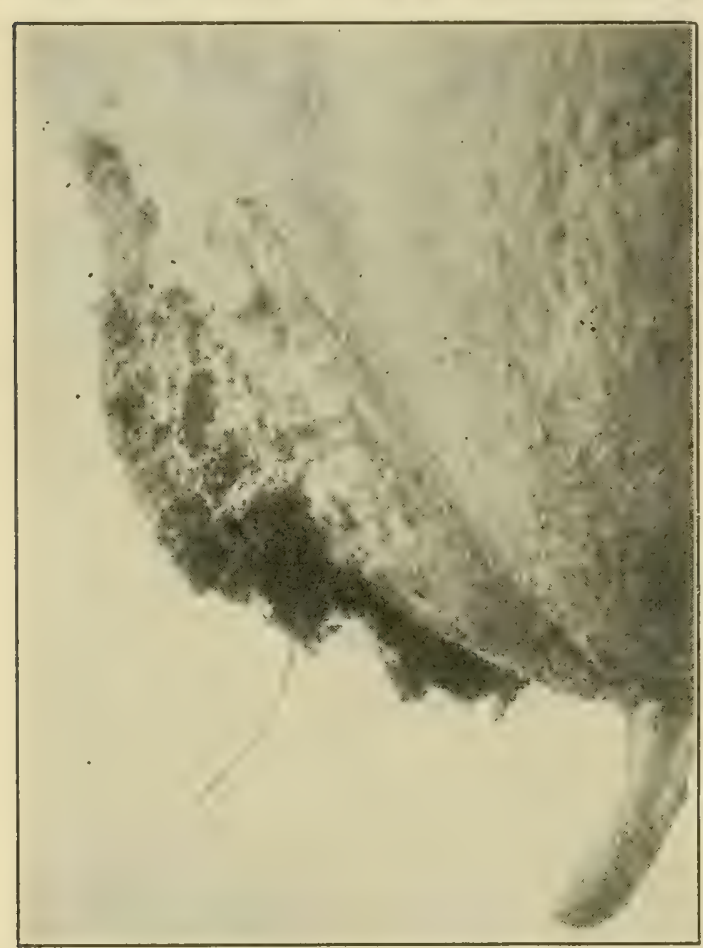

FIG. 102. - Sclerotium rolfsii Sace. growing upon a muskmelon at point of contact with the soil. After Hume. hole. Spots on the fruit are at first smail, 2-3 mm., and watery, and exude a gummy liquid which later dries to a white residue. Infection proceeds to the interior, and in a few days the central portion becomes a rotten mass. Young fruits are especially susceptible. Care should be taken in picking to avoid wounding the fruit, and all affected fruits should be most scrupulously sorted out of lots that are for shipment. The season's infection may originate either from diseased seed or from soil. The use of seeds treated with mercuric chlorid reduces infection.

Mosaic. ${ }^{237,} 238$ - Two mosaic diseases of cucurbits are: the White-pickle-mosaic, which affects many hosts, and the Mottled-leaf-mosaic, common to only a few hosts. The status of knowledge is much as in the case of other mosaics. See p. 258. Inoculations are readily made by rubbing. In the field, infection is carried by beetles and by the pickers. Experiments have shown 18 species in 10 genera of cucurbits 
to be susceptible, lout the disease is not identical with those of bean, tobaceo, tomato. Mosaic is regarded as the most serious disease of the cucumber in the Middle West, and it ranges from California to Virginia and Texas. Mosaic on squash and pumplin appears to be a distinct disease.

Powdery-mildew ${ }^{233}$ (Erysiphe polygoni DC.). - This mildew on cucurbits generally has the common characteristies of the powdery-mildews, a whitish flourlike coating upon the leaves and stems; at first in circular spots, but later diffuse. Its presence on cucumbers in America was first announced by Humphrey. It has since frequently been observed in the field and occasionally under glass.

The fungus appears chiefly upon the upper leaf surfaces and is most developed upon the older leaves. It renders the fruits bitter and distorts them. If it occurs in the greenhouse, flowers of sulfur applied to the hot water or steam pipes in the form of a paste is useful.

Stem-end-rot ${ }^{241}$ (Diplodia sp.). - In transit watermelons often shrivel and develop a wet, slimy rot, which may progress $11 / 2$ inches in a day. Many ears reach their destination with 75 to 95 per cent of their contents spoiled. In one day 100 cars showed an average of 25 per cent loss. Diseased refuse should be destroyed, clean culture and deep plowing practiced, and cutters in harvesting must avoid spreading the contagion. It is recommended that the freshly cut stem-end be coated with an antiseptic paste; hot water, $3 \frac{1}{2}$ qts., copper sulfate, $8 \mathrm{oz}$; add to starch paste, $4 \mathrm{oz}$. to $1 \mathrm{pt}$. of cold water.

Leaf-blight, fruit-spot ${ }^{234}$ (Cladosporium cucumerinum E. \& A.). - This spotting on cucumbers was first noted at Geneva, N. Y., in 1887, where it was so abundant as to ruin the pickle crop. It is occasional on melons.

The spots begin, when the fruit is only $2-5 \mathrm{~cm}$. long, as grav, slightly sunken areas with delicate, velvety surfaces. They are about $3 \mathrm{~mm}$. in diameter, but coalesce into irregular patches, particularly toward the flower end. As the spots age they darken to greenish black, and a gummy exudate often appears, 
Upon leaves, where injury is less common than upon the fruit, the spots are at first watery and translucent; later the leaf wilts, and is soon reduced to a decayed mass. The disease progresses so fast that a plant may be practically

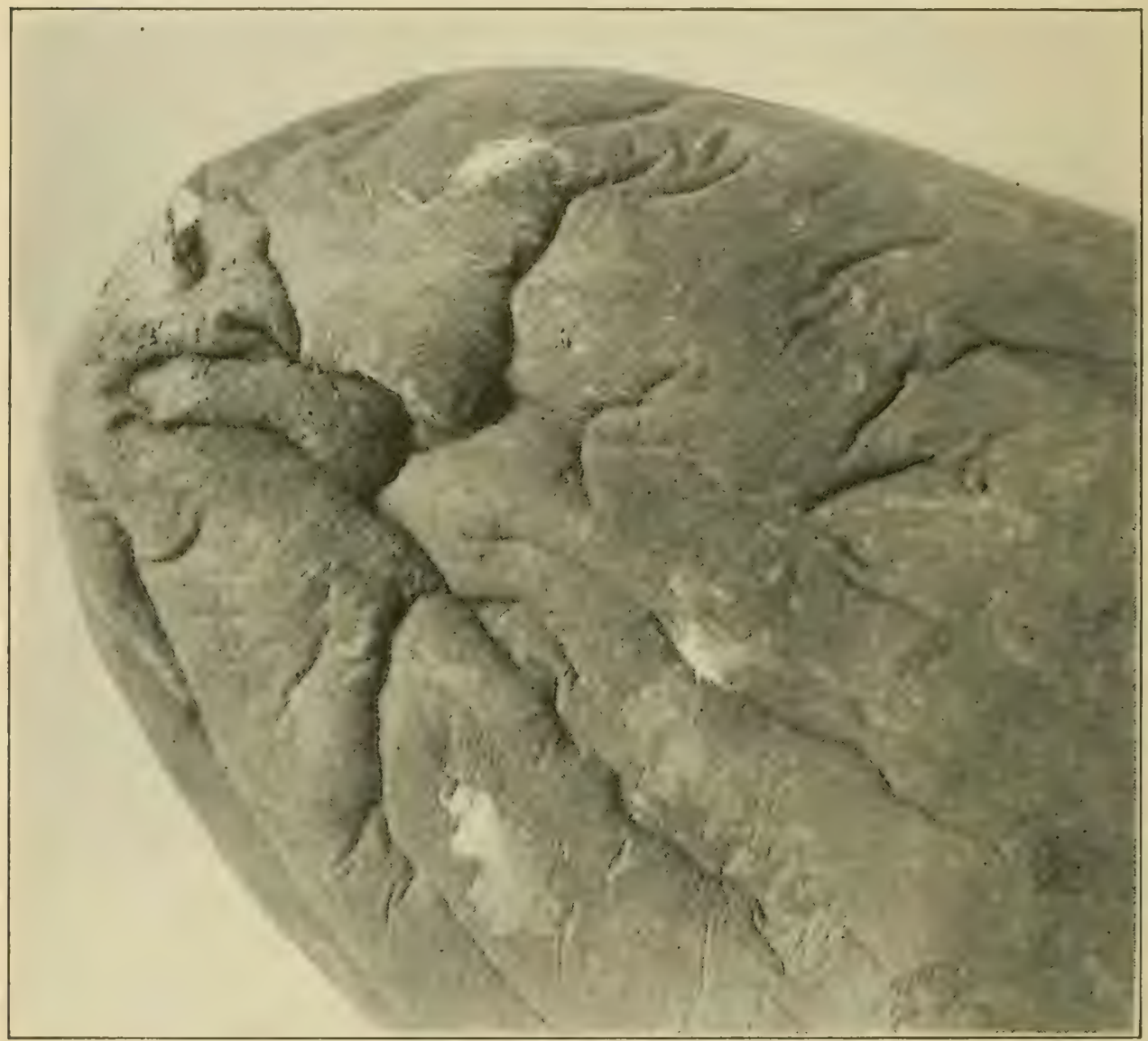

Fig. 103. - Part of watermelon with stem-end-rot. After Meier.

destroyed in a few days. Immediate and thorough spraying may be of service.

Soft-rot ${ }^{218,} 219$ (Bacillus melonis Giddl.). - This soft-rot was deseribed first by Giddings as causing 25 per cent loss of muskmelons in certain fields in Vermont in 1907. The decay usually begins on the lower side of the fruit, resulting in 
shrunken, diseased areas over which the skin remains unbroken. The flesh near the point of infection becomes completely decayed and has an offensive odor.

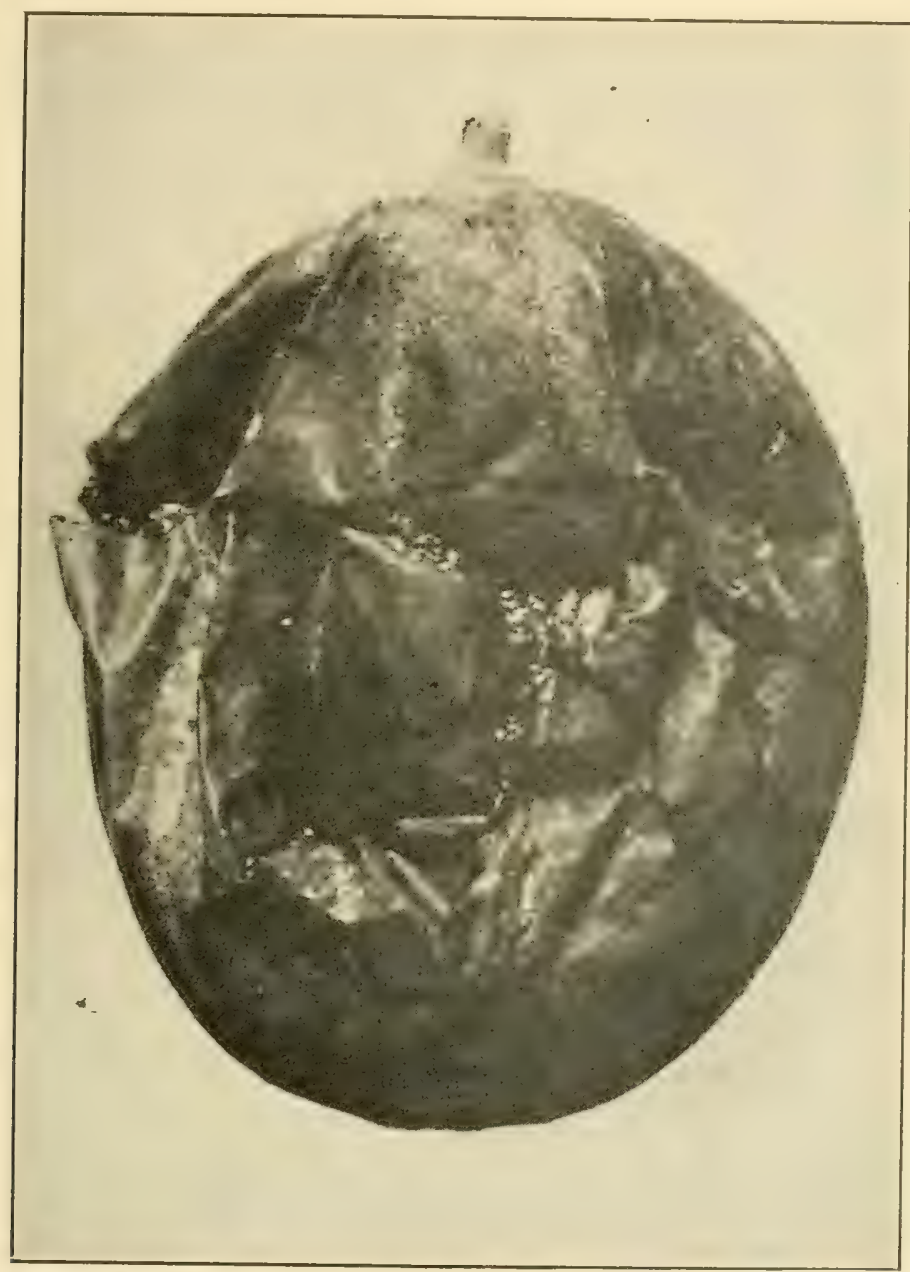

FIG. 104. - Muskmelon 65 hours after inoculation with Giddings' germ. After Giddings.

The cause is a bacillus which gains entrance through wounds, often through ruptures occasioned by excessively rapid growth. 
Spraying with Bordeaux mixture is recommended; also turning the melons so as to expose all sides to light and air.

Wilt ${ }^{220}$ (Mycosphcerella citrullina (Sm.) Gr., Diplodina).This wilt or canker seems to be rare, perhaps affecting to

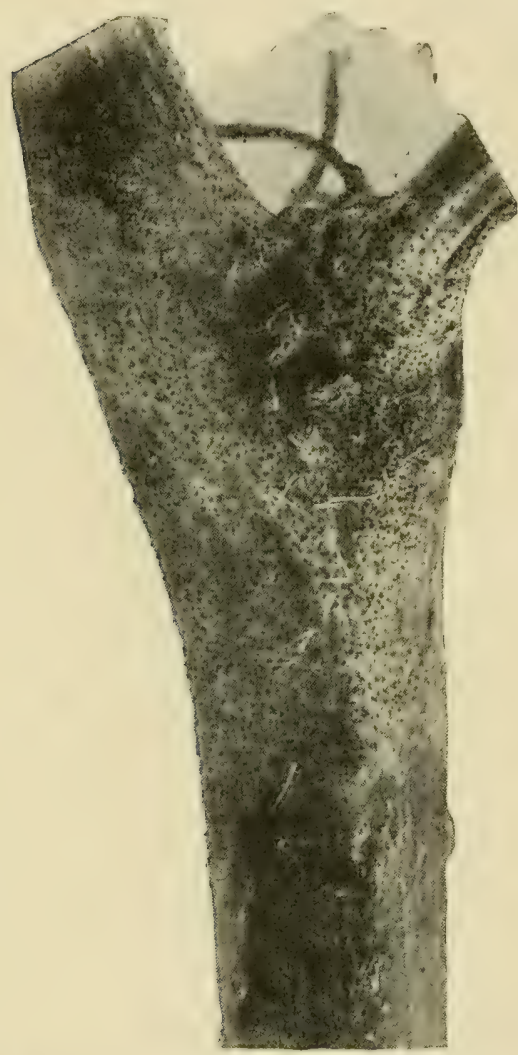

FIG. 105. - Portions of muskmelon vine showing pyenidia and perithecia of Mycosphærella. After Dorsey. serious extent greenhouse-grown muskmelons; only occasionally field muskmelons and other cucurbits.

Infection is local at the nodes in the leaf axil, never at internodes. The edges of the infected areas are "oily green" in color, often with resin-colored, gummy exudate. The older parts are either dark and gummy, or dry and gray, and bear many brown pycnidia.

Spraying with Bordeaux mixture after the plants are about half grown, but before the disease appears, and often enough thereafter to cover growing parts, is recommended.

\section{Minor diseases}

Leaf-spot (Phyllosticta cucurbitacearum Sacc.) on muskmelons has been destructive in several states, notably so in New Jersey and Ohio. The spots are light-colored and pycnidia appear in their centers.

A Leaf-spot ${ }^{242}$ (Stemphylium cucurbitacearum Osn.), 3-4 $\mathrm{mm}$. in diameter, circular or irregular in outline, visible from both sides of the leaf, with centers yellow-brown and red bordered, is reported from Indiana and Ohio as causing some loss. 
Two Cercospora leaf-spots also occur on cucumber and watermelon, and two Septoria leaf-spots on cucurbits generally.

Leaf-glaze ${ }^{239}$ (Acremonium sp.). - Shoots are stunted, fruits deformed, and leaves yellowed and killed. Upon the lower leaf surfaces a delicate white, glossy film like dried albumen is seen. Plants that are attacked may put forth new, vigorous shoots to survive for a time, then die. The disease has been known to reduce the yield 90 per cent. No treatment has been advocated.

Blossom-rot (Rhizopus nigricans Ehr., Choanephora cucurbitarum (B. \& Rav.) Thaxt.) spreads to the young squash, cucumber, or pumpkin, causing loss of the fruit by softrot.

Root-knot (nematodes). Of the cueurbits, the watermelon is very susceptible. Root-rot due to Thielavia is somewhat injurious.

\section{Cucurbit Spraying 240}

Planting should be at such distance as to facilitate machine spraying; that is, relatively close in the row, but with the rows wider apart than is usual in most sections of the country. In cultivating, the vines should be induced to spread along the row, and by the use of a vine turner a one-foot open alley may be maintained throughout the season for the wheels of the sprayer.

By means of a geared sprayer with proper length of axle to cover one row, three rows may be sprayed at one time. Particular attention must be given to reaching the under sides of the leaves with the spray. Spray first when the vines begin to run, using 3-6-50 Bordeaux mixture. For subsequent sprayings use 4-4-50 Bordeaux mixture at intervals of about ten days if the weather is dry; oftener, if growth is rapid. The net profits from this treatment have been as high as $\$ 163.50$ an acre. 


\section{EGGPLANT 243}

Wilt (Pseudomonas solanacearum). See tobacco.

Wilt (Nectria ipomoce Hals.). - Fields have been so attacked that scarcely a fruit was gathered. The affected plants when half grown take on a yellowish, sickly appearance, the foliage wilts, the lower part of the stem becomes coated with a whitish mold, and the plant usually dies. Numerous small, pink perithecia are found upon the stem just below, or at the surface of the ground.

This disease is close kin to the wilt of cotton, and what is said in that connection regarding treatment, applies here.

Another wilt due to a Colletotrichum is reported as the cause of large loss in Utah. A similar wilt due to Verticillium is also reported.

Leaf-spot (Phomopsis vexans (Sacc. \& Syd.) Hart.). Plants in the hotbed are subject to leaf-spot attack, the transplants dying, or it may appear later upon leaves and fruit, and result in more or less serious leaf injury.

Upon the leaf, large, irregular, brown or gray patches are produced. Here numerous black pyenidia appear, and later the leaf becomes torn. Upon the fruit the spots are at first soft and watery, but later become dry and leathery.

Treatment with Bordeaux mixture or ammoniacal copper carbonate before transplanting is recommended, followed by similar spraying in the field. Eight sprayings with Bordeaux mixture in one test yielded 100 fruits, while a similar plat, unsprayed, gave only about half as many. Clean culture should be followed.

Gray-mold (Botrytis fascicularis (Cda.) Sacc.). - In this rot the purple fruits show tan-colored blotches, followed by softening of the tissue and rapid development of a gray mold, the fruit in the meantime changing into a completely rotten mass.

\section{Minor diseases}

Anthracnose (Gloosporium melongence E. \& H.).- Pits appear upon the fruits, and in these the pink-tinted acervuli. 
Blue-mold (Penicillium sp.) is very similar to blue-mold on apples. Damping-off (Pythium debaryanum). - See p. 19. Southern-blight (Sclerotium) is common in the South; Corticium does some injury to roots and causes occasional fruit rot; Root-knot due to nematodes is common as is also Drop (Sclerotinialibertiana).

GARLIC. See onion.

\section{GINSENG ${ }^{244-246}$}

Blight (Alternaria panax Whet.). - Brown cankers upon the stem, and watery spots in the leaf, often involving the entire top of the plant, mark this disease. Badly blighted plants appear as if drenched with boiling water. It is a serious menace to the ginseng industry of New York state. The seed crop is sometimes completely lost.

It can be controlled by thorough spraying with 3-3-50 Bordeaux mixture as soon as the plants come up, repeated every other day during the first few weeks, less often later. Diseased refuse should be destroyed.

Wilt (Fusarium vasinfectum Atk.). - With the first symptom of attack the leaflets droop, yellow, and die; then the entire leaf dies to the base, dries up, and falls off. The immature seeds shrivel and fail to mature. Secondary decays, soft rots, may follow.

Methods of control suggested for watermelon wilt apply here also.

Stem anthracnose (Vermicularia dematium (Pers.) Fr.). Numerous black scars appear on the stems a few weeks after the plants come above ground. These spread and sometimes encircle the stems. The leaflets then brown. Often the plants fall over, even before they wilt. The greatest loss lies in the destruction of the seed crop.

Bordeaux mixture applied about three weeks after the plants appear in the spring and each three weeks thereafter, until August, more often if the season is wet, will control 
the disease. All dead stalks, leaves, etc., should be collected and burned in the fall.

Verticillium wilt (Verticillium albus (Preuss)). - This wilt is due to stoppage of the veins by fungous growth, and the chief symptom is wilting of the leaves, followed by death of the stem and leaves. Sections of the rootstock reveal a yellowing of the water ducts and veins, which contrasts strongly with the normal white of a healthy plant.

The disease is largely confined to the older, less vigorous roots. It is advisable to remove and dry the infected roots and to replace the soil of infested beds with new, healthy soil. Soil disinfection should be enployed if practicable.

Black-rot (Sclerotinia smilacina Dur.). - Black, warty sclerotia upon the root indicate this disease. The roots are very black, but upon drying, bleach somewhat. In old age this blackening may extend to the center of the root, which becomes wet, spongy, and pliable. The disease remains in the soil some years after infestation. Sick roots should be removed and burned if not marketable. Treat also as for wilt.

Soft-rot. - This rot occurs widely and causes large loss. The root decays rapidly, is sticky and ill smelling. The leaves turn red and yellow and soon die. A rot ${ }^{247}$ due to Phytophthora cactorum (C. \& L.) Schr. is reported as causing a loss of 20 per cent in some beds in New York. Damping-off (Corticium) is largely prevented by thorough ventilation, and the avoidance of excess of moisture in soil and air. Stirring the soil to hasten drying, aids. See p. 19. Leaf-anthracnose (Pestalozzia funerea, Desm.) is destructive to young plants. It appears as a black, velvety growth at the bases of the leaves and flower stalks, causing them to die and fall off. Spray as for blight. Thielavia-root-rot (Thielavia basicola) is especially harmful to seedlings, resulting in sudden wilting, which causes them to bend over and dry up. The fine roots are affected as are the roots of tobacco. Dark brown, dry lesions are also produced on the roots by a Ramularia. 
Sclerotinia white-rot (Sclerotinia libertiana) occurs to some extent (see lettuce). Root-knot (nematodes) and Southern blight (Sclerotium rolfsii) are also common.

\section{GOLDENSEAL (Hydrastis)}

Botrytis-blight. This is the most common and widely distributed disease of this plant. Ten to 20 per cent of the tops are reported affected in New York, Michigan, and Wisconsin.

Blight (Alternaria sp.). - Spots oceur upon the leaves. The disease seems to be identical with that of ginseng.

\section{HOP}

Powdery-mildew (Sphorotheca humuli (DC.) Burr.). Powdery-mildew, while serious in many parts of Europe, has been seen but rarely on the hop in America, and has seldom been reported as seriously injurious. It is recognized by the usual characters of the powdery-mildews. See grape. If it should become troublesome, spraying with Bordeaux mixture or ammoniacal copper carbonate must be practiced.

Leaf-spot (Cylindrosporium humuli E. \& E.). - Small, rusty brown, angular leaf-spots largely limited by the veins are present. They show most clearly upon the lower sides of the leaves. Minute black acervuli are present. The clisease has been reported from several states, but has not been regarded as serious.

\section{HORSE-RADISH}

Leaf-blight (Septoria armoracice Sace. and Ascochyta armoracice Fel.). - Ruin is occasionally brought to a crop by these diseases. The leaves bear numerous circular spots, blanched in the center and pale yellow at their borders. Pycnidia are borne in the centers of the spots. Budly affected leaves turn yellow and become filled with holes caused by the dropping of the dead tissue of the spots. 
Leaf-spots (Ramularia armoraciœ Fel. and Cercospora armoracio Sacc.). - These spots are much like those of leafblight except that no pycnidia are present.

Black-mold (Macrosporium herculeum E. \& M.). - In late summer circular, blanched, and later black, moldy leafspots are prevalent. The injury is not sufficient to warrant treatment.

White-rust (Albugo candida) and Downy-mildew (Peronospora). - These diseases are the same as upon cabbage. They are often present but usually insignificant upon horseradish. Root-rot due to Thielavia also occurs.

KALE and KOHL-RABI. See cabbage.

\section{LETTUCE 251}

Drop ${ }^{248}$ (Sclerotinia libertiana Fcl.). - The outer lower leaves wilt, droop, and fall flat upon the ground; a similar fate rapidly overtakes the inner leaves, and so on over the whole plant, until within a few days the entire plant is dead, lying flat upon the ground, appearing much as though scalded by hot water. The disease progresses with wonderful rapidity, the plants appearing to die in a day.

Upon the under sides and at the bases of the leaves occur, at this time, dense, cotton-like growths of mycelium, and in later stages, small, irregular black bodies, the sclerotia, which vary from $3-10 \mathrm{~mm}$. long, somewhat less in thickness. The sclerotia and the mycelium are unmistakable signs of this disease.

Drop was first definitely recognized in America in 1900, though it doubtless did much damage before then. It has since then followed the rapidly extending lettuce industry into many states and is particularly destructive in the South Atlantic seaboard states from Virginia to Florida, where its inroads upon the crop grown under cover are especially damaging. The causal fungus may persist from year to year, as sclerotia, in beds once infested - beds cost- 
ing originally often $\$ 1000$ per acre - and thus destroy their value for lettuce culture. The damage is thus much more than injury wrought merely to the current crop.

The sclerotia, when favorably situated, are capable of germination, each producing several trumpet-shaped organs (Fig. 106), with stems about $15 \mathrm{~mm}$. long and disks 3-8 $\mathrm{mm}$. or less in diameter. Spores, capable of initiating the fungous growth upon dead or sick lettuce tissue, issue in great numbers from these disks, and from material thus infested the fungus can make its way into the healthy lettuce plant.

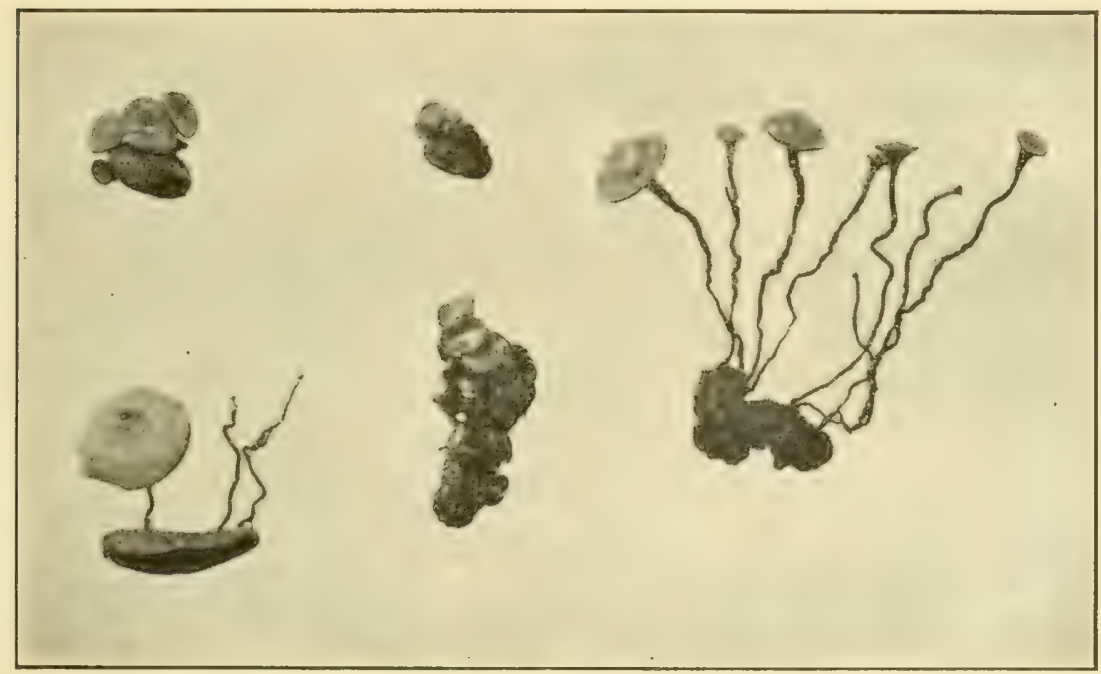

FIG. 106. - Selerotia of Selerotinia from lettuce germinating.

If all infected plants be pulled and burned as soon as the first indication of dlisease is observed, the formation of sclerotia will be prevented. As an additional precaution it is well to spray the areas occupied by diseased plants thoroughly with Bordeaux mixture or bluestone solution.

A few years of such procedure will much reduce the infection or perhaps eliminate it entirely. All lettuce trash should be removed from the beds, since it serves as the initial point of attack for the fungus. Crowers whose land is free from the disease should guard against its introduction 
upon diseased refuse in any form. Compost which may be contaminated with lettuce refuse bearing this disease should be avoided. Those growing lettuce under glass have found soil disinfection effective and practicable.

\section{Damping-off. See p. 19.}

Gray-mold (Botrytis cinerea Pers.). - Gray-mold is essentially a leaf disease, beginning usually at the leaf edges, and there causing wilted, flaceid patches which soon become coated with a straw-colored downy fuzz, the sporiferous hyphæ. The whole leaf, ordinarily an outer one, may droop and die.

Weak plants may succumb entirely to such attack, the disease passing slowly from the outer to the inner leaves. In all cases after the death of the affected parts a characteristic, brownish, fuzzy coating appears. This disease may be distinguished from drop by the absence of the white mycelium and selerotia, and by the presence of the gray Botrytis growth, which is not a feature of drop. The two diseases, while often occurring separate, may both infest the same beds or the same plants. Gray-mold may also cause damping-off.

High temperature, lack of ventilation, and lack of vigor in the plant, resulting from improper care, are conditions favorable to attack of gray-mold. Precaution with respect to these details is sufficient to insure against serious loss.

Rosette (Corticium vagum). - A moist rot sets in, first upon portions of leaves which touch the ground, and spreads thence throughout the leaves, rotting away the blades but leaving the midribs standing, thus distinguishing this from all other discases. Infection proceeds from leaf to leaf at point of contact, often reaching the center of the head, while the outer leaves are infected only in spots. The inner leaves may all be reduced to a slimy mass though the outer leaves still remain, surromding it as a rosette.

Downy-mildew (Bremia lactuce Regel). - This occasionally destructive mildew shows the character of the downy milclews, $i$. e., downy fuzz below, yellow spots above 
(see grape). It is frequently reported as causing much loss to lettuce under glass, especially upon the older leaves. It is also noted upon old leaves on seed plants of both cultivated and wild lettuce.

Close attention to proper cultural conditions in the greenhouse, especially as to moisture, ventilation, and temperature, usually suffice to hold it in check. Evaporated sulfur also aids in suppressing the mildew.

Bacterial rots ${ }^{25: 9}$ (Pseudomonas sps.). - Several different rots due to bacteria oceur upon this host. In some instances the head rots at the center, or at the top. In other cases leaves may become spotted with large brown or black areas, or shriveled, or give way to a soft rot, or the tips of the heart leaves may die. In other instances, small translucent leaf spots occur; extending and coalescing, they occupy large areas, the affected tissues becoming dry and papery.

Various species of Pseudomonas, associated with these rots have been considered causal agents, but predisposing conditions, as extreme cold, or other unfavorable conditions of temperature, ventilation, or nutriment seem to be necessary to enable these bacteria to gain entrance into the plant.

Leaf-perforation, anthracnose ${ }^{249}$ (Marssonina panattoniana (Berl.) Magn.). - The most conspicuous character is perforation resulting from the fall of the tissue killed by the attacking fungus. These perforations are from 1-2 mm., or more, in diameter, with irregular horders. Upon the midrib and petiole depressed spots result. With small, young leaves dwarfing and distortion is produced, especially at the apex. The disease appears to be limited to greenhouses and to be spread largely by watering.

It was first described by Selby in Ohio in 1896 and has since been noted in several other states, ranging from the Atlantic to the Pacific, and in Europe. Diseased lettuce should be burned. Watering by overhead systems leads to a minimum of infection.

Blight (Septoria lactuce Pass. and Septoria consimilis E. \& M.). - Upon the old, outer head-leaves there often appear 
numerous, black pycnidia, so small as to remain unnoticed unless by special search. The injury is usually insignificant, though some dwarfing and curling of the leaf results. Upon seed plants these same diseases attack the leaves with greater vigor, causing pale brown, discolored areas and the death of the older leaves. Sometimes, through neglect to destroy plants of the seed bed, these diseases may gain such foothold as to cause injury in other beds. This can usually he avoided hy destruction of the seed-bed plants as soon as transplanting is over.

Root-knot (nematodes) occurs on lettuce, doing some damage.

MANGOLD and MANGEL WURZEL. See beet.

MELON. See cucumber.

\section{MUSHROOM}

Mold ${ }^{252}$ (Mycogone perniciosa Magn.). - Though noted in Germany as early as 1887 this disease was not called to attention in America until 1909.

French experts detect the disease first in the spawn as an abnormal, white, fluffy growth. Later the mycelium of the mushroom fails to develop normally, but instead produces monstrous soft glowths. Whole clumps develop into moldy masses, which soon putrify with a disagreeable odor.

Infested heds or houses may be abandoned or cleaned thoroughly, then fumigated with formalin, 3 pints. per 1000 cubic feet of space.

Bacterial-spotting. ${ }^{254}$ Small areas, pale yellow to brown, on cap, stipe, or gills, or even covering the whole plant, occur. Fumigating the beds with sulfur before planting has given excellent results.

MUSKMELON. See cucumber. 


\section{OKRA}

Wilts ${ }^{253}$ (Fusarium rasinfectum Atk., Terticillium alboatrum R. \& B.). - Two wilts of okra, macroscopically indistinguishable from each other, oceur; both partake of the general character of wilts discussed elsewhere, pp. 26, 253.

Pod-spot (Ascochyta abelmoschi Hart.) is reported from New York and Maryland, and a Leaf-spot (Cercospora) from Porto Rico. Texas-root-rot (Ozonium) is injurious in the Gulf states.

\section{ONION, GARLIC, CHIVE ${ }^{550}$}

Smut ${ }^{255-257}$ (Urocystis cepulce Frost). - As with the wilt of tobaceo and cotton, this fungus resiles in the soil and is therefore destructive not only to the present crop, but is also prohibitive of successful culture of susceptible crops in the future.

The smut, which seems to have originated upon a wild variety of onion, occur's in both Europe and America. It was known in Connecticut as early as 1860, Massachusetts, Pennsylvania, and ()hio in 1889, later in New York, New Jersey, and Delaware, and has since been recorded from Iowa and Georgia. The first mention of serious loss by onion smut in America was in 1870. Its inroads upon the crop are often such as to prohibit profitable onion culture unless preventive measures are taken against the disease.

The smut attacks the very young seedlings through the still tender, delicate leaf sheaths. Onions grown from sets are immune, and onions from seed, if they pass the very young state without infection, are so protected by hardening of the outer plant parts as to resist attack, even if the bulb is surrounded by thoroughly infested soil.

Upon the infected seedling leaves, dark, opaque spots may be noted, especially upon holding the leaves against the light. The portions of the leaf above such spots soon die, and the spots rupture, exposing sooty, powdery masses. Badly infected seedlings succumb early, while others may sur- 
vive until harvest. The disease is more often fatal if attended by dry weather, which reduces the vigor of the host plant.

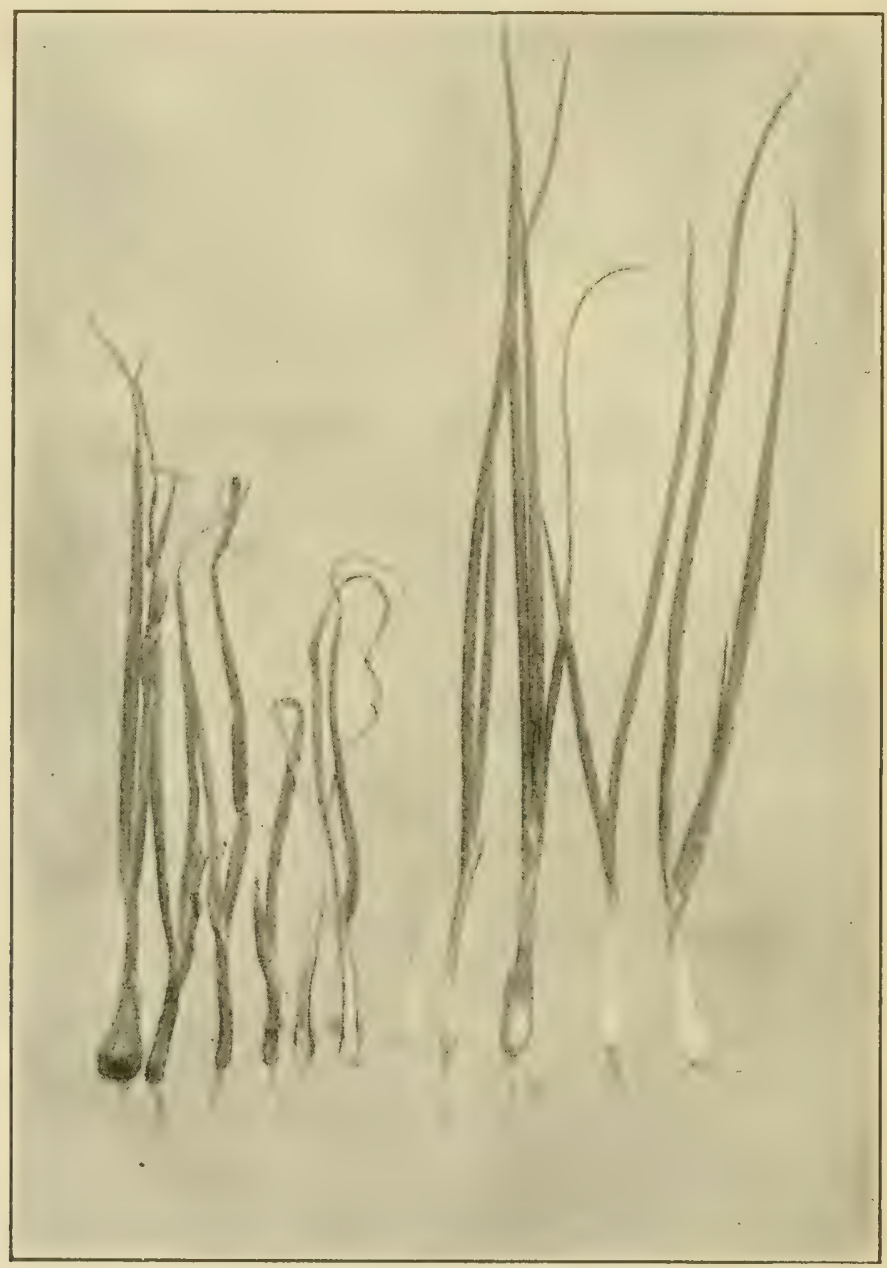

FIG. 107. - Young onion plants showing effect of smut. At left, smutted plants; at right, healthy plants of the same age. After Hinman.

Plants surviving the disease show smut in the outer leaves, often also within. Diseased bulbs dry up and rot. In handling they may readily be distinguished from sound bulbs. The spores are liberated freely in the soil, where they 


\section{Vegetable and Field Crops}

may remain alive for many years. The disease may be carried to adjacent ficlds by insects, also by the means suggested under soil discases. There is little or $n$ danger of disease carriage by the seed.

Since onion sets are immune, the effects of the smut can be avoided by sowing seed in soil that is free of disease and then transplanting into the field. With this mode of onion culture the only difficulty is to secure plats free from infestation, and this is not often a serious one. In extreme cases disinfection of the soil in plats may be resorted to. (See soil disinfection, p. 460.) On farms once infested all refuse (screenings, tops of infected sets) should be collected and burned to reduce the amount of spores. Where soil, known to be infested, is to be planted, formalin ( 1 ounce in 1 gallon of water) should be used and applied with a drip attachment on a seed drill in the proportion of one gallon of solution for each 1200 linear feet of row.

Ground quicklime or stone lime, better the former, applied at the rate of 75 to 125 bushels per acre on the freshly prepared soil just before seeding, has been useful. If applied by drill, harrowing will not be required; if broadeast, harrowing should preecele planting. One hundred pounds of sulfur mixed with fifty pounds of air-slaked lime applied in the drills is also effective.

These methods used separately or combined are sufficiently established to warrant general use on smutted soils devoted to onion culture.

Downy-mildew, ${ }^{258,}{ }^{259}$ blight (Peronospora schleideni Ung.). - Close kin to the disastrous blight of potatoes, this disease partakes of many of its characters, particularly in the rapidity of its spread through an infested field. It may first be noted on a small area of the field in which the tips appear as though dashed with scalding water. Often under favorable climatic conditions the affected areas increase many fold in a single night, carrying complete destruction.

It was first described in 1841 by Berkeley as "common and destructive," and has long been known to onion growers 
in this country, in Europe, and in Bermuda. In the latter place it was so injurious that the legislature applied to the

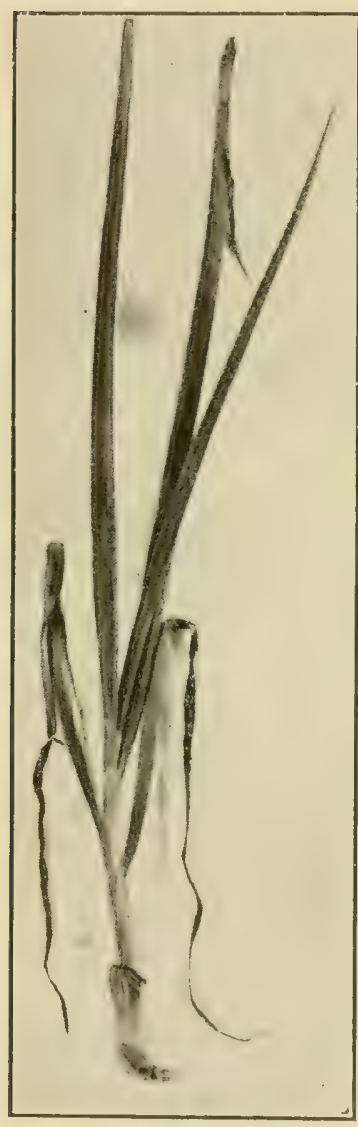

FIG. 108. - Onion plant illustrating manner of death of leaves affected with downy-mildew. After Whetzel. mother country for investigation and aid. The first reference to it in the United States was in 1872 . It is now reported from coast to coast.

The blight was described fully by Thaxter in 1889, again by Whetzel in 1904 , during which latter year it was particularly destructive in New York, causing a loss of half the yield, even more in some instances.

The attack in the field occurs first upon a few plants during warm, damp weather. Examined while the dew is still present, these plants, seen from considerable distance, display a peculiar violet tint especially easy to discern through the dewy covering. Close examination shows the affected part to be covered with a fuzzy coating. On the second day these parts lose their green color, turn pale, or even yellow. On the third or fourth day the plant is entirely collapsed.

The diseased spots in the field may each cover an area of only a few feet in diameter, enlarging slowly. If the weather favors the fungus, the disease may sweep rapidly across the whole field. Affected plants, under suitable weather conditions, brilliant, dry atmosphere, recover slowly, putting out new leaves. Subsequent attacks may occur if the weather favor's the growth of the fungus. The injury from this disease is through the loss of leaf surface, thus reducing the growing power of the plant. Usually little or 
no increase in the size of the bulb oc'urs after a severe attack.

To prevent the spread of the disease, and to lessen the danger from subsequent attacks, a spray of Bordeaux mixture, 5-5-50, should be applied as soon as the disease is noticed. Careful supervision and spraying to check renewed attacks of the fungus, particularly if the weather continues to favor its development, should not be neglected. New growth should also be protected by the use of Bordeaux mixture.

Infection in previous years warrants spraying before the disease appears; also throughout the scason, reaching all sides of the leaf with the fine spray and using high pressure to make the mixture adhere to the smooth onion leaves. Wet lands are more subject to this disease and should be avoided if possible. It is recommended to rake and burn the dead tops, to destroy the infective spores within them, and to practice crop rotation.

Black-spot ${ }^{481}$ (Cleistothecopsis circinans, S. \& T., Tolutella, also known as Vermicularia and Colletotrichum). The outer scales of the bulb) after harvest often show black growths of peculiar and striking character. They consist of central, black dots or very small rings, around which from one to several larger rings are arranged concentrically. Under moist conditions these markings enlarge rapidly by the production of more rings or wavy lines, or, under some circumstances, the whole area may be overgrown with black. Later the disease may extend through the outer bulb scale and into the next and succeeding layer's to considerable depth, causing rot.

While the disease is not conspicuous before harvest, it is really present in the incipient stage upon the bulbs in the field and continues to develop rapidly under storage conditions. Here it may pass to new bulbs by contact or by air currents. These dangers are much augmented by a moist atmosphere. While the growth is not retarded appreciably by this disease, the value of the onion is often 
much reduced by the disfiguring spot, and the loss from rot induced by it is also considerable.

Onions before they are placed in storage should be well dried. Storage bins with good ventilation, so arranged as to prevent all heating or sweating of the bulbs, should be provided. No infected bulbs should be stored, since they will carry infection to the sound bulbs. Bins that

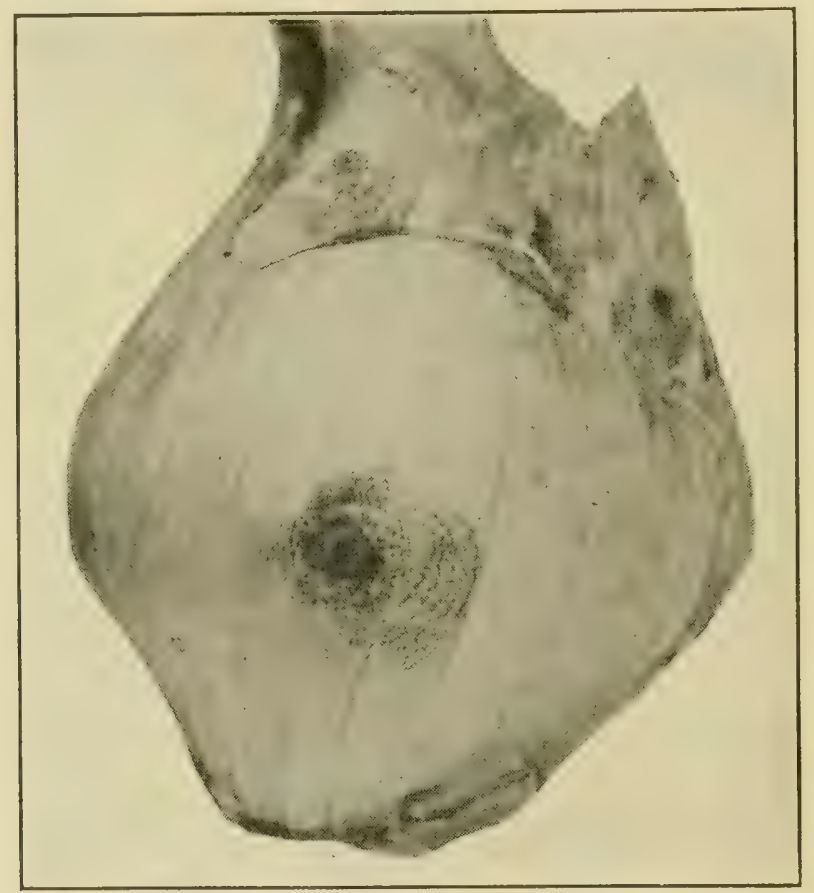

Fig. 109. - Black-spot on onion. Original.

are known to be infested, $i$. e., which held infected onions in any preceding year, should be disinfected by a thorough spraying with Bordeaux mixture or plain bluestone solution. The white varieties of onions are much less resistant than the red and yellow kinds.

Neck-rot ${ }^{261}$ (Botrytis allii Munn). - This rot is generally distributed in onion sections of the United States and Europe, and causes heavy losses to stored onions as well as to crops in 
the field. The neck of the onion, where the top has been cut off, is coated with a fuzzy, pale brown or gray mold, and later

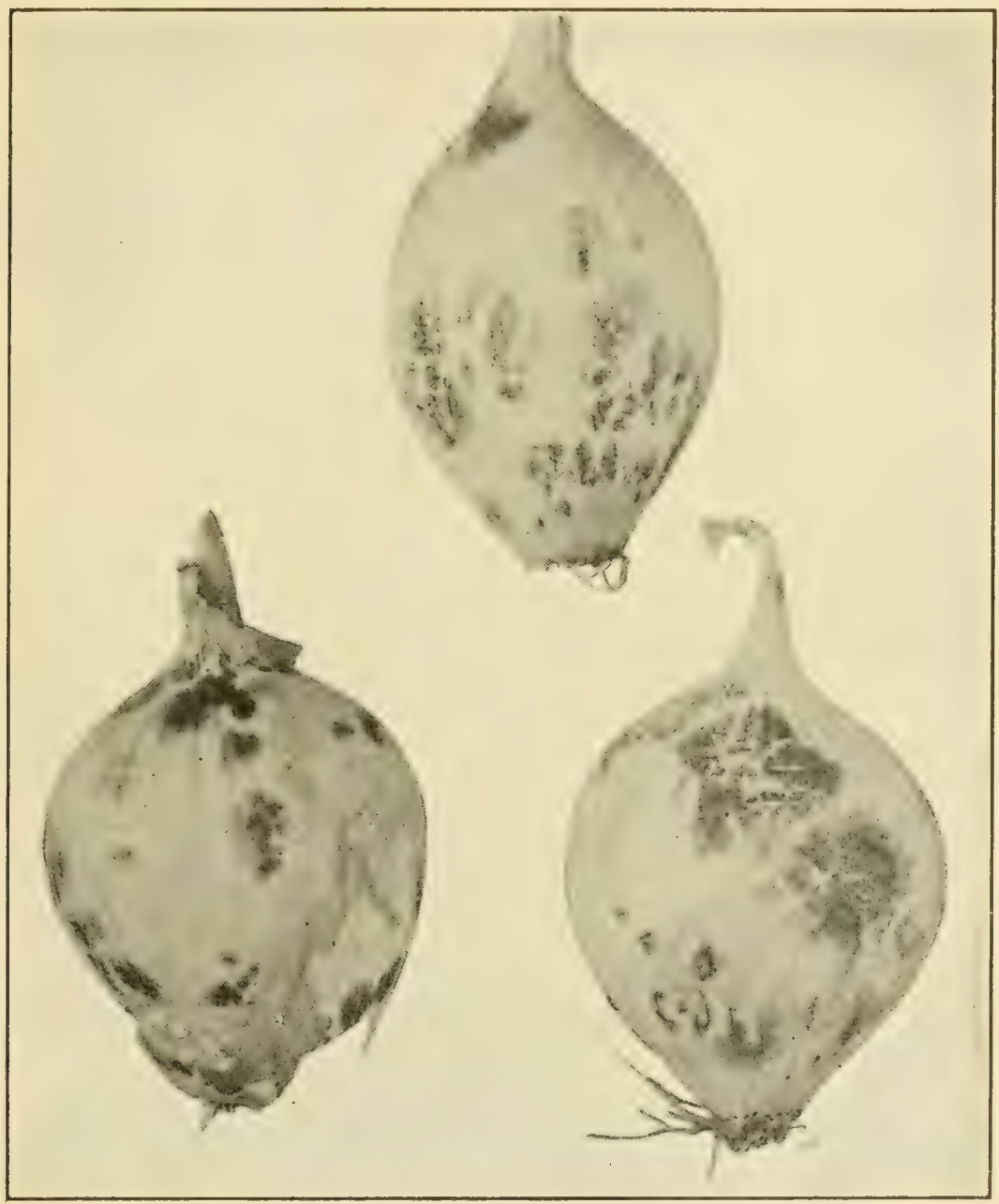

FIG. 110. - Black-spot showing variation. Original.

this area bears few or many black sclerotia. The mold occurs also in water-soaked spots on leaves and seed heads.

Diseased bulbs should never be set out. All diseased refuse should be destroyed. The crop must be thoroughly cured and dry before storage. 
Soft-rot ${ }^{260}$ (Bacillus carotovorus). - This soft-rot, first noted in New York in 1898, is a common cause of loss of onions. In many fields, one-third to one-half of the crop is

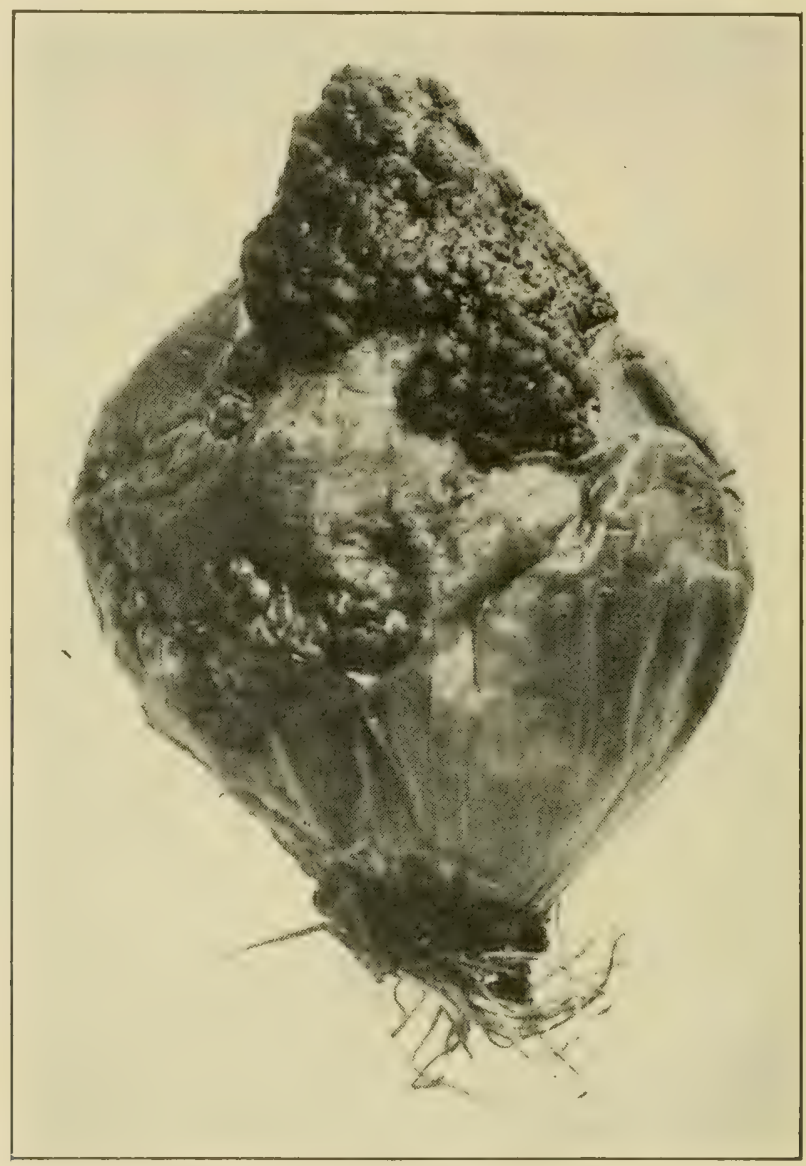

FIG. 111. - Botrytis sclerotia at necks of bulbs. After Munn.

destroyed, and the balance of the crop injured by the presence of the rot.

Frequently a single leaf scale of an otherwise sound onion is entirely rotten, or again several scales may be rotted. If the outer scale is rotted, the bulbs are designated by the growers as "slippery onions." The rot does not spread from 

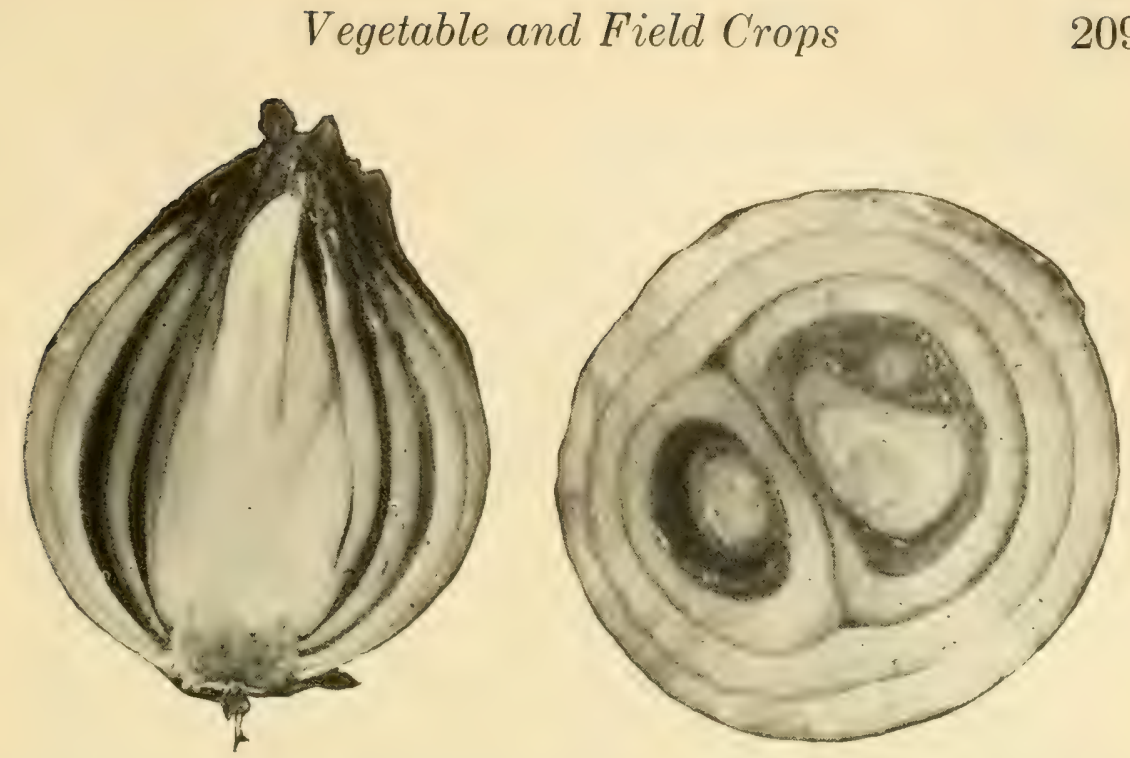

FJG. 112. - Onions affected with soft-rot; longitudinal and cross seĉtion. After Stewart.

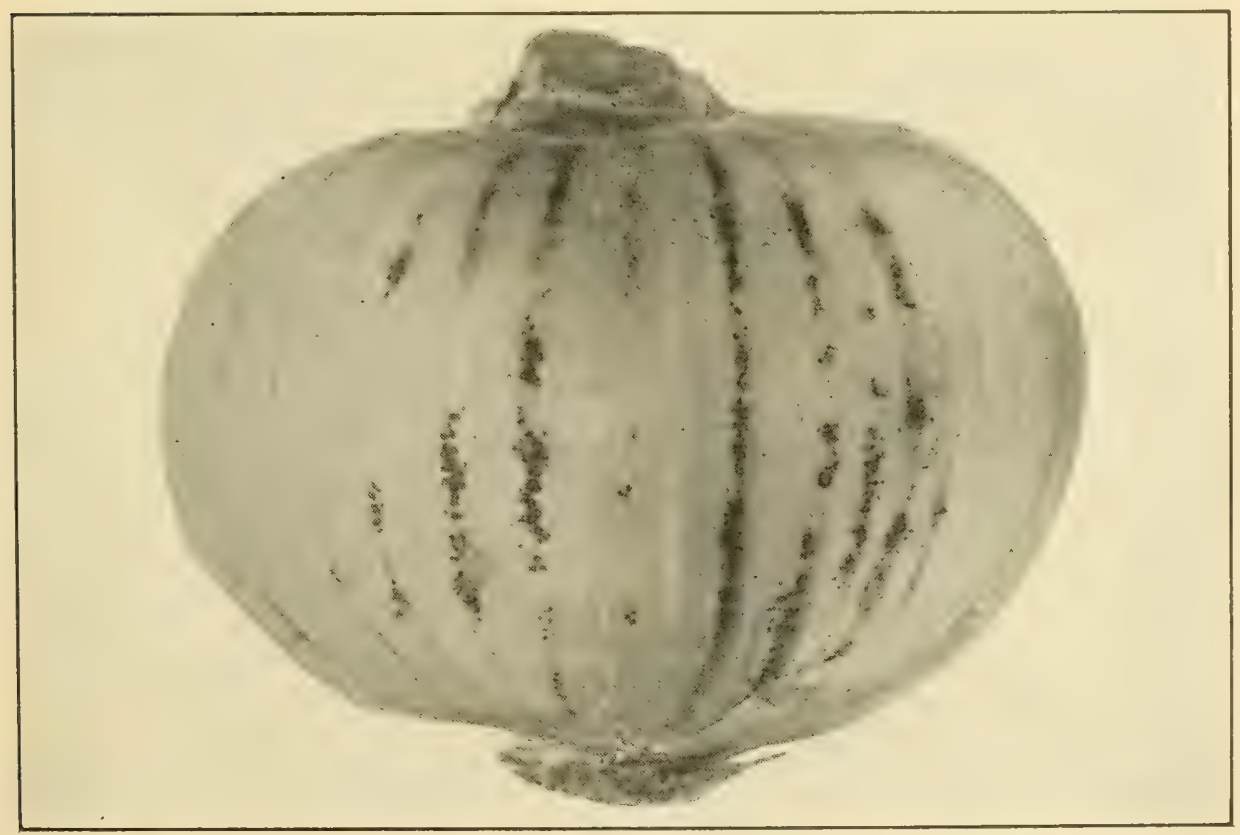

FIG. 113, - Black-mold due to Sterigmatocystis. Original. 
scale to scale within the bulb. In dry onions in storage its progress is slow, but wet onions decay rapidly. The only suggestion toward control is to keep onions dry in storage.

\section{Minor diseases}

Black-mold (Macrosporium parasiticum Thüm. and $M$. porri Ell.). - Frequently onion leaves that have been injured assume a velvety, black coating, which often appears in spots, or covers them entirely. Treatment against other diseases, and maintenance of the plants in full vigor is of most service in this case. Another cause of black-mold ${ }^{262}$ is Sterigmatocystis nigra $\mathrm{v}$. Tiegh. It most commonly appears forming dark masses of spores, resembling a smut, under the outer scales of the bulb. In this form, the injury is due only to unsightliness. Frequently, however, the fungus grows into the lower scales of the onion, causing a slimy, soft rot. It is not essentially a ficld disease, but one of chief importance during storage. Sanitary measures to prevent the development of the mold on refuse in the field are advised. Infested sacks, crates, bins, etc., should be disinfected. Pink-root ${ }^{263}$ (Fusarium malli Taub.). - The affected roots turn yellow, later pink, then dry up. New roots that develop also become diseased. The bulbs are dwarfed. The loss sometimes is as great as 40 per cent of the crop. The infection comes from the soil, and the general remarks under soil diseases (p. 26) apply here. Two rusts occur, Puccinia porri (Sow.) Wint. on the chive, P. allii DC. on onions.

PARSLEY. See celery.

PARSNIP. See celery.

\section{PEA}

Spot ${ }^{264}$ (Mycosphcerella pinodes Berik \& Blox., Ascochyta). - Spotting of pea leaves and pods has been known to 
farmers for many years. It is most conspicuous upon the pods as circular, somewhat sunken spots, $3-6 \mathrm{~mm}$. in diameter, which are dark bordered, pale in the centers, or, when ma-

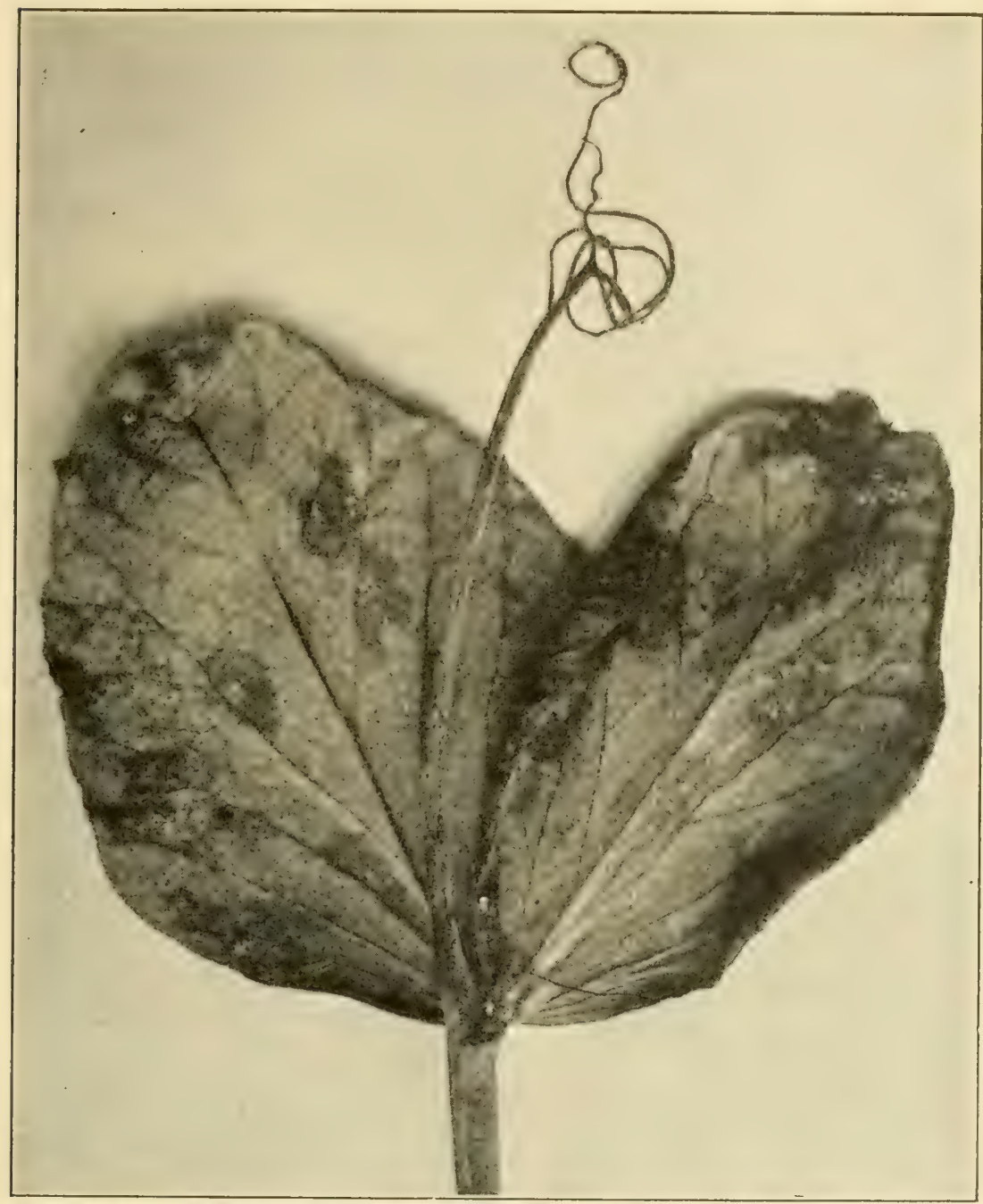

FIg. 114. - Pea leaves showing the spot disease. After van Hook.

ture, somewhat pink. In these spots numerous pyenidia are visible and under favorable conditions the spore masses issuing from them may be seen with the naked eye. Upon 
the leaves, similar oval spots, $3-10 \mathrm{~mm}$. in diameter, with the pycnidia usually in concentric circles, are abundant. The lower, older leaves are affected first, resulting in their
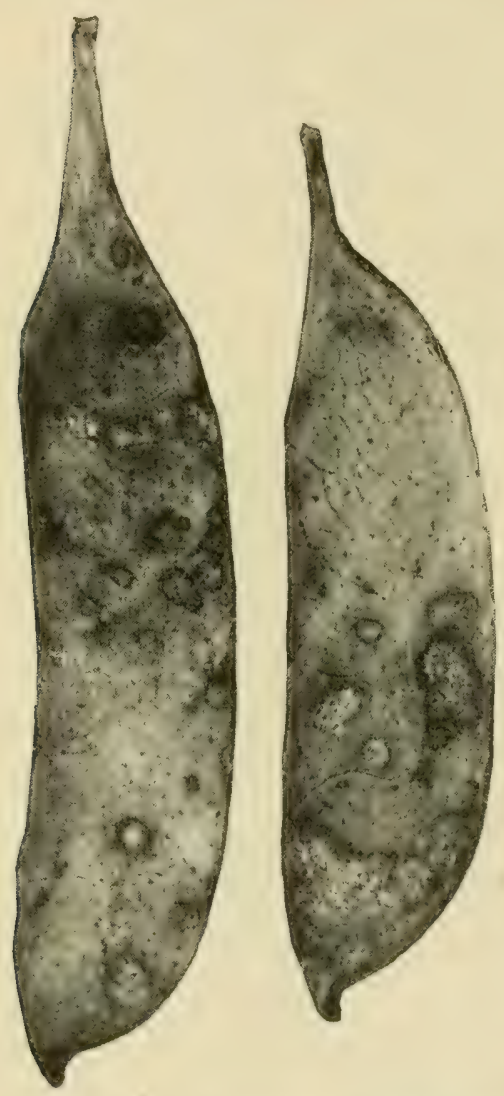

FIG. 115. - Spotted pods of French June field pea. After van Hook. death. The younger leaves die later. Stems are subject to the same attack - first near the ground, later upon all parts; the spots often penetrating through the woody part, thus causing wilting and death of the parts beyond. The stem attack is the most serious form, since it directly causes death to a large part of the plant. This is especially true if the disease be followed by dry weather.

All forms of the disease tend to decrease the yield in proportion to their prevalence. Plants not killed before flowering may develop pods, though of lessened yield.

Disease upon the pod may penetrate completely through it and appear upon the opposite side, or more frequently it may grow into the seed within the pod. Seeds badly diseased in this manner adhere to the pod; if less affected, they thresh out, are shrunken, and show, according to the color of the variety, more or less discolored spots. Often seeds are diseased, and yet so slightly disfigured as to escape observation.

Trial has demonstrated that of badly infested seeds only 6 per cent are capable of germination, and that even when they do germinate, the resulting plants seldom reach ma- 
turity. On young plants the disease often assumes the character of damping-off.

Aside from the pea this disease attacks alfalfa, bean, and hairy veteh. It was a grave menace in Europe in 1894, in Canada in 1903, in ()hio in 1904. In New York, in 1906, from 50 to 80 per cent of the crop was injured.

Two years' rotation in nonsusceptible crops lessens the evil. Diseased seed should be avoided.

Bacterial-blight ${ }^{26.5}$ (Pseudomonas pisi Sack.). - The stems are discolored, watery, olive-green to olive-hrown; the leaflets and stipules appear bruised and yollow. The disease is known in Colorado, Nebraska, Dakota, and Utah, and in severe outbreaks has been known to kill 30 per eent of the plants.

Wilt (Fusarium sps.). - Two wilts, both due to Fusarium, have been described. They agree esisentially with the description under cowpea.

\section{Minor diseases}

Powdery-mildew (Erysiphe polygoni Dr'.) develops most. conspicuously late in the season, and sometimes becomes so injurious that the plants do not mature seeel. Though it is not usually very destructive, 20 per ent injury has been reported from (Ohio; 33 per eent from some parts of Nebraska. The fungus hibernates in seed derived from affected pods. Such seed should not be used for planting. Liver of sulfur or Bordeaux mixture is effective in the field.

Black-mold (Pleospora pisi (Sow.) Fcl.). - Frequently moldy, black spots are noted upon pea pods, leaves, or other parts. This condition is chiefly a secondary disease following some other injury.

Stem-rot (Corticium ragum) is somewhat injurious, as is also the Root-rot (Thielavia), and Root-knot (nematodes).

Damping-off. See p. 19.

Rust is rare on pea. See bean. 


\section{PEANUT}

Leaf-spot (Cercospora personata (B. \& C.) Ell.). - This leaf-spot is circular in outline, indefinitely bordered, black to brown in the center and grading to green on its outer edge. The lower leaves are first affected and suffer most; later the disease spreads to the upper leaves. The leaves

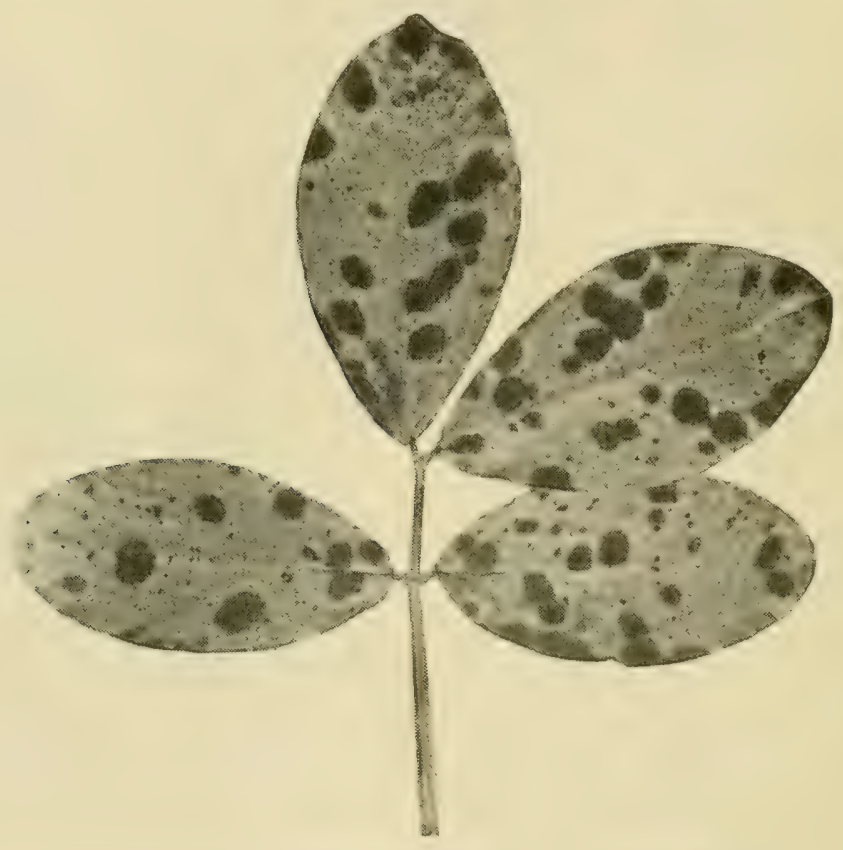

Fig. 116. - Peanut leaf-spot. After Wolf.

begin to fall soon after they spot, and in many cases the death of the plant results. It is often a pest. The causal fungus was first collected in Carolina and Alabama by Ravenel.

Southern-blight (Sclerotium rolfsii) does some damage. (See pp. 23, 215.) The true rust (Uredo arachidis Lag.) is injurious in the sub-tropies. Red-rot of the pods, characterized by brown discoloration and the presence of red perithecia (Neocosmospora) is of slight importance. 


\section{PEPPER}

Southern-blight, wilt ${ }^{1 \text { is }}$ (Sclerotium rolfsii Sacc.). - Blight shows itself first hy a slight drooping of the leaf tips by day,

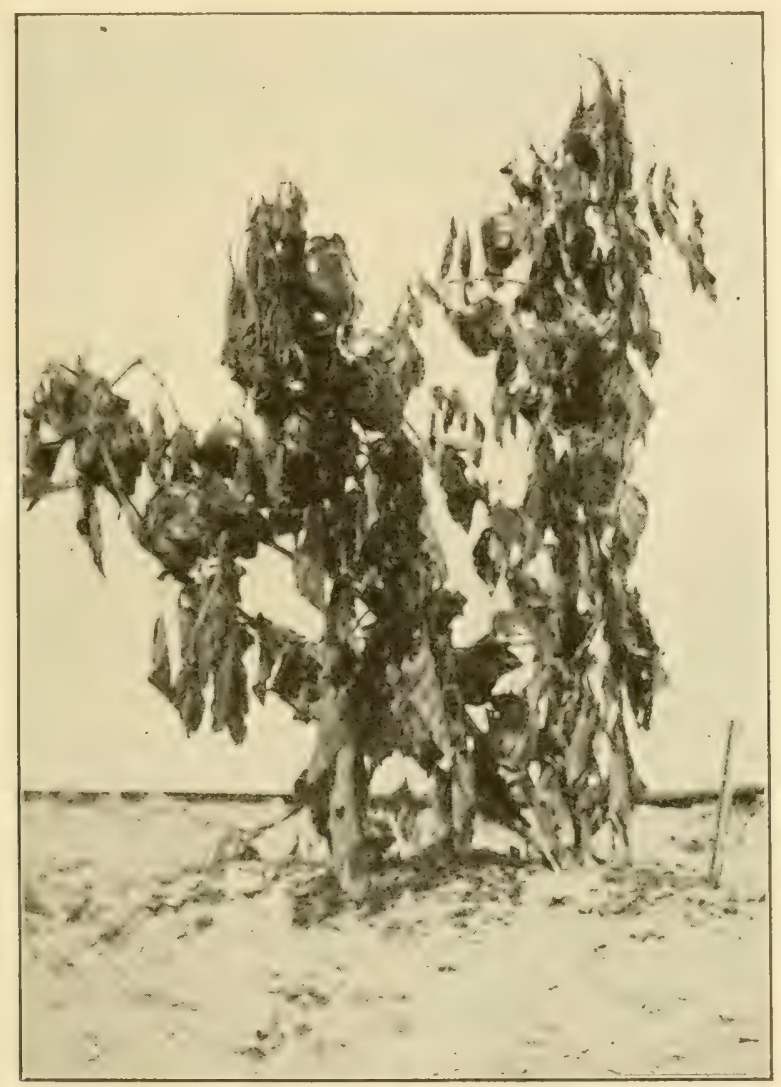

FIG. 117. - Pepper plant showing effects of the Southern-blight. After Fulton.

followed by night recovery. The wilt becomes more pronounced on succeeding days until in the third or fourth day the leaves wilt permanently, lose color, dry, and soon fall. These stages may succeed each other so rapidly as to appear almost simultaneous. The roots appear normal; but on the stem near the ground are found shrunken, dis- 
colored areas in the bark, often extending part of the way around the stem. Later the roots may rot from secondary causes.

Upon the diseased spots are fine mycelial strands, especially abundant under humid conditions. Soon these strands

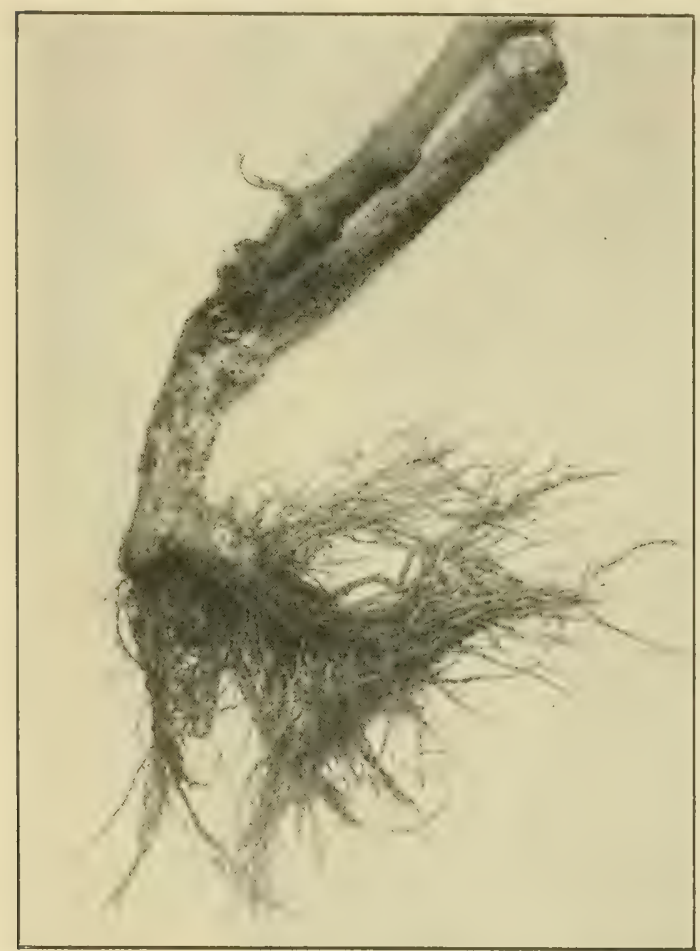

FIG. 118. - Pepner plant showing fungus of Southern-blight. After Fulton. unite into tufts, which round off, become hard and smooth, and change from white to yellow, and finally to dark brown. These bodies, the sclerotia, are about as large as mustard seeds. Attacks usually begin when the pods are forming and continue throughout the season. This disease has been found in many Southern states upon a wide range of plants. See p. 23.

The application of a clear, preventive fungicide, such as ammoniacal copper carbonate, to the ground at the base of the plant, and where any part touches the ground, so that it can soak into the ground near by and cover the stem itself, has proved beneficial. The first application should be marle at the earliest sign of blight, or still better, in anticipation of it, and should be followed by other applications at intervals of two to three weeks. Bordeaux mixture is not suitable, since the effective material is filtered out by the soil.

Black-mold (Macrosporium sp.). - This malady renders 
the fruit moldy and black, particularly at the blossom end. It is one of the most destructive of pepper diseases.

\section{Minor diseases}

Anthracnose (Glomerella piperata (E. \& E.) S. \& S., Glooosporium). - Soft, circular, pale, sunken spots upon the fruit accompanied by small, ruptured spots in the skin, through which the pink spore masses protrude, indicate this disease. Anthracnose due to Colletotrichum nigrum E. \& H. is of similar appearance except that the centers of the soft spots change to a decided black as they age. Mosaic similar to that of tobaceo is often present. Black-spot, caused by Alternaria entering through wounds due to sun-seald or frost, sometimes injures 45 per cent of the fruits. A Fruitrot is caused by Sclerotium botuticola Taub. Leaf-spot (Phyllosticta sp.) shows small, circular spots of ashen color, bearing pycnidia. ()ther diseases are: Leaf-spot (Cercospora capsici H. \& W.), Soft-rot (bacteria), Root-knot (nematodes).

\section{POTATO}

Late-blight 266-271, 342 (Phytophthora infestans (Mont.) De Bary). - In the year 1889 Lamson-ticribner, writing of this, the most serious potato disease, sairl, "It prevails in all potato countries of the world, and "auses more clamage to the potato than all other injuries combined." It is possible that all that he regarded as blight would not to-clay be included under late-blight; still the disease holds its place as one of the most destructive plant diseases of the world.

It is estimated that in New York state alone the blight caused a loss of $\$ 10,000,000$ in 1912 , and the total loss in the United States in 1917 is placed at 24,000,000 bushels. The loss reported in one year from Ohio was $\$ 2,000,000$; from Wisconsin $\$ 5,000,000$. The blight is supposed to have originated in South Ameriea and to have been brought to this country about 1840 .

The disease may appear on any part of the leaf, but the 
spots generally show first near the tip or margin, probably because surface water remains longer on these parts. The diseased area soon blackens and dies. The diseased part may temporarily dry out and curl up if the progress of the fungus is checked by drought, or the blight may, in rainy weather, rapidly proceed to transform the entire foliage into a moist,

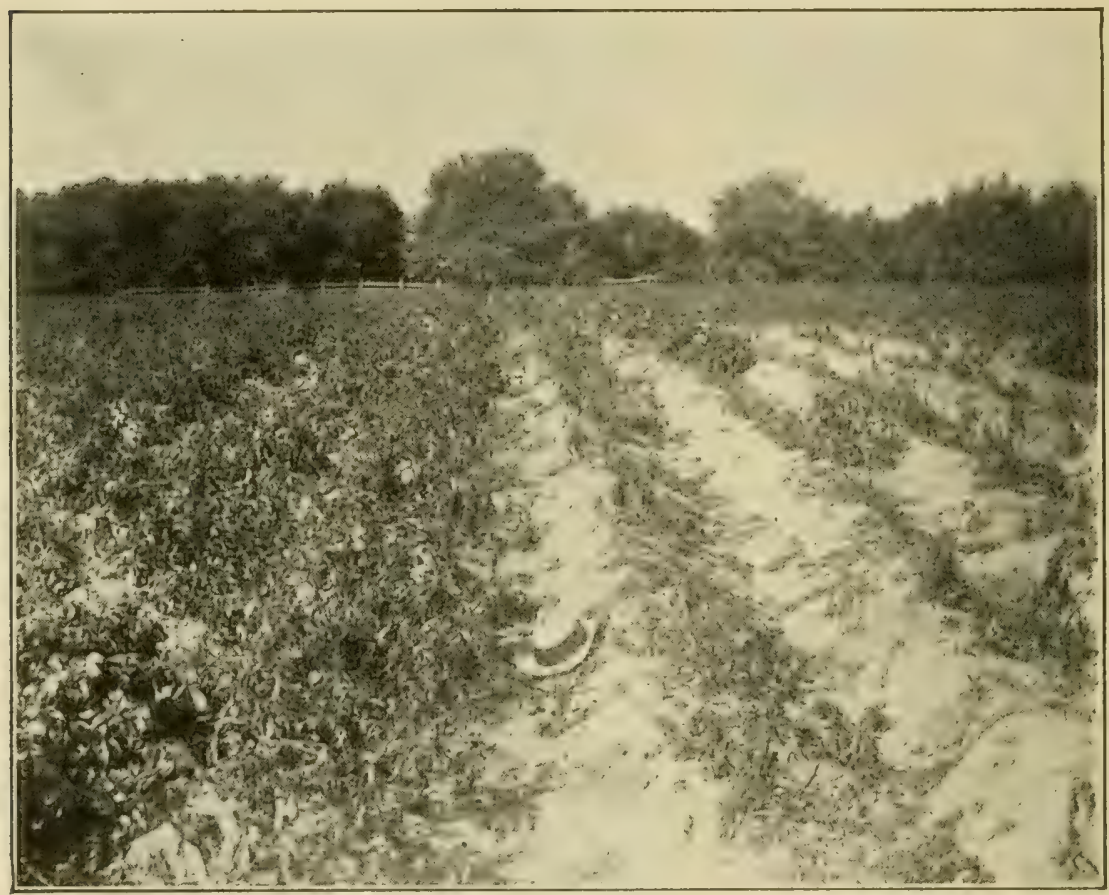

FIG. 119. - Potato late-blight. Rows at left sprayed with Bordeaux mixture and Paris green; rows at right received Paris green only. Original.

putrid mass. In the earlier stage the blackened part is bordered by a narrow region of light green, characterized by a slightly watery, flaccid appearance. Under conditions of especially humid atmosphere a fine, white down may be seen upon the more recently invaded parts. This affection of the leaves is accompanied by an offensive odor discernible at considerable distance from the field. The disease usually soon shows on the stems also, which in turn blacken and die. 
On the surface of the tuber slightly depressed, darkcolored areas appear while internally the normal white color changes to dirty brown. If the soil is dry, dry rot results; if wet, the tubers decay as wet, slimy, ill-smelling masses. In storage the disease continues, and the loss sustained in the field may be greatly augmented.

This blight is closely dependent upon conditions of heat and moisture. A daily mean of $22^{\circ}$ to $23^{\circ} \mathrm{C}$. $\left(72^{\circ}-74^{\circ} \mathrm{F}\right.$.) accompanied by moist weather conduces to its spread. A daily mean temperature above $25^{\circ} \mathrm{C}$. $\left(77^{\circ} \mathrm{F}\right.$.) for a few days retards its development.

Although the ronspicuous signs above noted first attract the attention of the general observer, the disease really commences as soon as the sprouts appear. Young plants grown from infected seed remain dwarfed, assume a reddish brown color, and when proper weather conditions obtain, furnish the spores to start the general attack.

Marked difference in rexistance exists among varieties. Thus in Maine the Rust-proof showed the highest resistance, about 1 per eent of disease, while no other varieties tried gave less than 30 per eent of disease. Of the standard crop varieties the following are reputed to possess some degree of resistance: Carmen No. 3, Sir Walter Raleigh, Rural New Yorker No. 2, Rural Blush, Green Mountain, State of Maine, Delaware, Enormous, and White Beauty.

Field trials have shown that certain German and English varieties are more highly resistant than the American varieties. It is a hopeful sign, therefore, that American potato breeders are now giving attention to disease resistance and that new varieties of greater excellence in this respect may be expected in the future.

Healthy potatoes only should be used for seed. Diseased potatoes may be recognized by their reddish brown surface color, which extends toward the center of the potato; also by the slight shrinking of the surface in such parts, or by the spotting described above.

The crop should be sprayed as recommended under the 
general heading, p. 236. Though the disease may not develop annually in severe form, splaying is necessary each year as a preventive measure. Sinee the blight develops rapidly, it is quite impracticable to wait for signs of the discase before spraying is hegun. Moreover, experiments extending over several years have shown that even in years when the blight

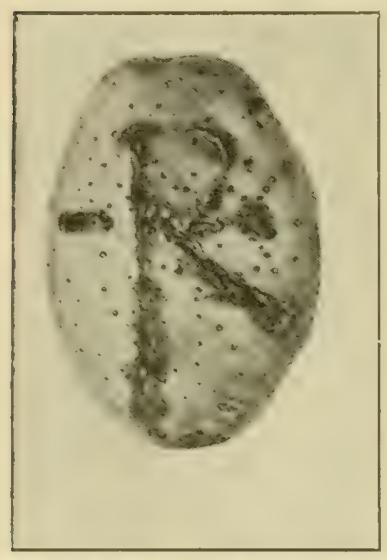

Fig. 120. - Common scab produced by inoculation forming monogram R. T. After Thaxter. does not become epidemic, sufficient benefit is derived from spraying to warrant its adoption.

The Geneva Experiment Station says: "Judging from the experiments thus far made, it appears that spraying for blight is an operation which no potato grower in New York can afford to neglect. Forty-eight farmers' business experiments show an average net profit of $\$ 20.51$ per acre due to spraying."

(commence splaying with Bordeaux mixture when plants are 6 to 8 inches high and repeat at intervals of ten to fourteen days throughout the season, making, in all, five or six applications. When bugs or flea beetles are numerous, add Paris green or other poison. In case the tops have blighted, the danger of tuber infection and consequent rot is lessened by delaying the harvest of the tubers until at least a week or ten days after the death of the foliage.

Common-scab ${ }^{272-274}$ (A ctinomycesscubies (Thaxt.) Güss.) Seal) prevails in Europe, Africa, New Zealand, in all parts of the United States, and probahly wherever the potato is grown. It was first attributed to its proper cause by Thaxter in 1890 .

Common-scah) is recognized by all potato growers as a characteristic rough pitting of the tuhers. If potatoes are attacked when quite young, the scahs are deep; if the attack is later, they are more shallow. In severe cases the tuber is 
furrowed or cracked. Mites often follow scab, making the pits much deeper.

The seab at first appears as a minute reddish or brownish surface spot, often when the potato is very young. It extends outward, deepens in color, and is attended with the development of an irregular, corky incrustation.

The disease is often prevalent to such an extent as to prohibit successful potato culture. The chief loss comes from depreciation in sale value, though there is also loss in yield.

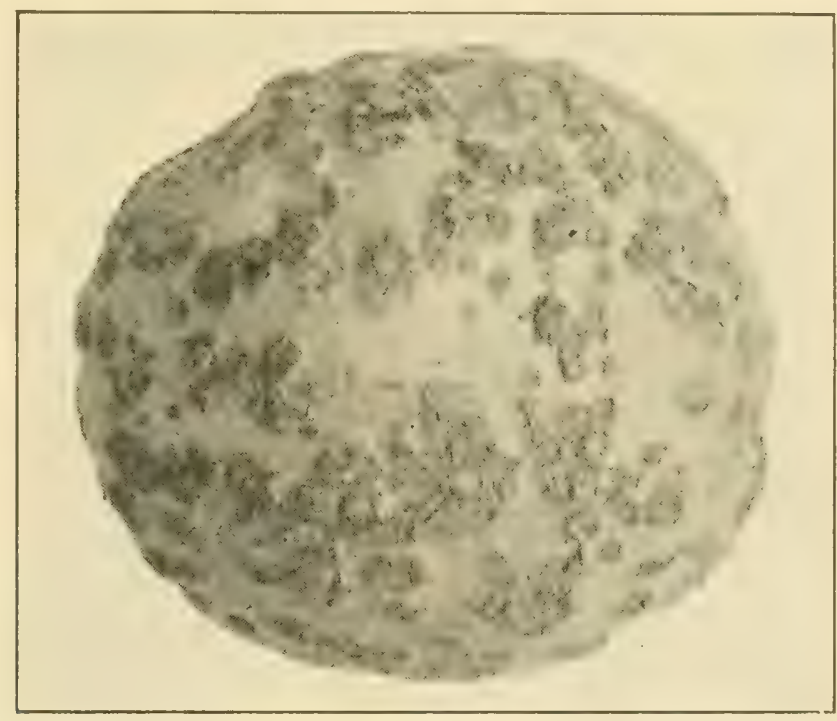

FIG. 121. - Potato common-scab. After Melhus.

Estimates show that from 5 to 75 per cent of the potato erop is unsalable on account of scab). The loss in California in one county alone is placed at $\$ 300,000$ yearly.

Common-scah is most prevalent in alkaline soils and is favored by moisture. Wood ashes, potash, soda, stable manure, lime, etc., increasing alkalinity, favor the growth of the fungus, and cause increase in the amount of scab in soil already infested. Materials which tend to decrease scah are commercial fertilizers, potash salts (except carbonate), land plaster, and ammonium sulfate. Rotation of crops tends 
to diminish the amount of scab, provided other susceptible crops, as beets, turnips, cabbages, etc., are avoided. A three-year rotation without a susceptible crop largely reduces it, though after five or even ten years the fungus may not be entirely exterminated. During rotation any practice that increases the acidity of the soil aids in reducing scab. Thus plowing under green crops is a favorable practice.

In general it may be said that scabby seed potatoes in any soil will produce a scabby crop, but the amount of seab is determined somewhat by the conditions. Seed potatoes free from scab, in a soil free from seab, will raise a crop free from scab. Seed potatoes free from scab will not produce a healthy crop if grown in infosted soil; but less scab will result than when diseased seed is used.

There is much difference in varietal resistance to seab. The more resistant varicties should be used on infested soil.

Two conditions arise requiring different cultural methods:-

1. The management of clean soils.

2. The management of soils already infested.

If the land is free from infestation, great care should be exercised to avoid introduction of the scab fungus by any of the general means suggested under soil discase, p. 26. In particular, infestation may occur by the use of scabby seed, or through the use of manure which has been infested by feeding uncooked, scalbly potatoes to stock. If seed must be planted that cannot safely be regarded as free from scab, and no seed from an unknown source can be so regarded, it should be disinfected to free it of seab germs. See p. 240.

No system of soil treatment has proved reliable in the management of infested land. Long rotation, avoiding susceptible root crops, should be practiced. The use of fertilizing materials which favor the fungus should be avoided and resistant varieties should be planted. The turning under of a green crop, $e . g$., rye, may gradually decrease the 


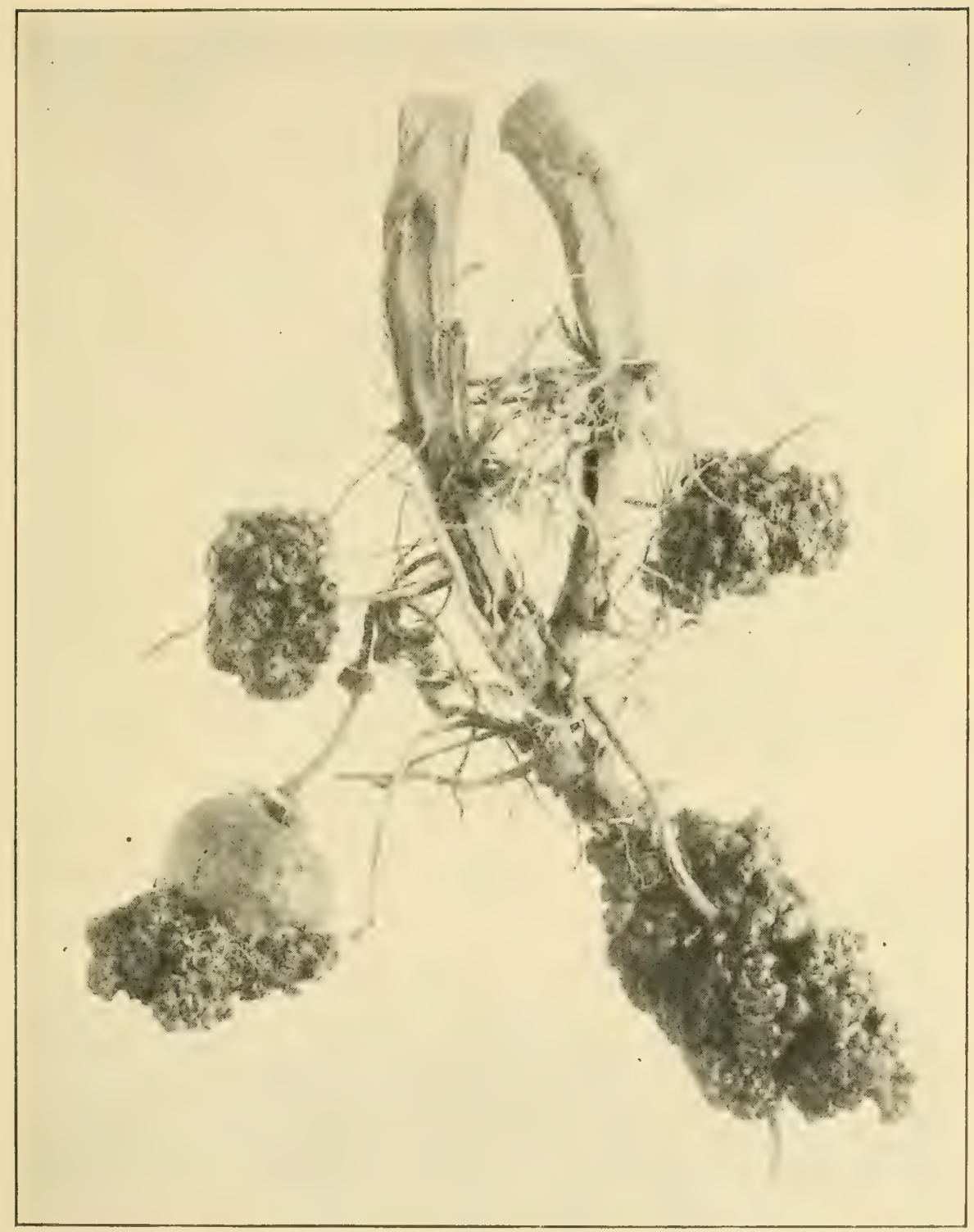

Frg. 122. - Fotato hadly infested with wart. After Kunkel. 
scab tendency. The benefit of treating seed to be used on infested soil varies largely with local conditions.

Wart $277,468,549$ (Synchytrium endobioticum (Schil.) Perc., also known as Chrysophlyctis). - This disease invaded America (Newfoundland) about 1909, and recently was (Sept., 1918) found in several counties of Pennsylvania; still more recently in Virginia and West Virginia. It has long been known in

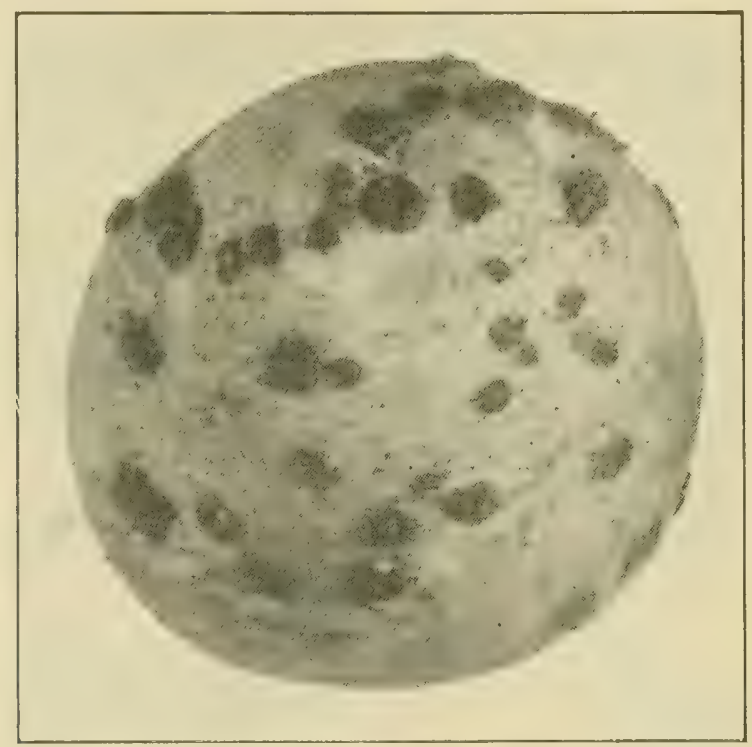

FIG. 123. - Potato infested with powderyscab. After Melhus.

England and Europe. Badly diseased potatoes are entirely replaced by a white, warty mass; in milder cases, only a few eyes are affected with either brown or black spots, or with dark warts of size varying from that of a pinhead, upward. Soil once infested must not be used for potatoes, neither may diseased seed be used. Great care should be exercised to prevent wider distribution of this dangerous disease in America.

Powdery-scab ${ }^{276}$ (Spongospora subterranea (Wallr.) Johns.). - Known in Europe since 1841, this disease was first reported in the United States in 1913, probably having been 
introduced through foreign shipment in 1911. It is now prevalent in certain parts of ('anada and in Maine, Massachusetts, Nobraska, New York, Washington, Oregon, and Ninnesota. The tubers are infected when very young. At maturity the infected area becomes a pit, filled with dusty, yellow spore-balls; the pit bordered by remnants of the tuber's skin. The sale value of the potato is decreased, the yield lessened, and its value for seed purposes lost.

Precautions should be taken to guard against infected seed.

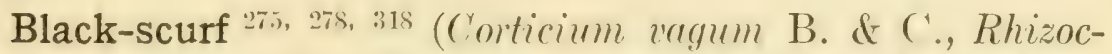
tonia). - Though particularly prevalent in the Middle West and Rocky Mountain states, this pest is also known generally in the East, from Connecticut southward. Infected tubers are largely responsible for the contamination of new soil. They may be recognized by the superficial, irregularly shaped, seurfy, dark-brown patehes (sclerotia) of fungous threads varying in size from a pinhead to a grain of wheat. They are seen clearly only when the tuber is wet.

Soon after planting the young sprouts are attacked by this waiting fungus. Black spots appear near the surface of the ground, destroying the bark and often girdling the stem. In such eases acrial tubers often form, and the plants are malformed and stunted. A clark network of fungous threads is sometimes seen upon the subterranean parts. The fungus advances above ground and develops a gray spore-bearing layer about the green stem, often extending upward several centimeters, causing the young shoots to wilt, droop, and die. Often a loss of one-fourth to one-third of the plants follows. Stems that survive this early attack, but succumb to later attack, produce only a few underground tubers, small and unsalable.

Stem lesions similar to those of black-scurf are also produced by a number of different fungi.

Only clean seed should be used. If there is any doubt, it should be treater as is recommended for potato commonscab, but even this treatment is not effective if large sclerotia 
are present on the seed. Liming the soil, clean culture methods, and crop rotation are palliative. Infested refuse

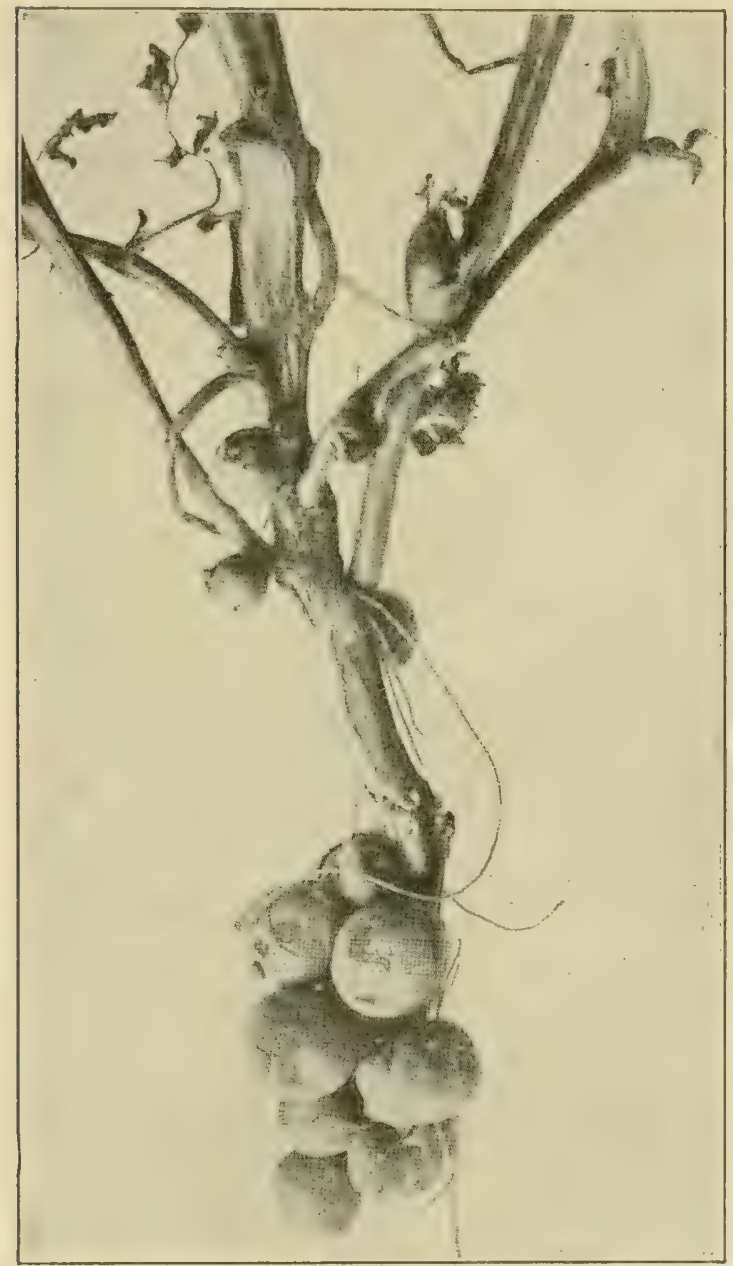

FIG. 124. - Little potatoes and aerial potatoes. After Rolfs. should be destroyed by fire. Soil badly infested should not be planted to potatoes. In general, the remarks made under soil diseases apply here.

While this disease has long been recognized in Europe, especially in Germany, no record of it was made in America until 1891. Since that date it has been noted upon many hosts in many states. See p. 21.

Early-blight ${ }^{279}(A l-$ ternaria solani (E. \& M.) J. \& G.). - This is one of the very serious potato diseases. In 1906 the loss in Wisconsin was placed at about $5,000,000$ bushels, and a 50 per cent loss was reported from Wyoming. The average loss in Michigan is estimated as 25 per cent of the crop. It is known throughout the United States, in Europe, Africa, and Asia.

The grayish-brown leaf-spots; which are brittle, irregularly circular, and concentrically marked, appear about the time 
the tubers begin to form. The coalescence of the spots involves large areas of leaf tissue and results in browned, withered leaves, the stems remaining green. The illusion

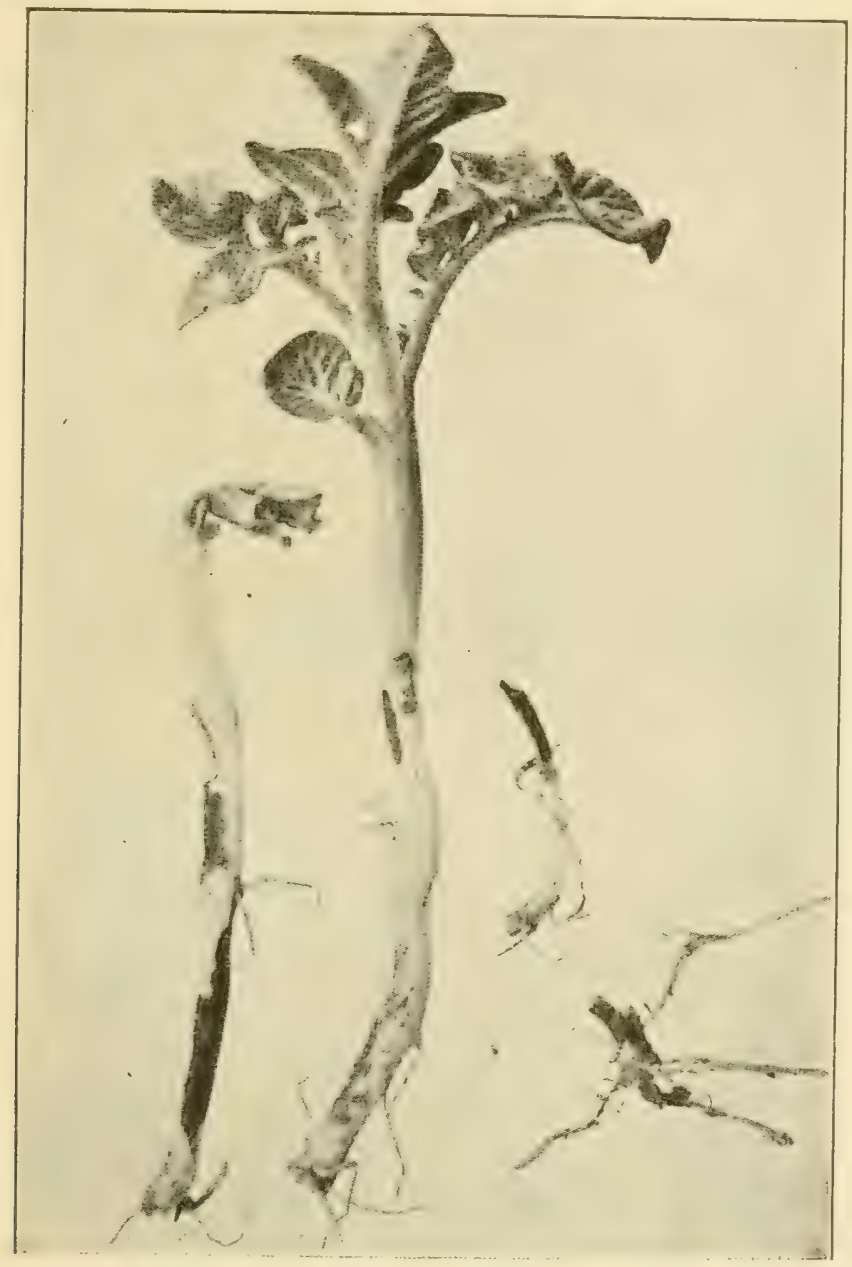

Frg. 125. - Potato attacked by Corticium. After Rolfs.

is often so complete as to lead the grower to think that the vines have died a natural death. The progress of the disease is slow, three or four weeks intervening before all the leaves are dead. The loss of efficient leaf tissue so diminishes the vigor of the plant that the yield is largely reduced. Early- 
blight is also serious on tomatoes in the South, on leaves and on fruits, where it produces a rot. It is found also upon eggplants. This is a disease characteristic of dry soils and seasons, and is likely to be associated and confounded with tip-burn.

General spraying (p. 236) will hold this blight in check.

Tip-burn. ${ }^{233,523}$ - Leaves die at the edges and tips, curl somewhat, and eventually the whole top withers. This

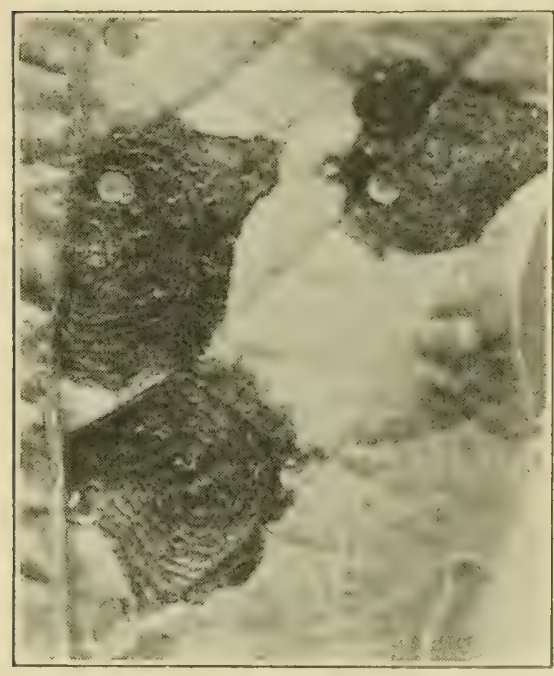

Fug. 126. - Potato early-blight spots enlarged. After Whetzel. condition occurs when the sun is hot and the winds dry, and is especially noticeable when a cool, wet period is followed by hot, dry weather. It has been asserted that the primary cause is attack by leaf-hoppers. Though not due to a parasite, spraying with Bordeaux mixture lessens the loss.

Wilt 280, 477, 531 (Fusarium oxysporum Schl. and Fusarium sps.). - This wilt is definitely known in many states, and is probably identical with a very destructive potato disease of England, Germany, France, and Belgium.

When the plants are about a foot high, or in mild cases a little later, the first trace of the wilt is noticeable. The leaves, which are usually light-colored, assume a dull, unhealthy appearance, with rolling or curling of the margins. Progressive disease gradually causes the top to fall, and gives a gencral effect of premature ripening. When the diseased plants are pulled up, the partially dead roots are found to be quite brittle, and frequently bear a white or pink mold. If the underground portion of the stem is cut across, a pronouncerl brown discoloration is visible. This brown stain is also found in the branches leading to the tubers, and a thin 
slice across the stem end of the tuber will often reveal its presence there as well.

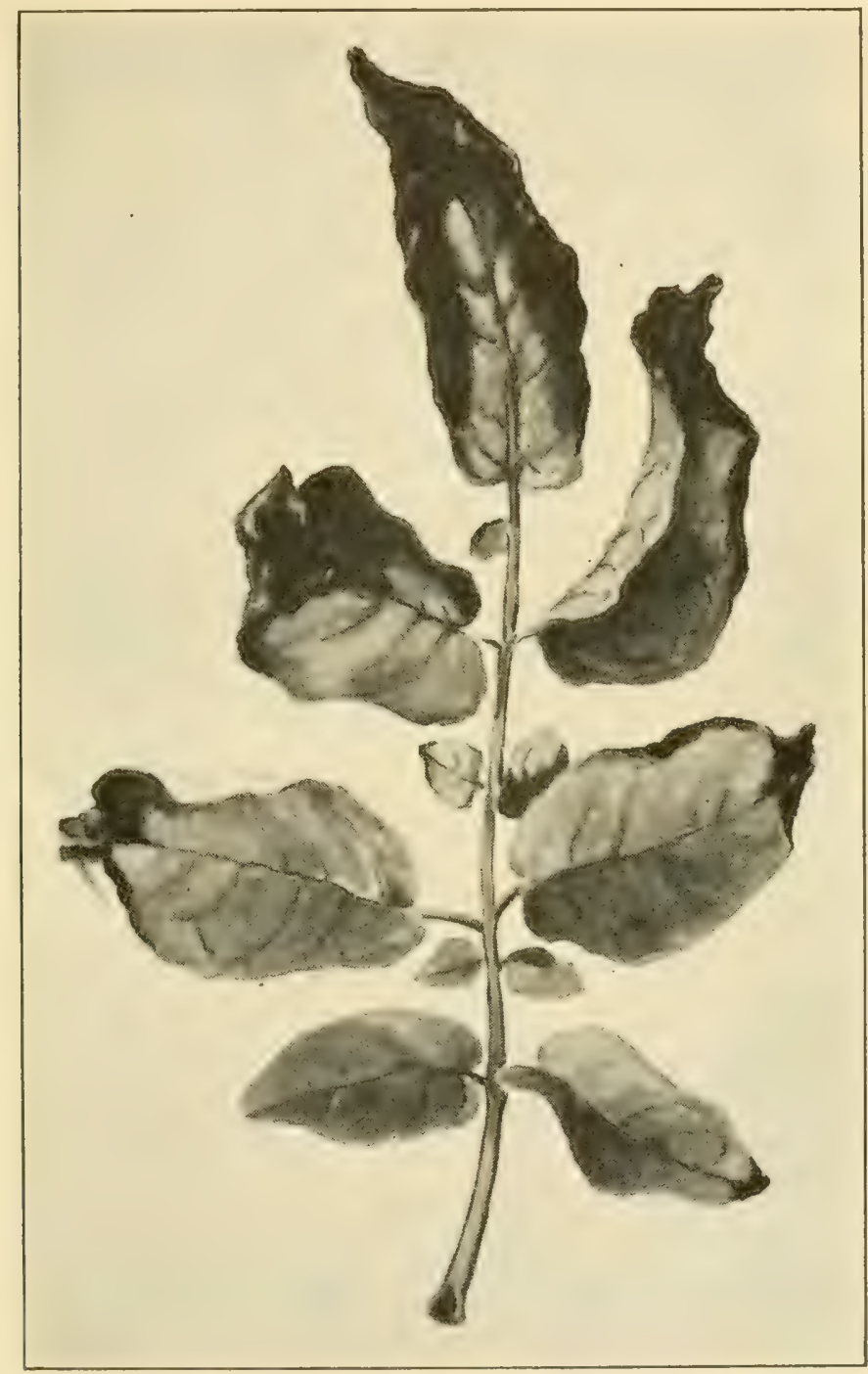

FIG. 127. - Tip-burn. After Wis. Agr. Exp. Sta.

The loss amounts to millions of dollars annually, due: (1) to deficient germination; (2) to early ripening and thus to diminished yield; (3) to rot in storage. 
When the potatoes are dug, there is rarely any external evidence of the disease. The major portion of the crop produced from wilted plants is nevertheless infected. If these potatoes are stored in a cold place, but little change occurs; but when infected potatoes are kept in a heated room or left out-of-doors in a warm climate, rot soon develops.

The presence of this disease can be detected, in otherwise normal tubers, only by making a thin slice across the stem end and searching for the brown discoloration. Such potatoes are not desirable for seed, but are not objectionable for food.

Soils which have once borne a sick crop will infect future crops. The general means by which a field may become infested are discussed on page 27. In addition to these means, the potato wilt is often carried to new fields by seed. It is a matter of record that this disease was largely introduced into California from Oregon by means of infected tubers. This could have been prevented by proper quarantine restrictions.

If potatoes must be stored for any length of time, all that are badly diseased should be rejected, and the remainder kept as cool as possible without freezing. It is best to sell or consume all affected tubers at once.

Another very similar wilt is due to Verticillium alboatrum Reink. Several types of tuber rot due to various Fusaria are distinguished, e.g., the jelly-end-rot, a soft rot of the stem end; dry-rot, also of the stem end. A tuber dry-rot is also caused by Phoma.

Wilt ${ }^{341}$ (Pseudomonas solanacearum (EFS.)). - This wilt, chiefly prevalent from Maryland southward, reported also from Indiana, Nebraska, and Iowa, is identical with that of eggplant, tobaceo, and tomato, and is to a large extent transmitted by insects.

The leaves wilt and dry up; the stems and tubers show yellowing and blackening in the veins, and the tubers give way to a soft rot. Squeezing the diseased tubers causes exudation of creamy drops from the diseased veins. 
Tubers from diseased vines rot rapidly and should not be stored. If stored, they should be kept at as low a temperature as possible. It is unwise to plant potatoes in land which has shown this disease upon any of its hosts, without a long intervening rotation. The precautions suggested under soil

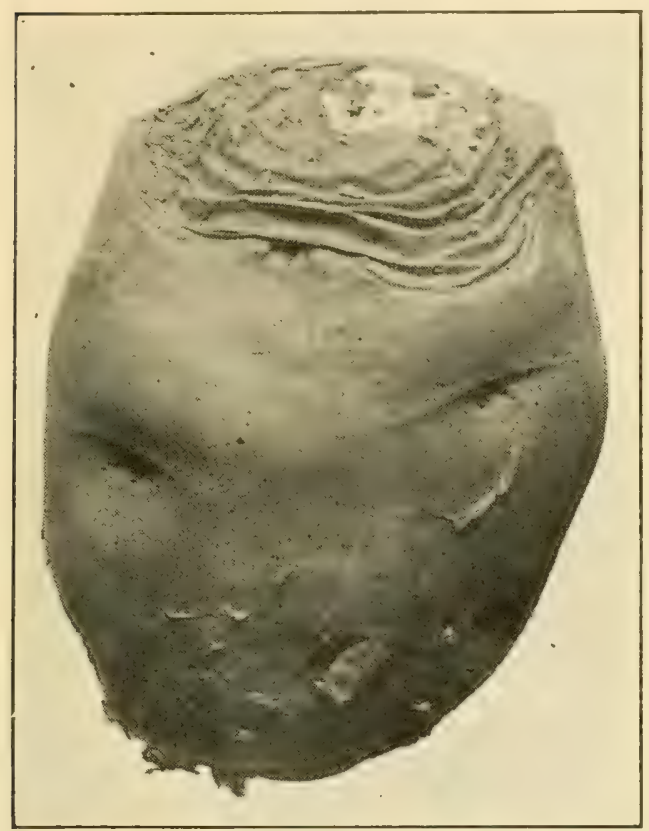

Fug. 128. - Dry-rot caused by Fusarium. After Coons. diseases, use of clean seed, and special attention to insect control, are preventive measures.

Black-leg 269, 281, 284, 285 (Bacillus phytophthorus Appel). - Much confusion has arisen concerning the identity of black-leg, since in many instances the mere occurrence of a black region upon the stem near the ground line has led to the use of the term. It is thus probable that in the literature of potato maladies several distinct diseases have been confused with black-leg.

A distinct, definite, and serious disease has, however, been known in Europe and England for several years under this name. Jones, who studied black-leg in the field in Germany and England and what appeared to be the same disease in Vermont, described it essentially as follows: The earliest conspicuous symptom was that the diseased plants were slightly below normal size, of a paler or yellowish-green color, the lateral branches and petioles becoming more erect and the leaf blades curving upward, giving the entire plant a narrowed aspect. The lower leaves, in the meantime, have possibly shriveled and died. The stem was more or less 
browned or blackened from near the surface of the soil downward. In extreme cases the discoloration was visible $2-3 \mathrm{~cm}$. above the soil. The tissues of the discolored part died, and

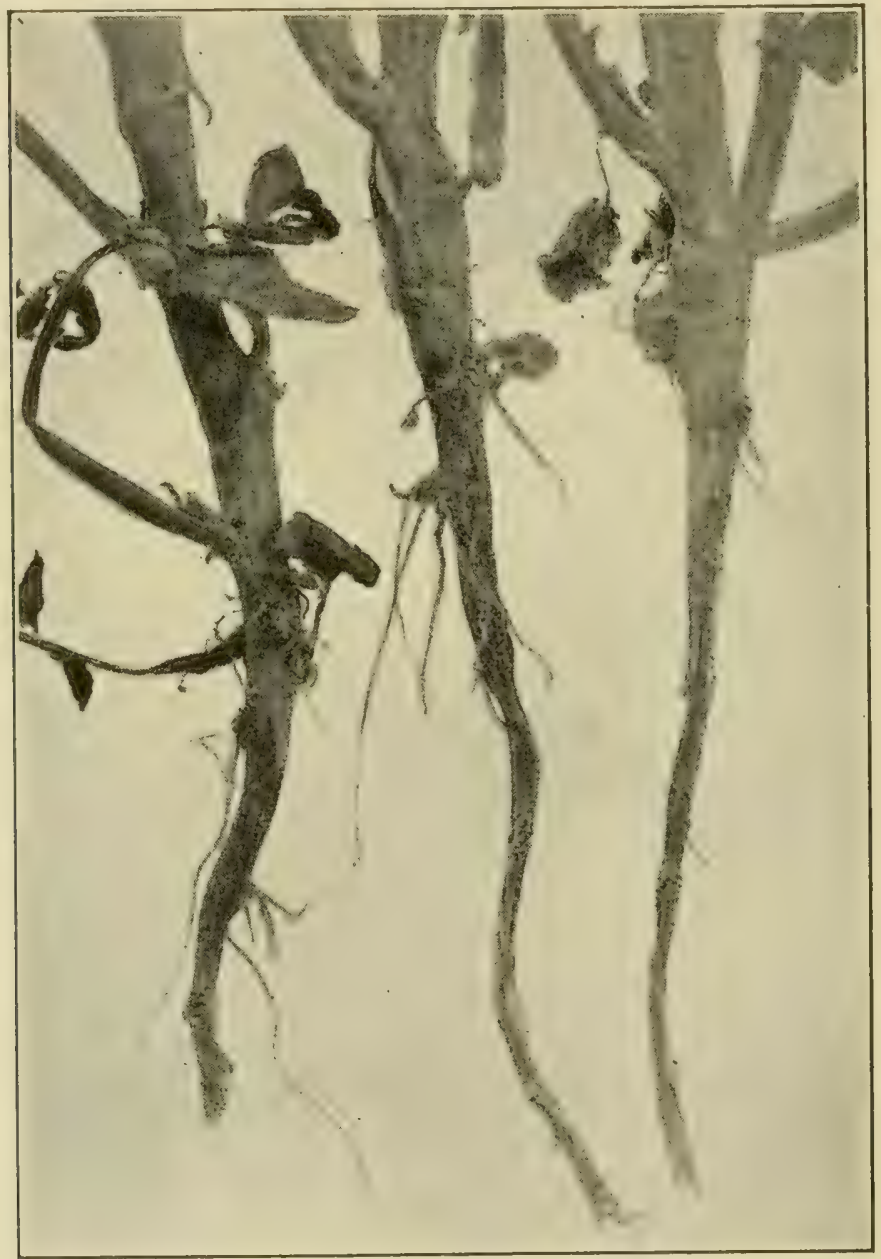

FIG. 129. - Potato black-leg.

the softer parts decayed. Usually the seed tuber also was rotted. Loss as high as 20 per cent is reported in Maine, 75 per cent in certain fields in Michigan; but such large loss is unusual.

The disease is carried over to succeeding crops in the seed, 
and is, therefore, of greatest importance to growers of seed potatoes. Seed should be carefully selected, and then disinfected.

Leaf-roll 286, 288 541, 547, 548 (Phloem-necrosis) and Mosaic (Leaf-curl or Curly-dwarf), two closely related cliseases of wide distribution, cause serious crop loss. In Bermuda, for example, the loss from leaf-roll is estimated to be well above 50

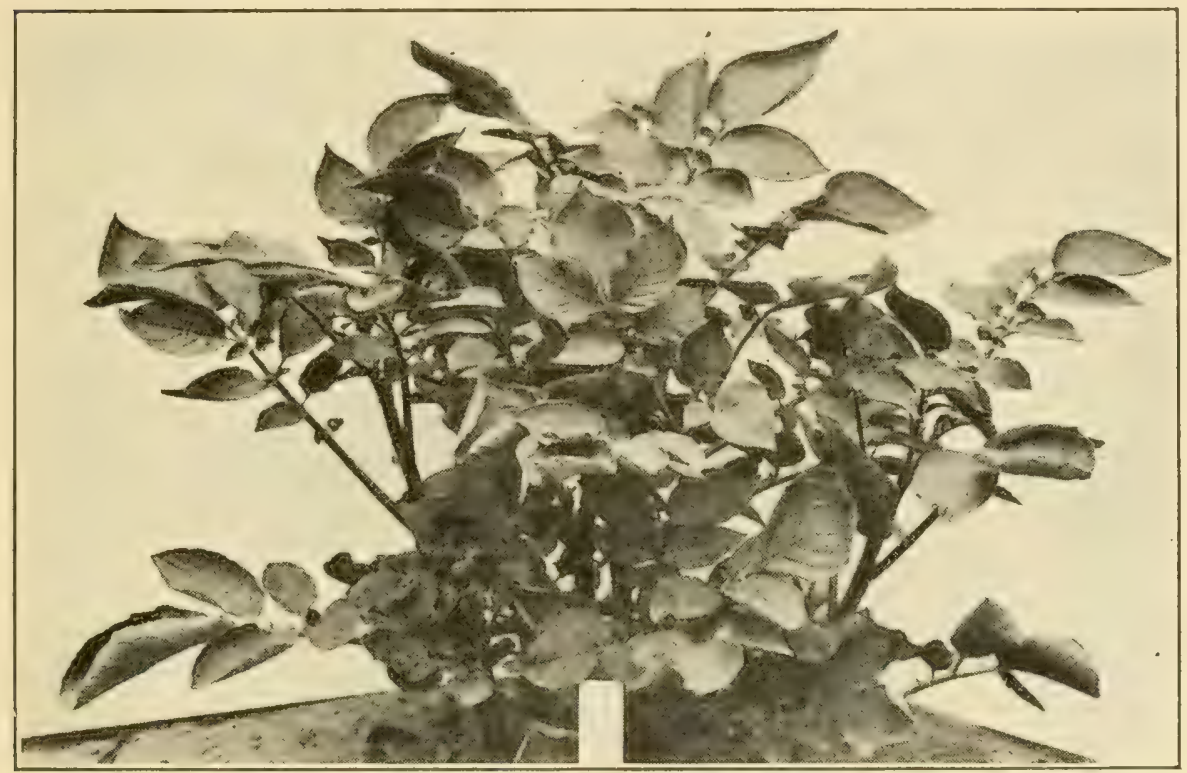

FIG. 130, - Potato leaf-roll. After Orton.

per cent of the crop. The two diseases, formerly regarded as three, are difficult to distinguish accurately without the use of the microscope, but in general in leaf-roll the segments of the lower leaves are pale, permanently rolled upward and rigid, the terminal segments becoming spoon-shaped; while in mosaic, generally, the leaf segments are distorted, the veins unduly prominent, and the blades mottled with light areas, and in severe cases the plants dwarfed by shortened internodes, giving rise to the designation "Curly-dwarf." Plants affected by either of these diseases show retarded tuber development and reduced yield. 
Both diseases are usually of such mild form during the first year as to be unnoticed; but appear in much more severe form during the second year. Though the causal organism is unknown, both are also contagious, and infection passes readily from plant to plant in the field. Such infection takes place chiefly through the soil and has been observed to occur at a distance of 2 meters. The disease is seed-borne and probably infestation does not persist in the soil. Therefore seed should be taken from a field free of these diseases, or seed-plants which grew fully 2 meters distant from diseased plants should be selected.

\section{Minor diseases}

Leaf-blotch ${ }^{281}$ (Cercospora concors (Casp.) Sacc.) appears when the plants begin to blossom. The lower leaves show obscurely defined, pale spots, $3-5 \mathrm{~mm}$. in diameter, these sometimes blending to form larger areas. The spots sometimes much resemble the early-blight spot, but more often the entire leaf slowly turns yellow and dies. The damage, especially to late potatoes, is considerable.

Leak ${ }^{282}$ (Rhizopus nigricans Ehr. and Pythium debaryanum Hesse.). - Orton has described a wet, soft rot of potato in the peat lands of California. It is characterized by dull brown discoloration of the skin and light brown or buff coloring of the flesh, accompanied by softening. Upon pressure a clear brown liquid without disagreeable odor, exudes.

The disease spreads rapidly in warm weather, and entire shipments may decay en route to market. To prevent infection the skin should not be broken in handling, and all refuse should be destroyed by fire. Diseased tubers should be scrupulously sorted out of lots intended for storage or shipment.

Silver-scurf (Spondylocladium atrovirens Harz.). - Dark blotches spotted with minute black specks appear on the surface of the tubers. Later these assume a silvery-gray tint. The disease, recently introduced from Europe, is widely distributed, but not of great importance. Infected seed should not be used. 
Black-heart. 289,290 - The centers of the tubers turn black or become hollow with a black lining. This is due to abnormal physical conditions, such as high temperature, or deficiency of oxygen, and occurs mainly in potatoes stored in artificially heated rooms, or piled too deep (over $6 \mathrm{ft}$.). Temperatures above $35^{\circ} \mathrm{C}$. $\left(95^{\circ} \mathrm{F}\right.$.) should be avoided, and ventilation provided.

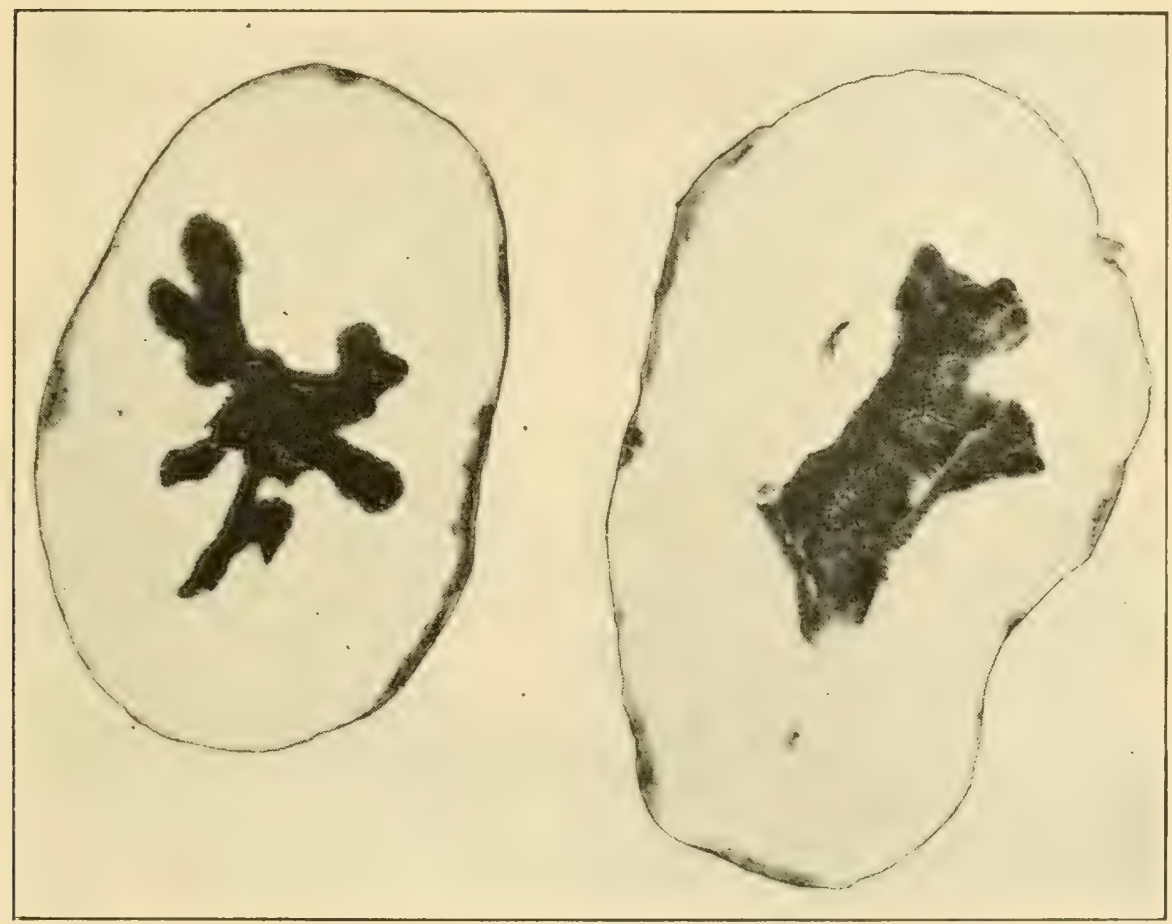

FIG. 131. - Black-heart of potato caused by exclusion of air. After Stewart and Mix.

Spindling-sprout, the cause of which is unknown, is a diseased condition in which the normal stout thick sprouts fail to develop and in their stead are slender abnormally long sprouts. Seed potatoes affected with this disease result in an uneven stand with many missing hills, weak plants, and corresponding decrease in yield.

Hollow-heart. - In years of abundant rainfall large pota- 
toes frequently show cavities at the centers, lens-shaped clefts with browned linings, due apparently to tension resulting from unequal growth. Though this is not a true disease such tubers are discriminated against in grading. Varieties subject to this trouble should be planted closely since crowding helps to overcome the tendency.

Internal brown-spot, scattered, rusty brown spots, 2-10 $\mathrm{cm}$. in diameter, occur irregularly throughout the potato. No parasite is present and the diseased condition is not transmitted through the seed. However seed showing this character should be avoided.

Net-necrosis. - Netted, brown or black areas, beginning at the stem end, extend through the tuber. The disease is not due to parasites and probably affects the yield but little. Seed potatoes showing this disease should be avoided. An Anthracnose (Colletotrichum) has been described on stems.

\section{Disease Prevention}

In general to prevent potato diseases:

1. Plant, if possible, in uninfested soil.

2. Destroy disease-bearing refuse.

3 . Rotate crops judiciously.

4. Use only seed free from seed-borne diseases, $i$. e., scabs, black-scurf, wilts.

5. Disinfect seed in case such diseases as scab and blackscurf are present, p. 240.

6. Spray with 4-4-40 Bordeaux mixture.

\section{Potato Spraying 291, 292}

As with other crops, spraying should not be directed or planned to meet merely one of the diseases, but rather to give the plant the best possible protection against all of its enemies. The chief enemies to be met by spraying are early-blight, late-blight, and the Colorado beetle or "potato bug." 
The gains from spraying potatoes with Bordeaux mixture as shown in trials at the Vermont Experiment Station, begun in 1891 by Jones and extending over twenty years, are shown below:

\section{Gains from the Use of Bordeaux Mixture on Late Potatoes}

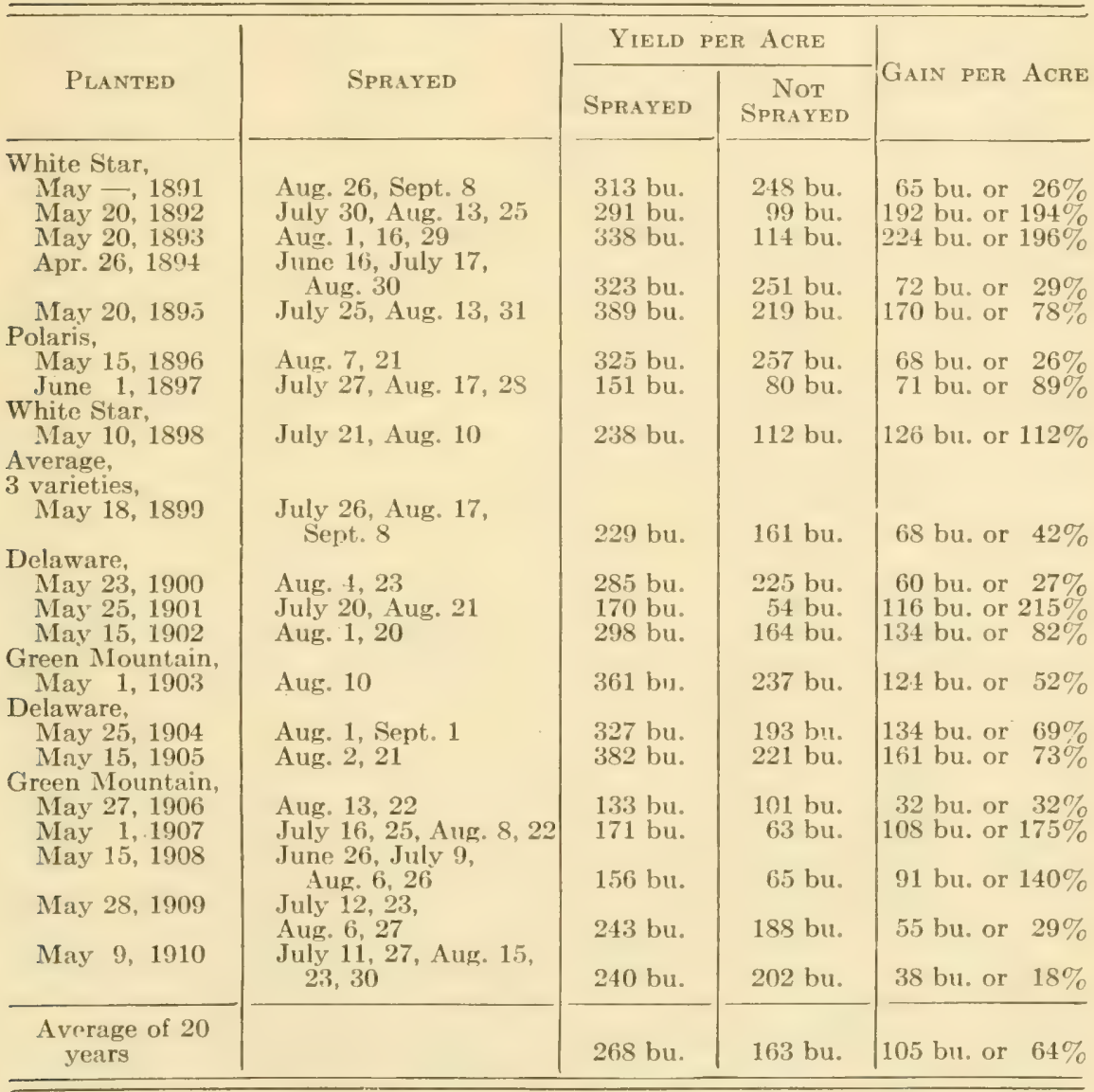


Extensive experiments were conducted for ten years by the New York Experiment Station. The following table taken from bulletin 349 summarizes the results:

\begin{tabular}{|c|c|c|c|c|}
\hline \multirow[b]{2}{*}{ YeAR } & \multicolumn{2}{|c|}{ At Geneva } & \multicolumn{2}{|c|}{ At RIVERHEAD } \\
\hline & \begin{tabular}{|c} 
Gain per A. due \\
to spraying \\
Every Two Weeks
\end{tabular} & $\begin{array}{c}\text { Gain per A. due } \\
\text { to spraving } \\
\text { Three Times }\end{array}$ & \begin{tabular}{|c|} 
Gain per A. due \\
to spraying \\
Every Two Weeks
\end{tabular} & $\begin{array}{c}\text { Gain per A. due } \\
\text { to spraying } \\
\text { Three Times }\end{array}$ \\
\hline $\begin{array}{l}1902 \ldots . . \\
1903 . . . \\
1904 \ldots \\
1905 \ldots \\
1906 \ldots \\
1907 \ldots \\
1908 \ldots \\
1909 \ldots \\
1910 \ldots \\
1911 \ldots \\
\end{array}$ & $\begin{array}{l}B u . \\
123.5 \\
118 \\
233 \\
119 \\
63 \\
73.66 \\
39 \\
49.7 \\
63 \\
93\end{array}$ & $\begin{array}{l}\text { Bu. } \\
98.5 \\
88 \\
191 \\
107 \\
32 \\
44 \\
29.5 \\
38.7 \\
22 \\
40\end{array}$ & $\begin{array}{l}\text { Bu. } \\
45 \\
56 \\
96 \\
82 \\
53 \\
31 \\
15.33 \\
52.5 \\
25.5 \\
.5\end{array}$ & $\begin{array}{l}B u \\
27.66 \\
39.5 \\
56.5 \\
31.5 \\
21.5 \\
18 \\
10.75 \\
28.7 \\
14.7 \\
1.1\end{array}$ \\
\hline Average. & 97.5 & 69 & 45.7 & 25 \\
\hline
\end{tabular}

Ten years of business experiments made on farms in order to determine the actual profits from spraying under farm conditions gave the following results:

\begin{tabular}{|c|c|c|c|c|c|c|}
\hline Year & $\begin{array}{l}\text { NUMBER } \\
\text { OF EXPERI- } \\
\text { MENTS }\end{array}$ & $\begin{array}{c}\text { Total } \\
\text { AREA } \\
\text { SPRAYED }\end{array}$ & $\begin{array}{l}\text { Average } \\
\text { INCREASE } \\
\text { IN YiFLD } \\
\text { PER ACRE }\end{array}$ & $\begin{array}{c}\text { AVERAGE } \\
\text { TOTAL } \\
\text { Cost OF } \\
\text { SPRAYING } \\
\text { PER ACRF }\end{array}$ & $\begin{array}{l}\text { AvERAGE } \\
\text { COST } \\
\text { PFR ACRE } \\
\text { FOR EACH } \\
\text { SPRAYING }\end{array}$ & $\begin{array}{c}\text { Average } \\
\text { NFt Profit } \\
\text { PER ACre }\end{array}$ \\
\hline $\begin{array}{l}1903 \\
1904 \\
1905 \\
1906 \\
1907 \\
1908 \\
1909 \\
1910 \\
1911\end{array}$ & $\begin{array}{r}6 \\
14 \\
13 \\
15 \\
14 \\
14 \\
12 \\
12 \\
14\end{array}$ & $\begin{array}{c}\text { A. } \\
61.2 \\
180 \\
160.7 \\
225.6 \\
152.75 \\
200.25 \\
203.14 \\
218.5 \\
161.6\end{array}$ & $\begin{array}{l}\text { Bu. } \\
57 \\
62.2 \\
46.5 \\
42.6 \\
36.8 \\
18.5 \\
24.4 \\
19.1 \\
18.2\end{array}$ & $\begin{array}{l}\$ 1.98 \\
4.98 \\
4.25 \\
5.18 \\
5.90 \\
4.30 \\
4.15 \\
4.04 \\
4.87\end{array}$ & $\begin{array}{c}\$ 1.07 \\
.93 \\
.98 \\
.98 \\
1.18 \\
.92 \\
83.5 \\
90 \\
96\end{array}$ & $\begin{array}{r}\$ 23.47 \\
24.86 \\
20.04 \\
13.89 \\
17.07 \\
8.53 \\
9.55 \\
4.39 \\
8.09\end{array}$ \\
\hline
\end{tabular}

In the Ceneva and Riverhead experiments, rows sprayed three times received Bordeaux mixture with Paris green twice and Bordeaux alone once, the dates being July 3, 17, and August 3. Other rows were sprayed six times, twice with Bordeaux mixture and Paris green and four times with Bordeaux alone, the dates being July 3, 17, August 3, 18, and September 1, 16. Still other rows were not sprayed at 
all with Bordeaux, but were treated twice, July 3 and 20, with Paris green in limewater, to control bugs. The Bordeaux mixture contained 6 pounds of copper sulfate to each 50 gallons of water, and lime to correspond. Paris green was used at the rate of 1 pound to 50 gallons of mixture.

The recommendation of the Geneva Station is: "Commence spraying when the plants are six to eight inches high and repeat the treatment at intervals of 10 to 14 days in order to keep the plants well covered with Bordeaux throughout the season. During epidemics of blight it may be necessary to spray as often as once a week. Csually six applications will be required. The Bordeaux should contain 4 pounds of copper sulfate to each 50 gallons in the first two sprayings, and 6 pounds to 5() gallons in subsecquent sprayings. Whenever bugs or flea beetles are plentiful, add one to two pounds of Paris green or two quarts of arsenite of soda stock solution or three to five pounds of arsenate of lead to the quantity of Bordeaux required to spray an acre.

"Thoroughness of applieation is to be desired at all times, but is especially important when flea beetles are numerous or the weather favorable to blight. Using the same quantity of Bordeaux, frequent light applications are likely to be more effective than heavier applications made at long intervals.

"Those who wish to get along with three sprayings should postpone the first one until there is danger of injury from bugs or flea beetles, and then spray thoroughly with Bordeaux and poison. The other two sprayings should likewise be thorough and applied at such times as to keep the foliage protected as much as possible during the remainder of the season. Very satisfactory results may be obtained from three thorough sprayings.

"A single spraying is better than none and will usually be profitable, but more are better.

"Except, perhaps, on small areas, it does not pay to apply poison alone for bugs. When it is necessary to fight insects, use Bordeaux mixture and poison together." 
Arsenicai Injury, due to insecticides, may be avoided by applying the arsenicals with lime or with Bordeaux mixture.

Potato seed disinfection. - The diseases against which seed disinfection is effective are only those in which the fungus is superficial on the tuber, $i$. e., primarily against common-scab) and black-scurf, and against these only under certain conditions. Before disinfecting, all tubers obviously bearing any other disease should be discarded, as well as tubers bearing large black-scurf sclerotia or deep scab pits, since the treatments will not kill the fungi on such. Many diseases of tubers cannot be detected until the potatoes are cut. Before treating, enough of them should be examined internally to give satisfaction that the lot is not generally infected with any internal disease, as for example, with black-leg or wilt. Disinfection should be done before cutting. Two chemicals are used according to the following formulæ:

1. Mercuric chlorid (corrosive sublimate). . $4 \mathrm{oz}$. Water.................... 30 gal.

2. Formalin. Water...

1 pt. 30 gal.

Mercuric chlorid must not be brought in contact with metal; is very poisonous to animals; deteriorates rapidly with use, and is more expensive than formalin. The formalin solution may be used in any kind of container; grows stronger on evaporation, and is generally preferable.

In either solution the potatoes are soaked for a half hour. The solution may be put in a large trough, and the potatoes, in crates or bags, set into it, left the requisite time, then substituted by another lot of potatoes. Potatoes should be dried immediately after treatment. If there is much blackscurf present, and no better seed are obtainable, the potatoes, if dormant, i.e., not sprouted, may be soaked for two hours in mercuric chlorid solution. With sprouted stock the mercuric chlorid is more injurious than the formalin, but the formalin is not effective against heavy infection of black-scurf. 
PUMPKIN. See cucumber.

RADISH. See cabbage.

RAPE. See cabbage.

\section{RHUBARB}

Anthracnose ${ }^{294}$ (Colletotrichum emumpens Sace.). - Rotted, sunken, soft spots, often several centimeters long, are produced on the petioles, and are thickly set in the older portions with black acervuli. Though reported as yet only from Illinois, the disease is probably widespread, and causes considerahle loss in the field, and additional loss in shipment.

Leaf-spot ${ }^{294}$ (Phyllosticta straminella Bres.). - Irregular, brownish, diseased spots, often several centimeters in diameter, occur on the leaf blade and hear numerous, minute, black pycnidia. Older spots become torn and ragged.

Crown-rot.-This soft rot of crown and petiole, probably due to bacteria, has caused large loss in southern Illinois.

\section{ROSELLE (Hibiscus sabdariffa)}

Powdery-mildew (Microsphera euphorbice B. \& C., Oidium). - This mildew of characteristic white, flour-like, circular patches has been noted in Florida.

Flowers of sulfur has proved effective in preventing its spread.

RUTABAGA. See cabbage.

\section{SALSIFY}

White-rust (Albugo tragopogonis (DC.) Gray). - White, rustlike blisters (sori) upon the leaf indicate this disease. In late stages of the disease the leaf, near the sori, blackens and withers, often tearing lengthwise.

Soft-rot. - A soft-rot of the roots, resulting in loss of green color and prostration of the plants, is attributed to 
bacteria. The slimy, offensive decay usually begins at the lower end of the main root and progresses upward. See carrot soft-rot.

Rust (Puccinia tragopogonis (Pers.) Cda.). - This true

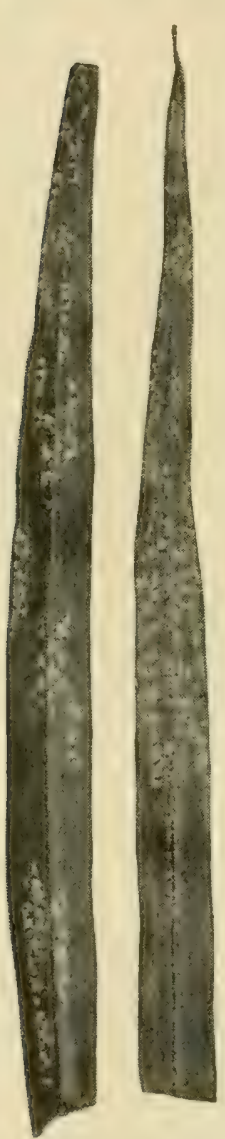
rust is of somewhat general distribution, but is not harmful.

Powdery-mildew (Erysiphe sps.) is common, but not serious. Southern-blight (Sclerotium) is injurious in the South.

\section{SPINACH 298}

Blight. ${ }^{295}$ - This is the most destructive spinach disease, causing a loss in eastern Virginia estimated between $\$ 200,000$ and $\$ 400,000$ annually. The diseased leaves are mottled and deformed, and the plants stunted. In general, the symptoms are much as in the mosaies with the exception that the plants are eventually killed. The disease is due to a virus, and can be artificially transmitted from plant to plant. In nature, infection seems to be carried by plant lice (aphids), and not to reside in the soil or to be carried by the seed. Spraying to kill the plant lice may be the means of conquering this trouble.

Anthracnose (Colletotrichum spinacioe E. \& H.). - Blotches appear upon the leaves, first FIG. 132.-Whitc- as small, moist, watery areas, associated with rust upon sal- slight local wilting, followed soon by the apsify $l \mathrm{e}$ a $\mathrm{v}$ es
After Heald. pearance upon either side of the leaf of small,

brown acervuli. The spots then change to gray and dry up. The disease spreads rapidly from plant to plant and is very destructive both under glass and in the open, rendering the plant unfit for use.

White-smut (Entyloma cllisii Hal.). — The attacked plants are unmarketable, due to lack of uniform green color 
and the presence of pale bleached spots upon the foliage. These spots are not definitely limited, nor does the tissue die as it does in the case of other spinach leaf spots.

Black-mold (Cladosporium macrocarpum Preuss) develops primarily upon old leaves, and renders the plant unsalable. The spots are distinguishable from all other spinach spot diseases by their irregularity, indefiniteness, and color.

To control the three latter spinach diseases, it is well to burn diseased refuse, practice rotation, and employ preventive sprays when the plants are young. Spraying the edible leaves as the plants approach maturity injures the sale and is not permissible.

Leaf-spot (Heterosporium variabile Cke.). - This disease was especially injurious to spinach in eastern Virginia during the winter of 1908-1909, and has also been noted in Connecticut. It appears early in January and continues to increase until the spinach season is over. Numerous leaf spots are produced, at

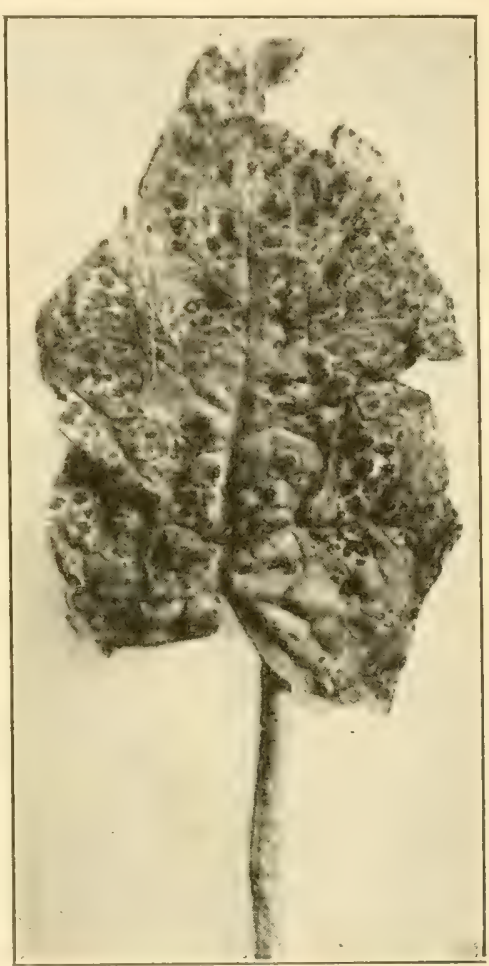

Fig. 133. - Spinach leaf spotted by Heterosporium. After Reed. first brown, later sooty, as the conidiophores and conidia of the fungus develop. The older leaves usually show more injury than the younger, but at times all leaves are seriously affected. The presence of the fungus renders the leares unsalable, and much additional labor is required at harvest. time to trim off the injured leaves.

The disease does not seem capable of attacking healthy, vigorous plants, but usually follows injuries produced by some other agencies. In Virginia it has been found to follow 
the injuries produced by Peronospora. Injuries produced by cold weather, prolonged rains, insects, etc., undoubtedly afford weak points where infection may begin.

The best preventive measures are to follow general hygienic precautions, rake up and destroy all dead and diseased leaves, keep the injuries from insects and other fungi at a minimum, and rotate crops as frequently as possible.

\section{Minor Diseases}

Downy-mildew (Peronospora effusa (Grev.) Rbh.).Gray to slightly violet, downy spots upon the lower surfaces of leaves, accompanied by pale yellow spots upon the corresponding upper surfaces, indicate downy-mildew. The disease in its habit and damage resembles that of the grape, p. 122. Serious loss is reported from New Mexico and Virginia.

Leaf-blight (Phyllosticta chenopodii Sacc.) affects the leaves, especially at their bases, producing spots which bear minute pycnidia. Leaf-spot (Cercospora beticola Sace.) often ruins crops by yellowing and dwarfing the plants, thus rendering them worthless for market. Soft-rot (Bacillus carotovorus) occurs on spinach in shipment.

SQUASH. See p. 178.

\section{SUGAR-CANE 158, 351}

Red-rot (Colletotrichum). - The first external evidences of disease are drooping, withering, and yellowing of the upper leaves, followed by wilting of the entire crown. Finally, the whole stool dies. In less severe cases buds die, and dead, black areas extend out from the nodes. The veins running lengthwise within the stems are reddened. Uncertainty exists as to identity of the causal fungus. The disease is one of the most serious affecting sugar-cane. Only healthy stock should be used in propagation, and cliseased refuse should be destroyed. 
Rind-disease (Trichosphriace sacchari Mass.). - This stem disease is first indicated by yellowing and drying of the leaves, often followed by death of the plant. The nodes are frequently discolored or black. In late stages black pycnidia appear on the diseased surface. Diseased refuse should be burned and cuttings should be disinfected by dipping in Bordeaux mixture.

Pineapple-disease (Thielaviopsis paradoxa v. Höhn.).-This disease originates in cuttings and derives its name from the odor of the affected stems. The fungus, which is a wound parasite, enter's through the ends of cuttings and may prevent their germination, or so retard growth that worthless plants develop. Dipping the cut ends in Bordeaux mixture lessens infection.

Ring-spot (Leptospheeria sacchari v. B. d. H.). - Oval, gray spots, $3-5 \times 5-15 \mathrm{~mm}$., surrounded by narrow brown rings, develop in the leaves, and hear minute, black perithecia.

Leaf-spot (Cercospora longipes Butler). - Narrow, oval, brown spots, about $2 \mathrm{~mm}$. in diameter, surrounded by a yellow zone, occur.

Cacao-disease (Diplodia cacaoicola Hen.). - This is caused by a fungus that also grows on cacao. It causes the canes to wrinkle.

Root-rot. This, one of the most troublesome of cane diseases, is due to various fungi, one of which is a stink-horn (Phallus), another Marasmius sacchari, Wak., both of which can be recognized in late stages by the sporophores of the fungi. Proper drainage and cultivation, the use of immune varieties and healthy stock, the destruction of infected refuse, and rotation of crops are helpful.

SWEET CORN. See p. 283.

SWEET POTATO ${ }^{299,553}$

Soft-rot ${ }^{478}$ (Rhizopus nigricans Ehr.). - The most prominent soft-rot of the sweet potato, the only one that is com- 
monly met, may be recognized by the soft, wrinkled condition of the potato, its sweetish odor, and usually by the presence of a white, later black, growth of mold, appearing through the skin of the rotted portion at points of rupture.

The decay most often begins at one end and passes rapidly through the root, but it may start at a wound upon any

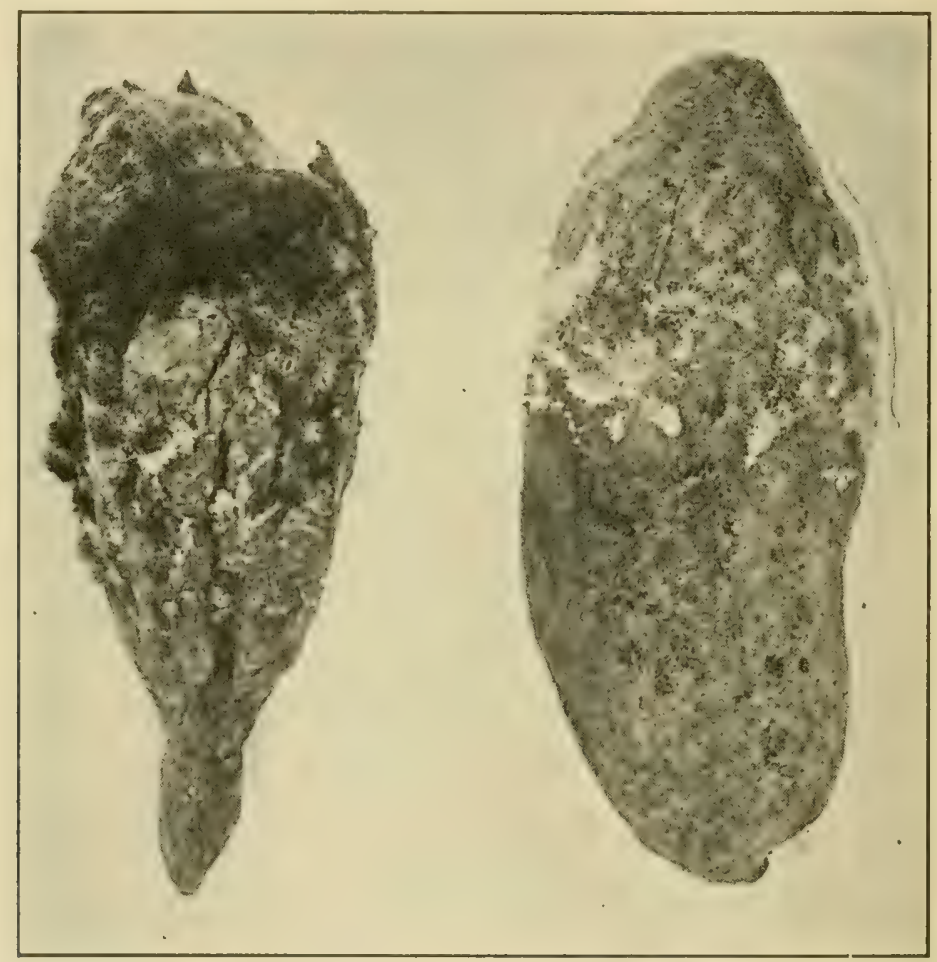

FIG. 134. - Sweet potato soft-rot.

part of the potato. It progresses with such rapidity that the whole potato may give way in a few days after infection. Other tubers, if they have broken surfaces or wounds and lie in contact with affected ones, will also become infected. The rotten roots are therefore often found in groups throughout the pile. This rot is sometimes found in the field, but is not usually destructive until after digging. The loss in the United States in 1917 is estimated at about 5,000,000 bu. 
Normally it cannot enter a sound potato; a wound must furnish a passageway. Therefore all wounded roots should he laid aside for immediate consumption, and only sound roots put in storage.

Potatoes for storage should be fully matured, carefully handled to avoid bruising, thoroughly cured, and kept at uniform temperature, $26^{\circ}$ to $29^{\circ}\left(\mathrm{C}\left(80^{\circ}\right.\right.$ to $85^{\circ} \mathrm{F}$.), while curing, and at $12^{\circ} \mathrm{C}$. $\left(55^{\circ} \mathrm{F}\right.$.) after curing. Properly ventilated storage houses should he built when possible. Kiln drying at $29^{\circ}$ to $35^{\circ} \mathrm{C}$. $\left(85^{\circ}\right.$ to $95^{\circ} \mathrm{F}$.) for 10 to 15 days is a good practice.

It is well to destroy all infective material, rotten roots, etc., in or near the storage place, and if the house has been infested, to spray its walls and floors thoroughly with a good disinfectant, such as Bordeaux mixture or formalin.

Black-rot (Spheronema fimbriatum (F. \& H.) Sace.).This is among the most destructive of all sweet potato decays, causing much loss in storage as well as in the field. It is said to equal in damage that of all other sweet, potato diseases combined. Infected potatoes are bitter and worthless. Black-rot has been reported from nearly all states that raise sweet potatoes, also from the West Indies and New Zealand.

The rot may be known by its dark brown to black, irregular patches upon the potato surface. These begin as points and gradually extend in all directions, involving the whole root. Older spots, 2-5 cm. across, often break or crack irregularly near the center. This decay differ's from the soft-rot in that the spots are dry and hard and that it is present upon the roots before digging. With a hand lens, very small, hairlike, black structures, $1 \mathrm{~mm}$. high, are seen studding the centers of the diseased areas. These are the beaks of the pycnidia of the causal fungus.

Upon young sprouts before they are set out the disease causes black, dead patches, especially at the base of the shoot or even upon the young leaves. The wood of the stem may be browned. Such sprouts result in enfeebled plants 
with diseased roots. The fungus discharges myriads of spores into the soil. This disease thus falls under the general class of soil diseases.

In addition to the suggestions given on page 26, especial

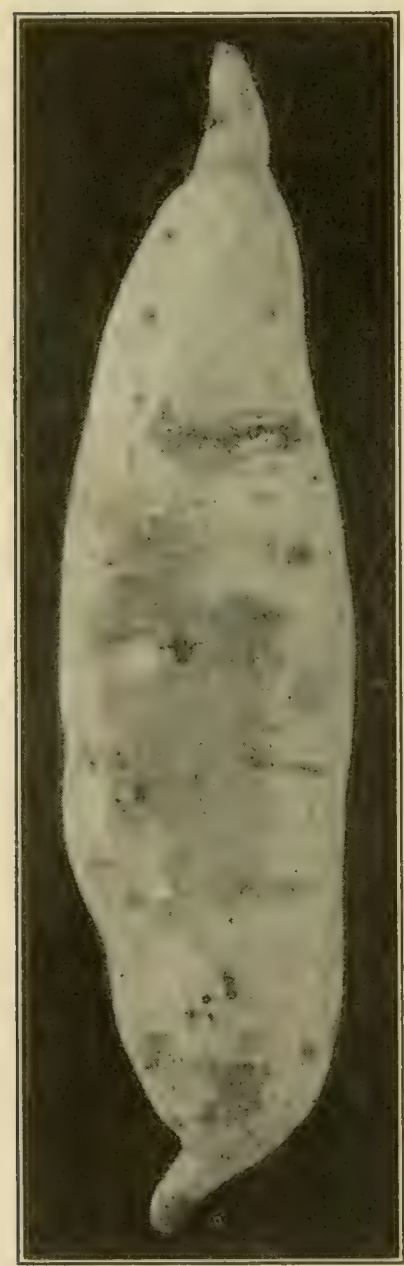

FIG. 135. - Black-rot of sweet potato. Original. precaution should be exercised to avoid sets already infected. Badly diseased shoots are easily recognized, but the closest scrutiny is needed to cull out those only slightly affected. Above all, infested seed beds should be avoided, and no infected potatoes should be used for growing sets. Crop rotation should be practiced, and every precaution taken to get the plants well established in the field. A strong, well-started plant will often resist the disease where a weak plant would succumb. Waite ${ }^{300}$ says: "The best remedy is to use slip seed. It is advisable to grow the crop of vine cuttings on new land which is not infested or on land which has never grown sweet potatoes, thus making an absolutely clean start even though the vine cuttings are taken from an infected crop."

Root-rot ${ }^{302}$ (Plenodomus destruens Hart.). - Small brown or black spots appear on the stem near the soil line, and eventually girdle the plant, which soon wilts. In some regions of Ohio, Virginia, and Iowa, losses of 50 per cent occur, but the disease is not so widely distributed as those mentioned above.

Texas root-rot (Ozonium). - A firm, brown rot is produced on the potatoes. Loss as high as 90 per cent is occasional. Rotation involving cereals should be adopted. 
Soil-rot ${ }^{301 .}{ }^{303}$ (Cystospora batatce (E. \& H.) Ell.). - The loss from this rot is sometimes almost total. Due to soil infestation the raising of the crop is prohibited for several years.

The roots are attacked when quite small, sometimes over the whole surface. The part infected ceases to grow, while adjoining parts enlarge. This results in a condition such as that shown in Fig. 136. The smallest rootlets are the points of attack, thence the disease proceeds to the potato and causes the surface spots as seen in the illustration.

The chief loss is in the cessation of growth. In badly infested fields no potatoes of marketable size mature, and the crop is not worth harvesting.

Long rotation to avoid placing sweet potatoes upon infested soil is advised. Halsted showed that soil-rot, even upon land badly infested with the fungus, can be controlled by sulfur and kainit; 400 pounds of each applied to the soil gave the best results. Treated plats gave 60 bushels of clean potatoes as contrasted with 5 bushels for the untreated plat.

Wilt, stem-rot (Fusarium sps.). - In this disease, prevalent from the Atlantic to Kansas, the leaves turn pale yellow and wilt; the stem is blackened within, and, later, ruptures. The whole vine dies unless supported by roots at some other point. Following the death of the original stem, the portion of the root still alive throws out a fresh growth of short stems and leaves near the center of the hill. Such efforts at recovery are inef-

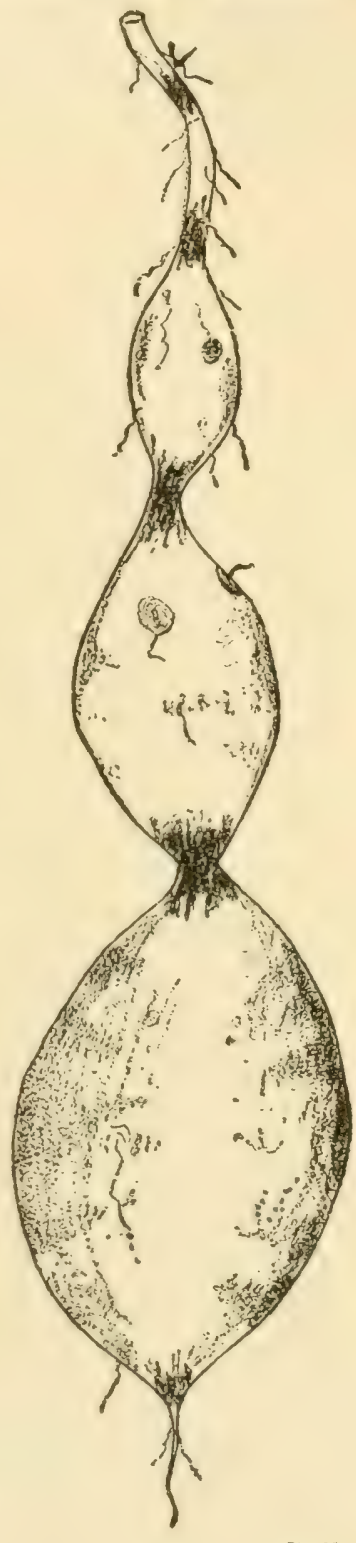

Frg. 136. - Soilrot of sweet potato. After Halsted. 
fectual. Losses range anywhere from 10 to 95 per cent of the crop, and the total annual loss is at least three-quarters of a million dollar's. Healthy potatoes must be used for seed; the hotbed should occupy uninfested soil, and rotation should be practiced. The suggestions given under soil diseases apply here.

\section{Minor diseases}

Dry-rot (Diaporthe bataiatis H. \& F., Phomopsis). - The affected part, often the upper end of the potato, becomes dry, wrinkled, and covered with numerous pycnidia, the flesh within changing to an almost powdery condition. Affected potatoes should be destroyed. Java dry-rot ${ }^{304}$ (Diplodia tubericola (F. \& E.) Taub.). - The potatoes show dark, shriveled patches with seattered pyenidia. The inner tissue is brittle and black. Scurf ${ }^{305}$ (Monilochotes infuscans E. \& H.). - A brown or rusty coat often forms over the whole potato. It causes no decay, but does result in shrinking, loss of volume, and unsightliness, which reduces the money value of the (rop). Blue-mold rot (Penicillium expansum). - The diseased parts, which may involve the whole potato, are of almost chalky color and consistency, dry, and inoffensive in character.

White-rust (Albugo ipomsece-pandurance (Schw.) Swingle). - White, glistening sori, $1 \mathrm{~mm}$. or so in diameter, appear upon the under sides of the leaves and upon the stems. These rupture and set loose a mass of powdery, snow-white spores. The tissue surrounding the scrus is pale, or yellow, as seen from the opposite side of the leaf. Later, brown patches result.

Leaf-blight (Phyllosticta batatas Cke.). - Spots of brown, dead tissue from 1-10 $\mathrm{mm}$. in diameter, round or angular, are frequent upon the leaf. They are very definitely bordered by a dark band, and bear numerous pyenidia, visible to the naked eye. In many instances these spots become so numerous as to cause the whole leaf to yellow and fall, and thus reduce the crop. 
Leaf-spot (Septoria bataticola Tauh).) is similar to leafblight, but with smaller spots. Charcoal-rot (Sclerotium bataticola Taub.) is similar in general character to Java dryrot. Rust (Colensporium ipomoere (Schw.) Burr.). - The alternate host is the pine. Rust is injurious in the tropies. Trichoderma-rot (Trichoderma lioningi Oud.) and Root-knot (nematodes) do some damage.

\section{TEA ${ }^{158}$}

The diseases of the tea plant are numerous and destructive, but since the crop is little grown in the continental United States, they may be enumerated, merely, as follows: Grayblight (Pestalozzia) and Brown-blight ('olletotrichum) spotting the leaves; Blister-blight (Exobusidium); Thread-blight (Stilbum) which kills branches or even the entire plant; Copper-blight (Lecstadia) causing copper-colored leaf-spots; Red-rust due to the alga, Cephaleurous, Canker due to Nectria; Blight due to Marasmius.

\section{TOBACCO.}

Root-rot ${ }^{\text {is, }}{ }^{469}$ (Thielania basicola (B. \& Br.) Zopf.). Known in Europe since 1897, this disease was first reported in the United States, in 1904, as occurring upon tobacco, though it has probably been long prevalent in tobaceo sections. It has been noted upon other hosts; namely, violets in Connecticut, Maryland, and District of Columbia; ginseng in Ohio and New York; also upon begonia, catalpa, and clover. Upon tobaceo it is now known in Ohio, Connecticut, Kentucky, and North Carolina, and its territory is increasing yearly. See also p. 23.

Root-rot in the seed bed often causes the entire crop of seedlings to be discarded, delaying planting or compelling a change of crop. In the field the loss sometimes amounts to 25 per cent.

The disease is recognized by the black decay upon the roots, sometimes by a cracking and deformation on the stem 
just above the roots and the failure of the plant to develop normally.

Damping-off due to Thielavia or other fungi may occur in seed beds. The plants are attacked when very young, and

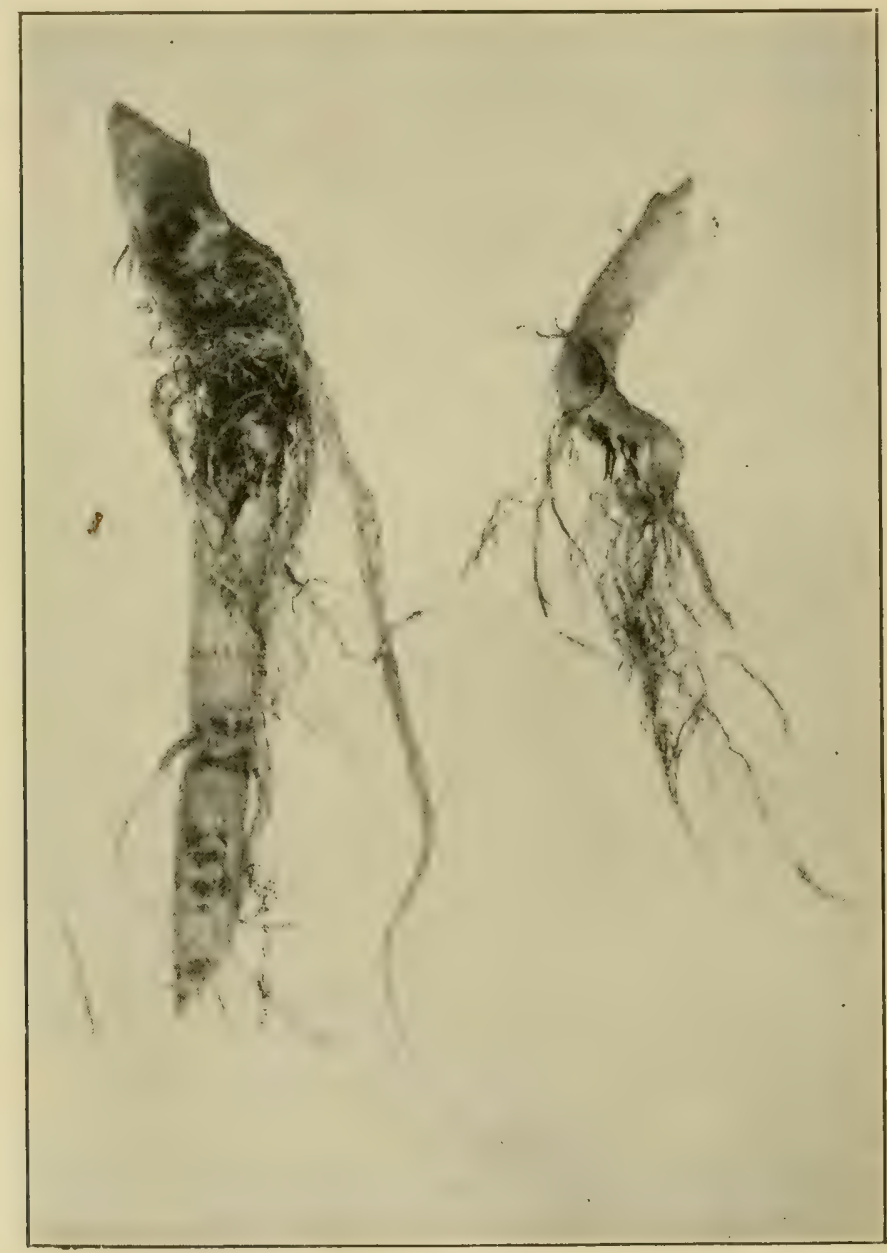

FIG. 137. - Tobacco roots showing effect of root-rot. After Gilbert.

death may result before they attain a height of more than $5-10 \mathrm{~mm}$. In other cases of milder attack the roots alone are invaded and the plants stunted. The tips of the rootlets 
become brown or black, and the entire root system is involved later. The decayed roots are brittle and break easily. Numerous lateral rootlets are put out to replace them, but these also succumb sooner or later. The leaves of diseased seedlings on rich soil are usually abnormally dark green. They may, however, in poor soil be of a sickly yellow color.

In the field the diseased seedlings may remain without growing for weeks; some yellowing, wilting, and dying. Others in light soil may survive and yield a fair, but late, crop; in heavy soil few survive to be of value. When large roots are attacked, the effect is generally limited to the outer surface, where a brownish, scurvy appearance is produced.

Sick plants in uninfested soil or healthy plants set in infested soil result in diseased crops, and the development of the disease when the causal fungus is present is favored by alkaline fertilizers.

To avoid loss, only uninfected plants from a clean seed bed should be used. A seed bed can be rendered safe and so maintained by disinfection, by the means suggested on page 460 , selecting the method best applicable to the conditions. Surface firing is the method most widely used in connection with the tobacco crop. Formalin and steam have also proved efficient in many instances.

The following measures conduce to reduction, though not to complete eradication of the disease: the use of light rather than heavy soils for the seed bed; avoidance of excess of water or fertilizer; the use of a new bed each year; avoidance of too heavy seeding. Infested fields should be given a rotation of nonsusceptible crops. A strain of white Burley has been developed to a state of high resistance.

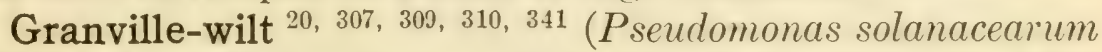
(EFS.) ). - This wilt was first noted in print in 1903 though known to tobacco growers in Granville County, N. C., as early as 1881. It takes possession of the soil, prohibiting successful tobacco culture in succeeding years, and in sections where tobacco is the chief, possibly the only profitable money 


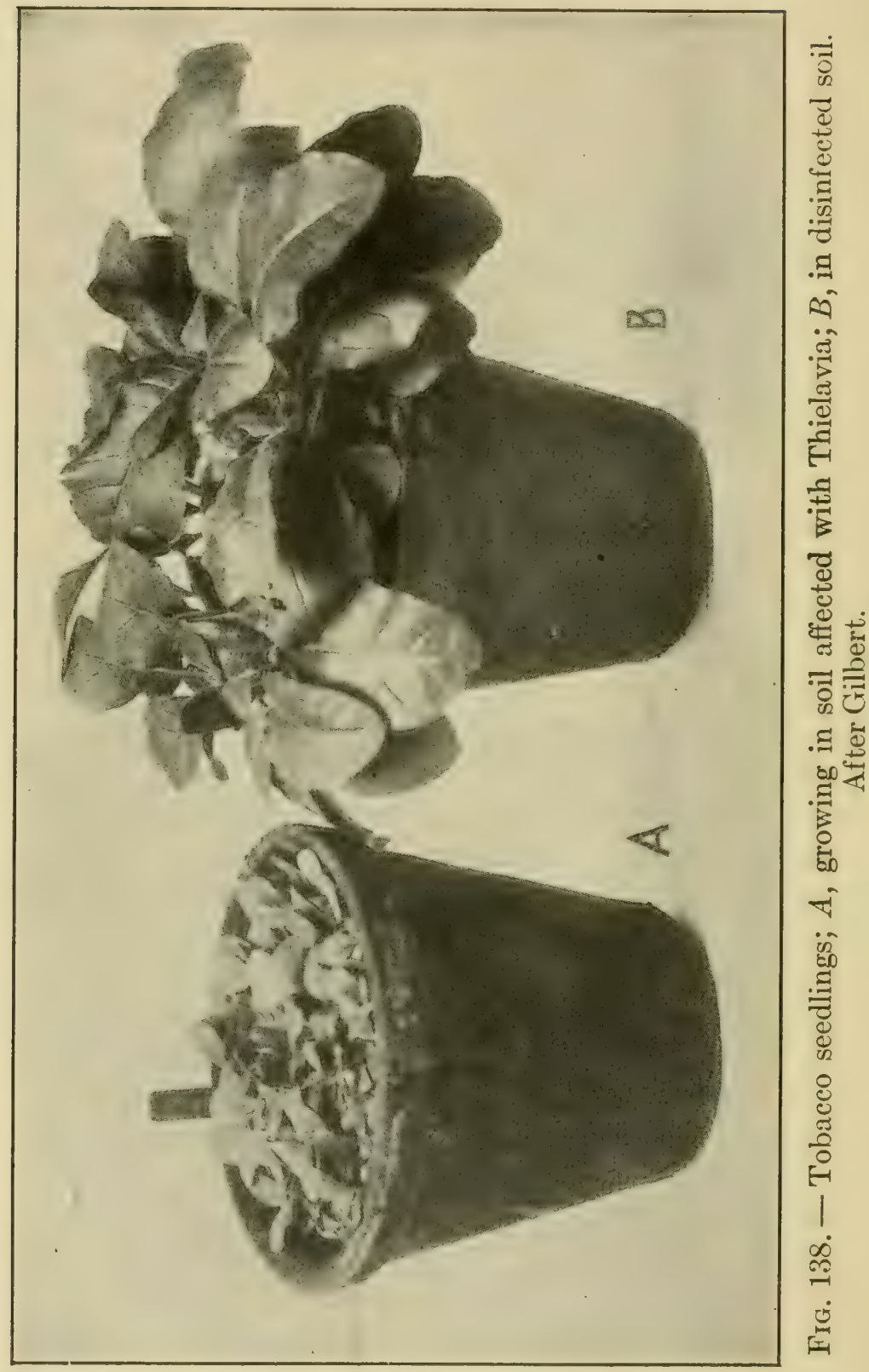


crop, the advent of this disease has caused great depreciation in farm values.

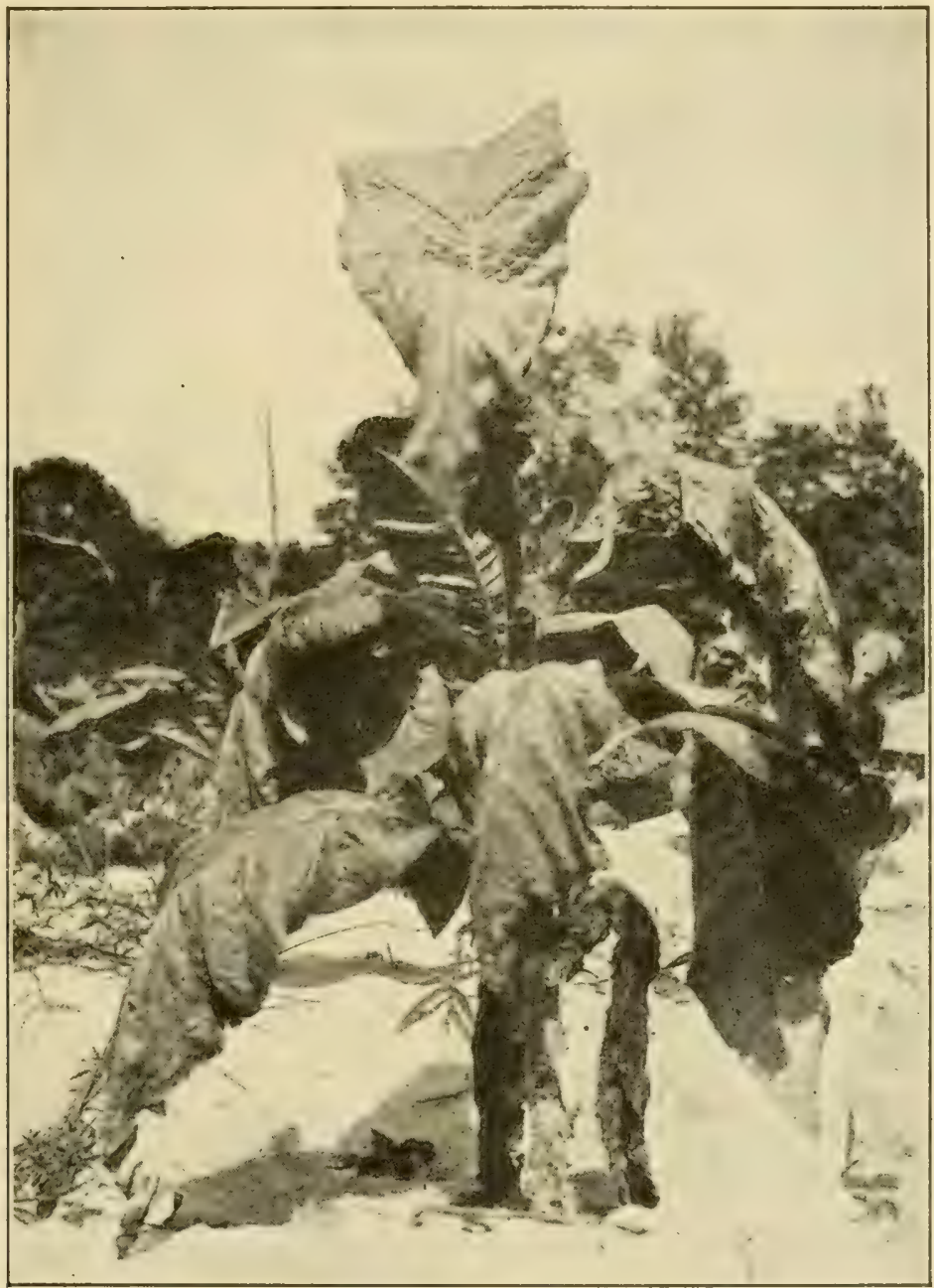

FIG. 139. - Tobacco plant in early stage of the Granvillewilt. Original.

The wilt is now known in North Carolina, Florida, Georgia, possibly Connecticut, and what appears to be the same disease has been described in Cuba, Porto Pico, France, the Dutch East Indies, and Japan. 
The first indication of the disease is given through the leaves, which droop, becoming soft and flabby as though suffering from want of water, the leaves remaining green. A typical case is shown in Fig. 139. Frequently the leaves on one side of the

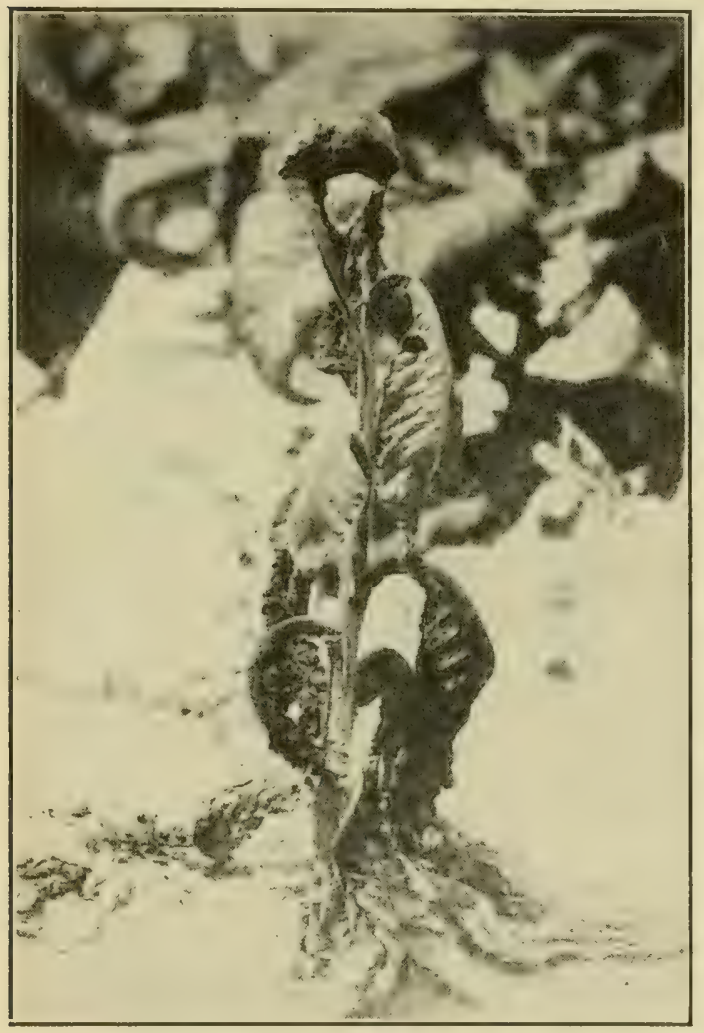

FIG. 140. - Tobacco plant in late stages of the Granville-wilt. Original. plant succumb earlier than those on the other side, and even a single leaf may show one-sided infection. The wilted leaves dry up, and eventually leaves and stalk die, though the stalk remains standing with its dead leaves still clinging to it.

At the stage of earliest wilting a section across the stem shows a yellowish discoloration of the woody portion. In more advanced stages, or in sections taken lower on the stem, the wood is found to be penetrated longitudinally by black streaks.

When all the leaves are wilted, the wood and bark at the base of the plant are blackened and the pith decayed, leaving the stem hollow or filled with a soft, rotten residue. If a badly diseased plant is cut off near the ground, a dirty, yellowish, viscous exudate issues from the cut wood.

The root is the seat of the original infection, and any plant which shows symptoms in its foliage possesses roots already in a pronounced stage of decay. In early stages 
one root or more may be diseased; in later stages all succumb.

In a series of rotation tests, planned and inaugurated by the author, ${ }^{310}$ it was found that growing corn, wheat, cowpeas, clover, and mixed grasses, either singly or in rotation for a period of five years on badly diseased soil, reduced the loss from wilt to an almost negligible quantity.

The means by which this disease spreads from field to field, and methods to prevent such spreading, are adequately discussed under soil diseases, p. 26.

A similar wilt, but due to a Fusarium, has been reported from Maryland.

Wildfire 306, 479 (Pseudomonas tabacum (IT. \& F.)).A hacterial leaf-spot, first noticed in 1917, is widespread in North Carolina, Virginia, and occurs also in Wisconsin. Loss of $\$ 100$ per acre for entire crops is commonly reported. The spot is $2-3 \mathrm{~cm}$. in diameter, often concentrically marked, and has a translucent border surrounded by a chlorotic halo. Another bacterial leaf-spot known as Angular leaf-spot (P.s. angulatum (F. \& M.)) was also described in 1917 as destructive in Virginia. The spots are angular and are not surrounded by the halo common in "wildfire."

Leaf-spot ${ }^{308}$ (Cercospora nicotiance E. \& E.). - This disease, most abundant upon the lower leaves, appears as brown, circular spots from the size of a pinhead to a centimeter or more in diameter. Older spots bear white centers bordered by a darker, raised line, and the centers often fall away, leaving irregular holes. The whole leaf yellows and ripens prematurely.

The disease was first described by Sturgis from specimens sent from South Carolina, where it was destructive, practically ruining the crop. A damage of $\$ 1000$ to one crop alone was noted. The use of Bordeaux mixture early in the season is permissible and advantageous.

Bed-rot (Corticium vagum). - Damping-off and rot of seedlings occur in the seed bed. The causal fungus may often be seen as spots of web-like white mold upon the ground around the affected plants. The general characters and 
prophylaxis are discussed under damping-off, p. 19. Seed

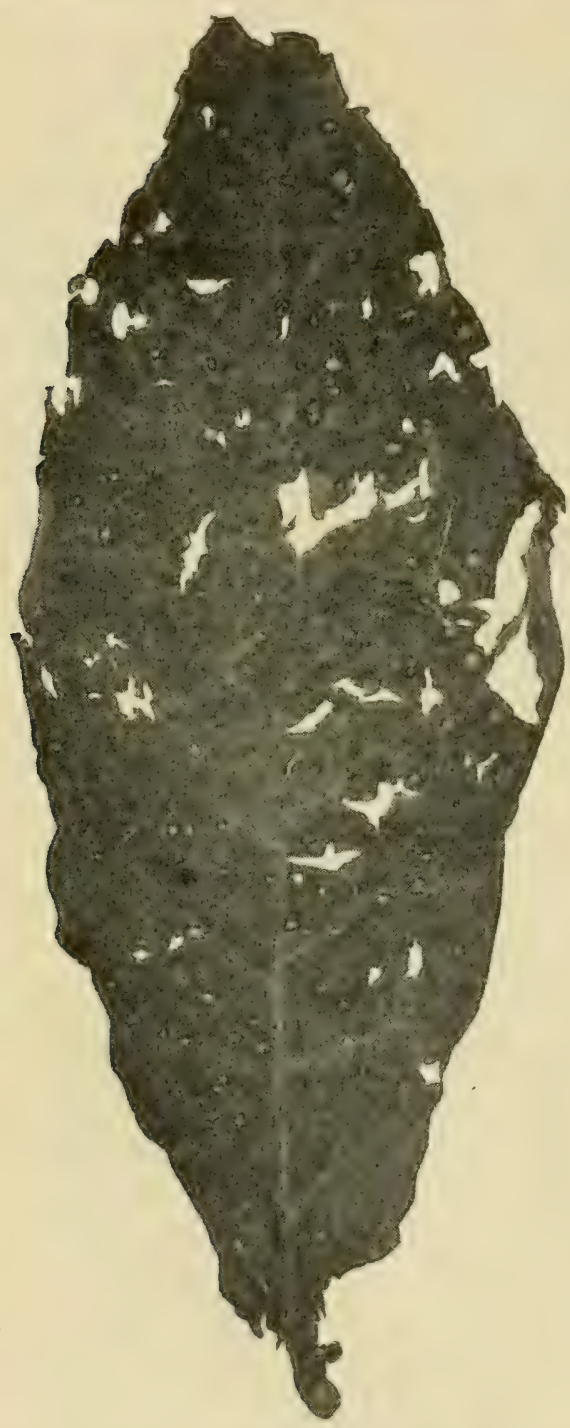

Fig. 141. - Tobacco leaf showing leaf-spot. After Conn. Agr. Exp. Sta. beds known to be diseased should be avoided unless previously disinfected.

Drop ${ }^{311}$ (Sclerotinia libertiana). - Damping-off due to Sclerotinia is reported as a common trouble in seed beds. The injury to the plant is similar to that of the usual damping-off while the fungus presents the characters described under lettucedrop. Young plants are killed; older plants may survive, and if set in the field, develop poorly.

Mosaic. ${ }^{312,313}$ — Wherever tobacco is grown the mosaic is very widely distributed and destructive. Depreciation of $\$ 50,000$ in quality was attributed to it in Ohio in 1905. It produces a mottled appearance of the leaves due to variation in texture and greenness; parts of the leaf showing full green and normal thickness, other spots pale or yellowish green, and thin. Accompanying these signs are distortions due to unequal growth, wrinkled or curled leaves, and leaves of one-sided growth. Slightly affected leaves are depreciated in value; badly diseased leaves are worthless. 
The cause of mosaic is unknown, but it has been repeatedly shown experimentally that it can be communicated from plant to plant by first touching a diseased plant and later touching a healthy. one. The disease then appears within six to fourteen days. Thus the disease is spread largely by topping. In nature it is probably spread by insects. The virus appears to be present in all parts of an affected plant, even in the trichomes, and, when inoculated locally, spreads rapidly throughout the plant, though the disease is not transmitted to the offspring through seed from diseased capsules. Tomatoes, petunia, physalis, datura, solanum (but not the potato), and pepper are susceptible to inoculation from tobacco plants.

The seed bed should be either new or thoroughly disinfected by steam or firing, and no tobacco refuse or tobacco water used on it. Diseased seedlings in the bed, if any appear, should be destroyed. It is well to top, worm, and sucker the healthy and sick plants separately, on different days, thoroughly washing the hands with soap and water before passing from the diseased to healthy plants.

Orobanche. - This is a true flowering plant, which draws its nourishment from the roots of the tobaceo plant to which it is attached. The orohanche occurs in.small elusters, its stalks are from 1-4 dm. tall, and entirely devoid of green color.

They should be pulled and burned before they produce seed. Root-knot (nematodes), see p. 24.

Curing-house "diseases." - When tobaceo is cured by natural heat, various rots may oceur. Among these are: Stem-rot, due to various fungi; Pole-rot, consisting of small, blackened areas upon the leaf, linited at first to the regions near the veins. These spots may enlarge within two days to cover whole leaves, and the contents of the entire barn may become worthless, the leaf having become so wet and soft as to readily fall apart. The cause of these rots is not certainly known; indeed there may he several separate organisms, each capable of inducing such rot. 
These troubles can largely be controlled by proper regulation of the moisture and temperature conditions, i. e., by building such barns that outside air, when too damp, can be excluded, and yet with proper provision for ventilation to carry off the moisture from the drying tobacco.

Wet-butts is due to freezing before curing is complete; White-vein to rapid drying; Black-rot (Sterigmatocystis nigra $\mathrm{v}$. Tieg.) occurs during the sweating, the tobacco turning black and losing its proper texture. It is brought about by too high moisture content.

\section{TOMATO. ${ }^{314,341}$}

Bacterial Wilt, blight (Pseudomonas solanacearum (EFS.)). - This disease of the tomato is widespread, especially in the South, and prohibits tomato culture upon many thousands of acres of land. It occurs especially in the states south of Maryland, and has also been noted in New Jersey, Delaware, Ohio, and Colorado.

The leaves wilt, either singly or throughout the entire plant at once; growth stops and the plant dies. The stem appears at first dirty green, then brown, then black. It soon shrivels, and the veins become brown and show as narrow black lines, or in section as black dots. The wilting of the foliage and the blackening of the vascular bundles are distinctively characteristic.

Soil bearing diseased plants one season remains infested during succeeding years and must be abandoned for tomato culture. The disease is spread from plant to plant largely by the potato bug (Colorado beetle) and other insects. For this reason all leaf-infecting insects should be given special attention. In other respects this disease in symptoms, cause, dissemination, and treatment is similar to the usual soil diseases.

Another wilt, similar but of slower development, is described as caused by Bacterium michiganense EFS. ${ }^{341}$

Wilt ${ }^{315}$ (Fusarium lycopersici Sacc. and Fusarium sps).This wilt is also widespread. It occurs not infrequently 
as the cause of partial or even total losses of the crop. The plants usually reach considerable size, blossom, and set fruit before showing the disease, which first appears in the field on single plants, generally sickly looking, and of unhealthy color, followed by symptoms of wilt. In the worst cases all of the plants die before the end of the growing season, sometimes quite suddenly at the last; or the crop may mature with plants missing more or less extensively. If a badly affected or dead plant be pulled up, the roots are

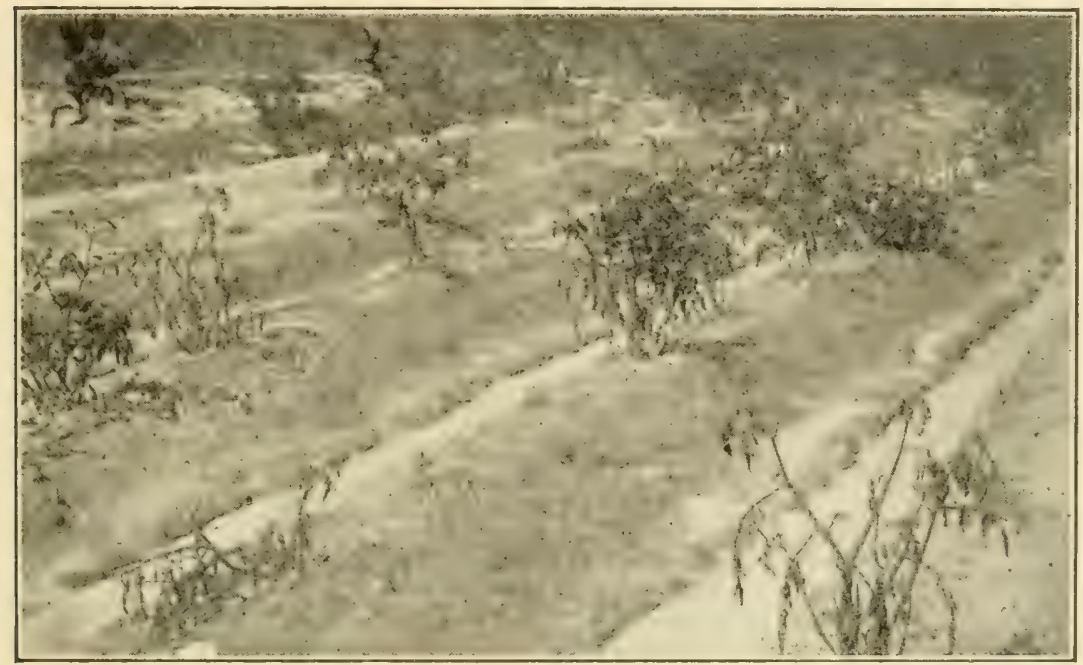

FIG. 142. - Tomato field showing effect of wilt.

found to be decayed. If a plant is pulled up as soon as it begins to show wilting, the roots look healthy and sound, but close inspection shows that many of the larger laterals are decayed at the ends. The disease consists of a dry rot of the roots, commencing at the ends and working upward.

The first symptom is a pale yellowish color of the lower leaves, which soon dry from the tip toward the base without spotting. The veins and woody portion of the stem are darkened, especially upon the side bearing the diseased leaves.

As to means of dissemination and control, what is said under soil diseases will apply. 
Leaf-mold (Cladosporium fulvum Cke.). - Under glass in the North and occasionally in the open, especially in the South, this disease is destructive. It occurs as rusty or cinnamon brown blotches on the lower side of the leaf, which

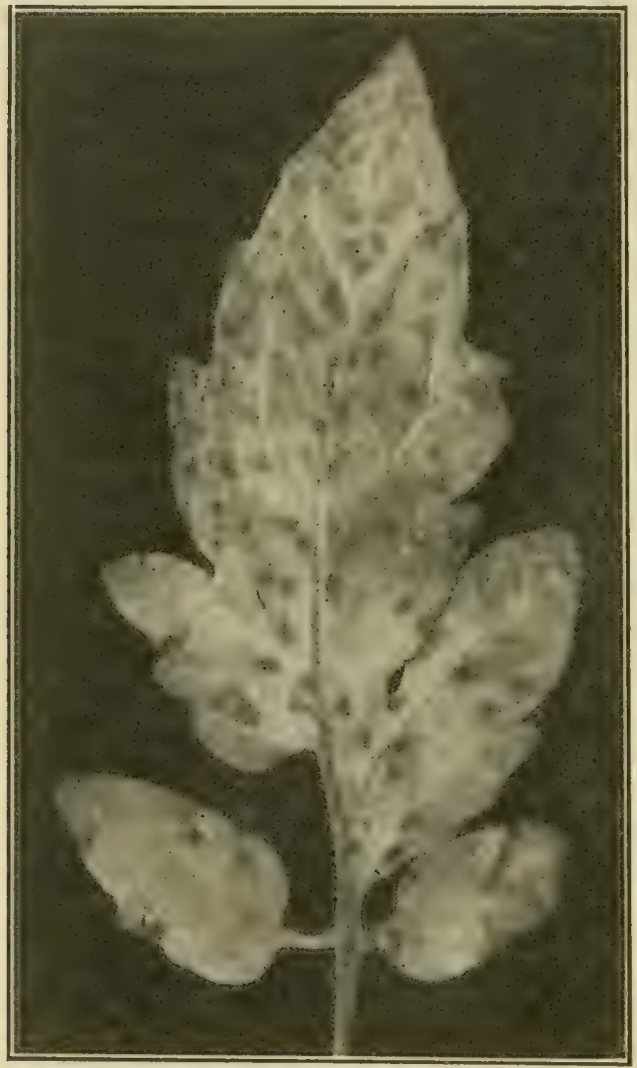

FIG. 143. - Tomato leaf showing spots of mold. turns yellow above, then brown or black, curls, and dies. The loss of food supply consumed by the parasite, together with the loss through destruction of the leaf green, injures the yield seriously.

Indoors ventilation is the best remedy, coupled with clean culture to avoid carrying the pest over to another year. On fields Bordeaux mixture would doubtless serve well.

The causal fungus of this disease was first described in 1883 by Cooke from specimens collected in North Carolina.

Leaf-spot ${ }^{316}$ (Septoria lycopersici Speg.). - A very common leaf-spot has almost precisely the general appearance illustrated in Fig. 143, except that small pycnidia occupy the spots. It is known throughout the United States, South America, Europe, and Australia, and often causes large loss. In some states it is the most important tomato disease. The total loss in the United States is estimated as $\$ 5,000,000$ annually.

The disease attacks the older leaves first and proceeds toward the top of the plant, often causing the loss of so 
many leaves as to give the plant the appearance of blight, and resulting in complete ruin of the crop. The presence of the leaf-spot distinguishes this from any of the blights. Spraying with Bordeaux mixture is effective against this disease though valueless against the various wilts. Especial attention should be given to guard, by spraying, the seedlings in the seed bed, using a weak Bordeaux mixture. Moving among the plants when they are wet spreads infection. All refuse should be burned or plowed under.

\section{Downy-mildew, late-blight ${ }^{315}$ (Phytophthora infestans} (Mont.) De Bary). - Arising from the same cause as the dreaded potato blight, of which host the tomato is close kin, is the tomato blight which causes large loss of the crop in some sections of California. It has been reported also in Massachusetts and Colorado.

As with the potato, the amount of damage is closely dependent upon weather conditions, the disease being greatly favored by a warm, humid atmosphere. It appears suddenly as dark, discolored spots on the fruit and other green parts. On the fruit the spot, usually upon the upper side, is watery and large. Many tomatoes, apparently healthy when picked, rot in shipment, the rot being accompanied, under humid conditions, by a fine, white surface mold. Dark spots upon stems and branches soon extend throughout the whole plant, giving it the appearance of one stricken by frost.

Protective spraying with 5-5-50 Bordeaux mixture, as recommended for the potato, will probably serve in case of this disease. In regions of infrequent rainfall it is necessary to spray only after each rain.

Fruit-rot ${ }^{317}$ (Phoma destructiva Plow.). - Leaf-spots are present, but it is as a spot upon either green or ripe fruit that greatest injury is incurred. The spots are $1-3 \mathrm{~cm}$. in diameter, brownish-black, and depressed. This trouble is most prevalent on tomatoes, originating in the South, and shipped to northern markets, and on such fruits causes heavy losses.

Blossom-end rot. - Readily recognized from its name, this troublesome disease is essentially a dry, black rot ap- 
pearing on the blossom end and injurious chiefly to early tomatoes. It is especially harmful, owing to the high value of the early fruit that it destroys. Various factors have been named as the cause, and it cannot yet be said with certainty which is responsible.

The trouble is more serious upon droughty soils and can to some extent be controlled by irrigation or moisture conservation, $i$. e., increasing the water-holding power of the soils by the addition of organic matter and surface tillage.

Early-blight (Alternaria solani (E. \& M.) J. \& G.).Ruin is brought to the crop in many seasons, particularly in the southernmost states, by this blight, which is identical with the potato early-blight. The leaves bear numerous, small, usually angular spots, often concentrically marked, which appear first as minute brown specks, later showing a pale center with a darker border. In badly affected leaves the tips dry and curl up. Petioles and stems are also attacked.

Thorough spraying with the usual Bordeaux mixture should be begun at the first indication of the disease and continued weekly, or semiweekly if growth is rapid and the weather damp. Often it is still better to begin spraying in the seed bed.

Southern-blight (Sclerotium rolfsii Sacc.). - This blight is often completely destructive to the tomato in the southernmost states. The first sign is wilting of the terminal portion of the plant, distinguishing Southern-blight from other wilts, which commence with the lower leaves.

For discussion and treatment, see pepper.

Leak (Rhizopus nigricans). - The effect is much as on strawberries and the loss during shipment is large.

\section{Minor diseases}

Anthracnose (Colletotrichum phomoides (Sacc.) Chest.). This is chiefly a disease of the ripe fruit, either upon the vines or after harvest. It appears as sunken, discolored spots with wrinkled surfaces and black specks, the acervuli. The disease does much damage to fruit before it is picked, and also injures the keeping quality. 
Sooty-mold (Fumago vagans Pers.). - Dense, olive-black growths of mold form upon the leaves. Damping-off occurs in the seed bed. Timber-rot (Sclerotinia), see lettuce. Buckeye-rot (Phytophthora terrestria) is a zonate, hard rot of fruit. Winter-blight. - Loss of $\$ 2,500 \mathrm{in}$ one house is reported, but the disease is not generally distributed. Development is dwarfed, and the stems show brown lesions in cortex and bundles, but no parasite has been demonstrated. Rosette ${ }^{318}$ (Corlicium vagum). - This is identical with the potato black-scurf, showing similar lesions upon the root and stem near the ground. The tops have long internodes and dwarfed leaves which are somewhat curled.

Upon the ripe fruits, especially those touching the ground, this disease occurs as a brown rot upon a slightly wrinkled epidermis. Hollow-stem appears to be due to improper growth con-

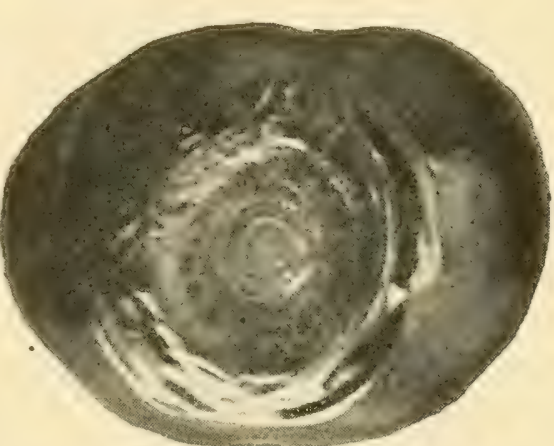

Fig. 144. - Tomato anthracnose. After Heald.

ditions. Blossom-drop is due to unknown cause. Leaf-roll is similar to that of potato. Root-knot (nematodes) is common.

CEdema. ${ }^{460}$ - This is a condition of overgrowth of certain cells of the plant, causing swelling of veins and leaf tissues, and curling of the leaves in irregular growth. Usually confined to the greenhouse, it is caused by excess of water, lack of light, improper temperature, and especially by overheated soil, and is readily controlled by careful management.

Chlorosis. - The leaves show completely whitened areas. The cause is unknown. Mosaic. - Upon the tomato appears a mosaic, similar to that of tobaceo. Aside from this apparent kinship little is known about it.

TURNIP. See p. 165.

WATERMELON. See p. 178. 


\section{CEREALS}

Cereal Smuts in General 526

Dark or black masses usually dusty, though sometimes compact, replace floral parts, grain, glumes (chaff), or in some cases involve the leaves and stem. The smut mass consists almost wholly of the spores of the causal fungus which gains entrance to the plants when they are in a susceptible condition of development, the time varying with different kinds of plants, and grows within the plant as an active parasite, drawing its nourishment from its involuntary host. When the host plant has attained the right age, and correspondingly, too, the fungus has reached its proper stage of maturity, the disease becomes apparent to the eye as the familiar smut.

Smut spores under suitable conditions of moisture, food, and heat sprout, and produce smaller spores, sporidia, which, if they fall upon the right host plant in the proper period of its development, penetrate into it and grow. The host plant may or may not outgrow its enemy. In any event, its presence is not apparent to the naked eye until the period of maturity arrives again, and another crop of dark-colored spores is produced.

Kinds of smut. ${ }^{320}$ - In all, something more than 600 species are now recorded. Over 205 of these are found in the United States, growing upon some 442 different kinds of plants, most of which are unimportant and wild; although some of them, such as the corn smut, onion smut, and the smuts of wheat, oats, rye, barley attack plants of high economic value and cause great damage. The yearly toll from three of these that are easily preventable has been estimated to be as high as $25,500,000$ bushels of wheat, $110,000,000$ bushels of oats, $6,000,000$ bushels of barley. 


\section{Cereals}

Negligence thus involves a total of more than $100,000,000$ bushels of grain annually.

The common corn smut develops upon any part of the corn plant, but is usually most conspicuous upon the ear and tassel. Another smut of corn growing only upon the tassel is less widely known. Rye smut develops mainly in the stem; the smut of oats, wheat, and barley in the ovary, the grain; onion smut grows upon the leaves, often in the bulb.

It is evident that to know precisely what parts and at what periods the various crop plants are open to infection is of utmost importance in looking to the prevention of the smuts. It was early proved that oats are susceptible to infection only in the early stages of their development. The exact work of Brefeld proved that corn is susceptible to infection on all young, tender, growing parts, and in 1896 Maddox, Brefeld, and others showed that in the case of the loose smut of wheat and the barley smut infection occurs while the plant is in bloom, this infection affecting the seeds and resulting in smutted plants in the crop raised from such infected seeds.

It is upon these facts that our present modes of prevention are based. The treatment for oat smut is such as to kill the spores adhering to the grain and thus prevent infection during the period of susceptibility, $i$. e., the very young seedling condition. The same treatment is effective for the stinking smut of wheat. The loose smut of wheat gaining entrance to the plant before the grain is harvested cannot be prevented by such means without danger to the seed, but can be prevented by the use of clean, uninfected seed. Corn, being susceptible at all ages of its growth, cannot be protected by seed treatment.

Owing to their great damage and conspicuousness, smuts have attracted attention from very early times, and many references to them are found in ancient writings. Probably not until 1791, however, was their true nature as vegetable parasites recognized. Many were the means that were 
suggested for the prevention of these pests: placing laurel branches in the field, change of seed, avoidance of manures, thorough screening, soaking in brine, etc.

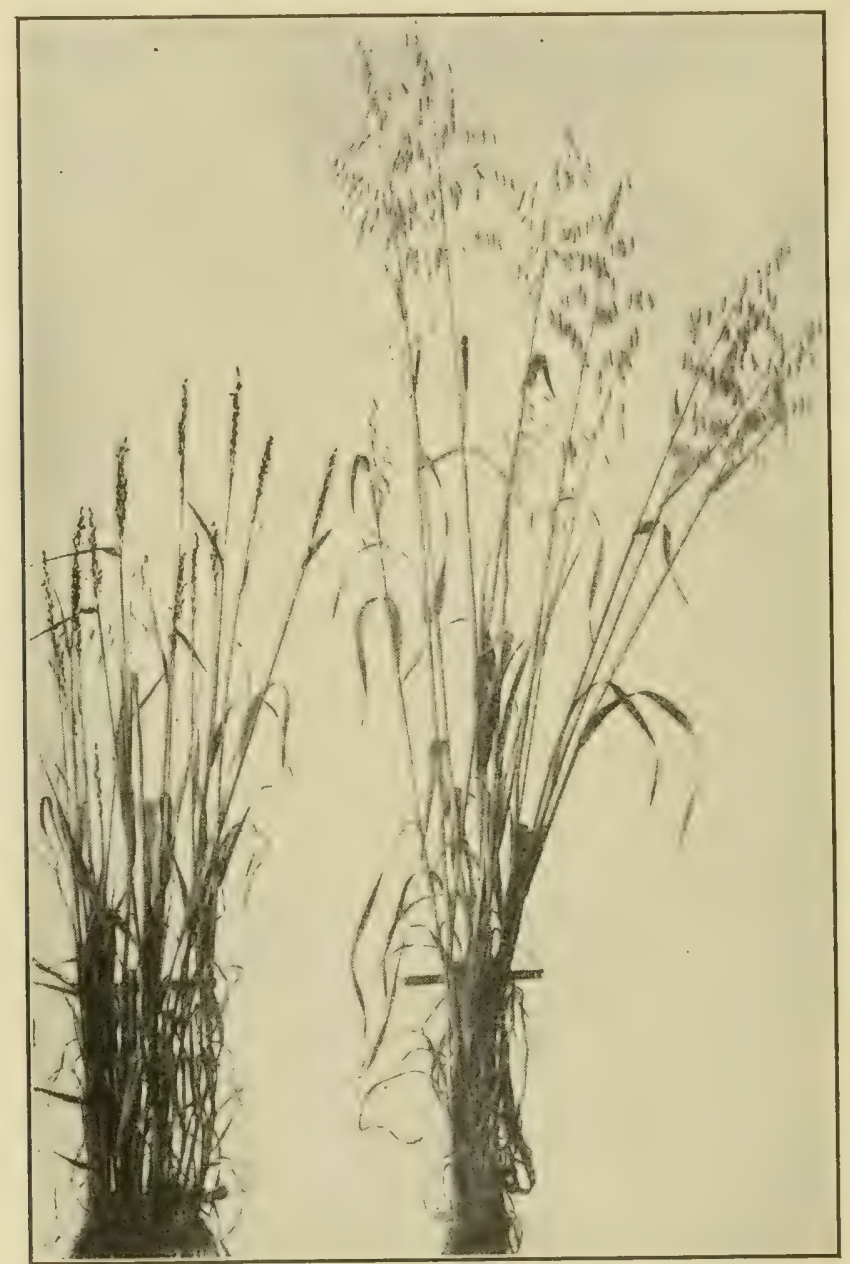

FIG. 145. - Oat plants, smutted and healthy; note difference in height.

Preventive treatments. - One early remedy that has proved its value and remained in common use, soaking the seed in copper sulfate, was first tried by Tessier in 1789, after he, in 1786, and Young, in 1787, had tested numerous chem- 
icals. His test was without results, since, during the season of his experiment, neither treated nor untreated wheat was smutted. Prévost of France in 1807 was the first to publish an account of the successful use of copper sulfate for wheat smut. He recommended a solution of about 6 per cent strength, and the remedy was, and is, still widely used. Solutions varying in strength have been employed, one-half per cent being most highly recommended. In 1873 Dreisch improved the copper-sulfate treatment by using limewater following the copper sulfate; thus, to a large extent, diminishing the amount of seed killed by the treatment.

Jensen, a Dane, in 1887 and 1888 reported excellent results with oat, barley, and wheat smuts from dipping the seed in hot water. Untreated seed gave 36 per cent of smut. One-fourth per cent of copper sulfate gave one-half per cent smut. Warm water, $56^{\circ} \mathrm{C}$. $\left(133^{\circ} \mathrm{F}\right.$.) for five minutes, gave no smut. Kellerman and Swingle soon afterward introduced this last treatment into this country.

In 1888 the germicidal action of formalin was discovered and this substance was used as a preventive for oat smut by Bolley of North Dakota during the years 1894 to $1897 .^{321}$

The use of the various smut remedies is usually attended by an increase in vigor of the plants, and by an increase in yield in excess of that due simply to the elimination of the smutted grains. Thus increases of over $t$ bushels per acre have been found in wheat fields in which only about $11 / 2$ bushels were destroyed by smut. Similarly, with oats, the increase in yield is often five times as great as the quantity of grain lost by smut in fields not treated. This may be due to elimination of the fungus from plants which otherwise would have to resist it throughout a portion of their growth period or it may be due to the killing of spores of numerous fungi other than those of smut on the seed which exert an adverse influence during and following germination. An excellent account of the early history of smuts in general may be found in the Report of the Kansas Agricultural 
Experiment Station for 1889, and a comprehensive article upon corn smut in the Twelfth Report of the Indiana Agricultural Experiment Station.

Present methods of seed treatment. ${ }^{324,325}$ - Preliminary to any form of seed treatment, the seed should be thoroughly cleaned, in some cases floating-out of the spore-filled grains is necessary, and after treatment it should be protected from contamination. Sacks, bins, drills, etc., with which seed will come in contact, should be disinfected with formalin.

The common methods of cereal seed treatment now are by formalin, hot water, or copper sulfate. The first is simpler and easier and is preferable whenever it is effective. In treating for certain kinds of smut, however, the formalin treatment is not so effective as is the hot-water method. These three methods with their limitations are as follows:

The formalin wet method. - The seed to be treated is either dipped in the solution of formalin, 1 pint to 30 or 40 gallons of water, or this solution is sprinkled on the seed, with thorough mixing, at the rate of one gallon to each bushel of seed. The pile is then blanketed and later spread out to dry.

In a modification known as the formalin dry method ${ }^{323}$ the seed is shoveled from one pile to another and each shovelful is sprayed or sprinkled with a solution consisting of, formalin (37 per cent formaldehyde) diluted with an equal amount of water, and applied at the rate of one quart (1 pint of formalin) to 50 bushels of seed. A quart sprayer is convenient for use. After treating, the seed should be blanketed for five hours, when it is ready for planting. Workmen will find the formalin irritating to the mucous membrane, and therefore should apply the solution as directly as possible to the seed. A variation from this method is to mix 1 pint of formalin with 10 or 12 gallons of water and sprinkle on the seeds as they are shoveled over. They may then be sacked immediately and sowed next day. This method, employing a strong solution, seems to be both safe and efficient with oats, but its use with wheat and other grains is 
still in the experimental stage and is apparently attended with danger to the seed.

On a large scale, oats may be treated by the formalin method at the rate of 500 bushels an hour, by throwing the formalin solution, by means of a steam pump, against the grain as it falls through elevators arranged with deflectors so as to give proper contact. ${ }^{322}$

The formalin treatments as above given are effective against those smuts in which the spores lie upon the surface of the seeds and in which the smut fungus is not within the seed itself, e.g., oat smuts, wheat bunt, covered smut of barley and rye, rice smut, sorghum, and millet kernel-smut.

Long time formalin treatment. - Seeds are immersed for two hours in the formalin solution, 1 pint to 40 gallons of water. Favorable results are reported even in those cases of floral infection where the hot-water treatment was formerly thought necessary, $e . g$., in the cases of wheat loose smut and the covered smut of barley, but complete reliability of this treatment for these diseases is not yet demonstrated.

Copper-sulfate treatment. - This is the oldest effective treatment of cereal seeds. It has, however, on account of its greater cost and the larger injury done to the seed, in the main been superseded by formalin methods. It is effective against the same smuts for which formalin is used, but is recommended only where there is heavy soil infestation. A solution of 1 pound of copper sulfate and 1 pound of common salt to 5 or 10 gallons of water is used, and the seed either soaked, sprinkled, or dipped. Treatment should be completed by dipping or sprinkling with milk of lime ( 1 pound of quicklime to 10 gallons of water).

The hot-water treatment ${ }^{32-4}$ is employed for those smuts in which the fungus is within the seed, not superficial. There are three forms: 1 , the short treatment; 2 , the modified hotwater treatment; 3 , the long treatment or pasteurization. The first consists, in general, in subjecting the seed to water at a temperature ranging from $52^{\circ} \mathrm{C} .\left(120^{\circ} \mathrm{F}\right.$.) to $61^{\circ} \mathrm{C}$. $\left(142^{\circ} \mathrm{F}\right.$.) for 10 to 15 minutes. It is of use in only those 
cases where formalin can be used, and will therefore not be described further. The directions for the modified hot-water treatment, drawn from Freeman and Johnson, ${ }^{326}$ with slight changes, are as follows:

After the secd has been cleaned by thorough fanning and sifting, it should be soaked for from five to seven hours in water at ordinary room temperature, $17^{\circ}$ to $22^{\circ} \mathrm{C} .\left(63^{\circ}\right.$ to $72^{\circ} \mathrm{F}$.), then placed in small, loose sacks or wire baskets, containing not more than one-half peck each, and drained for a short time. The seed must be treated in small lots in order that all of the grain may quickly and uniformly reach the desired temperature. Two tubs or vats of water should be provided. In one tub (No. 2) the exact temperature required should be maintained. The other tub (No. 1) is used for bringing the grain to the temperature of the treatment, so as not to lower the temperature in tub No. 2. Galvanized iron tubs of 20 to 40 gallons capacity, and kerosene or gasoline double-burner stoves, are convenient. The drained sacks or baskets of seed should be plunged into tub No. 1 for a minute, then transferred to tub No. 2, and kept agitated while immersed at temperatures and for the periods specified below, the temperatures mentioned being maintained as nearly as possible: For barley, 13 minutes at $52^{\circ} \mathrm{C} .\left(125.6^{\circ} \mathrm{F}\right.$.) ; for wheat, 10 minutes at $54^{\circ} \mathrm{C}$. $\left(129.2^{\circ} \mathrm{F}.\right)$. In treating barley, if the temperature should rise above $52^{\circ} \mathrm{C} .\left(125.6^{\circ} \mathrm{F}\right.$.), the time of immersion must be reduced to ten minutes at $53^{\circ} \mathrm{C} .\left(127.4^{\circ} \mathrm{F}\right.$.), or five minutes at $54^{\circ} \mathrm{C} .\left(129.2^{\circ} \mathrm{F}\right.$.). Above $54^{\circ} \mathrm{C} .\left(129.2^{\circ} \mathrm{F}\right.$.) there is no safe margin. If the temperature falls slightly below $52^{\circ} \mathrm{C}$. $\left(125.6^{\circ} \mathrm{F}\right.$.), the time of treatment should be increased in proportion. A temperature lower than $51^{\circ} \mathrm{C} .\left(123.8^{\circ} \mathrm{F}\right.$.) is not effective. In treating wheat, if the temperature should rise above $54^{\circ} \mathrm{C} .\left(129.2^{\circ} \mathrm{F}\right.$.) or fall below $52^{\circ} \mathrm{C} .\left(125.6^{\circ} \mathrm{F}\right.$.), the time for immersion must be diminished or increased accordingly. Under no circumstances should a temperature of more than $55^{\circ}$ (.$\left(131^{\circ} \mathrm{F}\right.$.) be allowed. Temperatures below $51^{\circ} \mathrm{C} .\left(123.8^{\circ} \mathrm{F}\right.$.) are ineffective. A reliable thermometer 
is necessary, since the use of an inaccurate instrument may result in injury to the germinating power of the grain or in failure to prevent the smut. At the end of the period of treatment, the grain should be transferred to a cold bath to terminate the action of the heat.

Two men working together can easily treat one bushel of grain an hour, or enough seed in one day to sow a seed

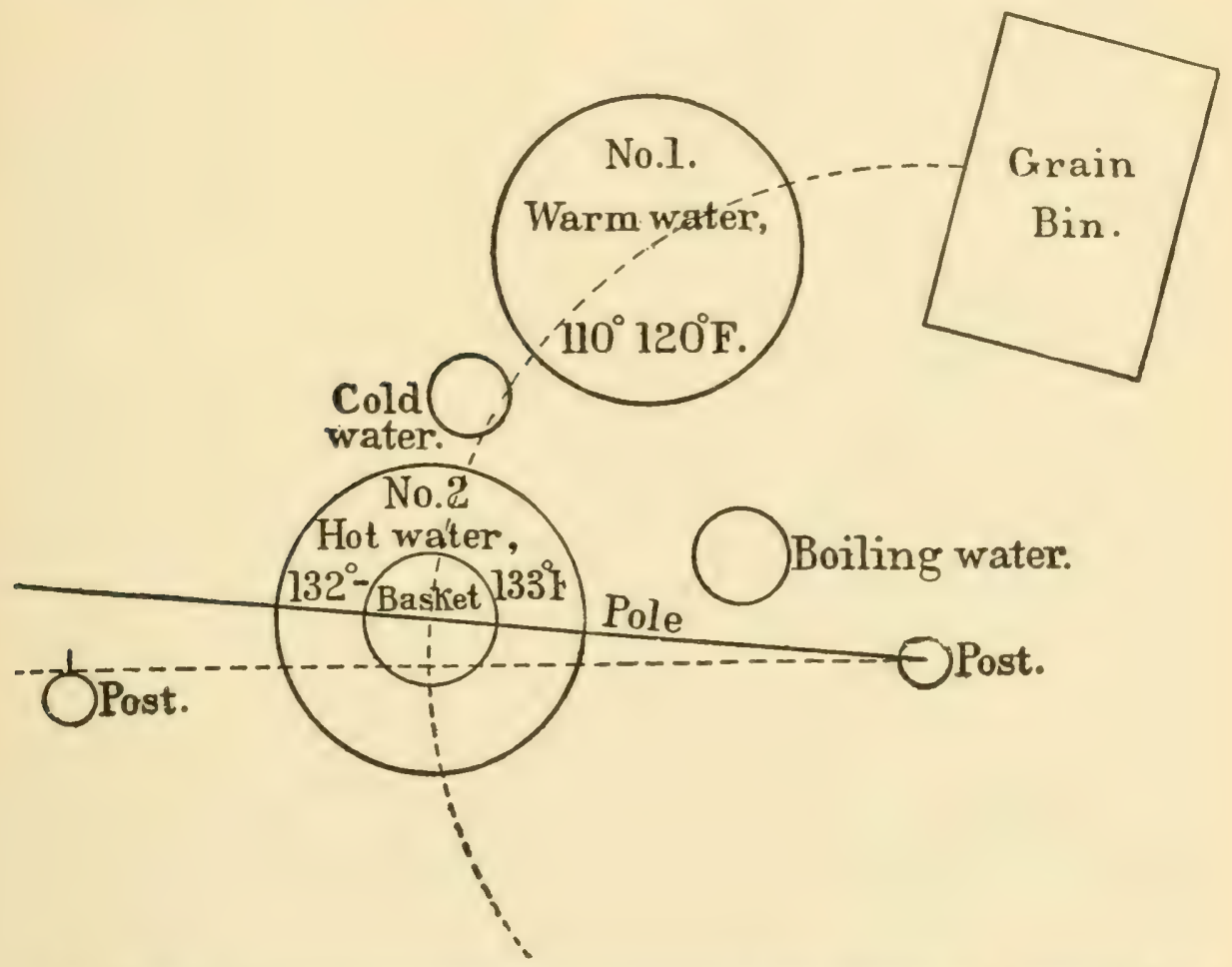

FIG. 146. - Diagram showing a convenient arrangement of utensils for the Jensen hot-water treatment. After Swingle.

plat of from 6 to 10 acres. The seed may be dried by spreading it out in thin layers, not over $5 \mathrm{~cm}$. in depth, on a clean granary floor or on canvas, and shoveling or raking it from time to time. It should not be allowed to sprout. Care must be taken to prevent freezing of the grain when it is moist, as this will impair germination. 
Seed treated as indicated may be planted as soon as it is sufficiently dry to run freely through the drills, making allowance for the swollen seed.

The long hot-water treatment or pasteurization consists in subjecting the seed to a temperature of $45^{\circ} \mathrm{C}$. $\left(113^{\circ} \mathrm{F}\right.$.) for three hours, the permissible range being $44^{\circ}$ to $46^{\circ} \mathrm{C}$. $\left(111^{\circ}\right.$ to $115^{\circ} \mathrm{F}$.). The advantages of this method are greater efficiency, less danger of killing the seed, and the need of but a single bath. It is difficult, however, to maintain the proper temperature for so long a time.

These hot-water treatments, though effective against both smuts of wheat and of barley, are used primarily for the loose smuts of barley and wheat, and are generally combined with the seed-plat, see p. 275, and rogueing. Hot-water treatments are much simpler and more accurate of application if steam is available for heating purposes.

Injury to seed by treatment. - The germinating power of treated seed should be tested, and if low, the rate of planting should be correspondingly increased. The formalin treatment does but inappreciable injury to sound seed, though cracked seed are injured by chemicals. The softer wheats are more often cracked than the harder varieties, therefore are more liable to injury by chemical treatments. Seed subjected to wetting may be injured in germination power if dried too slowly. However, poor stands attributed to seed injury often are really due to the use of too little seed, since the treated, swollen grain feeds more slowly through the drill.

The sensitiveness of various seeds ${ }^{327}$ to treatments is indicated in the following table. 0 shows no injury, tr a trace only, +++ very serious, ++ less serious. It is to be added, however, that some experimenters report injury to wheat from the dry treatment.

Formalin

$$
\text { Wheat Rye Oats Barley }
$$

Dip.............. 0

Sprinkle............ 0

Dry.............. 0

Soaking 1 hour....... 0
0

0

0

0
0

0

0
0

0

0

0 
Copper sulfate

\section{Wheat Rye Oats}

Barley

10 minutes......... 0

Long time...........+ + +

$\begin{array}{cc}0 \\ ++\end{array}++$

tr

Hot water

$\begin{array}{lll}133^{\circ} 12 \text { minutes.......t+ } & ++ \\ 101-115^{\circ} 3 \text { hours......tr } & 0 & \text { tr } \\ \text { tr }\end{array}$

Modified

$129^{\circ} 10$ minutes........ ++

tr

The Seed Plat. - A good, clean, well-cultivated piece of land should be selected for raising seed. The plat should be large enough to provide at least twice as much grain as will be necessary for farm seed the following year in order to allow for loss in cleaning and selecting. This seed plat should not lie near fields of smutted crops of the same cereals, nor should it be so located that the prevailing winds at flowering time can carry spores to the seed plat from a neighboring field of the same grain. This isolation is absolutely necessary. A strip of wood, a cornfield, or a large meadow is a valuable protection. In this plat should be planted seed treated by the hot-water methods. The seed plat may be maintained from year to year, as long as any smut is present in the grain fields.

\section{Cereal Rusts in General ${ }^{328}$}

The rusts constitute a complex, intricate, difficult, but interesting group of diseases. It is said that the "average annual loss from rust throughout the United States far exceeds that due to any other enemy, insect or fungous, and often equals those from all others combined."

The black-stem-rust alone in the United States and Canada in 1916 was estimated to have caused a loss of about $280,000,000$ bushels of wheat and additional loss on oats, barley, and rye.

The rusts in their most complete form exhibit three distinct stages (ef. p. 150). The spring stage, or cluster-cup, consists of a group or cluster of very minute, cup-like, spore- 
bearing regions. These cups are sunken in the tissue of the host, often with their rims only protruding. The second, or summer, stage, also called the uredinial stage, is of entirely different appearance, consisting usually of elongated sori, bearing a mass of spores the color of iron rust or verging toward orange or yellow. These spore masses are at first covered by the epidermis of the host, but this covering eventually ruptures, disclosing the usually dusty or pulverulent mass of spores, surrounded by a fringe of the remaining epidermis. The third, winter or telial, stage consists of sori almost exactly like those of the uredinial stage except that the spores within are usually darker in color and in a compact, cushion-like mass. The sorus is often identical in the two latter stages, a uredinium gradually changing as the season advances into a telium.

These three stages have, in general, three separate functions. The function of the teliospores is to live over winter or over the long resting period of the fungus. They are essentially long-lived and hardy. The cluster-cup spores multiply and spread infection, especially in the earliest part of the season. The urediniospores continue the multiplication and infection throughout the growing season of the host. The last two forms of spores are in general comparatively short-lived. If the host plant remains alive over winter, as is the case with winter wheat, the fungus, in the South, may continue to grow and produce summer spores throughout the winter. Even in colder climates the urediniospores of some rusts live over winter and start infection in the spring.

In the case of some rusts these three forms are all known to be present. In the case of other rusts one stage or even two stages may either be unknown or may not exist at all. When all three stages do exist, the spring stage often develops upon some host other than that bearing the uredinial and telial stages. Thus the spring stage of the wheat rust is found upon the barberry; of corn upon oxalis; of oats upon buckthorn. 
That some intimate relation existed between the barberry bush and the black-stem-rust of wheat was suspected very early in the seventeenth century, and in 1660 a barberry eradication law was passed in France, while between 1726 and 1779, Connecticut, Rhode Island, and Massachusetts did likewise. In 1818 Schroeter, a Danish school-teacher, published many observations concerning the relation of the cluster-cup upon the barberry and the rust of grains. This relation was finally definitely proved by De Bary in 1865, who, by sowing the teliospores from the wheat upon the barberry, produced the cluster-cups.

Some rusts are closely limited in host range and can grow on very few, perhaps on only one host; others are able to grow on various hosts. The host relation of several important cereal rusts is shown in the following table: ${ }^{493}$

\begin{tabular}{|c|c|c|c|c|c|c|c|}
\hline & $\underset{\Xi}{\tilde{\Xi}}$ & $\stackrel{\infty}{\tilde{\sigma}}$ & $\stackrel{\vec{E}}{\vec{e}}$ & $\frac{\sqrt{5}}{\overparen{\Xi}}$ & 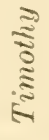 & 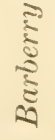 & $\begin{array}{c}\text { Also on other genera of grasses } \\
\text { as below }\end{array}$ \\
\hline $\begin{array}{l}\text { Puccinia } \\
\text { graminis } \\
\text { secalis }\end{array}$ & 0 & $\operatorname{tr}$ & + & + & 0 & + & $\begin{array}{l}\text { Agropyron } 9 \text { sps., Elymus } 3 \text { sps. } \\
\text { Hordeum } 4 \text { sps., Hystrix } 1 \text { sp. } \\
\text { Secale } 1 \text { sp., Sporobolus } 1 \text { sp. } \\
\text { Bromus } 2 \text { sps., Avena sativa and } \\
\text { Triticum vulgare. }\end{array}$ \\
\hline $\begin{array}{l}\text { Puccinia } \\
\text { graminis } \\
\text { tritici }\end{array}$ & + & 0 & $\mathrm{tr}$ & + & 0 & + & $\begin{array}{l}\text { Agropyron } 7 \text { sps., Elymus } 5 \text { sps. } \\
\text { Hordeum } 5 \text { sps., Hystrix } 1 \text { sp. } \\
\text { Secale } 1 \text { sp., Triticum } 8 \text { sps. } \\
\text { Bromus } 3 \text { sps., Alopecurus } 1 \text { sp }\end{array}$ \\
\hline $\begin{array}{l}\text { Puccinia } \\
\text { graminis } \\
\text { avene }\end{array}$ & 0 & + & $\mathrm{tr}$ & $\mathrm{tr}$ & $\mathrm{tr}$ & + & $\begin{array}{l}\text { Avena } 2 \text { sps., Agrostis } 3 \text { sps. } \\
\text { Anthoxanthum } 1 \text { sp., Dactylis } 1 \\
\text { sp.; Kloeria } 1 \text { sp., Panicularia } 1 \\
\text { sp., Arrhenatherum } 1 \text { sp., Alope- } \\
\text { curus } 2 \text { sps., Bromus } 3 \text { sps., Cala- } \\
\text { magrostis } 1 \text { sp., Holcus } 1 \text { sp. } \\
\text { Phalaris } 1 \text { sp., Agropyron } 1 \text { sp. } \\
\text { Beckmannia } 1 \text { sp., Elymus } 2 \text { sps. } \\
\text { Festuca } 2 \text { sps., Hordeum } 3 \text { sps. } \\
\text { Hystrix } 1 \text { sp., Lolium } 3 \text { sps. } \\
\text { Phleum } 1 \text { sp., Secale cereale. }\end{array}$ \\
\hline
\end{tabular}




\begin{tabular}{|c|c|c|c|c|c|c|c|}
\hline & $\underset{\tilde{E}}{\stackrel{\tilde{E}}{E}}$ & $\stackrel{\Xi}{\Xi}$ & $\stackrel{0}{\stackrel{2}{+}}$ & 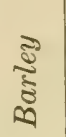 & 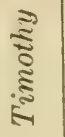 & 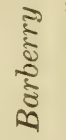 & $\begin{array}{c}\text { Also on other genera of grasses } \\
\text { as below }\end{array}$ \\
\hline $\begin{array}{l}\text { Puccinia } \\
\text { graminis } \\
\text { phleipra- } \\
\text { tensis }\end{array}$ & 0 & $\operatorname{tr}$ & $\mathrm{tr}$ & $1 \mathrm{r}$ & + & 0 & $\begin{array}{l}\text { Dactylis } 1 \text { sp., Festuca } 2 \text { sps., } \\
\text { Koeleria } 1 \text { sp., Phleum } 1 \text { sp., Alo- } \\
\text { pecurus } 2 \text { sps., Holcus } 1 \text { sp., } \\
\text { Avena } 2 \text { sps., Arrhenatherum } 1 \text { sp., } \\
\text { Bromus } 1 \text { sp., Elymus } 1 \text { sp., Hor- } \\
\text { deum } 2 \text { sps., Lolium } 2 \text { sps., Secale } \\
\text { cereale. }\end{array}$ \\
\hline $\begin{array}{l}\text { Puccinia } \\
\text { graminis } \\
\text { agrostis }\end{array}$ & () & $\mathrm{tr}$ & $\mathrm{tr}$ & $\mathrm{tr}$ & 0 & + & $\begin{array}{l}\text { Agrostis } 3 \text { sps., Alopecurus } 2 \\
\text { sps., Bromus } 1 \text { sp., Dactylis } 1 \text { sp., } \\
\text { Holcus } 1 \text { sp., Kaleria } 1 \text { sp., Avena, } \\
1 \text { sp., Calamagrostis } 1 \text { sp., Hor- } \\
\text { deum } 1 \text { sp., Secale } 1 \text { sp. }\end{array}$ \\
\hline $\begin{array}{l}\text { Puccinia } \\
\text { graminis } \\
\text { airae }\end{array}$ & & & & & & & Aira caspitosa, A. bottnica. \\
\hline $\begin{array}{l}\text { Puccinia } \\
\text { graminis } \\
\text { poa }\end{array}$ & & & & & & & $\begin{array}{l}\text { Poa compressa, } P \text {. caesia, } P \text {. pra- } \\
\text { tensis. }\end{array}$ \\
\hline $\begin{array}{l}\text { Puccinia } \\
\text { graminis } \\
\text { tritici- } \\
\text { compacti }\end{array}$ & + & 0 & $\operatorname{tr}$ & + & 0 & + & $\begin{array}{l}\text { Agromyron } 7 \text { sps., Elymus } 4 \text { sps., } \\
\text { Hordeum } 2 \text { sps., Triticum } 7 \text { sps., } \\
\text { Bromus } 1 \text { sp., Secale } 1 \text { sp. }\end{array}$ \\
\hline $\begin{array}{l}\text { Puccinia } \\
\text { simplex }\end{array}$ & & & & + & & & \\
\hline $\begin{array}{l}\text { Puccinia } \\
\text { coronata }\end{array}$ & & + & & $\mathrm{tr}$ & + & 0 & $\begin{array}{l}\text { Alopecurus } 1 \text { sp., Anthoxanthum } \\
1 \text { sp., Avena } 1 \text { sp., Dactylis } 1 \text { sp., } \\
\text { Elymus } 1 \text { sp., Hordeum several } \\
\text { species. }\end{array}$ \\
\hline $\begin{array}{l}\text { Puccinia } \\
\text { dispersa }\end{array}$ & & & $\mathrm{tr}$ & & & & \\
\hline $\begin{array}{l}\text { Puccinia } \\
\text { purpurea }\end{array}$ & & & $\operatorname{tr}$ & & & & $\begin{array}{l}\text { Sorghum vulgare, and } \varsigma_{\text {. holo- }} \\
\text { penses. }\end{array}$ \\
\hline $\begin{array}{l}\text { Puccinia } \\
\text { triticina }\end{array}$ & + & & & & & & \\
\hline $\begin{array}{l}\text { Puccinia } \\
\text { glumarum }\end{array}$ & + & & + & + & & & \\
\hline
\end{tabular}


All cereal rusts multiply much more rapidly in damp than in dry weather, and are more destructive to late crops. There is no evidence that these maladies can be carried by seed from rusted plants, though such seeds should not be used for seed purposes, since they do not have stored nourishment sufficient to give the seedling a vigorous start.

Great difference in rust resistance has been shown; thus while one variety of grain was so badly affected as to yield only $2 \frac{1}{2}$ bushels per acre, a resistant variety under the same conditions gave $381 / 2$ bushels.

The greatest hope lies in the use of varieties which can resist the disease. A number of different kinds of grain are now known which possess sufficient resistance to give good yields even when the rust is in its worst form. Since serious outbreaks of rust must be looked forward to with certainty, the item of rust resistance must have due weight in the selection of the variety to be grown.

Several varieties of oats of the red group, among them the Burt, Appler, and Cook when grown in the Southern States, are known to possess valuable resistance to the oat rust. Similarly there is large difference between varieties of wheat as to rust susceptibility.

Early maturity in oats is of especial value in that it enables the plant to evade the heaviest part of the rust attack. Good drainage and clean culture conduce to plants of more resistance to rust, as does also good preparation of the seed bed. Drilled wheat is better lighted and better ventilated and resists rust more effectively than wheat that is broadcast.

Wild grasses that harbor rusts identical with the rusts of crop plants, such as wild meadow oat grass, orchard grass, wild wheat grasses, quack grass, wild rye grasses, etc., may propagate the fungus and increase infection. If such grasses are rusted, they should be burned, plowed under, or avoided in the location of the grain fields.

While sprays of various kinds may be effective in checking the spread of rusts, the use of such means of prevention is impracticable, owing to the nature of growth of the crop, 
and the difficulty and expense of the application. Moreover the question of use of such treatment is complicated by the different kinds of rusts to be met and by their different behavior in different seasons.

\section{Anthracnose of Cereals}

Anthracnose ${ }^{329}$ (Colletotrichum cereale Manns). - Upon many cereals and forage crops, as rye, wheat, oats, orchard grass, timothy, red-top, and blue-grass, occurs a blight, resulting in shriveling of the grain and spotting of the leaves and stalks. The fungus is marked by small, black acervuli, located upon the spikes, stems, and sheaths. The chief attack is made as the plants approach maturity.

For further discussion, see rye.

\section{Special Diseases of Cereals}

\section{BARLEY.}

Loose-smut ${ }^{324}$ (Ustilago nuda (Jens.) K. \& S.). - This disease, previously thought insignificant, seems to be increasing in importance. It now often causes losses in Wisconsin and Minnesota of from 5 to 10 per cent of the crop, and is generally prevalent in this country, though often unnoticed on account of the early season of its development, and its absence at harvest time. Every spikelet of the smutted head is usually affected and entirely changed into smut, the central stalk of the head alone escaping. Adjacent leaves are also occasionally smutted.

The smut masses, when they first appear, are covered by a white or gray membrane which soon ruptures, loosing a powdery, olive-brown mass of spores, which soon blow away. This character enables one to distinguish it easily from the covered smut. Smutted plants head early, the smut reaching its maximum at flowering time, though scattered heads of smut may appear at other periods. The smutted heads stand high on tall stalks, which affords excellent wind distribution of the spores to the surrounding 
blossoms. The fungus, reaching the blossoms, gains such foothold upon the developing grain that its use as seed, without treatment, insures a smutted seedling as offspring. In

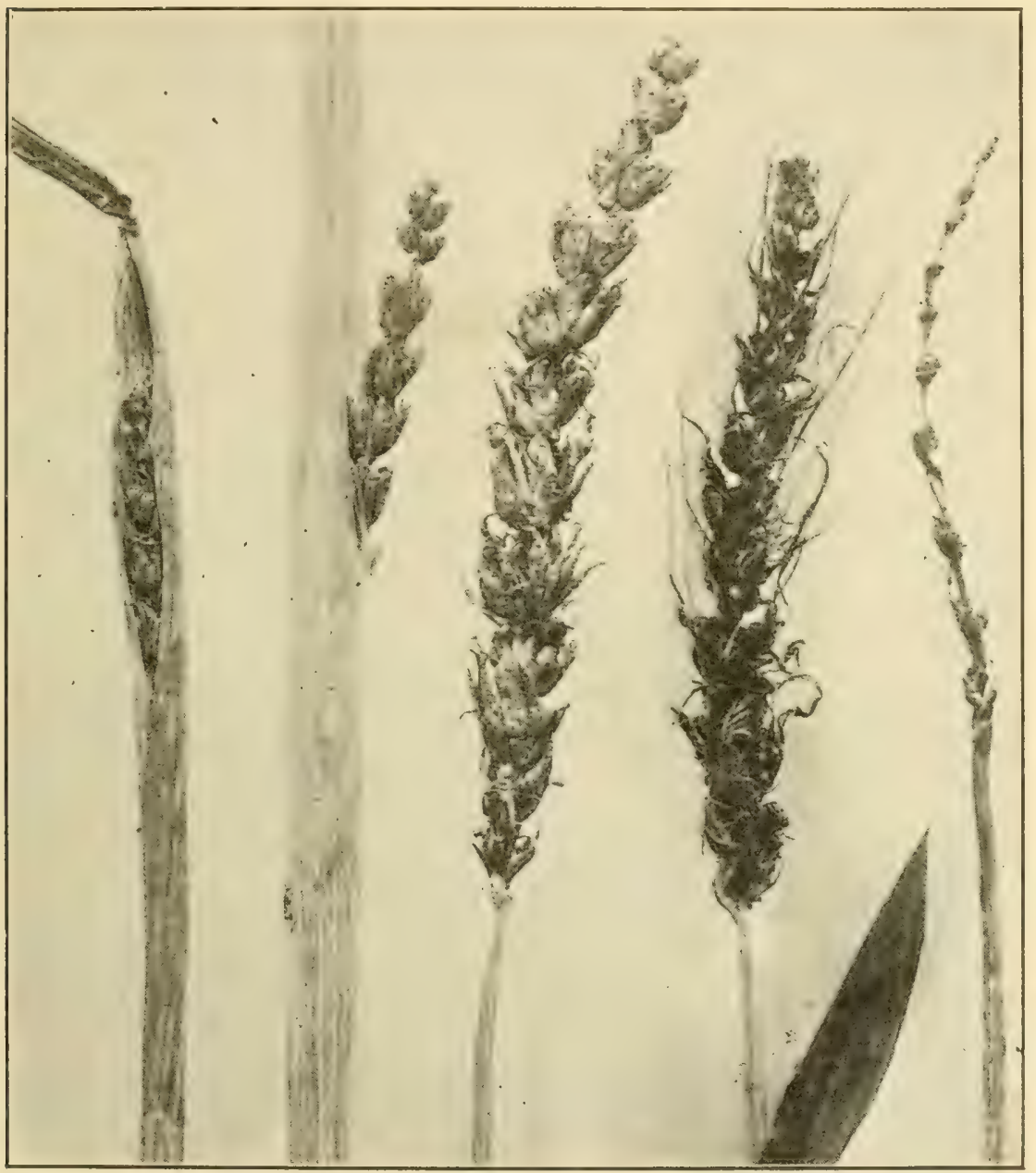

FIG. 147. - Loose-smut of barley in various stages of development. After Johnson.

the plant developing from such an infected seedling the disease does not show externally until the smut ripens at the next blossoming season.

The life history of this smut is thus similar to that of 
wheat loose-smut, and the same treatment, $i$. $e$, rogueing, combined with a modified Jensen hot-water treatment, is effective. See p. 272.

Covered-smut ${ }^{324}$ (Ustilago hordei (Pers.) K. \& S.).In the covered-smut, the smut masses replacing the grains and glumes are at first covered by a membrane composed of the outer surface of the glumes of the spikelet. This membrane retains the spores for some time after harvest. The spores, as seen en masse, after the rupture of this cover are very dark to purplish black, with no tint of olive.

The formalin treatment applies here.

Ergot. See rye.

Black-stem-rust (Puccinia graminis Pers.).- The forms occurring on both wheat and rye develop equally well on barley, and severe attacks of either form are common. See wheat.

Dwarf-leaf-rust (Puccinia simplex (Koern.) E. \& H.).Reported from Iowa in 1896, later from California, Minnesota, Virginia, Wisconsin, Wyoming, and Maryland, this rust seems to be of recent introduction and generally of minor importance, though serious in the extreme West.

Blight ${ }^{330}$ (Pseudomonas translucens J. J. \& R.). - Watersoaked areas appear on the leaves extending in longitudinal stripes or blotches between the veins. Later they turn brown. Small, gray drops of exudate appear on either leaf surface. Distortion of the head may be caused by disease of the enveloping leaf. It has been observed in nine states from Ohio to Oregon, on many varieties of barley. Infection appears to be by means of the seed.

Stripe-disease (Pleospora gramineum Diet., Helminthosporium). - This leaf blight was discovered in America by Pammel in 1890. It is characterized by longitudinal, yellowish-green spots in parallel rows upon the leaves. The plants die prematurely, and the yield is thus reduced. It is reported from many states. The loss in some fields amounts to from 10 to 50 per cent of the crop. Stripe is almost entirely prevented by formalin seed treatment (1 pt. to 30 gals., 2 hrs.). 
Net-blotch ${ }^{331}$ (Helminthosporium teres Sacc.). - First known in the United States in 1907, this disease has been observed in Iowa, South Dakota, Minnesota, and Saskatchewan. It occurs as brownish, circular, or somewhat elongated dark spots which soon cause the leaves to turn brown. It also occurs upon sheaths, glumes, spikelets, and grain. The straw at harvest is dull brown and lacks strength.

Scab, Powdery-mildew, Yellow-stripe-rust. See wheat.

\section{BROOM CORN}

Kernel-smut ${ }^{332}$ (Sphacelotheca sorghi (Link) Clinton). Irregular, elongated branches of inferior value indicate the presence of the smut. The branches are further damaged by blackening occasioned by the loose spores. The seeds are destroyed. Of the fields examined by Clinton in Illinois few showed over 1 per cent of the stalks infected, though sometimes parts of a field bore as high as 20 per cent of diseased stalks. Infection can occur only upon very young plants. Between the times of infection and the appearance of the smut masses in the panicle no signs of the disease are seen without the aid of the microscope.

The smut can be prevented by the use of clean seed, obtained either from clean fields or by disinfecting the seed by the hot water $\left(58^{\circ} \mathrm{C}\right.$. $\left(135^{\circ} \mathrm{F}\right.$.) for 10 to 15 minutes) or formalin methods.

\section{CORN, TEOSINTE}

Smut ${ }^{333}$ (Ustilago zeøe (Beckm.) Ung.). - Corn smut is well known to every farmer, occurring wherever the corn plant is grown, as black, pulverulent masses most conspicuous upon the ear and tassel. The damage in 1917 is estimated at $108,000,000$ bushels. In Iowa a loss of two-thirds of the crop was at one time reported.

Corn smut is first mentioned in literature in 1754, and the first record of it in America is in North Carolina in 1822. Experiments looking to its prevention were made 
as early as 1760 . The disease may attack any part of the plant at any age, - leaves, stalks, aërial roots, ears, tassels, - provicled only that they be still in tender growing condition, not mature and hard.

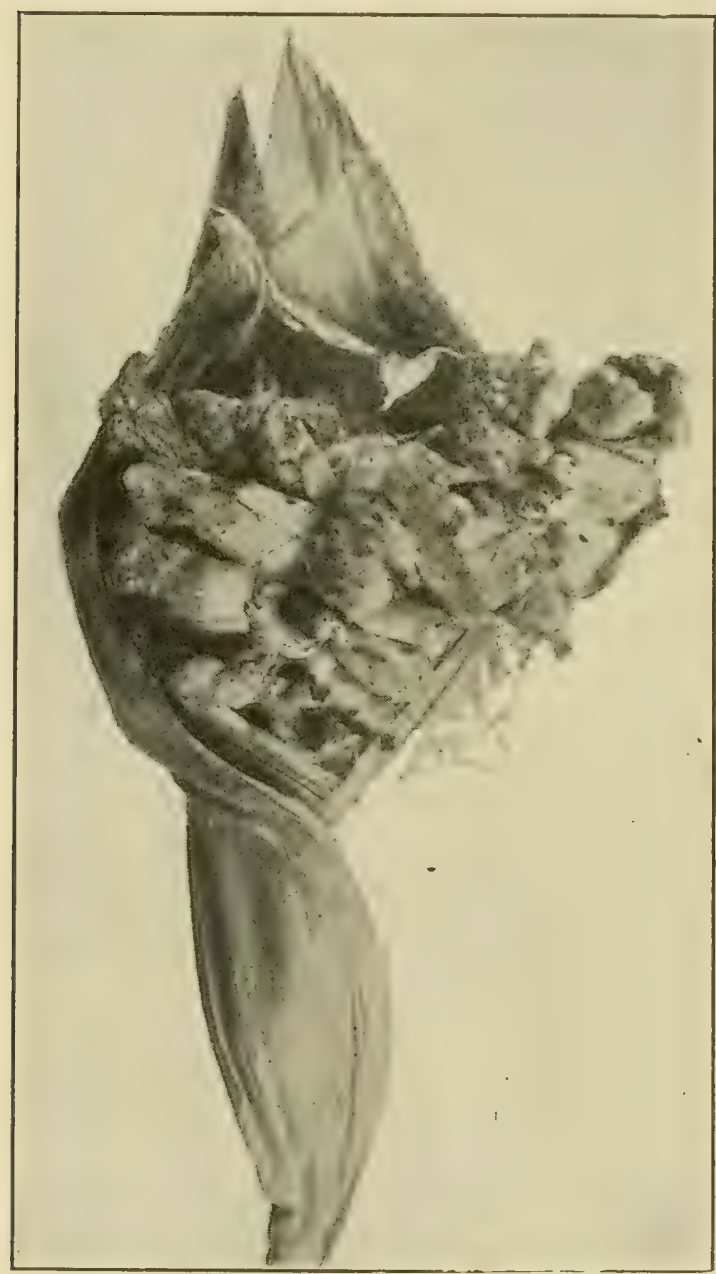

FIG. 148. - Corn smut upon the ear. Original.

The first symptom is a pale, glistening, swollen area covered with a white membrane, which soon appears black owing to matured spores within. The membrane eventually bursts, loosening a powdery, dry, black mass of spores through which fibrous veins of the corn plant still penetrate. It has been conclusively demonstrated that the causal fungus is not conveyed to the new crop in the seed, as is the case with so many other smuts, and that therefore no form of seed treatment is of value for its prevention.

It has been clearly shown that infection is produced by the spores which, under suitable conditions of moisture, fall upon any tender part of the corn plant. The silks furnish the requisite conditions, and it is through them that ear infection occurs. The 
sheaths of the leaves hold water, and inclosing as they do the tender growing portion of the stem, are admirably suited to infection. Since infection cannot oceur without moisture, weather conditions are of predominating influence.

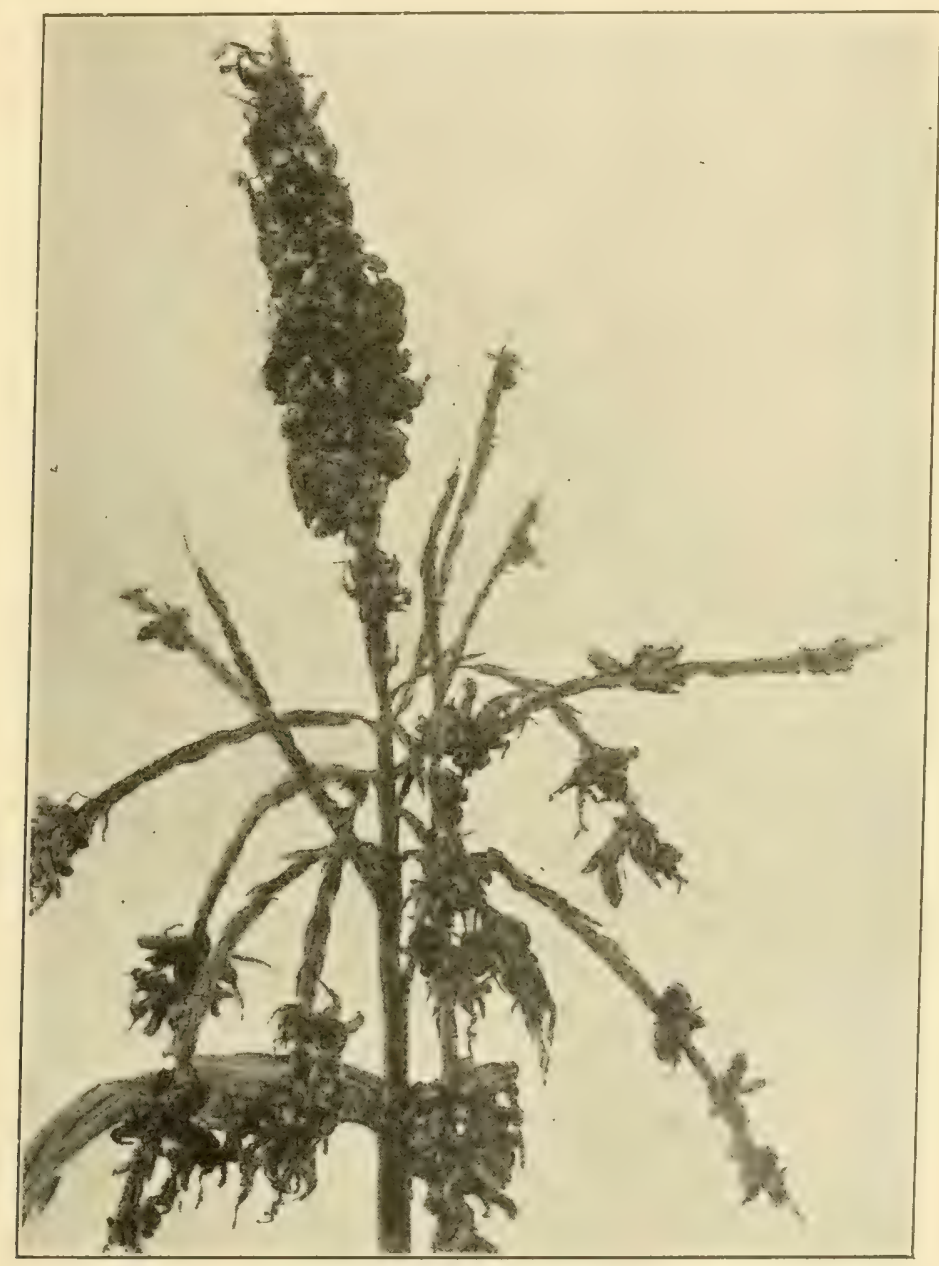

Fig. 149. - Smut upon sweet corn tassels. After Jackson.

The longer the crop grows, the longer the period of susceptibility is maintained. Thus a late-planted crop in Indiana showed half as much infection as a crop which was 
planted earlier, chiefly because it was exposed to contagion only about half as long. Moisture and richness of soil predispose to disease by increasing growth and giving a greater number of susceptible points of attack. Corn thickly planted is more liable to infection because ventilation is restricted, and thus a more humid atmosphere is maintained around the plants.

It has been shown that corn smut can be reduced by spraying with Bordeaux mixture, but the saving does not warrant the expense. To go through the field several times during the season and cut out and burn all the developing smut masses that can be seen, thus to destroy the spores and prevent the continued spread of the disease, is recommended, but the actual utility of such practice has not been demonstrated, though it is probable that this practice continued yearly would result in continued diminution of smut. The use of the silo in which the smut spores are rendered nonviable tends to lessen the amount of smut. The smut fungus can live and even increase in manure. Therefore live smut spores may infest the manure pile and thereby increase the disease in fields to which such manure is applied. The smut itself, contrary to popular belief, is poisonous to stock only under very rare and exceptional conditions, so rare as to be practically negligible. Fresh smut balls that have not yet turned dark are edible, and, prepared as mushrooms, are delicious.

Head-smut (Sphacelotheca reiliana (Kuehn.) Clint.).This smut, identical with that of sorghum, occasionally oceurs upon corn and is somewhat more injurious though less common than the usual corn smut. It cannot be controlled by seed treatment.

\section{Corn EAR Rots ${ }^{334}$}

Four types of ear rot, due to four distinct diseases, are described below. In the aggregate the loss from these is enormous, constituting as it cloes 10 per cent or more of a crop annually. Infection comes from definite species of 
fungi, and is not comparable to ordinary molding of dead organic matter by fungi of varying kind.

Dry-rot (Diplodia zece (Schw.) Lév. and Diplodia macrospora Earle). - This is one of the very widespread, dry ear rots of corn variously known to growers as mold, mildew, rot, dry-rot, ete.

Though the disease is really present soon after silking, and even much earlier from root infection, it is not usually recognized until husking, when a whitish covering of the kernels within the husk is noted. This white mycelium also forms dense masses between the individual grains, among the husks, and over the cob. The grains on the affected ear are shrunken, loosely attached, light in weight, darker in color, and more brittle than those of a healthy ear. Upon breaking open an ear, very small black pycnidia may be seen embedded in the white masses of mycelium, especially at the bases of the kernels. Diseased ears left in the field may develop these pycnidia in such abundance as to make the grains black.

Much of the food value of the corn is lost, owing to the consumption of starch within the grain, as well as to the prevention of starch storage. The germinating power of the grain is also lost.

Upon the stalks the fungus first appears as very small dark specks under the rind, near the nodes, and at broken places, usually in over-wintered stalks.

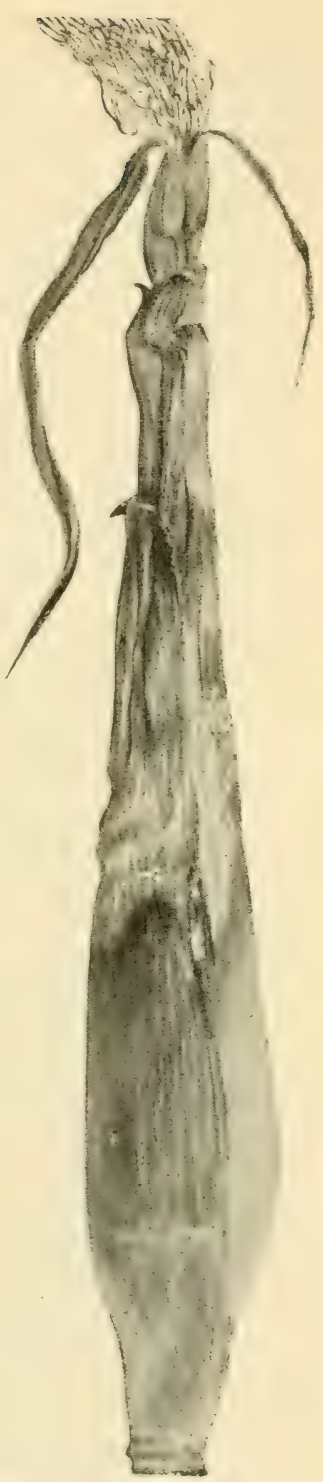

FIG. 150. - Young ear of corn inoculated in the silk with Diplodia. After Burrill and Barrett. Three-year-old stalks have been found bearing pycnidia. 
Although the green stalks are not naturally susceptible, the shanks are particularly so.

The causal fungus gains entrance to the ears from attacked stalks which bear them, and these are in turn infected

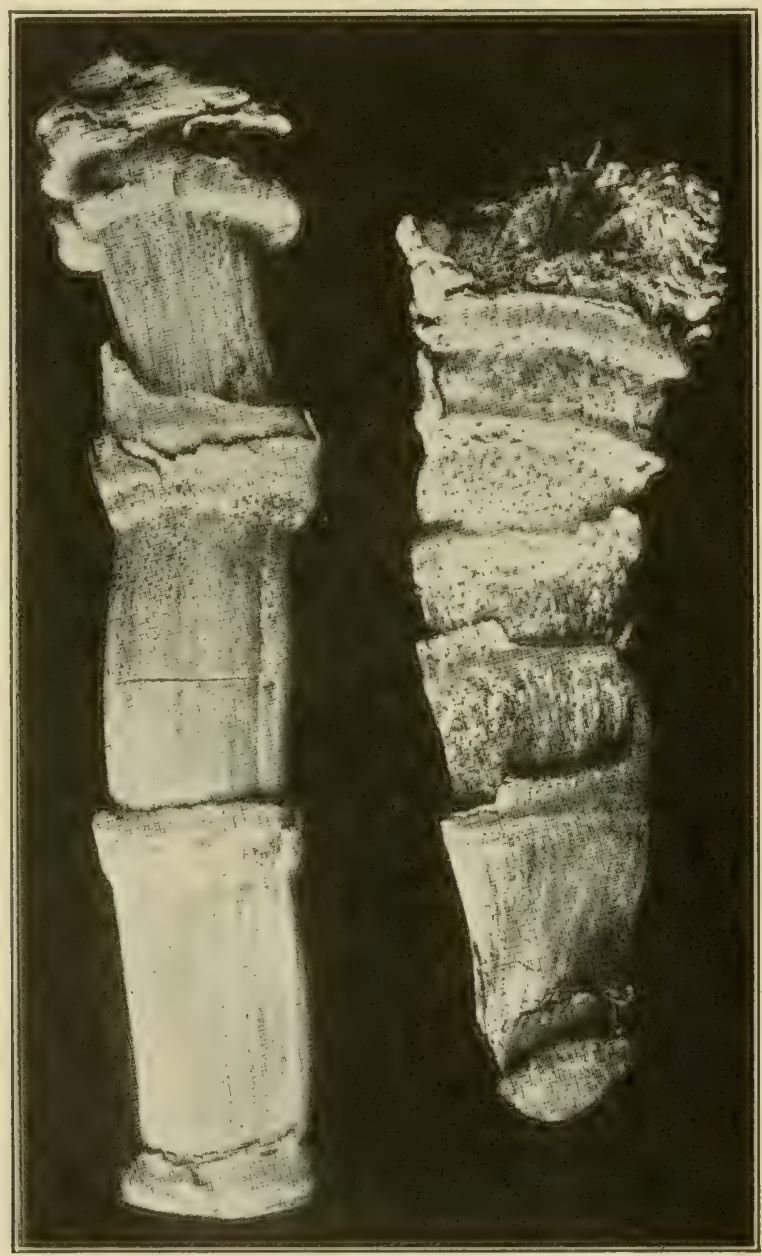

FIG. 151. - Diplodia on old shanks. After Burrill and Barrett.

through the roots from the soil. Ears are also invaded through the silks by wind-borne spores, which come, in part, from diseased ears, but more largely from diseased stalks left in the field. 
Any method of reducing the amount of infective trash, particularly old stalks near or in the fields, aids in control of this pest. Practically, this means to take out of the field and destroy all rot-infected ears and to cut infected stalks low and haul them away or burn them. It is still better to practice such rotation that corn will not follow corn within two years.

Dry-rot (Fusarium sps). Upon the ears this disease appears as a dense, felted, white mycelium, extending between the kernels to the cob. The kernels are killed and their starch partly consumed.

A second Fusarium disease is characterized by a deep pink to red color noted on the ear when the husks are removed. The kernels are brittle and the starchy portion within is powdery.

A third Fusarium disease causes less complete destruction of the ear than the preceding; often only a few scattered kernels are affected. The mycelium is white and sparse. A cobrot ${ }^{335}$ due to Coniosporium softens the cob without materially injuring the grain.

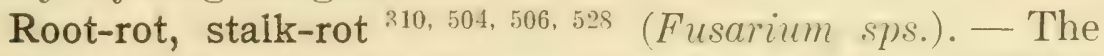
first record of root and stalk-rots of corn was made in 1907 by 
Selby, in Ohio. In 1914, Pammel, in Iowa, called attention to a serious root-rot of corn caused by a Fusarium. The disease is now known to prevail generally throughout the corn belt both in the South and the North. Though no ac-

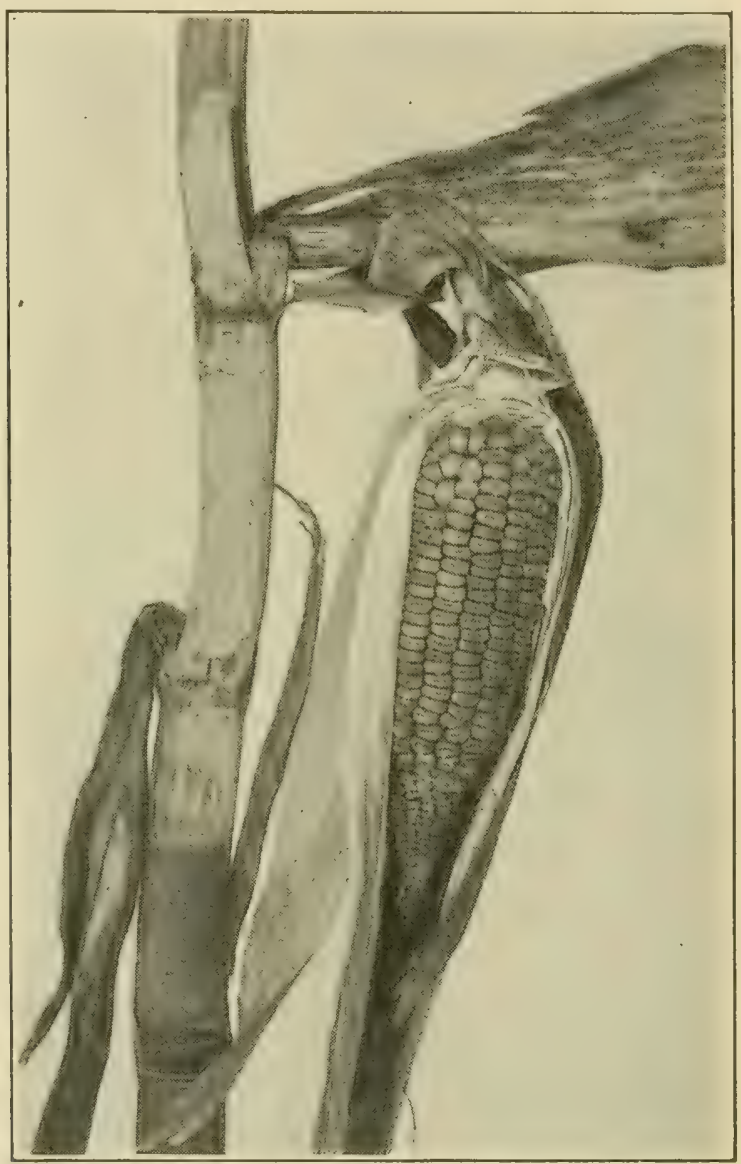

FIG. 153. - Rotten stalk and the nubbin resulting. After Hoffer.

curate estimate has been made of the amount of damage, it is known that the loss is large.

Among the symptoms are: 1 . Poor stands due to missing hills, caused by defective germination. 2. Weak and stunted seedlings, many of which may eventually die. Stunted 
plants show decayed roots and purplish-brown discolored stalks when split lengthwise. 3. Down-stalks due to rotting of the roots, so that the plant falls over. 4. Broken stalks due to weakening, chiefly at the nodes. 5. Barrenness and nubbin formation. The infected plant lacks vitality to form a perfect ear. 6. Broken shanks due to rot. 7. Diseased kernels. The kernels may be molded and cracked, though no sign of disease may be apparent and the infection or weakening of the kernels shows only on germination. The severity of the attack depends upon the stage of development, the vigor and resisting power of the corn plant as determined by the conditions for growth and development, and by its heredity.

Root-rot is caused by fungi, mainly Fusarium, and arises chiefly from primary infection, from infected seed, though to some extent from secondary infection in the field. The planting of infected seed is largely responsible for missing hills, down-stalks, nubbins, and other signs of disease.

No infected corn should be used for seed. To eliminate the infected seed, special adaptation and care in using the ragdoll tester, or the use of special testers, devised by Hoffer, is necessary, whereby the seedlings that show infection, when less than three inches in height, may be recognized and the ears from which they originated discarded.

Since the wheat scab organism (Giberella) causes rot of stem and shank of corn, corn so diseased increases the amount of wheat scab in succeeding crops.

Wilt ${ }^{336,341}$ (Pseudomonas stewarti EFS.). - This corn wilt was first described by Stewart as prevalent in nearly all parts of Long Island upon many different varieties of sweet corn. In some cases the entire crop was ruined, and 20 to 40 per cent of loss was frequent, though in the majority of cases the loss was so slight as to pass without notice. It has been noted on sweet coln in Kentucky and Illinois, but rarely on field corn.

The diseased plants wilt and dry up much as though from lack of water, yet in soil that is amply supplied with water. 
While the wilting is most likely to occur at flowering time, it may appear at any stage of growth when the plants are $25 \mathrm{~cm}$. or more in height. In mild cases the lower leaves wilt first, while in severe cases all wilt at one time. The death of the plant may occur in four days after the first signs of disease, or may be delayed a month, possibly with recovery and relapse intervening.

The roots remain normal, but the veins in the stems appear as yellow streaks, in older cases black, instead of their normal color. Such stems, if cut crosswise, shortly exude a yellow, viseid drop at the ends of the veins. This is the most distinctive character, and infallibly indicates the presence of the wilt. Death is caused by the plugging of the water passages with this viscid substance, which consists mainly of bacteria.

In the fields the diseased plants, representing young and old stages of infection, grow side by side with normally healthy plants. Health and disease may appear, even in the same hill; yet there appears to be no direct plant-to-plant infection, nor any of that centrifugal spreading from a diseased center that is so noticeable in most wilt or soil-borne diseases.

The causal organism is found in the seed from affected plants, and it has been proved experimentally that such seed carries the disease to the offspring.

As a preventive measure resistant varieties should be selected for planting, and all seed from plants which are at all diseased should be avoided. The disease may be carried from one locality to another by any of the means suggested under soil diseases, and especially by manure infested with stalks of diseased plants.

\section{Minor diseases}

Brown-spot ${ }^{337}$ (Physoderma zece-maydis Shaw) was first noted in India in 1910, in Illinois in 1911. Its distribution is shown in the accompanying map. (Fig. 154.) Considerable damage is done in the region indicated by the darker shading, 
but it is hardly probable that this disease will extend seriously or become very destructive, except locally, and in very humid, hot seasons. In some eases, the injury is as high as 6 to 10 per cent of the crop). The fungus grows in leaf, sheath, and stem, rarely in the husks. Bleached or yellow spots about $1 \mathrm{~mm}$. in diameter first appear, and within a few days darken, eventually becoming reddish-brown. Coales-

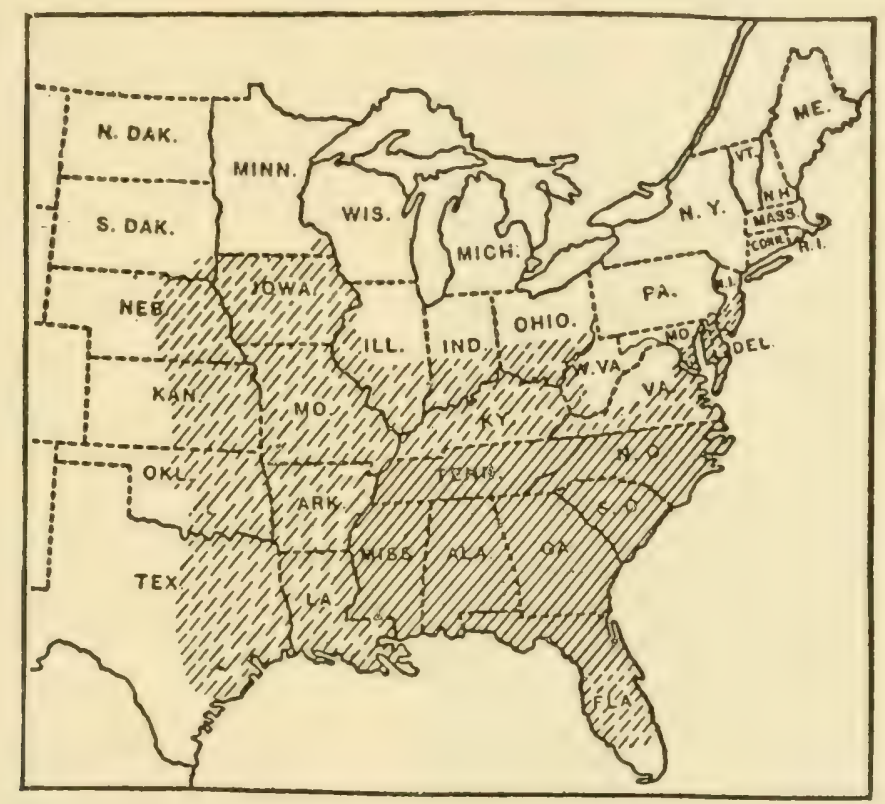

FIG. 154. - Map showing the distribution of Physoderma zex-maydis in the United States. Broken lines, P. zex-maydis present: solid line, P. zex-maydis causing damage. After Tisdale.

cence of many spots may lead to discoloration of large areas and a rusted appearance. These diseased areas are often in bands across the leaf. Leaves are often killed. The dry epidermis eventually ruptures over discased spots and the dusty, brown spores are freed. Diseased stems break easily, resulting in considerable lodging of the corn. Ceneral sanitary measures are recommended, chiefly destruction of infested refuse and rotation of crops. 
Blight ${ }^{552}$ (Pseudomonas sp.). -- This disease was described by Burrill in 1889 .

It shows chiefly as a dwarfed condition which may occur in spots in the field, varying in size from a few square rods

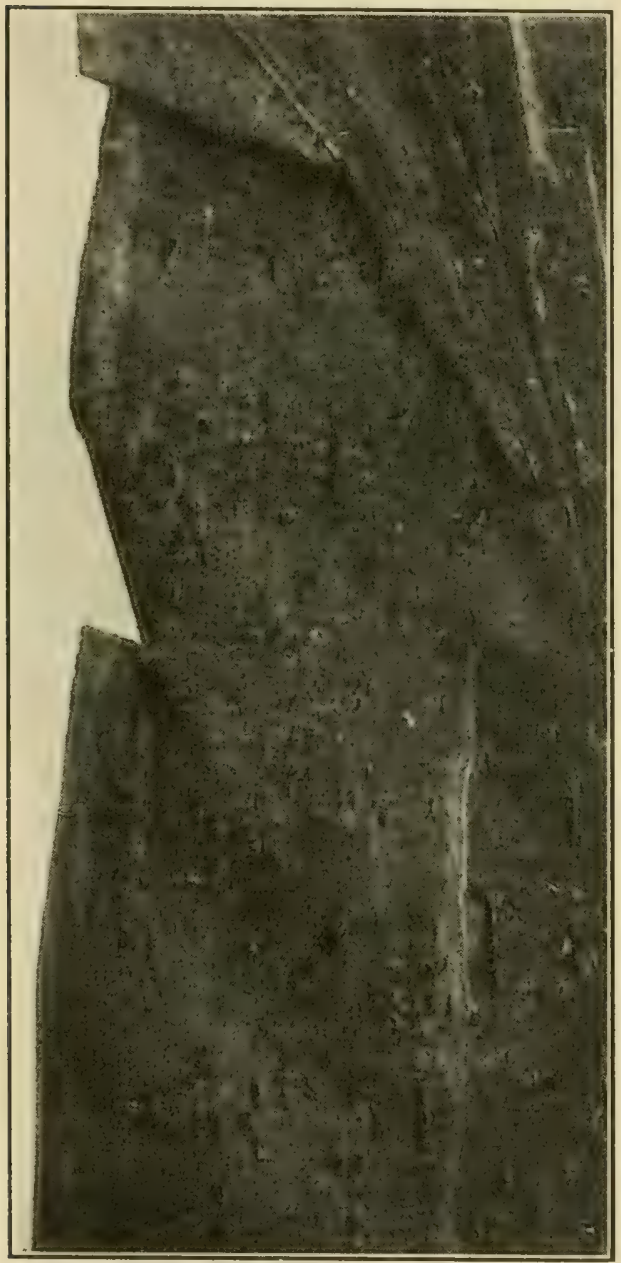

Fig. 155. - Portion of corn leaf showing sori of rust.

to an acre or more. The affected plants finally turn yellow, and most of them die.

The lowest roots of diseased plants, in some cases comprising half of the root system, die. The stalk near the base, when split lengthwise, shows a uniform, dark color which also appears in the upper nodes in lesser degree.

Rust (Puccinia sorghi Schw.). - Corn rust seems to have taken its place in literature in 1815. It is comparatively of slight importance, since it does not usually develop early in the season, though in exceptionally favorable climatic conditions it may do so. The brown summer spores appear first in linear sori, and the black winter spores come later in the season. The clustercup stage is found upon the wood sorrel (Oxalis).

Yellow-leaf ${ }^{338,} 339$ (Helminthosporium inconspicuum C. \& E.). - This blight gives a somewhat frostbitten appearance to the plants, producing also a thin olive-green 
mold upon the lower sides of the leaves. Sometimes only the tips of the leaves are affected, but usually whole leaves die.

Yellowish, elongated spots limited by the veins, sometimes covered with dark-colored spores, are produced. The disease is confined almost entirely to late-planted corn, and is prevalent during its early growth, though it has never been reported upon seedlings.

It is known to cause much loss in Delaware, New York, and Connecticut, and is of widespread occurrence in the United States.

Chlorosis appears to be related to the mosaics in that it is transmitted by sap or by contact. It occurs also in the embryo. Two species of Sclerospora cause considerable injury to corn in Italy, and have been collected in the United States. The tassel is chiefly affected. Phyllachora causes damage to corn in the warmer climates. In the Orient very great loss is caused by a downy-mildew (Peronospora).

EMMER, EINKORN. See p. 310.

KAFIR. See p. 307.

\section{MILLET}

Leaf-spot ${ }^{177}$ (Piricularia grisea (Cke.) Sace.). - Upon the lower leaves the disease occurs as a spot which is at first dark purple or reddish, and elongated parallel with the length of the leaf. Later the center turns black and finally strawcolored, bordered by a black ring which merges into reddishpurple at its outer edge. Badly diseased leaves turn yellow, dry and shrivel from the tip toward the base, lessening the fodder value and seed yield of the plant.

Smut (Ustilago crameri Koern.). - This smut infects the individual flowers of the fox-tail millets, destroying the lower parts of the glumes and the grain. It has been noted in Ohio, Minnesota, Connecticut, Illinois, Indiana, Iowa, Maine, Michigan, Colorado, North Dakota, and South Dakota. U. panici-miliacei similarly affects the Panicum millets. 
The formalin treatment, 1 pint to 40 gallons, is applicable to both of these smuts.

MILO. See p. 307.

\section{OAT}

Loose-smut 324, 343-345 (Ustilago avence (Per's.) Jens.). Under the name "smut," "blackheads," etc., this disease is known wherever oats are

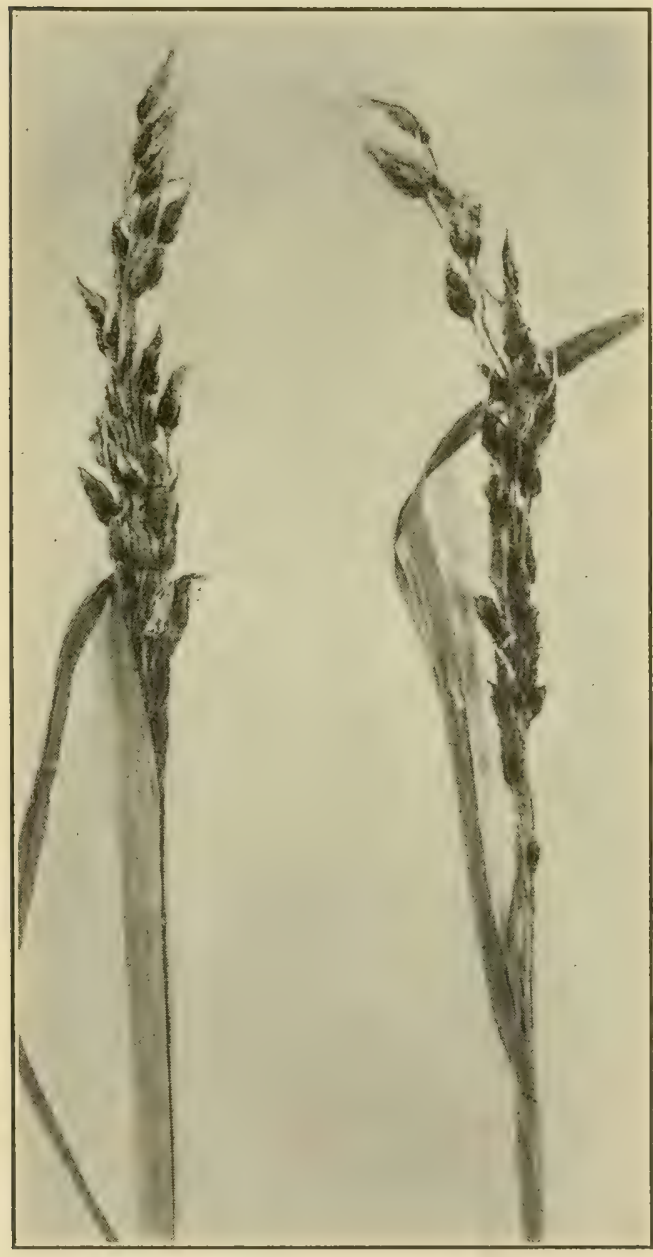

Fig. 156. - Loose smut on oats. After Jackson. grown. Grain and more or less of the chaff are replaced by a powdery, black mass, which shatters out as it ripens, leaving later only the naked branches of the panicle. Usually all the spikelets of a head and all the heads of the affected plant are smutted. There is considerable difference in the resistance offered by different varieties, but in view of the perfect protection afforded by proper treatment this is of little significance.

The damage caused by smut is commonly underrated. In 1884 Arthur in New York by actual count found the oat smut to constitute from 8.5 to 10 per cent of the ordinary crop. By actual count of nearly 
11,000 heads Plumb in 1886 determined the amount of smut to be 8.4 per cent; in some fields he found as high as 20,28 , and even 30 per cent. Kellerman and Swingle, counting smutted heads in Kansas, found different fields to have 8, 15.3 , and 18.3 per cent of smut, while single portions of a field showed as high as 30 per cent. The loss in this country in 1917 was estimated as approximately 91,000,000 bushels.

The reasons for underestimation of oat smut are: 1 , the dwarfing of many of the affected plants, which thus remain unnoticed by a casual glance over the field; 2 , the fact that many smutted panicles remain invisible unless unrolled from their enveloping leaves.

It was proved as early as 1858 that infection can occur only upon the very young oat plant; that older plants are immune. It was later determined by Brefeld that the plants are immune after the leaves have protruded $1 \mathrm{~cm}$. beyond the leaf sheath. From this and other experiments it follows that practically all infection comes from smut spores which are upon the seeds when they are planted. These germinate, producing sporidia which infect the young plant. The fungus develops in these plants throughout the season without conspicuous effect until, at blossoming time, the fungus seeks the ovaries and the glumes and appears again as the familiar black spore masses.

Any treatment which kills the spores upon the seed without materially injuring the seed itself results in a clean crop.

The copper sulfate treatment endangers germination of oats. The hot water treatment is less convenient than the formalin treatments which are thoroughly satisfactory. See p. 270.

Covered-smut (Ustilago levis (K. \& S.) Magn.). - This differs from the loose smut in the less complete destruction of the flowers and in its less dusty spore masses, which are also blacker than in the loose smut. The smut masses are usually limited to the parts within the flowering glume and the palet or to the bases of these.

The treatment is that given for loose smut. 
Black-stem-rust (Puccinia graminis avence E. \& H.).The black-stem-rust on oats shows but slight differences from the black-stem-rust of wheat, but it is racially distinct (see p. 277) and a field of one of these crops may be badly affected by its fungus, while adjacent fields of the other crop show no rust or indication of infection such as they might be supposed to do were the two rusts identical.

As with the wheat black-stem-rust, its attacks fluctuate greatly in abundance and destructiveness from year to year.

Crown-rust (Puccinia coronata Cda.).This rust is found only upon species of oats and closely related grasses and in the telial stage clearly differs, even to the naked eye, from the oat rust mentioned above.

It occurs upon oats in practically all fields but is more injurious in its southern range. The damage is not serious, or very rarely so.

The cluster-cup stage is known to grow upon the common buckthorn (Rhamnus cathartica) and the lance-leaved buckthorn ( $R$. lanceolatus). The yellow uredinial stage is most conspicuous. Later the black telia appear under the epidermis as long streaks which, unlike most rusts, do not rupture the epidermis.

Marked varietal resistance is shown. In California black oats are reputed to be less

FIG. 157.- Covered-smut on oats. After Jackson.

Minor diseases subject to rust than white oats. In the North, the White Russian is said to be resistant, while in the South, the red oats resist attack.

Scab. See wheat. Leaf-spot (Phyllosticta sp.). - Browned or reddened leaves, with the black pycnidia profuse upon the 
affected surfaces, sometimes so abundant as to lend a blackish hue to the leaf, comprise the diagnostic symptoms of this malady. Eventually the leaves are killed.

Blight 346, 347 (Pseudomonas avence Manns). - A disease prevalent throughout the Eastern and Central States was attributed to bacteria by Galloway and Southworth in 1890. It appears when the plants are only about $10 \mathrm{~cm}$. high, first causing the leaves to turn brown and die at the tips, then throughout their length. The affected plants revive, but, are so reduced in vigor as to prevent effective stooling, and a loss of from 35 to 75 per cent of the crop commonly occurs.

The disease was carefully investigated by Manns, who claims that it is caused by the symbiotic action of two species of bacteria, a Pseudomonas and a Bacillus.

Manns describes the disease as follows:

The preliminary effect is yellowing of the leaf, beginning either as small, round lesions on the blade, or as long, streaklike lesions extending throughout the blade and even the whole length of the culm and blades. Occasionally it begins at the tips and works back into the culn; again the upper leaves often break down due to a weakened condition of the plant from defoliation below.

The ultimate symptoms, wherever the disease has made much progress, are partial or general collapse of the leaves, which take on a mottled to almost red color.

It prevails from New England to Georgia, and from the Atlantic to Indiana and Illinois. The damage in Ohio has been estimated at from 14 to 37 per cent of the crop. Rain and moisture favor it.

When prevalent, the soil may become infested as in typical soil diseases. The only hope seems to rest in resistant strains.

Halo-blight (Bacteria). - Oval, chlorotic areas 1-2 cm. in diameter, bordering a minute, sunken, dead center, occur in the leaf. Stripe-blight (Bacteria). - The diseased tissues are water-soaked, translucent, with an abundant exudate and 
no halo. The spot is long and narrow, between the veins. Anthracnose (Colletotrichum cereale). - The effect of this disease upon oats is similar to that described for rye. Yellowleaf (Helminthosporium inconspicuum C. \& E. var. brittanicum Grove). - Oat leaves turn yellow and develop dark, brown, spore-bearing spots. Little is known as to its severity or prevention. Powdery-mildew. See wheat. Ergot occurs but rarely on oats.

\section{$\operatorname{RICE}^{348}$}

Blast, rotten-neck ${ }^{349}$ (Piricularia oryzo Cav.). - This is a world-wide rice disease, which in Italy is controlled by the use of resistant varieties. It has probably been present for many years in American rice sections, but did not become of serious economic importance until about 1895. What seems to be the same disease occurs upon crab grass, and apparently infection may come from this host. It is reported from South Carolina and Louisiana, also from Texas, where it has been serious. The disease occurs upon upland as well as irrigated fields.

The most characteristic symptom consists of lesions at the sheath nodes just over the joints of the stem, at the region where the stem comes to be the axis of the head (the "neck region") and at the points where the blades of the leaves join their sheaths, appearing first as very small, water-soaked, sunken spots on the node of the sheath. Spots upon the neck are not water-soaked, and the skin does not rupture until the head breaks off. Later the spot becomes brownish or black, and similar discoloration runs upward and downward. The affected stem tissue gradually extends laterally, shrinks, and dies, cutting into or through the joint, which results in an open wound. The region above the wound becomes pale and dies.

Upon young plants leaf spots occur, first brown with ashen center, later coalescing and taking the whole leaf. If the attack is early, the grain does not fill at all; if late, it may 
partially fill. The dead portion of the plant may bleach or darken according to environment, resulting in varied characters in later stages of the disease. In 70 per cent of the cases examined by Metcalf the lowest joint of the rachis was affected, and in consequence the heads broke off at this point. This gives rise to the common name "rotten-neck," but since the character is not universal, the name is not an appropriate one.

The chief damage results from the failure of the grain to fill on the diseased stalks. An early attack may render a crop entirely worthless. Plants attacked later, yield some grains which are of poor, light quality, easily broken or blown away, and consequently largely lost in threshing and milling. The variation in size of the grain also largely depreciates the quality. Many of the heads, especially the heavier ones, fall off, and some fields show at least one-third of the crop thus left upon the ground.

The Rice Committee of the Agricultural Society in South Carolina, March, 1904, estimated the loss, up to that time, to be very nearly $\$ 1,000,000$. Depreciation in land values, necessitating abandonment of land, is a significant item of charge against this disease.

The chief hope lies in the use of resistant varieties. Withholding nitrogenous fertilizers and removal of infective trash by burning are good sanitary measures.

Green-smut (Ustilaginoidea virens (Cke.) Tak.). - This grain disease, though partaking of the appearance of a true smut, is in reality more closely related to the ergot of rye. 
The grains, usually only a few in each head, become enlarged, spherical, $5 \mathrm{~mm}$. or more thick, and coated with a dark green powder. Some-

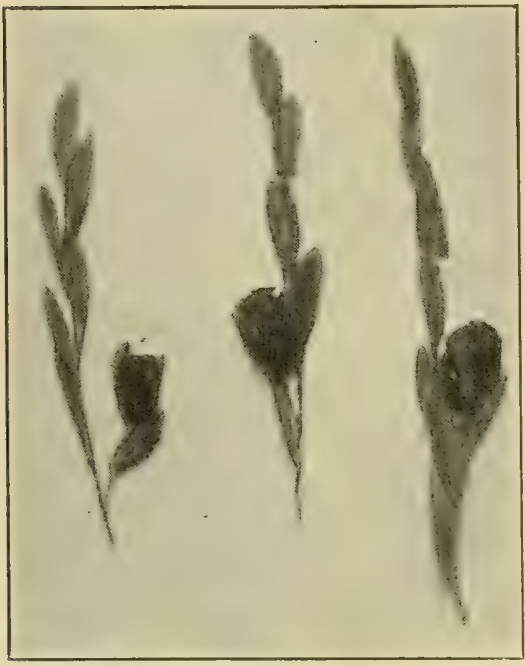

Fig. 159. - Rice showing "green-smut." After Fulton. times a yellow color prevails instead of the green. In section the interior is seen to be filled with a compact white mass bordered by a brownish yellow zone, then by the green coating.

Though the disease has been known in Louisiana for ten or

more years, and is present to some extent in most fields, it is not considered serious, since rarely more than 0.25 per cent of the heads, and only a few grains per head, are affected.

Black-smut ${ }^{350}$ (Tilletia horrida Tak.). - A dark, unsalable flour, made from rice in the region of Georgetown, S. C., was reported in 1898. Anderson found that many heads of rice from these fields bore as much as 25 per cent of smutted grains.

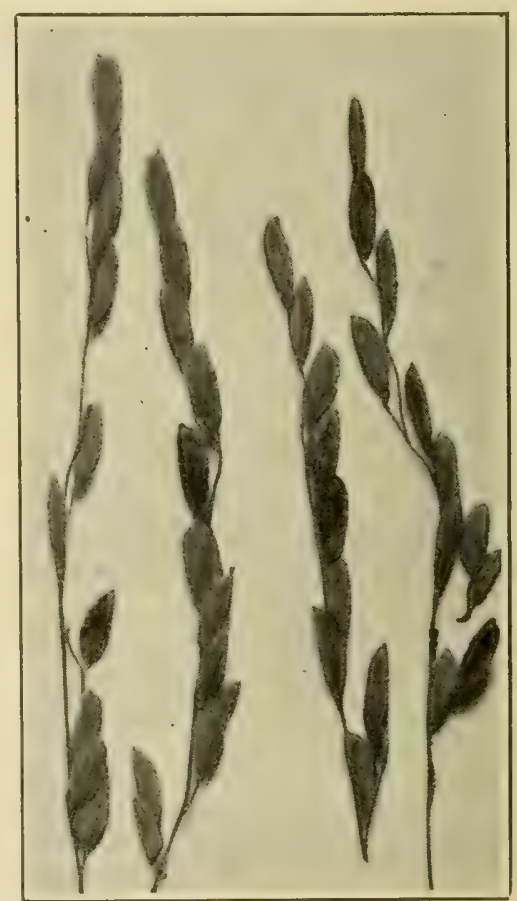

Fig. 160. - R ic e showing black-smut. After Fulton.

This smut was probably imported from Japan in infected seed, but due to the immediate action of Anderson and Walker the pest seems to have been completely stamped 
out in South Carolina within the first few years after its advent. No reports whatever of its presence there have been made since 1903. It has since entered the United States through Louisiana.

The smut closely resembles the stinking smut of wheat. The affected ovaries or grains are transformed into smut masses which remain within the glumes, and so resemble the normal grains as often to be mistaken for them. The fungous mycelium grows within the stem tissue of the diseased plant and, as is the case with wheat bunt, infection probably occurs in the seedling stage, the fungus remaining unnoticed
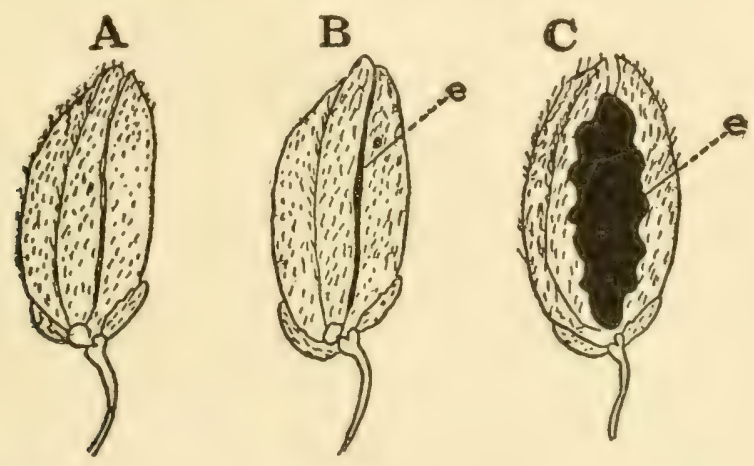

FIG. 161. - Three rice spikelets: $A$, normal; $B$, smutted; $C$, glumes partly torn away exposing the spore mass. After Anderson.

until its presence in place of the grain is disclosed as a black spore mass.

The disease can be controlled by the method which stamped it out in South Carolina; that is, by the formalin treatment.

Damping-off. - Two forms of damping-off of seedlings are known:

1. Rice, not covered, but simply flooded with water, frequently shows soft rot of the shoot in very young seedlings.

2. Covered rice often shows damping-off spots just above the surface of the ground. 
The causes of these rots have not been fully studied, but they are probably due to fungi or bacteria or both.

\section{Minor diseases}

Spotted-blight (Macrosporium sp.). - Small black spots of mold upon poorly filled grains sometimes occur, occasionally affecting field areas of considerable size.

Speck, pip (Saprophytic fungi and bacteria). - The grain in some instances bears one or more discolored, often sunken, circular areas, 1-3 mm. in diameter, bounded by dark margins with gray or pale-buff centers and often with a minute dark spot in the very center. In other cases the grain is shriveled and distorted without any definite spot. The interiors of the grains are chalky and brittle, and of such inferior quality as to be largely depreciated in value. Not infrequently from 10 to 25 per cent of the grain is affected, and in some cases nearly 100 per cent. The germinating power is much reduced.

The disease is caused by the invasion of saprophytic fungi or bacteria into wounds caused by sucking bugs. Methods to control these insects have not been thoroughly worked out.

Rust (Physiological). - The leaves die gradually, beginning with the tips of the lower ones. Red spots and streaks usually appear before the leaves lose their green color. The roots are poorly developed, the plants dwarfed, and the heads small and light.

\section{RYE}

Ergot (Claviceps purpurea (Fr.) Tul.). - Ergot is widely known as a black or purplish body, several times larger than the seed of the affected plant, which displaces the ovary or grain. Ergot occurs commonly upon rye and many other species of grass, as wheat-grass, wild ryes, bluejoint, Kentucky blue-grass, Canada blue-grass, red-top, timothy, and rye-grass. Of the last named, one farmer reports 1000 tons of hay so badly affected as to be worthless. Ergot is occasionally injurious on wheat. 
This disease is caused by the attack of a fungus upon the ovary while the plant is in bloom. The fungus invades and consumes the ovary and replaces it with the ergot, which consists of a dense mass of tangled, interwoven mycelium, a sclerotium. Ergots, when mature and under suitable conditions, germinate, sending forth several stalks each, with club-shaped, knobbed tops. From these the spores issue to infect susceptible plants then in blossom. For some days the fungus spreads from blossom to blossom by means of other spores, and each infected ovary results in another ergot.

Loss to the grain and the damage to the plant are slight. Chief injury from ergot arises from its effect upon cattle that are fed ergotized grain or graze upon badly infected grass. Animals become emaciated and rough-haired as the result of continuous feeding of ergot. Further symptoms of ergot poisoning are tardy circulation in the extremities, gangrenous sores upon the teats or mouth, and sloughing off of parts of the tail, ears, or hoofs. Abortion may also follow as an additional effect.

Fields should be examined for the presence of ergot. If large quantities are found, the grass should not be used for hay or pasture. Ergot can be lessened by cutting susceptible grasses about flowering time, thus checking the spread of the fungus. Badly infested hay lands should be burned over to destroy sclerotia; roadside grasses should be cut often enough to prevent the formation of ergot, and seed should be examined to prevent the spread of ergot through this means. Seed may be freed of ergot by immersion in a 20 per cent solution of common salt, which will float the ergot to the surface.

Black-stem-rust (Puccinia graminis secalis E. \& H.).The description given in connection with wheat applies here.

Brown-leaf-rust (Puccinia dispersa E. \& H.).- This rust bears a very close resemblance to the rust caused by Puccinia triticina upon wheat, but in careful inoculation ex- 


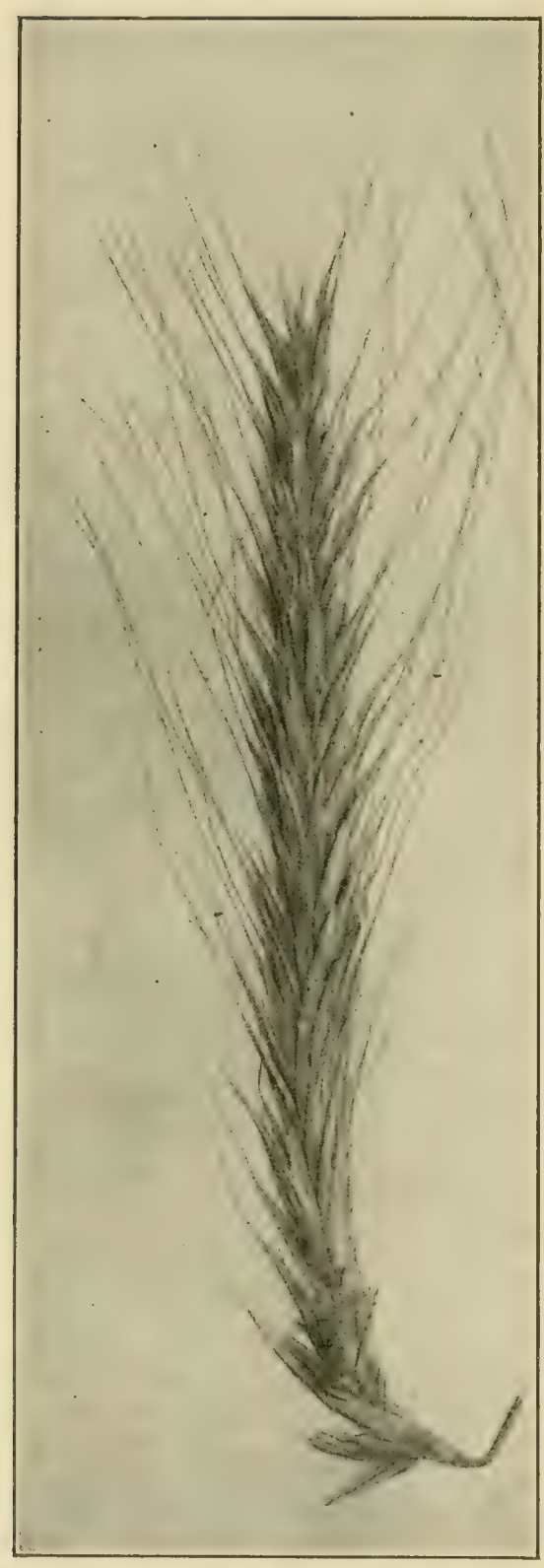

FIG. 162. - Head of rye attacked by anthracnose. After Manns.

cent in Australia. Seedlings periments it has been impossible to infect one of these hosts from the other. It is invariably present where rye is grown and is particularly abundant in the Southern States, though notwithstanding its universal presence it is not destructive. The uredinial mycelium remains alive in the South and continues to produce spores during winter in the leaf, as it probably does in colder climates as well. It is possible that it is in this way carried from season to season by volunteer rye in the fields. The cluster-cup stage occurs upon a member of the Borage family, but has never been found occurring naturally in America.

Stem-smut ${ }^{324,53 \times}$ (Urocystis occulta (Wallr.) Rab.). - Unlike many of the cereal smuts the stems and leaves as well as the floral parts are affected. It may be recognized by the usual, dusty, black spores, which occur especially at the joints. While this disease does not directly attack the grain, it does diminish the yield by weakening the plant. Loss from 25 to 40 per cent is reported in Minnesota, 60 per may be infected from spores 
in the soil. When serious, the formalin treatment combined with crop rotation should be emplnyed.

Anthracnose ${ }^{329}$ (Colletotrichum cereale Manns). - A serious disease of cereals and other grasses, chiefly rye, wheat, oats, timothy, blue-grass, red-top, and orchard grass, was discovered by Selby and Manns in 1908.

It is a destructive pest of very general distribution, being found in all the fields examined in Ohio. In one field it is estimated to have reduced the yield from 75 to 25 bushels, and it is assigned as a prominent cause of shriveling, such

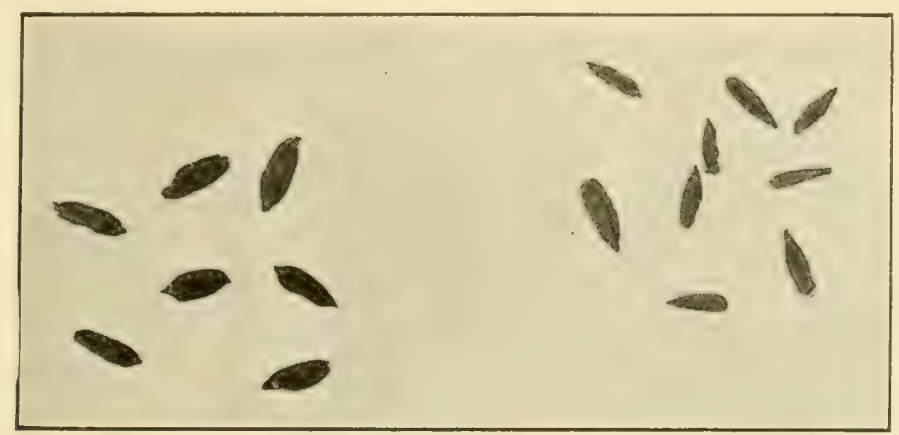

FIG. 163. - Normal rye kernels and shriveled ones due to anthracnose. After Manns.

as is often attributed to rust, as well as of whitening and blighting of plants preceding ripening. Parts of the head above the points of attack die. The portion of the head that is killed is a total loss, and the general decrease in vigor of the plant results in shriveled, light grains. Upon stalks and leaf sheaths, beginning at the ground and extending over several internodes, the acervuli may be so numerous as to cause blackening.

No remedy is known.

Powdery-mildew, Yellow-stripe-rustand Scab. See wheat. Stripe-disease and Stripe-blight. See barley.

SORGHUM, SUDAN-GRASS, KAFIR, MILO

Blight (Bacillus sorghi Burr.). - This blight was studied by Burrill in 1883 and described in 1887. It prevails upon 
sorghum, broom corn, Kafir corn, and Milo maize, and has been noted in Illinois, Kentucky, Iowa, Louisiana, Ohio, Michigan, Nebraska, West Virginia, and District of Columbia, often in serious form. The chief character is irregular-shaped, elongated blotches of red, at first faint orange, upon the leaves and leaf sheaths, sometimes limited by the veins, and always more conspicuous on the inner than the outer sides. Smaller patches later blend, and the affected parts die and finally turn black. The lower sides of diseased spots upon the leaves often bear red incrustations, resulting from the drying of the exudate from within. The roots show the same discoloration, and the outer parts of the rootlets die and become loose. If only slightly diseased, the plants may attain normal size.

Badly diseased roots are evidenced by the yellowed tops and other signs of malnutrition. In advanced stages the roots give such poor anchorage that the plants may be easily pulled from the ground.

Infected stalks should be burned and such rotation followed as to relieve the infested soil of susceptible crops for several years.

Kernel-smuts ${ }^{332}$ (Sphacelotheca sorghi (Lk.) Cl., S. cruenta (Kuehn) Potter). - These smuts infest the individual grains of the panicle, while the head as a whole remains nearly normal in appearance. The smutted grains are at first covered by a white, later gray, membrane. This membrane in time becomes broken by the winter exposure and frees the dark-colored spores.

Kernel-smut was reported by Kellerman in 1891 as limited to sorghum grown from imported seed. It was then known in the District of Columbia, Wisconsin, New York, Nebraska, and Kansas. It is widespread in Europe, Africa, and Asia, and was probably imported into the United States upon diseased seed. It was first recorded in the United States in 1884, and is now found in almost all places where sorghum is grown.

According to Clinton's estimates it may prevail upon 


\section{Cereals}

from 4 to 32 per cent of the plants. The same investigator found that the yield in juice was lessened about 30 per cent, owing to the smaller size of the smutted plants. The damage is particularly serious in kafir and broom corn. Sec p. 283.

These smuts gain entrance to the host only during the very young seedling state, before the plants appear above ground. The mycelium of the causal fungus grows through the plant until flowering time without any indication of its presence. At blossoming time the fungus seeks the ovary, destroys it, and becomes evident as smut.

Disinfection of the seed $b y$ formalin is an efficient remedy. Head-smut ${ }^{461}$ (Sphacelotheca reiliana (Kuehn) Clinton). Instead of involving the grains singly, as in the kernel-smut, the head as a whole is affected. A white membrane is at first present, but this later breaks open, exposing the pulverulent spore mass. Rarely, only

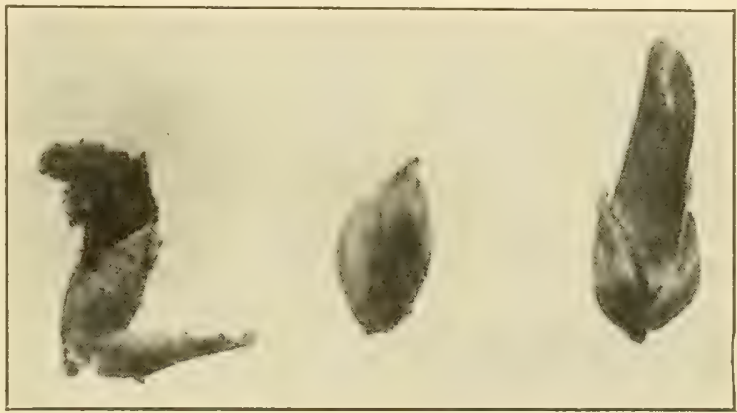

Fig. 164. - Three views of sorghum kernelsmut.

a portion of the head is smutted. The spores soon weather away, leaving behind only the veins of the part involved. This disease was first noted in Egypt in 1868, and is prevalent in America only in the Texas Panhandle. It occurs on sorghum and to some extent on corn. Milo is immune.

The only procedure to recommend is that employed for corn srnut.

Anthracnose (Colletotrichum falcatum Went.). - Anthracnose was first seen in America upon sorghum in North Carolina, where it did considerable damage. It has since been reported from Louisiana. The spots which are more prevalent on the lower leaves have very definite gray or tancolored centers which are surrounded by dark, reddish- 
brown rings, outside of which is the ordinary green of the healthy leaf. As the spots age they frequently grow together and form one large oblong area, sometimes several centimeters long. At a late period in the development of the disease the centers of the spots are occupied by small black specks, the black acervuli of the causal fungus.

\section{TEOSINTE. See p. 283.}

\section{WHEAT, SPELT, EMMER, EINKORN}

Black-stem-rust (Puccinia graminis Pers.). - Though in earlier years this rust was thought to grow indiscriminately upon a great variety of grasses, recent, thorough study has shown that what was formerly regarded as one species is in reality a number of races or varieties grouped under one name. Collected on about 70 species of wild and cultivated grasses including wheat, oats, rye, and barley, this rust is now separated into eight or more biologic forms. See p. 277.

It is the most serious of the rusts, of practically worldwide distribution, and causes more damage in the Central States than any other rust except the oat black-stem-rust. It is injurious to oats, rye, and barley as well as wheat. The damage done fluctuates largely. The injury is greater to spring wheat than winter wheat. In 1916, the direct loss was placed at $\$ 110,000,000$, in four states, $200,000,000$ bushels in the United States, and 100,000,000 more in Canada. Total loss of the crop often results in Kentucky, Indiana, Texas, Michigan, and Ohio.

In the spring or cluster-cup stage upon the barberry, swollen spots are produced upon the leaves, fruit, or young stems. These spots upon one side bear the cups in abundance and upon the other side appear as pale, circular regions which bear the small, black pyenia.

Upon the wheat the rust shows first its uredinia, which come later than the uredinia of the orange-leaf-rust, and are of more brownish tinge. The sori are most common 
upon the stems and leaf sheaths, more rare upon the leaf blade. Following this stage the black telia appear upon the stems and leaf sheaths, constituting the most conspicuous and predominating symptom.

The damage by this disease is due to the inroads of the fungus upon the green leaf tissue, destroying the starchproducing power, diminishing the vigor of the plant, and showing its effects finally in the shrunken, shriveled grain.

Since this rust usually appears late in the season, the varieties of wheat that mature early are likely to escape its attack to a greater extent than those varieties which are late in maturing. For a similar reason climatic or agronomic conditions which conduce to slow growth and late maturing of the crop favor the rust.

Since the common barberry (Berberis vulgaris) and its varieties, or Mahonia is necessary to the functioning of the teliospores, these plants should not be tolerated. ${ }^{551}$ In Denmark in 1903 laws enforced eradication of this barberry. Eleven years after we read ${ }^{462}$

"That black rust has disappeared gradually, contemporary with the barberry bush.

"That the violent, destructive black rust attacks, which affected the whole or most of the country, with two or three years interval, have now ceased.

"That the weaker attacks which affected the grain and grasses and especially the oats in Jutland are now practically unheard of, or at least come late in the fall."

Influenced by such evidence, in 1918 and 1919 the Federal authorities and those of many states, particularly in the Middle States and Northwest, took energetic measures to eliminate the barberry and Mahonia. Anti-barberry laws were passed in Saskatchewan, Manitoba, Canada, and many states, notably in North Dakota, Iowa, Colorado, Minnesota, Montana, Nebraska, South Dakota, Wisconsin, Michigan, Illinois. It is clear from experimental evidence that the rust does not commonly pass to the next crop on the seed, nor does it commonly overwinter in the living host plants, except 
in the extreme South. The evidence is also to the effect that such rust as does overwinter in the South does not pass to the North, but that the main source of infection in the North is from the barberry.

Some durum wheats are highly resistant to rust, and recently, by selection, the Kansas Agricultural Experiment Station produced a bread wheat of the Crimean group that under Kansas conditions was highly rust-resistant. Before the rust problem can be solved by breeding resistant plants, much fundamental knowledge must be gained regarding the biologic races of the parasites and their host ranges. Many wild grasses propagate and spread the rust and, especially if they are exposed to infection from the barberry, may bridge the way to a wheat field. Prominent among those grasses are wild barley, slender-wheat-grass, western-wheat-grass, and wild rye grasses. Obviously they should be kept down as much as possible.

Orange-leaf-rust (Puccinia triticina Eriks.). - This rust of wheat and possibly of several wild grasses is the most common and widely distributed of all rusts of the United States and is especially injurious in the southern states. It is said by Carleton that it is not only never absent from the wheat fields throughout the year, but that it is sometimes abundant even in dry seasons. Notwithstanding its prevalence its inroads upon the crop are not usually serious, and in no case on record has it caused shriveling of the grain such as is common from the black-stem-rust.

The most conspicuous character of this rust is the presence of many orange-colored sori upon the leaves, especially upon their lower surfaces. The grayish black telia are neither so prominent nor so profuse as in the black-stem-rust. Both of these rusts possess the uredinial stage, and it is difficult to distinguish them apart in this condition except by the microscope.

As with the rye orange-leaf-rust, this fungus also can winter in its live uredinial mycelium and continue to bear urediniospores throughout the year, spending its entire existence, if 
necessary, in this one stage upon the single species of host. While no variety of wheat is entirely proof against it, large difference is shown in this respect, some presenting high resistance, even under most adverse conditions. Early maturity is an important factor in evading rust.

The following standard rarieties are recommended by Carleton as possessing considerable resistance to the orangeleaf-rust in every part of the country- "Winter wheats: Turkey, Mennonite, Pringles No. 5, Tieti, Odessa, Pringles Defiance. Spring wheats: Haynes Blue Stem, Saskatchewan Fife.

"The following varieties seem to be resistant, but have not yet been well established as such: Theiss, Oregon Club, Sonora, Diehl Mediterranean, Fulcaster, Arnolds Hybrid, California Spring.

"Some of the hardy prolific sorts not yet well known in this country, but likely to be more or less rust-resistant after thorough acclimation and selection, are - Winter wheats: Prolifero, Banatka, Red Winter, Nashi, Tangarotto, Bearded Winter, Winter Ghirka, Budapest, Crimean, Yx, Bellevue, Talavera. Spring wheats: Alsace, Spring Ghirka.

"Two varieties which are quite susceptible to rust, but which usually ripen early enough to escape the worst effects of it, are: Early May and Zimmerman.

"Some others not quite so well known, but probably worthy of trial as rust-escaping sorts, are-Early Baart, Allora Spring, Kathia, Roseworthy, Japanese No. 2, Yemide, Canning Downs.

"These last varieties are not likely to withstand very severe winters, and are therefore best adapted to southern districts, where they may perhaps in time become acclimated. Yemide and Kathia are probably the most hardy of the six. Canning Downs winter-killed in one trial, even in Mississippi."

Yellow-stripe-rust (Puccinia glumarum (Schum.) E. \& H.). - This rust, which is serious in Europe on wheat and barley and less so on rye and several wild grasses, was found in 
Arizona in 1915 on wheat; since then, in the western United States, on barley, rye, and many wild grasses. On barley it has appeared as far east as South Dakota.

Bunt, Stinking-smut ${ }^{324}$ (Tilletia lavis Kühn, Tilletia tritici (Bjerk.) Wint.). - Tilletia tritici causes heavy losses in the Northwest, T. lavis in the eastern United States. Where both occur the first is known as "low smut," the second as "high smut" from their respective habits. This smut (for practical purposes the two may be considered as one) is readily distinguished from loose-smut by the fact that it attacks only the grain, not the inclosing chaff. The head therefore remains of much more nearly normal appearance, and it is often not until the glumes have been opened, and their contents examined, that the presence of the smut mass is detected, covered with its membrane, and resembling the wheat grain in size and shape. It may be recognized by an expert observer by its peculiar, disagreeable, penetrating odor, and by the deeper green color of the diseased heads. The smut masses are often so firm as to remain unbroken through threshing, but they may be recognized among the grains by their darker color, greater plumpness, absence of groove and germ, and finally by crushing them and liberating the black spores.

The disease is particularly destructive, since its presence signifies not only loss of grain due to replacement by smut, but also loss in value to the good wheat, which may be largely depreciated in price by the presence of the bunt. Often bunted wheat is worthless for milling purposes and even for cattle feed. Bunt constitutes, for these reasons, one of the worst smuts in the world. Strong fanning removes part of the smutted grains, but troublesome washing processes must be employed to remove them all, and even then the results are not entirely satisfactory. The annual loss from bunt in the United States is about 25,000,000 bu., to which should be added the frequent loss from explosion of threshing machines, estimated at $\$ 1,000,000$ in two years, due to the oily combustible spores. Where low smut alone is 
present and the heads only are harvested, the sickle-bar may be so adjusted as to leave the bunt behind.

Many smut spores naturally find lodgment upon the surfaces of healthy grains from smutted fields, or they may be carried from farm to farm upon the threshing machine. Upon planting such seed the following season these spores are ready to attack the seedling grain plant. The fungus, after gaining entrance into the seedling, grows with it throughout the season, and appears again at harrest time as spore masses within the chaff. Every grain of every head of an affected plant is usually smutted.

The seedling age, like that of the oat, is the only age susceptible to smut infection. Treatment of seed wheat with formalin is usually complete in its efficiency and trifling in cost. In some sections of the Northwest, however, the soil has become so heavily infested from previous cropping and by "smut showers" that formalin seed treatment is of but little value. In such regions early sowing and crop rotation are recommended.

Loose-smut ${ }^{324}$ (Ustilago tritici (Pers.) Rostr.). - Like the loose smut of barley, this smut seems to be increasing in importance. In some regions it prevails to a greater extent than the bunt, causing at times a loss of more than a quarter of the crop though the loss is usually not more than 2 per cent. Loose-smut may readily be distinguished from stinking-smut of wheat by the fact that the spore masses involve the whole spikelet, which becomes dry and powdery and falls away; also by its much earlier appearance in the field, $i$. c., at flowering time. The spore masses are dark, olive-black, and are produced exclusively in the spikelets. The bearded spring wheats seem to be more susceptible than the blue-stem varieties, but the smut is common on all varieties.

From the studies of Maddox in Tasmania, Wakagwa in Japan, Brefeld in Germany, and others, it was known in 1896 that with the loose-smuts of wheat and barley, totally unlike the bunt of wheat and the loose-smut of oats, infection 
occurs exclusively at blossoming time; that at all other times the plants are immune. Smut spores from near-by smutted heads are blown into the wheat or barley flowers. Infection follows. The fungus then lies dormant in the grain until the seed sprouts. If the grain ripening from such infected flowers be used for seed, the fungus develops in the seedling, and an infected plant, producing smut but no grain, results, though no external symptom of the disease appears until blossoming time. Conversely, if seed resulting from blossoms which were not infected be used, plants free from smut will be raised.

The remedy in this case, therefore, lies in the use of uninfected seed. To obtain such seed, grain must be secured from a field in which there is no loose smut, or if this is not practicable, seed grain must be raised under such conditions as will afford clean seed.

It has been found that while the ordinary formalin seedtreatment is ineffective against wheat loose-smut, the hotwater treatment, in modified form, is effective, though somewhat difficult of manipulation. See p. 272.

Rogueing or weeding out all diseased plants from the crop that is to be used for seed, diminishes the smut largely, but does not entirely eliminate it.

A practicable, effective means, which results in complete and inexpensive eradication of this smut, consists of a combination of the seed plat with the hot-water treatment.

Flag-smut ${ }^{483,}{ }^{525}$ (Urocystis tritici Koern). - Linear, black streaks in the leaves, much like those shown in fig. 182, occur on wheat. Considerable damage is reported from Australia, India, and Japan. Flag-smut was found in Illinois in 1919. The usual formalin treatment is beneficial, though not so complete in control as with oat smut, since infection occurs, to some extent, from diseased refuse in the soil. If badly infested, the stubble should be burned to destroy as many spores as possible.

Foot-rots. ${ }^{485,525,554}$ - These diseases are characterized by a brown or black-rot on the lower part of the stem, the diseases 
occurring in the fields in spots. They are known in many countries on wheat, oats, barley, rye, and rice, and are very destructive in Europe and Australia. The discases in their various forms have many names, among them Take-all, Whiteheads, Piétin. Any one of several fungi may cause foot-rot, especially when the wheat plant is weakened by adverse environmental conditions. A foot-rot of wheat due to unknown cause was reported in Oregon in 1902, and one due to Helminthosporium in Illinois and Indiana in 1919. Burning of the stubble and crop rotation, accompanied by good drainage, are recommended.

Anthracnose (Colletotrichum cereale Manns). - This anthracnose seems to prevail on wheat as extensively as upon

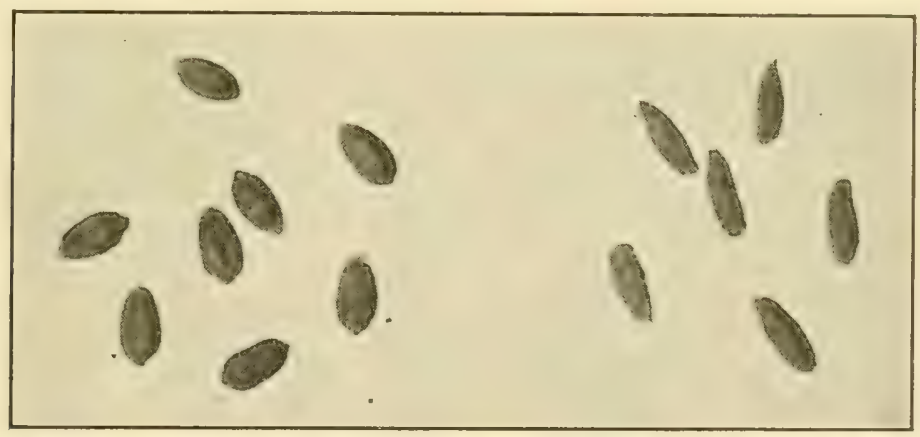

FIG. 165. - Normal wheat kernels and shriveled kernels due to anthracnose. After Manns.

rye. The head is not destroyed, as in the case of rye, but general weakness of the plant and light, shriveled grain follows the attack.

Powdery-mildew ${ }^{352}$ (Erysiphe graminis DC.). - The usual characters of the powdery-mildews are exhibited; a whitish, flour-like coating in irregular, circular spots upon the leaves and other plant parts. This mildew, together with the mildew of oats, rye, and barley, bears the same specific name, but upon each of these crops the form is so specialized as not to transfer readily, if at all, to the other crop plant. Thus from the farmer's viewpoint there are prac- 
tically four distinct kinds of mildew, although indistinguishable to the eye. The form upon wheat grows upon all species of Triticum though some varieties show much more resistance than others.

In damp, shaded spots the mildew is sometimes quite injurious, though it is rarely so over any considerable area.

The conditions favor-
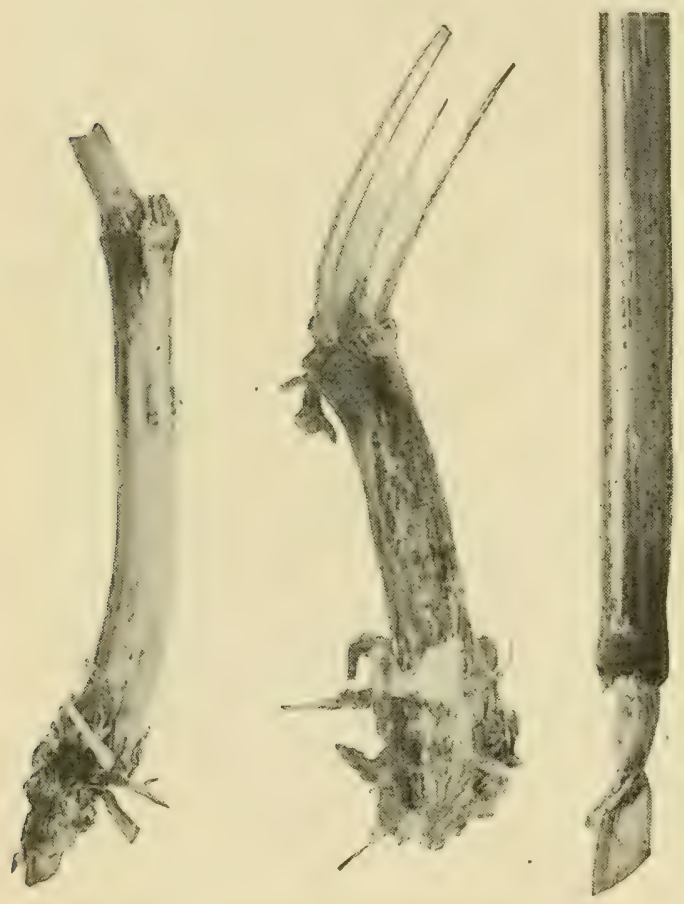
ing the disease should be avoided.

Scab ${ }^{329}$ (Gibberella saubinetii (Mont.) Sacc., Fusarium).- Scab, first described in 1884 in England, seems to be quite generally distributed in America, and is often the cause of large loss which, under conditions favorable to the disease, may reach from 10 to 30 per cent or higher. The loss in 1917 was estimated as about $10,000,000$ bushels. Scab appears upon the heads when about FIG. 166. - Anthracnose on wheat stems. half ripe, as yellow or pink incrustations on the spikelets, on the bases of the glumes, or covering the rachis. The affected spikelets ripen prematurely and turn yellow or brown before the normal parts mature. After ripening of the head, the diseased parts appear shrunken. The grain itself is shrunken, covered with a thick felted mycelium, and is incapable of germination.

Only a few spikelets upon the head may be affected, these occupying any position - basal, terminal, or intermediate - or the whole head may be diseased. The loss consists in 
injury to the quality of the grain and diminution in quantity.

Selby has shown that seedlings in the field are often killed by this disease, which is carried over in the seed. In this way as high as 5.9 per cent of death in seedlings has been caused.

It has recently been shown that the fungus that causes wheat scab grows also on corn causing root-rot, and winters

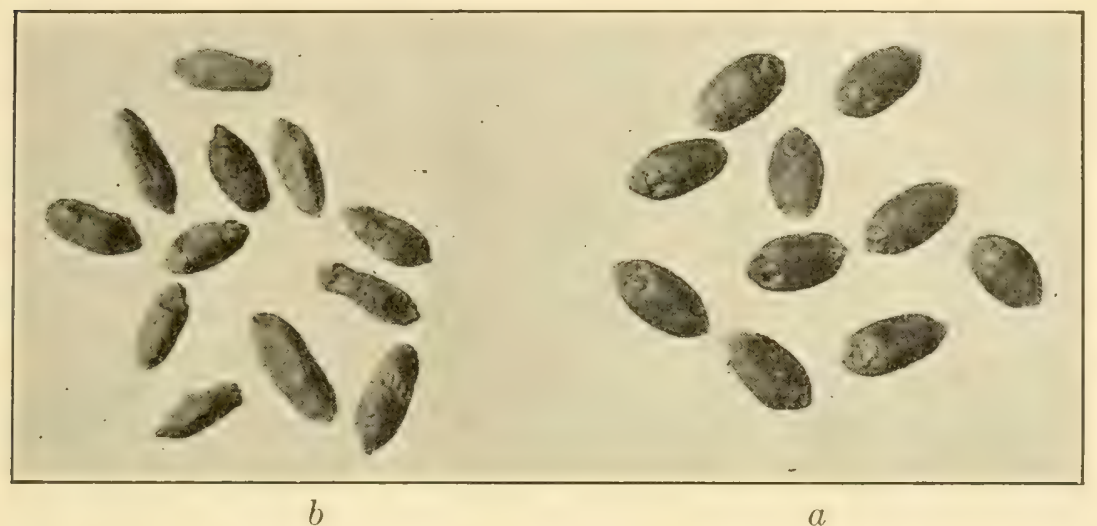

FIG. 167. - Wheat kernels: $a$, normal; $b$, shrunken and killed by scab. After Manns.

on corn refuse. Wheat planted in fields that bore infected corn becomes badly diseased. One corrective practice, therefore, is to avoid sowing wheat on land so infested.

\section{Minor diseases}

Black-chaff ${ }^{355,356}$ (Pseudomonas translucens). - As the wheat approaches maturity, black, sunken stripes appear lengthwise of the chaff. The rachis and leaves are also attacked. In severe cases the grain is shriveled. The disease was found in 15 states west of Indiana in 1917. Thorough screening and disinfection of seed by copper sulfate is advised. Leptosphæria leaf-blight ${ }^{353}$ (Leptosphceria tritici (Gar.) Pass.). - The lower leaves are killed early in the season. Large loss is not usual. The Glume-blotch ${ }^{354}$ 
(Septoria sps.) is common as small, dark spots upon the chaff of certain varieties of wheat. Another Septoria causes leafspots, especially upon the lower leaves. Eel-worms ${ }^{457}, 482,537$ (Nematodes) affecting the grain in the head have been found in several states, in some fields causing 25 per cent damage. Only clean seed should be used. Crop rotation is advised. Ergot is occasional on wheat. The Southern-blight (Sclerotium) sometimes injures the stand in the South. 


\section{FORAGE CROPS}

This group of crops, of high aggregate value and agricultural necessity, does not possess an acreage value which warrants such expensive modes of treatment as spraying. Protection against disease here must, in general, consist in modifications of agronomic methods tending to produce thriftier, more resistant plants, crop rotation to diminish the parasites, variation of time of sowing or harvesting to evade disease. Forage diseases are especially troublesome since they frequently prohibit planting of certain leguminous crops much desired in the rotation.

\section{LEGUMES}

\section{ALFALFA}

Leaf-spot ${ }^{359,}{ }^{487}$ (Pseudopeziza medicaginis (Lib.) Sacc.)No other disease of alfalfa is so universally prevalent. It constitutes the most important, in most sections the only really important, disease of this crop. Loss in vigor of the plants and loss in hay, by shedding of the leaves, result. Pammel in Iowa in 1891 estimated the loss in some fields at 50 per cent. It was first described in Europe in 1832, and noted in the United States in 1875.

The leaves first show small brown to black spots, irregular or circular, which extend through the leaf and are thus visible from both sides. They are about $1-2 \mathrm{~mm}$. in diameter, and are not sharply bordered, but shade off gradually into the surrounding tissue. With a hand lens very small, spore-bearing organs may be seen in the centers of the older spots, first as shiny amber-colored elevations. These elevations soon crack open and expose very small, cup-shaped sporiferous bodies, which remain surrounded by portions of the ruptured epidermis. Badly diseased leaves 
usually turn yellow and fall off. Spots upon the stems show the same general character as those upon the leaves.

The lower leaves, and the leaves of older plants, are most subject to the leaf-spot. Plants late in the season, as of the second and third euttings, suffer much more than earlier in the season. These crops, especially in a dry season, if allowed to stand a little too long before cutting may be badly spotted, and the loss in hay, through fallen leaves, may be

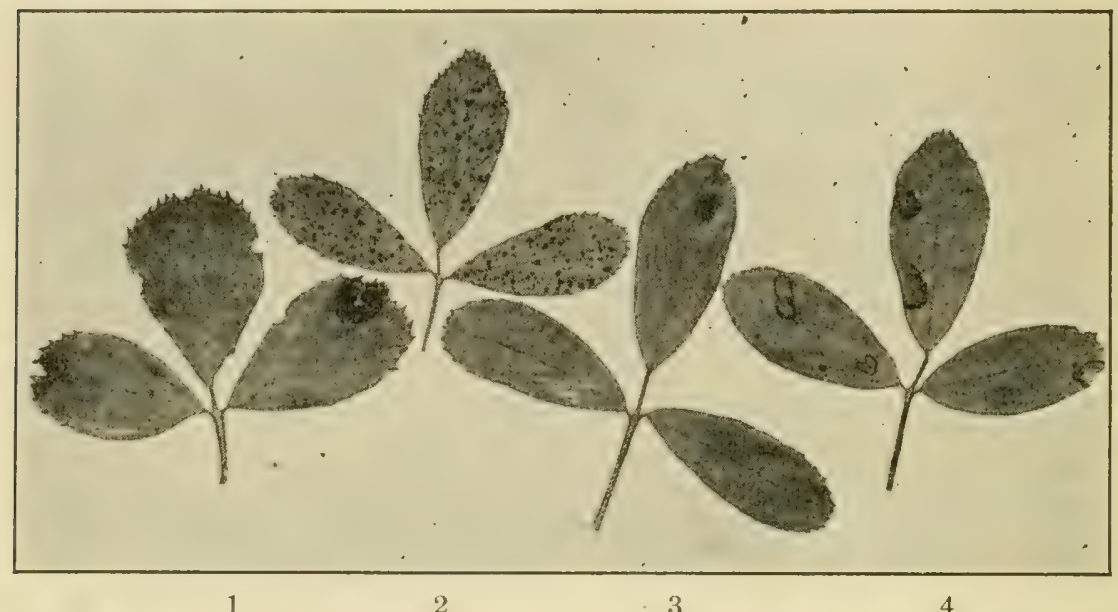

FIg. 168. - Four alfalfa leaf-spots due to: 1, Ascochyta; 2, Pseudopeziza; 3, Cercospora; 4, Stagonospora. After Stewart and others.

considerable. The plants are never killed by this disease, though young fields which have not yet become well established may be ruined.

Its mode of dissemination is unknown, and seed treatment is useless as a preventive.

The only practicable treatment is to mow down badly diseased plants with the hope that the new shoots which spring forth may overcome the disease. If the disease appears just before cutting time, the mowing should be hastened a few days in order to avoid loss from leaf shedding.

Yellow leaf-blotch ${ }^{3 i s}$ (Pyrenopeziza medicaginis Fcl., Sporonema). - This disease is known from Vermont to the Pacific, in Europe and South America, and under certain 
conditions does more damage than leaf-spot. The spot produced is deep yellow, verging to orange, and bears numerous orange-colored pycniclia. The fungus winters on infected leaves. Early cutting is beneficial.

Wilt ${ }^{357}$ (Sclerotinia trifoliorum Eriks.). - This wilt, which in some respects resembles lettuce drop, has been noted on alfalfa and the clovers, red, white, crimson, bastard, mammoth, and alsike, in several widely separated sections of the United States and Europe.

It kills the plants, and under farorable weather conditions, the chief factor of which is a humid atmosphere, it may extend from plant to plant and involve large areas in the field.

Plants may show a variety of symptoms. Sometimes the leaves droop, and become matted together in a sodden mass at the base of the plant, and overgrown with a white cottonlike layer of mycelium, in which black sclerotia, similar to those described under lettuce, are found. At other times the stems may be the point of attack, showing dead, brown sections covered with the mycelium and bearing sclerotia. Upon splitting a stem open the central part may be found filled with mycelium and with occasional sclerotia about the size of a grain of wheat. The white mycelium and black sclerotia are absolutely diagnostic.

Under unfavorable weather conditions the disease may die out and fail to reappear, but if the weather is favorable to this fungus, the wilt may reappear year after year with increased severity, involving larger and larger areas.

Stewart, French, and Wilson reported large areas where 50 per cent of the stalks were killed, though later the field recovered entirely.

Where the disease is troublesome, rotation of crops and deep plowing to bury the sclerotia seem to be the only recourse. Isolated, infested areas may be cleaned out by burning.

Texas root-rot ${ }^{16,17}$ (Ozonium). - This rot is a soil disease, which in its general characters is identical with that so disastrous upon cotton and the treatment applied to cotton 
is the only one to be recommended for alfalfa. It has been very destructive in Texas since 1892 .

Anthracnose ${ }^{360}$ (Colletotrichum trifolii Bain). - Alfalfa anthracnose was first mentioned in 1905 by Bain and Essary, who stated that it was prev-

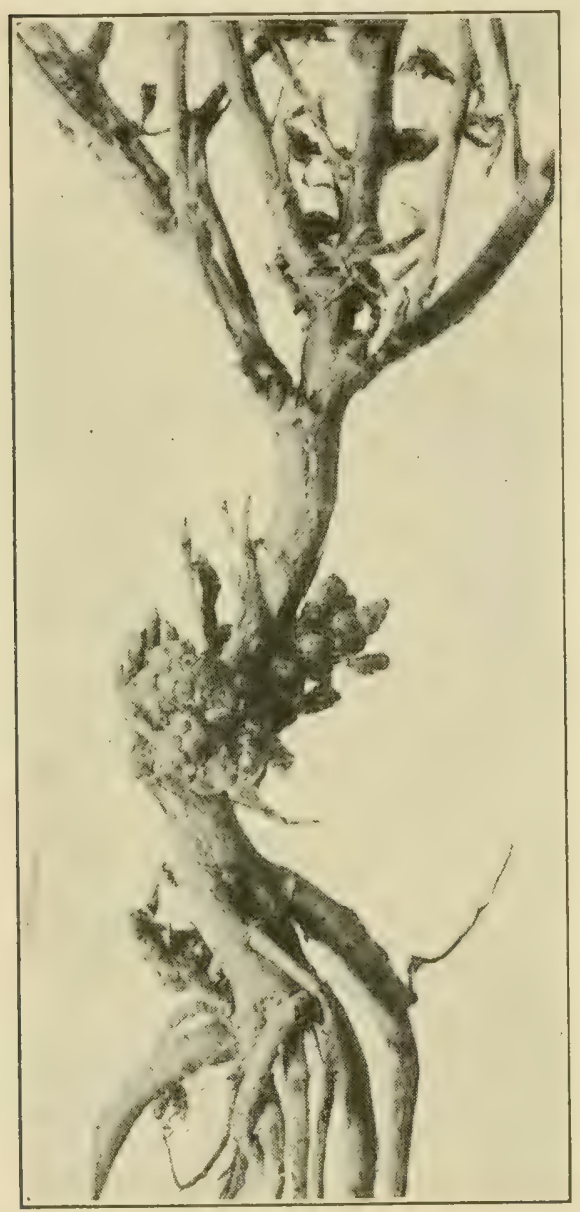

FIG. 169. - Alfalfa crown-wart.

After U. S. Department of Agriculture. alent in Tennessee in 1906 and was one of the chief causes of alfalfa failures in that state. It has also been noted in destructive form in Virginia and New York. It appears as elliptical, sunken spots, 5-6 $\mathrm{mm}$. long, upon the stems. The spots are gray and have dark acervuli scattered over them. Where the disease becomes aggressive, dead or withered stalks or plants are seen scattered over the field. These stalks arise from diseased crowns, which are characterized by blackening of the woody parts, below the point where the stalks are attacked. The only remedy seems to be the use of resistant varieties.

Blight ${ }^{361,362}$ (Pseudomonas medicaginis Sack.). From Colorado Paddock, in 1906, described a severe disease of alfalfa which has been noted for several successive years. It is due to bacteria and in its early stages produces a watery, semitransparent, yellowish to olive-green appearance along one 
side of the stem of the plant. The plants are at first weak, the stems light colored, later discolored or biackened. Drops of thick fluid exude from the stems and dry upon them, giving a glistening appearance as if they were varnished. The chief damage is to the first cutting, though in subsequent years the plants may die from decay of the crown, or roots, or from loss of nutrition. Infection takes place chiefly through rifts in the epidermis due to frost, thereby affording access to wind-borne bacteria.

Crown-wart ${ }^{363}$ (Urophlyctis alfalfce (Lag.) Magn.). The chief diagnostic character is the presence of numerous galls at or near the base of the stem. They vary greatly in size from that of a pea to an orange. Diseased plants have brown, dead stems, or stems that are weak and bear yellow leaves. The disease apparently originated in South America, is now widely distributed in Europe and was first noted in the United States, in California, in 1909, later in Arizona, Oregon, and Utah.

Dodder ${ }^{36+}$ (Cuscuta sps.). - Dodder, or love vine, is a parasitic, flowering plant. Its yellow, threadlike stems coil closely around the alfalfa stems, and take nourishment from them. It reproduces by seed, and the seed may readily pass with alfalfa seed unless very carefully inspected. The parasite is absolutely ruinous to the portions of the field that it infests and, since it spreads rapidly, it is a serious enemy.

If dodder occurs in spots, these should be dug over or burned over before it ripens its seed, using kerosene and straw to insure heat sufficient to kill every plant, with a margin of a few feet entirely around the infested spot. Badly infested fields should be plowed up.

\section{Minor diseases}

Root-rot, wilt (Fusarium sp.). - The first symptom of this wilt is a yellowing of the outer leaves which gradually spreads until all of the leaves and stems become discolored, wilt, and die. This rot is said to be quite generally destruc- 


$$
0 \%
$$

1

2

3

FIG. 170. - 1, Alfalfa seed; 2, seed of largeseeded dodder; 3 , seed of small-seeded dodder, natural size. After Stewart and others.

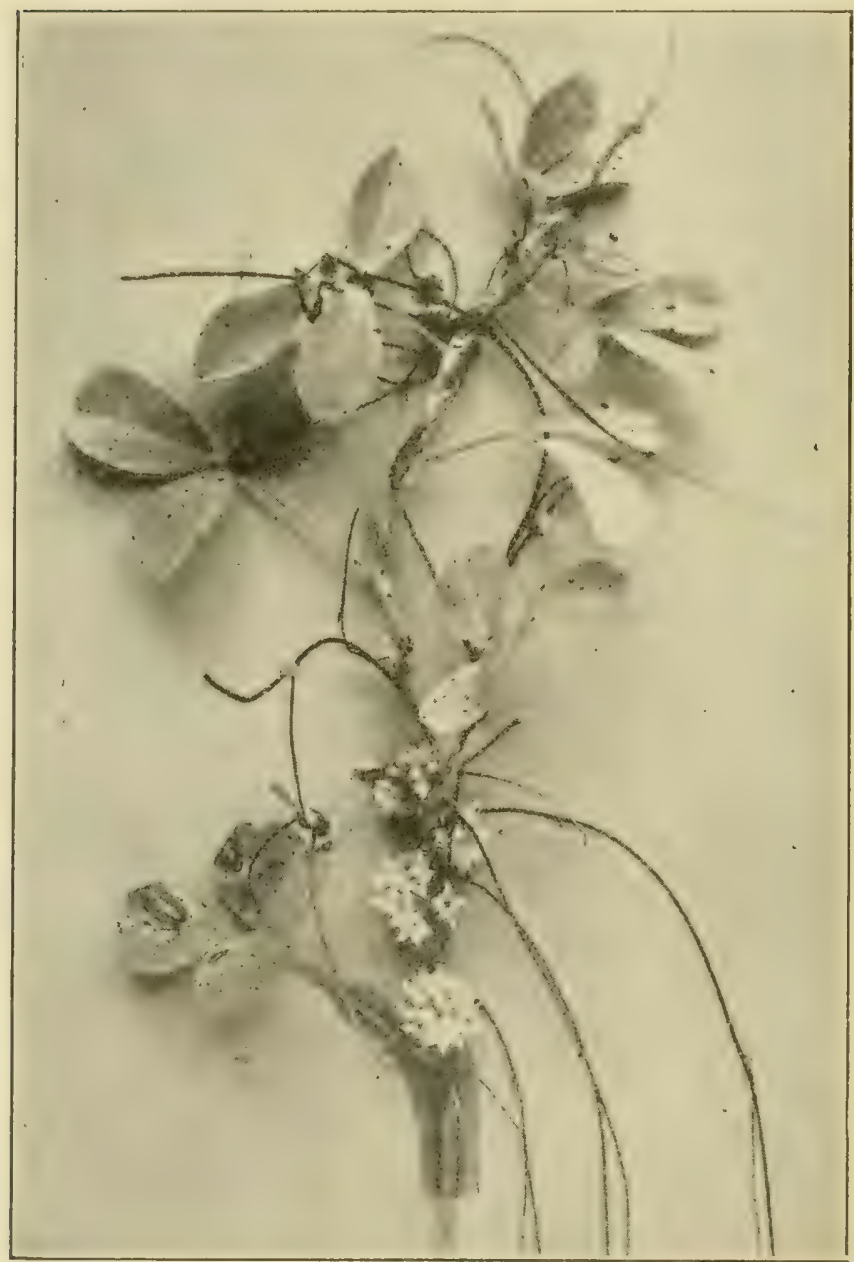

FIG. 171. - Alfalfa plant and dodder. After Stewart and others. 
tive in Arizona. It is a soil disease, and its general characters are those indicated on p. 26.

Root-rot (Rhizoctonia crocorum DC.). -- Similar to the effects of Rhizoctonia upon so many other hosts, the disease consists primarily of a root-rot in which the diseased parts are coated with matted strands of the fungous mycelium, usually brownish red or violet in color, accompanied by sclerotia. The tops of plants so diseased turn yellow and die.

The very aggressive fungus migrates through or over the soil to adjoining plants, and the affected spot in the field thus enlarges, sometimes at a rate of $7 \mathrm{~m}$. radially per year. Though long known in Europe, it has not yet appeared in many parts of America.

Rhizoctonia root-rot is a typical soil disease and is kept alive in the soil by its sclerotia, which may live at least two or three years. The general suggestions given under soil diseases apply.

Ascochyta leaf-spot (Ascochyfa menticaginis Bres.). - This leaf-spot has been noted in North Carolina, and what is probably the same disease, also in New York. The spots are irregularly circular except where they occur on the edge of the leaf, light brown in color, and bear small black dots.

Cercospora leaf-spot (Cercospora merlicaginis E. \& E.), which appeared in Delaware in 1889, has also been noted in New York and New Jersey. The leaf-spots are nearly circular, smoky brown to black, from $0.5-1 \mathrm{~mm}$. in diameter, and show equally well from either surface of the leaf. They have no well-clefined borders, but shade into the surrounding healthy tissue. Affected leaves turn yellow and die. It appears to be disseminated on the seed. Seed disinfection is therefore recommended. A leaf-spot has also been described due to Pleosphcerulina briosiana Poll., and others due to Septoria and Macrosporium.

Downy-mildew (Peronospora trifoliorum De Bary) is a serious pest on clover in Europe and has heen reported in America from Colorado, Kansas, New York, and North Carolina, though it has not yet been destructive in this 
country. The affected parts of the leaf turn yellowish gray to purple, and are frequently curled. The leaves, as seen from below, are coated with a downy fuzz, violet colored when old.

Rust (Uromyces striatus Schr.) may be recognized by the typical rust sori, which are present, in this case, chiefly upon the lower sides of the leaves. The cluster-cup stage is found on Euphorbia. Anthracnose (Gloeosporium medicaginis E. \& K.). - Black, rather prominent acervuli appear chiefly upon the lower surfaces of leaf-spots. The lower leaves often turn yellow and die. Seed-mold (Alternaria $s p$.). - Brown, dead, shriveled seeds are often noted in samples of alfalfa seed. Such seeds, if planted, develop, apparently from within, a dense black mold.

Damping-off (Rhizoctonia sp. and Pythium debaryanum Hesse) is caused chiefly by the two fungi named. It has been known to affect alfalfa seedlings in the greenhouse, and it may occur to some extent in the field, especially the form caused by Rhizoctonia.

Stagonospora leaf-spot (Stagonospora carpathica Baeu.) has been noted only in New York. Stewart, French and Wilson characterize this leaf-spot as follows: Unlike the Ascochyta leaf-spot, this disease attacks chiefly green leaves in the upper part of the plant. The spots are circular, $1-3 \mathrm{~mm}$. in diameter, and usually light brown with a narrow border of dark brown. Each spot bears several light brown pycnidia visible on both surfaces of the leaf. Yellow-top may appear simultaneously over whole fields. The cause is unknown. White-spot is common but also is of unknown cause.

\section{CLOVER}

Black-mold (Phyllachora trifolii (Pers.) Fel., Polythrincium). - Common red clover, crimson clover, white clover, alsike clover, and several other related plants are affected by this mold. The chief symptoms are pale spots upon the upper sides of the leaves accompanied by black dots on the lower sides. These spots at first glance so strongly resemble the 
sori of the rusts as to lead the casual observer to mistake the disease for a rust. Though the disease is often of considerable damage, no treatment is known.

Wilt ${ }^{535}$ (Sclerotinia trifoliorum Eriks.). - The fungus causing this wilt is probably identical with that of the wilt of alfalfa. It was first noted in America, in Delaware, by Chester in 1889, later in New Jersey by Halsted.

The affected plants wilt and rot to the ground. White mats of mycelial threads, and later black sclerotia, are found upon or within the dead stems. Sclerotia are especially abundant at the bases of diseased stems. Disk-like bodies, similar to those described in connection with lettuce drop, develop from the sclerotium and bear spores which spread the infection. While this malady has

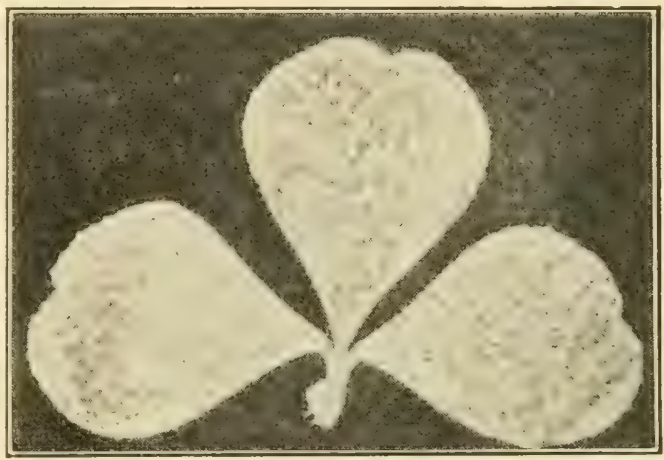

FIG. 172. - Clover leaf showing spots of black-mold. Original.

been very destructive in Europe upon several varieties of clover, it is not yet of wide distribution in America, though it has appeared as a serious pest in a few fields.

It is exceedingly difficult to eradicate when it has once gained foothold, and the European recommendation is to avoid planting the infested fields to susceptible crops.

Rust (Uromyces sps.). - The clover rusts are most injurious to the second cutting, to which they may cause a damage of 20 or even 50 per cent if conditions favorable to the disease - damp, cool weather - obtain. These rusts, long known in Europe, were first reported in America in 1884. At the present time they are found upon red, white, crimson, and alsike clovers over a large part of the United States, though of different species, or at least different biologic races upon some of the different hosts. 
These are true rusts, and on the white clover possess all of the three stages, cluster-cup, summer or uredinial, and winter or teliospores. They attack all green parts of the plant. The most conspicuous and destructive stage is the uredinial, which is marked by profuse, circular or elongated, chestnut-brown, powdery sori. These may be few and scattered, but more often they are abundant, nearly covering the leaf, which turns black, dies, and shrivels. The rust is conveyed from plant to plant throughout the summer by spores of this stage.

The teliospores or urediniospores may appear in the same or separate sori and in either event the teliospores appear

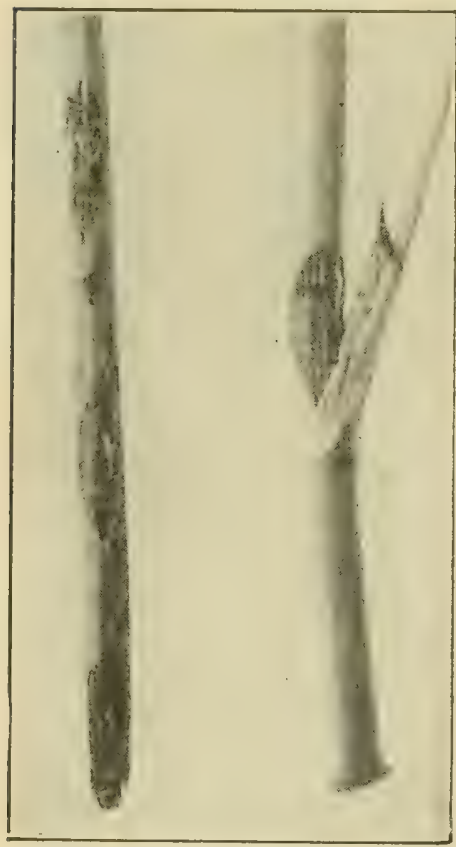

FIG. 173. - Anthracnose on red clover stem and petiole. After Jackson. later in the season. They are recognized by their darker brown color. The cluster-cup stage, which is less abundant and less injurious than the other stages, may often pass unnoticed. It appears first as pale, swollen regions upon the leaf or petiole. These regions soon show the characteristic cups with orange-colored spores. The clustercup stage, though not known on red clover, predominates in the early spring upon many other varieties; but the uredinial stage soon gains the ascendancy over it. All three forms may be produced side by side, to some extent, throughout the summer. Hibernation probably occurs in two ways, by the teliospores and by the mycelium, which may remain alive in the affected parts over winter.

Anthracnose ${ }^{305}$ (Colletotrichum trifolii Bain). - This anthracnose is now known on clovers and alfalfa in Tennessee, Ohio, West Virginia, Arkansas, Kentucky, and Delaware. 
It is first found chiefly upon the leat stalks, later upon the stems, near the surface of the ground and just below the flower clusters, as elongated sunken spots, which result eventually in the death of the whole plant. It frequently causes great loss, and is said, by Bain, to be the most serious plant disease in Tennessee. Alsike clover is nearly immune. Hope lies in the use of resistant varieties.

Anthracnose (Gloosporium caulivorum Kirch.). - Long, brown to black, sunken spots upon stems and petioles, causing death of the more distal parts, are diagnostic characters of this anthracnose, which was first reported in the United States by Sheldon in 1906, and has since been noted as serious in a number of states.

\section{Minor diseases}

Leaf-spot ${ }^{\mathrm{s}} \overline{\mathrm{T}}$ (Pseudopezizu trifolii (Biv-Bernh.) Fel.). This leaf-spot much like that of alfalfa occasionally causes considerable damage. A Cercospora leaf-spot is also recorded. Black-mold (Macrosporinem sarcinceforme Cav.) is widely distributed as the cause of concentric spots on leaf and petiole. Scab (Cribberella sanbinetii, Fusarium). - This parasite of cereals is also known to cause depressed, oblong spots upon clover. See wheat. Broom-rape (Orobanche minor L.) is similar to that upon tolncen. See p. 259. Rootrot (Rhizoctonia) is sometimes injurious. Dodder. See alfalfa.

\section{COWPEA}

Wilt ${ }^{366}$ (Fusarium rasinfectum Atk.). - This disease, closely like wilt of cotton, okra, and watermelon, is not communicable from one of these plants to the other, though it is identical with the wilt of the soy bean.

It first appears when the plants are about six weeks old. Up to this time they grow well and appear healthy. Scattered plants then begin to drop their leaves, the lower ones falling first. Growth is checked, and the stem shows a faint 
reddish brown tinge. After the leaves have fallen the stem dies and becomes covered with a light pink coating of the spores of the wilt fungus. The spread of the disease is more gradual and less conspicuous in the early part of the season, but after the peas begin to set fruit they succumb rapidly, and

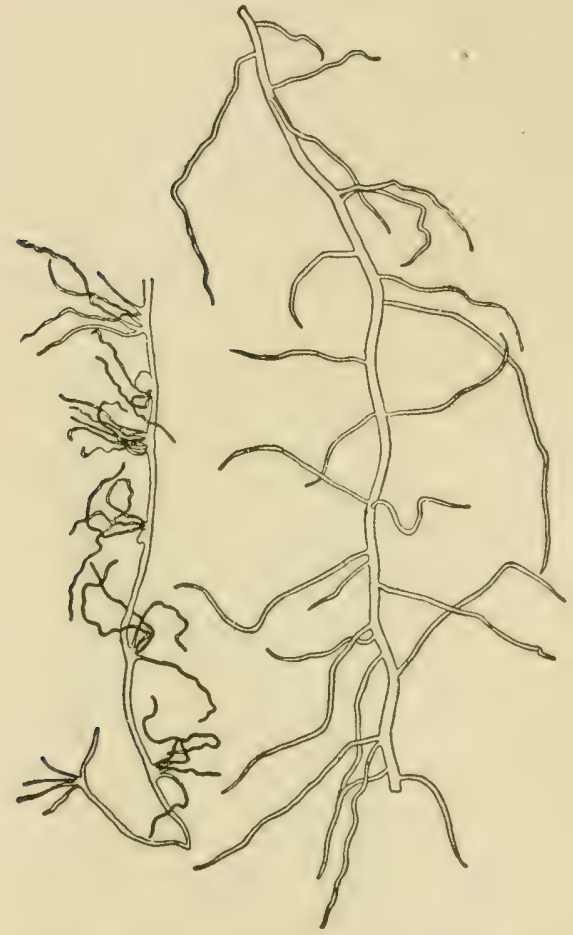

Fig. 174. - Roots of diseased cowpea at left; healthy roots on the right. After Orton. a field that in July gave promise of a fine crop may be entirely dead before September without having matured a pod. The disease usually appears in spots, like the cotton wilt, and these diseased areas may spread until a whole field is involved.

In moderate cases, or where the varieties planted are less subject to disease, only the weaker plants are killed, while the rest are dwarfed and their yield reduced. Careful examination of the roots shows that many of the small, lateral roots are dead, small tufts of roots marking the points of infection (Fig. 174). This tufting of the rootlets is similar to that produced on cotton by the cotton-wilt fungus.

In all cases the veins of the stem are brown, and the disease may clearly be distinguished by cutting across the stem to observe whether the color of the wood is normal. This discoloration, which may often be seen through the translucent stem of the cowpea, is characteristic of this class of diseases. The name "wilt" is somewhat misleading, since the leaves usually drop off before there is any conspicuous wilting. 


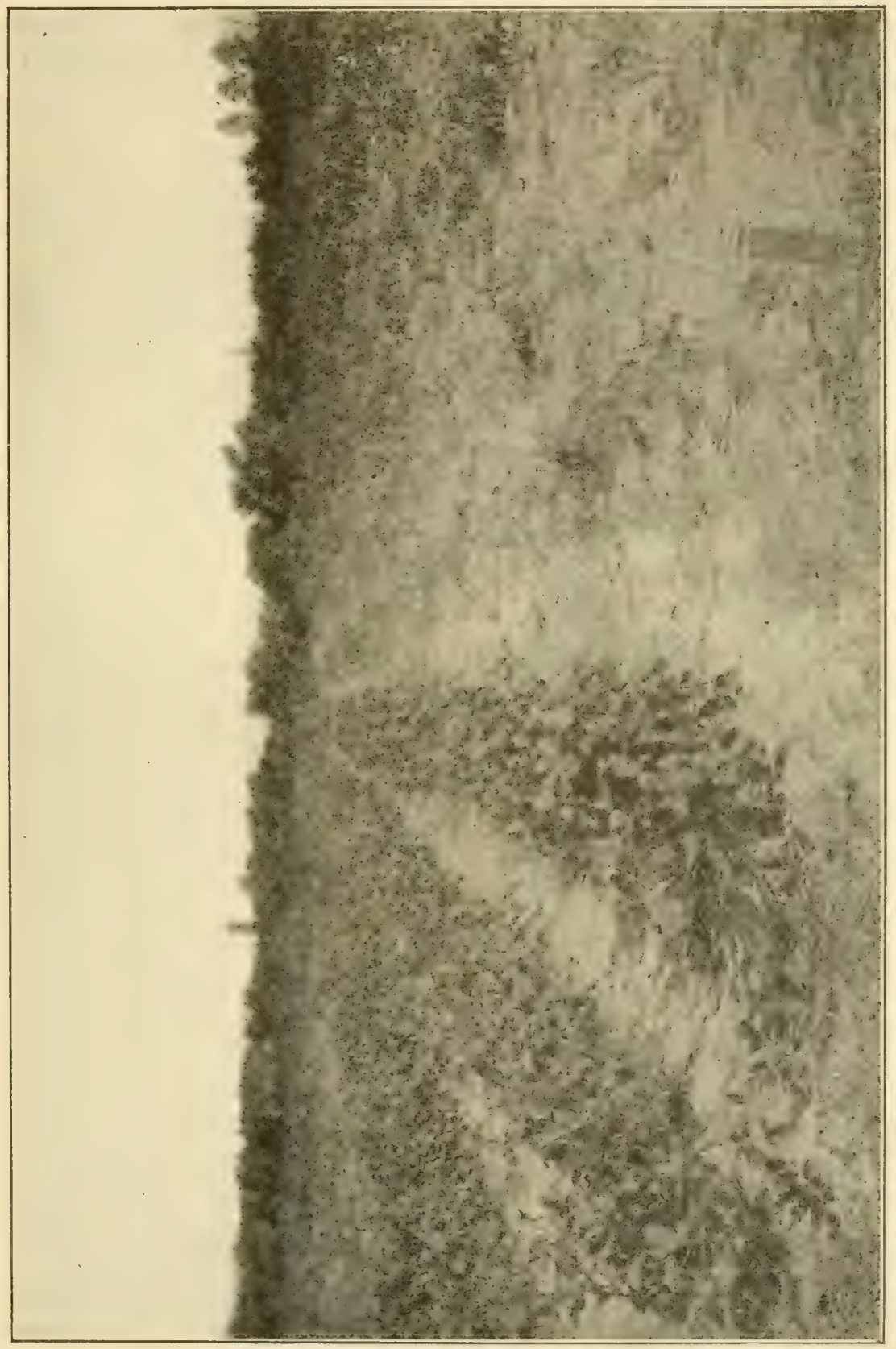


The causal fungus is spread by the ways suggested under soil diseases. The disease is now known in most of the Southern States from North Carolina to Florida, and west to Texas, and is yearly noted in new localities.

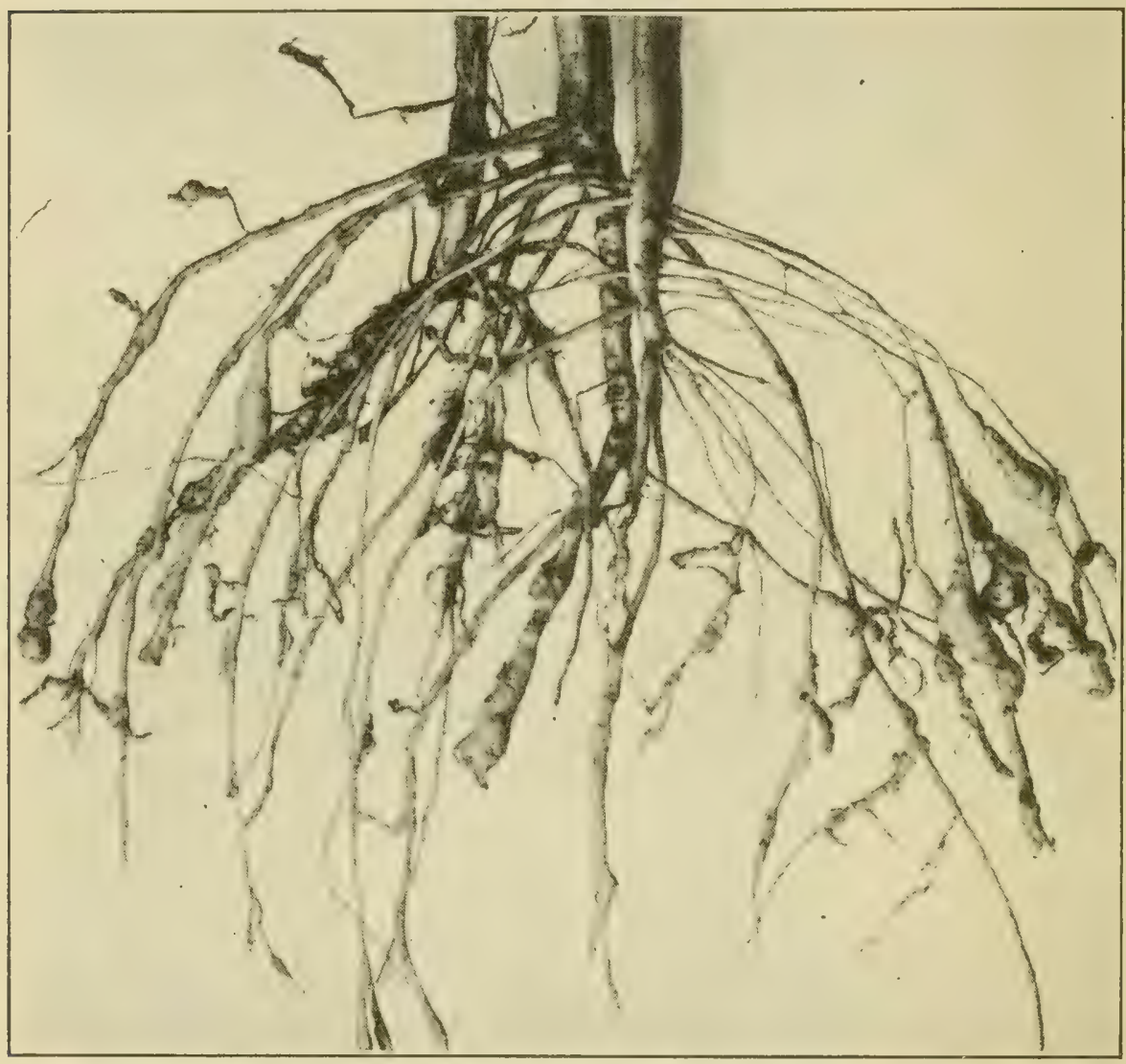

FIG. 176. - Nematode galls on roots of Unknown cowpea. After Lewis.

Owing to the all-important position the cowpea occupies in southern agriculture as a nitrogen crop, where the best rotation demands its frequent recurrence upon the same soil, the disease is of peculiar moment.

No remedy is known except the use of the Iron cowpea or 


\section{Forage Crops}

its derivatives, the resistanee of which was noted by Williams of South Carolina in 1900.

Root-knot (nematodes) is especially destructive on cowpeas. The Iron or Brabham varieties are resistant.

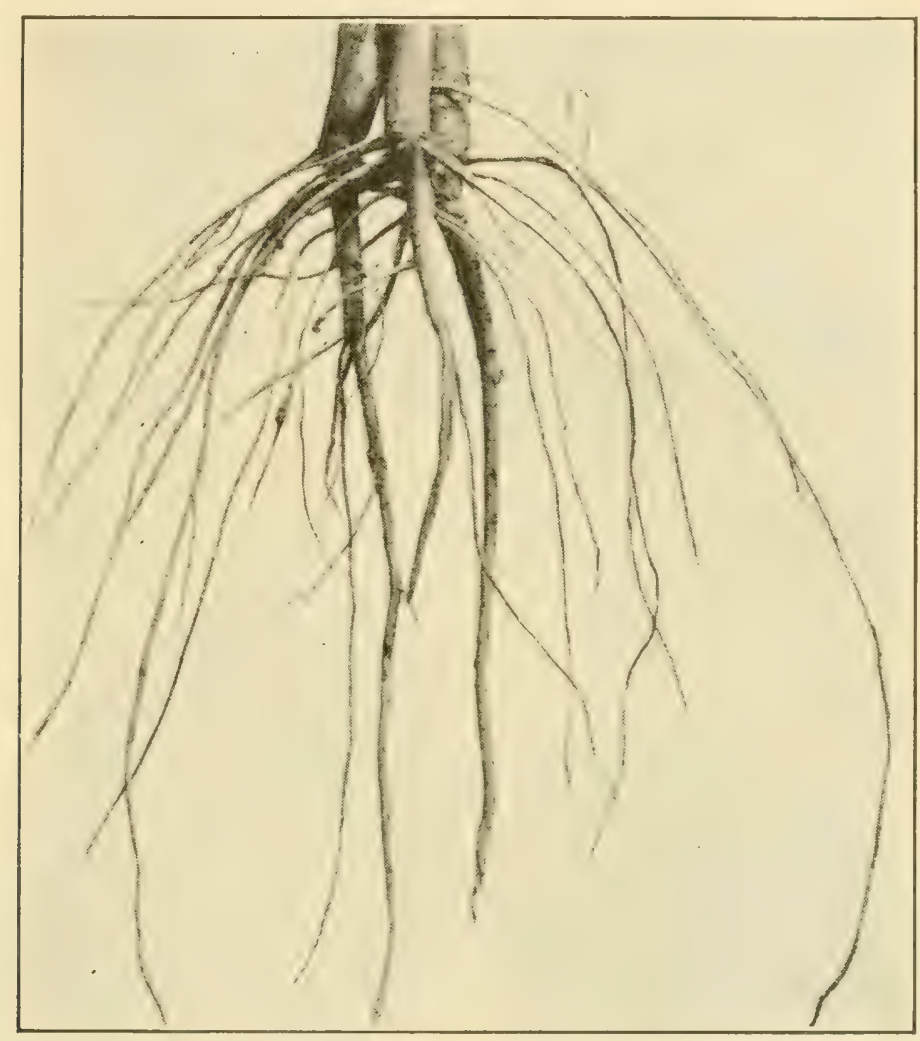

FIG. 177. - Roots of the Iron cowpea free from nematode galls. After Lewis.

\section{Minor diseases}

Leaf-spot (Amerosporium œconomicum E. \& T.). - This disease is readily distinguished from the angular leaf-spot in that the spots are circular, are of shiny whiteness, and are studded all over with black pycnidia, smaller than a pinhole (Fig. 178). The disease is often abundant, but is usually not so serious as the angular leaf-spot. 


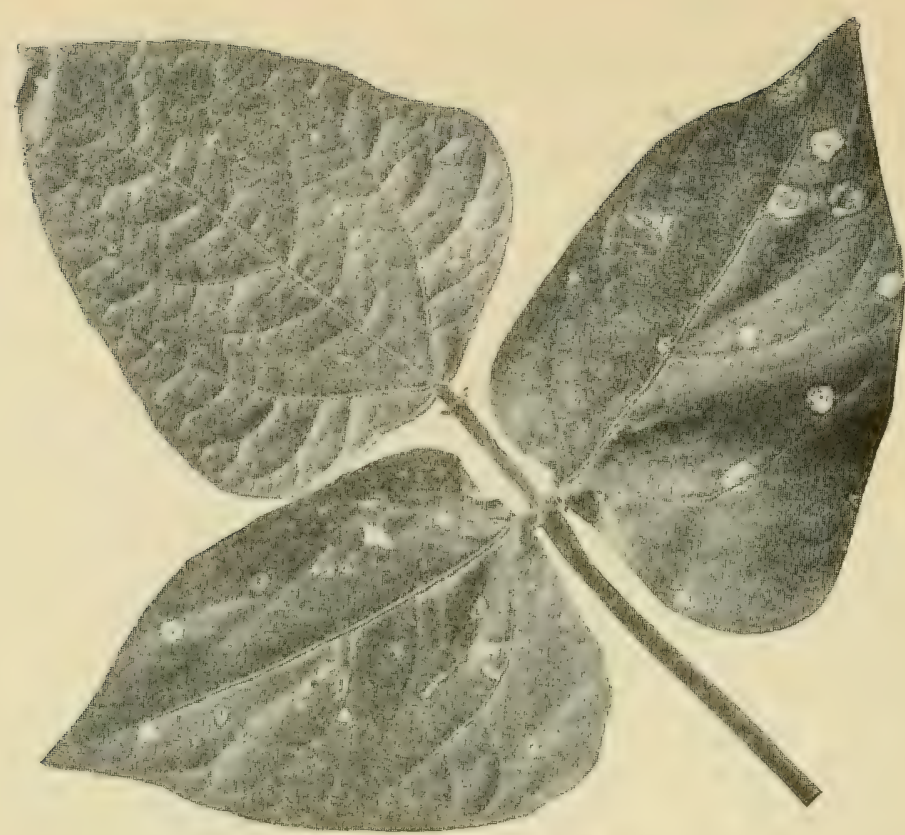

Fig. 178. - Cowpea leafspot. Original.

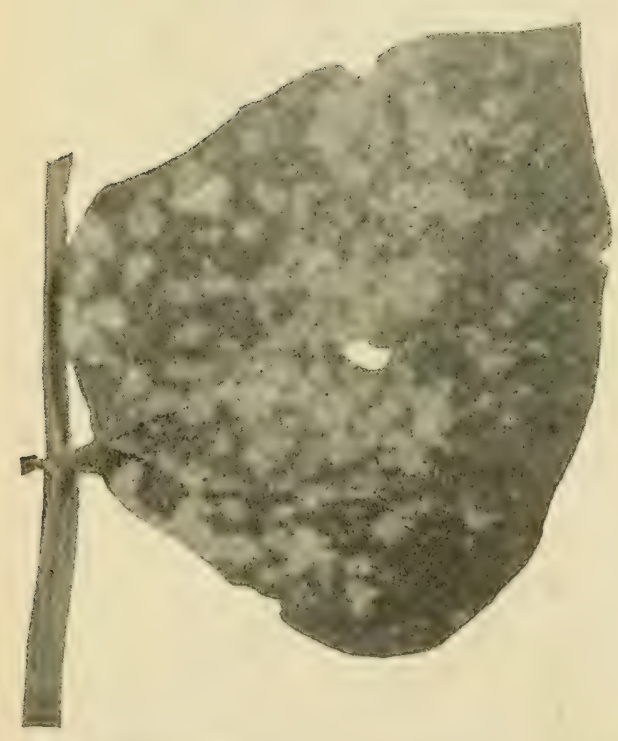

Frg. 179. - Cowpea leaflet spotted with powdery-mildew. Original.

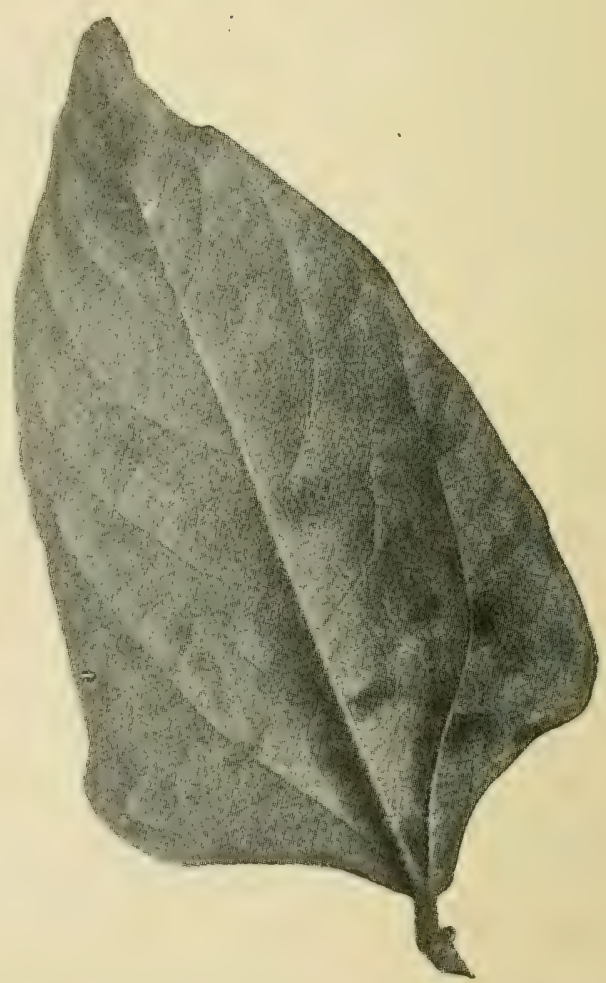

FIG. 180. - Leaflet of cowpea showing Carcospora spots. Original. 
Powdery-mildew (Erysiphe polygoni DC..). - The white spots of this mildew are strictly circular when young, but as they enlarge they coalesce and cover the whole upper surface of the leaves with a white powder.

The disease is very widespread, but even in the worst seasons does not do much injury.

Angular leaf-spot (Cercospora cruenla sace.). - The angular leaf-spots of this disease are a familiar sight in most cowpea fields. They are of various color's above, chiefly reddish, and are gray to purplish or state-colored below. The damage is rarely very great. In some instances the attack may proceed to the stems, where, esperially at the base, it may cause cracking and result in such lowering of the vigor of the plant as to cause sherding of leaves and failure to properly fill the pods. The loss of leaves is of course serious to the hay value of the crop.

Root-rot (Thielavia); a Phyllosticta leaf-spot and a Septoria leaf-spot also occur. Streak. See sweet pea.

JAPAN CLOVER (Lespedeza)

Powdery-mildew (Microsphren diffusen C $\ldots$ \& Pk.). The usual characters of the powdery-milders distinguish this disease sufficiently. The injury to this valuable southern forage plant, while considerable, is never sufficient to call for treatment.

\section{SOY BEAN (Soja)}

Bacterial blight 532-531 (Pseudomonas ylycineum Coerper). Small, angular spots, 1-2 mm. in diameter, at first water soaked, translucent, later yollow or hrown and eventually brown or purplish black, occur on the leaves and podis accompanied by a bacterial exudate.

The disease has been reported from Nebraska, Connecticut, Wisconsin, and North Carolina.

It is thought to be seed-borne.

Wilt. See cowpea. 


\section{VETCH}

Spot (Protocoronospora nigricans A. \& E.). - Upon the stems, leaves, and bracts of vetch very characteristic, long, narrow, or elliptical spots are formed, frequently with a dull purple border, and usually with a white center. When on the pods, they are obliquely situated. When old, they appear as black, oblique lines. No serious damage has been reported.

Downy-mildew (Peronospora vicice (Berk.) De Bary); Powdery-mildew (Erysiphe); Rust (Uromyces sps.), and Leaf-spot (Mycosphorella) see pea, are of minor importance.

\section{Grasses}

Many of the diseases listed below on special grasses should perhaps be considered as general grass diseases. Thus the smut, Ustilago striaformis, is known on many genera of grasses. Grasses in general are susceptible to powderymildew, Phyllachora, Ergot, and rust. The biologic relationships of but few of these have as yet been studied on account of their comparatively small economic significance.

\section{BARNYARD-GRASS (Panicum)}

Smut (Ustilago crusgalli T. \& E.) is common and is readily recognized by the usual smut characters. No treatment is recommended.

\section{BLUEGRASS (Poa)}

Rust (Puccinia poarum Niels.). - The uredinia of this rust take even greater prominence than do the uredinia of other rusts; indeed other forms of spores are almost entirely absent in most parts of the country, throwing the burden of perpetuation of the species entirely upon the uredinial mycelium and its spores. This stage is known to be perennial as far north as Washington, D. C., Nebraska, and Minnesota. The æcia occur on Tussilago. 
The rust is destructive, but seems to be limited to this one host.

Smut. See timothy.

Anthracnose. See rye.

Minor diseases are caused by Uromyces poce Rab., Phyllachora poce (Fcl.) Sacc., and Ergot.

\section{CRABGRASS}

Blast (Piricularia oryzce Cav.). - This is probably identical with rice blast. See p. 300 .

JOHNSON GRASS. See sorghum, p, 307, which has similar diseases.

MILLET. See p. 295.

ORCHARD-GRASS (Dactylis)

Leaf-spot (Scolecotrichum graminis Fel.). - Elliptical, dead spots may appear upon orchard-grass and on several other grasses, conspicuous upon the lower outer leaves. Death of the leaf follows sometimes, starting at the leaf tips and reaching to the base. In conditions favorable to the disease whole plants are involved. The spots, before they hecome confluent, are of quite characteristic appearance: large, dark brown to purplish brown. When old, they usually show at their center's spots of gray or white, and these spots may be marked with small, black specks arranged in rows lengthwise of the leaf.

Black-stem-rust (Puccinia graminis Pers.). - This rust fungus may be either of the oat, orchard-grass, or Agrostis strain.

Crown-Rust (Puccinia coronata Cda.). - See oats, p. 298. Anthracnose. See rye, p. 307.

Rathay's disease (Bacterium rathayi (EFS.)) ${ }^{341}$ develops with thick layers of hacteria on the surface of the plant, causing an unusual type of plant disease. 


\section{PASPALUM}

Ergot ${ }^{367}$ (Claviceps paspali S. \& H. and C. rolfsii S. \& H.). - The ergots displacing the grain are somewhat smaller than a pea, irregularly globular in outline, and pale yellow in

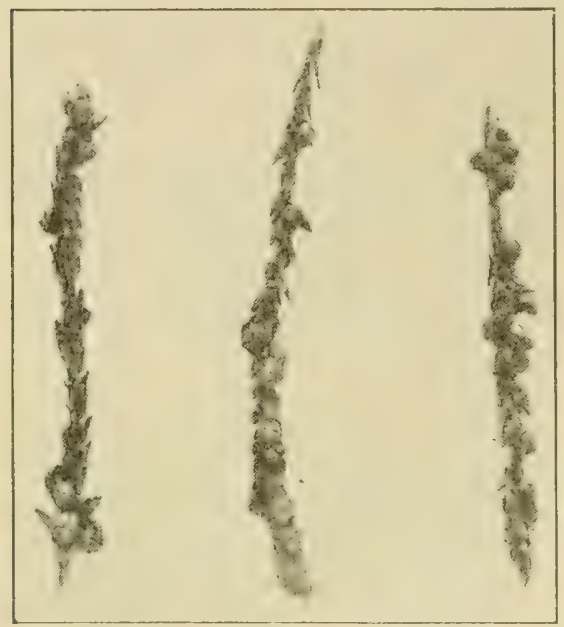

Fig. 181. - Ergot on Paspalum. After Beal. color. Stock poisoning from pasturing on grass bearing these ergots is common in the South. Mowing the green heads before the ergot develops will lessen the danger.

QUACKGRASS (Agropyron)

Smut (Urocystis agropyri (Preuss.) Schroet and Ustilago). - These smuts resemble each other in the general appearance of the sori, though microscopically the characters are quite different.

\section{REDTOP (Agrostis)}

Black-stem-rust (Puccimia graminis agrostis Erks.). The rust is identical with that upon wheat and oats, though infection does not readily pass from one host to the other.

Smut (Ustilago striceformis (West.) Niessl). - This is the smut described under timothy. It has been known to affect 30 per cent of the plants, and to reduce the seed yield from 300 hundredweight to 70 hundredweight.

Anthracnose. See rye.

\section{TALL OATGRASS}

Smut (Ustilago peremans Rostr.). - This snut closely resembles that of outs, though the flower parts are not so completely destroyed as in oat smut. The disease is peren- 
nial in its perennial host, and smutted plants bear smut, year after year.

\section{TIMOTHY (Phleum)}

Smut ${ }^{368}$ (Ustilago striaformis (West.) Niessl). - This smut occurs chiefly upon the leares, more rarely upon other parts of timothy, as well as upon many species of Agrostis, Poa, Elymus, Bromus, Dactylis, Festuca, in Europe, Australia, and generally throughout the United States. The spore masses form long black lines upon the leaf, and by merging and rupturing reduce the leaf to a torn, blackened state. The affected plants are small, weak, and often fail to make seed and the hay value is thus lowered. The disease is perennial within the host. Infection takes place in the blossom, resulting in a seed bearing the mycelium of the smut. Hotwater treatment of seed (cold water 6 hours, $52^{\circ}$ C. $\left(123^{\circ}\right.$ F.) 15 minutes $)$ gives promise of success.

Rust ${ }^{486}$ (Puccinia graminis phleipratensis). This rust in general resembles the black-rust of

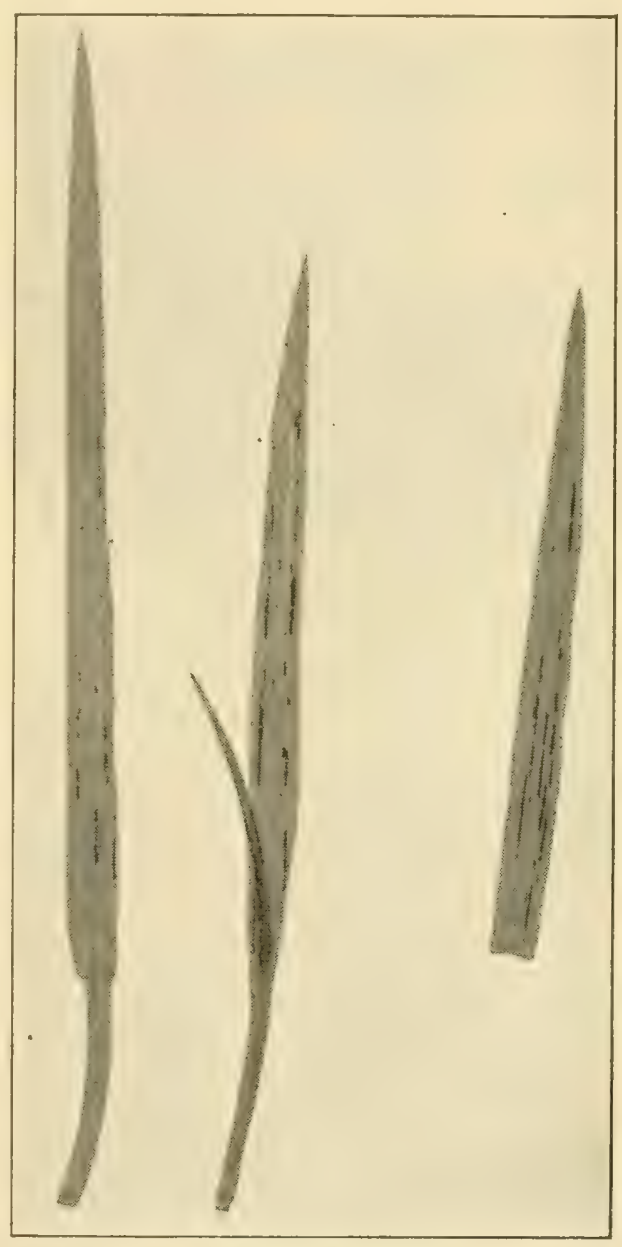

Frg. 182. - Sori of Ustilago striæformis in leaves of timothy. After Osner. 
the grains. It was first reported in 1882 and has of recent years increased rapidly. It can be transferred easily to various grasses. The æcial host is not definitely known, but probably is not the barberry. The rust winters mainly in the uredinial stage.
A Stripe-blight (bacteria) is recorded.
Powdery-mildew is common but not serious.
Anthracnose. See rye. 


\section{FIBER PLANTS}

\section{COTTON ${ }^{375}$}

Wilt ${ }^{369}$ (Fusarium vasinfectum Atk.). - The cotton wilt, now widely distributed and yearly preëmpting more territory, is caused by a fungus that plugs the water ducts in the veins of the stem and cuts off the water supply to the parts above, always reducing the vigor of the plants and usually resulting in speedy death.

Soil which produces a diseased crop one year is so infested with the causal fungus as to insure its reappearance in more extensive areas in subsequent croppings. The destructiveness of a clisease, which takes not only the crop, but in part the usefulness of the soil as well, cannot be estimated. Its injury can only be realized by those who have experienced its effects.

Wilt has long been known by Southern cotton planters, both on cotton and okra, and is now prevalent in many sections of Alabama, Arkansas, North Carolina, South Carolina, Georgia, Louisiana, and probably throughout the whole cotton belt. Many foreign countries also record it. Loss in Georgia was estimated as $\$ 1,000,000$ annually, prior to the use of resistant varieties.

The first indication of wilt appears as a yellowing of the lower leaves at the edges or between the main ribs, which portions may become almost white; later they turn brown and die. A single leaf often presents the three conditions, green (healthy), yellow (sick), and brown (dead), in bands side by side, parallel to the main ribs and radiating from the leaf stem. The dead parts may break away, leaving the leaf ragged. The upper leaves rapidly follow the course of the lower leaves. Badly affected leaves fall away, leaving only a bare stalk. In mild cases, where the disease runs its course 
more slowly, the intervals between the different stages are more prolonged.

In light sand the disease may progress very rapidly and may consist of two stages only, the sudden wilted condition followed by speedy death. The final diagnostic symptom of the disease, however, as in the case of many other wilts, is the darkening of the affected veins, which change from the normal white to light brown or black. Though in most cases the plant dies, occasionally one revives and seems to

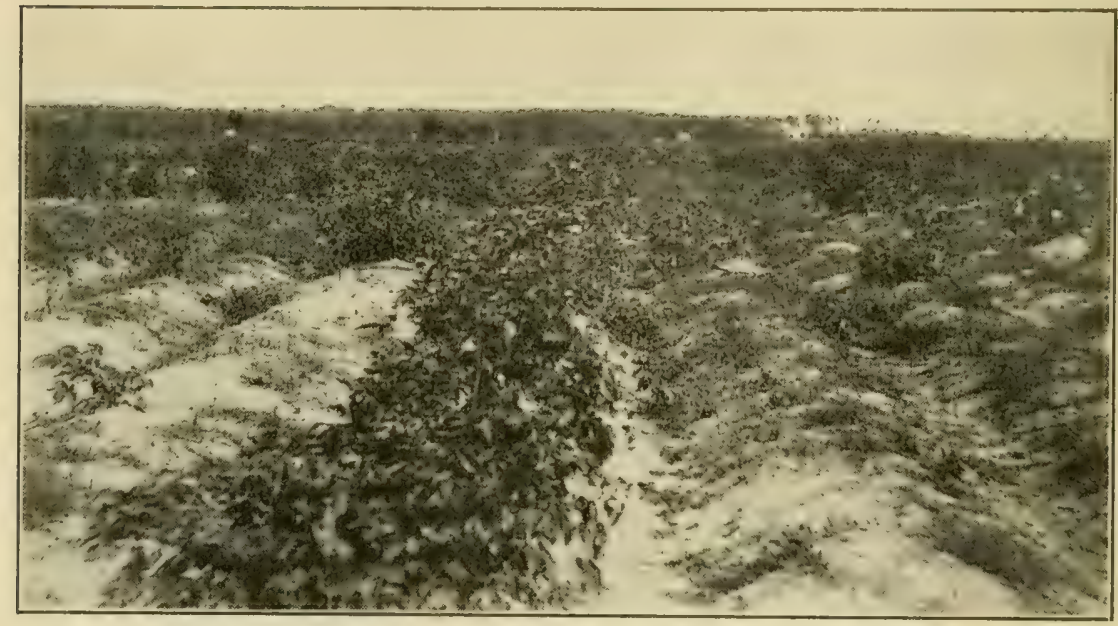

FIG. 183. - A variety of cotton resistant to the wilt; note the complete failure of the other varieties. After Orton.

outgrow the disease. In such plants relapses may follow, showing somewhat different symptoms, among them decay of the boll, and a different sequence of color changes.

Rotation of crops should be practiced, the diseased plants should be pulled and burned to check the spread of the disease in the soil, and in general the recommendations given under soil diseases should be followed. Cotton following cowpeas infected with root-knot, is highly susceptible. Therefore, only cowpeas resistant to nematodes should be used in cotton rotation (Fig. 177). The ultimate solution of the question must be in the employment of resistant varieties. 
Several such have been bred by the United States Department of Agriculture.

\section{Anthracnose ${ }^{370,371}$ (Gilomerella gossypii (South.) Edg.,} Colletotrichum). - The causal fungus of this disease was first described in 1890. It is very destructive in some localities and prevails throughout a large portion of the cotton belt of the United States and in the West Indies. The estimated loss for 1917 was 2.84 per cent or 364,000 bales.

It is most conspicuous upon the bolls, where it produces unsightly ulcers, at first black, and later covered with a pink coating. The ulcers have dark brown to black, watery borders and vary in diameter from a few millimeters to an area involving the entire boll. When small, the spots are reddish and slightly depressed. Attacks upon young bolls stop their growth and induce premature ripening and imperfect opening, or the bolls may die and decay without opening at all. In such bolls the fungus is found upon the lint and seed within. Upon the stems the fungus is limited mainly to injured parts, leaf scars, etc., and to very young, tender plants, causing damping-off. Here it is accompanied by reddening and by shrinkage in longitudinal lines. This disease upon young plants usually follows the use of diseased seed. Upon old stems it causes blighting of the bark, which becomes reddish brown and dies.

The attack upon the leaves as upon the stems is mainly limited to injured or weak parts. The seed leaves, being in a state of weakness, are especially susceptible to the fungus, which develops here with characters very similar to those on the stem and the boll. The leaves sometimes have a scalded look, assume a yellowish or leaden green color, wither and die, much as though frosted.

There is evidence that the disease is largely carried from year to year in the seed and may be spread to clean seed, also, in the gin. Therefore, only seed from healthy fields and seed that has been gimned only where healthy cotton has been ginned should be used.

Since the spores on the seed are short-lived, cotton seed 
three or four years old, still of satisfactory viability, is free from infection. Crops should be rotated and seed bred on isolated clean plats. Treatment with commercial sulfuric acid to remove the lint and kill the spores has given some success. Hot-water seed treatments are also beneficial against this and other cotton, seed-borne diseases. The temperature should be kept as nearly $65^{\circ} \mathrm{C}$. $\left(149^{\circ} \mathrm{F}\right.$.) as possible for fifteen minutes. Different varieties of cotton show different resistances to heat and their germination should be tested after treatment.

Boll-rot ${ }^{375}$ (Diplodia gossypina Cke.). - This is chiefly a black-rot of the bolls, which are thickly studded with pycnidia. These exude such quantities of black spores as to appear smutty. The entire contents of the boll also turns black. Similar effects are less common on the stem. The disease is cause of considerable loss in Louisiana. Fusarium boll-rot (Fusarium sps.). - This usually follows injury of some kind and the fungus is really a saprophyte. Other bollrots are produced by Rhinotrichum, Volutella, Sclerotium, Olpitrichum, Botryosphæria, and even by the gill fungus Schizophyllum.

Texas root-rot ${ }^{16}, 17,372,373$ (Ozonium omnivorum Sh.). The first technical description of this disease was given by Pammel in 1888. It has since been the subject of many papers, and is known to occur in very destructive form in Texas, Oklahoma, New Mexico, and Arizona, though it has not been seen east of Texas. The estimated loss from this root-rot in 1906 in Texas was about $\$ 3,000,000$. Some planters regard it as a worse enemy than the boll weevil.

In this disease a few of the plants may wilt and dry up in a day. Later, many plants suffer a similar fate, resulting in irregular spots of disease in the field, marked by the presence of numerous standing, dead plants. The plants succumb with marked rapidity on hot days following rain, not so rapidly in continuous dry weather. Especially after a rain, living plants surrounded by dead ones may show symptoms of the disease in the form of dense sterile mycelium upon the tap 
root. All diseased plants have diseased roots marked by injured rootlets and shrunken tap roots, accompanied by depressed spots which are at first bordered by red discoloration. The causal fungus is also apparent here, at first as a white mold which later turns brown or yellow and is finally accompanied by wart-like sclerotia. Enlargements, from which new roots are put forth, often occur near the soil surface. Even the lint of the diseased plants is affected, the fibers being wider and larger, and the spirals fewer and more uneven, than upon healthy plants. The disease is truly of the soil, and the affected soil centers enlarge yearly as in other soil diseases. It is subject to the modes of dissemination suggested on page 29.

Extreme precaution should be exercised against the use, for the purpose of legume inoculation, of soil which may possibly be infested with the disease. This warning is particularly necessary in view of the fact that alfalfa is affected by the same disease, and the causal fungus is now present in many alfalfa fields.

As to treatment, rotation with immune crops (see p. 23) in conjunction with deep fall plowing is recommended. To quote from Shear and Miles: "Rotation with immune crops at Terrell, Tex., resulted as follows: 1904, planted to cotton, about 95 per cent of which was killed by root rot; 1905 , planted to corn; 1906, planted to wheat, followed by sorghum the same season; 1907, cotton again planted, with the result that, as nearly as could be estimated, less than 5 per cent of the cotton was dead at the close of the season.

"Land badly infected with the root rot was plowed seven to nine inches deep November 11, 1906, at Petty, Tex. In experiment No. 1 the deep-plowed plat showed 42.75 per cent less dead plants than the adjoining check plat which received the customary tillage. In experiment No. 2 the deep-plowed plat showed 43 per cent less dead plants than the adjoining check plat, and in both cases a much larger amount of cotton was produced on the dead plants on the 
treated plats, because these plants did not die until later than those on the untreated plats, and therefore had greater opportunity to mature their bolls."

Root-knot (nematodes). - See p. 24. This knot is particularly destructive on cotton, not only because of the direct injury it does, but also because root-knot greatly increases the susceptibility of the cotton to wilt. All means to hold the development of the nematodes in check should be employed (pp. 24-25), particularly the use of nematoderesistant varieties of cowpeas in the cotton rotation.

\section{Minor diseases}

Frosty-mildew (S'eptocylindrium areola (Atk.) P. \& G.).This leaf-spot is limited sharply by the smaller veins, and bears upon the lower surface numerous colorless spores upon colorless hyphæ, thus lending a frosted appearance. Seen from above, the spots are light yellow or of a paler green than the normal leaf tissue. Widespread, though not especially destructive, it does not usually attract the attention of the planter.

Leaf-blight (Mycosphorella gossypina (Atk.) Earle, Cercospora). - The fungus which causes this disease was first described from Carolina specimens in 1883, at which time its presence was recognized in South Carolina, Georgia, and Florida. The disease prevails in all cotton sections of the United States, appearing first in damp localities upon the lower leaves, and with the progress of the season, spotting all of the leaves more or less. The leaf-spots appear at first as small red dots, which finally, as they enlarge, bear brown or white centers with a characteristic red border. A copious development of dark hyphæ upon the centers later gives them a blackish hue, and numerous white spores give these hyphæ a white coating. The old diseased centers of the spots are brittle and frequently break away, leaving perforations. The disease is widespread but unimportant, since it is largely limited to weakened tissues, especially to spots produced by cotton mosaic. 
Angular leaf-spot ${ }^{374,471}$ (Pseudomonas maluacearum EFS). - This disease was first described in 1891, and is widely distributed in the cotton producing states, in Natal and the West Indies. The diseased areas appear as angular leaf-spots bounded by the veins and are of a watery appearance. They may be scattered over the leaf, or they may be nearly contiguous and later become confluent, resulting in irregular dead patches. Frequently they are most numerous adjacent to the main ribs, and result in long, irregular, dead, black regions. The dead tissue is brittle and often falls away, causing holes or ragged edges. Badly affected leaves fall early and loss of 50 or 60 per cent of the leaves is not unusual. When on the boll, the spots may be a centimeter in diameter, and the seed may become infected. Seedlings from such seed are stunted and the stand poor. Cankers occur on the stems of young plants. Seed should be taken only from healthy plants. Treatment of seed with concentrated sulfurie acid to remove the lint, followed by either the mercuric chlorid or the hot-water treatments may be employed to advantage.

Damping-off (Pythium debaryamum and other fungi). Young cotton plants may suffer the characteristic soft rot of damping-off.

Sore-shin (Corticium ragum, Rhizoctonia). - Primarily this is an ulcerous wound upon the stem near the ground, accompanied by reddening or hrowning of the leaves. If the ulcer enters deep into the stem, so as to interfere with the ascending sap, it may cause death, though the wound usually heals before the disease has progressed far. The disease is often caused by the attack of Rhizoctonia, especially in tissues predisposed to such attack by weakness. Harrowing, to aid in drying the surface soil, to some extent prevents the attack and development of this fungus.

A similar disease may also result from purely mechanical injuries caused by tools.

Smut (Doassansia gossypii Lag.) occurs on the leaves in Equador and the West Indies. Rust (Kuehneola gossypii 
(Lag.) Arth.) is reported on the leaves from Florida, Cuba, Porto Rico, and British Guiana. Cluster-cup-rust (Ecidium gossypii E. \& E.). - An outbreak of this disease occurred in southern Texas in 1917, causing large defoliation, with an estimated loss in yield of 20 per cent. It is commonly present in the South to a degree, but usually does not assume destructive proportions. Crown-gall (Pseudomonas tumefaciens) does some injury.

Mosaic, black-rust. - The first signs of this disease are yellowish spots which give the leaf a checkered appearance. The discoloration occurs first in small areas, which are roughly rectangular owing to limitation by the veins, and which are situated at points most remote from the main feeding veins. Usually the centers of these spots soon turn brown, and the brown part enlarges and shows a series of concentric markings. In later stages these weakened areas may be overgrown by Alternaria or other saprophytic fungi. If very dark-colored fungi grow upon these spots, they soon become black-coated and take the popular name "black rust."

Kainit, used as fertilizer, often reduces the damage from mosaic.

Red leaf-blight. - This reddening, resembling autumnal coloration, occurs most frequently toward the season's end and is most common upon poor soil. It is due chiefly to lack of nourishment.

Attack of mites produces a similar appearance.

Shedding. - This occurs chiefly following extremes of either dry or wet weather or following a change from one extreme to the other.

\section{FLAX}

Wilt ${ }^{376}$ (Fusarium lini Bolley). - A condition of soil known as "flax sick" has prevailed in many sections of the country to such an extent as to cause the abandonment of flax culture. This is notably true in Iowa, Minnesota, North 
and South Dakota. On such soils flax plants are attacked at any age, and die early or late according to the time and intensity of the infection. Many of the plants are killed before they appear above the surface of the ground. Such field spots becoine centers of disease; they enlarge throughout the summer, and new plants sicken, wilt, and die around their margins, finally giving the entire field a spotted appearance. Young plants wilt suddenly and dry up, or decay if the weather is moist. Older, woody plants become sickly and weak, turn yellow, wilt at the top, and die slowly. Such plants are easily pulled up, owing to their decayed root system.

Many of the roots of diseased plants are dead and have a characteristic ashen-gray color. If the plant is attacked late in the season, this gray color may be limited to one side only of the taproot. In such cases the leaves and branches on the affected side are blighted. If the disease is carried with the seed into healthy soil, only a few plants may be attacked during the first year, and such plants may be very unevenly scattered throughout the field and escape notice until late in the season.

If the weather favors the disease, each new area of infestation may increase sufficiently to reach plants in several adjacent drill rows. These infested areas are nearly always circular, and enlarge each year that flax is grown thereon. Such a spot 1-2 m. in diameter the first year may become $2-3 \mathrm{~m}$. the second year. Thus only a few years are required for the disease to gain complete possession of a field. The fungus not only persists in a field not sown to flax, but the disease areas may even enlarge when no flax is present. When soil is once infested, no way is known to render it again suitable for flax culture.

This is essentially a soil disease, and it is spread in the ways suggested under soil diseases, notably by soil particles, drainage water, and especially by straw of diseased flax which may get into the manure. The chief agent of dissemination, however, is the seed. In threshing, the spores of the 
causal fungus, which are abundant upon the dead.straw, find lodgment upon the seed, especially if it be moist.

To prevent carrying the disease to land yet uninfested, all seed should be disinfected in the following manner:

Use formaldehyde at the rate of 1 pound to 40 or 45 gallons of water. Spread the seed upon a tight floor or upon a canvas and sprinkle or spray upon it a small amount of the liquid. Shovel, hoe, or rake the grain over rapidly. Repeat this spraying, shoveling, and raking until all of the seeds are evenly moistened, yet not wet enough to mat or gum together. Continue to stir the grain, so that the mass may become dry as soon as possible. Avoid any excess of moisture. If flax seeds are dipped in the solution or are allowed to become wet enough to soften the coats so that they stick together, they are liable to be considerably injured or even killed.

The solution recommended is strong enough to kill all seeds if they are thoroughly saturated or are allowed to remain damp for some hours. Less than one-half gallon of solution is required to treat one bushel of seed. It is well, also, to burn all the infested straw and to avoid too deep planting.

By continued selection of seed from resistant plants Bolley has developed a variety which is resistant to the wilt.

Damping-off of young plants may be caused by Alternaria or Colletotrichum.

Rust (Melampsora lini (DC.) Tul.). - Characteristic rust sori are in evidence and in the early season the leaves are yellow or orange. Later black sori appear, chiefly upon the stems. Badly affected plants turn brown and die earlier than plants not rusted. Large injury is not usual, though in 1904 and 1905 considerable damage was reported from North Dakota.

Dodder (Cuscuta epitimum Weihe) is similar to the dodder of legumes. See alfalfa. 


\section{HEMP}

Wilt ${ }^{377}$ (Botryosphceria marcomii (Cav.) C. \& J., Dendrophoma). - With the attack, appearing first upon the outer ends of the upper branches, the plant wilts rapidly. The foliage soon turns brown and dies. The disease seems to be a recent importation from China. 


\section{TREES AND TIMBER ${ }^{378,379}$}

\section{General Diseases}

\section{DECAY IN LIVE TREES ${ }^{388,} 389$}

Wood decay is caused by fungi. The mycelium penetrates through or between the wood cells, producing enzymes which soften the cells or disintegrate the middle layer between cells, thus destroying stability of the aggregate as by the crumbling of the plaster or the brick of a wall. Within the tree this disintegration may occur either to the heartwood or to the sapwood, or to both.

The life of a tree may be much reduced by decay of the heartwood, the main mechanical support. Decay of the sapwood further hastens death by interfering with the rise of the sap.

Upon the living tree the natural protection against fungous invasion is the bark, consisting of cells with specially resistant walls; cutinized or supplied with resin, gum, or other repellents. Moreover, the dead bark is not generally nutritious and does not offer attractive invitation to the fungus. The protection thus constituted is normally ample; but in case of removal of this natural protection and exposure of either sapwood or heartwood, especially the latter, the path is open, and it is through wounds offering such exposure that rot in standing timber usually begins. Such rots might therefore be appropriately termed "wound decays."

The fungi which cause these decays are, in the main, the larger fungi whose fructification is of the toadstool type (Figs. 191, 194). After the decay within is well under way the spore-bearing toadstools appear upon the surface of the diseased parts, and are quite generally recognized by lumbermen as a sign of rottenness within. 
A branch, broken or sawed off, split by wind, bruised by a falling tree, gnawed by animals, pecked by birds,

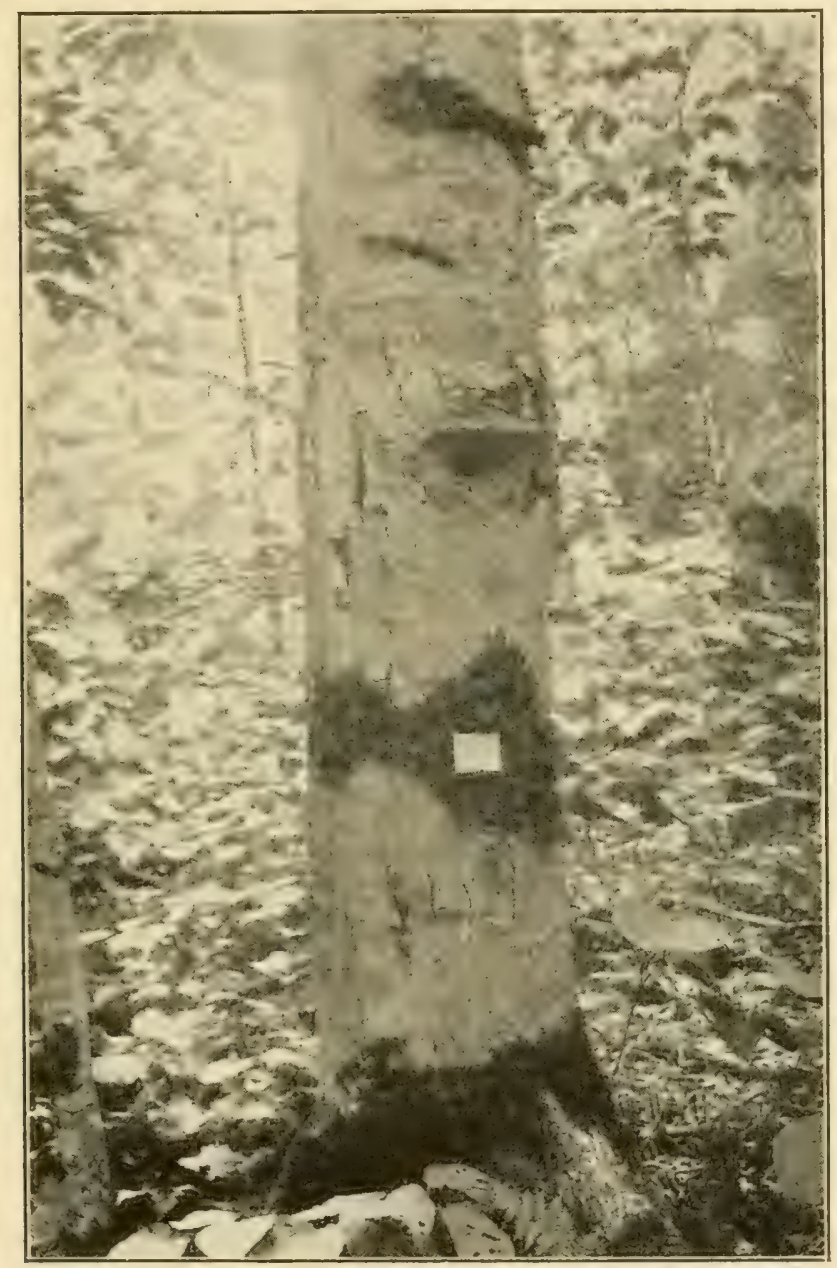

FIG. 184. - Fomes igniarius upon live beech tree After Atkinson.

eaten by insects, or wounded in any way, may result in the exposure of heart or sapwood to the fungous spore. From this point of invasion rot spreads in every direction. When decay reaches the trunk, it spreads upward and downward 
and into all branches to which it has access. Thus trees, hollow with rot, may trace their downfall to infection of some small branch or bark wound months or even years earlier. Trees bearing the sporophores of fungi (conchs or toad-

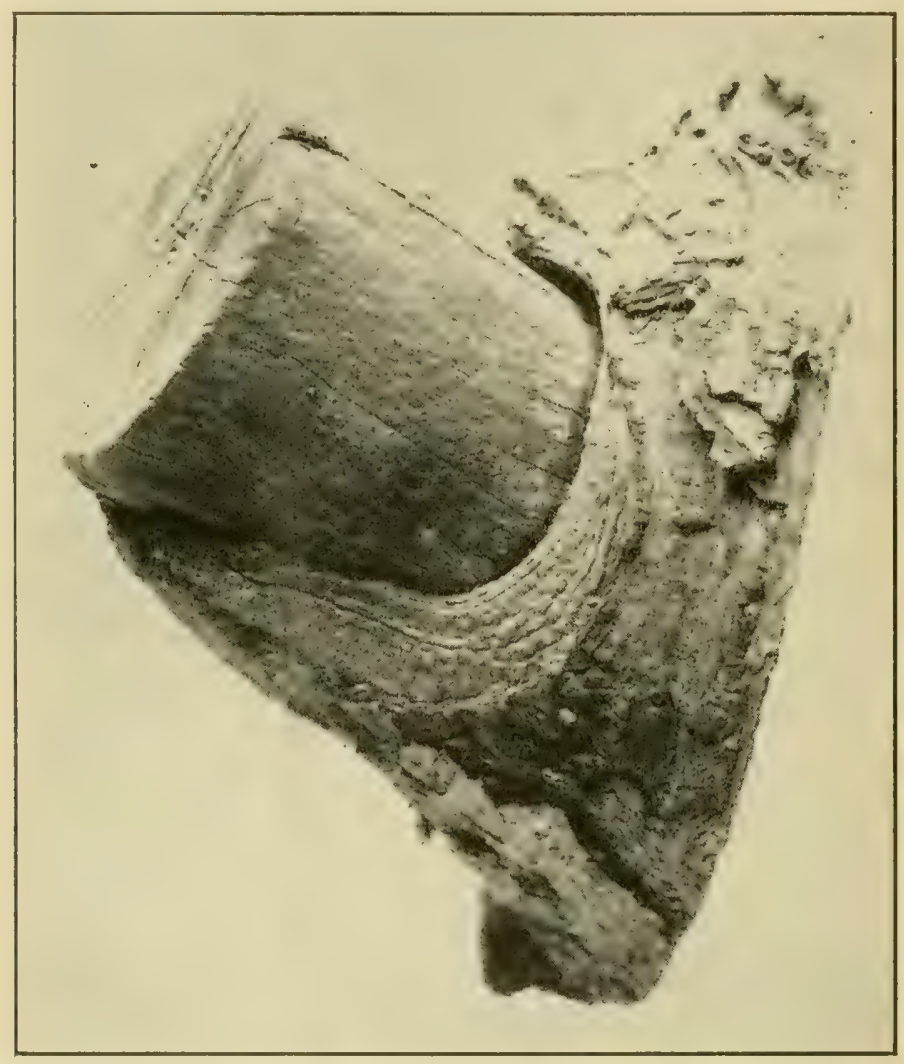

FiG. 185. — Stump of limb improperly removed. After Ind. Agr. Exp. Sta.

stools) are surely infected, while the absence of such evidence is no sign that a tree is healthy since the infection may be very old and the sporophore earlier in evidence may have rotted away.

The fungi involved in these decays are manifold. In some cases one species of fungus grows upon many different kinds of wood. Other fungi are more particular as to their 
food supply and are found upon fewer hosts. They chiefly fall into two groups; one bearing its spores upon gills (Fig. 194); the other with its spores borne in pores. Still others bear their spores upon spines. In describing the fructification of the causal fungi for recognition purposes it is necessary to note especially the stalk or stipe, and the cap or pileus (Fig. 194). A cap with no stalk is "sessile." To determine the particular species of fungus that is present, it is usually necessary to examine the sporophore, and even then expert or special knowledge is needed.* The determination of the species of the fungus is, however, not necessary to proper treatment, since this is much the same for all.

Care should be exercised in felling trees to avoid injuring other trees. In forests in

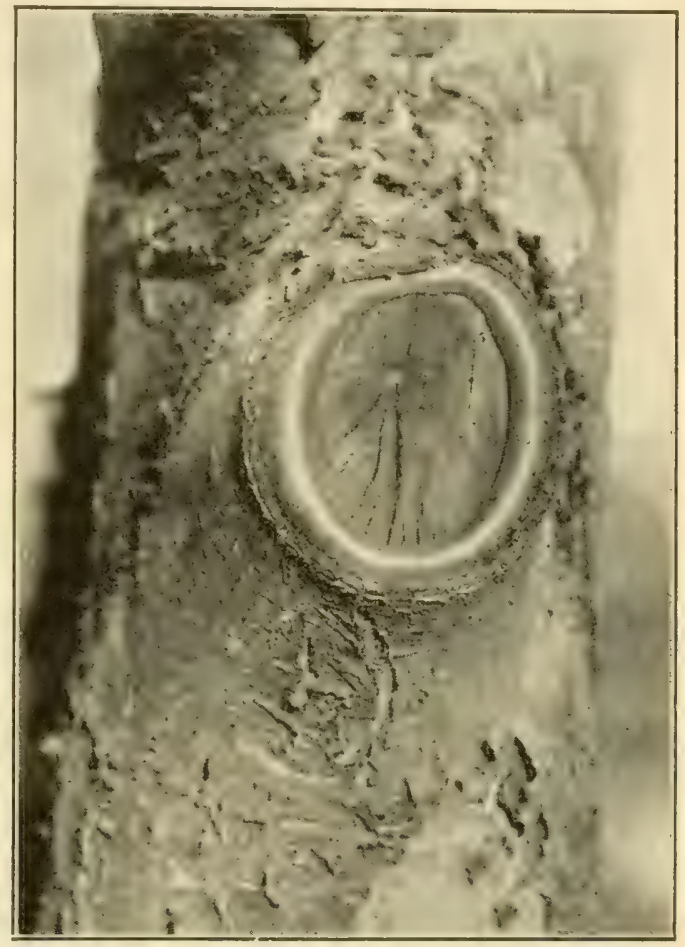

FIG. 186. - Wound of properly removed limb, beginning to heal over. After Ind. Agr. Exp. Sta.

general, cull material and infected standing trees should be burned to prevent spore formation. Excision of the infected tissue should be practiced in case of especially valuable trees. When there are pruning-wounds, apply an antiseptic to the exposed wound to prevent the effective germination of spores upon its surface. Suitable antiseptics are tar or paint.

* Useful books in such elassification are given in the bibliography, Nos. $381-387$. 
Red heart-rot, Pecky heart-rot ${ }^{380}$ (Trametes pini Fr.) .In the North this is the most destructive tree rot affecting practically all conifers, invading the heartwood, very rarely the sapwood. The wood is not wholly destroyed by the

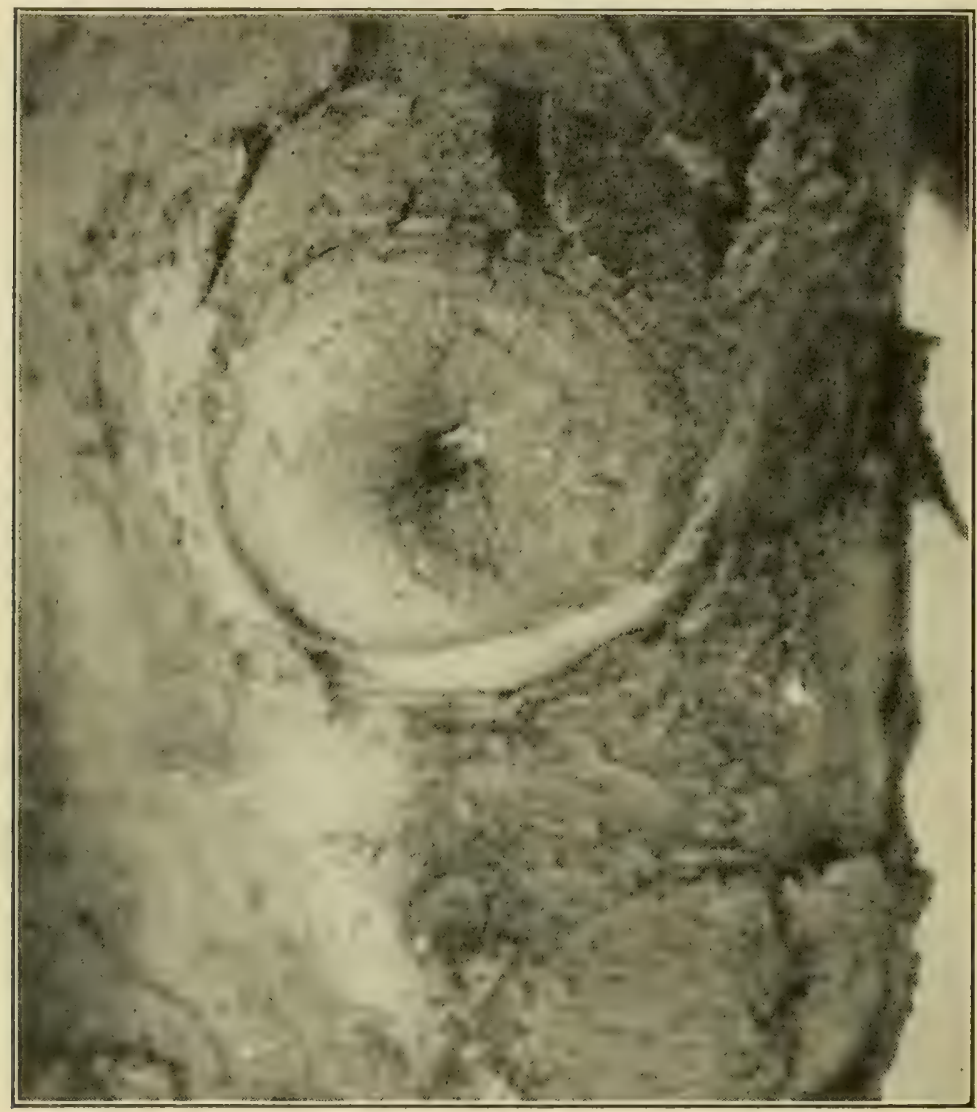

FIG. 187. - Wound of properly removed limb nicely healed over. After Ind. Agr. Exp. Sta.

fungus; but series of small holes with silvery lining are noted in early stages. In spruce the color of the wood itself is changed to a light purplish gray, later to a reddish brown netted with small black lines. Small patehes of white follow, which later develop into holes, arranged in series to corre- 
spond with the annual rings, and as the disease progresses result in a series of vacant spaces separated only by plates. In tamarack the decay finally destroys the plates, reducing the whoie wood mass to mere fiber.

The sporophores may consist either of brackets or of extended sheets with shallow, pit-like pores on the under side. They are cinnamon-brown on the lower surface and much fissured and broken on the black, charcoal-like upper surface. Prevention is best effected by proper thinning, removing diseased trees, and destroying fruiting bodies.

White heart-rot ${ }^{389}$ (Fomes igniarius Gill.). - This is the most important and widespread of the heart-rots, and one which has the widest range of host plants. It is known in Alaska, Canada, the United States, and in South America to Patagonia, growing upon beech, aspen, birch, poplar, willow, mountain maple, sugar maple, hornbeam, white elm, butternut, black walnut, oaks, and hickory. It is common on fruit trees, especially when near forests. The amount of damage done by it is beyond estimation. In many cases almost the entire timber stand is ruined. Actual count has shown from 90 to 95 per cent of otherwise marketable trees valueless.

Heart-rot, while chiefly of the heartwood, may, when started, encroach upon the sapwood, even to the youngest layers, and death may result by weakening the tree to the breaking point. The causal fungus enters through wounds, particularly broken stubs, and usually produces its sporophores at these points after the rot has extended a meter or so in both directions from the infection point. The first sure external sign of the disease is the presence of the sporophores, although sounding with the ax may sometimes be relied upon.

The sporophores, numbering sometimes as many as twelve on a tree, are shelving, hoof-shaped bodies from 25 to $30 \mathrm{~cm}$. wide. The upper surface is brown, in later stages black, hard, smooth, concentrically marked with age, finally seamed and cracked. The pores are in layers, approximately annual, and the lower surface is gray to redbrown. 
The trunk in cross-section shows rot at the center; the wood becomes soft and pulpy. The decayed region is ir-

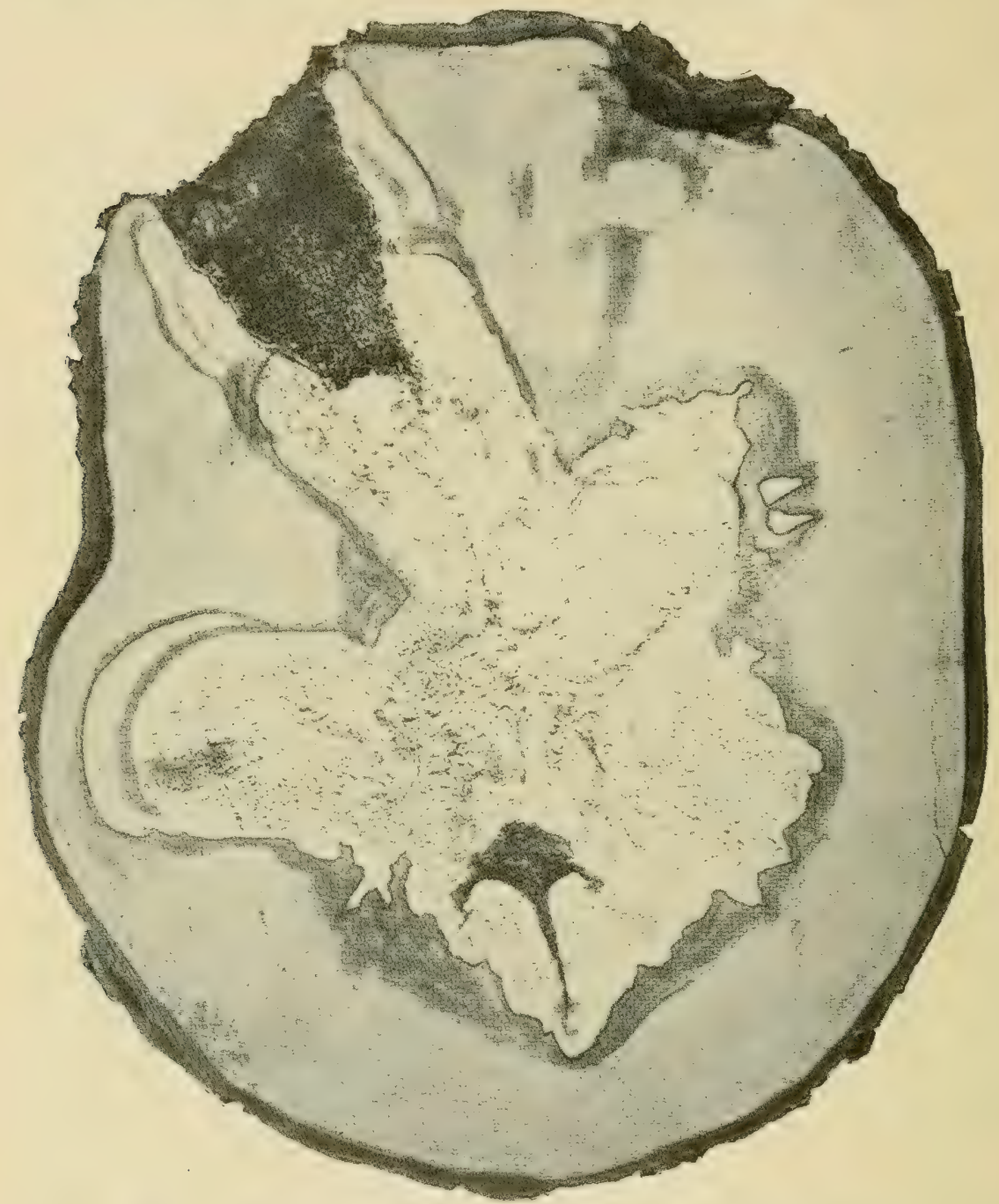

FIG. 188. - Fomes igniarius upon maple. After von Schrenk.

regular in outline and bounded by narrow black layers. The tree is rarely hollow, but remains filled with the decayed wood. Young trees which bear no dead branches to admit the fungus are usually immune. 
Infective material should be burned, wounds avoided, and excision practiced in case of valuable trees.

Red heart-rot, Brown-checked wood-rot ${ }^{355}$. ${ }^{359}$ (Polyporus sulphureus Fr.). - The conifers, also oak, chestnut, maple, walnut, butternut, alder, locust, apple, pear, cherry, and many other trees are affected. It is widely distributed, destructive, and is especially common on shade and ornamental trees.

The many-pored edible annual sporophores consist of a series of overlapping shelves, two to twenty or possibly more, with the upper surface in early stages a bright orange-red; later they are sulphur-yellow both above and below. The upper surface when bruised is brown. The sporophore is soft and fleshy when young, growing hard and brittle with age. This fungus abounds on knots and stumps. The rotted wood resembles red-brown charcoal and following decay bears concentric and radial cracks due to shrinkage. In these cracks are large sheets of fungous wefts.

Diseased trees should be cut and burned to prevent infection.

Piped-rot (Polyporus sps.). - The oak, chestnut, beech, and birch are susceptible to this rot, which is limited to the heartwood and is characterized by irregular, small, pocketlike patches of white fiber. These regions first appear in the wood as small, lenticular areas which increase, coalesce, and change into small pockets. These frequently become filled with a dark, red-brown mycelium. The speckled character of the wood is a distinctive mark.

White-rot (Hydnum erinaceus Bull.). - Although observed upon many kinds of trees, oaks are chiefly affected. The rotted wood is soft and wet, with numerous holes full of light yellow floccose mycelium. The fleshy sporophores are white, 1 to $25-30 \mathrm{~cm}$. in diameter, nearly spherical, and consist chiefly of immense numbers of white spines upon whose surfaces the spores are borne.

Heart-rot ${ }^{389}$ (Fomes fulmus Gill.). - In Missouri and Arkansas this heart-rot is found upon birch and a number of 
other trees. The wood turns brown, and crumbles under pressure. The rot extends from 3-4 $\mathrm{m}$. above and below the sporophores. These are pore-bearing, triangular in section.

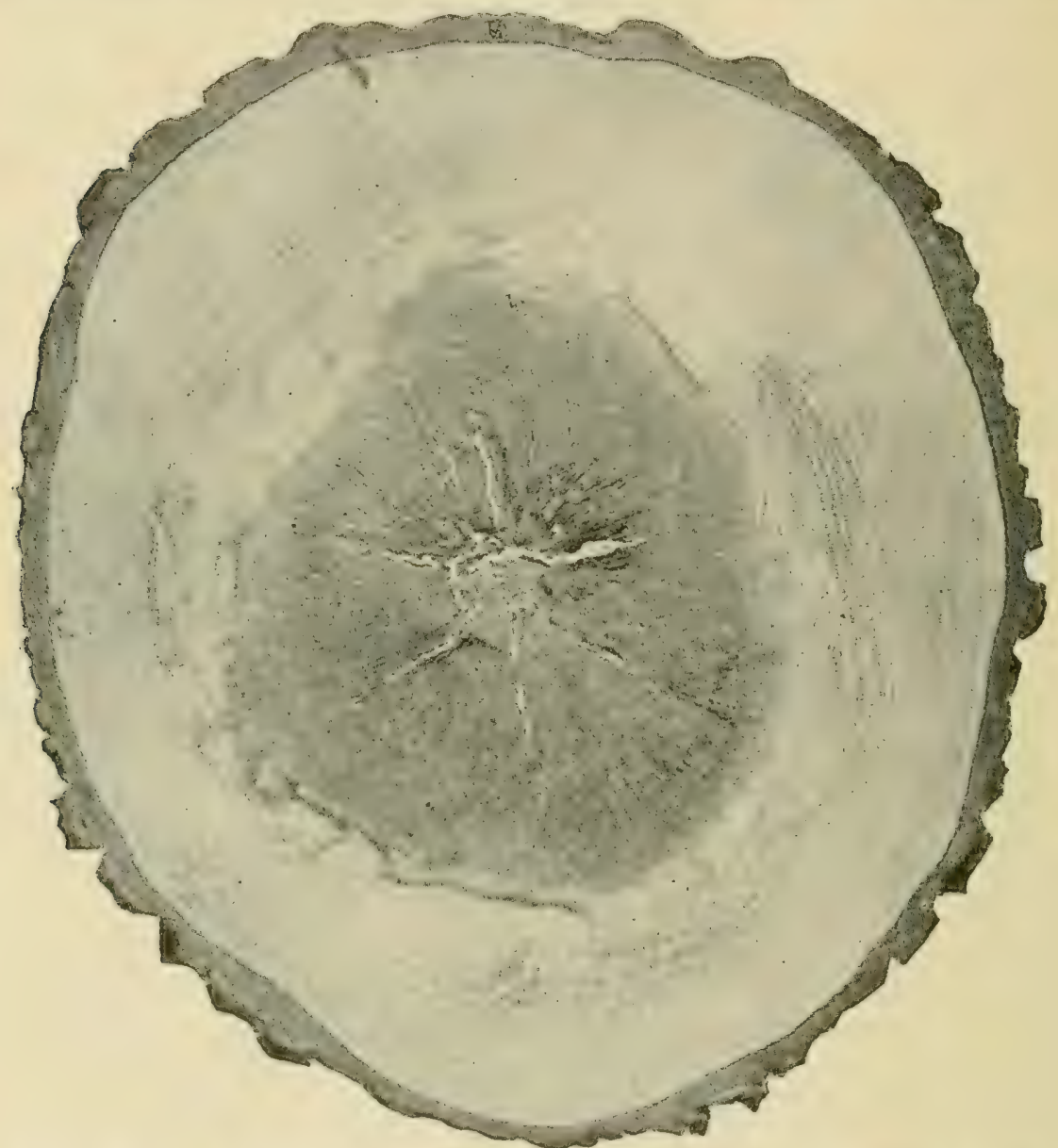

FIG. 189. - Polyporus sulphureus showing effect upon wood of oak tree. After von Schrenk.

The upper surface is very hard and bears fine, irregular fissures parallel to the edge. When mature, the upper surface is red-brown. The pores are barely visible without a hand lens.

Soft-rot ${ }^{389}$ (Polyporus obtusus Berk.). — The black oaks 
(Q. marylandica and Q. velutina) are chiefly affected by this rot, which is found in Missouri, Arkansas, Iowa, Tennessee, Mississippi, New Jersey, and Maryland.

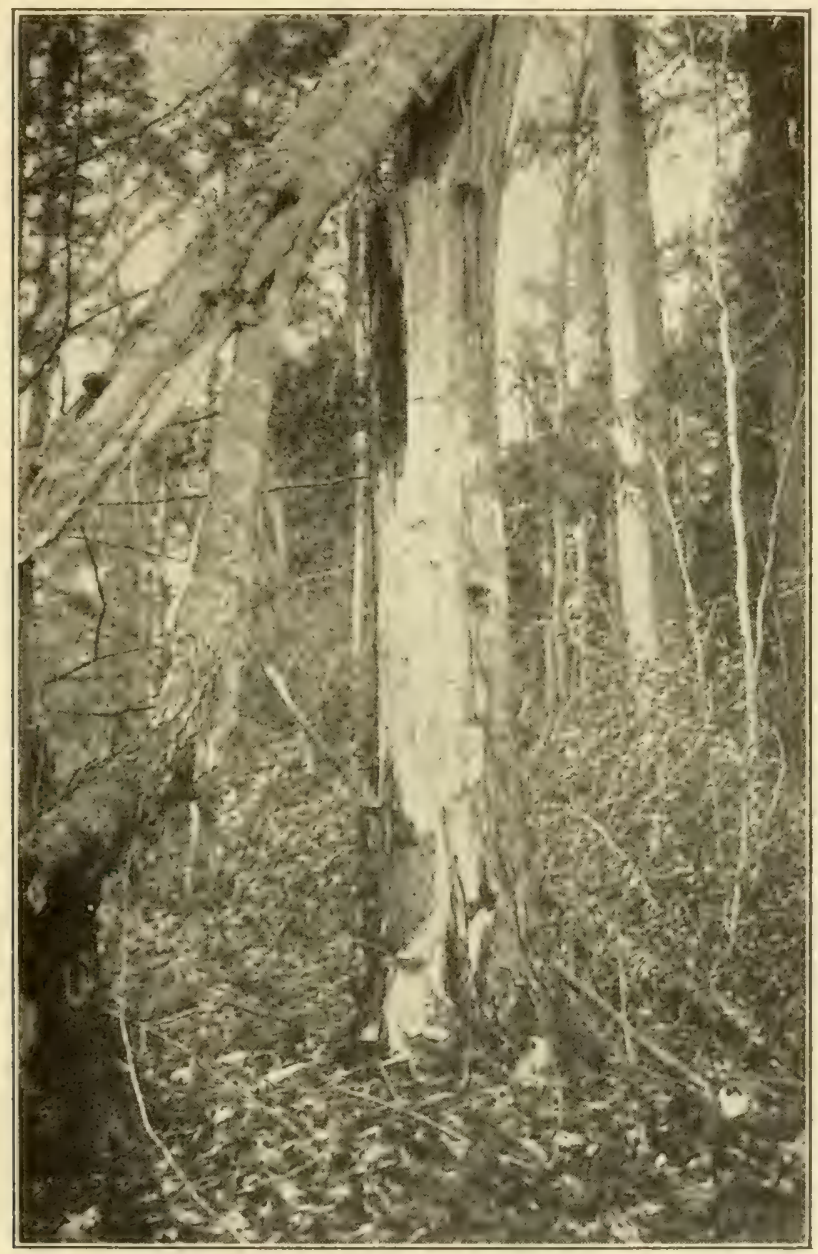

Fig. 190. - Tree weakened by Fomes fomentarius. After Atkinson.

The causal fungus enters through the burrows of a wood borer. The heartwood turns light yellow, then white, and becomes brittle. Strings and sheets of white mycelium 
are found in the wood. Death results either from diminution of water supply or from breaking of the trunk.

Heart-rot, White wood-rot ${ }^{389}$ (Fomes everhartii (E. \& G.) Schr.). - This closely resembles the rot produced by Fomes igniarius. Large, rusty-brown, woody sporophores,

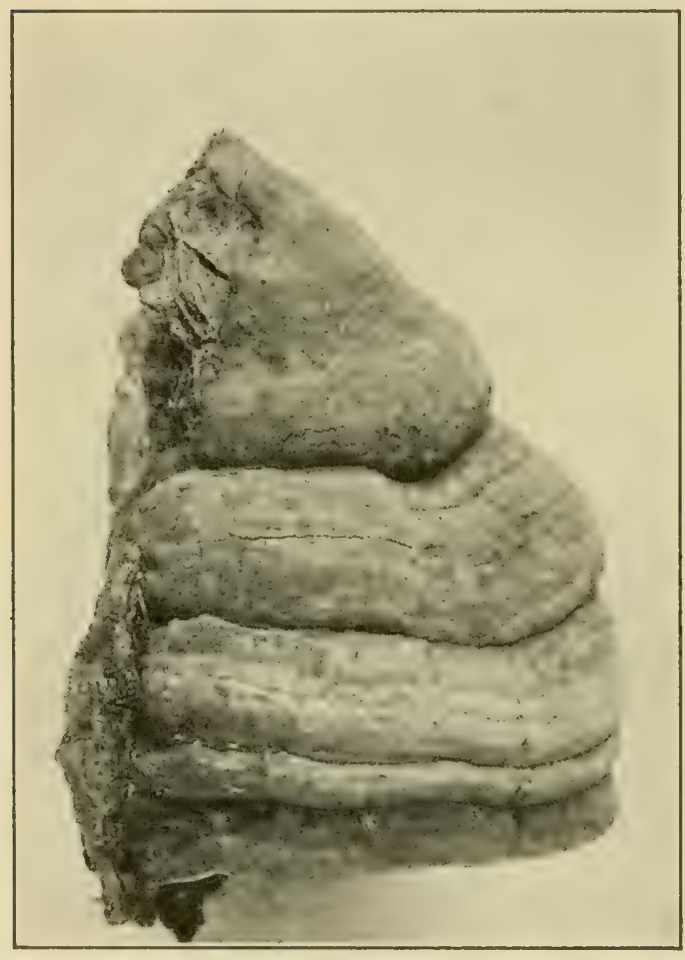

Fici. 191. - Fomes fomentarius showing hoof-shaped sporophore. After Atkinson. red-brown below, grow from wounds and bear very small pores. White-rot ${ }^{389}$ (Polyporus squamosus Fr.). - In Europe this rot affects pear, oak, elm, walnut, linden, willow, ash, birch, beech, horse-chestnut, and maple. In America it has been reported from Minnesota. The wood becomes unusually white and bears scattered series of white lines.

The nearly circular fruiting bodies are stalked and often attain a diameter of $15 \mathrm{~cm}$. When young, they are soft, but later become very tough. The upper surface is scaly and rough.

Sapwood rot ${ }^{389}$ (Fomes fomentarius Gill.). - This rot abounds throughout the northern part of the United States, as one of the most common diseases of deciduous trees, chiefly affecting the beech and birch.

Decay begins in the outer sapwood and proceeds inward. The wood is marked by irregular black lines, the boundaries between diseased and normal wood. When en- 
tirely rotten, the wood is soft and spongy and light yellow in color.

The pore-bearing sporophores are hoof-shaped, smooth above, and concentrically ridged and gray. Below they are red-brown.

Rot (Fomes applanatus Wallr.).The shelving, perennial, pore-bearing sporophores are very large, woody, and $\mathrm{gray}$ ish to brown above, and are commonly found on dead wood, as well as on live trees of poplar, beech, oak, birch, maple.

Red-brown rot $^{883}$ (F o mes pinicola Fr.). - The causal fungus is of worldwide distribution upon conifers, especially spruce,

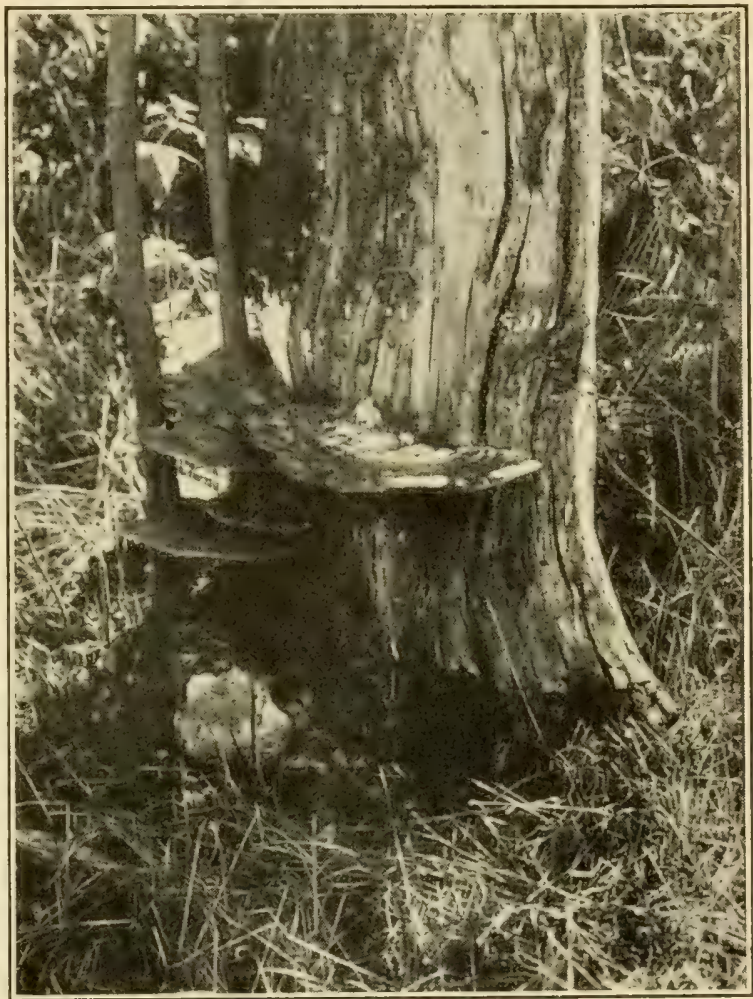

FIG. 192. - Fomes applanatus upon trunk of dead tree. After Freeman.

pine, fir, and hemlock. It occurs also upon birches and other deciduous trees. Entrance is made through wounds. The rotted wood is brittle, eracked, and permeated by numerous sheets of mycelium. In early stages of decay the color changes from red-brown to dark-brown, after which small, irregular, scattered white areas appear. The sporophores vary from $2.5-30 \mathrm{~cm}$., averaging $10-15 \mathrm{~cm}$., are bracket-shaped and lobed. The young lobes are bright red to pale yellow, old ones dark red-brown. 


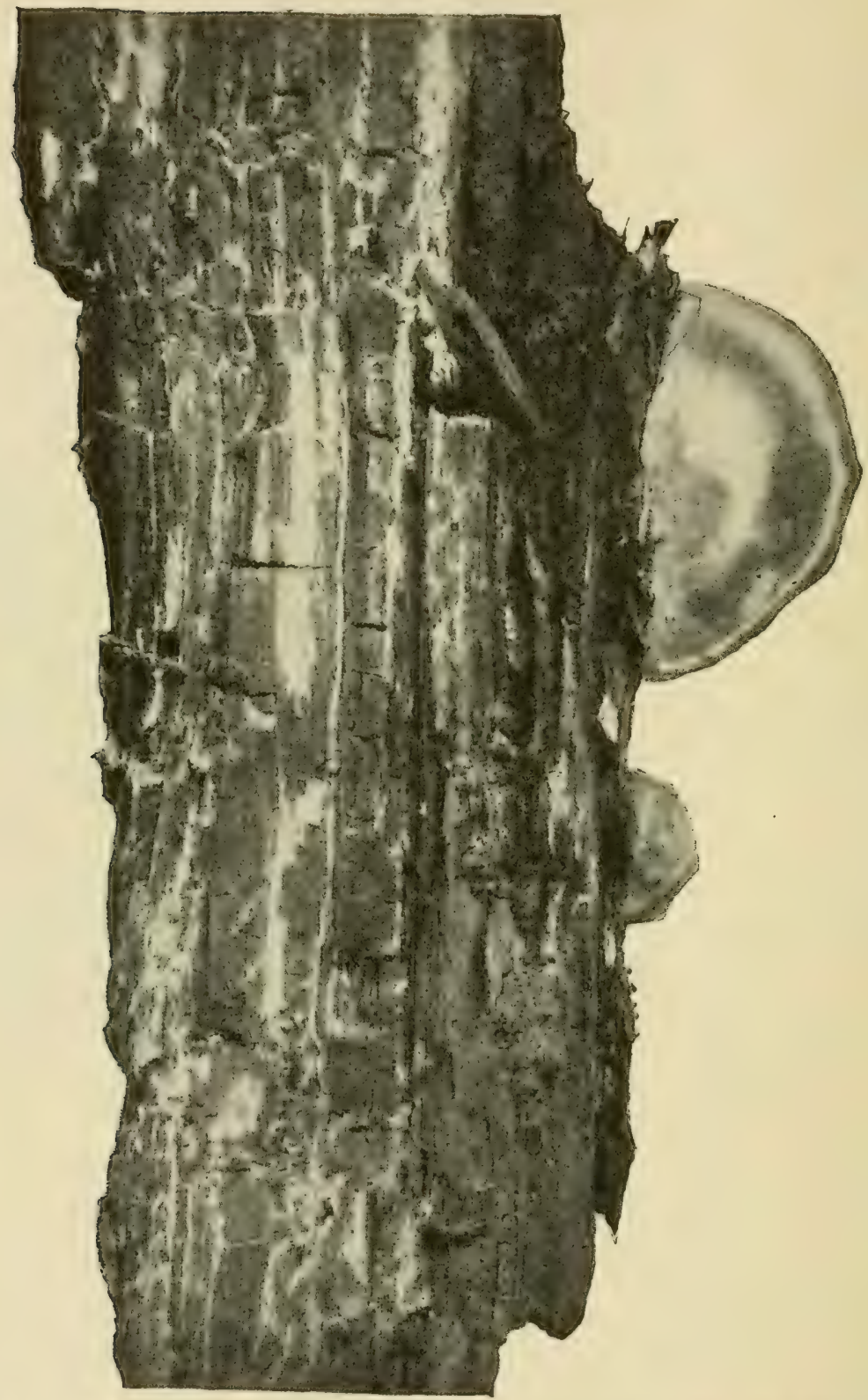

FIG. 193. - Fruiting body of Fomes pinicola upon log rotted by the fungus. After von Schrenk. 
The lower surface is pale and smooth, watery when bruised.

Following is a list of the principal genera of wood-rotting fungi with the names of the trees on which they grow. Such as bear page references are discussed on the pages indicated.

\section{Fungus Hosts}

Armillaria, p. 370. Oak, apple, and trees in general.

Collybia.

Dædalea.

Echinodontium.

Favolus.

Fistulina.

Fomes, pp. 359, 364.
Horse-chestnut and deciduous trees generally.

Chestnut, maple, oak.

Fir, hemlock, p. 389, spruce.

Deciduous trees.

Chestnut, oak.

Alder, apple, arbor-vit $x$, ash, p. 381, aspen, balsam, beech, birch, butternut, cottonwood, currant, cypress, elm, fir, gooseberry, hemlock, hickory, juniper, p. 383, larch, locust, p. 391, maple, oak, olive, orange, peach, pine, plum, poplar, rose, sassafras, p. 402, spruce, sycamore, walnut, willow, and conifers and deciduous trees generally.

Hydnum, p. 361. Apple, beech, maple, oak, spruce, and deciduous trees generally.

Irpex.

Lentinus. Trees generally.

Aspen, birch, pine, poplar.

Lenzites.

Pholiota.

Pleurotus.

Pluteus. Beech, fir, pine, poplar, spruce, and conifers and deciduous trees generally. Apple, oak, poplar, and trees generally. Elm, fir, maple, mulberry, pine, poplar, willow.

Deciduous trees generally.

Polyporus, p. 361. Alder, apple, arbor-vitæ, ash, balsam, beech, birch, p. 382 , butternut, catalpa, p. 382, cedar, cherry, chestnut, elm, fir, 
Polystictus.

Poria.

Schizophyllum.

Septobasidium. Steccherinum. Stereum.

Thelephora. Trametes, p. 358 .

Tricholoma. Volvaria. hemlock, juniper, p. 384, larch, linden, locust, maple, oak, orange, pear, pine, poplar, Pseudotsuga, spruce, walnut, willow, and conifers and deciduous trees generally.

Ash, catalpa, mountain ash, and deciduous trees generally.

Birch, catalpa, fir, hemlock, juniper, pine, spruce, and conifers and deciduous trees generally.

Chestnut, horse-chestnut, mulberry, and many other trees.

Apple, oak, palmetto, tupelo, etc.

White cedar (Chamcecyparis).

Birch, larch, oak, poplar, willow, and drupes and pomes.

Oak and trees generally.

Birch, fir, hemlock, larch, locust, pine, spruce, willow.

Deciduous trees.

Trees generally.

Canker, gall, twig-blight. -- These diseases occur upon nearly all kinds of trees. Galls are swollen parts, of the general character illustrated in Figs. 44-212. Cankers are bark diseases of varied extent (Figs. 10, 14). Twig-blight consists of death of a twig through disease (Figs. 30, 214). When occurring on valuable trees, excision or spraying may be warranted, but on forest trees, manifestly no such treatment is possible, and the only recourse is to adopt general sanitary measures, particularly the burning of infective material.

The principal causes of these diseases with the hosts are given below. Those with page references are given more complete discussion on the pages indicated.*

* References to books where descriptions of these fungi may be found are given in the bibliography under numbers 390-394. 
Fungus

Ascochyta.

Bacteria.

Botrytis.

Cenangium.

Cronartium.

Cryptosporella.

Cyanospora.

Cytospora.

Dasyscypha.

Diaporthe.

Diplodia.

Dothidea.

Dothichiza.

Dothiorella.

Endothia.

Gymnosporangium.

Myxosporium.

Nectria.

Nummularia.

Phoma and Phyllosticta.

Physalospora

(Sphæropsis).

Pseudomonas tumefaciens.

Strumella.

Valsa.

\section{Hosts}

Spruce.

Filbert, p. 389, mountain ash, mulberry, p. 393, oleander, olive, pomes, poplar, walnut, p. 404.

Fir, hemlock, horse-chestnut, larch, linden, orange, pine, Prunus, spruce, sycamore. Pine.

Pine, p. 395.

Hazel, p. 389.

Juniper.

Chestnut, maple, mulberry, poplar, p.401, willow.

Hemlock, p. 390, larch, pine, spruce.

Dogwood, fir.

Oak, p. 394.

Oak.

Cottonwood, poplar, p. 401.

Walnut, p. 404.

Chestnut, p. 396.

Cupressus, incense cedar (Libocedrus), white cedar (Chamacyparis), juniper. Apple, beech, conifers, oak, pear, sycamore, tulip.

Alder, apple, arbor-vitæ, ash, beech, birch, box elder, China berry, cherry, dogwood, elm, fir, hazel, horse-chestnut, linden, maple, mulberry, oak, pine, spruce, walnut, and conifers generally. Mountain ash, pomes.

Apple, juniper, p. 385, pine.

Birch, chestnut, oak, willow, fir, pomes, mulberry, elm, magnolia.

Apple, chestnut, oleander, peach, pecan, poplar, quince, spruce, willow.

Chestnut, oak.

Alder, apple. 


\section{ROOT-ROTS}

Fungi similar to those that cause wood-rot may also attack the roots of trees and thus cause death either with or without any previous rotting of the trunk wood. Prominent among such diseases are the following:

Shoe-string root-rot ${ }^{389}$ (Armillaria mellea Vahl). - The fungus usually enters the root through wounds, and grows in

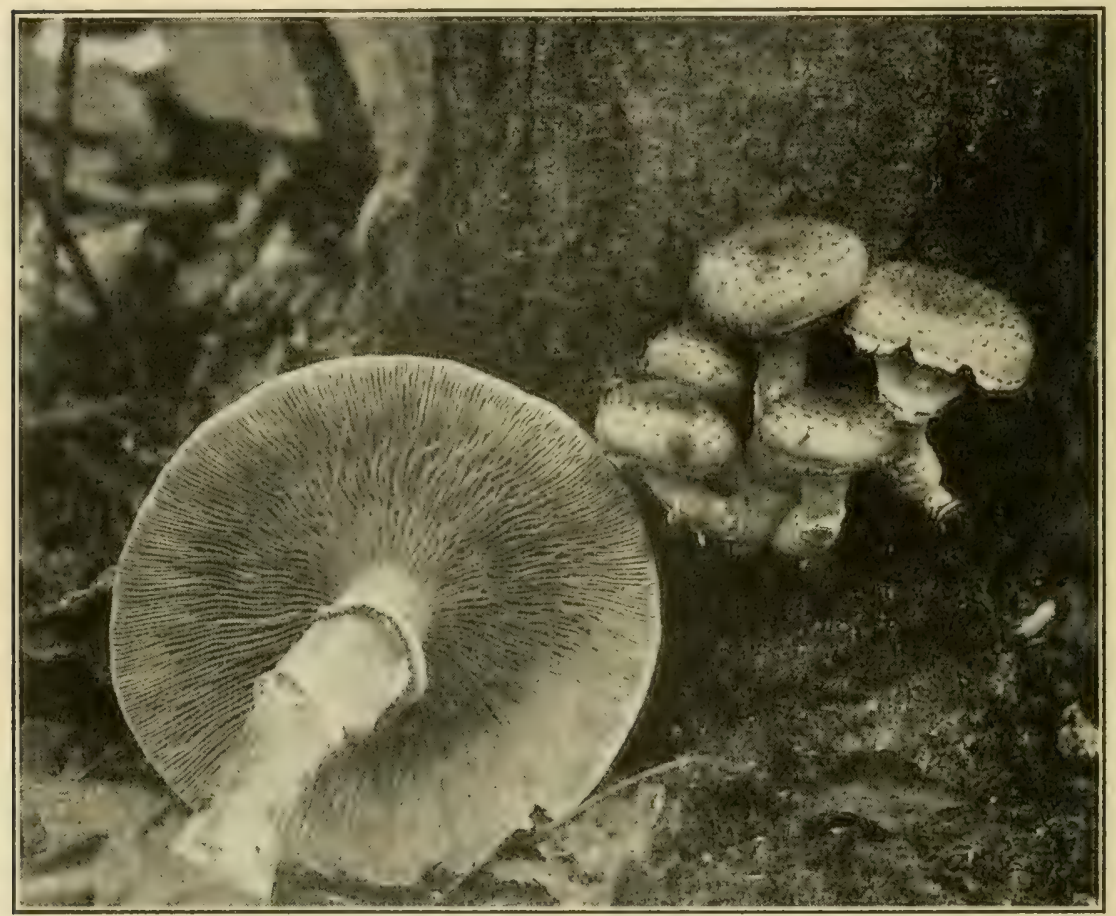

FIG. 194. - Armillaria mellea attacking a tree. After Freeman.

the cambium, through which it spreads until it encircles the tree. As its growth proceeds the layers adjacent to the cambium become dry, and the top of the tree is killed by stoppage of its water supply. A characteristic accompaniment is the profuse development of string-like, hard, black mycelial strands which permeate the soil near the base of the affected tree. From the mycelium around the base 
of the tree rise the numerous white-gilled, honey-colored sporophores, their viscid tops flecked with white; the stems swollen and with a ring (annulus).

This disease may spread for long distances through the soil by means of the fine roots and infect neighboring trees. Upon newly cleared land diseased roots of forest trees may be a source of infection to fruit trees subsequently grown thereon. The disease is common to both conifers and deciduous trees and has been particularly troublesome on oak, pine, chestnut, larch, sycamore, poplar, locust, hemlock, birch, alder, maple, and orchard trees.

Red-rot ${ }^{388}$ (Fomes annosus Fr.). - Though not very destructive in this country, this fungus has been found on pine, spruce, fir, and other conifer's, more rarely on deciduous trees, where it brings about a brown or recl-rot of the root system, which ultimately results in the death of an affected tree. The fruiting bodies form small, cup-shaped shelving or irregular masses on the roots or around the base of the trunk. The fungus has also been found growing on old, dead trees. Neighboring trees generally become infected from a diseased tree, through the small fibrous roots.

Red-brown Root-rot ${ }^{38 s}$ (Polyporus schueinitzii Fr.). A destructive root-rot of spruce, fir, arbor-vita, hemlock, larch, and pine, by weakening the root or trunk, leads to the overthrow of the tree by wind.

The point of attack is always the root, through the heart of which invasion is made into the trunk. This often leads to one-sided decay of the trunk's heartwood. The wood is rendered brittle, yellow, and later of cheese-like character, so that it can readily be cut cross grain when wet or reduced to a powder when dry.

The pore-bearing sporophores, which appear in July or August, are from 10-35 cm. across, growing either from the roots or the trunk. If from the trunk, they are sessile; from the roots they are stalked. The fresh spore layer is rosecolored, and turns dark red if bruised.

This disease is very common throughout northern for- 
ests. In Europe, where it is greatly dreaded, it is customary to prevent its spread by trenching. Groups of infected trees and trees near them may be cut to advantage to protect other trees. Other toadstool fungi that cause root-rot are Cli-

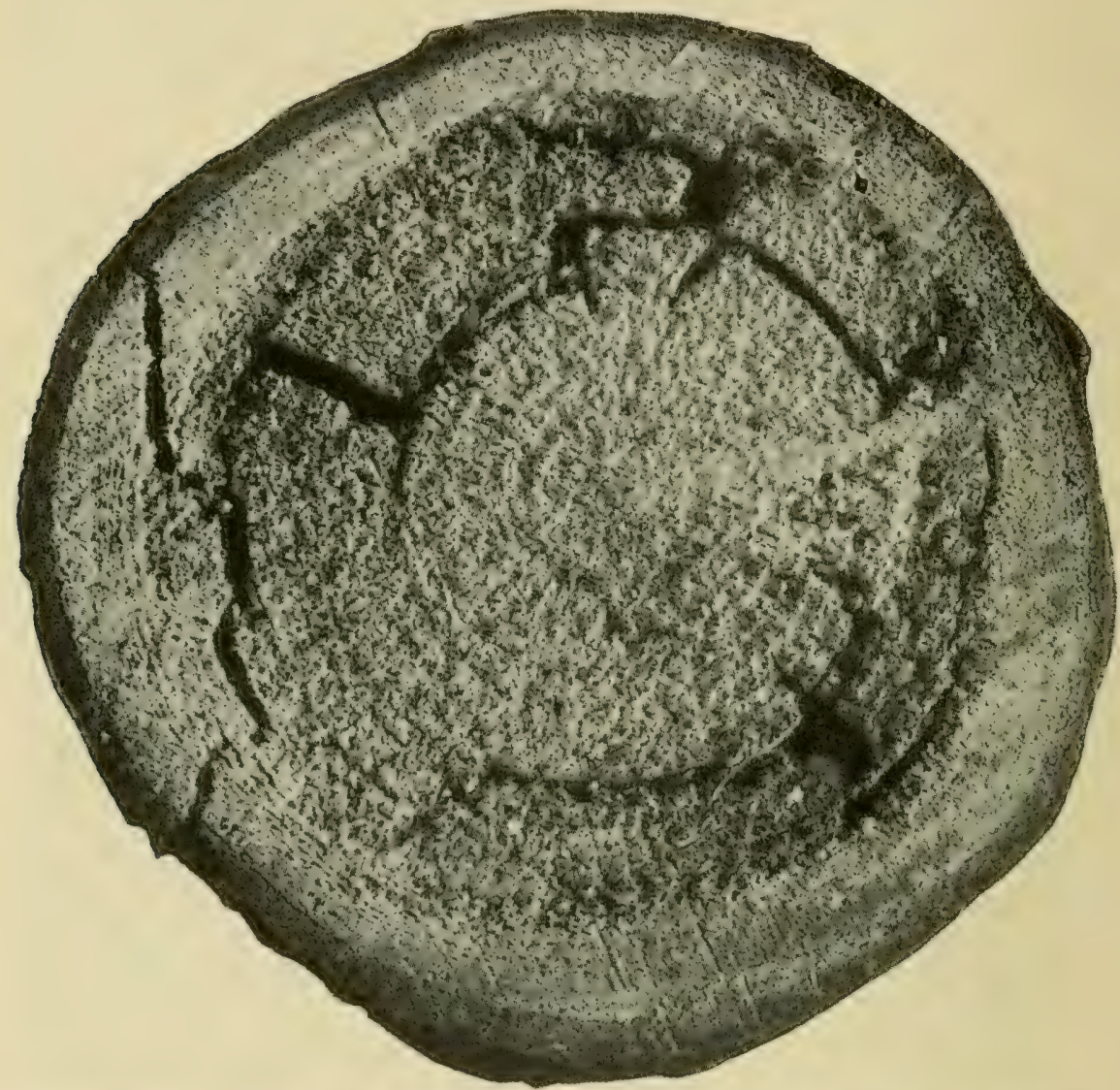

Fig. 195. - Log rotted by Polyporus schweinitzii. After von Schrenk.

tocybe, Tricholoma, and Septobasidium. Root-rots are also due to other fungi, chiefly the following:

Ozonium Root-rot (Ozonium omnivorum Sh.). - Elm, basswood, oak, cottonwood, mesquite, china tree, mulberry, apple, and pear are affected by this rot, which has been described and discussed on page 23. 
Rhizina on fir, pine, larch, spruce, hemlock, Pseudotsuga, chestnut; Sparassis on fir, spruce, pine, larch; and Thielavia (see p. 23) on catalpa; Xylaria, see p. 53.

\section{DECAY OF DEAD TREES OR DEAD PARTS}

While decay of dead trees cannot be regarded strictly as a condition of disease, but rather as a post-mortem
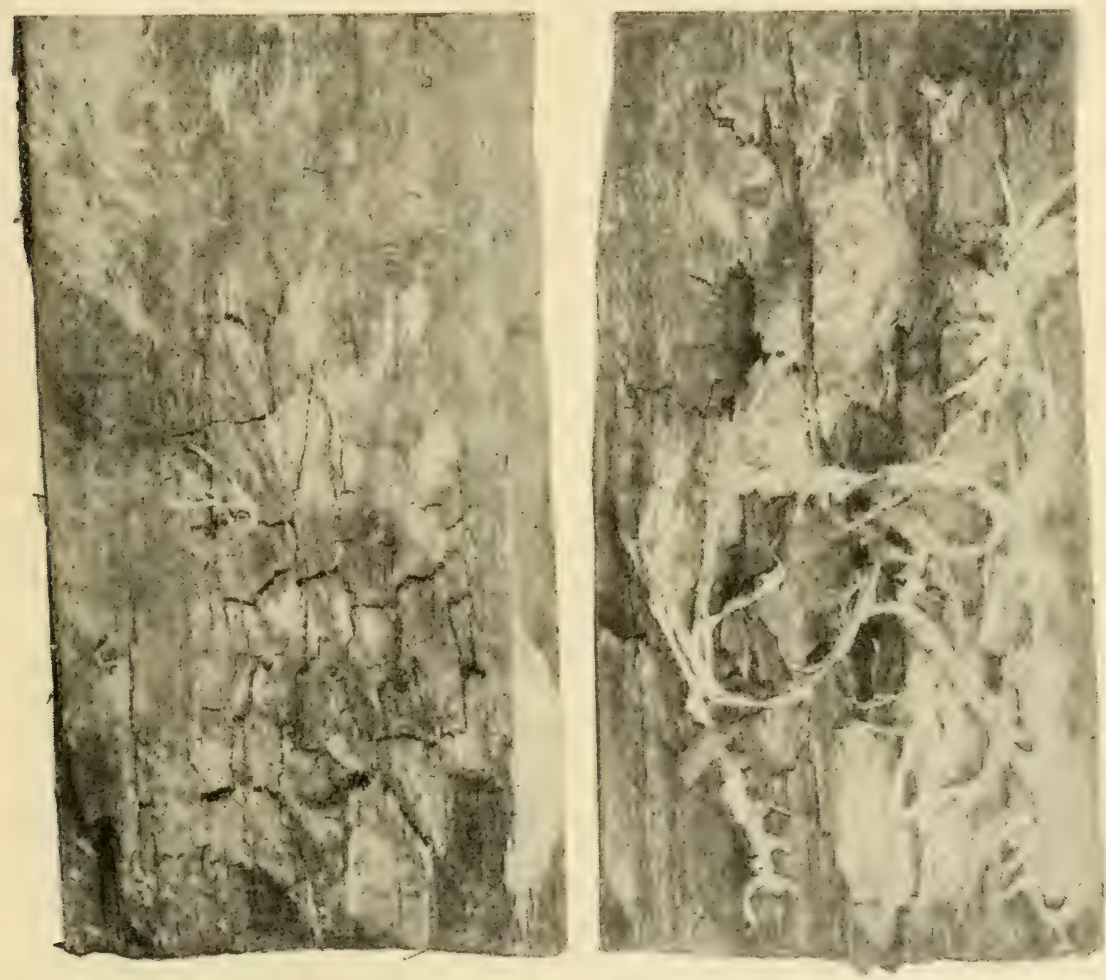

FIg. 196. - Dry-rot fungus (Merulius lacrymans); on the right the mycelium is visible as white strings. After Freeman.

change, a word is due on account of its vast importance, involving, as it does, all structural wood. The fact that the railroads purchased $121,402,611$ cross-ties in the year 1915 , and larger numbers in preceding years; that the number of posts in use in 1910 was approximately 4,000,000,000, 
necessitating an annual replacement of some $500,000,000$ in the United States, indicates the enormous money values involved.

Decay of timber is brought about by agencies similar, sometimes identical, with those causing rot in living trees, but cannot occur unless both moisture and oxygen are available. Decay can be prevented by impregnating the wood with various antiseptics, as creosote or zinc chloride. 395,396 Merely removing the bark from posts increases their length of utility.

A few of the chief causes of the decay of dead wood are as follows:

Dry-rot (Merulius lacrymans (Jeq.) Fr.). - One of the most common and destructive of all the rots of structural timber, it renders the wood spongy and brownish. If very moist, a profuse, superficial, pure white mycelium may develop, at first loosely, later in dense sheets or strands. The sporophores are flat, at first white, later red, and still later yellow-brown. The spore-bearing surface carries shallow pores penned between folds and wrinkles.

Sap-rot ${ }^{389}$ (Polyporus versicolor Fr.). - In addition to its parasitic life upon the chestnut and catalpa, this fungus grows as a saprophyte upon all kinds of deciduous woods, and is regarded as the most serious of all wood-rotting fungi which attack the dead wood of broad-leaf trees. It destroys probably 75 per cent or more of the broad-leaf species of timber used for tie purposes. Whenever such species are used for fencing, for posts or poles, or for any purpose where they come in contact with the soil, they are sure to be attacked sooner or later by $P$. versicolor. $P$. pergamenus $\mathrm{Fr}$ is similar to $P$. versicolor, and also of great importance, appearing upon cut timber or on large wounded surfaces of standing trees, especially following fires. It is found throughout the United States on all deciduous woods.

Numerous genera and species of fungi other than those mentioned above can also bring about similar changes. 
Mistletoe ${ }^{397}$ (Phoradendron and Razoumofskya). - While not generally considered pests, these parasites under favorable weather conditions may become so, especially upon trees

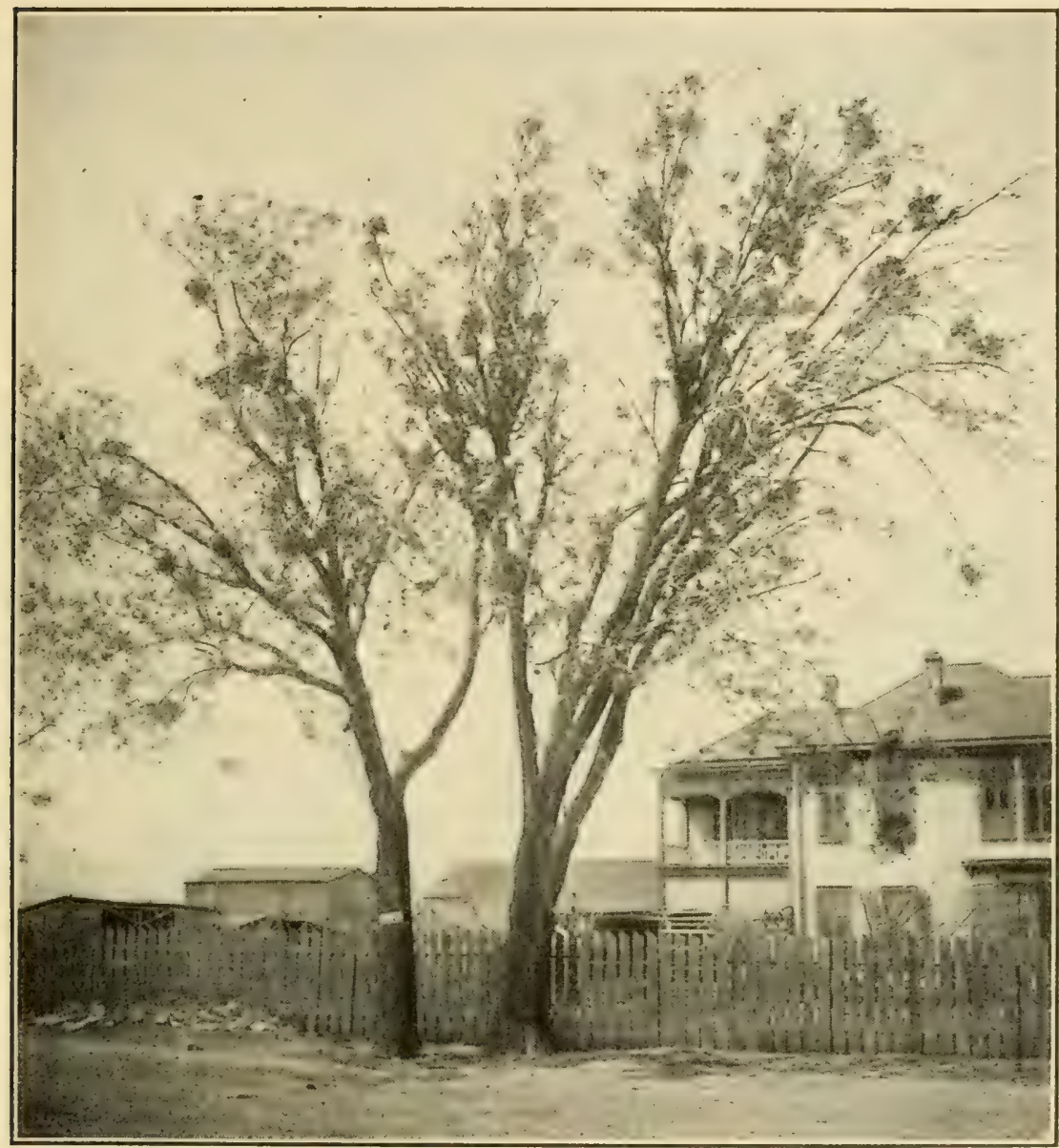

FIG. 197. - Trees infested with mistletoe. Courtesy of the School of Botany of the University of Texas.

in lawns and parks. They usually attack the smaller branches of the trees, and thus cut off the nourishment from their tips and eventually cause these portions to die. The general effect is to spoil the beauty of the tree. On forest trees they cause small diameters, reduced height, and scraggy crowns. 
To destroy mistletoe the infected branches should be cut from the trees and no berries allowed to mature, thus preventing dissemination of the pest by birds. Razoumofskya, the dwarf mistletoe, is represented by some eleven species in the United States, parasitic on conifers, spruce, pine, fir, hemlock, larch. Phoradendron, or the leafy mistletoe, consisting of several species is found on practically all kinds of broad-leaf trees.

Witches-brooms. - The production of numerous adventitious buds may result in the close, broomlike branching which gives rise to this common name. The condition is prevalent on many kinds of trees, particularly so on the hackberry, which is rarely without the witches-brooms in profusion. They are also common on horse-chestnut, juniper, and fir. The cause of this abnormal branching is a stimulus imparted by insects (mites), or by any one of several fungi as for example: Taphrina, Gymnosporangium, Peridermium, or the Powdery-mildews.

Slime-flux. - This is a term applied to a condition in which portions of the tree are covered by a slimy, fermenting, wet, often foamy, flow. This usually originates in sap oozing from a crack or other wound, often following surgical work, and is most in evidence when the sap flows freely. The organisms, yeast, bacteria, or their products, that induce the fermentation, may cause death of neighboring cells of the tree and result in a chronic wound, though the injury is at most little more than unsightly. Excision and disinfection may be practiced.

Damping-off 11, 12, 399 (Corticium, Pythium, and Fusarium). - Coniferous seedlings chiefly are affected. Soil disinfection by sulfuric acid, copper sulfate, zinc chlorid, or formalin, or when practicable by steam, are advised. See p. 460 .

\section{Tree Surgery 401, 402, 403, 378}

Ornamental, shade, and even nut and fruit trees are often of value sufficient to warrant careful surgical treatment to 
prevent further inroads by fungi already established in them. The real value of surgical treatments is somewhat problematical. The practice is of comparatively recent popularity, and a long interval of time is necessary to determine the amount of benefit. The procedure is as follows: First, all decayed, diseased, or injured wood or bark must be removed, either by severing a limb entire or by cutting out a cavity, in which case a mallet, sharp gouges, chisels, and a knife are needed. To reach all of the diseased wood it is usually necessary to enlarge the opening and frequently to make one or more holes above or below the main opening, or, what is perhaps better, to cut a narrow opening of the required length. The excavation should be enlarged in all directions until only sound, uninfected wood is left. The bottom of the cavity should be so shaped as to provide drainage. The edges of the cavity should

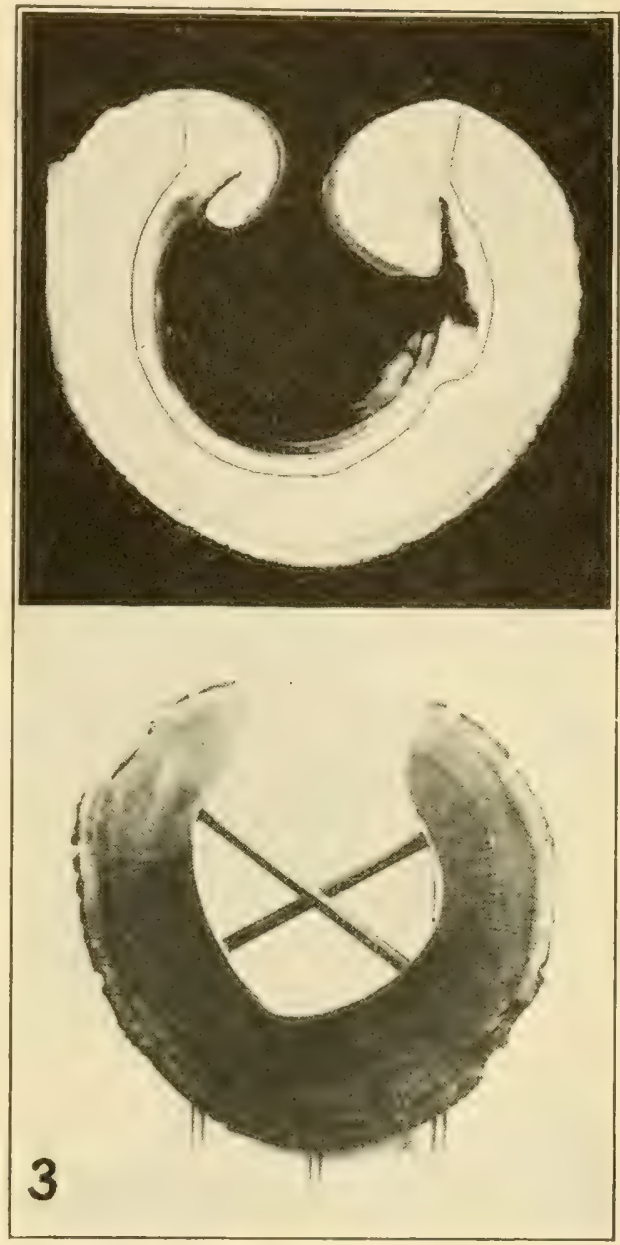

FIG. 198. - Detailed view of excavated and bolted cavities. Above cross-section of a young tree trunk showing how the new wood and bark grow into an unfilled cavity from the margin. (The line on the wood indicates the amount of excavating that would be needed before filling the cavity.) 3. - Crosssection of a tree trunk showing the manner of using two singleheaded bolts to brace a cavity. After Collins. 
be undercut so that the filling will be held firmly in place, but, lest they dry out, should not be less than threequarters of an inch thick, better an inch and a half. If there is but little undercutting, nails may be driven into the interior to hold the filling. The final cutting around the cambium should be made with a sharp knife and immediately followed by a coating of shellac covering the edges of the cambium, bark, and sapwood. In cavities more than two feet long, it may be necessary to reinforce the remaining wood by bolts placed every 18 to 24 inches at appropriate angles. After excision is completed, the entire inner surface

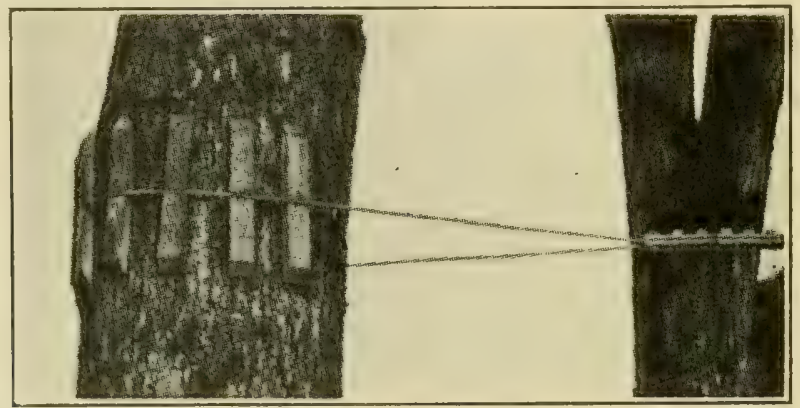

Fig. 199. - Least objectionable method of anchoring guy wires to trees. After Stone.

should be disinfected with creosote or carbolineum, and over this a heavy coating of tar or hot asphalt applied.

The eavity may then be filled, using Portland cement and sand (1 to 3 ) well tamped in, the cement being put in to form blocks about 12 inches high and separated by tarred roofing paper. The face of the cement should be trimmed back to the level of the cambium. Instead of filling the cavity with cement, a mixture of dry sawdust and, asphaltum, 3 or 4 parts to 1, may be used, with the advantage of greater elasticity to meet the winds. Or the cavity may be left unfilled and simply covered with a concrete layer with apparently equal advantages and much saving of cement. Metal coverings of tin or zinc are sometimes used, but in general are not so desirable. Shallow cavities are merely 
excavated and disinfected and left without filling. Tree surgery should be done in mild weather, when the sap is not running actively.

The necessity of surgical work can largely be avoided by early attention to wounds and especially by avoidance of wounds, and by the use of proper tree protectors and care in guying and staying branches to prevent galling or constriction.

Leaf-spots, flower-blight. Numerous fungi cause spotting of leaves or disease of flowers of trees. These injuries are in general similar to leaf-spot, for example of celery, tomato, and other crops discussed on preceding pages. Ordinarily the injury in forests is not large, and treatment or even sanitary measures are out of the question. In the case of valuable shade, nut, fruit, or ornamental trees, or of nursery stock, spraying or dusting with fungicide is often advisable. Only the more important of the tree leaf diseases are discussed below.

Following is a list of many of the fungi of leaf and flower diseases of trees with the hosts they most commonly infect. Page references are to further mention in other parts of this book.*

\section{Fungus Hosts}

Acanthostigma. Hemlock and conifers generally.

Ascochyta.

Asterina.

Butternut, oak, walnut.

Cercospora.

Colletotrichum. Magnolia.

Cylindrosporium. Alder, ash, birch, elm, hackberry, locust, maple, walnut.

Didymosphæria. Catalpa.

Entomosporium. Hawthorn.

Fusicladium. Pecan, p. 394.

* Books to aid in the study of these fungi are listed in the bibliography under numbers 390-394. 
Glœosporium.

Gnomonia.

Gnomoniella.

Hendersonia.

Herpotrichia.

Hypoderma.

Keithia.

Leptostroma.

Leptothyrium.

Lophodermium.

Macrosporium.

Marssonina.

Microstroma.

Monochætia.

Neopeckia.

Peridermium.

Pestalozzia.

Phleospora.

Phoma.

Phyllosticta.
Ash, beech, birch, butternut, hazel, hickory, horse-chestnut, linden, maple, p. 392, oak, pecan, p. 395, sycamore, willow.

Elm, p. 388.

Hazel.

Pine.

Fir, incense cedar, larch, spruce, and conifers generally.

Larch, pine, p. 397, conifers.

Arbor-vitæ, hemlock.

Locust.

Oak.

Fir, juniper, larch, pine, p. 398, spruce. Catalpa, hackberry.

Ash, butternut, p. 382, chestnut, p. 388, hickory, oak, poplar, p. 402, walnut, willow.

Hickory, walnut, Inga.

Chestnut, p. 388, oak.

Pine.

Fir, hemlock, pine, p. 401, spruce.

Oak, spruce, and conifers generally.

Elm, hackberry, sycamore, walnut.

Fir, pine.

Ash, beech, catalpa, p. 382, chestnut, elm, hackberry, hickory, horse-chestnut, p. 390, linden, maple, p. 392, oak, poplar, sycamore, willow.

Ash.

Piggotia.

Ramularia.

Rhytisma.

Ash, hackberry, willow.

Maple, p. 392, oak, willow.

Rust (Uredinales). Ash, p. 381, birch, p. 382, cottonwood, fir, larch, mountain ash, osage orange, p. 394, pine, p. 395, poplar, p. 401, shadbush, willow, p. 405.

Septoglœum. 
Septoria.

Stigmatea.

Taphrina.

Venturia.
Alder, ash, birch, (hestnut, dogwood, hackberry, maple, oak, pine, poplar, sweetgum, sycamore, walnut, willow. Juniper, sequoia.

Alder, birch, elm, hornbean, horse-chestnut, maple, oak, p. 394, poplar. Ash, birch, mountain ash, poplar, willow.

Powdery-mildews. - The general character of these diseases and modes of treatment are discussed on p. 122. The remarks made above regarding leaf-spot apply to the powderymildews as well. The chief trees on which they oceur are: alder, ash, beech, birch, butternut, catalpa, chestnut, dogwood, elder, elm, hackberry, hickory, horse-chestnut, honeylocust, linden, locust, maple, mulberry, oak, p. 394, pecan, p. 394, poplar, shadbush, sycamore, walnut, willow.

\section{Special Hosts}

\section{ASH}

White-rot ${ }^{404}$ (Fomes fraxinophilus Peck). - In certain localities in Missouri, Iowa, Oklahoma, Nebraska, and Kansas this disease affects 90 per cent of the trees. It prevails in the Mississippi valley and east to the Atlantic. The heartwood first darkens, and later becomes soft, pulpy, and yellowish. The shelving, pored sporophores, 5-10 cm. long and nearly triangular in section, are numerous, chiefly near stubs or wounds, appearing soon after infection. The old, upper surface is brown or black, and very hard. Trees of any age are susceptible, but those over $10 \mathrm{~cm}$. in diameter are most subject to attack. Diseased trees should be cut down, or excision practiced.

Rust (Puccinia fraxinata (Lk.) Arth.). - This is a rust which may be recognized by the orange-colored cluster-cups upon the swollen parts of the leaves and petioles of nearly all species of ash. The winter condition is found upon marsh-grass, Spartina. Usually the injury is not large, but in seasons favorable to the disease defoliation may result. 
ASPEN. See poplar.

\section{BIRCH}

Sapwood-rot ${ }^{389}$ (Polyporus betulinus Fr.). - Several species of birch are affected by this rot, which is of wide distribution in the northern United States. The fungus enters the sapwood from the bark through wounds or through the lenticels, and progresses inward. When completely decayed the yellowish, cracked, diseased wood crumbles.

Rust (Melampsoridium betuline (Schm.) Arth.). - This is much like the willow rust. See p. 405.

BUCKEYE. See p. 390 .

\section{BUTTERNUT}

Anthracnose (Gnomonia leptostyla (Fr.) C. \& de Not. Marssonina). - The affected leaflets bear circular, dead, indefinitely bordered spots. The disease spreads very rapidly throughout the tree, and to other trees. Defoliation results.

\section{CATALPA}

Leaf-spot (Phyllosticta catalpœ E. \& M.). - Affected leaves bear round, brown spots, often with a yellowish gray border. The spots, from 3-6 $\mathrm{mm}$. in diameter, often coalesce to form large blotches which are fragile, sometimes dropping from the leaf. Young leaves develop poorly and are deformed, while severe infection may cause complete defoliation of the tree.

Soft heart-rot ${ }^{405}$ (Polyporus versicolor Fr.). - The wood at the center of the tree is discolored and disintegrated, eventually becoming straw-colored and soft. The sporophores appear near the wound which afforded entrance. They are sessile, grouped, soft, hairy above with alternate bands of light and dark color. When old, they are tough with edges curled in. See also p. 374. 
CEDAR, RED (Juniperus)

Rusts ${ }^{406}$ (Gymnosporangium sps.). - Several distinct species of the parasite occur on Juniperus, some of which produce the usual "cedar-apples," others produce cankers or witches-brooms on the branches, or spots on the leaves. They are usually of but small significance to the cedar tree itself unless exceptionally abundant. See apple rust.

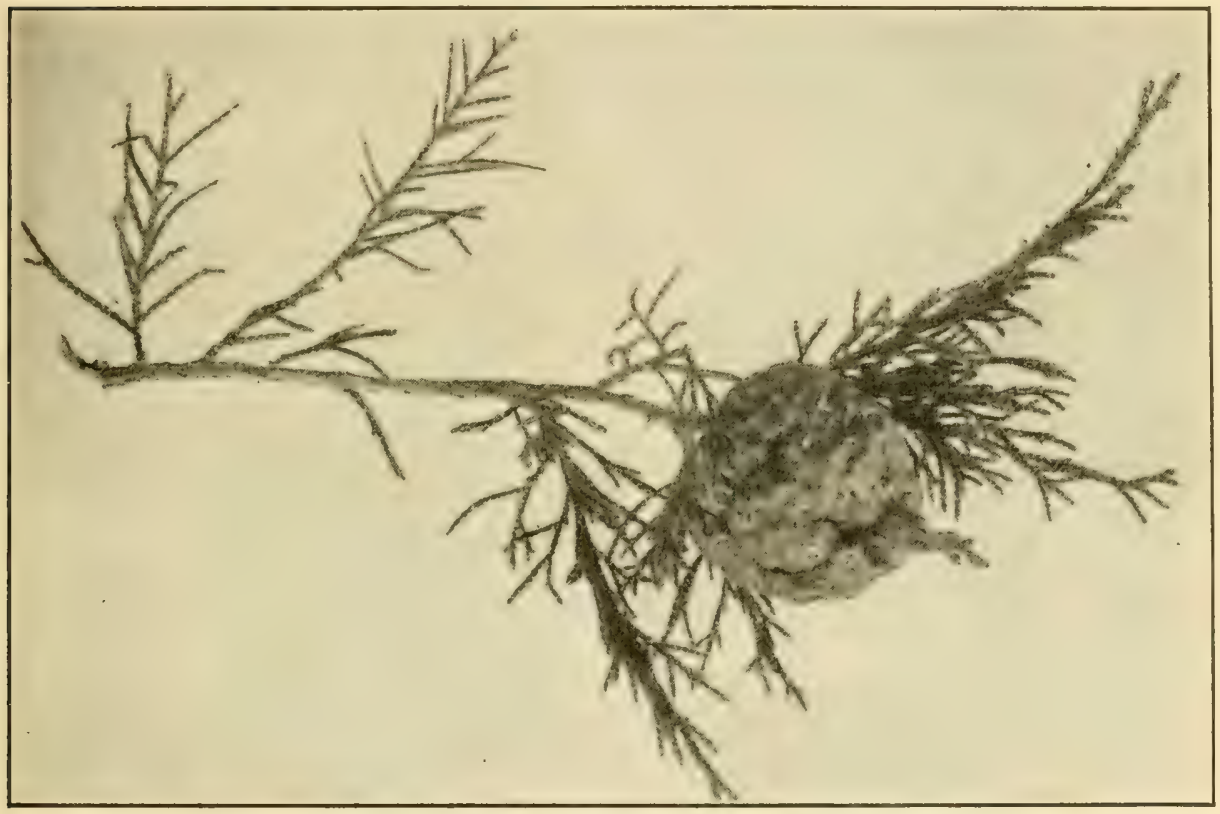

FIG. 200. - "Cedar-apple," gall of the rust fungus. Original.

White-rot ${ }^{407}$ (Fomes juniperinus v. Sch.). - In this disease holes appear in the heartwood, extending longitudinally with a partition of sound wood between. These cavities eventually may unite to form tubes throughout the tree. The wood between one cavity and the next is not the normal red, but is somewhat browned, and the holes themselves are coated with a brilliant white lining. The cavities, partially filled with a velvety reddish-yellow mycelium, may be from 4-9 cm. long. The pore-bearing sporophore is hard and 
woody, rough above, later fissured, yellow-brown at the margin, later deep brown. The pore layer is yellow to brown.

Red-rot, pecky-cedar ${ }^{407}$ (Polyporus roseus Fr.). - More common than white rot, this has been observed in Missouri,

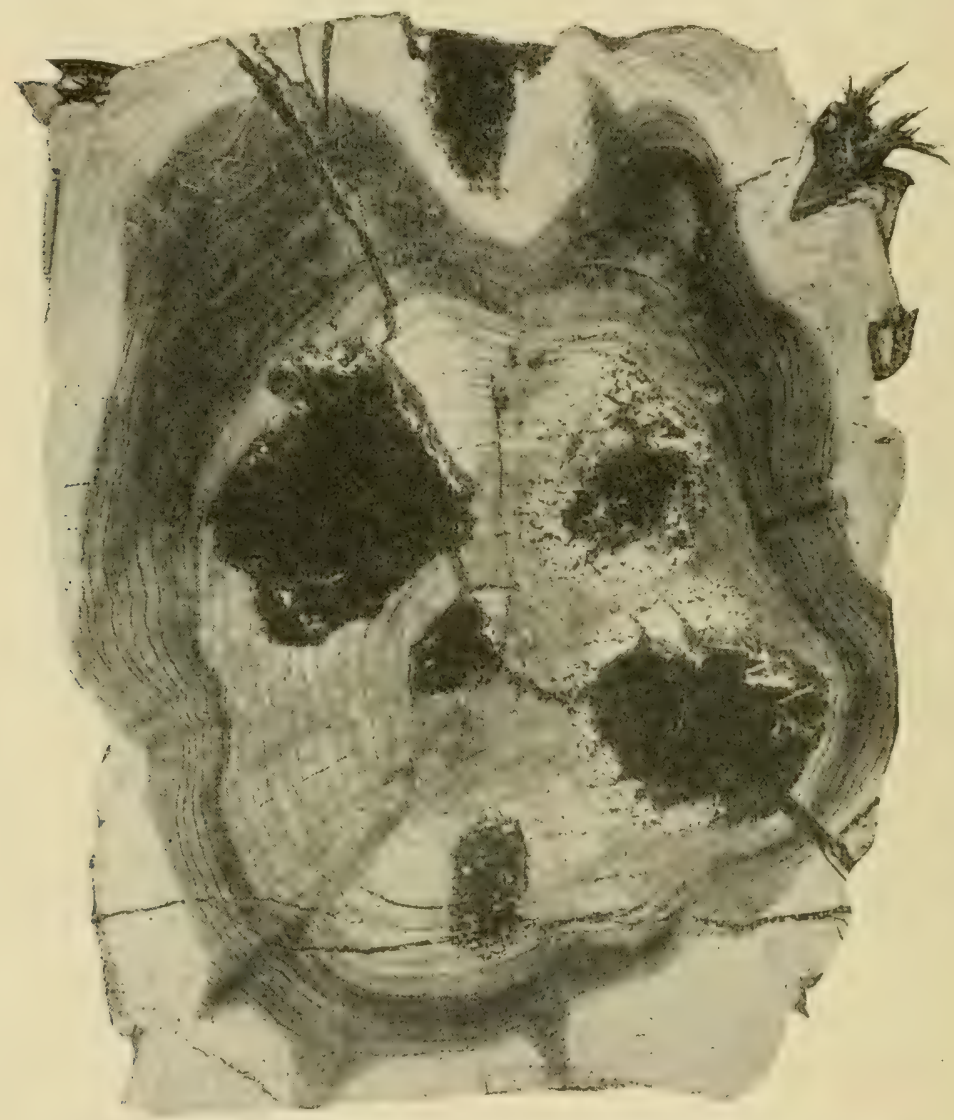

FIG. 201. - Cross-cut of cedar log showing effect of Fomes juniperinus. After von Schrenk.

Arkansas, Kentucky, Tennessee, Virginia, New York, and Mississippi.

The wood is full of pockets of brown, brittle wood, varying from a centimeter to a meter or so in length. The sporo- 
phore, formed in the cavities under dead branches, is from $0.5-35 \mathrm{~cm}$. in length by $1 \mathrm{~cm}$. wide. The pore-bearing layer is flesh-colored.

This and the preceding disease of the cedar taken together have been estimated to cause 60 per cent loss in some local-

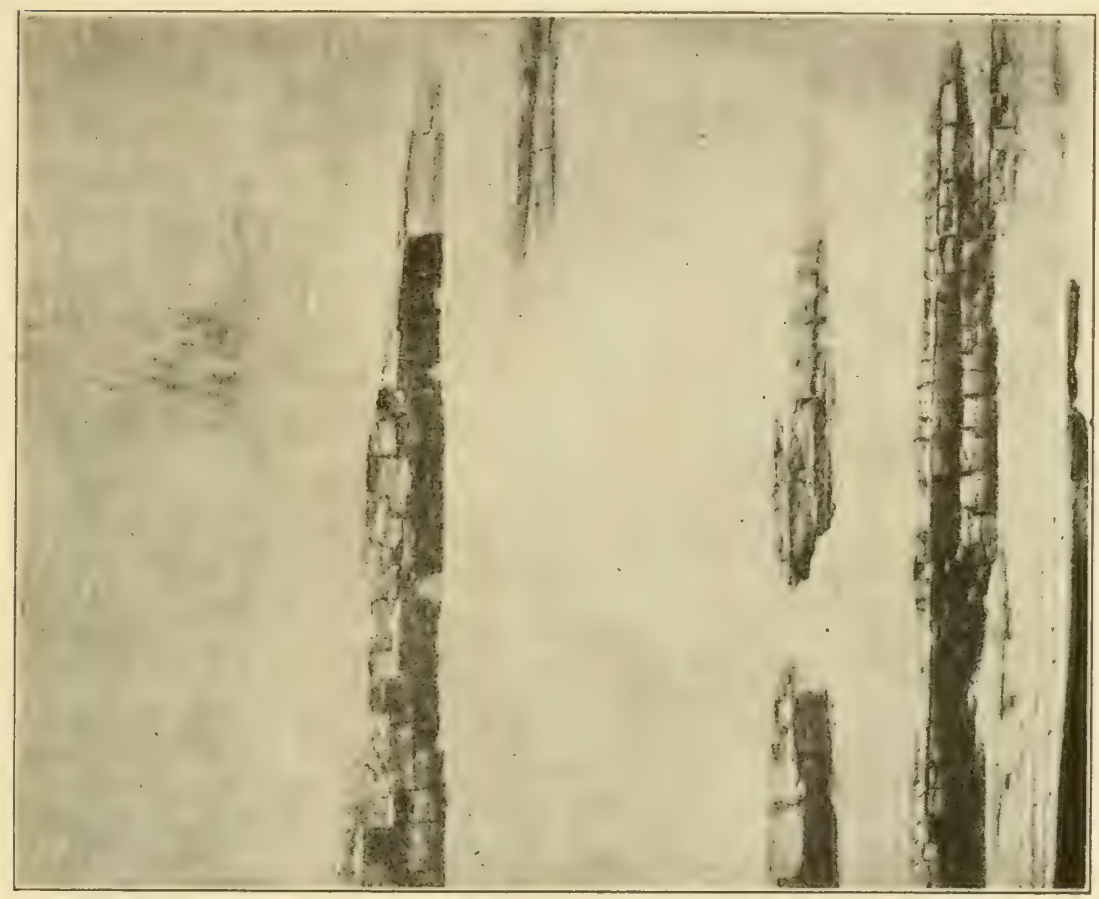

FIG. 202. - Longitudinal section of cedar showing effect of Fomes juniperinus. After von Schrenk.

ities. Since they are caused by wound parasites, the removal of diseased trees and the destruction of sporophores is recommended.

Cedar canker (Phoma sp.). - This canker is found on juniper and arbor-vitæ. Injury apparently occurs only on trees under four years old. Prior to that age entire seed beds may be destroyed. 


\section{CHESTNUT}

Bark-disease ${ }^{408,409,496}$ (Endothia parasitica (Murrill) A. \& A.). - First noted in 1904 by Merkel in New York, this

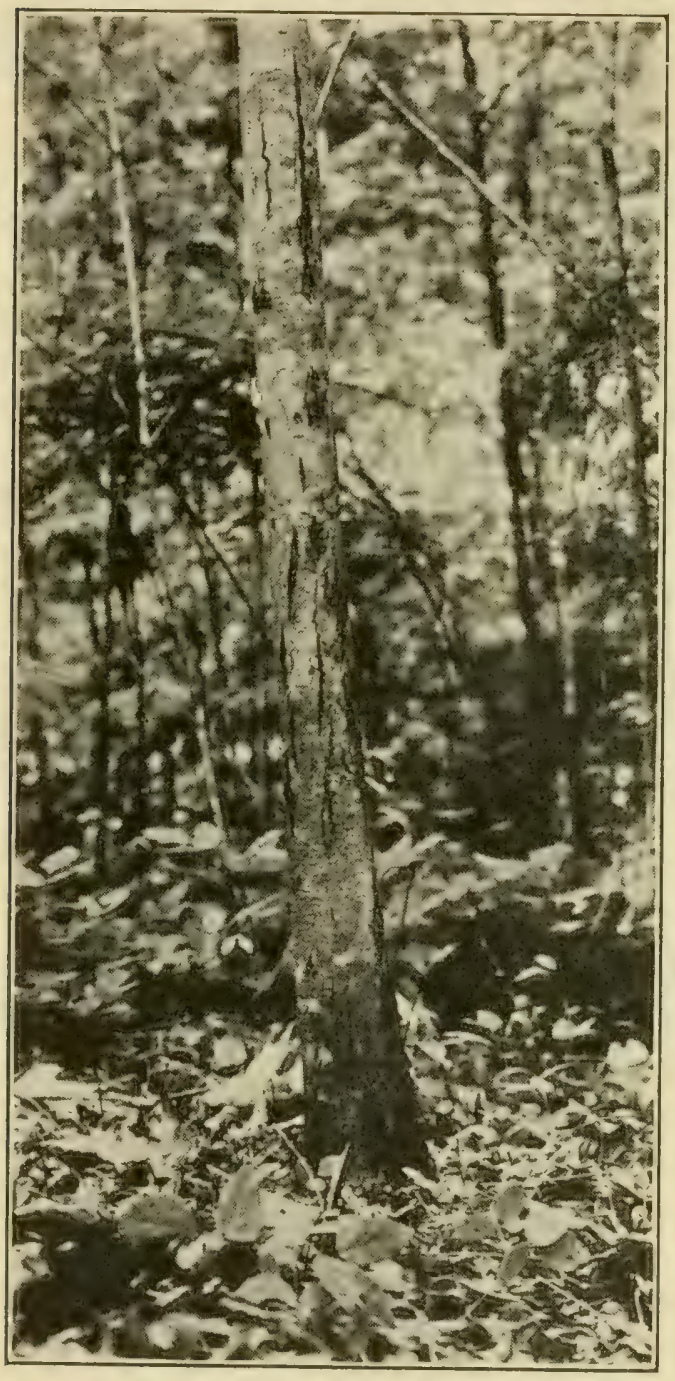

FIG. 203. - Chestnut-bark disease. After Beattie. disease has spread with a rapidity and destructiveness without parallel in plant pathology. Its distribution in 1918 is indicated in Fig. 205. The disease extended by natural agencies

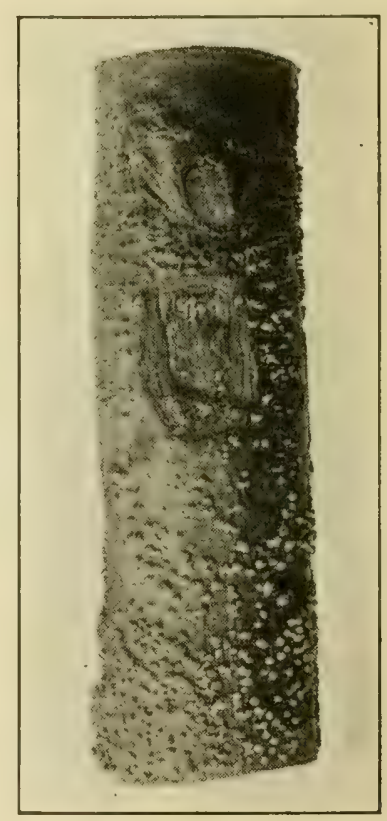

Fig. 204. - Chestnutbark disease, showing the sporiferous pustules. After U. S. Bur. Pl. Ind.

through the native chestnut forests from Maine to Virginia, but shipments of nursery stock have been responsi- 
ble for its spread to distant points, to British Columbia, California, Nebraska, etc. In most of these new, distant foci, the disease has since been eradicated. In Brooklyn 16,695 trees were killed on 350 acres, and the loss in and about New York City in 1908 was placed at from $\$ 5,000,000$ to $\$ 10,000,000$. The total damage prior to the year 1911 is conservatively placed at $\$ 25,000,000$, and may now aggregate

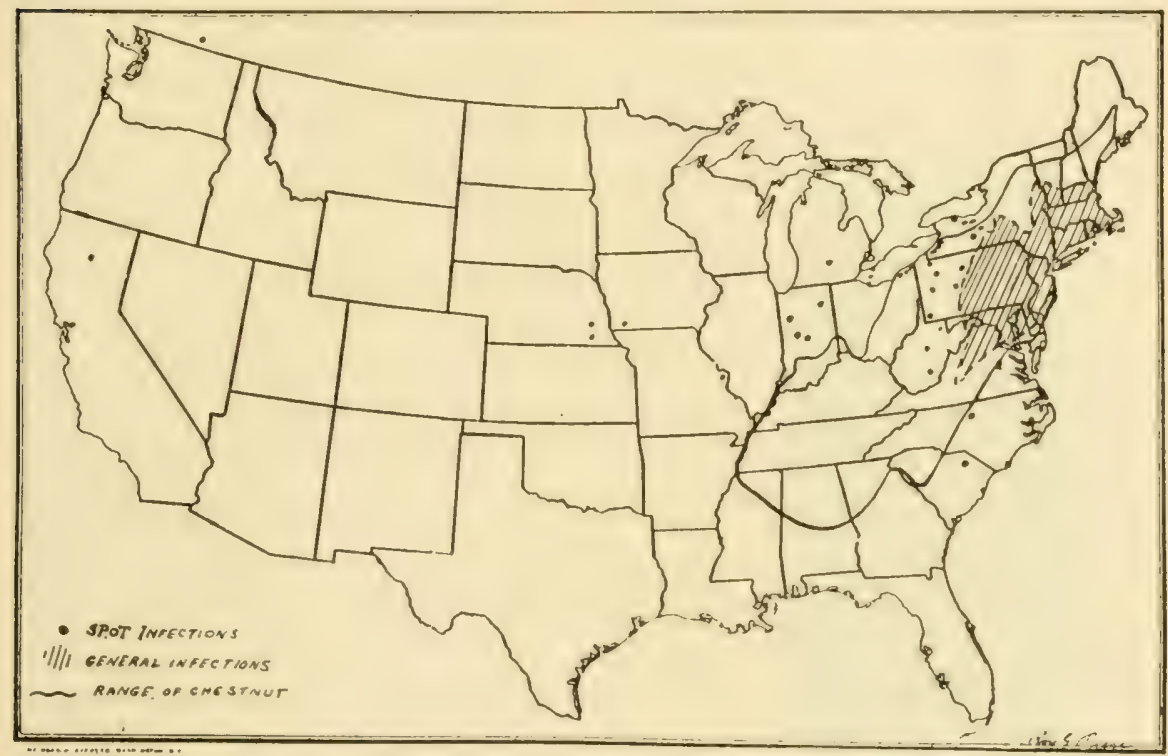

FIG. 205. - Distribution of chestnut blight in 1918. Courtesy of the Office of Forest Pathology.

twice that amount, but this is insignificant compared with the loss that will ensue in the chestnut forests of the Appalachians. It has already caused more damage to forest trees in America than any other fungus. The same disease has been found in China, and it is reasonably certain that it was introduced into the United States from the Orient some time prior to 1904 . This pest is vigorously parasitic on members of the genus Castanea alone, and among the species of this genus the Japanese and Chinese varieties are highly resistant. The attack occurs upon the bark through wounds, but twigs and leaves are not directly affected. From the point of attack 
it spreads in all directions until the diseased parts meet on the opposite side of the branch, thus girdling the twig. Dead, discolored, sunken patches with numerous yellow, orange, or reddish-brown pustules are produced; spores are extruded in greenish or yellow horns. Canker's in midsummer may enlarge at the rate of a half-inch in diameter each week. The appearance of the fungus upon the trunk indicates speedy death, but if small branches are first diseased, the tree may continue to live for a few years. When once established, no means of checking this blight is known. Only preventive measures can be taken, such as destruction of diseased trees by fire, careful inspection of all nursery stock, and excision in the case of isolated trees which are considered valuable enough to justify this mode of treatment. Every general measure that has been tried has been abandoned, and at present the outlook indicates that the disease will eventually exterminate the American chestnut. To the present time $\$ 165,000$ has been used by Federal appropriation and $\$ 282,500$ by states, $\$ 275,000$ by Pennsylvania alone, in combating this disease.

Anthracnose, leaf-spot (Marssonina ochroleuca B. \& C.). The characters of this disease are small bleached areas bearing spore pustules. It has been quite injurious to nursery varieties.

Bordeaux mixture is advised.

Large leaf-spot (Monochetia desmazierii Sacc.). - This leaf-spot is abundant in forests, and causes much loss of vigor to the tree. It is recognized as large, $1-5 \mathrm{~cm}$., circular spots with irregular concentric marking. No treatment is feasible in forests, but isolated trees can be protected by spraying.

\section{ELM}

Leaf-spot ${ }^{556}$ (Gnomonia ulmea (Schw.) Thm.). - The leaf spots are $1-3 \mathrm{~mm}$. in diameter, and each spot is seen to contain a cluster of small, black, rounded elevations, the cluster 
surrounded by a border of dead tissue. Premature defoliation results. The disease is prevalent in all parts of the United States.

\section{FILBERT, HAZEL}

Blight ${ }^{410}$ (Bacteria). - A serious blight, which in many respects resembles blight of pear, affects the filbert in Oregon. It occurs on buds, shoots, leaves, and as cankers on larger limbs.

Black-knot ${ }^{413}$ (Cryptosporella anomala (Peck) Sace.). - In 1892 Halsted noted black-knot as destructive to several hundred trees in New Jersey, and in 1893 Humphry described the same disease upon hazel canes in Massachusetts. It is characterized by numerous small, elliptical, warty emergences upon the bark of the diseased branches. The diseased portions are sunken, owing to the contraction of the inner bark to a mere line. The girdling produced results in death of the affected canes and general injury similar to that produced by plum knot. Affected branches should be cut and burned.

HEMLOCK, WESTERN (Tsuga heterophylla)

\section{Heart-rot ${ }^{411}$ (Echinodontium tincto-} rum E. \& E.). - The fungus enters

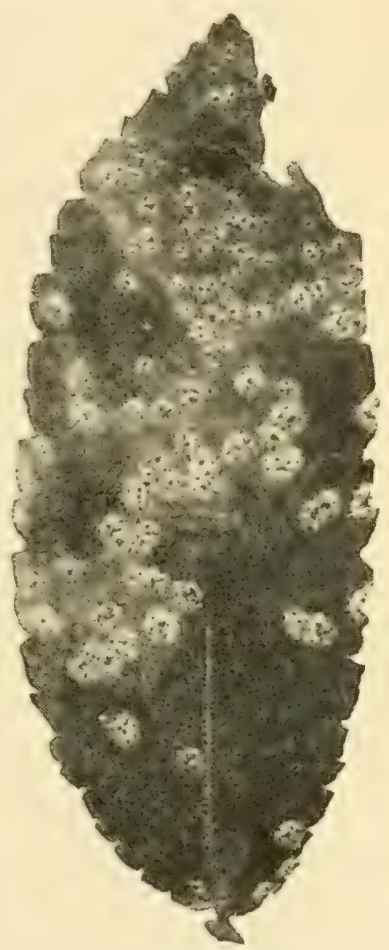

Fig. 206. - Elm leafspot. After Heald. through wounds, chiefly branch stubs, and produces a stringy brown rot of the heartwood, which extends to all parts of the tree. A single sporophore of the fungus on the first 16 -foot log of the tree trunk may be taken to indicate that the heartwood is unmarketable in both the first and second logs. The position of the largest sporophore usually indicates the region of greatest decay. 
Rust (Melampsorella elatina (A. \& S.) Arth, Ecidium). This cluster-cup fungus produces bushy distortions, "witches' brooms," by causing profuse branching of the affected part of the tree. These abnormal branches soon lose their leaves, and cluster-cups are produced upon them. The brooms are perennial and increase in size each year, in some cases largely covering a whole tree with the brooms. In such cases the trees are stunted and may even be killed. Infection may be reduced by destroying the spore-bearing branches or by eliminating the alternate hosts, Alsine and Cerastium.

Canker (Dasyscypha resinaria (C. \& P.) Rehm). — Swollen cankers occur in the stems and branches, even girdling the main trunk and killing the tree. After the branch is dead the causal fungus produces spores in small disks, orange-colored within, about 4-6 $\mathrm{mm}$. wide and high.

\section{HORSE-CHESTNUT, BUCKEYE}

Leaf-blotch ${ }^{412}$ (Guignardia asculi (Pk.) Stew., Phyllosticta). - Unsightly spots upon the leaflets, and premature defoliation, render this the most conspicuous disease of this tree. The brown spots are at first circular, but as they enlarge are limited by the larger ribs, thus becoming nearly rectangular. Pycnidia may be seen by means of a lens. This is a decided nursery pest and is also troublesome on park plantings.

Lime-sulfur or Bordeaux mixture have much reduced the spotting. Dusting (sulfur, 90 parts, arsenate of lead, 10 parts) has also proved effective.

\section{LARCH}

Mistletoe ${ }^{397}$ (Razoumofskya). - This is the chief enemy of the western larch, attacking trees of all ages. If the trees are not killed they produce but a poor grade of timber and poor growth, and are moreover rendered liable to the attacks of wood-rotting fungi. All larches infected with mistletoe should be cut, whether salable or not. 


\section{LINDEN}

Leaf-spot (Cercospora microsora Sacc.). — Small, circular or large, irregular, dead spots of the leaf indicate the presence of this disease. It has been reported as destructive in Mas-

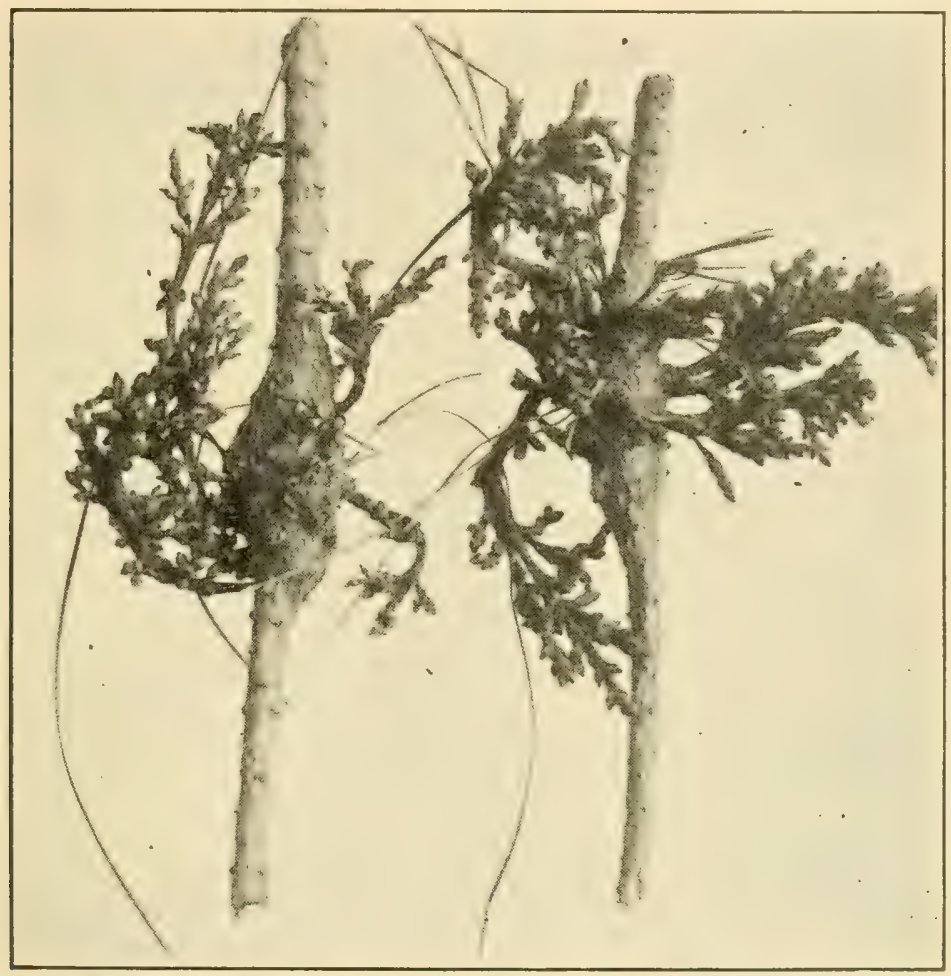

FIG. 207. - Mistletoe. After U. S. Bur. Pl. Ind.

sachusetts, New Jersey, and New York. Two sprayings in Massachusetts resulted in longer retention of the foliage and lessened infection.

\section{LOCUST}

Yellow wood-rot ${ }^{414}$ (Fomes rimosus Berk.). - From Massachusetts to New Mexico, over the entire black locust territory, this heart-rot prevails. It is a yellow rot extending 
from the center outward in radial lines through the medullary rays; the hard flinty wood is reduced to a soft, yellow, cheesy mass, spongy when wet. The pore-bearing, shelving, hoofshaped, sporophores develop chiefly from the burrows of the locust borers or from stubs. The young portions are light brown; older parts, dark to black and fissured. The lower side is dull red-brown.

The rot ceases with the death of the tree, and posts made from diseased wood do not continue to rot.

\section{MAPLE}

Leaf-spot (Phyllosticta acericola C. \& E.). - A large proportion of the leaf may become involved, causing premature defoliation which materially lessens the value of the tree for ornament or shade. The silver maples are especially susceptible, and their sale has thereby been reduced. The leaf spot was first noted in 1874 and is distributed throughout the United States. The blackish, subcircular spots as they enlarge change to brown and later to dirty white in the center with black borders. Small black pycnidia may be seen in the central regions of the mature spots, which are from 10-14 mm. in diameter. Burning diseased leaves is recommended, accompanied by use of Bordeaux mixture if economy justifies.

Tar-spot (Rhytisma acerinum Fr.). - Thick, shining, irregular black spots $1-1.5 \mathrm{~cm}$. across appear on the leaves in late summer and cause them to fall prematurely, thus weakening the tree. Considerable damage is often done to nursery stock. The leaves should be raked together and burned in the fall.

Leaf-spot (Rhytisma punctatum Fr.). - In this leaf-spot the causal fungus forms several small, black dots upon the leaves as contrasted with the one large black blotch of the tar-spot.

Anthracnose (Gloesporium apocryptum E. \& E.). - Nursery maples have been seriously injured by this anthracnose. The tips of leaves of pruned twigs turn yellow, then blacken 
and die as though frosted. Young leaves and shoots are killed and by their death induce abnormal branching, resulting in a compact head. The disease seems limited to young trees.

Bordeaux mixture is advised - three or more sprayings.

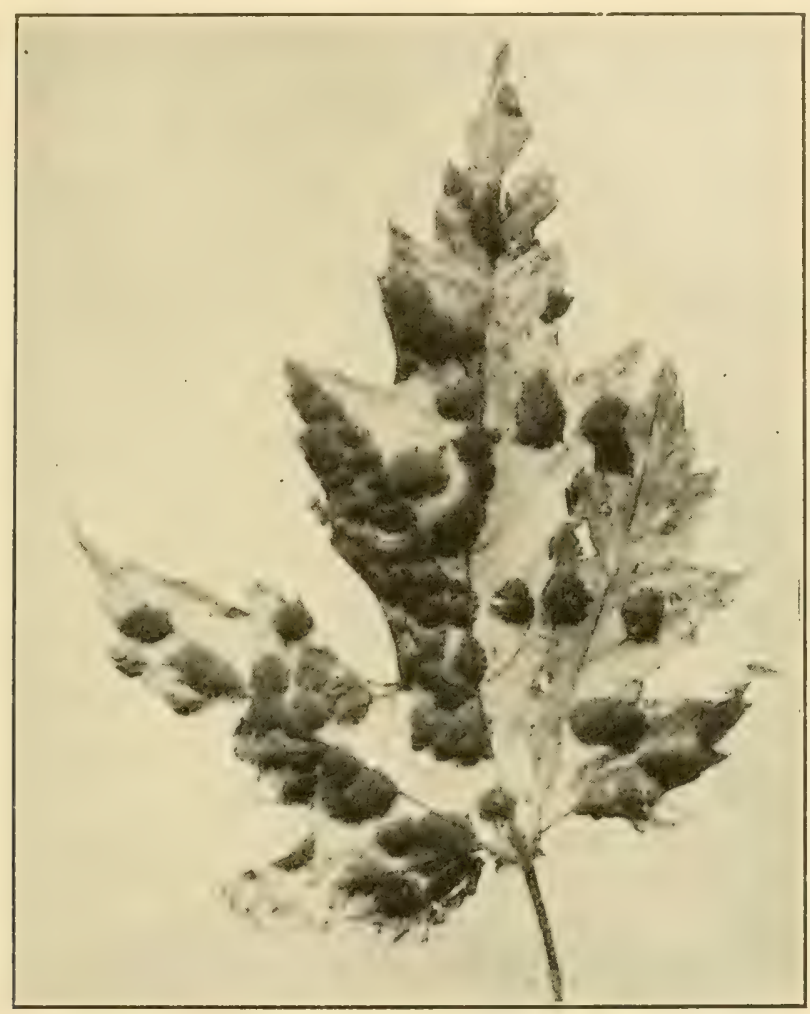

Fig. 208. - Maple tar-spot. After Heald.

Thrombosis (Verticillium). - Leaves wilt and branches die due to plugging of the veins by the fungus. Dark streaks show in the wood of affected twigs.

\section{MULBERRY}

Blight (Bacterium mori B. \& L.). - Upon the leaf small, reddish-brown spots, pellucid when moist, are produced. 
The twigs and even entire trees are stunted and yellowed. Cankers may almost or quite girdle the stem, the diseased area becoming dark. Prune as for blight of pear.

\section{OAK}

Leaf-curl ${ }^{463}$ (Taphrina cœrulescens (D. \& M.) Tul.). Though close kin to peach curl, only a small proportion of each leaf, spots 1-2 cm. in diameter, is involved. Defoliation may result in extreme cases, and continued disease each year may cause death. Affected leaves should be burned and if the tree value warrants it sprayed as for peach curl. Powdery-mildews (Microsphcra). - These appear late and do little harm except upon nursery stock. Flowers of sulfur or Bordeaux mixture are useful. Twig-blight (Diplodia longispora C.\& E.) does some injury. Blight. See sycamore.

\section{OSAGE ORANGE}

Rust (Physopella fici (Cast.) Arth.). - The sori which are scattered thickly over large areas of the lower side of the leaf are small, $0.1-0.3 \mathrm{~mm}$. in diameter and are pale cinnamon-brown. This rust is known from South Carolina to Texas.

\section{PECAN ${ }^{415,} 416$}

Scab (Fusicladium effusum Wint.). - In the Southern States, particularly Florida, Louisiana, Georgia, Oklahoma, and Texas, twigs, leaves, and nuts are affected with a dark green, smoky, superficial growth. Upon leaves and petioles dead spots, distortion, and defoliation are caused. The new growth of twig is often killed, but the greatest injury is to the nuts which drop before maturity.

Spraying with lime-sulfur or Bordeaux mixture, or dusting with sulfur has proved effective.

Powdery-mildew (Microsphcera alni (Wallr.) Salm.). During certain years in the South the pecan crop has been 
much injured by this mildew. It is recognized as a flour-like, white coating and is particularly damaging to the young nuts.

Spraying with Bordeaux mixture or lime-sulfur before the fungus appears is effective. Burning of infested fall refuse is also helpful.

Anthracnose (Glomerella cingulata, Gloesporium). - Large, light brown to reddish blotches occur on the leaves and cause them to fall. The nut hulls bear irregular, sunken, black blotches which may extend to the whole surface, and which eventually bear numerous pink acervuli. Many nuts fall prematurely.

All infested refuse should be burned; a dormant spray applied, another spraying given just after the buds open, and if need be, one to three additional sprayings later.

Rosette. ${ }^{417,418}$ - From 10 to 20 per cent of the trees in the Southeast are affected. The leaves at the branch ends are first yellow-mottled, then die. Later the twigs die back and the trees are seriously weakened. No parasite is present; the disease seems to result from deficiency of humus, food material, and moisture, and may largely be avoided by use of legumes, and by plowing under green cover crops.

Die-back (Botryosphceria berengeriana de Not.). - - Young twigs die and their surfaces bear numerous black perithecia. Dead wood should be pruned out and burned. Pink-mold (Cephalothecium sp.) affects the hulls, nut, and the embryo. It frequently follows scab. Brown leaf-spot (Cercospora fusca (H. \& W.) Rand.), Nursery-blight (Phyllosticta caryce Pk.), a kernel-spot (Coniothyrium) and Mistletoe do some damage. Pollen-blight (Microstroma juglandis (Ber.) Sace. var. robustum Hig.) presents an interesting case of a fungus parasitic in the anthers.

\section{PINE}

Blister-rust ${ }^{419,}{ }^{420}$ (Cronartium ribicola F. deW., Peridermium). - This rust which has done much damage in northern Europe on the 5-leaved or white pines, of which there are some eighteen species, entered the United States in 
quantity from Germany, between 1900 and 1909 on diseased pine seedlings, though isolated cases occurred here prior to those dates, even as early as 1892. It is now known in Maine, New Hampshire, Vermont, Massachusetts, Con-

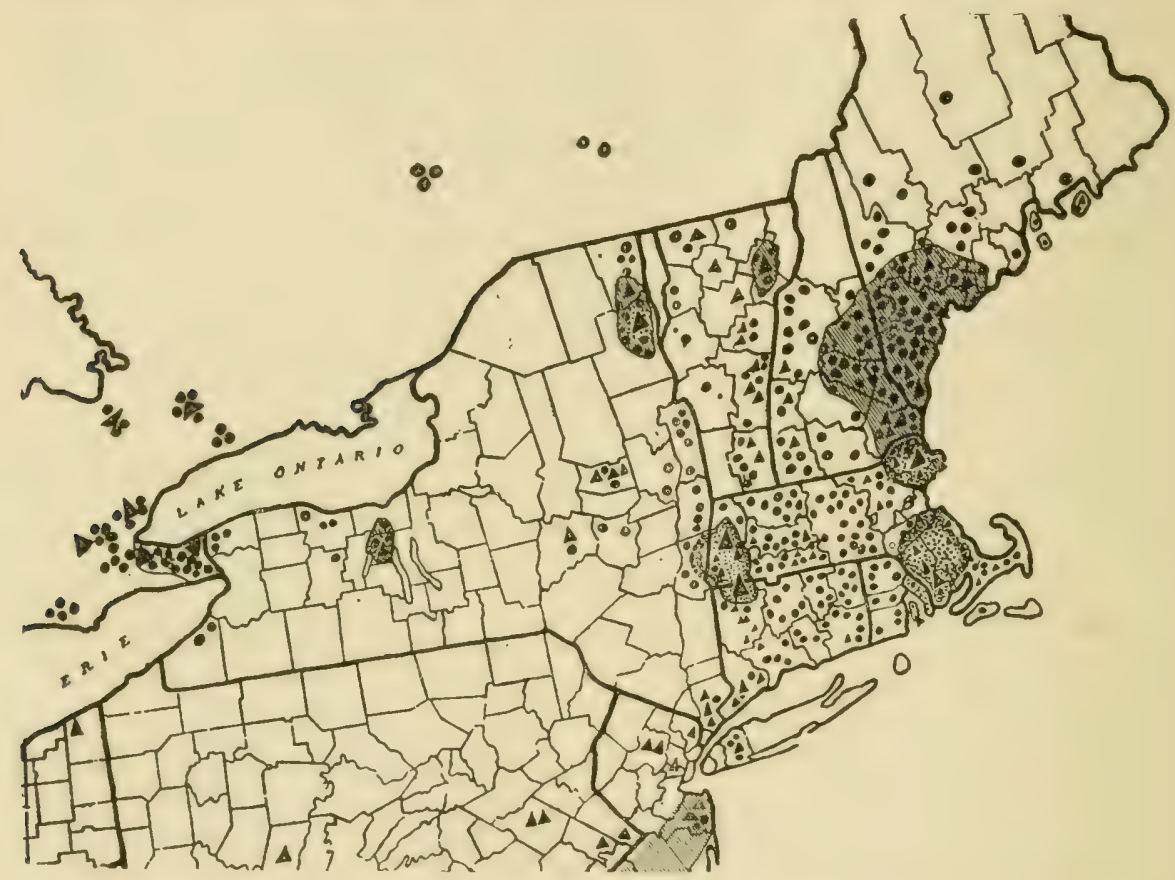

FIG. 209. - Map showing general location of pine blister infections.

ه Diseased white pines found in 1816.

- Diseased currants and gooseberries found in 1916.

Areas of heavily infected currants and gooseberries.

Centers of heavy infection where the principal efforts were made to eradicate diseased plants.

(Three centers of infection also exist in Wisconsin and Minnesota.)

Courtesy of the Office of Forest Pathology.

necticut, New York, Pennsylvania, Rhode Island, New Jersey, Kansas, Ohio, Indiana, Wisconsin, Minnesota. The alternate host is Ribes (see p. 116), some twenty-one species of which are susceptible. In the spring, sporidia from the 
Ribes telial stage of the rust may infeet pines on which they fall. The first external evidence of disease appears one to several years later. The bark thickens and later pyenia develop. In the spring, xcia, numerous or few, mature on the swollen bark and free their orange-colored spores. These spores falling on Ribes produce the next stage of the rust, though they cannot directly infect pine. The rust is perennial in the pine, the cankers enlarging year after year. Trees attacked when young, $c . g$., under 25 years of age, are liable to be killed. Older trees may merely lose branches or the central, top shoot. The damage to white pines is very serious. In 1909 the value of standing white pine was estimated at $\$ 600,000,000$, the sugar pine at $\$ 120,000,000$. A loss of even 1 per cent of this, which is a low estimate, is significant.

In 1912 laws were enacted to prevent entry into the United States of foreign stock likely to harbor and introduce dangerous fungi and insect pests. Rigid Federal and state inspection is now exercised to prevent further spread of this disease. Imported Ribes and white pine must be kept well separated. If the disease is present, all Ribes should be removed from the vicinity. At the present time, $\$ 530,448$ of Federal appropriations and $\$ 267,300$ of state funds have been used to combat this disease.

Bluing ${ }^{421}$ (Ceratostomella pilifera (Fr.) Wint.). - The characteristic symptom, bluing of the sapwood, begins in August and September after the trees have been attacked by beetles. The blue color starts near the base of the tree and gradually spreads upward until the entire sapwood becomes blue. The presence of the mycelium of the abovenamed fungus, which gains entrance through openings made by the beetle and is initiated by spores carried by the beetle is responsible for the color phenomenon. Blue wood is as strong as normal, green wood, is tougher, and when dry, it will last as long; but when wet, it rots rapidly.

Leaf-cast (Hypoderma). - The needles die from the tips toward the bases, becoming first reddish, then gray. Black 
lines which extend longthwise of the leaves are produced by the ascus-bearing organs.

Premature defoliation results.

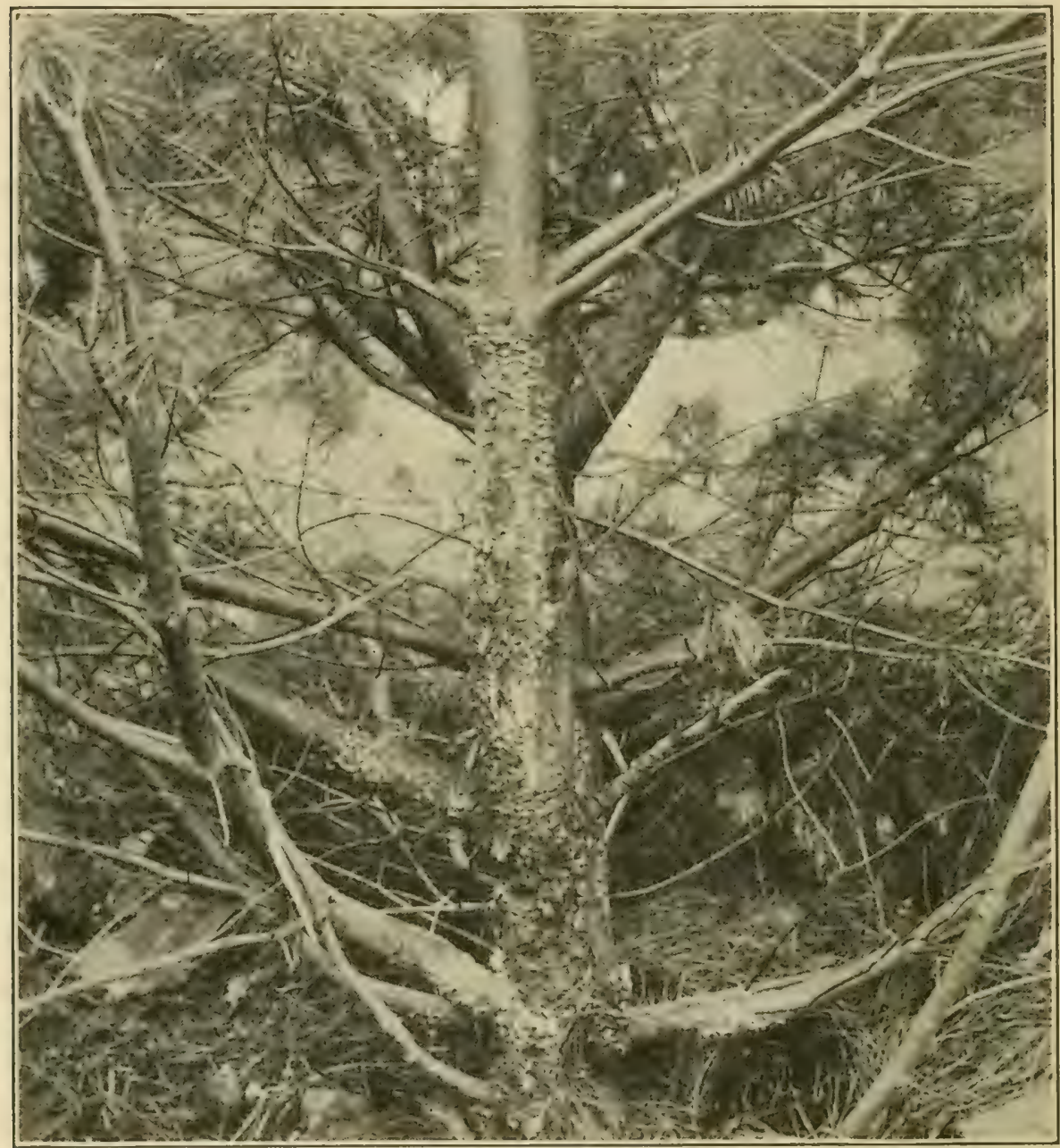

FIG. 210. - Cronartium ribicola on pine showing general aspect of disease. After Colley.

Leaf-blight, twig-blight (Lophodermium brachysporum Rostr.). - In Maine the leaf-blight has been noted as destructive to a considerable number of small trees and in- 
juring the lower branches of large trees; serious damage, however, is not common.

Damping-off (Fusarium sp.). - The general character's are those mentioned under damping-off. It is serious in

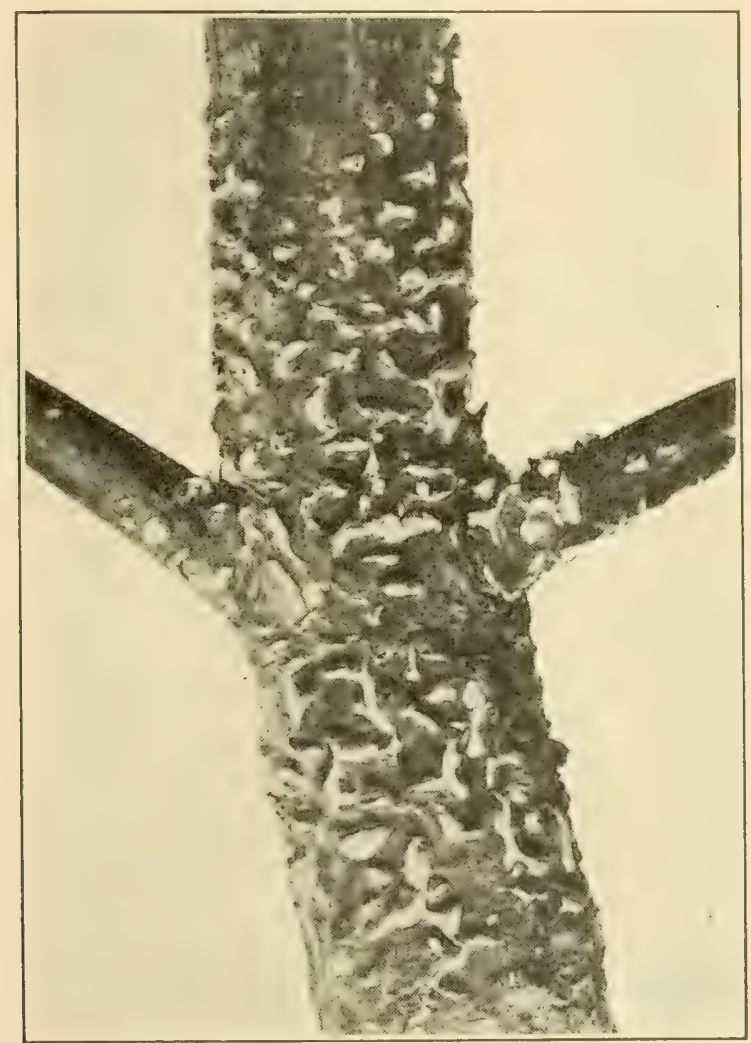

FIG. 211. - Cronartium ribicola on pine showing sporiferous pustules. After Colley.

Vermont, New York, Missouri, and probably in many other states, killing the seedlings in nurseries as soon as they appear above ground. The beds should be given all ventilation possible. A top-dressing of sterilized sand sprinkled over the beds immediately after germination resulted in 30 per cent of disease against 42 per cent in the untreated part. For disinfection of soil, see p. 460. 
Rust (Cronartium cerebrum (Pk.) H. \& L., Peridermium).Swollen areas occur upon the branches and young stems which are gradually killed. The gall-like growth sheds a

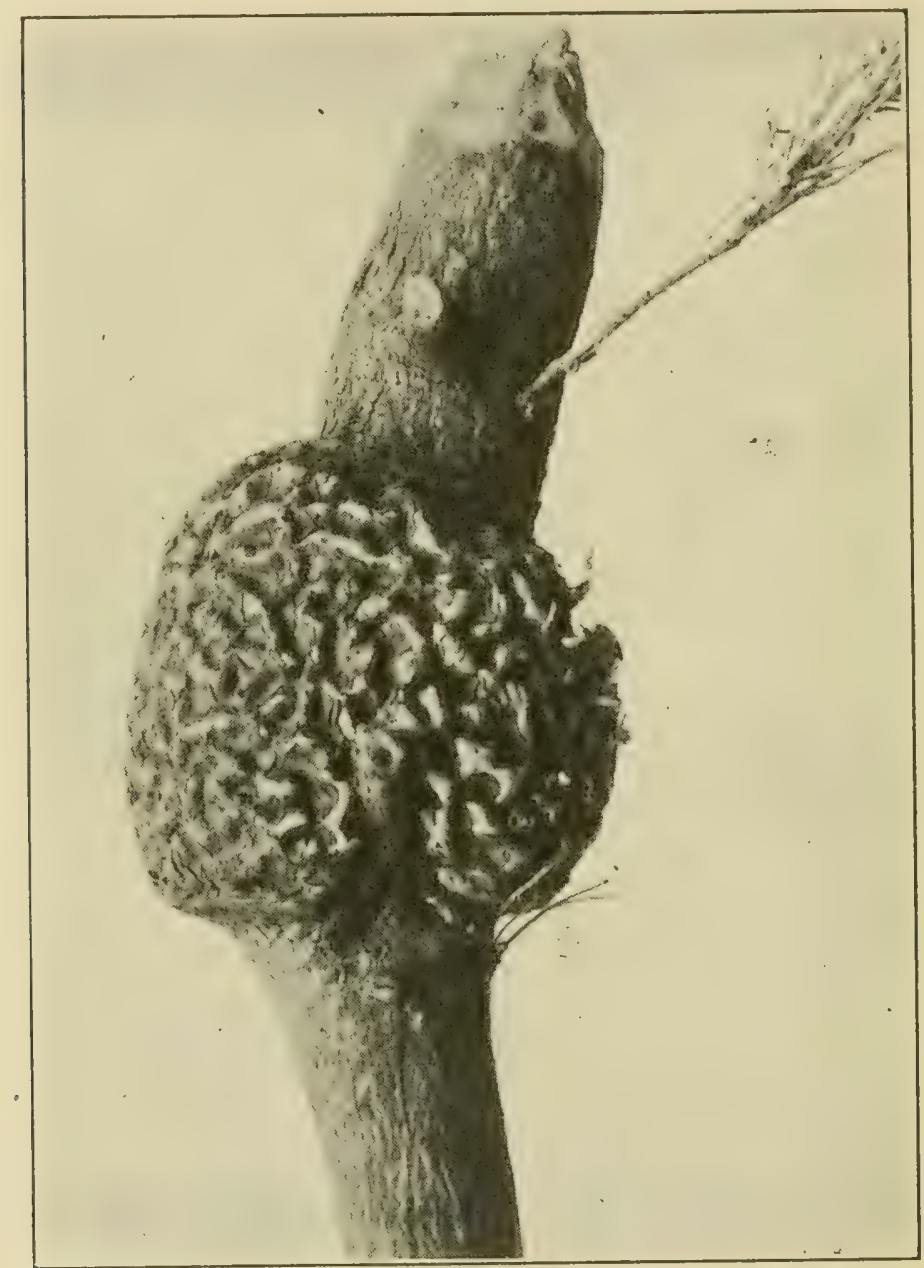

FIG. 212. - Gall produced by Cronartium (Peridermium) cerebrum on pine. After Hedgeock.

profusion of orange-colored spores each spring. Chiefly by . its interference with the sap current the swellings bring about the death of many trees. The galls are perennial and may 
persist for many years. One stage of this rust oceurs upon the oaks.

Rust (Coleosporium solidaginis (Schw.) Thün., Peridermium.. - Another species of Peridermium oceurs upon leaves, producing small, sac-like, tubular outgrowths which contain the spores. This is a stage of a rust which appears later in the season upon golden-rods and asters.

Red-rot (Fomes pinicola Cke.). Upon dead trees this rot begins just under the bark, usually near the tree top, often following bluing. The wood is at first wet and soggy, but soon becomes brittle, so that it crumbles readily. The cracks become filled with felted fungous threads. The sporophores first appear as fleshy knots, soon red, which widen to pore-bearing shelves.

\section{POPLAR, COTTONWOOD}

Rust (Melampsora sps.). - This is similar to willow rust. See p. 405.

European-canker ${ }^{422}$ (Dothichiza populea S. \& B.). - Species of poplar and cottonwood in nine states show this disease. Death of the cambium results, and following this numerous cankers and dead branches render the trees unsightly. The disease was probably recently imported on the Lombardy poplar from Europe. New stock should be carefully inspected. Infected wood should be cut out and burned.

Canker ${ }^{530}$ (Cytospora chrysosperma (Pers.) Fr.). -- This serious canker is prevalent in the southwestern United States 
on willow and poplar, the lesions occurring on the trunks, limbs, and twigs, with reddish pycnidia on the dead areas near the edge of the canker or over the entire dead surface. Strict inspection should guard against further spread of the disease. Resistant varieties should be used, the trees given plenty of water and protected against mechanical injury.

Leaf-blight (Marssonina populi (Lib.) Sacc.). - Primary infection occurs upon the leaves, resulting in small, $3-8 \mathrm{~mm}$., circular, black dead spots which are quite definitely bordered. As the leaves die, the patches upon the stems also turn black and die. Infection proceeds to the supporting twigs and may result in dead patches of bark upon quite large shoots.

Cutting and burning infected twigs is advised.

Galls (Macrophoma tumefaciens Sh.) occur on the branches.

\section{RUBBER ${ }^{158}$}

Trees and shrubs that produce rubber are subject to numerous destructive diseases, among them Cankers due to various species of Nectria, Corticium, Fusicladium, and Diplodia; Die-back (Thyridaria) which kills the young shoots; seedling diseases due to Pestalozzia, Helminthosporium and numerous leaf fungi, and Root-rot due to Fomes, Irpex, Hymenochæte and Poria.

\section{SASSAFRAS}

Heart-rot (Fomes ribis (Sch.) Ir.). - Spaulding in 1907 described this rot as a serious injury to sassafras in Missouri. It is also found upon stems and roots of various shrubby plants, as rose and currant. By means of a wound the attack is made upon exposed heartwood, proceeding slowly into the sapwood. The sassafras is thus immune until it reaches an age bearing heartwood. The decaying wood is abnormally light in color and slightly reddish, and the affected region is bounded by a narrow black zone. Trees sometimes die from the attack. 
The causal fungus has been reported in America from Kansas, Missouri, New York, and New Jersey.

\section{SYCAMORE}

Blight (Gnomonia veneta (S. \& S.) Kleb., Gloosporium). First noted in 1848, this anthracnose is very wiclely distributed on sycamore and oak from New Jersey to California and Mississippi. In extreme cases it may so weaken the trees as to cause their death. The scorched appearance of the leaves and defoliation render the trees unsightly. Just before they become full-grown the leaves give the first indication of the attack. Beginning near the veins or ribs or upon the petiole, the disease causes a stoppage of the water supply to the more distant portions of the leaf, resulting in dead areas.

Dead twigs should be pruned out, and infected material collected and burned. Spraying with Bordeaux mixture may be practiced if the expense is warranted.

\section{WALNUT}

Anthracnose (Gnomonia leptostyla (Fries) C. \& d. Not. Marssonina). - Conspicuous brown spots, 2-4 $\mathrm{mm}$. in diameter, appear upon the leaflets, which soon yellow and fall. Upon the

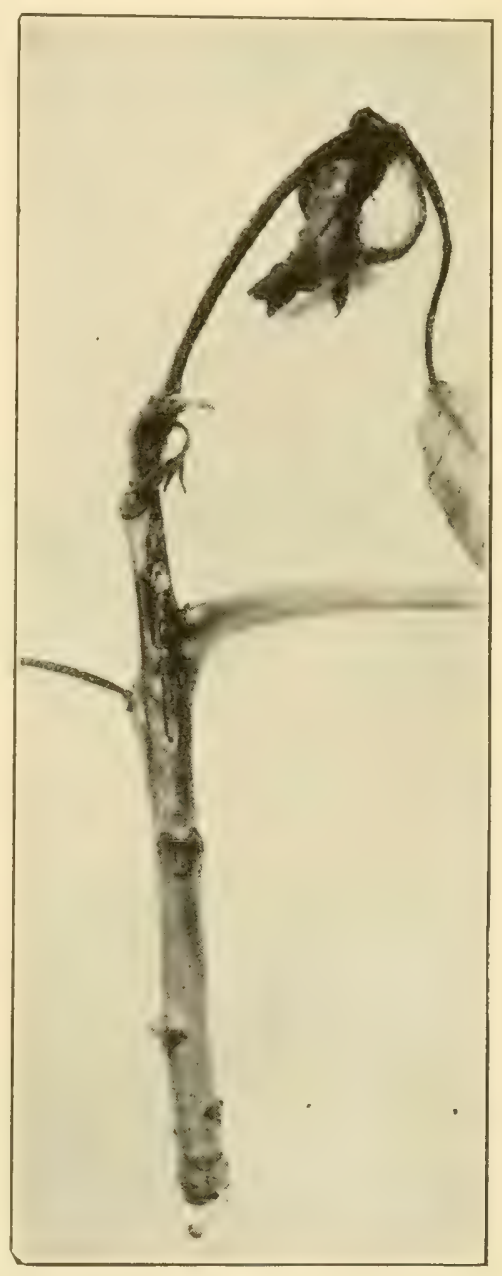

FIG. 214. - W a lnut twig blighted by bacteria. After R. E. Smith. 
lower sides of the leaf spots are small, concentrically arranged, black acervuli.

The disease has been troublesome on black-walnut in Delaware, Iowa, Maryland, and West Virginia.

Blight 423, 42.4 (Pseudomonas juglandis Pierce). - This blight known in 1901 only on the Pacific coast is now recorded in California, Oregon, Texas, Louisiana, Maryland, Delaware, Pennsylvania, and New York on English-walnut.

Black cankered spots upon the young nuts, which fall prematurely, or similar spots upon the young, green shoots are characteristic. Chief damage is to the nuts, but in seasons.

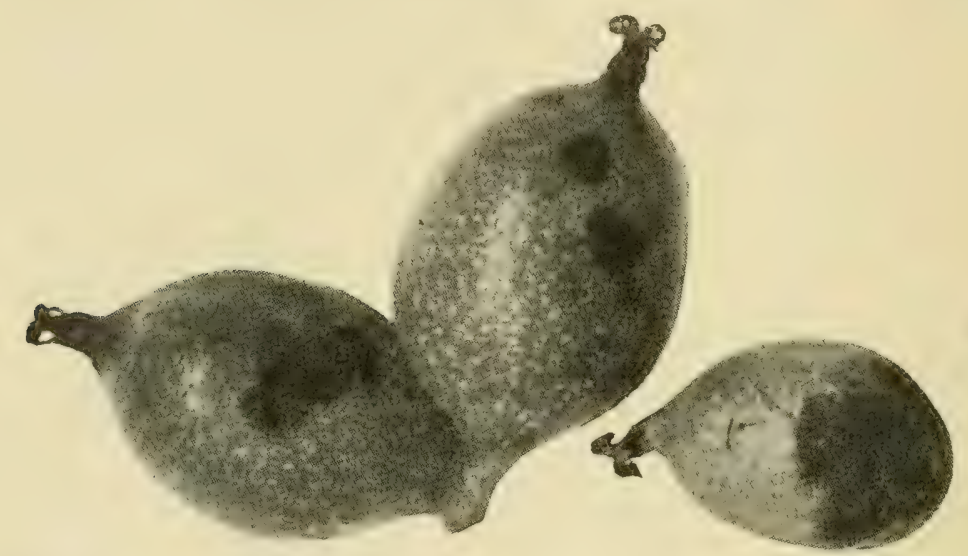

Fig. 215. - Bacterial blight of walnuts. After R. E. Smith.

favorable to blight much of the terminal growth is killed and the succeeding crop is thereby reduced.

Spraying is of questionable value. Care should be taken to select resistant trees for propagation.

Melaxuma ${ }^{425}$ (Dothiorella gregaria Sacc.). - In this disease, reported from California, black sunken cankers develop on the trunk and larger limbs, and the leaves on the smaller limbs suddenly wilt. The first indieation of disease is often a black area like a bloteh of tar on the gray bark. Exeision and disinfection should be practiced.

Other walnut troubles are: Die--back, often due to lack of or 
excess of soil moisture; Sun-burn of nuts or tree trunk; Crown-gall; Perforation, an imperfection in shell development; Root-rot; Wilt; Yellows; and Leaf-spot (Marssonina).

\section{WILLOW}

Rust (Melampsora saliciscaprce (Pers.) Wint.). - Of tree rusts this is one of the most prevalent, occurring as dusty, yellow sori upon the lower leaf surfaces. Trees are rendered unsightly by the defoliation induced. In the latter part of the season the winter sori appear as reddish brown to black, waxy or crusty spots. A similar rust is common upon cottonwood, Balm of Gilead, poplar. Canker (Cytospora).--See poplar. 


\section{ORNAMENTAL PLANTS}

The ornamentals give rise to problems unique in the field of plant pathology due to the fact that the number of species of plants involved is much larger than with any other group of crop plants, and moreover, because they vary greatly in value; some of them, as for example the rare orchids, have a market value higher than that of any other individual cultivated plant; other ornamentals are of negligible commercial value. There is large diversity of financial interest; some crops are grown on a large scale by only a few individuals, others to considerable extent by nurserymen and seedmen, other crops are rarities in only a few greenhouses, while to many the flower garden in the yard has a high sentimental, though small money, value. Aside from a few standard flowers, as for example roses, violets, chrysanthemums, carnations, etc., and certain nursery stock, so few individuals are interested, or have so small a financial risk in these crops that large expenditures of public funds have not been made for investigation or control of the diseases. The result is that aside from the standard ornamental crops and a few isolated cases of other crops, the diseases have received no such complete study as has been given for example to diseases of other plants of general interest and large commercial value. Indeed in many cases knowledge is limited to a mere note of the occurrence of certain diseases or parasites, and the course of procedure is only to be inferred from knowledge of similar diseases. Flower fanciers and the commercial growers of ornamentals are able and willing and can well afford to use the best methods of treatment, and it is unfortunate that so much is lacking here concerning treatment for the specific diseases. 


\section{General Diseases}

\section{Powdery-mildews. - For description, see p. 122.}

These diseases are particularly common on ornamentals under glass or in the open. The following list comprises the hosts on which they are most frequently found; Adonis, Alyssum, Anemone, Aquilegia, Begonia, Berberis, Calendula, Chrysanthemum, p. 420, Clematis, Coreopsis, Cosmos, Dahlia, p. 421, golden glow, hawthorn, honeysuckle, lilac, p. 426, larkspur, peony, phlox, p. 429, rose, p. 431, spirea, sunflower, sweet pea, p. 435 , verbena, p. 436, violet, Virginian creeper.

In-door or out-of-door treatments are essentially those given under rose mildew (p. 432).

Cutting-bench and Seed-bed Diseases. - If plants in the cutting-bench are wounded or weak they are subject to attack by many fungi that could not injure them under normal conditions. The chief point in preventing inroads by these fungi is to keep the cutting-bench and seed bed in good sanitary condition, i. e., proper degree of moisture and temperature, well ventilated, and free from infestation by injurious fungi. Soil and bench, if once infested, should be disinfected (p. 460). No diseased refuse should be allowed to contaminate it. The chief trouble in the seed bed is damping-off (p. 19).

Stem-rot (Corticium). - See p. 21. Numerous plants are affected, among them: Abutilon, Acalypha, Achillea, Ageratum, Alyssum, Amarantus, Antirrhinum, Aquilegia, Asparagus, Aucuba, Bartonia, Begonia, Berberis, Calendula, Callistephus, Campanula, Celosia, Centaurea, Chrysanthemum, Cineraria, Coleus, Coreopsis, Cuphea, Dianthus, Eriobotrya, Erysimum, Euphorbia, Godetia, Gypsophila, Helianthus, Hibiscus, Iberis, Impatiens, Iresine, Kochia, Lathyrus, Lavatera, Ligustrum, Linaria, Linum, Lobelia, Lychnis, Lythrum, Matthiola, Pæonia, Pelargonium, Petunia, Phlox, Physalis, Piqueria, Platycodon, Portulaca, Potentilla, Primula, Punica, Pyrethrum, Reseda, Richardia, Ricinus, Salvia, Santolina, Schizanthus, Sedum, Seradella, Silene, Stachys, Taxus, Telanthera, Verbena, Vinca, Viola. 


\section{Slime-mold (Physarum cinereum (Bat.) Pers.). - This} mold grows as a slimy mass over any plants that are in its path, often covering an area meter square. It later changes to the gray, dusty, sporing stage. It is not really parasitic or even injurious, but by its unsightliness, arouses the apprehension of the gardener. No treatment is needed.

Root-rot (Thielavia). See p. 23. Among the ornamentals, this disease has been noted particularly on Aralia, Begonia, Cyclamen, Dahlia, sweet pea, violet, Tropœolum.

Sooty-mold (Capnodium) may occur on almost any plant, though usually with little or no injury. It is most harmful on the camellia. (See p. 413). Other plants on which it is often seen are privet, Lonicera, palms, Cornus, yew, oleander, rhododendron.

Crown-gall (Pseudomonas). See p. 87. Crown-gall is not usually troublesome on ornamentals. It has been noted on daisy. Evonymus, honeysuckle, rose, flowering almond, chrysanthemum.

Southern-blight (Sclerotium rolfsii). See p. 23. The fungus that causes this disease may be found on almost any host, especially in the South. Even as far north as Illinois it was destructive in gardens on Campanula, Erigeron, Dianthus, Dracocephalum, Pentstemon, Phlox, Eupatorium.

\section{Special Diseases}

\section{AGAVE}

Anthracnose (Colletotrichum agaves Cav.). - Spots are produced on the leaves, and often cause the death of young plants. Diseased leaves should be removed and burned, and the remaining leaves sprayed.

AMARANTUS (Various cultivated varieties).

White-rust (Albugo) is common but not serious. See p. 164. 


\section{ANDROMEDA}

Gall (Exobasidium sps.). - See azalea.

\section{ANEMONE}

Rust (Cluster-cup). - The alternate stage of the rust of drupes occurs here. Drop (Sclerotinia tuberosa Fel.) also occurs occasionally.

\section{ASPIDISTRA}

Anthracnose (Colletotrichum omnivorum Hals.) is common everywhere especially upon variegated plants.

\section{ASTER, CHINA (Callistephus)}

Wilt ${ }^{426,}{ }^{467}$ (Fusarium conglutinans Wall. var. callistephani Beach.). - The wilt, mentioned as early as 1896 by Galloway, has since been reported from Massachusetts and Colorado, and is probably the most important disease of the China aster. The time of transplanting the beds and blossoming time are most susceptible periods, though the wilt is present to some extent at other times.

The most conspicuous symptom is the sudden death of the plants. The bark of the stem is rotted at the ground line. Close observation earlier shows the leaves upon one side of the plant, particularly the lower leaves, yellowed and wilted, and the youngest leaves to be smaller than normal. The wilting effect may sometimes be found first on one side only of one of the lower leaves. Plants attacked early may die, or in milder cases may survive to produce a few small blooms. If the symptoms first show at blooming time, their sequence is the same.

The roots in early stages appear healthy, but the stem near the ground, in longitudinal section, shows darkening of the outer wood, local at first upon the affected side, but. extending rapidly in all directions. Eventually the discoloration extends into the bark, which rots away. 
In the seed bed the same disease may occur as dampingoff. See p. 19. It seems that original infection always occurs in the seed bed, never in the open.

Plants started in the open are not susceptible. If it is necessary to start them under glass, too thick sowing should be avoided, and they should be ventilated thoroughly.

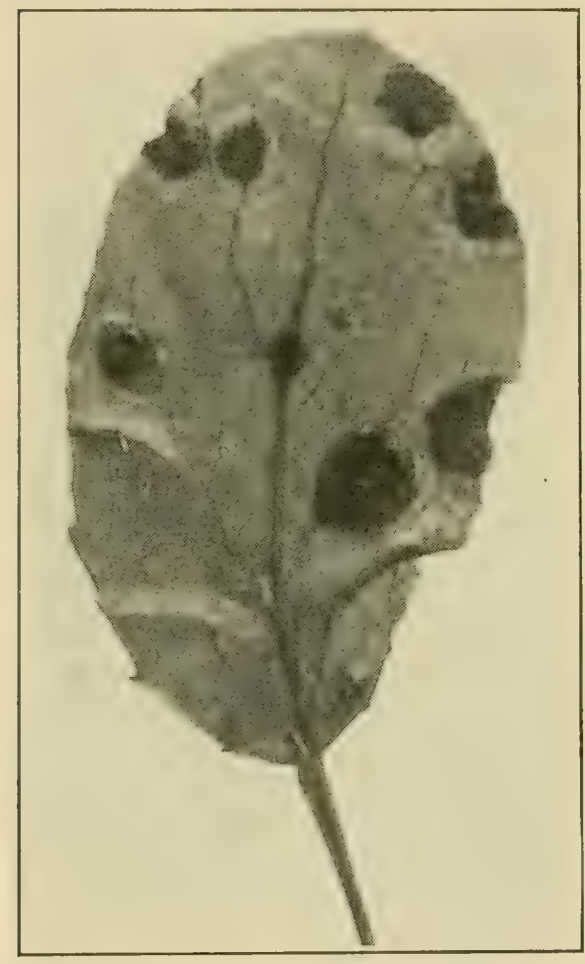

Fig. 216. - Rust on barberry. After Stakman.

Soil that is known to be infested should not be used. The disease may be prevented by avoidance of the conditions that favor damping-off.

Yellows. ${ }^{426}$ - Growth is spindling and the shoots and leaves are yellow, but no death of affected parts occurs. In badly diseased plants no flowers, or only rudiments of such, develop upon the sick shoots. In other cases the flowers turn greenish-yellow, wholly or in part, with malformed floral parts producing little or no seed. No parasites are present and the cause of the condition is unknown, but the striking similarity to peach yellows is obvious.

The same disease affects the marguerite.

Rust (Coleosporium solidaginis (Schw.) Thuem.).Orange-red sori, waxy in consistency, are produced in great numbers upon the leaves, which when badly affected curl, die, and thus bring about the death of the plant. Stemrot (Corticium). - See p. 21. 


\section{AZALEA}

Leaf-spot (Septoria) is common on the leaves. Gall (Exobasidium sps.). - Leaves, flowers, or shoots are enlarged and distorted. Diseased parts should be cut and burned and the plant sprayed with Bordeaux mixture.

\section{BALM, SILVER}

Rust (Puccinia menthe Pers.). - Some thirty species of the mint family, including peppermint, thyme, catnip, monarda, are affected by this rust. It is recognized by its sori, which are at first cinnamon-colored, later chestnut-brown. Badly diseased leaves curl and die.

Infested $\mathrm{refuse}$ should be burned.

\section{BAMBOO}

Smut (Ustilago shiraiana Hem.). - The short branches still covered by the leaf sheaths are attacked.

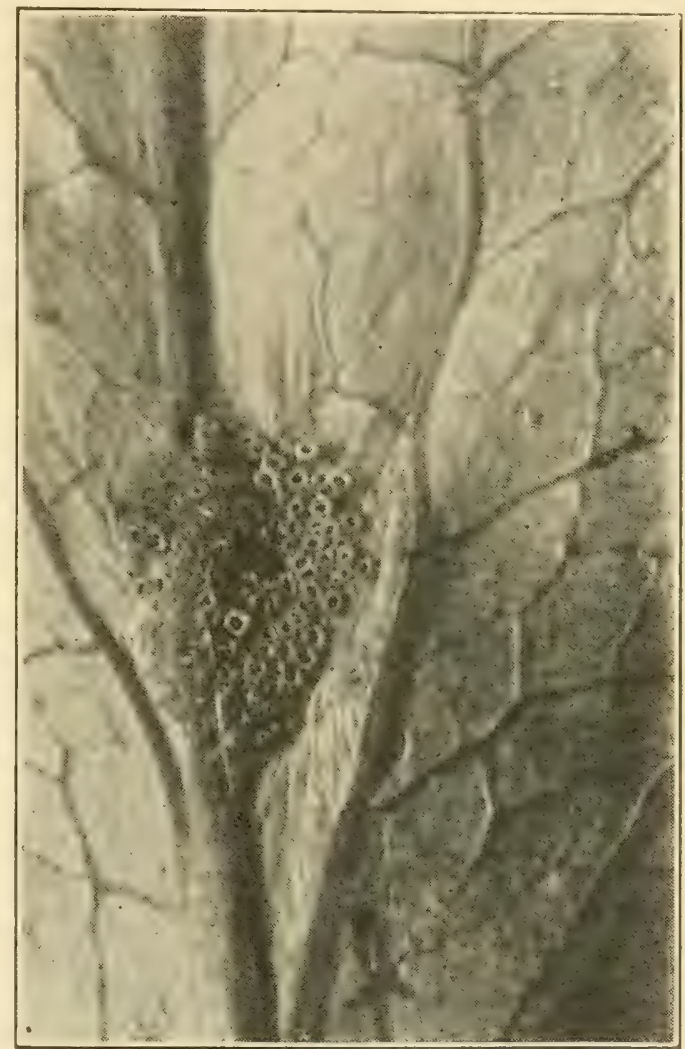

FIG. 217. - Barberry rust enlarged. After Stakman.

Witches-brooms are frequently formed. It has been found in this country on two species of bamboo. Diseased plants should be burned.

\section{BARBERRY}

Rust (Puccinia graminis, Ecidium). - This is of chief interest on account of the damage the other stages of the 
rust causes to cereals. Rusts from many grasses pass to the common barberry though not to the Japanese barberry. See p. 277.

Wilt (Verticillium alboatrum R.\& B.) affects the Japanese barberry. The foliage turns yellow or red; the sapwood is streaked with dark lines; ultimately the wood turns black. Frequently the disease is severe.

\section{BEGONIA}

Eel-worms in the leaves cause translucent watery spots. Powdery-mildew does some harm.

\section{BLETIA}

Anthracnose (Colletotrichum bletioe Hals.). - The leaves of this orchid are frequently disfigured by very dark, almost black spots. In late stages the dead tissue falls away, leaving merely shreds of veins traversing the place of disease.

The tips of the leaves are often frayed.

Volutella rot (Volutella concentrica Hals.). - Numerous lemon-colored acervuli surrounded by concentric bluish rings render these spots different from those above described.

\section{CALLA}

Soft-rot ${ }^{427}$ (Bacillus carotovorus Jones). - A large annual loss and frequently the abandonment of calla growing is due to this disease, which is known throughout the United States.

The affected plants rot off near the soil surface, and the rot progresses from this point up into the leaves or down into the corm. Usually the rot first shows at the top of the corm, but in some instances it is seen first at the edge of a petiole, or on the corm below ground.

In section the diseased portion is brown, soft, and watery. Leaves whose bases are diseased become pale at the edges, then brown. Similar changes occur in spots on the leaf, and the whole leaf eventually dies, or the rot may progress so rapidly that the leaf falls before losing its green color. The 
flower or its stalk are similarly diseased. Through the corm the roots are reached. Here the skin is unaffected and remains as a parchment-like tube filled with the creamy residue of decay. Rot of the bulb may be arrested by unfavorable conditions and show only as dark sunken spots.

The course of the disease extends from a few days to several weeks, or the disease may lie dormant for months, even from season to season. Such cases of dormant disease carry the infestation to the succeeding crop and in commercial corms from country to country. The rot spreads rapidly from plant to plant by way of the diseased roots and through the soil itself. The causal bacillus remains in the soil and may attack healthy corms planted therein at later periods.

No known treatment of diseased plants is practicable. Infestation of soil may be prevented by careful inspection of all corms so as to avoid diseased ones. It is best to test commercial corms in pots to be assured of their healthfulness before putting them in the beds. All soil from badly infested beds should be disinfected or removed and fresh soil supplied.

Leaf-spot (Phyllosticta richardice Hals.). - Blighted leaves bear large ashen spots upon which are numerous minute dark pycnidia.

Another Leaf-spot due to Cercospora richardicecola Atk. was first mentioned by Atkinson in 1891 as occurring in Alabama. The edges of the leaves turn black in circular spots.

\section{CAMELLIA}

Sooty-mold (Capnodium sp.). - The sooty-mold is perhaps more injurious on this plant than on any other ornamental, not as an actual disease but by injury to salability of the foliage. Leaf-spot (Pestalozzia guepini Desm.) is common.

\section{CANNA}

Rust (Puccinia cannce (Wint.) P. Henn.). - This true rust is common and injurious in the warmer climates but is rare in the more temperate regions. 


\section{CARNATION}

\section{Rust 428, 429 (Uromyces caryophyllinus (S'ch.) Wint.). -} The carnation rust was first described in 1789 in Germany and was noted in the United States by Arthur in 1891, evidently a recent importation. It rapidly became widespread through sale of infected plants and cuttings and was soon present in almost all greenhouses. Though widely known in Europe, it did not seem to be especially destructive there; but upon entrance into America its character changed to that of an aggressive pest, and ruin was brought to the beds in many greenhouses. The entire contents of large houses valued at thousands of dollars was in many instances utterly lost. After a short period of extreme destructiveness, which was at its height about 1893, the vigor of the attack waned, until to-day the pest does only a small fraction of damage as compared with that of the early years of its invasion, though it still causes one of the serious carnation diseases.

The rust is easily recognized by the sori filled with powdery, brown spores. The sori, at first covered by the white epidermis, are 1-2 $\mathrm{mm}$. in diameter, round or elongated in the direction of the length of the stem or leaf. When very numerous, the affected part is slightly bleached or yellowed and appears swollen, owing to the much-ruptured epidermis. The mycelium of the causal fungus is usually general throughout affected plants, but may, in case of new infection, be limited to the immediate region of the sorus.

There is much difference in varietal resistance, a fact that should receive due weight in the selection of varieties for culture.

Cuttings should never be taken from diseased stock. If there is doubt as to the presence of superficial spores, it is well to dip the cuttings in potassium sulfid, one ounce to one gallon. A weekly protective spray of copper sulfate, one pound to twenty-five gallons, throughout the life of the plant is also recommended. The leaves should be 
kept as free from moisture as possible by free rentilation, and still better by subirrigation.

Fumigation of the houses in the fall before the introduction of the plants serves to lessen infection from old spores.

Rust sori are occasionally the seat of attack by a Fusarium, ${ }^{433}$ the result being a leaf-spot a centinneter' or more in diameter.

Leaf-spot (Septoria dianthi Desm.). - The spots of this disease - usually upon the leaves, sometimes upon the stems - are circular or oblong, blanched or pinkish, and purple bordered. Numerous small, black pycnidia lie in the central region. The discase is especially abundant upon the lower portion of the leaves and the sheath:s. The diseased part often becomes contracted, which results in bending and curling of the leaves. Surface watering of the plants or humid atmosphere tend to increase the trouble.

Another Leaf-spot is due to Trermicularia subeffigurata Schw. - The bases of the leaves or the stems are usually the points of attack. Black spore-bearing bodies appear in abundance. Spraying with ammoniacal copper carbonate has given good results.

Alternariose ${ }^{130}$ (Alternaria dianthi S. \& H.). - This leaf and stem disease has heen reported as quite troublesome in Connecticut, Pemnsylvania, District of Columbia, North Carolina, Missouri, and elsewhere. It consists of spots mostly upon the leaver, sometimes upon the stems, especially at the nodes. These are strikingly characteristic, of ashen whiteness, with the centers occupied by a scanty, to profuse, black fungous growth. The diseased spot is dry, somewhat shrunken, thinner than healthy portions of the leaf, approxinately circular, though often somewhat elongated in the direction of the longitudinal axis of the leaf. When at the node, the disease usually involves the bases of both of the leaves, as well as the stem between them. As these nodal spots age, the disease penetrates through the stem, killing its tissue, which shrinks somewhat and becomes soft 
and disintegrated, resulting in the death of the more distal portions of the plant.

A striking feature is the tendency of this disease to infect to a large degree one variety, the Mrs. Thomas W. Lawson, to the exemption of others.

Stem-rot, wilt ${ }^{432}$ (Fusarium sp.). - Described in 1897 by Sturgis, this rot occurs chiefly upon the stems and larger branches, discoloring the wood and killing the bark, but rarely causing soft rot. The diseased plant dies gradually with yellowing and drying of the foliage, much as though due to insufficient water supply.

When practicable, beds should be disinfected and new uninfected stock introduced. The disease when first introduced upon a few plants can be stopped by the immediate removal and destruction by fire of the diseased plants.

Leaf-mold (Heterosporium echinulatum (Berk.) Cke.). Circular spots, $1-4 \mathrm{~mm}$. in diameter, bearing more or less concentric zones of dark mold, appear upon the leaves, especially the younger ones, also upon the stems and sometimes upon the calyx. Mold upon the calyx results in deformed flower parts. In some instances the whole top of a plant becomes moldy.

Infested refuse and leaves should be burned and Bordeaux mixture employed as a spray.

Bacterial-spot 431, 340 (Pseudomonas woodsii (EFS)). The spots of the leaves and stems are small, usually surrounded by a narrow water-soaked area, while the center is commonly slightly brown. As the spots grow larger they resemble Septoria spots with the exception of the watersoaked margin. Later they dry and collapse. Badly diseased leaves wither. In some cases nearly all the leaves on many of the stems are so badly diseased as to be hopeless.

This trouble can be checked by removing and burning all diseased leaves, then spraying with formalin, 1 part to 500 . A somewhat similar spot caused by Aphides is known as Stigmonose.

Gray-mold (Botrytis sp.). - A gray-mold similar to that 
upon lettuce sometimes attacks the carnation bud, rotting it before it opens.

Infested refuse should be burned and thorough ventilation provided.

Bud-rot ${ }^{434}$ (Sporotrichum anthophilum Peck). - In this malady some buds never open, others fail to expand to perfect flowers, still others deviate only slightly from the normal. Badly affected flowers, if not picked, wither and turn brown - first the petals, then the sepals. All parts of the flower within the calyx are eventually affected with a rot, and in some cases, though not always, hyphr of the causal fungus may be seen with the naked eye. Mites are usually present, but they are not responsible for the disease.

Neglect is among the prominent predisposing causes, especially the presence of too much water in the soil or air, and the accumulation of débris, leaves, trimmings, and other organic matter on the benches.

The disease may cause considerable damage; thus a daily loss of from $\$ 1.50$ to $\$ 2$ is recorded in one small house. Since the buds only are affected, not the plants themselves, no permanent injury is done, and clean culture, destruction of all refuse which might harbor the fungus, maintenance of moisture at the minimum, and the picking and burning of all infected buds will soon bring relief.

Rot (Volutella dianthi Atk.). - The affected parts are pale and studded with minute, black acervuli. This disease is of greatest injury in the cutting bench.

Stem-rot ${ }^{529}$ (Corticium vagum). - Plants suddenly wilt, dry, and die, while the outer portion of the stem becomes soft and rotten. Sclerotia as described in connection with potato stem-rot are present. For further discussion of stem-rot, see p. 21. High growing temperatures and excess of moisture should be avoided. Infested soil can be disinfected by steam.

Yellows. - Irregular, sunken spots occur. The cause is unknown. 


\section{CHRYSANTHEMUM}

Leaf-spot ${ }^{435}$ (Septoria chrysanthemella Cav.). - Large brown to black blotches, often irregularly circular and of indefinite border, appear upon the leaves. These enlarge and coalesce to involve the whole leaf, which withers, dies, and falls away.

The lower leaves are first affected, but in later stages all the leaves of the plant may be badly spotted, and practically complete defoliation may result. Cuttings from infected stock should be avoided. All diseased foliage should be picked, collected, and burned, and the remaining foliage should be sprayed with Bordeaux mixture with addition of soap sufficient to form a suds to increase its adhesive power. Five or six sprayings during the season are usually sufficient.

Leaf-spot (Phyllosticta chrysanthemi E. \& D.). - This

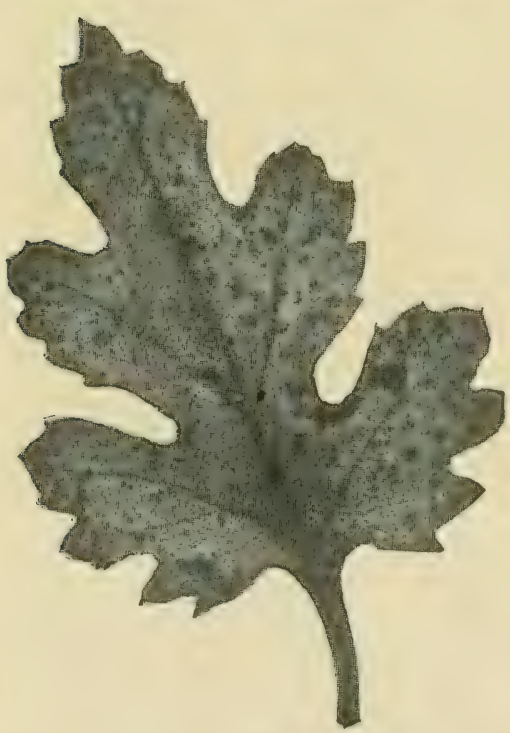

Fig. 218. - Chrysanthemum leaf showing rust sori. Original. disease, first described in 1893, is very similar to the above, except that the spots are more regularly circular, are purplish brown, and have a distinct border. Pycnidia which may often be seen with the naked eye are present.

Wilt (Fusarium sp.) occurs occasionally.

Rust ${ }^{436}$ (Puccinia chrysanthemi Roze). - Apparently a native of Japan, the rust was introduced into England (1895) and Europe through commercial agencies, and similarly into the United States, where it was first noted in 1896 in Massachusetts. It was rapidly spread throughout this country by diseased stock, and is now known in nearly all localities where the chrysanthemum is cultivated. The 
loss occasioned by the diminution in vigor of the plant and consequent imperfection of bloom is large.

The sori, 2-3 mm. in diameter, which are diagnostic, first appear as small blisters covered by the epidermis. The rupture of this covering discloses a dark brown mass of spores. The sori are usually numerous upon the lower leaf surface, and the spores form dusty coatings upon the leaves. Badly affected leaves curl, shrivel, and die. The plants are dwarfed and fail to produce flowers of value.

All new stock introduced to the houses should be carefully inspected and all diseased stock destroyed by fire. New stock should be isolated and watched for a month or more to be sure that no rust develops. If disease appears, all affected leaves should be picked and burned with precautions to avoid scattering the spores. If the rust continues to appear, all parts above ground must be destroyed by fire at the end of the season, and plants for the next year raised in un-

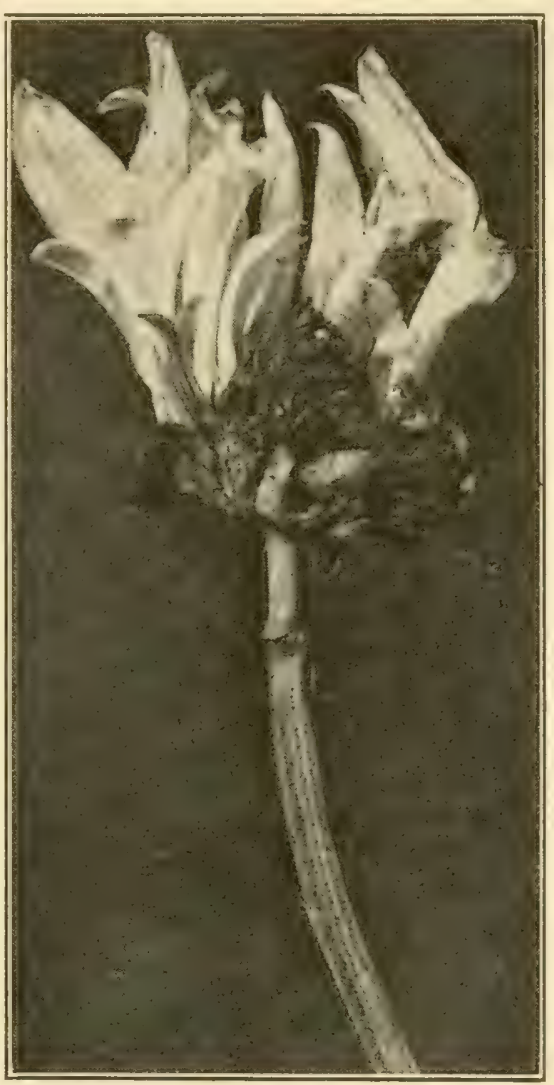

FIG. 219. - Chrysanthemum blossom distorted with rayblight. Original. contaminated soil and house.

Ray-blight ${ }^{437}$ (Ascochyta chrysanthemi Stev.). - In this disease, described by Stevens as doing considerable damage in North Carolina, the ray flowers are blighted, resulting in imperfect opening of the buds. Thorough spraying with Bordeaux mixture from the beginning of the season until 
blossoming, accompanied by destruction of infested refuse, has proved a satisfactory treatment.

Powdery-mildew (Erysiphe cichoracearum DC., Oidium).This mildew occurs as white, flour-like spots upon the green parts of the plant. It is not often serious, but if it should become so, can readily be controlled by the means suggested for rose mildew.

Leaf-spot (Cylindrosporium chrysanthemi E. \& D.).First described in 1893, this closely resembles Septoria spot, though it develops somewhat more rapidly and is consequently more injurious. Often the leaves die and flowers fail to form. Treatment is the same as for Septoria leafspot.

Gall (Pseudomonas tumefaciens). - Galls upon the stems of this plant have been proved by Smith and Townsend to be due to Pseudomonas. Treatment has not yet been discussed.

\section{CINERARIA}

Rust (Coleosporium senecionis (Schum.) Fr.) is occasionally serious.

\section{CLEMATIS}

Stem-rot ${ }^{439,} 441$ (Ascochyta clematidina (Thuem.) Gloy.). Plants affected with this disease were first noted in 1883. A leaf spot is produced; the petioles are affected and the fungus grows down to, and girdles the stem at the node. Diseased leaves should be removed and the plant sprayed. Leaf-spot (Cylindrosporium clematidis E. \& E.). - This occurs on clematis in propagating houses causing the loss of the lower leaves.

\section{COLOCASIA}

Rot. ${ }^{438}$ - Several kinds of rot occur on the cormels, prominent among these are the Java black-rot (Diplodia sps.), Powdery gray-rot (Fusarium), Southern blight (Sclerotium rolfsii), Soft-rot (Bacillus carotovorus). 


\section{COSMOS}

Stem-blight ${ }^{40}$ (Phomopsis stewartii Pk.). - The first indication of disease is seen in brown discoloration of the stem or branches, the attack often, though not always, occurring at a wound. The diseased branches at the point of attack are weak and frequently break off. Minute pycnidia are present in the diseased parts. The disease appears oniy on mature plants and is very destructive.

\section{CYCLAMEN}

Leaf-spot (Phoma cyclamence Hal.). - A disease of the foliage which sometimes causes almost entire loss of the crop is marked by large, dark, irregularly shaped spots upon the leaf. These spots later dry, turn lighter in color, and show a series of concentric light and dark bands, at the same time becoming brittle and often breaking away. Diseased leaves should be burned and the plants sprayed with Bordeaux mixture or ammoniacal copper carbonate. Several fungi as Ascochyta, Botrytis, Phyllosticta, Ramularia, Septoria, cause leaf-spots.

Anthracnose (Gilomerella cingulata var. cyclaminis P. \& C.). - The spots on the leaves are circular, watery, with definite borders. Black, hairy acervuli are often present in great numbers.

Nematodes and Thielavia occur on the roots.

\section{DAHLIA}

Powdery-mildew (Erysiphe communis Wallr, Oidium). This powdery-mildew is quite common, affecting particularly the lower leaves late in the season.

Blight (Phoma dahlin Berk.). - The stems of the flowers are the chief seats of attack. The flowers are small and are often dropped before opening. Root-rot (Botrytis) occur's in storage as a wet soft rot. Wilt (I'erticillium dahlice Kleb.). - Cf. p. 180. 


\section{DAISY}

Crown-gall (Pseudomonas) does but slight injury.

\section{DRACANA}

Leaf-spot (Phyllosticta maculicola Hal.). - This may be recognized as small, brown, somewhat angular spots on the leaves, each spot surrounded by a rather wide yellow border. Minute pycnidia are present.

\section{FERNS}

Blight (Phyllosticta pteridis Hal.). - The tender growing tips of ferns are subject to blight, and blighted spots may also occur lower upon the leaf. The brown dead tips and leaf spots bear minute pycnidia. Blighted parts should be cut away and burned and the remaining foliage sprayed with Bordeaux mixture. The disease is strictly local, and close attention will stop its spread, even after it has considerable foothold. Numerous other fungi are recorded on various species of ferns, chiefly causing leaf-spots.

Prothallium-blight (Completoria complens Lohde). - Upon sporelings (prothallia of Aspidium and Pteris) this disease is first shown by a yellow or yellow-brown color, as seen in mass. Under a hand lens the abnormal color is seen as spots, varying from green to yellowish-brown and later to black. In later stages disintegration of the affected cells gives the prothallia a ragged appearance.

\section{GERANIUM (Pelargonium)}

Gray-mold (Botrytis sp.). - Frequently this mold appears on old blossoms, thence spreads to buds and even to leaves. Proper sanitation, destruction of all refuse, and attention to ventilation usually prevents this mold.

Bacterial leaf-spot (Pseudomonas erodii Lew.). - The spots are watery, brown when old. The affected leaves fall. 


\section{GLADIOLUS}

Hard-rot 442 (Septoria gladioli Pass.). - Leaves are affected with brown or purplish, irregularly circular spots having gray centers and bearing numerous, black pyenidia. On the corms lesions appear as water-soaked, dark spots which later become sunken and black. The diseased tissue is extremely hard. Spraying of seedlings is effective, but a simpler method is to plant the seed in soil that has not borne Gladioli, and to bring to it no infective material.

\section{HAWTHORN}

Rust (Gymnosporangium sps.). - The rust, similar to that of the apple, is often abundant.

\section{HEPATICA}

Rust (Transchelia, Ecidium). - This is perennial in the plants which should therefore be burned when the rust appears. See p. 96.

\section{HIBISCUS, ROSE-OF-SHARON}

Canker (Cytospora). - Death of twigs or of whole plants results. Diseased parts are thickly covered with wart-like, black pycnidia.

\section{HOLLYHOCK}

Rust (Puccinia malvacearum Mont.). - This rust, native to Chili, was introduced into France about 1868. It spread rapidly over all Europe, from whence it came to the United States about 1886 upon infected seed. It was rapidly disseminated throughout this country, and is now known from Maine to Louisiana, in many places rendering the plants unsightly. It is easily recognized by its yellow to brown sori, each sorus considerably raised above the surface of the leaf 
or stem as a small, wart-like protuherance. Badly rusted leaves, or even whole plants, wither and die as though blighted. In mild cases the leaves remain green and the plant may bloom.

It is recommended to sponge the diseased parts with permanganate of potash: two tablespoonfuls of saturated solution diluted with one quart of water.

Leaf-spot (Cercospora althicena Sace.). - Upon the leaves and other green parts of the hollyhock, velvet leaf, and mallow rather large, dark, angular spots are produced in abundance, each spot with a dark border and an ashen center upon which numerous, black hyphæ may be seen. Badly diseased leaves fall, and by midsummer only dead, leafless stalks may remain. Even in mild cases, by decreasing the amount of green surface, the spots both injure the appearance of the plant and lessen productiveness.

Spraying with Bordeaux mixture or ammoniacal copper carbonate at intervals of about ten days is thoroughly effective.

Leaf-spot (Phyllosticta althoina Sacc.). - This pest, long known in Europe, is recognized as large, brown, circular spots, 1-2 cm. or more in diameter, upon the leaves. The centers are brittle and usually break away irregularly.

Anthracnose (Colletotrichum malvarum (B. \& C.) South.). - Since about 1885, this disease has been noticed in destructive form in greenhouses, particularly in the propagating beds; in some cases to such serious extent as to nearly prohibit commercial culture of the hollyhock. It occurs upon any green part of the plant. On the leaves it forms brown spots and causes withering; upon young succulent petioles or stems, collapse of the parts beyond follows; if the parts be older, sunken spots varying from light yellow to black are produced.

The plants should be sprayed with Bordeaux mixture as soon as the first leaves appear and every second day thereafter.

Angular leaf-spot (Septoria) is also common. 


\section{HYDRANGEA}

Leaf-spot (Phyllosticta hydrangece E. \& E.).- Large, rusty, brown blotches occur upon the leaves, in some cases to such extent that the tops of the plants must be cut away, to the entire destruction of their decorative value.

Rust (Pucciniastrum hydrangere (B. \& C.) Arth.) is common and often serious.

Leaf-spot (C'ercospora sp.). - Small, round, or angular white spots with a very small amount of dark hyphal growth in the centers are common upon this plant. The spots are definite and are bordered by a narrow reddish purple line.

\section{IRIS}

Leaf-spot ${ }^{527}$ (Didymellina iridis (Desm.) v. H., Heterosporium). - The disease occur's only on the Cerman iris, affecting mainly the upper portion of the leaf with oval spots with water-soaked margins. Dead leaves should be removed as soon as the snow melts away.

\section{IVY (Hedera)}

Blight (Vermicularia trichella Fr.). - This blight usually begins midway between base and apex of the leaf, and is especially common upon the white portions of the variegated varieties. The diseased portions turn black, and small black acervuli appear.

\section{LAUREL, MOUNTAIN (Kalmia)}

Leaf-blight (Phomopsis lialmia Enl.). - Dead spots appear on the leaves and may involve the entire blade, later extending to the stems and even killing entire plants. Leafspot (Septoria lialmicola (Schw.) E. \& E.) is of common occurrence. 


\section{LARKSPUR}

A black leaf-spot due to bacteria has been noted in Massachusetts.

Drop (Sclerotinia). - See lettuce.

\section{LILAC}

Powdery-mildew (Microsphora alni (Wallr.) Salm.).The characteristic spots of the powdery-mildew, white and flour-like, are frequent upon the lilac. Black perithecia are abundant late in the season.

Leaf-spot (Bacteria) is of minor consequence.

\section{LILY}

Gray-mold ${ }^{443}$ (Botrytis sp.). - This exceedingly destructive mold of the lily was noted about 1885, and was first closely studied by Ward in 1888 . It makes its appearance in the spring as small, orange-colored spots upon the leaves and buds. These enlarge, and later become coated with a light brown, dusty, fuzzy mold which destroys the leaves and blossoms, often leaving only the naked stalks standing.

Sclerotia much like those described under lettuce drop appear in association with the decay in its late stages. Their subsequent history is like that of lettuce sclerotia.

Bermuda lily-disease. ${ }^{444}$ - The plants are stunted and the leaves are distorted and bear spots that are yellowish to white and usually sunken. Frequently a commercial loss of from 20 to 60 per cent follows. No parasite is present, and the actual cause of the disease is unknown. Rogueing in the field to eliminate affected bulbs is necessary.

\section{LILY-OF-THE-VALLEY}

Drop (Sclerotinia sps.). — See lettuce.

\section{MIGNONETTE}

Leaf-spot ${ }^{46.4}$ (Cercospora resedoe Fcl.). - This disease occasionally ruins the greenhouse crop. The spots are at 
first minute, pale, with brownish or yellowish borders, or they spread over the leaf as a reddish discoloration. In late stages they are uniformly brown, with dark hyphæ scattered over the central portions. The dead areas enlarge irregularly, and the leaves finally curl and die.

Bordeaux mixture and ammoniacal copper carbonate, used once a week, have proved effective remedies.

\section{MORNING-GLORY, MOON-FLOWER}

The following are common but usually not serious:

Rust (Coleosporium ipomoece (Schw.) Burr.); White-rust (Albugo ipomøec-panduranc); Leaf-spots due to various fungi.

\section{NASTURTIUM (Tropcolum)}

Blight (Pseudomonas aptatum). - In this disease the leaves are wilted and bear water-soaked spots usually about 3-5 mm. in diameter. Black-mold (Pleospora tropooli Hal., Alternaria). - The leaves which are affected turn light green, later yellow, and still later are covered with a black mold.

Damping-off (Colletotrichum). - Damping-off due to a species of Colletotrichum is common in the cutting-bed. The diseased parts bear numerous black acervuli.

White-rust (Albugo candida) occurs rarely.

\section{OLEANDER}

Knot, gall ${ }^{445}$ (Bacillus). - This disease both upon leaves and stems appears to be identical in character with that upon the olive.

\section{ORCHIDS}

Mold (Botrytis). - The presence of straw-colored spots often renders the plants unsightly and the flowers valueless. A gray mold similar to that found upon the lily appears later. All infested refuse should be burned. 
Numerous anthracnoses, leaf-spots, rusts, and other diseases also occur on orchids. Their discussion would involve many pages. See also, p. 412.

\section{PALM}

Anthracnose (Colletotrichum). - Palms often die and turn black at the tips of the leaf segments, or similar spots may appear upon other parts of the leaf. These spots near their edges have a watery appearance. When they become dry, purplish acervuli appear. Upon seedlings the disease is particularly troublesome, resulting in failure of the leaves to unfold.

The blighted parts should be cut away and burned and the remaining foliage sprayed at least once each week with Bordeaux mixture or ammoniacal copper carbonate.

Graphiola blight (Graphiola phonicis (Mong.) Poit.). Small, gray, tubercular growths, 1-2 mm. in diameter, appear scattered over the leaves. In greenhouses the disease is commonly present but not in destructive form as it is further south in the open. Numerous other leaf-spots also occur on the many varieties of palms.

PANSY. See violet.

\section{PEONY}

Mold ${ }^{448}$ (Botrytis). - This mold was first noted in 1897 in Europe. It has since been reported in Canada, Massachusetts, Rhode Island, Pennsylvania, and Maryland as causing serious loss.

Young plants are attacked almost as soon as they appear above ground, and ashen gray spots are produced upon the bud-scales, and stems. Among older plants the rot develops upon the leaves, unopened buds, and at the base of the stem. Brown mold similar to that deseribed for lettuce not infrequently develops upon the affected parts. Numerous 
greenish-black, flat sclerotia, 1-1/2/2 mm. in diameter, are formed in the stems.

Dead leaf and stem remains should be removed from the peonies before they are set in the ground. Bordeaux mixture may be used after the plants appear in the spring. Infested beds should be steamed. Drop (Sclerotinia). See lettuce.

\section{PETUNIA}

Drop (Sclerotinia). See lettuce.

\section{PHLOX}

Powdery-mildew (Erysiphe cichoracearum DC.). - This is of general distribution and injurious. Leaf-spot (Cercospora phlogina Pk.). - Brown circular spots occur on the leaves.

\section{PINK}

Rust (Puccinia arenarioe (Schm.) Schr.). - This rust was described in 1803 by Schumacher. It is quite common upon various members of the pink family, for example, chickweeds, corn cockle, Bouncing Bet, etc. The sori are large, raised blisters arranged in characteristic concentric circles.

Diseased plants should be burned.

\section{PRIMROSE}

Leaf-spot (Phyllosticta primulicola Desm.). - Large, circular, brown, dead spots are produced upon the leaves. Minute dark pycnidia may be seen. Leaf-spot (Ascochyta primulce Trail). - Well-defined oval spots, resembling those of the phyllosticta leaf-spot, are formed. These two diseases cannot be distinguished without the aid of the microscope. Leaf-spot (Ramularia primulce Thuem.). - In this disease the blotches are yellow with centers of ashen whiteness. No pycnidia are present, but instead a gray coating of mold. Anthracnose (Colletotrichum primulo Hal.). - In this blight 
the entire leaf is more often involved than in the above diseases, and definite spots are more rare. Dark acervuli are present.

Gray-mold (Botrytis sp.). - This occurs upon leaves and flowers much as upon lettuce.

Bordeaux mixture is useful with all of these primrose diseases.

\section{PRIVET}

Anthracnose ${ }^{108}$ (Glomerella cingulata, Gloosporium). Twig blight superficially resembling that of the pear is a character of this disease in its later stages, terminal parts of the twigs $2-5 \mathrm{~cm}$. long being affected. The line of separation between diseased and healthy tissue is sharp through shrinking and depression of the diseased part. In early stages depressed, oblong, diseased spots, at first very minute, are seen upon the bark. These spots enlarge, eventually girdle the twig, and cause the death of the distal part. Minute black elevated acervuli, visible to the naked eye, are scattered over the surface of the original disease spots.

Affected branches should be cut well below the diseased portion and burned. A spring spraying, before the buds swell, with any good dormant spray will still further reduce infection.

\section{ROSE 466}

Black-spot ${ }^{449}$ (Diplocarpon rosce Wolf, Actinonema). Both in and out of doors, this is a widely known and destructive rose disease. It was first described in 1824, and is now widely distributed throughout Europe and the United States. It consists of irregular circular or oval indefinitely bordered, black spots upon the upper surface of leaves that are mature or nearly so. The larger spots are a centimeter or more in diameter, and they frequently coalesce so as nearly to cover whole leaflets.

With age the spots turn gray at the centers, at which part 
the leaf dies. They also become more regular in outline than in their earlier stages. Portions of the leaflets outside of the area actually spotted often turn yellow, and the diseased leaflets fall off prematurely. Thus the beds beneath diseased plants are often strewn with fallen leaves.

All infective material should be gathered and burned, and by use of a good dormant spray both bushes and ground be

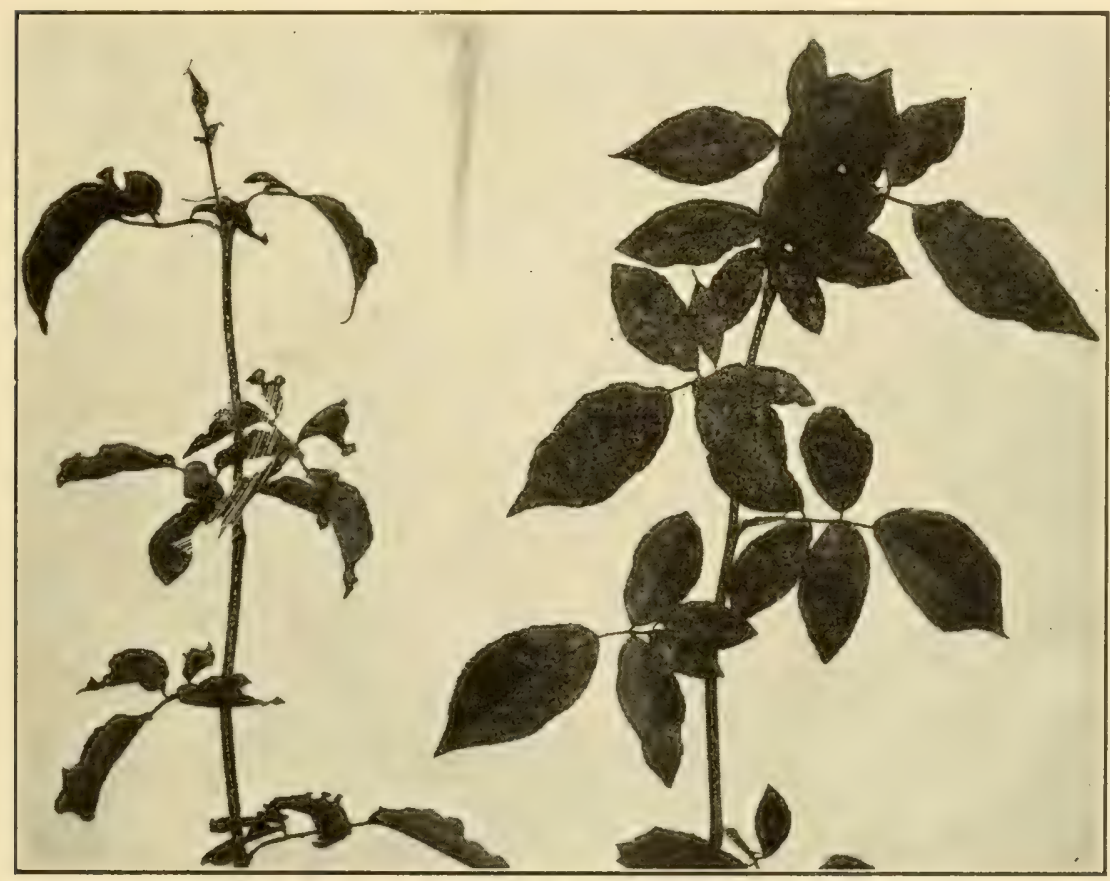

FIG. 220. - Rose mildew; diseased and healthy shoots.

well cleared of superficial spores. Ammoniacal copper carbonate used once each week is effective after the plants are in foliage. Lime-sulfur or Bordeaux mixture may be used when the residue on the foliage is not objectionable.

Powdery-mildew (Sphcerotheca pannosa (Wallr.) Lév. or S. humili (DC.) Burr, Oidium.). - This is perhaps the most wide-spread and destructive of all rose diseases both under glass and in the open, being especially destructive to the 
rambler varieties. In mild cases it occurs merely as flour-like, dusty white patches upon the leaves. But when present, it usually becomes aggressive, attacking the young leaves and tender shoots, which become dwarfed, curled, reddened, variously deformed (Fig. 220), and covered with the white powder of spores and spore stalks. The vitality of the plant is so lowered by repeated attacks and even by direct attack upon the buds that the plants become worthless.

Indoors sulfur is serviceable. The house should be closed and the sulfur boiled in a kettle for two to three hours twice weekly, or the house may be closed in the morning, the temperature raised to $24^{\circ} \mathrm{C}$. $\left(75^{\circ} \mathrm{F}\right.$.), and the air well filled with sulfur from bellows. The temperature should then be raised to $31^{\circ}-32^{\circ} \mathrm{C}$. $\left(85^{\circ}-90^{\circ} \mathrm{F}\right.$.), and allowed to cool gradually.

Either out doors or in, dusting (sulfur 90 parts, arsenate of lead 10 parts) is effective and more convenient than spraying with Bordeaux mixture or lime-sulfur.

Canker ${ }^{450}$ (Cylindrocladium scoparium Morg.). - Brown, dead cankers are formed on the stems and branches, or at the crown, and often encircle the stem for several centimeters. Considerable injury is done to roses under glass. Examine new stock carefully to exclude canker. If the disease enters the house remove all old soil and disinfect the benches with formalin. Brown-canker ${ }^{451}$ (Diaporthe umbrina Jenk., Phomopsis) also occurs on roses of many varieties.

Rust (Phragmidium subcorticum (Schr.) Wint.). - This true rust is common in Europe, and is found in many parts of the United States from the Atlantic to the Pacific; still it is not a very serious pest.

Early in the season orange-yellow sori appear upon the green parts of the plant: on the leaf as small, circular spots; on the stems and petioles often as quite large, powdery masses. Later in the season the color of the sori changes to brick red.

Affected branches should be burned promptly, and all infective material should be burned in the autumn. If 
the disease reappears, the whole plant should be dug up and burned. In beds where the disease has occurred, a dormant spray should be applied in early spring. Another rust is due to Earlea speciosa (Fr.) Arth. - Though much like the last, this is limited in its attack to the stems, rarely petioles. The sori are irregular and black. Since the causal fungus is perennial in the stems, excision and burning are to be practiced.

Anthracnose (Glœosporium rose Hal.). - This anthracnose is very similar to that of the raspberry. The diseased canes, bearing small, pale leaves, die from the tip backward for $2-3 \mathrm{dm}$., and red acervuli appear upon them after death. Often the canes become completely defoliated.

Affected plants should be sprayed with Bordeaux mixture or ammoniacal copper carbonate.

Leaf-spot (Mycosphcerella rosigena E. \& E.). - The leaves are marked with gray, irregular, indefinite blotches which bear minute black perithecia in their centers. Another leaf-spot is due to Cercospora rosøicola Pass. Circular, gray spots bordered with dark purple but without pycnidia are present.

Downy-mildew (Peronospora sparsa Berk.). - This mildew is kin to that of the grape. Its spots are indefinite, and the characteristic, downy, white to purple coating is noted upon the lower surfaces of the leaves. It is not common in America. Bronzing, its name indicating its character, occurs frequently. It is not due to parasites and does no real harm.

Crown-gall. See peach.

\section{SEDUM}

Leaf-spot (Septoria sedi West.). - Dark, circular blotches appear upon the leaves and result in such defoliation that the stems often become naked nearly to the tips of the branches. Infected parts should be burned. Anthracnose (Vermicularia telephii Karst.). - This disease usually appears first at the 
point of attachment of the leaves, and later it passes to the stem, causing soft rot and shrinking of the outer parts. After defoliation the disease spreads slowly toward the base of the stem. Infected parts should be burned.

\section{SNAPDRAGON}

Anthracnose ${ }^{452}$ (Colletotrichum antirrhini Stew.). - This disease which often ruins the crop is the most destructive of this host, both under glass and in the open. It attacks plants of any age, producing on the stem elliptical sunken spots, 5-8 mm. long, and on the leaves circular dead spots. These are at first dirty white with narrow brown margins; later acervuli appear in the center, at first brown, then black. Diseased plants show numerous, dead, hanging leaves. The stems or lateral shoots may be girdled, killing the parts beyond.

It is recommended to use only healthy plants for cuttings and to clean up and burn all diseased refuse. The cuttings should be sprayed when well rooted and repeatedly until transplanted. Excess of water should be avoided and thorough ventilation provided.

Leaf-spot ${ }^{524}$ (Phyllosticta antirrhini G. \& A.). - Circular, brown or black spots about one centimeter in diameter, usually marked by concentric ridges, appear on the leaves. Lesions on the petioles cause death of the leaf and infection of the axils. Stem lesions may be 2 or $3 \mathrm{~cm}$. long and eventually girdle the stem, resulting in death of all distal parts. Young plants die from typical damping-off. Bordeaux mixture is recommended for forms of the disease other than damping-off, which must be met by soil disinfection.

Rust ${ }^{453}$ (Puccinia antirrhini D. \& H.). - This rust has recently appeared in greenhouses in destructive form. Diseased stock should be excluded and sub-irrigation adopted if possible. 


\section{SPURGE}

Anthracnose (Gloosporium euphorbice Hal.). - The attack usually begins upon the flower cluster and passes down the stem to the leaves, which then fall away, leaving the naked, blighted branches. The disease often interferes seriously with the ornamental effect of this decorative plant.

\section{SUNFLOWER, JERUSALEM ARTICHOKE}

Rust (Puccinia helianthi Schw.). - Both wild and cultivated species of sunflowers are often badly rusted. The early sori are yellow to brown, the later black. Badiy rusted leaves die and much injury follows both to flower and seed. In the spring the cluster-cup stage is sometimes found upon the same host. Burning of infested refuse is the only remedy known.

Drop ${ }^{455}$ (Sclerotinia perplexa Law.). - The disease appears first in the root or lower stem and spreads upward to the heads. It in general character resembles lettuce drop. Leaf-spot (Septoria helianthi E. \& K.) is common but not serious.

\section{SWEET-PEA 454}

Anthracnose (Glomerella cingulata, Glocosporium) occurs as spots on stems, leaves, and pods. Seed from diseased pods should be avoided.

Powdery-mildew (Microsphora alni, Oidium). - This is not usually troublesome if proper greenhouse conditions are maintained. See rose.

Streak (Bacillus lathyri M. \& T.). - Dark streaks occur on the stem. Wilt (Fusarium). - See cowpea wilt. Drop (Sclerotinia). - See lettuce. Mosaic. - See tobacco. Rootrots are numerous, due to Nematodes, Thielavia, Corticium, and other fungi. 


\section{TULIP}

Gray-mold (Botrytis). - All parts of the host except the roots are affected. The disease was apparently imported from Europe and is now established throughout the United States.

\section{VERBENA}

Powdery-mildew (Erysiphe cichoracearum DC., Oidium). - Powdery-mildew is quite common upon verbena under glass or in the open.

The use of potassium sulphid, 1 ounce to 3 gallons, twice a week has proved effective.

\section{VINCA}

Rust (Puccinia vince (DC.) Berk.) was apparently imported from Europe and does occasional damage. Vinca leaf-spot (Sphoropsis vincee Sacc.) occasionally injures leaves and stems.

\section{VIOLET, PANSY}

Spot-disease ${ }^{456}$ (Alternaria violce G. \& D.). - This is one of the widespread and destructive violet diseases. It attacks the plant at any stage of its growth and upon any green part, but is most destructive upon the foliage. It first appears as small, definite, circular, greenish or yellowish-white spots, varying from mere dots to $1 \mathrm{~mm}$. in diameter. The light center is surrounded by a narrow ring, usually dark brown to black, but turning lighter with age. As the spot enlarges the freshly diseased tissue is usually watery and translucent, and the center changes to yellow or gray-white and may fall out. Frequently by the combined effects of several spots the whole leaf is destroyed. If the air is damp, a thin coating of rusty-colored spores may be seen in the old spots.

Damp, warm, cloudy, summer weather, unclean houses, 
weak plants, poor stock, poor beds, are predisposing conditions to disease.

To avoid the disease the houses should be kept scrupulously clean, only strong stock used, infested material picked and burned, and insects banished. Close attention must also be given to ventilation, heating, shading, and watering. The soil should be removed each season and every means used to produce strong resistant plants. Other leaf-spots are due to Cercospora viole Sace., Phyllosticta viole Desm. and Marsonina violce (Pass.) Sacc. No pycnidia are present, but the centers of the spots are darkened by the presence of hyphæ.

Anthracnose 4.46 (Colletotrichum viola-tricoloris RES.). This blight has been noted in many states. It is characterized by the appearance of dead, black-bordered spots on the leaves and petals, thus disfiguring the flower's, and affecting the production of seed, or even bringing premature death to the plant.

Thorough and frequent spraring with Bordeaux mixture is advocated.

Wilt ${ }^{447}$ (Fusarium violce Wolf). - This was noted as of economic importance in Nebraska, where it caused sudden dying of apparently healthy plants. Slightly sunken areas were evident on the stems just above the ground, and the roots were reduced to mere stumps.

Rust (Puccinia viola (Schm.) DC.). - One of the most common of pansy diseases is this true rust which affects all aërial parts of the plant. It is recognized by its sori.

Downy-mildew (Peronospora viola De Bary). - The downy-mildew is in general character like that of the grape. The spots are indefinite, and affected plants droop and die.

Anthracnose (Gloosporium viola B. \& Br.). - The anthracnose often begins at the edge of the leaf, as an irregular discoloration which extends inward, eventually blighting the whole leaf.

Root-rot (Thielavia). - Affected plants are stunted and yellow. The underground parts show numerous dark spots 


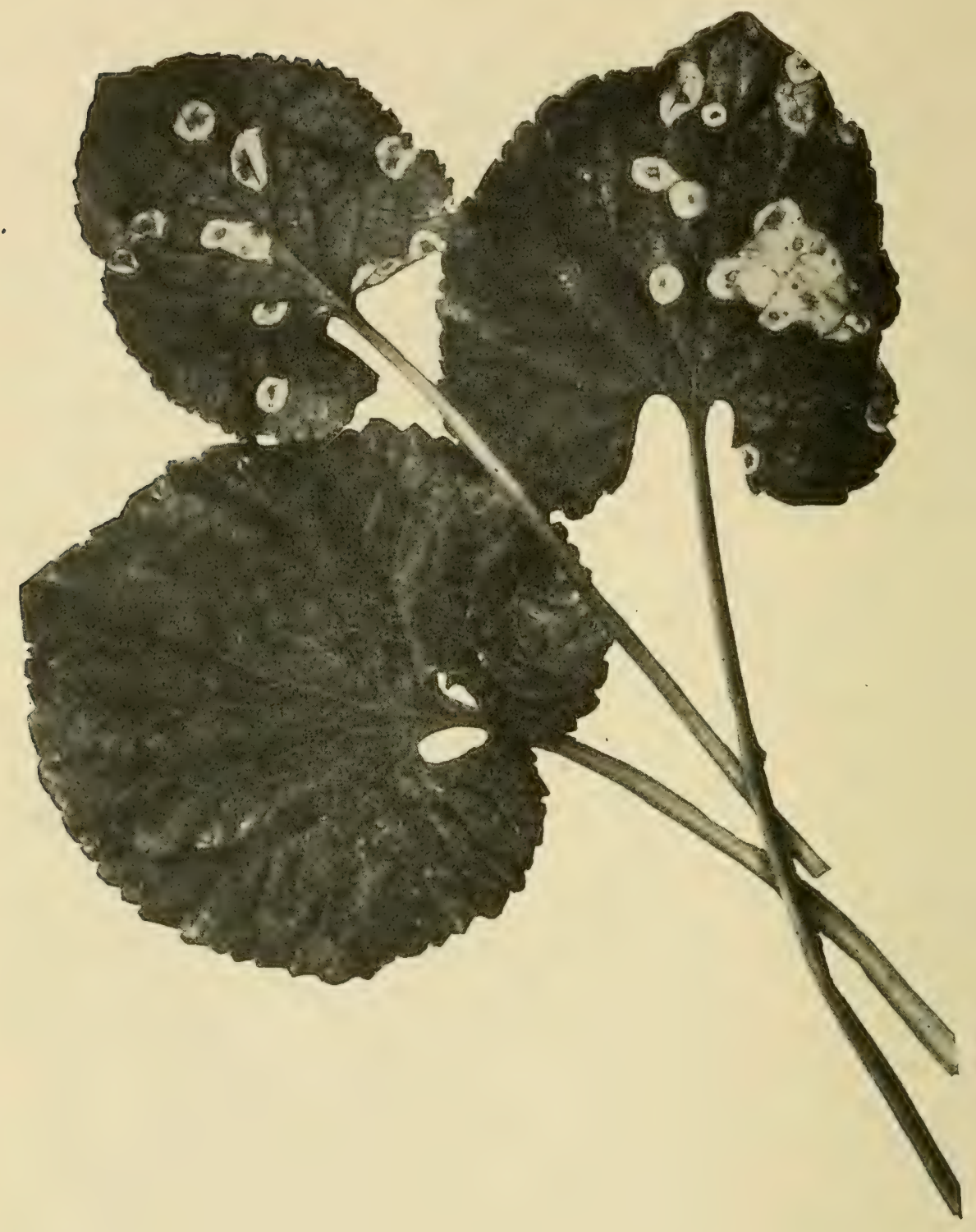

FIG. 221. - Violet leaves, healthy and affected by spot-disease. After Dorsett. 
of dead tissue which often involve the roots for considerable distances. The disease is the same as that of tobacco. Rootrot (Corticium), see p. 21.

Mold (Zygodesmus albidus E. \& H.). - This mold forms a white, flour-like coat over the leaf.

\section{VIRGINIA CREEPER (Ampelopsis)}

Leaf-spot (Guignardia bidwellii, Phyllosticta). - The spots occurring upon the leaves and shoots are identical in appearance with those upon the grape, and the same treatment is recommended.

Powdery-mildew. See grape.

Stem-rot (Cladosporium herbarum Lk.). - Large branches or even the entire plant may be killed.

\section{WATER-LILY}

Leaf-spot (Cercospora). - Circular spots, at first pale green, later yellow, and finally brown and dead, are produced upon the leaves. The dead tissue may break away, leaving irregular holes.

Soda-Bordeaux mixture is recommended, since it is effective and does not spot the leaves. It is beneficial also in removing undesired algal growth. Another leaf-spot is due to Helicosporium nymphøarum Rand. - Dark spots often red-bordered occur on the leaves and may enlarge to involve the whole leaf. 


\section{FUNGICIDES *}

Bordeaux mixture. ${ }^{494,495,497,498,517}$ - The 4-4-50 formula (4 pounds of copper sulfate crystals and 4 pounds of stonelime to 50 gallons of water) is one in common use.

According to the common formulas several times as much lime is used as is necessary to precipitate the copper. A mixture used abroad, known as the Woburn mixture, calls for a solution of copper sulfate with lime water and subsequent dilution as contrasted with milk-of-lime used in the ordinary Bordeaux mixture. According to Pickering ordinary Bordeaux mixture and the Woburn mixture, containing only one-sixth as much copper, seem to be equivalent in fungicidal action.

To make large quantities of Bordeaux mixture, or small amounts repeatedly, it is desirable to prepare separate concentrated stock solutions of copper sulfate and of lime. These are made up at the rate of approximately one pound of each to the gallon. In preparing a stock solution of copper sulfate, a weighed amount of the commercial crystals, "bluestone," is placed in a sack and suspended in water in a barrel or other wooden vessel. The volume of the water should equal in gallons the weight of the copper sulfate in pounds. The solution, as formed, will flow to the bottom, leaving comparatively fresh water in contact with the remaining crystals. Stirring partially defeats the purpose of this method by increasing the concentration of copper sulfate in the liquid in contact with the undissolved part. If the copper sulfate is placed in the bottom of the barrel, it will dissolve but slowly even with frequent stirring. When dissolved, the solution should be made uniform by stirring. In preparing the stock solution of lime (the term in com* Prepared by W. A. Ruth. 
mon use in this connection for a suspension of calcium hydroxid) a definite quantity of fresh stone-lime is placed in a trough, slaked, and made up to a volume corresponding in gallons to the weight of the lime in pounds. In slaking the lime a small quantity of water is used to start the reaction, and just enough water is added, as the lime slakes, to prevent crumbling. The lime and water are stirred from the time the lime starts to slake until the reaction appears to be complete.

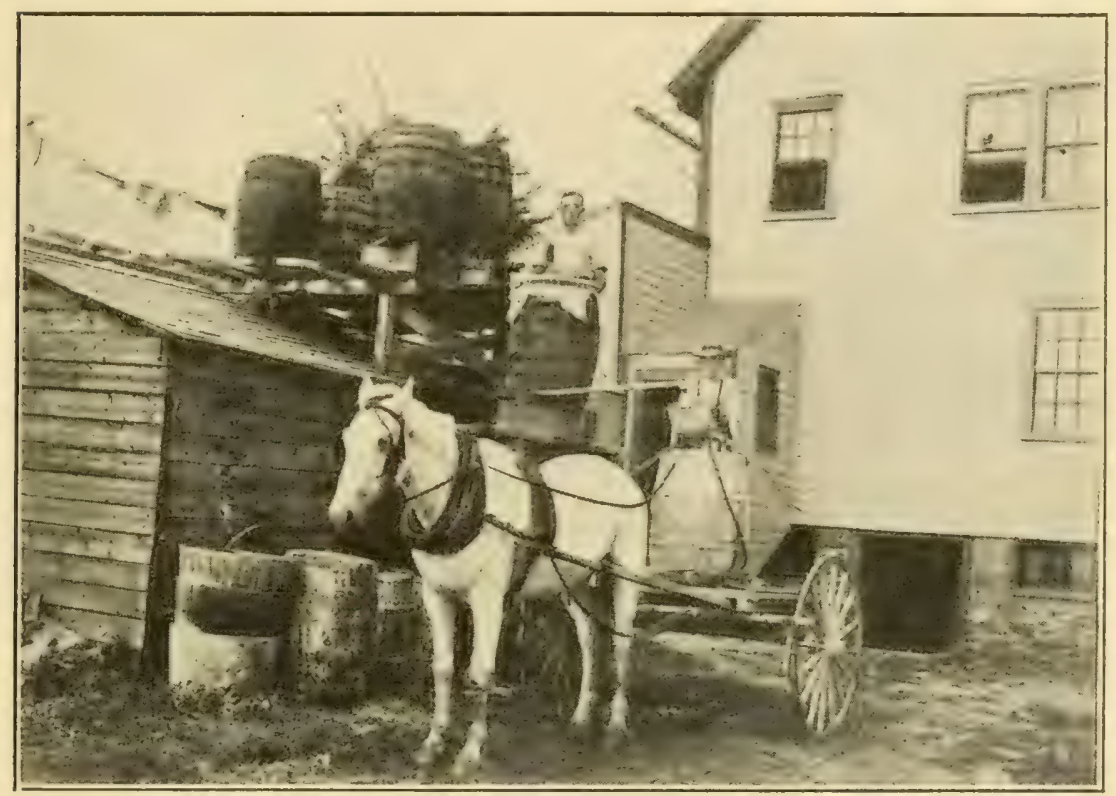

Fig. 222. - A convenient arrangement for mixing Bordeaux mixture. After Vermont Agr. Exp. Sta.

Instead of diluting to the final volume at this point, it is somewhat desirable to add just enough water to prevent drying out and to allow the mixture to cool before the further addition of water. This procedure permits further slaking, which results in a noticeably creamier stock solution, with fewer particles of unslaked lime to clog the nozzles.

The common method in use in making Bordeaux mixture in the field has been to dilute the required quantities of copper sulfate and lime separately to half the final volume 
required and to pour them together into a separate container, usually the tank of the sprayer. The colloidal suspension obtained by this method of mixing settles very slowly and can be applied with the maximum uniformity. To make 200 gallons, the content of the usual power sprayer, by this method, an elevated platform, or a series of elevated platforms, is required. The diluted lime and copper sulfate are run simultaneously from 100 -gallon wooden containers standing on the platform into the sprayer, or into an elevated 200-gallon tank, where the resulting Bordeaux mixture is held in readiness to supply the power sprayer while the smaller containers are being refilled.

The above method is open to improvement because of the large amount of apparatus and labor involved.

Hawkins claims "a Bordeaux mixture in which the suspension of the copper compound settles out slowly may be prepared by adding the concentrated calcium hydroxid to the diluted copper sulfate solution or vice versa, provided the mixture is sufficiently agitated." He states that "the agitation necessary for preparing Bordeaux mixture with a low rate of subsidence by this method could hardly be obtained in practice except by means of a power outfit provided with a good agitator." This method can be used to advantage with the tank-filler, a jet pump, with which any power sprayer can be equipped, which permits the rapid filling of the spray tank by means of the spray pump. The construction of a platform and the expense of pumping water into the elevated containers are thereby obviated. Sixteen gallons of stock copper sulfate or lime is first diluted in the spray tank to within sixteen gallons of the final volume, the stock solution of the other component is poured in, and the mixture is thoroughly agitated. A method very similar to this has proved satisfactory in the field and is in common use in Illinois.

Wooden containers should always be used for the copper sulfate solutions, and the lime or Bordeaux mixture should always be strained before it enters the tank. 
Lime-sulfur. ${ }^{499}$ - This fungicide (the material is also used in the control of San Josê scale) is prepared by boiling. in water, lime and sulfur in the proportion of approximately two parts of sulfur to one of lime. The products in the resulting solution are calcium thiosulfate $\left(\mathrm{C}_{\mathrm{a}} \mathrm{S}_{2} \mathrm{O}_{3}\right)$, calcium tetrasulfid $\left(\mathrm{C}_{2} \mathrm{~S}_{4}\right)$, and calcium pentasulfid $\left(\mathrm{C}_{2} \mathrm{~S}_{5}\right)$. The material may be made by the orchardist or bought from manufacturers. The commercial product is more concentrated than that made by the formulas usually recommended for home use, and contains a higher proportion of polysulfid sulfur (that is, sulfur in the form of $\mathrm{C}_{a} \mathrm{~S}_{4}$ and $\mathrm{C}_{\mathrm{a}} \mathrm{S}_{5}$ ).

The combination of constituents ${ }^{499}$ that appears best to meet the largest number of desirable conditions is the following, stated in round numbers:

36 pounds of lime (pure lime, $\mathrm{C}_{\mathrm{a}} \mathrm{O}$, used as a basis).

80 pounds of high grade, finely divided sulfur.

50 gallons of water.

When lime containing impurities is used, more than 36 pounds must be taken in order to obtain 36 pounds of pure lime.

Use 38 pounds of lime containing 5 per cent of impurities (95 per cent pure).

Use 40 pounds of lime containing 10 per cent impurities (90 per cent pure).

No lime should be used which contains more than 10 per cent of impurities. If the lime contains impurities (oxid of magnesium, iron, aluminum, etc., and carbonates of magnesium, calcium, etc.), these do not go into solution but remain as sediment, together with any undissolved sulfur not acted upon because of insufficiency of pure lime, due to impurities in the lime used. The amount of sediment thus formed can be utilized as a measure of the amount of impurities existing in the lime.

The level of the mixture during boiling should be kept near the 50-gallon mark - not being allowed to drop more than an 
inch below - this regulation is accomplished by adding water from time to time in the required amounts. It is preferable to add water in small amounts at frequent intervals rather than larger amounts less often, since the boiling is less interrupted. When the boiling is completed, the level of the liquid should be made up to the 50-gallon mark, if not already there. It will be found to have a density of $24^{\circ}$ to $25^{\circ}$ Baumé when cooled to about $16^{\circ} \mathrm{C}$. $\left(60^{\circ} \mathrm{F}\right.$.).

One gallon of this solution may be diluted with 25 gallons of water for summer use as a fungicide. Commercial solutions, which usually test about $33^{\circ}$ Baumé, may be diluted with 40 parts of water. The degree of dilution has relatively slight effect, however, upon the fungicidal properties of the solution, in comparison with the effect of thoroughness of application, and the amount of dilution may vary within wide limits.

Another method for making lime-sulfur consists in the use of live steam, furnished by a boiler, and led into wooden barrels or tubs, in which the mixture is boiled (Fig. 223). Large tubs provided with mechanical agitators are sometimes used. Less water is needed than is called for by the formula given above, because of the condensation of the steam used in heating.

Self-boiled lime-sulfur wash. - The self-boiled limesulfur wash is a combination of lime and sulfur boiled with only the heat of the slaking lime, and is primarily intended for summer spraying of peaches. Peach foliage is so susceptible to spray injury that ordinary Bordeaux mixture cannot be used as a summer spray; neither can the sulfur washes which contain any considerable quantity of sulfids in solution. The self-boiled lime-sulfur wash, however, when prepared as a mechanical mixture of lime and sulfur with only a small percentage of the sulfur in solution, is not injurious to peach foliage and has proved to be a good fungicide.

The mixture that appears to be the most satisfactory is composed of 


\section{Fungicides}

Lime....................... 8 pounds

Sulfur...................... 8 pounds

Water........................... 50 gallons

This can best be prepared in rather large quantities 16 pounds, or even 32 pounds at a time - so as to get enough heat to produce a violent boiling for a few minutes. Place the

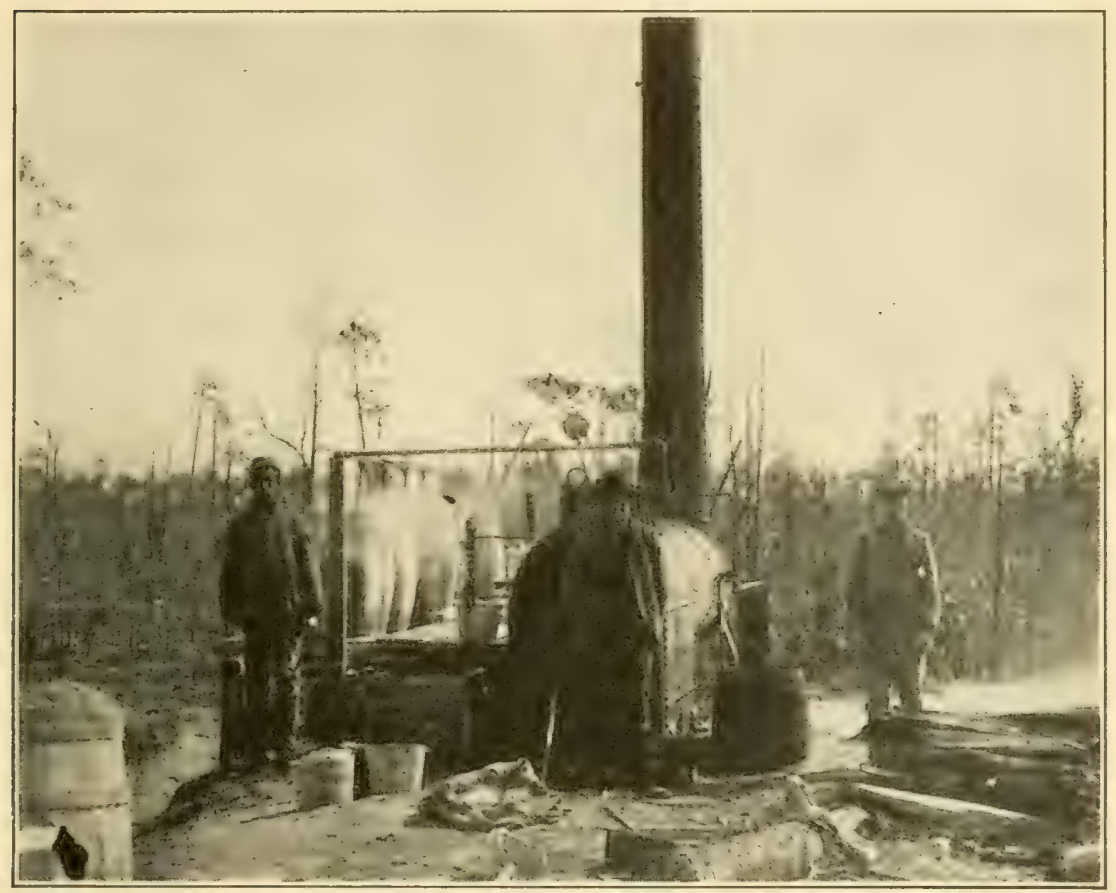

FIG. 223, - Making lime-sulfur wash. After Sherman.

lime in a barrel and pour on enough water (about 3 gallons to 16 pounds) to start it slaking and to keep the sulfur off the bottom of the barrel. Then add the sulfur, which should first be worked through a sieve to break up the lumps, and finally enough water to slake the lime into a paste. Considerable stirring is necessary to prevent caking on the bottom. After the violent boiling which accompanies the slaking of the lime is over, the mixture should be diluted ready for use, or at least enough cold water added to stop the cooking; 
5 to 15 minutes, according to whether the lime is quick-acting or sluggish, are required for the process. At the end of 30 or 40 minutes, if the hot mass is permitted to stand undiluted as a thick paste, a liquid is produced that is dangerous to peach foliage and in some cases even to apple foliage.

The mixture should be strained through a sieve of 20 meshes to the inch in order to remove the coarse particles of lime, but all the sulfur should be worked through the strainer.

Hot water may be used to good advantage in preparing the mixture with sluggish lime, but with quick-acting lime hot water is not best. The mixture may be kept for a week or more without deterioration, but it should be thoroughly stirred before using.

In applying the self-boiled lime-sulfur wash the spraying outfit should be equipped with a good agitator. The agitator of the ordinary barrel sprayer is not usually adequate.

Sulfur-dust. ${ }^{501,502,503,505,512}$ - Very favorable reports have appeared recently of the results secured by the use of sulfur dust as a fungicide for apple scab in New York. Results obtained by experiments carried on further south have not been favorable to its use for this purpose. Thus Giddings states that as the result of four years' trial it can not be recommended for use on apples where scab or sooty blotch is severe, or for the treatment of bitter-rot, black-rot, or blotch. Brock finds in Illinois that spraying is much superior to dusting for the control of fungi, but believes that in favored localities, where fungi are comparatively easy to control, the sulfur dust has its uses.

Reddick and Crosby recommend, for the average Western New York conditions, a mixture containing 85 per cent of exceedingly finely ground sulfur (especially ground, "superfine") and 15 per cent of dry arsenate of lead (the "fluffy" sort is used for this purpose). The exact quantity of material to be used per tree will be determined by the wind, the size and the shape of the trees, and also by the thorough- 
ness of distribution effected. From 1.25 to 2.5 pounds are applied per tree in each application. "In localities where apple scab is less abundant than in the lake counties, as seems to be the case in most of the Hudson River section, the quantity of sulfur applied per tree may be reduced. It would be well, however, to regard these as minimum amounts until experience has shown that they can be reduced with safety."

Dusting appears to be slightly more expensive than spraying. The cost of materials is higher, but this factor in the total cost is partially overcome by the lower cost of application. The chief adrantage in dusting, however, lies in the extreme rapidity with which the dust can be applied. This appears to permit the application of the fungicide at periods when the weather conditions favor infection with apple scab, and to result in comparative flexibility in the spray schedule.

Ammoniacal solution of copper carbonate. - This solution contains no sediment, and on drying leaves no unsightly marks. It may therefore be used when the spotting that the Bordeaux mixture causes precludes the use of that fungicide. The mixture consists of a solution made by dissolving copper carbonate in ammonia-water in the following proportions:

Copper carbonate.................... 6 ounces Ammonia, about.................... 3 pints Water........................ 50 gallons

Weigh out the proper amount of copper carbonate. Set a very small portion of this aside, and dissolve the remainder of it in diluted ammonia, using only enough ammonia to dissolve it. Then add the portion of copper carlonate which was reserved. This will insure the use of no more ammonia than is necessary. It is better to have a little too much of the carbonate in the solution than to have too much ammonia. The strong solution made in this way can be diluted with the proper amount of water. The copper carbonate may be purchased directly from the drug-store, or it may be prepared at home. 
To make copper carbonate proceed as follows: Dissolve 10 pounds of copper sulfate in 10 gallons of water. Also dissolve 12 pounds of carbonate of soda in the same amount of water. Allow these two solutions to cool, then mix them slowly together, stirring in the meantime. Allow the mixture to settle about 12 hours, pour off the liquid, and add water equal in amount to the liquid poured off. Stir thoroughly and allow it to settle as before. Repeat this operation again, then drain off all the liquid possible, and dry the blue powder which remains. This powder is the copper carbonate.

\section{Burgundy mixture.}

Copper sulfate.

2 pounds

Sodium carbonate (sal soda)

3 pounds Water. 100 gallons

Each chemical should be dissolved separately in half the water, then mixed as in making Bordeaux mixture. This mixture may be used, as may ammoniacal copper carbonate, when it is advisable to avoid the spotting of fruit which would result from use of the Bordeaux mixture.

Copper sulfate solution, 1-17. - A solution consisting merely of copper sulfate and water to kill spores on the bark and supports may be used before the leaves appear.

Dissolve the copper sulfate as in preparing the Bordeaux mixture, dilute it to the required strength, and spray upon the trees. The addition of a little lime, one half pound to 50 gallons of mixture, enables the operator to see exactly what portions of the tree have been sprayed.

This mixture must not be used after the leaves appear.

\section{Potassium sulfid solution.}

Potassium sulfid (liver of sulfur) . . . . . . . . . 1 ounce Water.

This solution should be freshly prepared. It is used as a substitute for the Bordeaux mixture, to avoid spotting, in 
the same way that the ammoniacal solution of copper carbonate is used. Potassium sulfid is also especially effieient as a protection against the powdery-mildews.

Formalin. - Formalin is a very powerful germicide which came into wide use about 1889. Its interest to the farmer lies chiefly in its power to prevent the potato scab, onion smut, and the various smuts of eereals. Full directions for its use are given under special crops.

This substance appears on the market under two names: "Formalin" and "37 per cent formaldehyde." These substances are absolutely identical, and since the formaldehyde solution is cheaper, owing to the fact that the word "Formalin" is protected by patent, the customer will of course do well to purchase the 37 per cent solution.

\section{Corrosive sublimate.}

Corrosive sublimate................ 1 part Hydrochloric acid.................. 2 parts Water. 1000 parts

This is employed chiefly as a seed disinfectant particularly for black-rot of cabbage. It is intensely poisonous and should be so regarded.

Flowers of sulfur. - This substance is chiefly employed as a specific for the powdery-mildews. See grape, p. 122.

Proprietary fungicides. ${ }^{507}$ - There are several proprietary fungicides on the market. Of five tested on apples in 1916, at the Illinois Experiment Station, four produced serious foliage injury and more or less serious injury to fruit. There are several commercial Bordeaux pastes on the market. Wallace has shown that none which he tested remains in suspension as well as fresh home-made Bordeaux mixture (some are very poor in this respect) and that they are very expensive if diluted to contain a copper content equal to that of 4-4-50 Bordeaux mixture.

Combined fungicide and insecticide. - When an insecticide and a fungicide are to be used at the same time, it is 
usually possible to combine the two so that only one application is necessary. The stomach poison which is commonly used for spraying tree fruits is lead-arsenate. It comes in two forms, the powder and the paste. The latter contains 50 per cent of water. The powder should be the fluffy, finely divided kind. Either form may be used with Bordeaux mixture or boiled or self-boiled lime-sulfur. The powder is used at the rate of 1 pound to 50 gallons of spray, the paste at the rate of 2 pounds to 50 gallons.

Paris green can not be used with lime-sulfur, at least in spraying tree fruits, because of the resulting foliage and fruit injury. When used with Bordeaux mixture for spraying other plants it may be made up at the rate of 5 ounces to each 50 gallons of spray.

Calcium arsenate seems to be a promising stomach poison for use with Bordeaux mixture or lime-sulfur.

Nicotine preparations for the control of plant lice can be used with lime-sulfur, or with lime-sulfur and lead arsenate. There have been reports indicating that it should not be used with Bordeaux mixture.

Bordeaux injury. ${ }^{513,} 517,518$ - Many plants sprayed with Bordeaux mixture assume a deeper color and are more vigorous and live longer than unsprayed plants, even in the absence of fungous attacks. The potato is a notable example. Other plants are injured to a greater or less extent. The peach, plum, sweet cherry, and apricot are so severely affected by Bordeaux mixture that this fungicide is not used in spraying them.

Ever since the first trials of Bordeaux mixture upon the apple, some injury has been noted upon both leaves and fruit, due to the mixture itself. The amount of injury differs with different varieties and with other conditions. Water, deposited as rain or dew on the surface to which Bordeaux mixture has been applied, is a necessary contributing cause. As the season advances the foliage becomes more susceptible. On the other hand, the fruit is most susceptible early in the season. The most damage to the fruit occurs from the spray 
applied just after the petals have fallen, and even the most susceptible varieties become almost completely immune within a period of six or ten weeks after this stage.

On the fruit, injury is manifested by the formation of small black specks or the surface is russeted, sometimes very severely, and the fruit may be split or otherwise distorted. Injury to the foliage may first appear a few days after spraying or may be delayed for several weeks. Brown, dead spots are frequently caused, which may be followed by the yellowing and falling of the leaf. Yellowing may occur, however, when no brown spotting is observed.

Before the discovery of the fungicidal properties of limesulfur and its efficiency as an early summer spray, various methods were suggested for the mitigation of Bordeaux injury. At present, lime-sulfur has very largely replaced Bordeaux mixture for use in the early summer.

There are, however, circumstances under which Bordeaux mixture is still used at this season. It is generally conceded that lime-sulfur, applied with sufficient frequency, gives as good control of apple-scab as Bordeaux mixture, but that it is less adhesive and must be applied more frequently. Since the period when the trees are in blossom is sometimes prolonged by adverse weather conditions, Bordeaux mixture is still consistently used by some fruit growers for the prebloom spray, on varieties locally subject to severe injury from scab. Bordeaux mixture may be used for the early blotch sprays on varieties not subject to Bordeaux injury, for all varieties in the control of bitter-rot and blotch after the period of immunity to serious Bordeaux injury has been attained, and of course for the entire program for varieties immune to this form of injury.

Hedrick ${ }^{513}$ has published an extensive list of apples classified as to their immunity or susceptibility to Bordeaux injury.

Lime-sulfur injury. ${ }^{514-515}$ - Lime-sulfur injures many plants very seriously. Slight injury to the leaves of apples is of common occurrence. It is not usually of great consequence 
or of a lasting nature. The injury consists of irregular brown spotting, especially where the spray accumulates immediately after its application. If, however, the leaves have been injured by apple-scab, previous to the application of the spray, the damage done to the foliage is very serious. There is no marked degree of varietal susceptibility with apples. The injury occurs soon after the spray has been applied, not, as in the case of Bordeaux injury, at a period which may be long after its application. The foliage is least susceptible to injury soon after it has unfolded. Talbert states that the dormant spray consisting of commercial lime-sulfur, testing $33^{\circ}$ Baumé, may be applied to apple trees diluted 1 to 7 or 1 to 8 after growth starts and until the trees begin to bloom, without material injury to the leaves or flower buds. This is a much higher concentration than is usually used when the trees are in foliage.

Lime-sulfur injury to the fruit occurs occasionally, as the result of drenching. It is generally conceded that injury to the fruit occurs if lime-sulfur is used in hot weather, after the fruit has developed to approximately the size at which it becomes relatively immune to Bordeaux injury. From this stage onward, Bordeaux mixture is again used, regardless of the foliage injury produced. Lime-sulfur injury may, however, result from the application made just after the petals fall or those just following.

\section{Spraying Apparatus}

Whether for spraying a small garden or a large commercial orchard proper apparatus is needed.

The chief types of pumps are briefly mentioned below.

Bucket pumps. - These pumps are suited for use in the garden; to spray the bushes or a few small fruit trees in the yard. The fact that they may be used in any ordinary bucket or pail gives them an advantage over some of the other outfits. By the attachment of a foot rest which ex- 
tends outside the pail to the ground, the pump can be held firmly.

Compressed air sprayer. - After the tank is partly filled with the spray mixture and closed, air is pumped in, thus pressure is exerted upon the liquid, which is

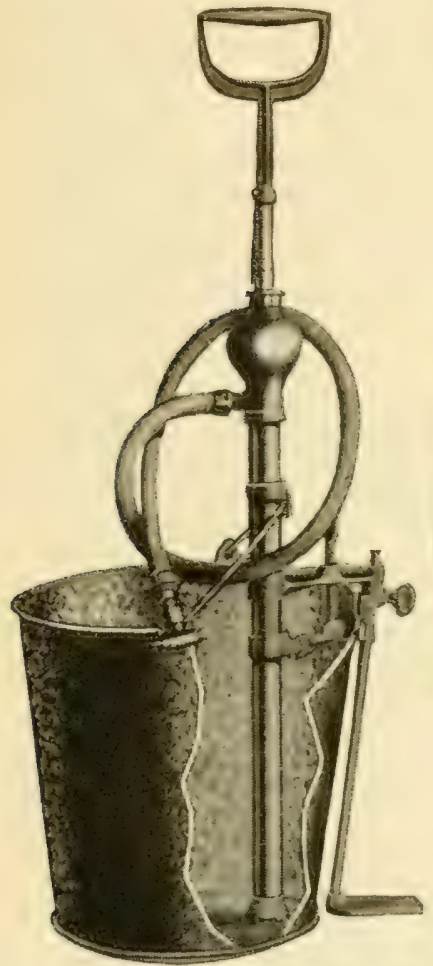

Fig. 224. 一 Bucket pump showing hose, nozzle, and bucket attachment. After Gould Mfg. Co.

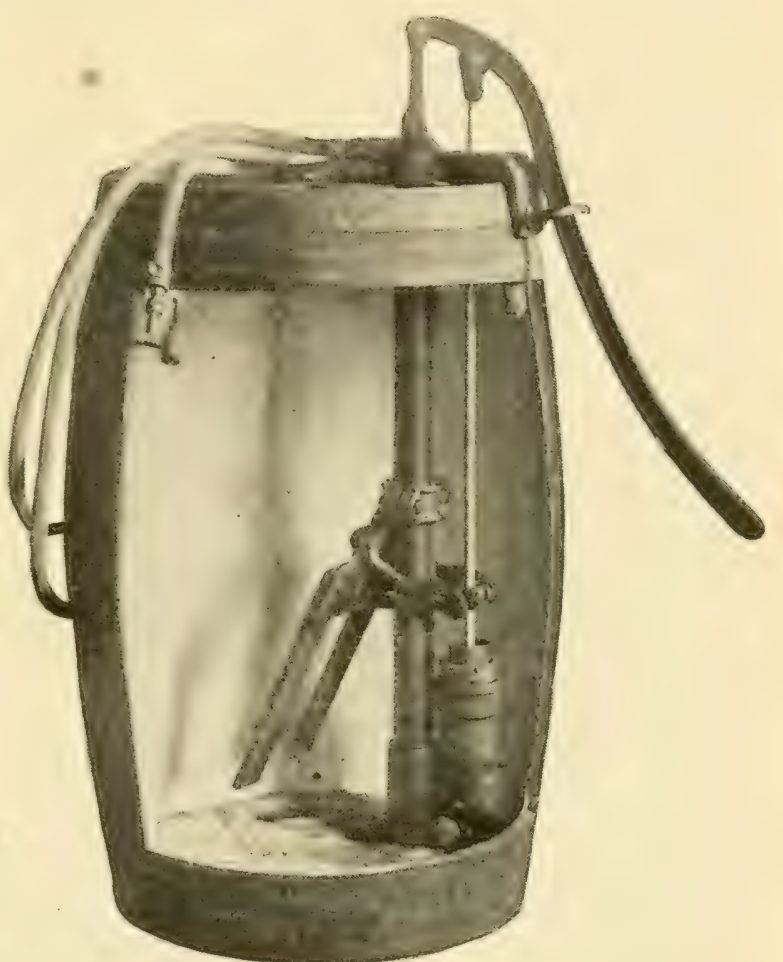

FI(: 225. -.- Barrel pump showing agitator. After Gould Mfg. Co.

forced out in the form of a fine spray when the nozzle is opened.

This type of sprayer is satisfactory in some instances, and is adapted to about the same fields as the bucket pump. It is not well alapted for spraying large areas, since the sprayers are inconvenient to carry, are slow and heavy. 
Knapsack sprayers. - These consist of 3 to 5-gallon tanks, with straps so attached that the outfit can be carried upon the back in the manner of a knapsack. The handle is so adjusted that it is operated in front of the carrier. These pumps are best adapted to spraying crops which grow breast high, as grapes. They may also be used in spraying small trees. For general garden use,

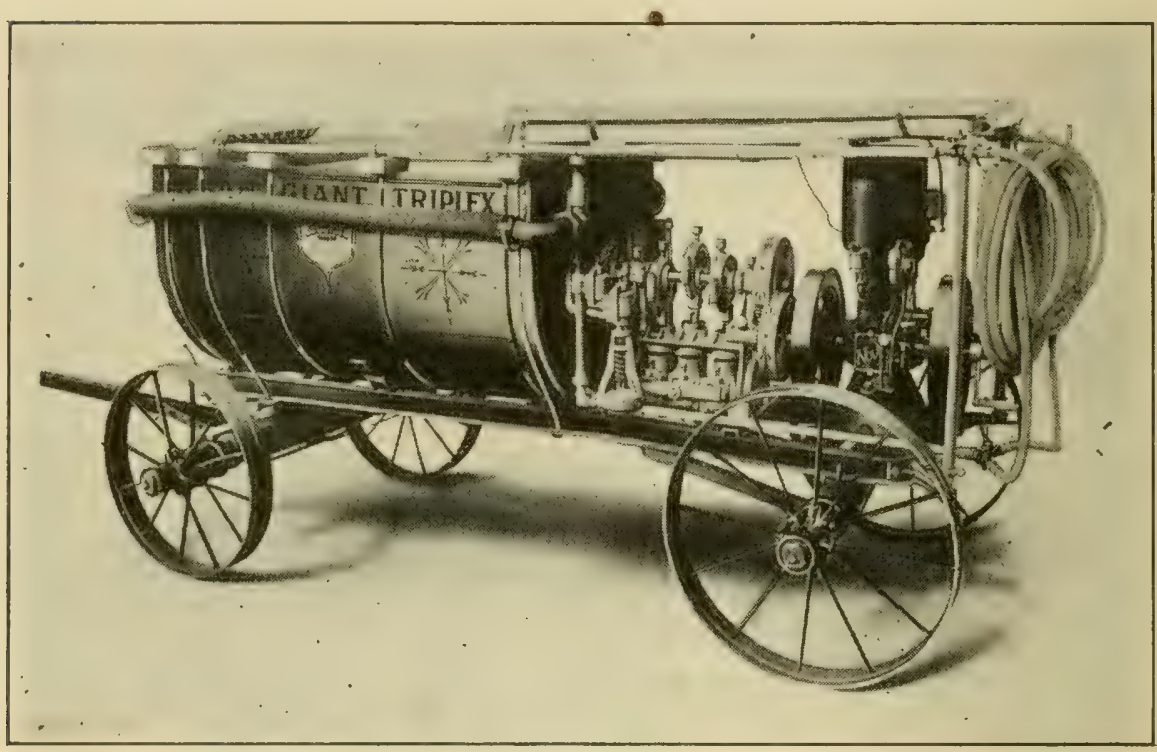

Fig. 226. - Modern power sprayer, equipped with high-pressure, slow-speed pump, with large bearings, ball valves, modern pressure regulator, etc. Such a machine is constructed to turn in a small space. A tower can be set on the tank for spraying tall trees with extension rods.

or small areas, a half acre to an acre, they are to be recommended.

Barrel pump. - For home orchard work the barrel sprayer is of most importance. The pump is adjusted to a barrel, at either the side or end. It should be provided with a good agitator to keep the spraying mixture stirred while in use.

Field sprayers. - This sort of sprayer is used in spray- 


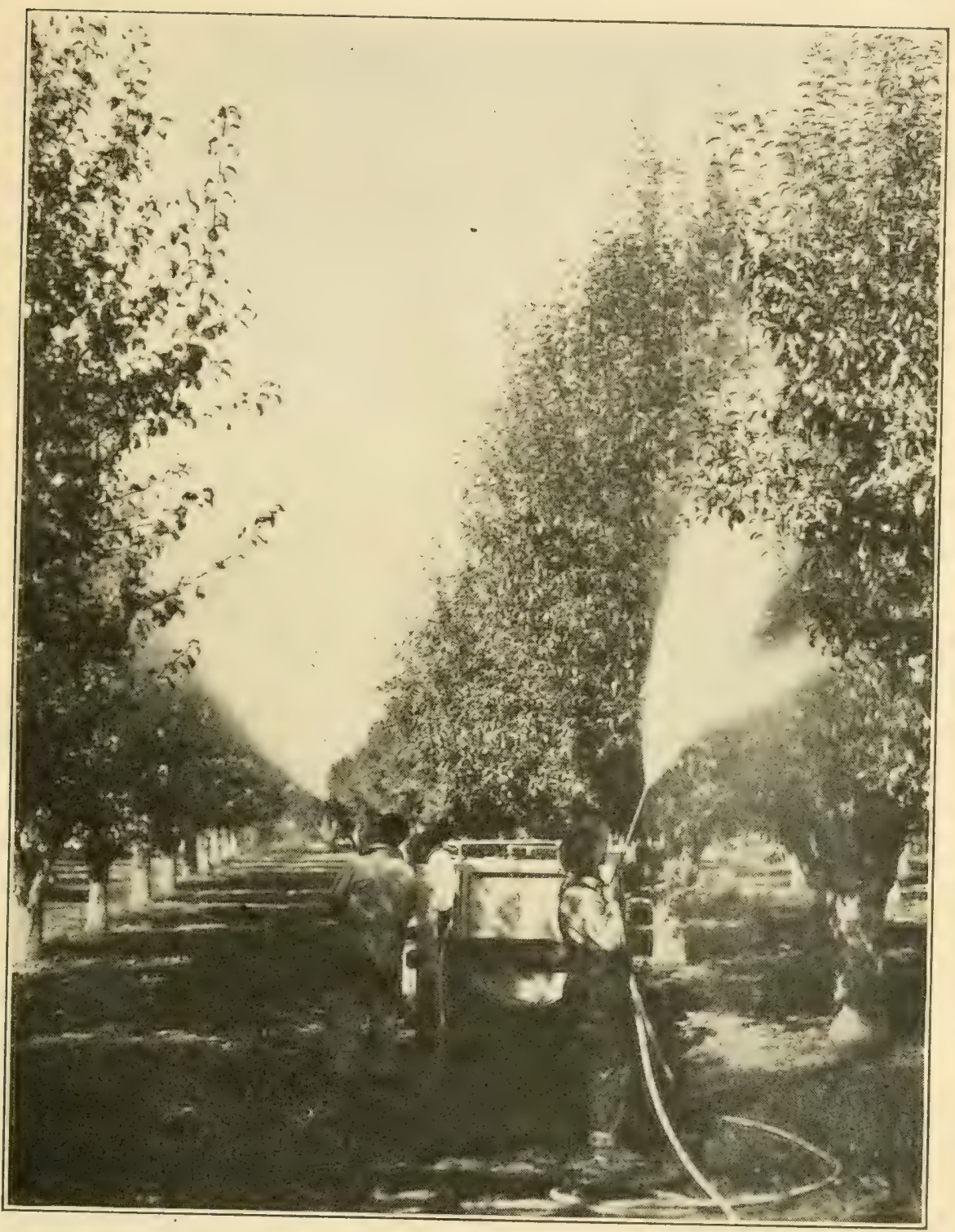

FIG. 227. - The power sprayer in use for spraying orchard trees. 


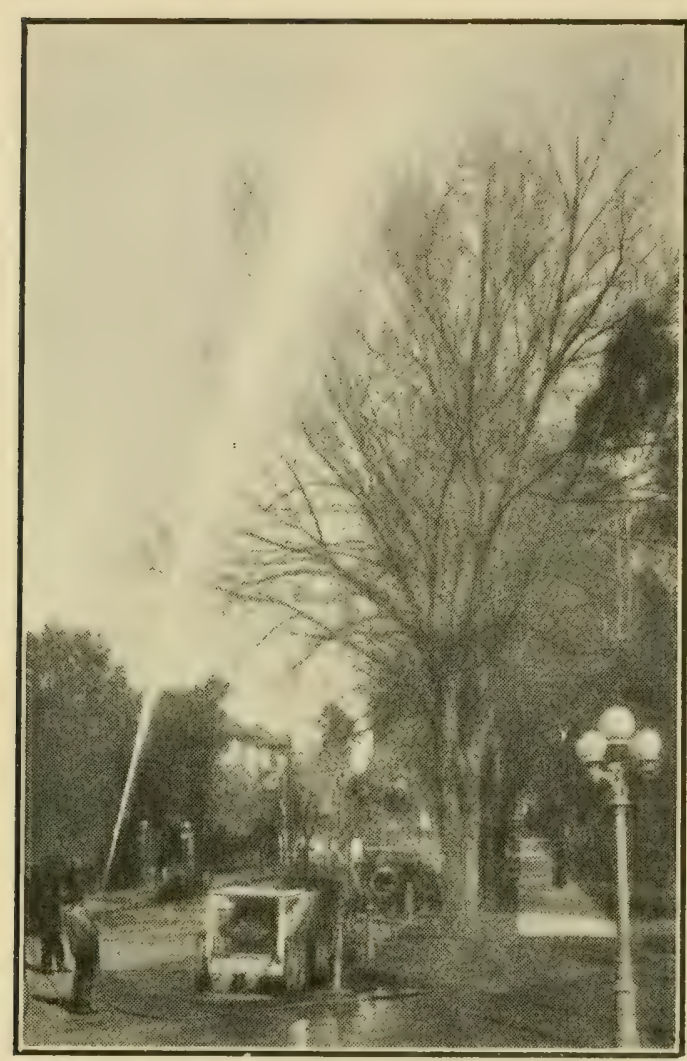

FIG. 228. - Power sprayer used in shade trees.

Fig. 227. Smaller machines differ essentially only in capacity.

The adaptation of such outfits to various purposes is shown in Figs. 228, 229.

The Spray Gun. A recent development in power spraying is the spray gun. By its use one man can ing low plants, such as strawberries, potatoes, tomatoes, cabbage, etc. Several nozzles are attached and several rows can be treated at one time. Where a number of acres of truck crops are grown, this sprayer is of great advantage.

\section{Power sprayers. -} For operating commercial orchards, power sprayers are a necessity, and are almost necessary for large home orchards, consisting, for example, of 50 or 60 large apple trees. A modern power sprayer for use in large orchards is illustrated in Fig. 226, a still larger one in

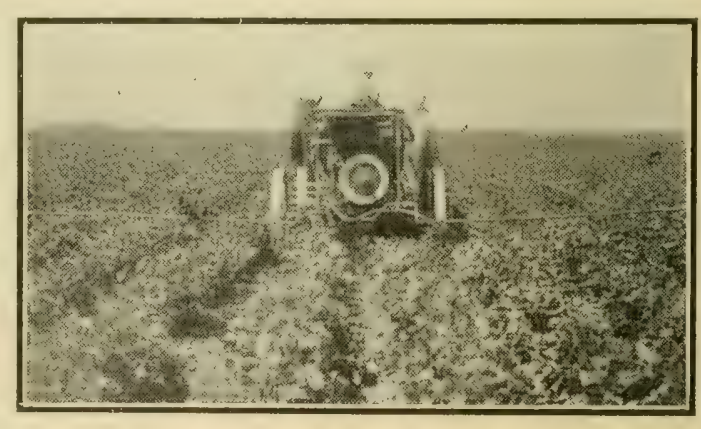

FIG. 229. - Power sprayer adapted to spraying beans. 


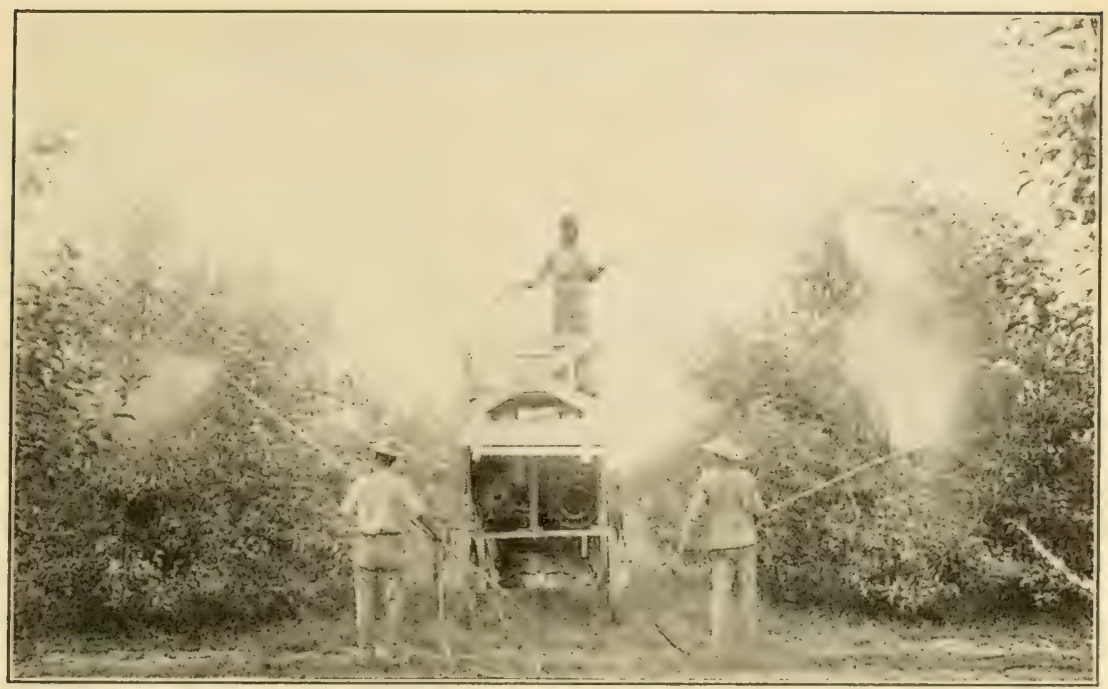

FIG. 230. - The nozzles are turned st an angle to the rod so that the spray may be directed upward or downward. After Faurot.

rapidly spray even the tallest fruit tree, a special device enabling the operator to throw the spray to different distances. Spray guns are being used by many commercial growers.

Conveyors. - To economize still further in time and labor, conveyors are used in many commercial orchards. These are 400-gallon tanks equipped with low-pressure, high-speed pumps, and gasoline engines. The conveyor carries the spray from the mixing plant to the sprayer. Two hundred gallons of spraying material can be transferred from the tank of the conveyor to that of the sprayer in less than two minutes. In this way the power sprayer is kept

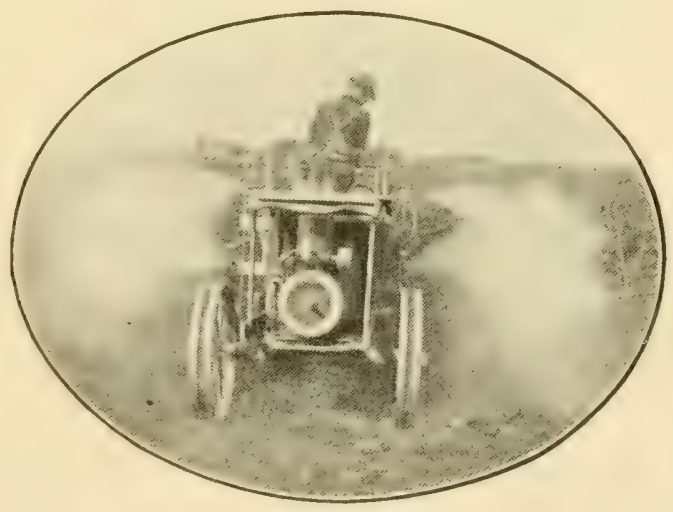

FIG. 231. - Spraying grapes. 
running almost continuously, thus sometimes doubling its output.

The use of extension rods and the tower in spraying is shown in Fig. 230.

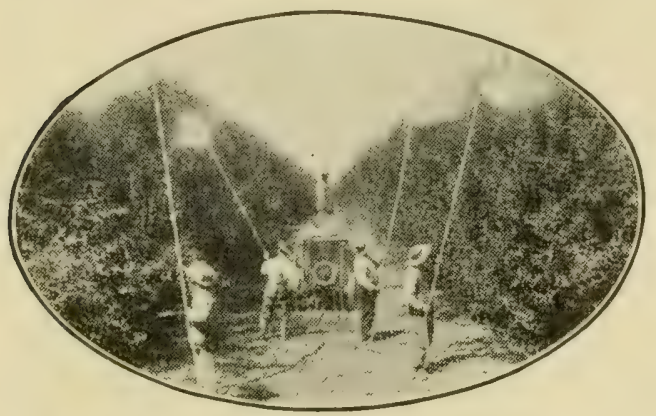

Fig. 232. - Spraying apparatus.

corner), and the eddy-chamber type. The last is the best type of nozzle for spraying, and many forms of it are on the market. The eddychamber angle nozzle (lower righthand corner) is a comparatively recent development.

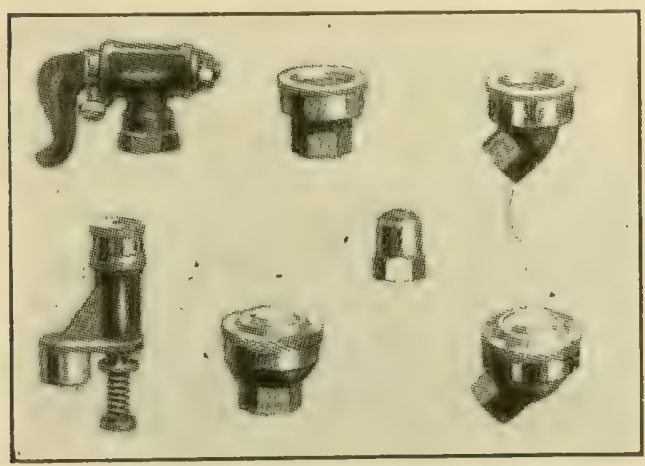

FIG. 234. - Various types of nozzles.

Dusting machines. - These consist of various forms of blowers driven by hand or by gasoline engines. Fig. 235 shows one of these machines in use for sulfuring.

Nozzles. ${ }^{508}$ - The various types of nozzles are illustrated in Fig. 234. These include the Bordeaux type (upper left corner), the Vermorel (lower left

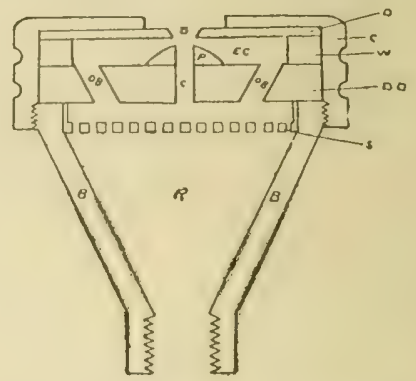

Fig. 233. - Diagram of longitudinal section of a spray nozzle showing all the parts that may be found in the eddychamber nozzles. O, orifice; EC, eddy-chamber; $\mathrm{P}$, post on the directing disc, DD; C, Cap; $\mathrm{W}$, washer; $\mathrm{OB}$, oblique supply holes; S, strainer; $R$, reservoir; $B$, base of nozzle; D, disc, C, central supply hole. After Crane. 


\section{Fungicides}

No matter what type of machine is in use, it is essential to keep on hand a supply of any parts that may be broken or

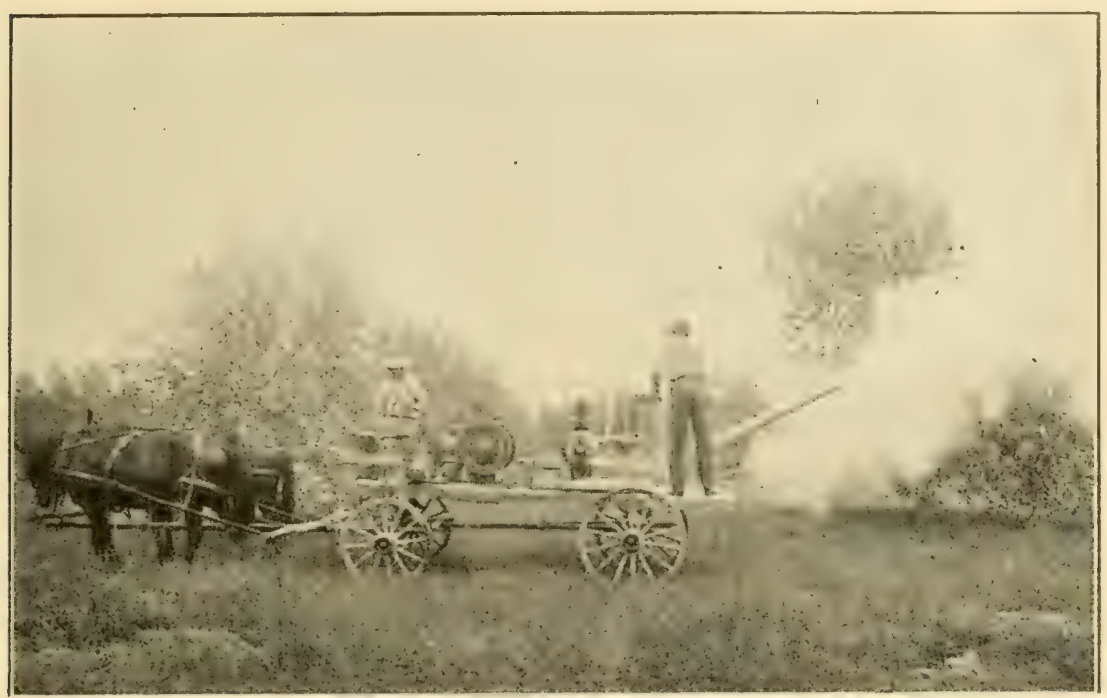

FIG. 235. - Sulfuring machine in use. After Faurot.

become worn out. The best companies are prompt in filling orders for repairs, but the grower cannot afford loss of even a very short time at critical periods. 


\section{SOIL DISINFECTION ${ }^{8-13}$}

Soil disinfection in the field has as yet in the main proved impracticable. All promising chemicals have been tried without avail. Electricity has not given beneficial results, and at present there is no hope of any practicable manner of ridding fields of parasites by any process of disinfection. In a few instances large applications of lime, formalin, or sulfur have proved beneficial (see sweet potato, onion, etc.), but the general practicability of such usage is doubtful.

Disinfection of limited areas is, however, practicable, is largely employed, and has already resulted in great benefit, eliminating not only injurious fungi but insects and weeds as well. Cutting benches, flats, and other benches in the greenhouse, cold frames, and seed beds, and other small areas may be disinfected with advantage. The means to be employed depend upon the area, its location, and the facilities at hand. The leading methods are given below:

Baking. - Flats, pots, and other small containers of earth may often be satisfactorily disinfected by placing them upon a boiler or over a stove, or in an oven for a comparatively long period.

Permanent steam disinfectors. - A system of $1 \frac{1}{2}$-inch pipes, which are perforated with 1/4-inch holes on their under side at intervals of 6 inches throughout their entire length, may be placed about one foot below the surface of the soil. The pipes should run lengthwise of the bed, 18 inches apart, and be connected with a steam boiler. Before treatment the soil should be thoroughly spaded up and pulverized to permit ready access of the steam to all parts, and all fertilizers except commercial ones should be applied at this time, since fresh spores of the fungus are likely to be carried in if manure be added after disinfection. 
The seed bed should be covered with several thicknesses of old burlap or blankets to confine the heat to the soil. The steam should be applied at a pressure of from 80 to 150 pounds, since at high pressure the soil does not become so wet as when low-pressure steam is used. A treatment of from one to two hours is usually sufficient to disinfect thoroughly the soil to a depth of 18 inches. A few potatoes laid in the surfaces oil will indicate the thoroughness of the treatment by the degree to which they are cooked. The blankets may advantageously be left on for some time.

While this method offers some advantages for seed beds of limited area, in that the pipes may be left in the ground and used year after year with little extra labor and may also be used for subirrigation, the initial cost of installation, especially on large seed-bed areas, may be prohibitive.

Inverted-pan method. - The method which has given the best results in practice, and which because of its simplicity and small cost recommends itself for use on large or small areas, is the invention of Mr. A. D. Shamel, of the U. S. Dept. Agr. Bur. of Plant Industry, and was devised by him to disinfect nematode-infested soils in Florida. The apparatus consists of a galvanized iron pan, $6^{\prime} \times 10^{\prime} \times 6^{\prime \prime}$ which is inverted over the soil and the steam admitted under pressure. The pan is supplied with steam-hose connections, has sharp edges, which are forced into the soil on all sides to prevent the escape of steam, and is fitted with handles for moving it from place to place, the weight of the entire pan being not over 400 pounds.

The soil is prepared as in the greenhouse method, a few potatoes being buried at a depth of a foot to gauge the degree of heat attained, or a soil thermometer may be used if desired. The steam should be kept at as high pressure as possible, from 80 to 150 pounds being best, and the treatment should continue from 30 to 60 minutes, depending upon the pressure maintained and the character of the soil. Wet soils require more time than dry soils. In experiments conducted on tobacco seed beds in the spring of 1907 , one hour's steam- 
ing at $80^{\circ} \mathrm{C}$. gave best results in killing both the fungi and the weed seeds. When one section of the bed is treated, the pan is lifted and carried to another portion, and the operation repeated until the entire bed is steamed.

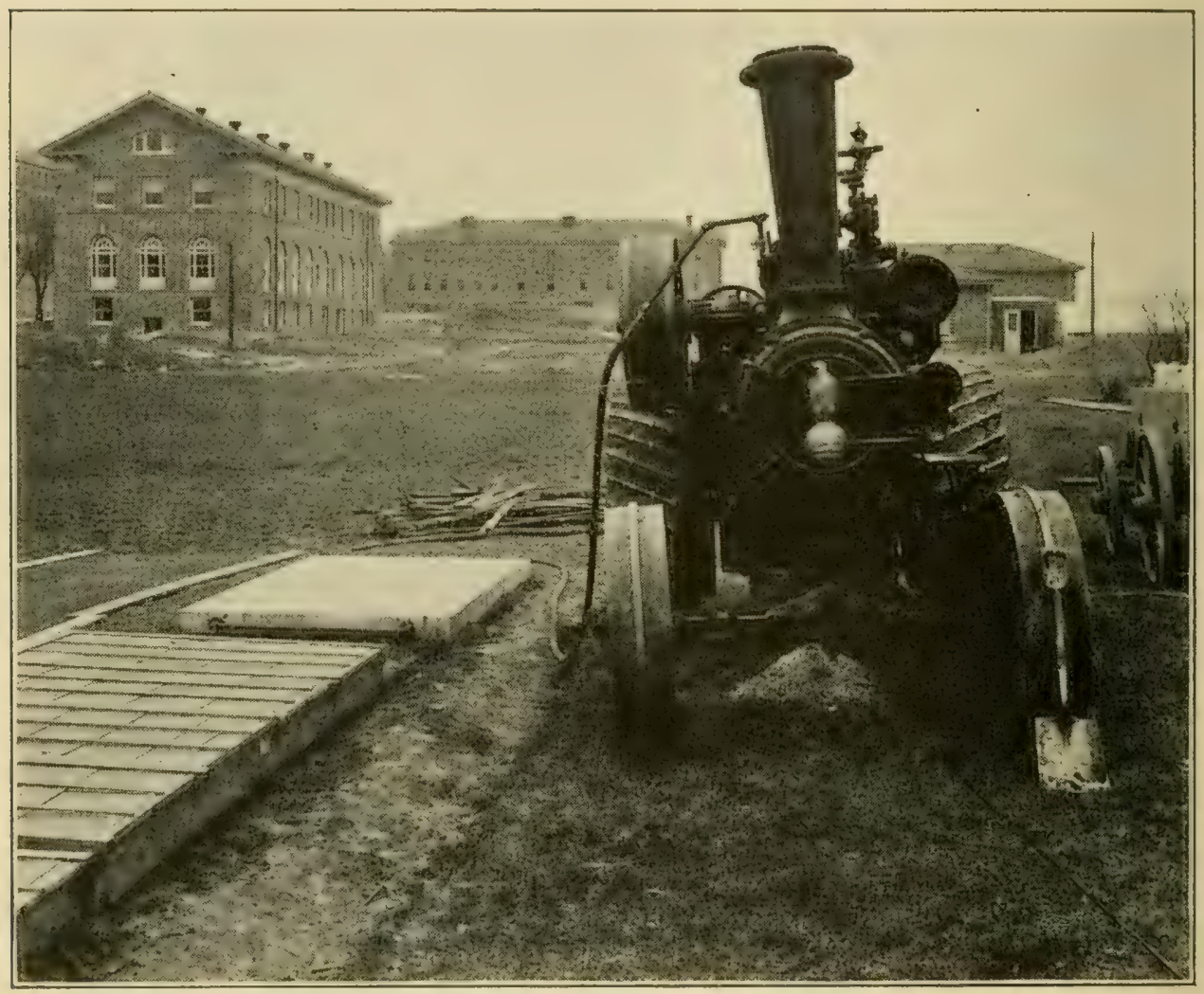

FIG. 236. - Disinfecting with steam by the inverted-pan method. After Johnson.

The inverted-pan method is particularly applicable in disinfecting greenhouse benches or flats. Streaming steam from the heating system passed into the pan for one and onehalf hours suffices. A steam hose connecting the pan with a traction engine makes a serviceable out-of-door outfit.

The Sargent method. - Disinfection by a system of steam pipes arranged in the form of a harrow, with hollow, 
perforated teeth, has proved satisfactory under some conditions.

Surface firing. - Surface firing of seed beds has been a common practice for years in some tobacco sections, particularly in Kentucky and other southern states, the end in view being the improvement of the tilth of the soil and the killing of weed seeds rather than the destruction of any fungous disease. In Italy burning is now considered a part

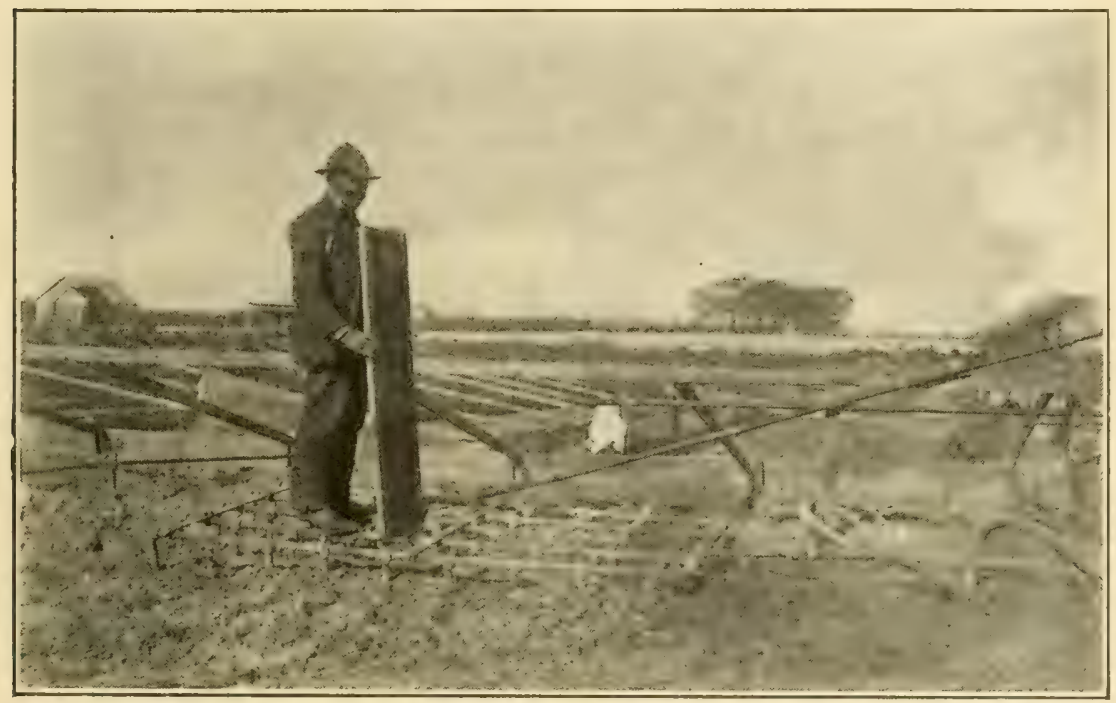

FIg. 237. - Disinfecting soil with a Sargent disinfector. Original.

of the regular method of tobacco seed-bed preparation, it having been resorted to as a preventive of root-rot due to Thielavia.

Two methods of surface firing are in vogue; the first, by direct firing, the second requiring the use of a pan. In the direct method, the land to be disinfected is first thoroughly pulverized and manure applied. It is then covered with straw, brush, and wood sufficient to make a hot fire. This is ignited and allowed to burn an hour or so, after which the ashes are raked into the surface soil.

The second method, pan firing, consists in the use of a sheet-iron pan, $3^{\prime}$ by $9^{\prime}$, which is set in the middle of the seed 
bed and a fire built under it. The soil on one side of the pan to a depth of 6 inches is shoveled and heated, great care being taknn to keep it moist, otherwise the humus would be burned out and the physical texture seriously altered. After an hour this soil is put back and that from the other side of the pan subjected to the same treatment, and then the pan moved along to a new place. The soil underneath the pan itself is thereby subjected to heat for two hours.

Disinfection by formalin. - The use of formalin for the disinfection of greenhouse soil and of tobacco seed beds against Corticium has been in vogue for some time with excellent results. It furnishes a very simple means of disinfection as follows: The beds are thoroughly prepared as for the other methods of disinfection described and are then drenched with a 2 per cent formalin solution using two quarts of this solution to the square foot of bed space. The solution should be put on with a watering pot with a rose orifice and distributed as evenly as possible over the bed, so as to wet the soil thoroughly to the depth of a foot. It will, in most cases, be necessary to put this solution on in two or three applications, as the soil will not immediately take in this quantity of water. The beds should then be covered with heavy burlap or a tarpaulin to retain the fumes for a day or so, and then aired for a week before sowing the seed.

Spring applications of formalin are open to the following objections: The addition of such a large quantity of water to the soil keeps it wet and cold longer than would naturally be the case, thus delaying germination as well as subsequent growth; the necessity of airing the beds to remove the formalin fumes and to allow the soil to dry out also causes delay in seeding. To obviate these difficulties the beds should be treated in the fall, before freezing.

Disinfection by sulfuric acid. - One-eighth to threesixteenths fluid ounce of commercial sulfuric acid in from one to two pints of water, according to the humidity of the soil, is applied per square foot of soil immediately after the seeds are covered. This treatment is used principally for conifers. 
Abundant watering is necessary to prevent root injury of the seedlings.

Disinfection by copper-sulfate. - This chemical may be used up to one-fourth ounce per square foot. It is employed chiefly for conifer seed beds.

Disinfection by zinc-chlorid. - Five-eighths of an ounce of this solution per square foot may be employed for conifer seed beds, but it is more expensive than copper-sulfate.

Disinfection by hot water. ${ }^{539}$ Pots, flats, etc., may be disinfected by submersion in hot water, $98^{\circ} \mathrm{C}$. (208 ${ }^{\circ} \mathrm{F}$.) for five minutes. The quantity of water necessary increases with the volume of soil to be treated; thus for $8^{\prime \prime}$ pots about 3000 cc. of water is needed at $98^{\circ} \mathrm{C}$. or 2000 cc. of boiling water. On shallow benches boiling water should be used at the rate of 7 gallons per cubic foot of soil. 

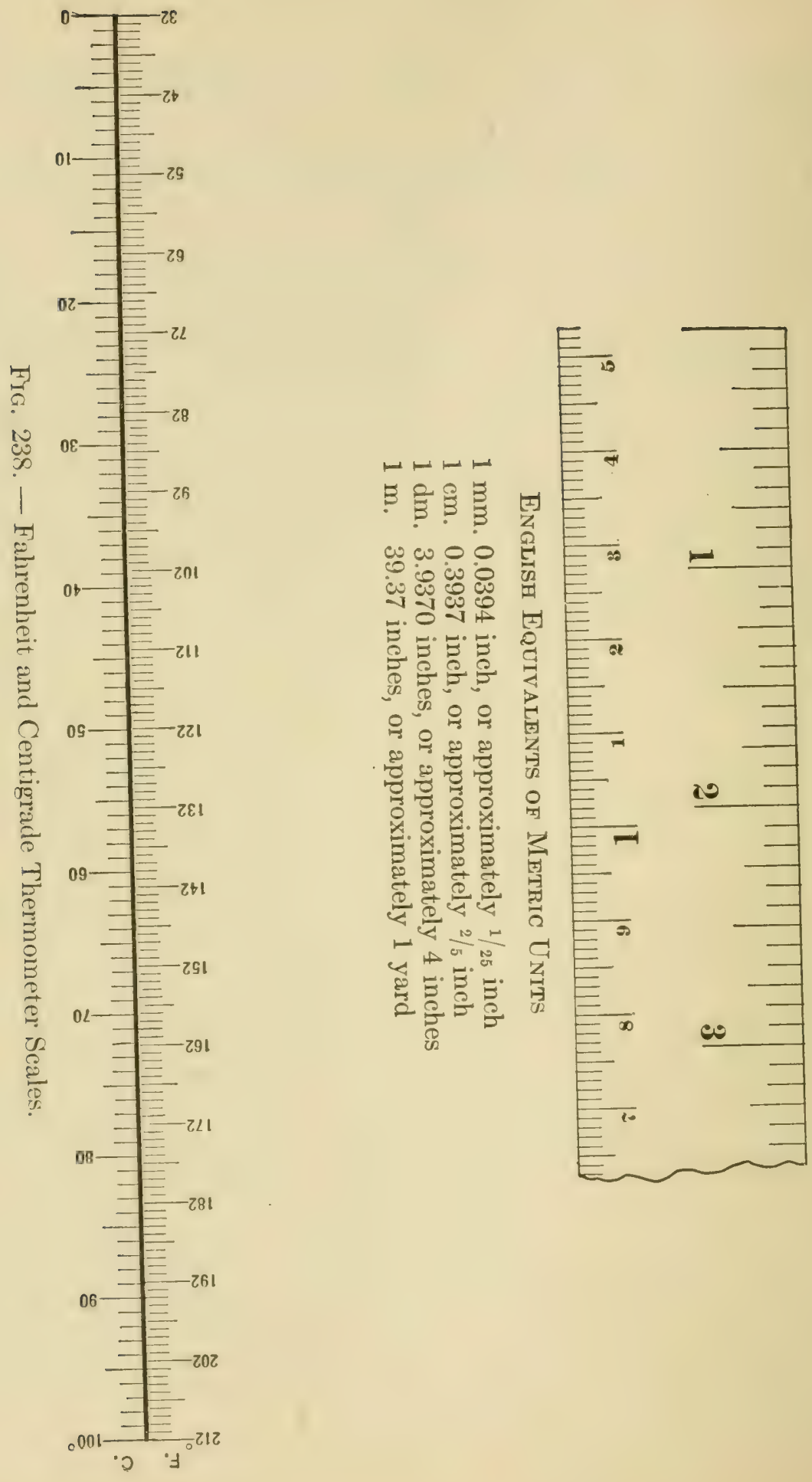


\section{BIBLIOGRAPHY}

1. Whetzel, H. H., An outline of the history of phytopathology. W. B. Saunders Co. 1918. 2. Sorauer, P., Manual of plant diseases. Trans. by F. Dorrance, Dorranceville, Pa. 1914. 3. Lodeman, E. G., The spraying of plants, 6. The Macmillan Co. 1913. 4. Stevens, F. L., Some problems in plant pathology in reference to transportation. Phytop. 5: 108. 1915. 5. Coons, G. H., and Nelson, R., The plant diseases of importance in the transportation of fruit and vegetables. Am. R. R. Per. Fr. Assn. (ir. 4r.3. 1918. 6. Lyman, G. R., War Emergeney Board, American Plant Pathologists, Midyear Rept. June 25, 1918. 7. Roberts, J. W., and Pierce L., Control of cherry leaf-spot. U. S. Dept. Agr. Farms'. Bul. 1053. 1919. 8. Beinhardt, E. G., Steam sterilization of seed beds for tobacco and other crops. U. S. Dept. Agr. Farms'. Bul. 996. 1918. 9. Selby, A. D., and Humbert, J. A., Methods of soil sterilization for plant beds and greenhouses. Ohio Agr. Exp. Sta. Cir. 151. 1915. 10. Johnson, J., The control of damping-off disease in plant beds. Wis. Agr. Exp. Sta. Res. Bul. 31. 191.. 11. Hartley, C., and Pierce, R. G., The control of damping-off of coniferous seedlings. U. S. Dept. Agr. Bul. 453. 1917. 12. Gifford, C. M., The damping-off of coniferous seedlings. Tt. Agr. Exp. Sta. Bul. 15\%. 1911. 13. Peltier, G. L., Parasitic Rhizoctonias in America. Ill. Agr. Exp. Sta. Bul. 189. 1916. 14. Pammel, L. H., Fungous diseases of sugar beets. Ia. Agr. Exp. Sta. Bul. 15. 1891. 15. Fulton, H. R., Diseases of pepper and beans. La. Agr. Exp. Sta. Bul. 101. 1908. 16. Pammel, L. H., Cotton root-rot. Tex. Agr. Exp. Sta. Rept. 吕: 61. 1898. 17. Duggar, B. M., The Texas root-rot fungus and its conidial stage. Ann. Mo. Bot. Gard. 3. 1916. 18. Gilbert, W. W., The root-rot of tobacco caused by Thielavia basicola. U. S. Dept. Agr., B. P. I. Bul. 15s. 1909. 19. Johnson, J., Host plants of Thielaria basicola. Jour. Agr. Res. 7: 289. 1916. 20. Stevens, F. L., and Sackett, W. G., The Granville tobacco wilt. N. C. Agr. Exp. Sta. Bul. 18s. 1903. 21. Stone, G. E., and Smith, R. E., Nematode worms. Mass. Agr. 
Exp. Sta. Bul. 55. 1898. 22. Bessey, E. E., and Byars, L. P., The control of root-knot. U. S. Dept. Agr. Farms'. Bul. 648. 1915. 23. Bessey, E. E., Root-knot and its control. U. S. Dept. Agr., B. P. I. Bul. 21\%. 1911. 24. Widtsoe, J. A., The relation of smelter smoke to Utah agriculture. Utah Agr. Exp. Sta. Bul. 88. 1903. 25. Bakke, A. L., The effect of city smoke on vegetation. Ia. Agr. Exp. Sta. Bul. 145. 1913. 26. Arthur, J. C., History and scope of plant pathology. Cong. Arts and S'. 5: 149. 1906. 27. Waite, M. B., Vegetable pathology an economic science. Cong. Arts and Sc. 5: 165. 1906. 28. Hesler, L. R., and Whetzel, H. H., Manual of fruit diseases. The Macmillan Co. 1917. 29. Schrenk, H. v, and Spaulding, P., The bitter-rot of apples. U. S. Dept. Agr., B. P. I. Bul. 44. 1903. 30. Burrill, T. J., Bitter-rot of apples. Ill. Agr. Exp. Sta. Bul. 118. 1907. 31. Blair, J. C., Bitter-rot of apples. Ill. Agr. Exp. Sta. Bul. 11\%. 1907. 32. Roberts, J. W., and Pierce, L., Apple bitter-rot and its control. U. S. Dept. Agr. Farms'. Bul. 938. 1918. 33. Roberts, J. W., The sources of apple bitter-rot infections. U. S. Dept. Agr. Bul. 684. 1918. 34. Wallace, E., The scab disease of apples. N. Y. (Cornell) Agr. Exp. Sta. Bul. 335. 1913. 35. Morris, H. E., A contribution to our knowledge of apple scab. Mont. Agr. Exp. Sta. Bul. 96. 1914. 36. Scott, W. M., and Rorer, J. B., Apple blotch. U. S. Dept. Agr., B. P. I. Bul. 144. 1909. 37. Lewis, D. E., The control of apple blotch. Kan. Agr. Exp. Sta. Bul. 196. 1913. 38. Clinton, G. P., Apple-rot in Illinois. Ill. Agr. Exp. Sta. Bul. 69. 1902. 39. Scott, W. M., and Quaintance, A. L., Spraying for apple diseases and the codling moth in the Ozarks. U. S. Dept. Agr. Farms'. Bul. 283. 1907. 40. Roberts, J. W., Apple blotch and its control. U. S. Dept. Agr. Bul. 534. 1917. 41. Reed, H. S., and Crabill, C. H., The cedar rust disease of apples caused by Gymnosporangium juniperi-virginianæ Schw. Va. Agr. Exp. Sta. Tech. Bul. 9. 1915. 42. Jones, L. R., and Bartholomew, E. T., Apple rust and its control in Wisconsin. Wis. Agr. Exp. Sta. Bul. 25\%. 1915. 43. Whetzel, H. H., The blight canker of apple trees. N. Y. (Cornell) Agr. Exp. Sta. Bul. 236. 1906. 44. Hesler, L. R., Black-rot, leaf-spot, and canker of pomaceous fruits. N. Y. (Cornell) Agr. Exp. Sta. Bul. 379. 1916. 45. Paddock, W., The New York apple tree 
canker. N. Y. (Geneva) Agr. Exp. Sta. Bul. 163. 1899. 46. Stevens, F. L., and Hall, J. G., Some apple diseases. N. C. Agr. Exp. Sta. Bul. 196. 1907. 47. Lawrence, W. H., Black spot canker. Wash. Agr. Exp. Sta. Bul. 66. 1904. 48. Cordley, A. B., Apple tree anthracnose. Ore. Agr. Exp. Sta. Bul. 60. 1900. 49. Hasselbring, H., Canker of apple trees. Ill. Agr. Exp. Sta. Bul. \%o. 1902. 50. Gloyer, W. O., Apple blister canker and methods of treatment. Ohio Agr. Exp. Sta. Cir. 12.j. 1912. 51. Cooper, J. R., Studies of the etiology and control of blister canker on apple trees. Neb. Agr. Exp. Sta. Res. Bul. 12. 1917. 52. Paddock, W., European apple tree canker in America. S'e. n. s. 12: 297. 1900. 53. Crabill, ( $`$ H., The frog-eye leaf spot of apples. Va. Poly. Inst. Bul. 209. 1915. 54. Lewis, I. M., Apple leaf-spot. N. H. Agr. Exp. Sta. Rept. 19-20: 365. 1908. 55. Sheldon, J. L., Another leaf-spot fungus of the apple. Torreya 8: 139. 1908. 56. Stevens, F. L., and Hall, J. G., Hypochnose of pomaceous fruits. Ann. Myc. 7: 49. 1909. 57. Burt, E. A., Corticiums causing Pellicularia disease of the coffee plant, hypochnose of pomaceous fruits and Rhizoctonia disease. Amm. Mo. Bot. Gard. 5: 119. 1918. 58. Eustace, H. J., A destructive apple rot following scab. N. Y. (Geneva) Agr. Exp. Nta. Bul. 2.2\%. 1902. 59. Eustace, H. J., Two decays of stored apples. N. Y. (Genera) Agr. Exp. Sta. Bul. 235. 1903. 60. Clinton, (r. P., Apple rots of Illinois. Ill. Agr. Exp. Sta. Bul. 69. 1902. 61. Ballard, W. S., Apple powdery mildew and its control in the Pajaro Valley. U. S. Dept. Agr. Bul. 120. 1914. 62. Fisher, D. F., Apple powdery mildew and its control in the arid regions of the Pacific Northwest. U. S. Dept. Agr. Bul. 712. 1918. 63. Stevens, F. L., and Hall, J. G., Some apple diseases. The Volutella rot. N. C. Agr. Exp. Sta. Bul. 196. 1907. 64. Brooks, Charles, The fruit spot of apples. N. H. Agr. Exp. Sta. Rept. 19-20. 1908. 65. Wilcox, E. M., A rhizomorphic root rot of fruit trees. Okla. Agr. Exp. Sta. Bul. 49. 1901. 66. Wolf, F. A., and Cromwell, R. O., Xylaria root rot of apple. Jour. Agr. Res. 9: 269. 1917. 67. Horne, W. T., Wood decay in orchard trees. Cal. Agr. Exp. Sta. Cir. 18\%. 1915. 68. McAlpine, Bitter pit investigation. Repts. 1, 2, 3, 4. Australia. 1911-1915. 69. Scott, W. M., and Roberts, J. W., The Jonathan fruit-spot. U. S. 
Dept. Agr., B. P. I. Cir. 112. 1913. 70. Morse, W. J., and Lewis, C. E., Maine apple diseases. Me. Agr. Exp. Sta. Bul. 185. 1910. 71. Brooks, Chas., Some apple diseases and their treatment. N. H. Agr. Exp. Sta. Bul. 15\%. 1902. 72. Roberts, J. W., The rough bark disease of the Yellow Newton apple. U. S. Dept. Agr., B. P. I. Bul. 280: 7. 1913. 73. Burrill, T. J., Trans. Ill. Hort. Soc. for 1878, 12: 80. 1879. 74. Waite, M. B., The cause and prevention of pear blight. U. S. Dept. Agr. Yearbook. 295. 1895. 75. Whetzel, H. H., and Stewart, V. B., Fire blight of pears, apples, quinces, etc. N. Y. (Cornell) Agr. Exp. Sta. Bul. 27刃. 1909. 76. Stevens, F. L., Ruth, W. A., and Spooner, C. S., Pear blight wind borne. Sc. 48: 449. 1918. 77. Smith, R. E., Pear scab. Cal. Agr. Exp. Sta. Bul. 163. 1905. 78. Swingle, D. B., Fruit diseases in Montana. Mont. Agr. Exp. Sta. Cir. 37. 1914. 79. Duggar, B. M., Some important pear diseases. N. Y. (Cornell) Agr. Exp. Sta. Bul. 145. 1898. 80. Halsted, B. D., Some fungous diseases of the quince. N. J. Agr. Exp. Sta. Bul. 91. 1892. 81. Smith, R. E., California plant diseases. Cal. Agr. Exp. Sta. Bul. 218. 1911. 82. Paddock, W., An apricot blight. Colo. Agr. Exp. Sta. Bul. 84. 1903. 83. Higgins, B. B., Contribution to the life history and physiology of Cylindrosporium on stone fruits. Am. Jour. Bot. 1: 145. 1914. 84. Keitt, G. W., Control of cherry leaf spot in Wisconsin. Wis. Agr. Exp. Sta. Bul. 286. 1918. 85. Scott, W. M., Lime-sulfur mixtures for the summer spraying of orchards. U. S. Dept. Agr., B. P. I. Cir. 27. 1909. 86. Jackson, H. S., Diseases of drupaceous fruits. Ore. Crop Pest and Hort. Bien. Rept. 19111912: 250. 1913. 87. Stewart, V. B., Some important leaf diseases of nursery stock. N. Y. (Cornell) Agr. Exp. Sta. Bul. 358. 1915. 88. Heald, F. D., Tree fruits. Neb. Agr. Exp. Sta. Rept. 19: 29. 1906. 89. Scott, W. M., and Quaintance, A. L., Spraying peaches for the control of brown rot, scab, and curculio. U. S. Dept. Agr. Farms'. Bul. 440. 1911. 90. Smith, E. F., Peach blight. Jour. Mye. 7: 36. 1891. 91. Wormald, H., The Cytospora disease of the cherry. Jour. So. E. Agr. Coll. Wye (England) 1912: 367. 1914. 92. Keitt, G. W., Peach scab and its control. U. S. Dept. Agr. Bul. 395. 1917. 93. Pierce, N. B., Peach leaf curl, its nature and treatment. U.S. Dept. Agr. Div. Veg. Phys. \& Path. Bul. 20. 1900. 
94. Rolfs, F. M., Winter killing of twigs, cankers, and sun scald of peach trees. Mo. St. Fruit Farm Bul. 1\%. 1910. 95. Smith, R. E., California peach blight. Cal. Agr. Exp. Sta. Bul. 191. 1907. 96. Hedgcock, G. G., The cross inoculation of fruit trees and shrubs with crown gall. U. S. Dept. Agr., B. P. I. Bul. 131. 1908. 97. Smith, E. F., and Townsend, C. O., A plant tumor of bacterial origin. Sc. n. s. 2.5: 671. 1907. 98. Townsend, C. O., A bacterial gall of the daisy and its relation to gall formation on other plants. Sc. n. s. 29: 273. 1909. 99. Swingle, D. B., and Morris, H. E., Crown-gall injury in the orchard. Mont. Agr. Exp. Sta. Bul. 121. 1918. 100. Smith, E. F., Brown, N. A., and Townsend, C. O., Crown gall of plants. U. S. Dept. Agr., B. P. I. Bul. 213. 1911. 101. Smith, E. F., et al., The structure and development of crown gall: a plant cancer. U. S. Dept. Agr., B. P. I. Bul. 255. 1912. 102. Hedgeock, G. G., Field studies of the crown-gall and hairyroot of the apple tree. U. S. Dept. Agr., B. P. I. Bul. 186. 1910. 103. Rolfs, F. M., A bacterial disease of stone fruits. N. Y. (Cornell) Agr. Exp. Sta. Mem. 8. 1915. 104. Roberts, J. W., Control of peach bacterial spot in southern orchards. U. S. Dept. Agr. Bul. 543. 1917. 105. Smith, E. F., Observations on a hitherto unreported bacterial disease the cause of which enters the plant through ordinary stomata. Sc. 1. s. 1\%: 456. 1903. And Bacteria in relation to plant disease, I, Figs. 11, 15, 70, 71, 72, and Pl. 19. 106. Rorer, J. B., A bacterial disease of the peach. Mycologia 1: 23. 1909. 107. Selby, A. D., Preliminary report upon diseases of the peach. Ohio Agr. Exp. Sta. Bul. 92. 1898. 108. Atkinson, G. F., A new anthracnose of the privet. N. Y. (Cornell) Agr. Exp. Sta. Bul. 49. 1892. 109. Smith, E. F., Peach yellows and peach rosette. U. S. Dept. Agr. Farms'. Bul. 17: 7. 1894. 110. Smith, E. F., Additional evidence on the communicability of peach yellows and peach rosette. U. S. Dept. Agr. Div. Veg. Path. Bul. 1. 1891. 111. Smith, E. F., Notes on the Michigan disease known as "Little Peach." Fenville (Mich.) Herald, October 15, 1898. 112. Blake, M. A., Peach yellows and little peach. N. J. Agr. Exp. Sta. Bul. 226: 10. 1910. 113. Farlow, W. G., The black knot. Bussey Inst. Bul. 18\%6: 440. 1876. 114. Galloway, B. F., Plum pockets. U. S. Agr. Commr. Rept. 1888: 366. 1889. 115. Whetzel, H. H., 
and Stewart, V. B., Fire blight of pears, apples, quinces, etc. N. Y. (Cornell) Agr. Exp. Sta. Bul. 272. 1909. 116. Jones, L. R., Studies upon plum blight. Centrbl. f. Parasitenk. u. Infek. 2 (Abt. II), 825. 117. Higgins, B. B., Plum wilt. Ga. Agr. Exp. Sta. Bul. 118. 1916. 118. Burkholder, W. H., The anthracnose disease of the raspberry and related plants. N. Y. (Cornell) Agr. Exp. Sta. Bul. 395. 1917. 119. Rees, H. L., Experimental spraying for blackberry anthracnose. Wash. Agr. Exp. Sta. Mo. Bul. 3. 1915. 120. Lawrence, W. H., Anthracnose of the blackberry and raspberry. Wash. Agr. Exp. Sta. Bul. 97. 1910. 121. Clinton, G. P., Orange rust of raspberry and hlackberry. Ill. Agr. Exp. Sta. Bul. 29. 1893. 122. Stone, G. E., and Sinith, R. E., A late rust of the blackberry. Mass. (Hatch) Agr. Exp. Sta. Rept. 9: 74. 1897. 123. Lawrence, W. H., Bluestem of the black raspherry. Wash. Agr. Exp. Sta. Bul. 108. 1912. 124. Shear, C. I., ('ranberry diseases. U. S. Dept. Agr., B. P. I. Bul. 110. 1907. 125. Halsted, B. D., Some fungous diseases of the cranberry. N. J. Agr. Exp. Sta. Bul. 64. 1889. 126. Franklin, H. J., Report of the cranberry substation for 1916. Mass. Agr. Exp. Sta. Bul. 180. 1917. 127. Shear, C. L., End rot of cranberries. Jour. Agr. Res. 11: 35. 1917. 128. Durand, E. J., A disease of currant canes. N. Y. (Cornell) Agr. Exp. Sta. Bul. 125. 1897. 129. Grossenbacher, J. G., and Duggar, B. M., A contribution to the life history, parasitism, and biology of Botryosphæria ribis. N. Y. (Geneva) Agr. Exp. Sta. Tech. Bul. 18. 1911. 130. Pammel, L. H., Spot diseases of currants and gooseberries. Ia. Agr. Exp. Sta. Bul. 13. 1891. 131. Stewart, V. B., Some important leaf diseases of nursery stock. N. Y. (Cornell) Agr. Exp. Sta. Cir. 32. 1916. 132. Stewart, F. C., and Eustace, H. J., An epidemic of currant anthracnose. N. Y. (Geneva) Agr. Exp. Sta. Bul. 199. 1901. 133. Cook, M. T., The double blossom of the dewberry. Del. Agr. Exp. Sta. Bul. 93. 1911. 134. Close, C. P., Treatment for gooseberry mildew. N. Y. (Geneva) Agr. Exp. Sta. Bul. 161. 1899. 135. Giddings, N. J., Infection and immunity in apple rust. W. Va. Agr. Exp. Sta. Bul. 170. 1918. 136. Shear, C. L., Miles, G. F., and Hawkins, L. A., The control of black-rot of the grape. U. S. Dept. Agr., B. P. I. Bul. 155. 1909. 137. Wilson, C. S., and Reddick, D., The black rot of 


\section{Bibliography}

the grape and its control. N. Y. (Cornell) Agr. Exp. Sta. Bul. 266. 1909. 138. Reddick, D., The black rot disease of grapes. N. Y. (Cornell) Agr. Exp. Sta. Bul. 293. 1911. 139. Edson, A. W., The black rot of grapes in North Carolina and its treatment. N. C. Agr. Exp. Sta. Bul. 185. 1903. 140. Bioletti, F. T., Oidium or powdery mildew of the vine. Cal. Agr. Exp. Sta. Bul. 186. 1907. 141. Farlow, W. G., On the American grape-vine mildew. Bussey Inst. Bul. 1. 1876. 142. Quaintance, A. L., and Shear, C. L., Insect and fungous enemies of the grape east of the Rocky Mountains. U. S. Dept. Agr. Farms'. Bul. 28.4. 1907. 143. Hawkins, L. A., Experiments in the control of grape anthracnose. U.S. Dept. Agr., B. P. I. Cir. 10\%. 1913. 144. Reddick, D., Dead arm disease of grapes. N. Y. (Cornell) Agr. Exp. Sta. Bul. 389. 1914. 145. Reddick, D., Necrosis of the grape vine. N. Y. (Cornell) Agr. Exp. Sta. Bul. 263. 1909. 146. Pierce, N. B., The California vine disease. U. S. Dept. Agr., Div. Veg. Phys. and Path. Bul. 2. 1892. 147. Hedgcock, G. G., Field studies of the crown-gall of the grape. U. S. Dept. Agr., B. P. I. Bul. 183. 1910. 148. Stubenrauch, A. V., Factors governing the successful storage of California table grapes. U. S. Dept. Agr. Bul. 35. 1913. 149. Gladwin, F. E., A nonparasitic malady of the vine. N. Y. (Geneva) Agr. Exp. Sta. Bul. 449. 1918. 150. Paddock, W., Anthracnose of the black raspberry. N. Y. (Geneva) Agr. Exp. Sta. Bul. 12, 1897. 151. Stewart, F. C., and Eustace, H. J., Raspleerry cane blight and raspberry yellows. N. Y. (Geneva) Agr. Exp. Sta. Bul. 2.26. 1902. 152. Sackett, W. G., Spur blight of the red raspberry caused by Sphærella rubina. Colo. Agr. Exp. Sta. Bul. 206. 1915. 153. Garman, H., Some strawberry pests. Ky. Agr. Exp. Sta. Bul. 31. 1890. 154. Hume, H. H., Strawberry leaf spot. Fla. Agr. Exp. Sta. Rept. 95. 1901. 155. Stevens, F. L., A destructive strawberry disease. Sc. n. s. 39: 949. 1914. 156. Halsted, B. D., A new strawberry leaf blight. N. J. Agr. Exp. Sta. Rept. 329. 1893. 157. Stevens, F. L., and Peterson, A., Some new strawberry fungi. Phytop. 6: 259. 1916. 158. Cook, Mel. T., Diseases of tropical plants. Macmillan \& Co. 1913. 159. Smith, R. E., The brownrot of the lemon. Cal. Agr. Exp. Sta. Bul. 190. 1907. 160. Stevens, H. E., Florida citrus diseases. Fla. Agr. Exp. Sta. Bul. 150. 
1918. 161. Rorer, J. B., Enfermedades y plagas del cacao en el Ecuador y metodos modernos apropiados al cultivo del cacao. 1918. 162. Smith, C. O., Cottony rot of lemons in California. Cal. Agr. Exp. Sta. Bul. 265. 1916. 163. Fawcett, H. S., Scaby bark of Citrus. Fla. Agr. Exp. Sta. Bul. 98. 1909. 164. Powell, G. H., The decay of oranges while in transit from California. U. S. Dept. Agr., B. P. I. Bul. 123. 1908. 165. Coit, J. E., and Hodgson, R. W., The June drop of Washington navel oranges. Cal. Agr. Exp. Sta. Bul. 290. 1918. 166. Matz, J., Some diseases of the fig. Fla. Agr. Exp. Sta. Bul. 149. 1918. 167. Johnson, R. J., The history and cause of the cocoanut bud-rot. U. S. Dept. Agr., B. P. I. Bul. 228. 1912. 168. Hodgson, R. W., Black smut of figs. Mo. Bul. of St. Comm. of Hort. (Cal.) 7: 188. 1918. 169. Rorer, J. B., The anthracnose of the mango. Bul. Dept. Agr. Trinidad and Tobago 14: 164. 1915. 170. Swingle, W. T., and Webber, H. J., The principal diseases of citrus fruits in Florida. U. S. Dept. Agr. Div. Veg. Phys. and Path. Bul. 8. 1896. 171. Webber, H. J., Sooty mold of the orange and its treatment. U. S. Dept. Agr. Div. Veg. Phys. and Path. Bul. 13. 1897. 172. Taubenhaus, J. J., Diseases of truck crops. E. P. Dutton \& Co. 1918. 173. Halsted, B. D., The asparagus rust, its treatment and natural enemies. N. J. Agr. Exp. Sta. Bul. 129. 1898. 174. Norton, J. B., Washington asparagus. U. S. Dept. Agr., B. P. I., Cotton, truck, etc. Feb., 1919. 175. Smith, R. E., Asparagus and asparagus rust in California. Cal. Agr. Exp. Sta. Bul. 16j. 1905. 176. Sirrine, F. A., Spraying for asparagus rust. N. Y. (Geneva) Agr. Exp. Sta. Bul. 188: 251. 1900. 177. Jackson, H. S., Diseases of field crops in Delaware. Del. Agr. Exp. Sta. Bul. 83. 1907. 178. Burkholder, W. H., The production of an anthracnose-resistant white marrow bean. Phytop. 8: 353. 1918. 179. Barrus, M. F., An anthracnoseresistant red kidney bean. Phytop. 5: 303. 1915. Idem. 8: 589. 1918. 180. Whetzel, H. H., Bean anthracnose. N. Y. (Cornell) Agr. Exp. Sta. Bul. 255. 1908. 181. Beach, S. A., Some bean diseases. N. Y. (Geneva) Agr. Exp. Sta. Bul. 48. 1892. 182. Duggar, B. M., and Stewart, F. C., The sterile fungus Rhizoctonia. N. Y. (Cornell) Agr. Exp. Sta. Bul. 186. 1901. 183. Hedgcock, G. G., A note on Rhizoctonia. Sc. n. s. 19:268. 1904. 184. Halsted, 
B. D., Bean diseases and their treatments. N. J. Agr. Exp. Sta. Bul. 151. 1901. 185. Thaxter, R., A new American Phytophthora. Bot. Gaz. 14: 273. 1889. 186. Reddick, D., and Stewart, V. B., Varieties of beans susceptible to mosaic. Phytop. 8: 530. 1918. 187. Miles, L. E., Some diseases of economic plants in Porto Rico. Phytop. 7: 345. 1917. 188. Harter, L. L., Podblight of the lima bean caused by Diaporthe phaseolorum. Jour. Agr. Res. 11: 473. 1917. 189. Macmillan, H. G., Sunscald of beans. Jour. Agr. Res. 13: 647. 1918. 190. MeClintock, J. A., Sclerotinia blight. Va. Truck Exp. Sta. Bul. 20. 1916. 191. Townsend, C. O., Leaf spot. U. S. Dept. Agr. Farms'. Bul. 618. 1914. 192. Halsted, B. D., Some fungous diseases of beets. N. J. Agr. Exp. Sta. Bul. 10\%. 1895. 193. Pool, V. W., and McKay, M. B., The control of the sugar-beet leaf-spot. U. S. Dept. Agr., B. P. I. Cir. 121. 1913. 194. Duggar, B. M., and Stewart, F. C., The sterile fungus Rhizoctonia. N. Y. (Cornell) Agr. Exp. Sta. Bul. 186. 1901. 195. Bolley, H. L., Potato scab and possibilities of prevention. N. Dak. Agr. Exp. Sta. Bul. 4. 1891. 196. Metealf, H., A soft rot of the sugar beet. Neb. Agr. Exp. Sta. Rept. 1\%: 69. 1904. 197. Brown, N. A., A new bacterial disease of nasturtiums. Sc. n. s. 29: 915. 1909. 198. Hedgcock, G. G., Proof of the identity of Phoma and Phyllosticta on the sugar beet. Jour. Myc. 10: 2. 1904. 199. Smith, R. E., and Bonequet, P. A., Connection of a bacterial organism with curly leaf of the sugar beet. Phytop. 5: 335. 1915. 200. Shaw, H. B., The curly top of beets. U. S. Dept. Agr., B. P. I. Bul. 181. 1910. 201. Ball, E. D., The beet leaf-hopper and the curly-leaf disease that it transmits. Utah Agr. Exp. Sta. Bul. 155. 1917. 202. Stewart, F. C., Leaf-scorch of the sugar-beet, cherry, cauliflower, and maple. N. Y. (Geneva) Agr. Exp. Sta. Bul. 162. 1899. 203. Shaw, H. B., Control of the sugar-beet nematode. U. S. Dept. Agr. Farms'. Bul. 7\%2. 1916. 204. Edson, H. A., Seedling diseases of sugar-beets and their relation to root-rot and crown-rot. Jour. Agr. Res. 4: 135 and 279. 1918. 205. Stevens, F. L., and Wilson, G. W., Rhizoctonia on buckwheat. Sc. n. s. 83: 943. 1911. 206. Russell, H. L., A leaf-rot of cabbage. Proc. Amer. Assoc. Adv. Sci. 1895. 1896. 207. Russell, H. L., A bacterial rot of cabbage and allied plants. Wis. Agr. Exp. Sta. Bul. 65. 
1898. 208. Harter, L. I. and Jones, L. R., Cabbage diseases. U. S. Dept. Agr. Farms'. Bul. 925. 1918. 209. Lutman, B. F., Studies in club-root. Vt. Agr. Exp. Sta. Bul. 175. 1913. 210. Cunningham, G. C., Studies in club-root. Vt. Agr. Exp. Sta. Bul. 185. 1914. 211. Stewart, F. C., Prevention of cabbage club-root. N. Y. (Geneva) Agr. Exp. Sta. Rept. 14: 528. 1896. 212. Hedgcock, G. G., A disease of cauliflower and cabbage caused by Sclerotinia. Mo. Bot. Gard. Rept. 16: 149. 1905. 213. Henderson, M. P., The black-leg disease of cabbage caused by Phoma lingam (Tode) Desmaz. Phytop. 8: 379. 1918. 214. Manns, T. F., Two recent important cabbage diseases in Ohio. Ohio Agr. Exp. Sta. Bul. 238. 1911. 215. McCulloch, L., A spot disease of cauliflower. U. S. Dept. Agr. Bul. 225. 1911. 216. Orton, W. A., Watermelon diseases. U. S. Dept. Agr. Farms'. Bul. 821. 1917. 217. Blinn, P. K., A rust resistant canteloupe. C'olo. Agr. Exp. Sta. Bul. 104. 1905. 218. Giddings, N. J., A bacterial rot of the muskmelon. Sc. n. s. 29: 911. 1909. 219. Giddings, N. J., A bacterial soft-rot of muskmelon caused by Bacillus melonis 11. sp. Vt. Agr. Exp. Sta. Bul. 148. 1910. 220. Grossenbacher, J. G., A mycosphærella wilt of melons. N. Y. (Geneva) Agr. Exp. Sta. Tech. Bul. 9. 1909. 221. Harding, H. A., Jones, L. R., and Morse, W. J., The bacterial soft-rots of certain vegetables. N. Y. (Geneva) Agr. Exp. Sta. Tech. Bul. 11. 1910. 222. Jones, L. R., A soft-rot of carrot and other vegetables. Vt. Agr. Exp. Sta. Rept. 13: 299. 1901. 223. Harrison, F. C., A bacterial disease of caulifiower (Brassica oleracea) and allied plants. Ont. A. C.\& E. F. Bul. 13\%. 1904. 224. Stevens, H. E., Gray mold of castor beans. Fla. Agr. Exp. Sta. Press Bul. 296. 1918. 225. Lamson-Scribner, F., Celery leaf blight. U. S. Dept. Agr. Rept. for 1886. 117. 226. Coons, G. H., and Levin, E., The septoria leaf-spot disease of celery or celery blight. Mich. Agr. Exp. Sta. Sp. Bul. 7ry. 1916. 227. Chubb, C., Studies on club-root of crucifers. N. Y. (Cornell) Agr. Exp. Sta. Bul. 38\%. 1917. 228. Harding, H. A. et al., Vitality of the cabbage black rot germ on cabbage seed. N. Y. (Geneva) Agr. Exp. Sta. Bul. 251. 1904. 229. Jones, L. R., and Gilman, J. C., The control of cabbage yellows through disease resistance. Wis. Agr. Exp. Sta. Res. Bul. 38. 1915. 230. Austin, C. F., and White, T. H., Second report on the cause of 
pithiness in celery. Md. Agr. Exp. Sta. Bul. 93. 1904. 231. Stewart, F. (., The downy mildew of the cucumber. N. Y. (Cieneva) Agr. Exp. Sta. Bul. 119. 1897. 232. Gardner, M. IV., Anthracnose of cucurbits. U. S. Dept. Agr. Bul. r2\%. 191\$. 233. Humphrey, J. E., The powdery mildew of the cucumber. Masi. Agr. Exp. Sta. Rept. 9: 222. 1892. 234. Arthur, J. C., A fungous clisease of the cucumber. N. Y. (Genera) Agr. Exp. Sta. Rept. 6: 316. 1887. 235. Burger, O. F., Cucumber rot. Fla. Agr. Exp. Sta. Bul. 121. 1914. 236. Gilbert, W. W., and Gardner, M. W., Seed treatment control and over-wintering of cucumber angular leaf-spot. Phytop. 8: 229. 1918. 237. Jagger, I. C., Mosaic diseases of cucurbits (abstract). Phytop. S: 7t. 191s. 238. Doolittle, S. P., and Williams, W., Further notes on cucumber mosaic diseases (abstract). Phytop. 8: 77. 1918. 239. Humphrey, J. E., Diseases of the cucumber plant. Nass. Agr. Lxp. Nta. Rept. 1892: 227. 1893. 240. Orton, W. A., Spraying for cucumber and melon diseases. U. s. Dept. Agr. Farms'. Bul. 231. 190s. 241. Meier, F. C., Melon stem-end rot. Jour. Agr. Res. 6: 149. 1916. 242. Osner, (i. A., Stemphylium leaf-spot of cucumbers. Jour. Agr. Res. 1.3: 295. 1918. 243. Harter, I. L., Fruit-rot, leaf-spot, and stem-blight of the egg plant caused by Phomopsis vexans. Jour. Agr. Res. 2: 331. 1914. 244. Whetzel, H. H., et al., Ginseng diseases and their control. U. s. Dept. Agr. Farms'. Bul. ^36. 1916. 245. Whetzel, H. H., and Rosenbaum, J., The diseases of ginseng and their control. U. S. Dept. Agr., B. P. I. Bul. 2:00. 1912. 246. Reed, H. S., Three fungous diseases of the cultivated ginseng. Mo. Agr. Exp. Sta. Bul. 69. 1905. 247. Rosenbaum, J., Phytophthora disease of ginseng. N. Y. (Cornell) Agr. Exp. Sta. Bul. 363. 1915. 248. Stevens, F. L., A serious lettuce disease and a method of control. N. C. Agr. Exp. Sta. Tech. Bul. S. 1911. 249. Brandes, E. W., Anthracnose of lettuce caused by Marssonina panattoniana. Jour. Agr. Res. 13: 261. 1918. 250. Brown, N. A., Some bacterial diseases of lettuce. Jour. Agr. Res. 13: 367. 1918. 251. Selhy, A. D., Diseases of lettuce. Ohio Agr. Exp. Sta. Bul. \%3. 1896. 252. Veihmeyer, F. J., The Mycogone disease of mushrooms and its control. U. S. Dept. Agr. Bul. 12\%. 1914. 253. Carpenter, C. W., Wilt diseases of okra and the Verticillium wilt problem. Jour. Agr. Res. 12: 529. 
1918. 254. Tolaas, A. G., A bacterial disease of cultivated mushrooms. Phytop. 5: 51. 1915. 255. Stone, Geo. E., The control of onion smut. Mass. (Amherst) Agr. Exp. Sta. Cir. 41. 1914. 256. Thaxter, R., The "smut" of onions. Ct. Agr. Exp. Sta. Rept. 1889: 129. 1900. 257. Selby, A. D., The prevention of onion smut. Ohio Agr. Exp. Sta. Bul. 131. 1900. 258. Thaxter, R., Report of Roland Thaxter, Mycologist. Conn. Agr. Exp. Sta. Rept. 1889: 127. 1890. 259. Whetzel, H. H., Onion blight. N. Y. (Cornell) Agr. Exp. Sta. Bul. 218. 1904. 260. Stewart, F. C., A bacterial rot of onions. N. Y. (Geneva) Agr. Exp. Sta. Bul. 164. 1899. 261. Munn, M. T., Nerk-rot disease of onions. N. Y. (Geneva) Agr. Exp. Sta. Bul. 437. 1917. 262. Von Pelt, W., Black mold of onions. Ohio Agr. Exp. Sta. Mo. Bul. 2. No. 5. 1917. 263. Taubenhaus, J. J., Pink-rot of onions. Sc. n. s. 49: 218. 1919. 264. Selby, A. D., The blighting of field and garden peas. Ohio Agr. Exp. Sta. Bul. 173. 1906. 265. Sackett, IV. G., A bacterial stem blight of field and garden peas. Colo. Agr. Exp. Nta. Bul. 218. 1916. 266. Lamson-Scribner, F., Diseases of the Irish potato. Temn. Agr. Exp. Sta. Bul. 2: 2. 1889. 267. Orton, W. A., The development of farm crops resistant to disease. U. S. Dept. Agr. Yearbook. 453. 1908. 268. Melhus, I. E., Germination and infection with the fungus of the late blight of potato (Phytophthora infestans). Wis. Agr. Exp. Sta. Res. Bul. 3\%. 1915. 269. Jones, L. R., Disease resistance of potatoes. U. S. Dept. Agr., B. P. I. Bul. 87. 1905. 270. Jones, L. R., and Morse, W. J., Report of the botanists. Vt. Agr. Exp. Sta. Rept. 16: 163. 1902-1903. 271. Stewart, F. C., et al., Potato spraying experiments in 1906. N. Y. (Geneva) Agr. Exp. Sta. Bul. 290: 240. 1907. 272. Lutman, B. F., and Cunningham, G. C., Potato scab. Vt. Agr. Exp. Sta. Bul. 184. 1914. 273. Thaxter, R., The potato scab. Ct. State Agr. Exp. Sta. Rept. 14: 81. 1891. 274. Norton, J. B. S., Irish potato diseases. Md. Agr. Exp. Sta. Bul. 108: 67. 1906. 275. Morse, IV. J., and Shapavalov, M., The Rhizoctonia disease of potatoes. Me. Agr. Exp. Sta. Bul. 230. 1914. 276. Melhus, I. E., Powdery scab (Spongospora subterranea) of potatoes. U. S. Dept. Agr. Bul. S2. 1914. 277. Spaulding, P., and Field, E. C., Two dangerous imported plant diseases. U. S. Dept. Agr. Farms'. Bul. 489. 1912. 278. Edson, 
H. A., and Shapavalov, M., Potato-stem lesions. Jour. Agr. Res. 14: 213. 1918. 279. Rands, R. D., Early-blight of potato and related plants. Wis. Agr. Exp. Sta. Res. Bul. 42. 1917. 280. Smith, E. F., and Swingle, D. B., The dry rot of potatoes. U. S. Dept. Agr. B. P. I., Bul. 55. 1904. 281. Jones, L. R., and Pomeroy, C. S., The leaf blotch disease of the potato eaused by Cercospora concors. Vt. Agr. Exp. Sta. Rept. 19: 236. 1907. 282. Orton, W. A., Potato diseases in San Joaquin county, California. U. S. Dept. Agr., B. P. I. Cir. 23. 1909. 283. Jones, L. R., Certain potato diseases and their remedies. Vt. Agr. Exp. Sta. Bul. 72. 1899. 284. Morse, W. J., Control of blackleg disease of the potato. Me. Agr. Exp. Sta. Bul. 194. 1911. 285. Morse, W. J., Studies upon the blackleg disease of potato. Jour. Agr. Res. 8: 79. 1917. 286. Murphy, P. A., War Emergency Board Rept. Aug. 16-17, 1918. 13. 287. Wortley, E. J., War Emergency Board Rept. Aug. 16-17. 1918. 5. 288. Orton, W. A., Potato wilt, leaf-roll, and related diseases. U, S. Dept. Agr. Bul. 64. 1914. 289. Bartholomew, E. T., Black heart of potatoes. Phytop. 3: 180. 1913. 290. Stewart, F. C., and Mix, A. J., Black heart and the aëration of potatoes in storage. N. Y. (Geneva) Agr. Exp. Sta. Bul. 436. 1917. 291. Lutman, B. F., Twenty years' spraying for potato diseases and the weather. Vt. Agr. Exp. Sta. Bul. 159. 1911. 292. Stewart, F. C., et al., Potato spraying experiments 1902-1911. N. Y. (Geneva) Agr. Exp. Sta. Bul. 349. 1911. 293. Orton, W. A., Selection and treatment of seed potatoes to avoid disease. U. S. Dept. Agr., B. P. I. Cir. 3. C. T. \& F. C. D. 1918. 294. Sterens, F. L., Two Illinois rhubarl diseases. Ill. Agr. Exp. Sta. Bul. 213. 1919. 295. MicClintock, J. A., and Smith, L. R., True nature of spinach blight and the relation of insects to its transmission. Jour. Agr. Res. 14: 1. 1918. 296. Zundel, G. L., Wheat smut control. 13th Ann. Conv. Washington Grain Growers, etc., Asso., Jan., 1919. 297. Halsted, B. D., Identity of anthracnose of the bean and watermelon. N. J. Agr. Exp. Sta. Rept. 11: 351. 1890. 298. Halsted, B. D., Some fungous diseases of the spinach. N. J. Agr. Exp. Sta. Bul. 70. 1890. 299. Harter, L. L., Sweet potato diseases. U. S. Dept. Agr. Farms'. Bul. 714. 1916. 300. Waite, M. B., Sweet Potatoes. Cyclopedia of Amer. Agr. 2: 622. 1907. 301. Elliott, J. A., The sweet 
potato "soil rot" or "pox," a slime mold disease. Del. Agr. Exp. Sta. Bul. 114. 1916. 302. Harter, L. L., The foot rot of the sweet potato. Jour. Agr. Res. 1: 251. 1914. 303. Halsted, B. D., Experiments with sweet potatoes. N. J. Agr. Exp. Sta. Rept. 350. 1898. 304. Clendenin, Ida, Lasiodiplodia E. \& E. n. gen. Bot. Gaz. 21: 92. 1896. 305. Taubenhaus, J. J., Soil-stain, or scurf of the sweet potato. Jour. Agr. Res. 5: 995. 1916. 306. Wolf, F. A., and Foster, A. C., Tobaces) wildfire. Jour. Agr. Res. 12: 449. 1918. 307. Stevens, F. I., The Granville tobaceo wilt. N. C. Agr. Exp. Sta. Press Bul. 11. 190:3. 308. Sturgis, W. C., On a destructive fungous disease of tobaceo in South Carolina. Comn. State Agr. Exp. Sta. Rept. 20: 27:3. 1896. 309. Smith, E. F., A dangerous tobacco disense. U. S. Dept. Agr., B. P. I. Bul. 141. part II. 1908. 310. Garner, W. W., et al., The control of tobaceo wilt in the flue-cured district. U. S. Dept. Agr. Bul. 562. 1917. 311. Clinton, G. P., Notes on fungous discases for 1905. Conn. State Agr. Exp. Sta. Rept. 276. 1905. 312. Chapman, G. H., Mosaic disease of tobacco. Mass. (Amherst) Agr. Exp. Sta. Bul. 17.5. 1917. 313. Allard. H. A., The mosaic disease of tobaceo. U. S. Dept. Agr. Bul. 40. 1914. 314. Smith, E. F., A bacterial disease of the tomato, eggplant, and Irish potato. U. S. Dept. Agr. Div. Veg. Phys. \& PathBul. 12. 1896. 315. Smith, R. E., Tomato diseases in California, Cal. Agr. Exp. Sta. Bul. 1\%5. 1906. 316. Levin, E., The leafspot disease of tomato. Mich. Agr. Exp. Sta. Tech. Bul. 25. 1916. 317. Jamieson, C. O., Phoma destructiva, the cause of a fruit-rot of the tomato. Jour. Agr. Res. 4: 1. 1915. 318. Selby, A. D., Studies in potato rosette. Ohio Agr. Exp. Sta. Bul. 145. 1903. 319. Pammel, L. H., Rutabaga rot. Ia. Agr. Exp. Sta. Bul. 27. 1895. 320. Clinton, G. P., North American Ustilagineæ. Proc. Boston Soc. Nat. Hist. 31: 334. 1904. 321. Bolley, H. L., New studies upon the smut of wheat, oats, and barley. N. D. Agr. Exp. Sta. Bul. 2\%. 1897. 322. Arthur, J. C., Rapid method of removing smut from seed oats. Ind. Agr. Exp. Sta. Bul. 103. 1905. 323. Haskell, R. J., The spray method of applying concentrated formaldehyde solution in the control of oat smut. Phytop. \%. 1917. 324. Humphrey, H. B., and Potter, A. A., Cereal smuts and the disinfection of seed grain. U. S. Dept. Agr. Farms'. Bul. S8S. 
1918. 325. Melchers, L. E., Smuts of grain and forage crops in Kansas. Kan. Agr. Exp. Sta. Bul. 210. 1916. 326. Freeman, E. M., and Johnson, E. C., The lonse smuts of barley and wheat. U. S. Dept. Agr., B. P. I. Bul. 15\%. 1909. 327. War Emergency Board of Plant Pathologists. Aug., 1918. 328. Carleton, M. A., Cereal rusts of the United States. U.S. Dept. Agr., Div. Veg. Phys. \& Path. Bul. 16: 19. 1899. 329. Selby, A. D., and Mamns, T. F., Studies in diseases of cereals and grasses. Ohio Agr. Exp. Sta. Bul. 203. 1909. 330. Jones, L. R., Johnson, A. G., and Reddy, C. S., Bacterial blight of barley. Jour. Agr. Res. 11: 625. 1917. 331. Pammel, L. H., King, C. M., and Bakke, A. L., Two barley blights. Ia. Agr. Exp. Sta. Bul. 116. 1910. 332. ('linton, G. P., Broom corn smut. Ill. Agr. Exp. Sta. Bul. 47. 1897. 333. Arthur, J. C., and Stuart, W., Corn smut. Ind. Agr. Exp. Nta. Rept. 18: 81. 1900. 334. Burrill, T. J., and Barrett, J. T., Ear rots of corn. Ill. Agr. Exp. Sta. Bul. 133. 1909. 335. Arzherger, E. ('., ('ob) rot of corn. Ohio Agr. Exp. Sta. Bul. 265. 1913. 336. Stewart, F. C., A hacterial disease of sweet corm. N. Y. (Genera) Agr. Exp. Sta. Bul. 130. 1897. 337. Tisdale, W. H., Physoderma disease of corn. Jour. Agr. Res. 16: 137. 1919. 338. Stewart, F. C., Blight of com leaves. N. Y. (Geneva) Agr. Exp. Sta. Rept. 15: 452. 1897. 339. Thaxter, R., Report of Plant Pathologist, Conn. State Agr. Exp. Sta. Rept. 13: 171. 1889. 340. Smith, E. F., Bacteria in relation to plant disease II. Pub. Carnegie Inst. Washington, 1911. 341. Idem, 3. 1914. 342. Jones, L. R., ct al., Investigations of the potato fungus, Phytophthora infestans. U. S. Dept. Agr., B. P. I. Bul. 245. 1912. 343. Arthur, J. C., Smut of oats. N. Y. (Geneva) Agr. Exp. Sta. Rept. 3. 1884. 344. Plumb, C. S., Smut experiments with oats. N. Y. (Genera) Agr. Exp. Sta. Rept. 5: 109. 1886. 345. Kellerman, W. A., and Swingle, IT. T., Report on the lonse smuts of cereals. Kan. Agr. Exp. Sta. Rept. 213. 1889. 346. Galloway, B. T., and Southworth, E. A., Preliminary notes on a new and destructive oat disease. Jour. Myc. 6: 72. 1891. 347. Manns, T. F., The blade blight of oats. Ohio Agr. Exp. Sta. Bul. 210. 1909. 348. Fulton, H. R., Diseases affecting rice. La. Agr. Exp. Sta. Bul. 105. 1908. 349. Metcalf, Haven, A preliminary report on the blast of rice. S. C. Agr. Exp. Sta. Bul. 121. 
1906. 350. Anderson, A. P., Rice blast and a new smut on the rice plant. S. C. Agr. Exp. Sta. Bul. 41. 1899. 351. Cobb, N. A., Fungus maladies of the sugar-cane. Hawaiian Sug. Pl. Assn. Bul. 5. 352. Reed, G. M., The powdery mildews of Avena and Triticum. Mo. Agr. Exp. Sta. Res. Bul. 23. 1916. 353. Heald, F. D., Report on the plant diseases prevalent in Nebraska during the season of 1905. Neb. Agr. Exp. Sta. Rept. 19: 46. 1906. 354. Selby, A. D., Some diseases of wheat and oats. Ohio Agr. Exp. Sta. Bul. 97. 1898. 355. Smith, E. F., A new disease of wheat. Jour. Agr. Res. 10: 51. 1917. 356. Sinith, E. F., In the Plant Disease Bulletin 2: No. 6, 98, issued by the Plant Disease Survey. 1918. 357. Gilbert, A. H., and Bennet, C. W., Sclerotinia trifoliorum, the cause of stem-rot of clovers and alfalfa. Phytop. \%: 432. 1917. 358. Jones, F. R., The yellow-leaf blotch of alfalfa caused by the fungus Pyrenopeziza medicaginis. Jour. Agr. Res. 13: 307. 191S. 359. Stewart, F. C., French, G. T., and Wilson, J. K., Troubles of alfalfa in New York, N. Y. (Geneva) Agr. Exp. Sta. Bul. 305. 1908. 360. Bain, S. M., and Essary, S. H., A preliminary note on clover diseases in Tennessee. Sc. n. s. 22: 503. 1905. 361. Paddock, W., A new alfalfa disease. Colo. Agr. Exp. Sta. Press Bul. 2S. 1906. 362. Sackett, W. G., A bacterial disease of alfalfa. Colo. Agr. Exp. Sta. Bul. 158. 1910. 363. Field, E. C., Ms. Article. U. S. Dept. Agr., B. P. I. 364. Hillman, F. H., Dodder in relation to farm seeds. U. S. Dept. Agr. Farms'. Bul. 306. 1907. 365. Bain, S. M., and Essary, S. H., Selection for disease-resistant clover. Tenn. Agr. Exp. Sta. Bul. 75. 1906. 366. Orton, W. A., Some diseases of the cowpea. U. S. Dept. Agr., B. P. I. Bul. 17. 1902. 367. Brown, H. B., and Ranck, E. M., Forage poisoning due to Claviceps paspali on Paspalum. Miss. Agr. Exp. Sta. Tech. Bul. 6. 1915. 368. Osner, G. A., Leaf smut of timothy. N. Y. (Cornell) Agr. Exp. Sta. Bul. 381. 1916. 369. Lewis, A. C., Cotton wilt in Georgia. Ga. St. Bd. Ent. Bul. 40. 1915. 370. Barre, H. W., Cotton anthracnose. S. C. Agr. Exp. Sta. Bul. 164. 1912. 371. Rolfs, F. M., Cotton anthracnose. Okla. Agr. Exp. Sta. Cir. 40. 1916. 372. Shear, C. L., and Miles, Geo. F., The control of Texas root-rot of cotton. U. S. Dept. Agr., B. P. I. Bul. 102. Part V. 1907. 373. Shear, C. L., and Miles, Geo. F., Texas root-rot of cotton. U. S. 
Dept. Agr., B. P. I. Cir. 9. 1908. 374. Rolfs, F. M., Angular leafspot of cotton. S. C. Agr. Exp. Sta. Bul. 184. 1915. 375. Edgerton, C. W., The rots of the cotton boll. La. Agr. Exp. Sta. Bul. 18\%. 1912. 376. Bolley, H. L., Flax wilt and flax sick soil. N. Dak. Agr. Exp. Sta. Bul. 50. 1901. 377. Charles, V. K., A fungous disease of hemp. Jour. Agr. Res. 3: 81. 1915. 378. Rankin, W. H., Manual of tree diseases. The Macmillan Co. 1918. 379. Schrenk, H. v., Fungous diseases of forest trees. U. S. Dept. Agr. Yearbook 1900: 199. 1901. 380. Abbott, F. H., The red-rot of conifers. Vt. Agr. Exp. Sta. Bul. 191. 1915. 381. Kauffman, C. H., The Agaricaceæ of Michigan. Mich. Geol. and Biol. Surv. Pub. 26. Biol. ser. 5. 1918. 382. Overholts, L. O., The Polyporacex of the middle-western United States. Wash. Uni. Studies 3. Part 1. No. 1. 1915. 383. Hard, M. E., The Mushroom. The Ohio Library Co. 1908. 384. McIlvaine, C., One thousand American fungi. The Boden Merrill Co. 1900. 385. Atkinson, G. F., Mushrooms. Ithaca, N. Y. 1901. 386. Marshall, N., The mushroom book. Doubleday Page \& Co. 1905. 387. Moffatt, W. S., The higher fungi of the Chicago region. Chicago Academy of Sciences. 1909. 388. Schrenk, H. v., Some diseases of New England conifers. U. S. Dept. Agr., Div. Veg. Physs. \& Path. Bul. 25. 1900. 389. Schrenk, H. v., and Spaulding, P., Diseases of deciduous forest trees. U. S. Dept. Agr., B. P. I. Bul. 149. 1909. 390. Stevens, F. L., The fungi which cause plant disease. Macmillan Co. 1913. 391. Duggar, B. M., Fungous diseases of plants. Ginn \& Co. 1909. 392. Saccardo, P. A., Sylloge fungorum omnium hucusque cognitorium, Pavia. R. Friedlander \& Sohn. 1882. 393. Engler and Prantl, Natürlichen Pflanzenfamilien. Wm. Engelmann. 1897. 394. Rabenhorst, Kryptogamen Flora von Deutschland Oesterrich und der Schweiz. 1887. 395. Sherfesee, W. F., Wood preservation in the United States. U. S. Forestry Service Bul. 78. 1909. 396. Hunt, G. M., The preservative treatment of farm timbers. U. S. Dept. Agr. Farms'. Bul. r44. 1916. 397. Wier, J. R., Larch mistletoe: some economic considerations of its injurious effects. U. S. Dept. Agr. Bul. s1\%. 1916. 398. Shear, C. L., Grape anthracnose in America. Int. Cong. Vit. San Francisco. 1915. 399. Hartley, C., Merrill, T. C., and Rhoades, A. S., Seedling diseases of 
conifers. Jour. Agr. Res. 15: 521. 1918. 400. Reddick, D., and Gladwin, F. E., Powdery mildew of grapes and its control in the United States. Int. Cong. Vit. San Francisco. 1915. 401. Collins, J. F., Practical tree surgery. U. S. Dept. Agr. Yearbook 1913: 163. 1914. 402. Stone, G. E., Shade trees. Mass. Agr. Exp. Sta. Bul. 170. 1916. 403. Peets, E., Practical tree repair. McBride \& Co. 1916. 404. Schrenk, H. v., A disease of the white ash caused by Polyporus fraxinophilus. U. S. Dept. Agr., B. P. I. Bul. 32. 1903. 405. Sehrenk, H. v., The hardy catalpa. U. S. Dept. Agr. Bur. For. Bul. 3\%. 1902. 406. Kern, F. D., A biologic and taxonomic study of the genus Gymnosporangium. Bul. N. Y. Bot. Gard. $\%$ : 391. 1911. 407. Schrenk, H. v., White rot of the red cedar. U. S. Dept. Agr. Div. Veg. Phys. \& Path. Bul. 21. 1900. 408. Shear, C. L., et al., Endothia parasitica and related species. U. S. Dept. Agr. Bul. 3S0. 1917. 409. Anderson, J. P., and Rankin, W. H., Endothia canker of chestnut. N. Y. (Cornell) Agr. Exp. Sta. Bul. 34\%. 1914. 410. Birss, H. P., A new filbert disease in Oregon. Bien. Crop Pest and Hort. Rept. 2: 213. 1915. 411. Weir, J. R., and Hubert, F. E., A study of heart-rot in western hemluck. U. I. Dept. Agr. Bul. Y.s. 1918. 412. Stewart, V. B., The leaf bloteh of horse chestnut. N. Y. (Cornell) Agr. Exp. Sta. Bul. 3\%1. 1916. 413. Humphry, J. F., A hazel fungus. Mass. (Amherst) Agr. Exp. Sta. Rept. 10: 242. 414. Schrenk, H. v., A disease of the black locust. Mo. Bot. Card. Rept. 12:21. 1901. 415. Rand, F. V., Some diseases of pecans. Jour. Agr. Res. 4: 303. 1914. 416. Matz, J., Diseases and insect pests of the pecan. Fla. Agr. Exp. Sta. Bul. 14\%. 1918. 417. Orton, W. A., and Rand, F. V., Pecan rosette. Jour. Agr. Res. 3: 149. 1914. 418. MeMurran, S. M., Pecan rosette in relation to soil deficiencies. U. S. Dept. Agr. Bul. $\% 56$. 1919. 419. Spaulding, P., The whitepine blister rust. U. S. Dept. Agr. Farms'. Bul. 742. 1916. 420. Spaulding, P., The blister rust of white pine. U. S. Dept. Agr., B. P. I. Bul. Pof. 1911. 421. Schrenk, H. v., The bluing and the red-rot of the western yellow pine with especial reference to the black hills forest reserve. U. S. Dept. Agr., B. P. I. Bul. 36. 1903. 422. Hedgeock, (i. (i., and Hunt, N. R., Dothichiza populea in the United States. Myc. 8: 300. 1916. 423. MeMurran, S. M., Wal- 
nut blight in the eastern United States. U. S. Dept. Agr. Farms'. Bul. 611. 1917. 424. Smith, R. E., Walnut culture in California. Walnut blight. Cal. Agr. Exp. Sta. Bul. 231. 1912. 425. Fawcett, H. S., Melaxuma of the walnut. Cal. Agr. Exp. Sta. Bul. 261. 1915. 426. Smith, R. E., Growing China asters. Mass. Agr. Exp. Sta. Bul. 79. 1902. 427. Townsend, C. O., A soft-rot of the calla lily. U. S. Dept. Agr., B. P. I. Bul. 60. 1904. 428. Arthur, J. C., Bot. Gaz. 321. 1891. 429. Stewart, F. C., Combating earnation rust. N. Y. (Geneva) Agr. Exp. Sta. Bul. 100. 1896. 430. Stevens, F. L., and Hall, J. G., Carnation alternariose. Bot. Gaz. 4\%: 409. 1909. 431. Woods, A. F., Bacterial spot, a new disease of carnations. Sc. n. s. 18: 537. 1903. 432. Stewart, F. C., The stem-rot diseases of the carnation. Bot. Gaz. 2\%: 129. 1899. 433. Stewart, F. C., Notes on various plant diseases. N. Y. (Genera) Agr. Exp. Sta. Bul. 164. 1899. 434. Stewart, F. C., and Hodgkiss, H. E., The Sporotrichum bud-rot of carnations and the silver top of June grass. N. Y. (Geneva) Agr. Exp. Sta. Tech. Bul. \%. 1908. 435. Beach, S. A., Leaf spot of chrysanthemums. N. Y. (Geneva) Agr. Exp. Sta. Rept. 11: 557. 1893. 436. Arthur, J. C., Chrysanthemum rust. Ind. Agr. Exp. Sta. Bul. 85: 150. 1900. 437. Stevens, F. L., The chrysanthemum ray-blight. Bot. Gaz. 44: 241. 1907. 438. Harter, L. L., Storage-rots of economic aroids. Jour. Agr. Res. 6: 549. 1916. 439. Arthur, J. C., Disease of clematis. N. Y. (Geneva) Agr. Exp. Sta. Rept. 3: 383. 1884. 440. Stewart, F. C., Notes on New York plant diseases. N. Y. (Genera) Agr. Exp. Sta. Bul. 328. 1910. 441. Gloyer, W. O., Ascochyta clematidina, the cause of stem-rot and leaf-spot of clematis. Jour. Agr. Res. 4: 331. 1915. 442. Massey, L. M., The hard rot disease of gladiolus. N. Y. (Cornell) Agr. Exp. Sta. Bul. 389. 1916. 443. Ward, H. M., A lily disease. Ann. Bot. 2: 319. 1888. 444. Woods, A. F., The Bermuda lily disease. U. S. Dept. Agr. Div. Veg. Phys. \& Path. Bul. 14. 1897. 445. Smith, C. O., A bacterial disease of oleander. Bot. Gaz. 42: 301. 1906. 446. Smith, R. E., A new Colletotrichum disease of the pansy. Bot. Gaz. 27: 203. 1899. 447. Wolf, F. A., A Fusarium disease of the pansy. Myc. 2: 19. 1910. 448. Patterson, Mrs. Flora, and Charles, Vera K., Disease of peonies caused by Botrytis. U. S. Dept. Agr., B. P. I. Bul. 171. 1910. 449. 
Wolf, F. A., Black-spot of roses. Ala. Agr. Exp. Sta. Bul. 172. 1913. 450. Anderson, P. J., Rose canker and its control. Mass. Agr. Exp. Sta. Bul. 183. 1918. 45i. Jenkins, A. E., Brown canker of roses caused by Diaporthe umbrina. Jour. Agr. Res. 15: 593. 1918. 452. Stewart, F. C., An anthracnose and a stem-rot of the cultivated snapdragon. N. Y. (Geneva) Agr. Exp. Sta. Bul. 1\%9. 1900. 453. Peltier, L. R., Snapdragon rust. Ill. Agr. Exp. Sta. Bul. 2221. 1919. 454. Taubenhaus, J. J., The diseases of the sweet pea. Del. Agr. Exp. Sta. Bul. 106. 1914. 455. Lawrence, W. H., Plant diseases induced by sclerotinia perplexa, nov. sp. Wash. Agr. Exp. Sta. Bul. 107. 1912. 456. Dorsett, P. H., Spot disease of the violet. U. S. Dept. Agr., Div. Veg. Phys. \& Path. Bul. 23. 1900. 457. Coleman, D. A., and Regan, S. A., Nematode galls as a factor in the marketing and milling of wheat. U. S. Dept. Agr. Bul. 734. 1918. 458. Whetzel, H. H., Some diseases of beans. N. Y. (Cornell). Agr. Exp. Sta. Bul. 239. 1906. 459. Sinith, R. E., Tomato diseases in California. Cal. Agr. Exp. Sta. Bul. 1\%5. 1906. 460. Atkinson, G. F., Edema of the tomato. N. Y. (Cornell) Agr. Exp. Sta. Bul. 53. 1893. 461. Clinton, C. P., The smuts of Illinois Agricultural plants. Ill. Agr. Exp. Sta. Bul. $5 \%$. 1900. 462. Lind, J., The barberry bush and its law. Denmark MIs. translation issued by the U. S. Dept. of Agr. 463. Wilcox, F. M., A leaf-curl disease of oaks. Ala. Agr. Exp. Sta. Bul. 126. 1903. 464. Fairchild, D. G., A mignonette disease. U. S. Dept. Agr. Rept. 89: 429. 1889. 465. Gregory, C. T., Studies on Plasmopara viticola (downy mildew of grapes). Int. Cong. Vit. San Francisco. 1915. 466. Massey, L. M., The diseases of roses. Trans. Mass. Hort. Soc. 1918. 467. Beach, W. S., The Fusarium wilt of China asters. Mich. Acad. Sc. Rept. 20. 1918. 468. Kunkel, L. O., Wart of potatoes: a disease new to the United States. U. S. Dept. Agr., B. P. I. Cir. 6. C. T. \& F. C. D. 1919. 469. Johnson, J., and Milton, R. H., Strains of white Burley tobacco resistant to root-rot. U. S. Dept. Agr. Bul. \%65. 1919. 470. Coons, G. H., An undescribed bark canker of apple and the associated organisms. Mich. Acad. Sc. Rept. 17. 1915. 471. Faulwetter, R. C., The angular leaf spot of cotton. S. C. Agr. Exp. Sta. Bul. 198. 1919. 472. Colby, A. S., Sooty blotch of apples. To be published in Trans. Ill. Acad. Sc. 1919. 
473. Brooks, C., Effect of temperature, aëration, and humidity on Jonathan-spot and scald of apples in storage. Jour. Agr. Res. 2: 287. 1917. 474. Brooks, C., and ('ooley, J. S., Apple-scald. Jour. Agr. Res. 16: 195. 1919. 475. Fromme, F. D., and Wingard, S. A., Bean rust. Var. Agr. Exp. Star. Bul. 르. 1918. 476. Carsner, E., Angular leaf-spot of cucumber. Jour. Agr. Res. 15: 201. 1918. 477. MareMillan, H. (r., Fusarium-blight of potatoes under irrigation. Jour. Agr. Res. 16: 279. 1919. 478. Harter, L. L., Weimer, J. L., and Adams, J. M. R., Sweet potato storage rots. Jour. Agr. Res. 15: 337. 1918. 479. Fromme, F. D., Angular leaf-spot of tobaceo, an undescribed bacterial disease. Jour. Agr. Res. 16: 219. 1919. 480. Sterens, F. L., An apple canker due to Cytospora. Ill. Agr. Exp. Sta. Bul. 21\%. 1919. 481. Stevens, F. L., and True, E. Y., Black spot of onion sets. Ill. Agr. Exp. Sta. Bul. 2.20. 1919. 482. Byars, L. P., The eelworm disease of wheat and its control. U. S. Dept. Agr. Farms'. Bul. 1011. 1919. 483. Darnell-Smith, (i. P., and MeKimnon, E., Diseases of wheat. X. S. Wales Dept. Agr. Farms'. Bul. 10?. 1915. 484. Swingle, D. B., and Morris, H. E., Plum pocket and leaf gall of American plums. Mont. Agr. Exp. Sta. Bul. 13.3. 1918. 485. Stevens, F. L., Foot-rot disease of wheathistorical and billiographic. Ill. Nat. Hist. Surv. Bul. 13, Art. 9. 1919. 486. Johnson, E. ('., Timothy rust in the United States. U. S. Dept. Agr. B. P. I. Bul. 2⿱口儿. 1911. 487. Jones, F. R., The leaf spot diseases of alfalfa and red clover caused by the fungi psendopeziza medieaginis and Pseudopeziza trifolii, respectively. U. S. Dept. Agr. Bul. 759. 1919. 488. Stevens, F. L., Progress in control of plant diseases. Pop. Sc. Mo. May. 1911. 489. Hasse, Clara H., Pseudomonas citri, the cause of citrus-canker. (A preliminary report.) Jour. Agr. Res. 4: 97. 1915. 490. Tanaka, Tyzalsuro, A brief history of the discovery of citrus-canker in Japan and experiments in its control. Quart. Bul. State Plant Bd. Fla. 3: 1. 1918. 491. Berger, E. W., Citrus-canker in the Gulf coast country, with notes on the extent of citrus culture in the localities visited. Proc. 27th Ann. Meeting, Fla. State Hort. Soc. 120. 1914. 492. Stirling, Frank, Eradication of citrus canker. Fla. Agr. Exp. Sta. Bul. 1.34: 4t. 1914. 493. Stakman, E. C., Piemeisel, F. J., Biologic forms of Puccinia graminis on cereals and 
grasses. Jour. Agr. Res. 10: 480. 1917. 494. Duke of Bedford and Pickering, S. U., Potato spraying. Woburn Exp. Fruit Farm, Rept. 14: 1. 1914. 495. Pickering, S. U., Copper fungicides. Jour. Agr. Sc. 4: 273. 1912. 496. Metcalf, H., and Collins, J. F., The present status of the chestnut bark disease. U. S. Dept. Agr. B. P. I. Bul. 141. 1909. 497. Hawkins, L. A., Some factors influencing the efficiency of Bordeaux mixture. U. S. Dept. Agr. B. P. I. Bul. 265. 1912. 498. Ruth, W. A., Spraying experiments in 1912 at Flora, Clay county. Ill. Agr. Exp. Sta. Bul. 185: 107. 1916. 499. Van Slyke, L. L., Bosworth, A. W., and Hedges, C. C., Chemical investigation of best conditions for making lime-sulphur wash. New York (Geneva) Agr. Exp. Sta. Bul. 329. 1910. 500. Blodgett, F. M., Experiments in the dusting and spraying of apples. N. Y. (Cornell) Agr. Exp. Sta. Bul. 349. 1914. 501. Reddick, Donald and Crosby, C. R., Further experiments in the dusting and spraying of apples. N. Y. (Cornell) Agr. Exp. Sta. Bul. 354. 1915. 502. Reddick, Donald and Croshy, C. R., Dusting and spraying experiments, with apples. N. Y. (Cornell) Agr. Exp. Sta. Bul. 369. 1916. 503. Stewart, V. B., Dusting and spraying nursery stock. N. Y. (Cornell) Agr. Exp. Sta. Bul. 385. 1917. 504. Hoffer, G. N., and Johnson, A. G., Atanasoff, D., Corn root rot and wheat scab. Jour. Agr. Res. 14: 611. 1918. 505. Brock, W. S., Results of spraying experiments at Neoga Station, Cumberland County, 1916. Trans. Ill. Hort. Soc. 50: 260. 1916. 506. Hoffer, G. N., and Holbert, J. R., Selection of disease free seed corn. Ind. Agr. Exp. Sta. Bul. 224. 1918. 507. Wallace, Errett, and Evans, L. H., Commercial Bordeaux Mixtures. U. S. Dept. Agr. Farms' Bul. 994. 1913. 508. Crane, H. L., A study of the factors governing the efficiency of distribution and rate of discharge of spray nozzles. W. Va. Agr. Exp. Sta. Bul. 169. 1919. 509. Childs, Leroy, New facts regarding the period of ascospore discharge of the apple scab fungus. Oregon Agr. Exp. Sta. Bul. 143. 1917. 510. Blair, W. S., Ann. Rept. Fruit Growers' Assoc. Nova Scotia, 132-159. 1917. 511. Morse, W. J., Apple spraying experiments in 1916 and 1917. Maine Agr. Exp. Sta. Bul. 271. 1918. 512. Fromme, F. D., and Ralston, G. S., Dusting Experiments in peach and apple orchards. Va. Agr. Exp. Sta. Bul. 223. 1919. 513. Hedrick, U. P., Bordeaux injury. N. Y. (Geneva) Agr. Exp. Sta. Bul. 287: 142. 1907. 514. Wallace, Errett, Spray 
injury induced by lime-sulfur preparations. N. Y. (Cornell) Agr. Exp. Sta. Bul. 288: 123-125. 1910. 515. Talbert, T. J., Combined dormant and first summer spray in apple orchards infested by San José scale. Mo. Agr. Exp. Sta. Bul. 161. 1919. 516. Pollock, J. B., The longevity in the soil of the Sclerotinia causing the brown-rot of stone fruits. Mich. Acad. Sci. Rept. 20: 279. 1918. 517. Bain, S. M., The action of copper on leaves. Temn. Agr. Exp. Sta. Bul. Vol. 15, No. 2: 44. 1902. 518. Crandall, C. S., Bordeaux mixture. Ill. Agr. Exp. Sta. Bul. 135: 233. 1909. 519. Selby, A. D., A brief handbook of the diseases of cultivated plants in Ohio. Ohio Agr. Exp. Sta. Bul. 214. 1910. 520. Pammel, L. H., King, C.. M., Seal, J. L., Studies on a Fusarium disease of corn and sorghum. Ia. Agr. Exp. Sta. Res. Bul. 33. 1916. 521. Gunderson, A. J., Field experience in spraying apple orchards for the control of apple blotch. Ill. Agr. Exp. Sta. Bul. 222. 1919. 522. Schoene, W. J., and Reppert, R. R., Growth of apple trees injured by crown gall and woolly aphis. Quart. Bul. Va. State Crop. Pest. Comm., I. No. 2. 1919. 523. Ball, E. D., The potato leafhopper and its relation to the hopperburn. Journ. Econ. Ent. Ames, Iowa, 12: 149. 1919. 524. Guba, E. F., and Anderson, P. J., Phyllosticta leaf spot and damping off of snapdragons. Phytop. 9: 315. 1919. 525. Humphrey, H. B., and Johnson, A. G., Take all and flag smut, two wheat diseases new to the U. S. U. S. Dept. Agr. Farms'. Bul. 106.3. 1919. 526. Humphrey, H. B., Cereal diseases and the national food supply. U. S. Dept. Agric. Yearbook 191\%: 481. 1918. 527. Tisdale, W. B., Iris leaf spot caused by Didymellina iridis. Phytop. 10: 147. 1920. 528. Hoffer, G. N., Disease free sweet corn seed. Ind. Agr. Exp. Sta. Bul.233: 1920. 529. Peltier, G. L., Carnation stem rot'and its control. Ill. Agr. Exp. Sta. Bul. 223: 1919. 530. Long, W. H., An undescribed canker of poplars and willows caused by Cytospora chrysosperma. Jour. Agr. Res. 13: 331. 1918. 531 Bisby, G. R., Studies on Fusarium diseases of potatoes and truck crops in Minnesota. Minn. Agr. Exp. Sta. Bul. 181. 1919. 532. Tisdale, W. H., Bacterial blight of soy bean. N. C. Agr. Exp. Sta. Rept. 1918. 59. 533. Coerper, Florence M., Bacterial blight of soybean. Jour. Agr. Res. 18: 179. 1919. 534. Wolf, F. A., Bacterial blight of soybean. Phytop. 10: 1920. 535. Wolf, F. A., and Cromwell, R. O., Clover stem rot. N. C. Agr. Exp. Sta. Tech. Bul. 16. 1919. 536. 
Fisher, D. F., and Newcomb, E. J., Controlling important fungous and insect enemies of the pear in the humid sections of the Pacific northwest. Farms'. Bul. 1056. 1919. 537. Fromme, F. D., The Nematode disease of wheat in Virginia. Va. Agr. Exp. Sta. Bul. 222. 1919. 538. Stakman, E. C., and Levine, M. N., Rye smut. Minn. Agr. Exp. Sta. Bul. 160. 1916. 539. Byar's, L. P., and Gilbert, W. W., Soil disinfection with hot water to control the rootknot nematode and parasitie soil fungi. U. s.. Dept. Agr. Bul. 818 . 1920. 540. Rand, Frederick B., and Ella M. A. Fnlows, Bacterial wilt of cucurbits. U. S. Dept. Agr. Bul. S2S. 1920. 541. Schultz, E. S., Folsom, D., Hildebrandt, F. M., and Hawkins, I. A., Investigations of the mosaic disease of the Irish potato. Jour. Agr. Res. 17: 247. 1919. 542. Meier, F. C., Control of watermelon anthracnose by spraying. U. S. Dept. Agr. ('ire. 99. 1920. 543. McMurran, S. M., The anthracnose of the mango in Florida. U. S. Dept. Agr. Bul. 52. 1914. 544. Stevens, N. E., and Morse, F. W., The effect of the endrot fungus on cranberries. Amer. Jour. Bot. 6: 235. 1919. 545. Higgins, B. B., A ('ollecetotrichum leafspot of turnips. Jour. Agr. Res. 10: 157. 1917. 546. Brandes, E. W., Banama wilt. Phytop. 9: 339. 1919. 547. Quanjer, H. MI., The mosais disease of the solanacex, its relation to the philoem-necrosis, and its effect upon potato culture. Phytop. 10: 35. 1920. 548. Botjes, J. O., Raising phloem-necrosis and mosaic free potatoes, and a source of infection whose nature has not yet been elucidated. Phytop. 10: 48. 1920. 549. Orton, ('. R., and Keern, F'. D., The potato wart disease. Penn. Agr. Lxp. Sta. Bul. 15tj. 1919. 550. Walker, J. C., Onion diseases and their control, U. S. Dept. Agr. Farms'. Bul. 1060. 1919. 551. Stakman, E. C., The black stem rust and the barberry. U. S. Dept. Agr. Yearbook, 1918: 75. 1919. 552. Rosen, H. R., A Bacterial root-rot of field corn. Ark. Agr. Exp. Sta. Bul. 162. 1919. 553. Taubenhaus, J. J., Field diseases of the sweet potato in Texas. Texas Agr. Exp. Sta. Bul. 249. 1919. 554. Stevens, F. L., Foot-rot of wheat. Sc. N. A. 51: 517. 1920. 555. Greene, Laurenz and Melhus, I. F., The effect of crown gall upon a young apple orchard. Iowa Agr. Exp. Sta. Res. Bul. 50. 1919. 556. Miles, I. E., Elm leaf diseases. To be published in the Botanical Gazette. 


\section{INDEX}

Abutilon, 407.

Acalypha, 407.

Acanthorhynchus vaccinii, 111.

Acanthostigma, 379 .

Achillea, 407.

Acremonium, 191.

Actinomyces seabies, $163,220$.

Actinonema, 430.

Adonis, 407.

Ecidium, 119, 390, 411, 423. gossypii, 350.

Agave, 408.

Ageratum, 407.

Agropyron, 277, 278, 340.

Agrostis, 277, 278, 340.

Aira, 278.

Albugo, 173, 408.

bliti, 164.

candida, 172, 196, 427.

ipomøæ-panduranæ, 250, 427.

tragopogonis, 241.

Alder, 361, 367, 369, 371, 379, 381 .

Alfalfa, 22, 23, 24, 88, 163,321 .

Algal leaf-spot, 144, 147.

Allseed, 163.

Almond, 25, 74, 87.

Alopecurus, 277, 278.

Alternaria, 57, 69, 195, 217, 328, $352,415,427$.

brassicæ, 169 . var. nigrescens, 183.

citri, 141.

dianthi, 415.

panax, 193.

solani, 226, 264.

violæ, 436 .

Alyssum, 407.

Amarantus, 407, 408.

Amerosporium œconomicum, 335.

Ammoniacal copper carbonate, 447.
Ampelopsis, 439.

Andromeda, 409.

Anemone, 407, 409.

Angular leaf-spot, 114, 185, 257, $337,349,424$.

Anthostomella, 145.

Anthoxanthum, 277, 278.

Anthracnose, 102, 112, 115, 119, $128,135,143,147,151,152$, $173,180,192,194,199,217$. $241,242,264,280,300,307$. $309,317,324,328,330,331$, $339,340,342,345,383,388$. $392,395,408,409,412,421$, $424,428,429,430,433,434$, $435,437$.

Antirrhinum, 407.

Aposphæria, 134.

Apple, 23, 31, 87, 361, 367, 368, 369,372 .

Apricot, 74, 87, 90.

Aquilegia, 407.

Aralia, 408.

Arbor-vitæe, 367, 369, 371, 380.

Arbutus, 88.

Armillaria, 117, 367.

mellea, 53, 370 .

root-rot, $79,96,101$.

Arrenantherum, 277.

Arsenical injury, 240.

Artichoke, 435.

Ascochyta, 134, 210, 369, 379.

abelmoschi, 201.

armoraciæ, 195.

chrysanthemi, 419.

clematidina, 420 .

leaf-spot, 327.

medicaginis, 327 .

primulæe, 429.

Ash, 23, 364, 367, 368, 369, 379, 380,381 .

Asparagus, 10, 25, 149, 407. 
Aspen, 359, 367.

Aspidistra, 409.

Aster, 22.

china, 409.

Asterina, 379.

Aucuba, 407.

Avena, 277, 278.

Avocado, 135.

Azalea, 113, 411.

Bacillus, 427.

amylovorus, $41,62,70,74,79$, 101.

carotovorus, 172, 173, 178, 208, $412,420$.

coli, 144.

lathyri, 435.

melonis, 188.

phytophthorus, 231.

sorghi, 307.

tracheiphilus, 182.

Bacteria, 217, 299, 304, 342, 369, $389,426$.

Bacterial blight, 213, 337 .

leaf-spot, 164, 422 .

rot, 199 .

spotting, 200, 416.

wilt, 260.

Bacterium michiganense, 260.

mori, 393.

rathayi, 339 .

teutlium, 164.

Balm, 411.

Balsam, 367.

Bamboo, 411.

Banana, 135.

Barberry, 312, 411.

Bark canker, 56, 69.

disease, 386.

Barley, 163, 280.

Barnyard-grass, 338.

Barrel pump, 454.

Bartonia, 407.

Basswood, 372.

Bean, 22, 23, 25, 152, 163.

Beckmannia, 277.

Bed-rot, 257.

Beech, 359, 361, 364, 365, 367, 369, $380,381$.

Beet, 22, 23, 25, 27, 87, 159, 163.

Begonia, 24, 407, 408, 412 .
Bellflower, 23.

Berberis, 407.

Bermuda lily disease, 426.

Birch, 359, 361, 364, 365, 367, 368, $369,371,379,380,381,382$.

Bitter-pit, 54.

Bitter-rot, 31, 69, 72, 132.

Blackberry, 87, 102.

Black-chaff, 319 .

Black-heart, 148, 235.

Black-knot, $75,97$.

Blackleg, 169, 231.

Black-mold, 57, 69, 169, 196, 210, $213,216,243,328,331,427$.

Black-root, 163, 173.

Black-rot, 42, 47, 72, 120, 141, 165 , $194,247,260$.

Black-rot canker, 69.

Black-rust, 350.

Black-scurf, 225.

Black-smut, 146, 302.

Black-spot, 70, 74, 79, 90, 101, 205, 217.

canker, 430.

Black-stem-rust, 282, 298, 305, 310, $339,340$.

Black-walnut, 359.

Blast, 110, 339, 380.

Bletia, 412.

Blight, 62, 70, 74, 79, 101, 144, 155, $165,193,195,199,203,242$, $251,260,282,294,299,307$, $324,389,393,394,403,404,421$, $422,425,427$. (See also earlyblight, southern-blight, lateblight, blister-blight, blossomblight, brown-blight, bacterial-blight, body-blight, podblight, stem-blight, coryneumblight, leaf-blight, cane-blight.)

Blister-canker, 44.

Blister-rust, 119, 395.

Blossom-blight, 41.

Blossom-drop, 265.

Blossom-end rot, 263.

Blossom rot, 191.

Blotch, 37.

Blueberry, 110.

Bluegrass, 280, 338.

Blue-mold, 51, 108, 132, 141, 193, 250 . 
Blue-stem, 110.

Bluing, 397.

Body-blight, 41.

Boll-rot, 346.

Bordeaux-injury, 450.

Bordeaux mixture, 6, 440.

Botryosphæria, 346. berengeriana, 395 . marconii, 353.

ribis, 113.

Botrytis, 10, 20, 174, 369, 416, 421, $422,426,427,428,430,436$. ailii, 206.

blight, 195.

cinerea, 198.

fascicularis, 192.

rot, 134.

Box-elder, 369.

Breeding for resistance, 7.

Bremia lactucæ, 198.

Broccoli, 165.

Bromus, 277, 278.

Bronzing, 433.

Broom corn, 283.

Broom rape, 331.

Brown-canker, 432.

Brown-checked wood-rot, 361 .

Brown leaf-rust, 305.

Brown leaf-spot, 395.

Brown-rot, 55, 69, 73, 74, 75, 79, $101,135$.

Brown-spot, 292.

Brunnissure, 131.

Brussels-sprouts, 163, 165.

Bucket pumps, 452.

Buckeye, 390.

Buckeye-rot, 265.

Buckwheat, 22, 165.

Bud-rot, 144, 417.

Bunt, 314.

Burgundy mixture, 448.

Butternut, 359, 361, 367, 380, 381, 382.

Cabbage, 22, 23, 26, 163, 165.

Cacao, 135.

Cacao-disease, 245.

Calamagrostis, 277, 278.

Calendula, 407.

California vine-disease, 131.

Calla, 412.
Callistephus, 407, 409.

Calospora vanillie, 148.

Camellia, 408, 413.

Campanula, 407, 408.

Candytuft, 168.

Cane-blight, 105, 113.

Canker, 32, 35, 42, 69, 72, 135, 137 . $146,251,368,385,390,401$, $402,405,423,432$. (See also Pacific coast canker, blistercanker, black-rot canker, brown canker.)

Canna, 413.

Cantaloupe, 173.

Caper, 173.

Capnodium, 144, 408, 413.

Carnation, 22, 87, 414.

Carrot, 22, 23, 25, 173.

Cassandra calyculata, 113.

Castor-bean, 174.

Catalpa, 25, 368, 373, 379, 380, 381,382 .

Cauliflower, 23, 163, 165.

Cedar, 69, 367, 383.

Celery, 22, 25, 163, 174.

Celosia, 407.

Cenangium, 369 .

Centaurea, 407.

Cephaleuros, 251. virescens, 144, 147.

Cephalothecium, 395. roseum, 49.

Ceratostomella pilifera, 397 .

Cercospora, 201, 217, 348, 379, $439,524$.

althæina, 424 .

angulata, 114.

apii, 176.

armoraciæ, 196.

beticola, 159, 244.

bolleana, 146.

capsici, 217.

circumscissa, 96.

coffeicola, 145.

concors, 234.

cruenta, 159, 337.

fusca, 395.

leaf-spot, 132, 159, 191, 327, 331.

longipes, 245.

medicaginis, 327.

microsora, 391. 
nicotianæ, 257.

personata, 214.

phlogina, 429.

resedæ, 426.

richardiæcola, 413.

rosæicola, 433.

shot-hole, 96.

Cercosporella albomaculans, 173. persica, 96.

Cereal, 266.

anthracnose, 266.

rusts, 275 .

smuts, 266.

special diseases, 280 .

Chamæcyparis, 368, 369.

Charcoal-rot, 251.

Chard, 159.

Charrina, 132.

Cherry, 22, 25, 75, 87, 90, 96, 97, $361,367,369$.

Chestnut, 11, 87, 361, 367, 368, $369,371,373,380,381,386$, 388.

China-berry, 23, 369, 372.

Chive, 201.

Chlorosis, 148, 265, 295.

Choanephora cucurbitarum, 191.

Chrysanthemum, 23, 88, 407, 408, 418.

Chrysophlyetis, 224.

Cineraria, 24, 407, 420.

Citrus fruits, 135.

Citrus knot, 144.

Cladosporium carpophilum, 82, 99. citri, 142. cucumerinum, 187. fulvum, 262.

herbarum, 140, 439.

macrocarpum, 243.

viticolum, 132.

Claviceps paspali, 340.

purpurea, 304. rolfsii, 340 .

Cleistothecopsis circinans, 205.

Clematis, 24, 407, 420.

Clethra alnifolia, 113.

Clitocybe, 52, 372 . root-rot, 96.

Clover, 22, 24, 88, 163, 328.

Club-root, 26, 168,

Cluster-cup, 117, 119, 350, 409.
Coccomyces, 75 . prunophoræ, 98.

Cocoanut, 144.

Coffee, 144.

Coleosporium ipomœæ, 251, 427. senecionis, 420. solidaginis, 401, 410.

Coleus, 24, 407.

Collard, 165.

Colletotrichum, 20, 145, 148, 151, $192,205,244,251,345,352$, $379,427,428$.

agaves, 408 .

antirrhini, 434.

bletiæ, 412.

carica, 145.

cereale, $280,300,307,317$.

erumpens, 241.

falcatum, 309.

glœosporioides, 135, 143, 147.

higginsianum, 173.

lagenarium, 180.

lindemuthianum, 152 .

malvarum, 424.

nigrum, 217.

omnivorum, 409.

phomoides, 264.

primulæ, 429.

spinaceæ, 242.

trifolii, 324,330 .

violæ-tricoloris, 437.

Collybia, 367.

Colocasia, 420.

Combined fungicide and insecticide, 449.

Common-scab, 220.

Completoria complens, 422 .

Compressed air sprayers, 453.

Conifers, 355, 358, 361, 367, 368, $369,371,376,379,380$.

Coniothyrium, 105, 395.

fuckelii, 44.

Conveyors, $45 \%$.

Copper-blight, 251.

Copper sulfate, 448.

Copper-sulfate treatment, 271.

Coreopsis, 407.

Core-rot, 57.

Corn, 22, 88, 163, 283.

Cornus, 408.

Corrosive sublimate, 449. 
Corticium, 20, 135, 144, 146, 163, $193,194,376,402,407,410$, $435,439$.

keleroga, 145.

stevensii, 47.

vagum, $21,157,162,165,198$, $213,225,257,265,349,417$.

Coryneum beijerinckii, 87.

Coryneum-blight, 74, 87.

Cosmos, 407, 421.

Cotton, 22, 23, 24, 88 .

Cottonwood, 367, 369, 372, 380, 401 .

Cottony-rot, 137.

Covered smut, 282, 297.

Cowpea, 23, 24, 26, 331 .

Crab-grass, 339.

Cranberry, 110.

Cress, 163.

Cronartium, 369. cerebrum, 400. ribicola, 116, 395 .

Crown-gall, 51, 69, 73, 74, 79, 87, $101,104,132,164,350,405$, $408,422,433$.

Crown-rot, 144, 241.

Crown-rust, 298, 339.

Crown-wart, 325.

Crucifers, 24, 165.

Cryptosporella, 369 . anomala, 389. viticola, 129 .

Cucumber, 22, 25, 26, 178.

Cucurbit spraying, 191.

Cucurbits, 24, 178.

Cuphea, 407.

Cupressus, 369.

Curing-house disease, 259.

Curl, 77, 84.

Curly-dwarf, 233.

Curly-top, 160.

Currant, 22, 113, 367.

Cuscuta, 325. epilinum, 352.

Cutting-bench disease, 407.

Cuttings, 19.

Cyanospora, 369.

Cyclamen, 408, 421.

Cycloconium oleaginum, 147.

Cylindrocladium scoparium 432.

Cylindrosporium, 75, 98, 379 . chrysanthemi; 420. clematidis, 420 .

humuli, 195.

Cypress, 367.

Cystospora batatæ, 249.

Cytospora, 78, 86, 369, 405, 423. chrysosperma, 401.

Dactylis, 277, 278, 339 .

Dædalea, 367.

Dahlia, 24, 407, 408, 421.

Daisy, 408, 422 .

Damage caused by plant diseases, 10.

Damping off, 19, 24, 163, 173, 178, $193,194,198,213,252,258$, $265,303,328,349,352,376$, $399,427$.

Dandelion, 163.

Daphne, 23.

Dasyscypha, . 369.

resinaria, 390 .

Dead-arm, 129.

Decay in live trees, 354.

Decay of dead parts, 373.

Deciduous trees, $364,365,367,368$, $371,374$.

Dendrophoma, 353.

Dewberry, 88, 102.

Dianthus, 407, 408.

Diaporthe, 369.

batatatis, 250 .

phaseolorum, 158.

umbrina, 432 .

Dibotryon morbosum, 75, 97.

Didymellina viridis, 425 .

Didymosphæria, 379 .

Dieback, 74, 78, 86, 135, 144, 395, $402,404$. canker, 57, 69.

Diplocarpon rosæ, 430 .

Diplodia, 135, 144, 148, 187, 402, 420.

cacaoicola, 245.

gossypina, 346.

longispora, 394.

macrospora, 287.

tubericola, 250.

zeæ, 287.

Diplodina, 190.

Diseases due to impure air, 26.

Disease prevention, 236. 
Disinfection of seeds, 7 .

Doassansia gossypii, 349 .

Dodder, 144, 325, 331, 352 .

Dogwood, $369,381$.

Dothichiza, 369. populea, 401 .

Dothidea, 369.

Dothidella, 394.

Dothiorella gregaria, 404.

Double-blossom, 108.

Downy-mildew, 125, 158, 164, 171, $178,196,198,203,244,263$, $295,327,338,433,437$.

Dracæna, 422.

Dracocephalum, 408.

Drop, 26, 27, 158, 164, 170, 174, $193,196,258,409,426,435$.

Drupes, 74, 368.

Dry-rot, 230, 250, 287, 289, 374.

Dusting machines, 458.

Dwarf leaf-rust, 282.

Early-blight, 176, 226, 264.

Ear-rots, 286.

Echinodontium, 367. tinctorum, 389.

Eel-worms, 320, 412. (See also nematodes.)

Egg plant, 22, 23, 25, 26, 192.

Einkorn, 310.

Elder, 381.

Elm, 23, 25, 359, 364, 367, 369, 379, $380,381,388$.

Elymus, 277, 278.

Emmer, 310.

Endomyces, 57.

Endothia, 369. parasitica, 386.

End-rot, 112.

Entomosporium, 68, 70, 379.

Entyloma ellisii, 242.

Ergot, 282, 300, 304, 320, 339, 340.

Erigeron, 408.

Eriobotrya, 407.

Erysimum, 407.

Erysiphe, 173, 242, 338.

cichoracearum, 420, 429, 436.

communis, 421.

graminis, 317.

polygoni, 159, 165, 187, 213, 337 .

Eupatorium, 408.
Euphorbia, 328, 407.

European canker, 55, 72, 401. rust, 116.

Evonymus, 408.

Exoascus deformans, 84.

Exobasidium, 110, 251, 409, 411. oxycocei, 112.

Extension rod, 458.

Fabræa maculata, 68, 70. mespili, 73.

Falcata, 155.

Favolus, 367.

Ferns, 422.

Festuca, 277, 278.

Fiber-plant, 23, 343.

Field crops, 149.

Field sprayers, 454.

Fig, 23, 25, 145.

Filbert, $369,389$.

Fir, 365, 367, 368, 369, 371, 373, 380 .

Fire-blight, 41, 62, 74 .

Fistulina, 367.

Flag-smut, 316.

Flax, 23, 24, 26, 350.

Flower-blight, 379.

Flowering almond, 408.

Flowers of súlfur, 449 .

Flyspeck, 56, 69 .

Fomes, 367, 402.

annosus, 53, 371.

applanatus, 365 .

everhartii, 364.

fomentarius, 364 .

fraxinophilus, 381 .

fulvus, 361 .

igniarius, 359 .

juniperinus, 383.

pinicola, 365,401 .

ribis, 117,402 .

rimosus, 391 .

Foot-rot, 316.

Forage crops, 321.

Formalin, 449.

Formalin dry method, 270.

Formalin long-time treatment, 271.

Formalin wet method, 270.

Foxtail, 163.

Frost injury, 54.

Frosty-mildew, 96, 348. 
Fruit-rot, 57, 134, 145, 217, 263.

Fruit-spot, 57, 187.

Fumago vagans, 57, 265.

Fungicides, 440.

Fusarium, 20, 146, 178, 213, 249 , $257,289,318,325,331,346$, $376,399,416,418,420,435$. boll-rot, 346 .

conglutinans, 172, 409.

lini, 350 .

lycopersici, 250.

malli, 210.

oxysporum, 228.

rubi, 108.

vasinfectum, 181, 193, 201, 331, 343.

violæ, 437.

Fusicladium, 35, 68, 379, 402.

dendriticum, 147.

effusum, 394.

Fusicoccum, 129.

putrefaciens, 112.

Gall, 24, 113, 368, 402, 409, 420, 427. (See also crown-gall, nematode.)

Garlic, 201.

Gaultheria procumbens, 113.

Gaylussacia resinosa, 113.

General diseases, 19, 354.

Geranium, 422.

Gibbera, 110.

Gibberella saubinetii, 318, 331 .

Ginseng, 24, 193.

Gladiolus, 423.

Glœeodes pomigena, 55.

Glœeosporium, 20, 31, 44, 72, 102, $115,145,148,217,380,395$, $403,430,435$.

ampelophagum, 128.

apocryptum, 392.

caulivorum, 331.

euphorbix, 435.

medicaginis, 328 .

melongenæ, 192.

musarum, 135.

rosæe, 433.

violæ, 437.

Glomerella cingulata, $31,72,112$, $395,421,430,435$. gossypii, 345.

piperata, 217.

psidii, 146.

Glume blotch, 319.

Gnomonia, 380.

leptostyla, 382, 403.

ulmea, 388 .

veneta, 403.

Gnomoniella, 380.

Godetia, 407.

Golden glow, 407.

Goldenseal, 24, 195.

Gooseberry, 10, 117, 367.

Granville wilt, 253.

Grape, 25, 87, 120.

Graphiola-blight, 428.

Graphiola phoenicis, 428.

Grass, 23, 163, 338.

Gray-blight, 251.

Gray-mold, 108, 174, 192, 198, 416, $422,426,430,436$.

Gray-rot, 132.

Green-smut, 301.

Guava, 146.

Guignardia, 110.

æsculi, 390.

bidwellii, 120, 439 .

vaccinii, 110 .

Gummosis, 74, 141.

Gymnoconia interstitialis, 104.

Gymnosporangium, 39, 67, 369, 376, $383,423$. clavipes, 69.

Gypsophila, 407.

Hackberry, 379, 380, 381.

Hairy-root, 26, 87, 162.

Halo-blight, 299.

Hard-rot, 423.

Hawthorn, 379, 407, 423.

Hazel, 369, 380, 389.

Head-smut, 286, 309.

Heart-rot, 361, 364, 389, 402.

Hedera, 425.

Helianthus, 407.

Helicosporium nymphæarum, 439.

Helminthosporium, 282, 317, 402. carpophilum, 95.

inconspicuum, 294, 300 .

teres, 283. 
Hemileia vastatrix, 144.

Hemlock, 365, 367, 368, 369, 371, $373,379,380$.

Hemlock, western, 389.

Hemp, 163, 353.

Hendersonia, 145, 380.

Hepatica, 96, 423.

Herpotrichia, 380.

Heterosporium, 425. echinulatum, 416. variable, 243.

Hibiscus, 23, 407, 423. sabdariffa, 241.

Hickory, 359, 367, 380, 381.

Historical, 1. concerning prevention, 3. important events, 8.

Holcus, 277, 278.

Hollow-heart, 235.

Hollow-stem, 265.

Hollyhock, 10, 24, 423.

Honey-locust, 381.

Honeysuckle, 88, 407, 408.

Hop, 87, 163, 195.

Hordeum, 277, 278.

Hornbeam, 359, 381.

Horse-chestnut, 364, 367, 368, 369, $380,381,390$.

Horse-radish, 195.

Hot-water treatment, 271, 274.

Huckleberry, 110, 113.

Hydnum, 367. erinaceus, 361 .

Hydrangea, 23, 425.

Hydrastis, 195.

Hymenochæte, 402.

Hypertrophy, 112.

Hypochnose, 47, 69, 73.

Hypoderma, 380, 397.

Hystrix, 277.

Iberis, 407.

Illosporium, 47.

Impatiens, 407.

Incense cedar, 369, 380.

Inga, 380 .

Injury to seed by treatment, 277 .

Insecticide, 449.

Internal brown-spot, 236.

Inverted-pan method, 461.

Irpex, 67, 402.
Isariopsis griseola, 159.

Ivy, 425.

Japan clover, 337.

Java black-rot, 420 .

Java dry-rot, 250.

Jelly end-rot, 230.

Jerusalem artichoke, 435.

Johnson grass, 339.

Jonathan-spot, 54 .

Juniper, 367, 368, 369, 380, 381.

Juniperus, 40, 69, 383.

Kafir, 307.

Kale, 163, 165.

Kalmia angustifolia, 113.

Keithia, 380.

K ernel-smut, 283, 308.

Kernel-spot, 395.

Knapsack sprayer, 454.

Knot, 147, 427. (See also root-knot.)

Kochia, 407.

Koleria, 277, 278.

Kohl-rabi, 163, 165.

Kuehneola albida, 105. gossypii, 349 .

Labrella pomi, 56.

Læstadia, 251.

Larch, 367, 368, 369, 371, 373, 380,390 .

Large leaf-spot, 388.

Larkspur, 407, 426.

Lasiodiplodia trifloræ, 99.

Late-blight, 174, 217, 263.

Late-rust, 105.

Lathryus, 407.

Laurel, 425.

Lavatera, 407.

Leaf-anthracnose, 194.

Leaf-blight, $68,70,134,183,187$, $195,244,250,348,398,402$, 425 .

Leaf-blotch, 159, 234, 390.

Leaf-cast, 397.

Leaf-curl, 233, 394.

Leaf-glaze, 191.

Leaf-mold, 262, 416.

Leaf-perforation, 199.

Leaf-roll, 233, 265.

Leaf-rot, 145.

Leaf-scorch, 164. 
Leaf-spot, $47,68,75,98,104,114$, $119,134,135,144,145,146$, $147,159,165,173,176,178$, $185,190,191,192,195,196$, $201,214,217,241,243,244$, $245,251,257,262,295,298$, $321,331,335,338,339,379$, $382,388,391,392,405,411$, $413,415,418,420,421,422$, $424,425,426,427,428,429$, $433,434,435,439$.

Leak, 134, 234, 264.

Leather-leaf, 113.

Legumes, 23, 24, 321.

Lentil, 163.

Lentinus, 367.

Lenzites, 367.

Leopard-spot, 152.

Leptospharia coniothyrium, 105. leaf-blight, 319. sacchari, 245. tritici, 319.

Leptostroma, 380.

Leptothyrium pomi, 380 .

Lespedeza, 337.

Lettuce, 25, 27, 88, 196.

Libertella, 146.

Libocedrus, 369.

Lichens, 144.

Ligustrum, 407.

Lilac, 426.

Lily, 426.

Lily-of-the-valley, 426.

Limb-blight, 146.

Lime, 23.

Lime-sulfur, 443.

Lime-sulfur injury, 451.

Lime-sulfur wash, 445.

Linaria, 407.

Linden, 23, 364, 368, 369, 379, 380, $381,391$.

Linum, 407.

Little-peach, 95.

Lobelia, 407.

Locust, 23, 361, 367, 368, 371, 379, $380,381,391$.

Lolium, 277, 278.

Lonicera, 408.

Loose-smut, 280, 296, 315.

Lophodermium, 380. brachysporum, 398.
Loquat, 147.

Lupine, 163.

Lychnis, 407.

Lythrum, 407.

Macrophoma, 113, 146.

tumefaciens, 402.

Macrosporium, 216, 304, 380.

herculeum, 196.

leaf-spot, 173.

parasiticum, 210.

porri, 210.

sarcinæforme, 331 .

Magnolia, 369, 379 .

Malnutrition, 173.

Mangels, 159.

Mango, 147.

Mangold, 159.

Maple, 23, 359, 361, 364, 365, 367, $368,369,371,379,380,381$, 392.

Marasmius, 251. sacchari, 245.

Marigold, 88.

Marssonina, 380, 382, 403, 405.

ochroleuca, 388.

panattoniana, 199.

populi, 402.

Matthiola, 407.

Medlar, 73.

Melampsora, 401.

lini, 352.

saliciscapræ, 405.

Melampsorella elatina, 390 .

Melampsoridium betulinæ, 382 .

Melanose, 144.

Melaxuma, 404.

Melon, 178.

Merulius lacrymans, 374.

Mesquite, 372.

Microsphæra, 394.

alni, 394, 426, 435.

diffusa, 337 .

euphorbiæe, 241.

Microstroma, 380. juglandis, 395 .

Mignonette, 426.

Migration of diseases, 10.

Mildew. (See downy mildew, powdery-mildew.)

Millet, 295. 
Milo, 307.

Mistletoe, 144, 375, 390, 395.

Modified hot-water treatment, 272.

Mold, 75, 200, 427, 428, 439. (See also gray-mold, sooty-mold, black-mold, blue-mold.)

Monilia, 55, 75, 79, 101.

Monilochætes infuscans, 250.

Monochetia, 380. desmazierii, 388.

Moon-flower, 427.

Morning-glory, 23, 427.

Mosaic, 159, 186, 217, 233, 258, 265, $350,435$.

Mountain-ash, 368, 369, 380, 381.

Mountain-laurel, 425.

Mulberry, 23, 25, 367, 368, 369, $372,381,393$.

Mushroom, 200.

Muskmelon, 23, 25, 26, 178.

Mustard, 163.

Mycogone perniciosa, 200.

Mycosphærella, 135, 173, 338. citrullina, 190.

fragariæ, 132.

gossypina, 348 .

grossulariæ, 114.

leaf-spot, 114.

pinodes, 210.

rosigena, 433.

rubina, 107 .

sentina, 68 .

Myxosporium, 56, 369 .

Nasturtium, 427.

Necator decretus, 145.

Neck-rot, 206.

Necrosis, 129.

Nectarines, 90 .

Nectria, 135, 148, 251, 369, 402. galligena, 55, 72 .

ipomœer, 192.

Nematode, 24, 26, 146, 159, 162, $169,191,193,195,200,213$, $217,251,259,265,320,348$, 421,435 .

Neocosmospora, 214.

Neofabrea malicorticis, 44.

Neopeckia, 380.

Net-blotch, 283.

Net-necrosis, 236.

Nozzles, 458.
Nummularia, 369 .

discreta, 44.

Nursery-blight, 395.

Nursery stock, 23.

Nut-trees, 89.

Oak, 359, 361, 362, 364, 365, 367 , $368,369,371,372,379,380$, $381,394$.

Oat, 163, 280, 296.

CEdema, 265.

Oidium, 50, 122, 241, 420, 435, 436 . citri-aurantii, 144. mespilinum, 73.

Okra, 25, 201.

Oleander, 88, 369, 408, 427.

Olive, 147, 367, 369.

Olpitrichum, 346.

Onion, 25, 26, 201.

Orange, 367, 368, 369.

Orange leaf-rust, 312 .

Orange-rust, 104.

Orchard grass, 280, 339.

Orchard trees, 371.

Orchids, 427.

Ornamental plants, 406.

Orobanche, 159, 259. minor, 331.

Osage orange, 380,394 .

Ozonium, 146, 201, 248, 323. omnivorum, $23,53,346,372$. root-rot, 372 .

Pacific coast canker, 44.

Pronia, 407.

Pale-rot, 73.

Pale-spot, 173.

Palm, 408, 428.

Palmetto, 368.

Panicularia, 277.

Panicum, 338.

Pansy, 436.

Parsley, 174.

Parsnip, 88, 163, 174.

Paspalum, 340.

Patellina, 134.

Pea, 22, 24, 25, 163, 210.

Peach, 25, 79, 87, 90, 367, 369.

Peacock leaf-spot, 193.

Peanut, 23, 214.

Pear, 62, 361, 364, 368, 369, 372. 
Pecan, 25, 88, 369, 379, 380, 381, 394. Pecky heart-rot, 358.

Pecky-rot, 384.

Pelargonium, 407, 422.

Penicillium, 26, 108, 148, 193.

digitatum, 141.

expansum, 51, 250.

italicum, 141.

Pentstemon, 408.

Peony, 24, 88, 428.

Pepper, 23, 25, 215.

Perforation, 405.

Peridermium, 376, 380, 400, 401.

Peronoplasmopara cubensis, 178.

Peronospora, 164, 196, 295.

effusa, 244.

parasitica, 171.

schleideni, 203.

sparsa, 433.

trifoliorum, 327.

viciæ, 338 .

violæ, 437.

Persimmon, 23.

Pestalozzia, 251, 380, 402.

funerea, 194. guepini, 413.

Petunia, 407, 429.

Phalaris, 277.

Phallus, 245.

Phleospora, 380.

Phleum, 277, 278, 341.

Phloem-necrosis, 233.

Phlox, 407, 408, 429.

Pholiota, 367.

Phoma, 20, 163, 230, 369, 380, 385. apiicola, 178.

betæ, 162.

cyclamenæ, 421.

cydoniæ, 72 .

dahliæ, 421.

destructive, 263.

lingam, 169.

persicæ, 96.

pomi, 57.

root-rot, 162.

rot, 173.

Phomopsis, 158, 250, 432.

aitri, 144.

ka'miæ, 425.

mali, 57.

vexans, 192,421 .
Phoradendron, 375, 376.

Phragmidium, subcorticum, 432.

Phyllachora, 295, 338.

pox, 339.

trifolii, 338.

Phyllostieta, 217, 298, 369, 380, 390, 439.

acericola, 392 .

althæina, 424.

antirrhini, 434.

apii, 178.

batatas, 250 .

caryæ, 395.

catalpæ, 382.

chenopodii, 244.

chrysanthemi, 418.

circumscissa, 96.

cucurbitacearum, 190.

hydrangeæ, 425.

leaf-spot, 337 .

maculicola, 422 .

primulicola, 429.

prunicola, 56 .

pteridis, 422 .

richardiæ, 413.

shot-hole, 74, 96.

solitaria, 37 .

straminella, 241.

violæ, 437.

Phymatotrichum omnivorum, 23.

Physalis, 407.

Physalospora, 134, 369.

cydonix, 42, 69, 72 .

Physarum cinereum, 408.

Physoderma zeæ-maydis, 292.

Physopella fici, $145,394$.

Phytophthora, 20, 135.

cactorum, 57, 194.

infestans, 217, 263.

omnivorum, 26.

phaseoli, 158.

terrestria, 143, 265.

Piétin, 317.

Piggotia, 380 .

Pine, $11,22,117,365,367,368,369$, $371,373,380,381,395$.

Pineapple, 148.

Pineapple-disease, 245.

Pink, 23, 163, 439.

Pink-disease, 135.

Pink-mold, 395. 
Pink-rot, 49, 69, 210.

Pip, 304.

Piped rot, 361.

Piqueria, 407.

Piricularia grisea, 295. oryzæ, $300,339$.

Pithiness, 178.

Plantain, 135.

Plasmodiophora brassicæ, 168.

Plasmopara viticola, 125 .

Platycodon, 407.

Plectodiscella veneta, 102.

Plenodomus canker, 57. destruens, 248. fuscomaculans, 57 .

Pleospora gramineum, 282. pisi, 213. tropœoli, 427.

Pleurotus, 367.

Pleuteus, 367.

Plum, 87, 88, 90, 96, 97, 98, 367.

Poa, 278, 338.

Pod black-rot, 135.

Pod-blight, 158.

Pod-rot, 157.

Pod-spot, 152, 201.

Podosphæra leucotrichia, 50. oxyacanthæ, 51, 77, 91.

Pole-rot, 259.

Pollen-blight, 395.

Polyporus, 361, 367. betulinus, 382 .

obtusus, 362.

pergamenus, 379 .

roseus, 384 .

schweinitzii, 371.

squamosus, 364 .

sulphureus, 361.

versicolor, 374,382 .

Polystictus, 368.

Polythrincium, 328.

Pomaceous fruits, 31, 368, 369.

Poplar, 88, 359, 365, 367, 368, 369, $371,380,381,401$.

Poria, 368, 402.

Portulaca, 407.

Potassium sulfide, 448.

Potato, 10, 22, 23, 24, 25, 26, 87, $163,217$.

Potato spraying, 236. seed disinfection, 240.
Potentilla, 407.

Powdery gray-rot, 420.

Powdery-mildew, 50, 67, 77, 91, $101,117,122,134,159,165$, $173,187,195,213,241,242$, $283,300,307,317,337,338$, $342,376,381,394,407,412$, $420,421,426,429,431,435$, 436,439 .

Powdery scab, 224.

Power sprayer, 456.

Prevention of plant diseases, 12, 13. methods, 14 .

historical, 3, 13.

Primrose, 429.

Primula, 407.

Privet, 408, 430.

Proprietary fungicides, 449.

Prothallium-blight, 422.

Protocoronospora nigricans, 338.

Prune, 87.

Prunus, 23, 369.

Pseudomonas, 199, 294, 408, 422. angulatum, 257.

aptatum, 164, 427 .

avénæ, 299.

campestris, 165.

citri, 137.

erodii, 422.

glycineum, 337.

juglandis, 404.

lachrymans, 185.

maculicolum, 173.

malvacearum, 349 .

medicaginis, 324 .

phaseoli, 155 .

pisi, 213.

pruni, 74, 79, 90, 101.

savastanoi, 147.

solanacearum, 159, 174, 192, 230, $253,260$.

stewarti, 291.

tabacum, 257.

translucens, 282, 319 .

tumefaciens, $87,104,350,369$, 420 .

woodsii, 416.

Pseudopeziza medicaginis, 321.

ribis, 115.

trifolii, 331.

Pseudotsuga, 368, 373. 
Puccinia allii, 210. antirrhini, 434. arenariæ, 429. asparagi, 149. bullata, 178 . cannæ, 413. chrysanthemi, 418. coronata, 278, 298, 339 . dispersa, 278, 305. fraxinata, 381 . glumarum, 278, 313. graminis, $282,310,339,411$. agrostis, 278,340 . airæ, 278. avenæ, 277, 298. phleipratensis, 278,341 . poæ, 278. secalis, 277,305 . tritici, 277. tritici-compacti, 278.

helianthi, 435 .

malvacearum, 423. menthæ, 411. poarum, 338. porri, 210. pringsheimiana, 119. purpurea, 278. simplex, 278, 282. sorghi, 294.

tragopogonis, 242. triticina, 278, 312 . vincæ, 436. violæ, 437.

Puccinastrum hydrangeæ, 425.

Pumpkin, 22, 24, 178.

Punica, 407.

Pustular-spot, 95.

Pyrenopeziza medicaginis, 322. Pyrethrum, 88, 407.

Pythiacystis citriophthora, 135. Pythium, 163, 376. debaryanum, 193, 234, 328, 349.

Quackgrass, 340.

Quercus, 363.

Quince, 23, 69, 88, 369.

Radish, 22, 88, 163, 165.

Ramularia, 132, 194, 380. armoraciæ, 196. primulæ, 429.
Rape, 163, 165.

Raspberry, 22, 87, 88, 102.

Rathay's disease, 339.

Ray-blight, 419.

Razoumofskya, 375, 376, 390.

Red-brown root-rot, 371 .

Red-brown rot, 365 .

Red-bud, 379.

Red cedar, 40.

Red heart-rot, 358,361 .

Red-leaf, 69.

Red leaf-blight, 350 .

Red-rot, 214, 244, 371, 384, 401.

Red-rust, 251.

Redtop, $280,340$.

Reseda, $\ddot{407 .}$

Rhabdospora, 145.

Rhamnus cathartica, 298. lanceolatus, 298.

Rheosporangium aphanidermalus, 163.

Rhinotrichum, 346.

Rhizina, 373.

Rhizoctonia, 21, 178, 225, 328, 331, 349. crocorum, 327. leaf-blight, 146.

Rhizopus, 57. nigricans, 134, 191, 234, 245, 264.

Rhododendron, 408. viscosum, 113.

Rhubarb, 22, 23, 241.

Rhytisma, 380 . acerinum, 392. punctatum, 392.

Rice, 300.

Richardia, 407.

Ricinus, 407.

Rind-disease, 245.

Ring-spot, 173, 245.

Ripe-rot, 146.

Roestelia, 39, 67, 69 .

Root-knot, 24, 146, 159, 162, 169, $191,193,195,200,213,217$, $251,259,265,335,348$.

Root-rot, 21, 23, 24, 51, 117, 119 , $130,143,145,146,162,191,196$, $213,245,248,289,325,327,331$, $337,370,402,405,408,421$, $435,437,439$.

Root-tumor, 164. 
Rose, 24, 87, 367, 407, 408, 430 .

Rose-of-Sharon, 423.

Roselle, 94, 241, 265.

Rosette, 57, 101, 198, 395.

Rot, 111, 135, 148, 194, 365, 417, 420. (See also boll-rot, brownrot, blossom-rot, gray-rot, softrot, root-rot, ripe-rot, bitterrot, black-rot, pink-rot, redrot, pod-rot, white-rot, stemrot, wood-rot, root-rot, timberrot.)

Rotten-neck, 300.

Rough-bark, 57.

Rubber, 402.

Rust, 39, 67, 69, 74, 79, 96, 101, 116, $144,145,149,154,164,178$, $196,210,213,214,242,251$, $275,282,294,304,328,329$, $338,341,349,352,380,381$, $382,383,390,394,400,401$, $405,409,410,411,413,414$, $418,420,423,425,427,428$, $429,432,434,435,436,437$. (See also black-rust, blisterrust, black-stem-rust, whiterust, late-rust, orange-rust, yellow-rust.)

Rutaba.qa, 163, 165.

Rye, 163, 280, 304.

Salsify, 25, 88, 241.

Salvia, 407.

Santolina, 407.

Sap-rot, 374.

Sapwood rot, 364,382 .

Sargent sterilizer, 462.

Sassafras, 367, 402 .

Scab, 27, 35, 68, 74, 79, 82, 99, 132, $142,147,163,178,283,298,307$, $318,331,394$.

Scald, 54, 110 .

Scaly-bark, 140.

Schizanthus, 407.

Schizophyllum, 346, 368.

alneum, 78.

Sclerospora, 295.

Sclerotinia, 20, 164, 174, 178, 265, $426,429,435$.

cinerea, 55, 75, 79, 101 .

fuckeliana, 132 . libertiana, $26,137,158,170,183$, $193,195,196,258$.

linhartiana, 73.

oxycocci, 112.

perplexa, 435.

smilacina, 194.

trifoliorum, 323, 329 .

tuberosa, 409.

white rot, 195.

Sclerotium, 20, 174, 193, 242, 320, 346.

bataticola, 218, 251.

ricini, 174.

rolfsii, $23,144,146,158,185,195$, $214,215,264,408,420$.

Scolecotrichum graminis, 339.

Scurf, 56, 250.

Secale, 277, 278.

Sedum, 407, 433.

Seed-bed diseases, 407.

Seed mold, 328 .

Seed plat, 275.

Septobasidium, 53, 368, 372.

canker, 57, 69.

pedicillatum, 57 .

Septocylindrium rufomaculans, 165. areola, 348 .

Septoglœum, 380 .

Septoria, 68, 114, 328, 381, 411, 424. armoraceæ, 195.

bataticola, 251.

chrysanthemella, 418.

consimilis, 199.

dianthi, 415.

gladioli, 423 .

helianthi, 435.

kalmicola, 425 .

lactucæ, 199.

leaf-spot, $191,337$.

lycopersici, 262.

petroselini, 174.

ricini, 174.

rubi, 104.

sedi, 433.

Sequoia, 379, 381 .

Seradella, 407.

Shadbush, 380, 381.

Shedding, 350 .

Sheep laurel, 113.

Shelling, 131.

Shoe-string root-rot, 370 . 
Shot-hole, 74, 96.

Sida, 23.

Silene, 407.

Silver-leaf, 74, 96, 99, 117.

Silver-scurf, 234.

Slime flux, 376.

Slime-mold, 408.

Slimy-rot, 114.

Small fruits, 102.

Smut, 26, 201, 266, 283, 295, 338, $339,340,341,349,411$. (See also covered-smut, kernel-smut, loose-smut, black-smut, cerealsmut.)

kinds of, 266.

preventive treatments, 268 . seed treatments, 270.

Snap dragon, 434.

Soft-gall, 88.

Soft heart-rot, 382.

Soft-rot, 26, 51, 164, 172, 179, 188, $194,208,217,241,245,362$, $412,420$.

Soil diseases, 26.

Soil-disinfection, 460 .

Soil-rot, 249.

Sooty-blotch, 55, 69.

Sooty-mold, 144, 265, 408, 413.

Sore-shin, 349.

Sorghum, 163, 278, 307.

Sour-rot, 144.

Southern-blight, 23, 146, 158, 174, $185,193,195,214,215,242$, $264,320,408,420$.

Soy bean, 24, 337 .

Sparassis, 373.

Spartina, 381.

Speck, 304.

Spelt, 310.

Sphacelotheca reiliand, 286, 309. cruenta, 308. sorghi, 283, 308.

Sphæronema fimbriatum, 247.

Sphæronemella, 134.

Sphæropsis malorum, 42, 69, 72, 369.

tumefaciens, 144.

vincæ, 436.

Sphærotheca humuli, 134, 195, 431. mors-uvæ, 117.

pannosa, 91, 431.
Spinach, 25, 163, 242.

Spindling-sprout, 235.

Spirea, 407.

Spondylocladium atrovirens, 234.

Spongospora subterranea, 224.

Sporobolus, 277.

Sporonema, 323.

Sporotrichum anthophilum, 417.

Spot, 201, 257, 336. (See also leafspot, angular leaf-spot, blackspot, pod-spot.)

Spot-disease, 436.

Spotted blight, 304 .

Spray gun, 456.

Spraying, 191.

Spraying apparatus, 452.

Spraying schedule, conditions in-

fluencing, for apples, 57.

Spur-blight, 107.

Spruce, 365, 367, 368, 369, 371, 373 . 380.

Spurge, 435.

Squash, 22, 23, 178.

Stachys, 407.

Stagonospora carpathica, 328.

leaf-spot, 328.

Stalk-rot, 289.

Steccherinum, 368.

Stem anthracnose, 193.

blight, 96,421 .

disease, 145 .

Stem-end-rot, 144, 187.

Stem-rot, 21, 157, 213, 249, 259, 407, $410,416,417,420,439$.

Stem-smut, 306.

Stemphylium cucurbitacearum, 190.

Stereum, 368.

purpureum, 99.

Sterigmatocystis nigra, 146, 210, 260.

Stigmatea, 381.

Stigmonose, 416 .

Stilbella flavida, 145 .

Stilbum, 251.

Stinking-smut, 314.

Stocks, 168.

Strawberry, 25, 132.

Streak, 159, 435, 437.

Stripe-blight, 299, 307, 342 .

Stripe-disease, 282, 307.

Strophostyles, 155.

Strumella, 369. 
Sudan-grass, 307.

Sugar-beet, 24.

Sugar-cane, 23, 24, 244.

Sulfur-dust, 446 .

Sun-burn, 405.

Sunflower, 163, 407, 435 .

Sunscald, 54, 159.

Sweet-alyssum, 168.

Sweet-gum, 381.

Sweet-pea, 24, 163, 407, 408, 435.

Sweet potato, 22, 23, 24, 26, 245.

Sycamore, 367, 369, 371, 380, 381, 403.

Synchytrium endobioticum, 224. vaccinii, 113.

Take-all, 317.

Tall oat grass, 340 .

Taphrina, $376,381$. cerasi, 77. cœrulescens, 394. communis, 98. deformans, 84 .

Tar-spot, 392.

Taxus, 407.

Tea, 251.

Telanthera, 407.

Teosinte, 283.

Texas root-rot, $23,53,69,201,248$, $323,346$.

Thelephora, 368.

Thielavia, 191, 196, 213.

basicola, 24, 194, 251, 337, 373 , $408,421,435$.

root-rot, 194 .

Thielaviopsis paradoxa, 148, 245.

Thread-blight, 251.

Thrombosis, 393.

Thyridaria, 402.

Tilletia horrida, 302 .

lævis, 314.

trit:i, 314

Timber, 354, 373.

Timber-rot, 183, 265.

Timothy, 163, 280, 341.

Tip-burn, 228.

Tobaceo, 22, 25, 87, 251.

Tomato, 22, 23, 25, 87, 260.

Tower, 458.

Trametes, 368. pini, 358.
Transchelia, 423. punctata, 96.

Trees, 354.

Tree surgery, 376.

Trichoderma koningi, 251. -rot, 251.

Tricholoma, 368, 372 .

Trichosphæria, 148. sacchari, 245.

Triticum, 277, 278.

Tropical fruits, 135.

Tropœelum, 408, 427.

Tsuga heterophylla, 389 .

Tubercularia, 146.

Tulip, 369, 436.

Tupelo, 368.

Turnip, 88, 163, 165.

Tussilago, 338.

Twig-blight, 368, 394, 398.

Uncinula necator, 122 .

Uredinales, 380.

Uredo, 148.

arachidis, 214.

Urocystis agropyri, 340. cepulæ, 201. occulta, 306.

Uromyces, 148, 329, 338. appendiculatus, 154 . betæ, 164 . caryophyllinus, 414. poæ, 339. striatus, 328.

Urophlyctis, 164. alfalfæ, 325 . tritici, 316.

Ustilaginoidea virens, 301 .

Ustilago, 295, 340 . avenæ, 296. crameri, 295. crusgalli, 338. hordei, 282. levis, 297. nuda, 280. panici-miliacei, 295. perennans, 340 . shiraiana, 411. striæformis, 338, 340, 341. tritici, 315 . zeæ, 283. 
Valsa, 369. leucostoma, $74,78,86$.

Vanilla, 148.

Vegetable crops, 149.

Venturia, 381. inæqualis, 35. pyrina, 68.

Verbena, 407, 436.

Vermicularia, 148, 208. dematium, 193. subeffigurata, 415. telephii, 433. trichella, 425 .

Verticillium, 192, 393. alboatrum, 201, 230, 412. albus, 194. caulophagus, 110. dahliæ, 421. wilt, 194.

Vetch, 24, 163, 338.

Vigna, 155.

Vinca, 407.

Vinca leaf-spot, 436.

Viola, 407.

Violet, 22, 23, 24, 408, 436.

Virginia creeper, 407, 439.

Viruela, 145.

Volutella, 20, 205, 346.

concentrica, 412.

dianthi, 417.

fructi, 56 .

rot, 56,412 .

Volvaria, 368.

Walnut, 25, 87, 359, 361, 361, $367,368,369,379,380,381$, $403^{\circ}$

Wart, 224.

Water lily, 439.

Watermelon, 22, 23, 26, 178.

Watery-rot, 144.
Wet-butts, 260.

Wheat, 163, 280, 310.

White alder, 113.

White cedar, 368, 369.

White-head, 317.

White heart-rot, 359 .

White-rot, 132, 361, 364, 381, 383.

White rust, $164,172,173,194$, $241,250,408,427$.

White-smut, 242.

White-spot, 328.

White-vein, 260.

White wood-rot, 364 .

Wildfire, 257.

Willow, 25, 88, 359, 364, 367, 368, $369,376,379,380,381,405$.

Wilt, 26, 98, 112, 135, 148, 159. $172,174,181,182,190,192$, $193,201,213,215,228,230$, $249,257,260,291,323,325$, $329,331,337,343,350,353$, $409,412,416,418,421,435,437$.

Winter-blight, 265.

Wintergreen, 113.

Witches-broom, 135.

Wither-tip, 143.

Wood-rot, 53, 78, 144.

Xylaria, 53, 373.

Yellow leaf, 294, 300.

Yellow leaf-blotch, 322.

Yellow rust, 146.

Yellow-stripe rust, 283, 307, 313.

Yellow-top, 328.

Yellow wood-rot, 391.

Yellows, 74, 79, 91, 101, 108, 172, $405,410,417$.

Yew, 408.

Zygodesmus albidus, 439. 




